\title{
Physikalische und transkriptionelle Kartierung der mit dem Russell-Silver-Syndrom assoziierten Chromosomenregion 17q23-q24
}

\author{
Dissertation \\ zur Erlangung des Doktorgrades \\ der Mathematisch-Naturwissenschaftlichen Fakultäten \\ der Georg-August-Universität zu Göttingen
}

vorgelegt von

Sylvia Dörr

aus Oldenburg/(OLDB)

Göttingen 1999 
D7

Referent: Prof. Dr. W. Engel

Korreferent: Prof. Dr. M. Schäfer

Tag der mündlichen Prüfung: 27.01.2000 
1 EINLEITUNG

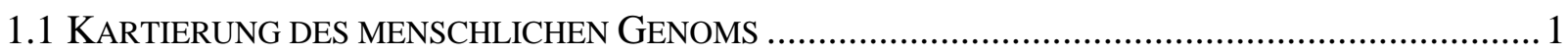

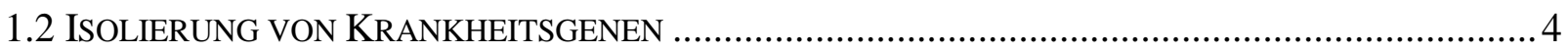

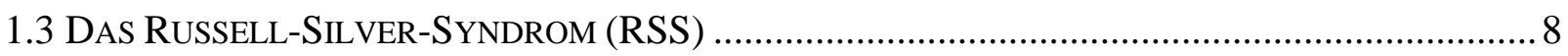

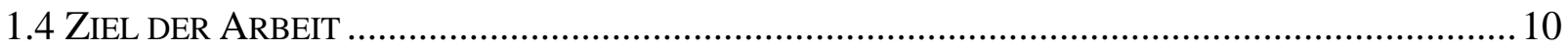

2 MATERIAL UND METHODEN....................................................................................12

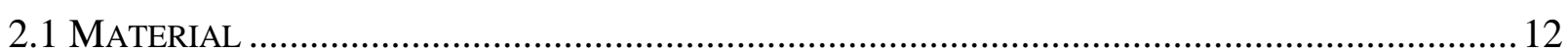

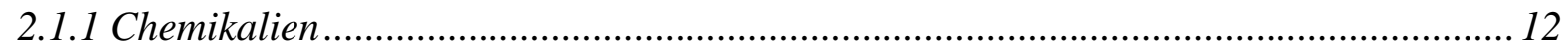

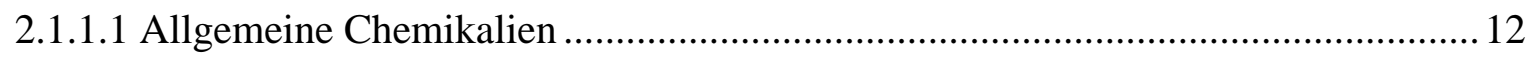

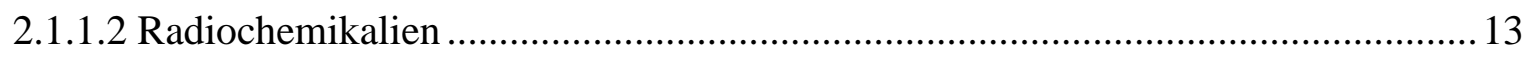

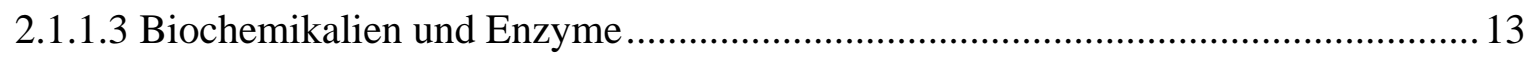

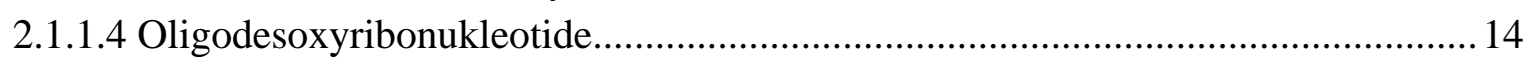

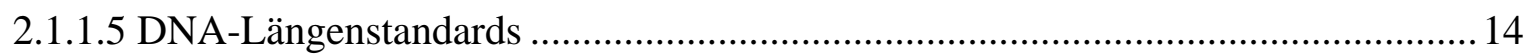

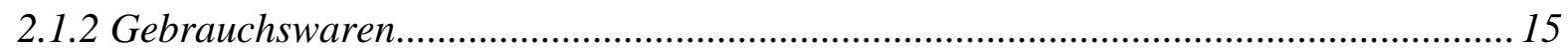

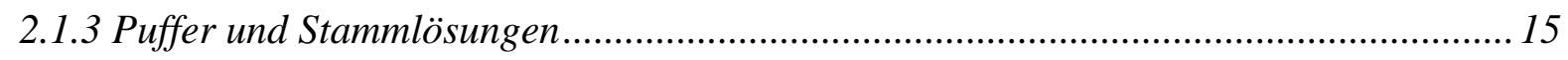

2.1.4 Art und Herkunft des verwendeten Untersuchungsmaterials ..................................... 16

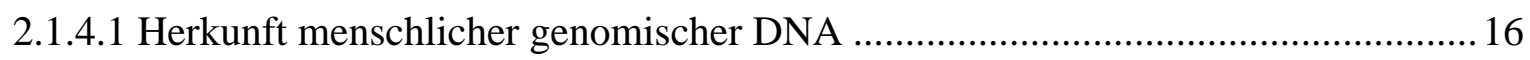

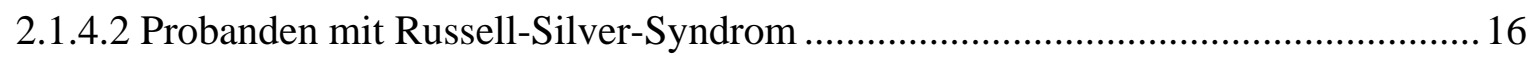

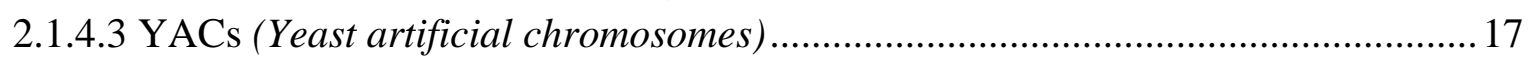

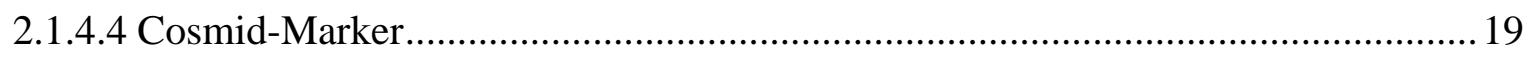

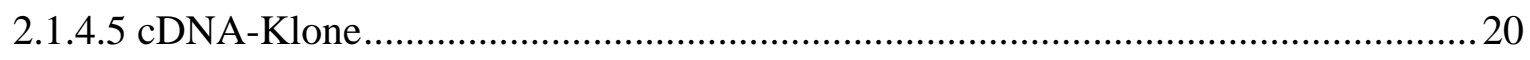

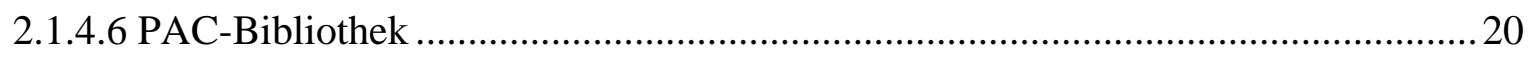

2.1.5 Sequenzen und Herkunft der verwendeten Primer ....................................................... 21

2.1.5.1 Mikrosatellitenmarker und anonyme Sonden für Chromosom 17 ........................21

2.1.5.2 Mikrosatellitenmarker für Chromosom 7, 18 und 20 .......................................... 22

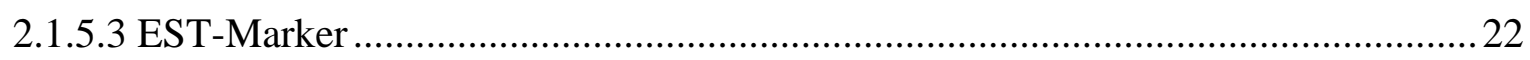

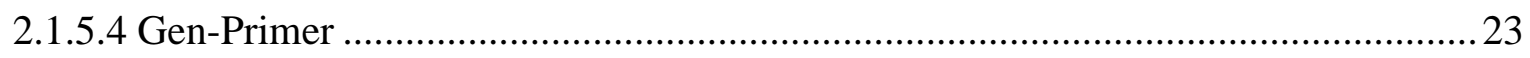

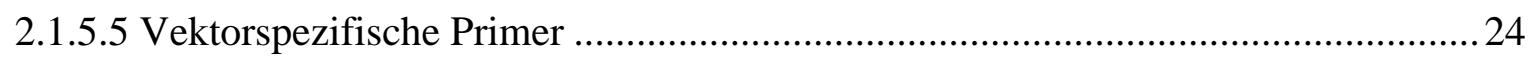

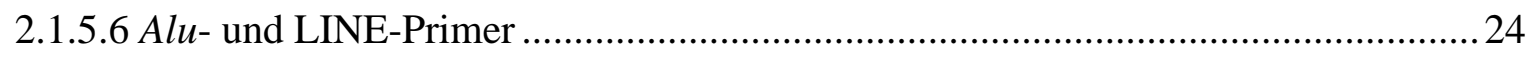

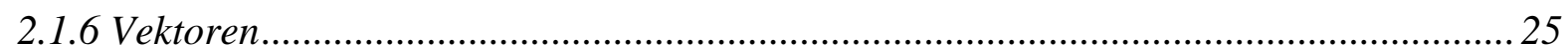

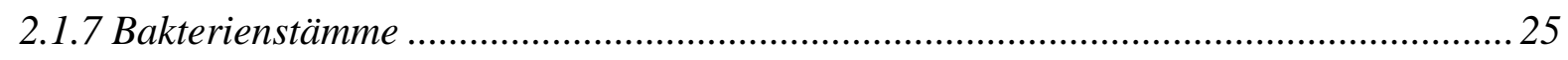

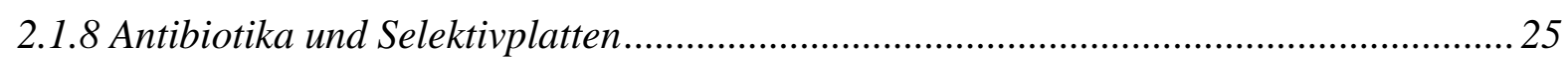

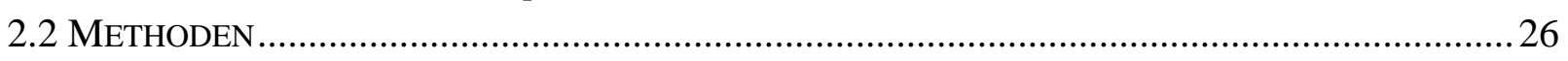

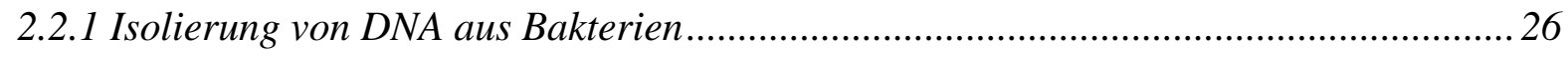

2.2.1.1 Alkalische Minipräparation von Plasmid-, Cosmid- und PAC-DNA .....................26

2.2.1.2 Alkalische Maxipräparation von Plasmid-, Cosmid- und PAC-DNA.....................26

2.2.1.3 Herstellung von Stammkulturen ........................................................................ 27

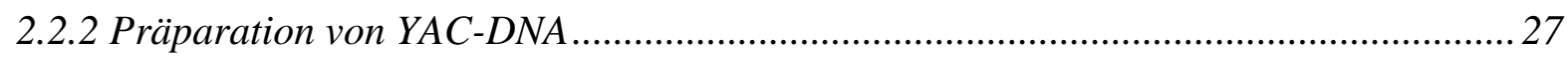

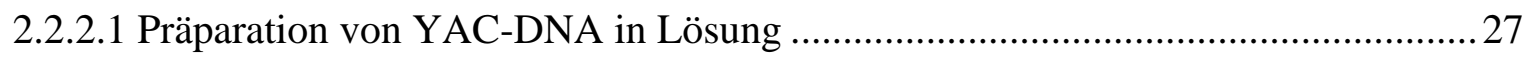

2.2.2.2 Präparation von Hefe-DNA in Agaroseblöckchen ................................................28

2.2.2.3 Isolierung von YAC-DNA aus Agaroseblöckchen ............................................28

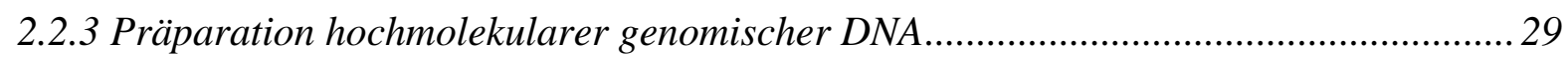


2.2.3.1 DNA-Isolierung aus Blut mit Proteinaussalzung ...............................................29

2.2.3.2 DNA-Präparation aus transformierten EBV-Lymphozyten...................................29

2.2.3.3 Präparation von hochmolekularer Lymphozyten-DNA in Agaroseblöckchen .......29

2.2.3.4 Präparation von hochmolekularer Lymphoblasten-DNA in Agaroseblöckchen .... 30

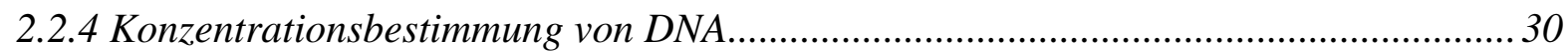

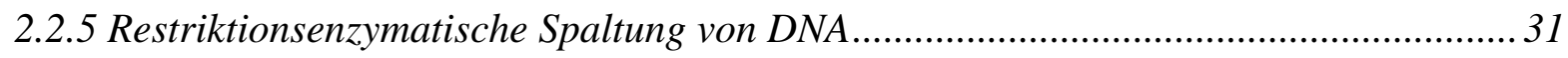

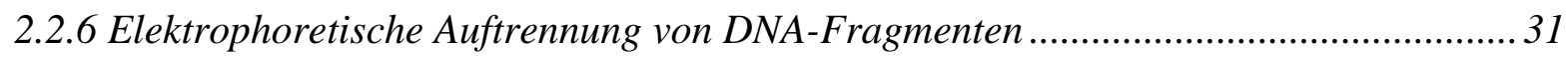

2.2.6.1 Polyacrylamid-Gelelektrophorese (PAGE) ..................................................... 31

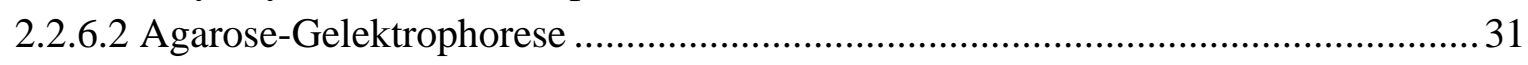

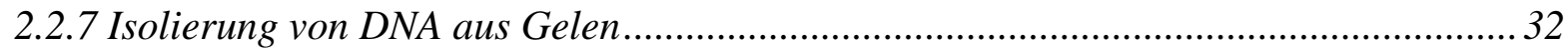

2.2.7.1 Extraktion von DNA-Fragmenten aus Agarosegelen ............................................ 32

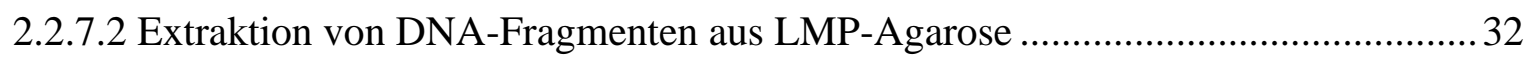

2.2.7.3 Extraktion von DNA-Fragmenten aus Polyacrylamidgelen ................................... 32

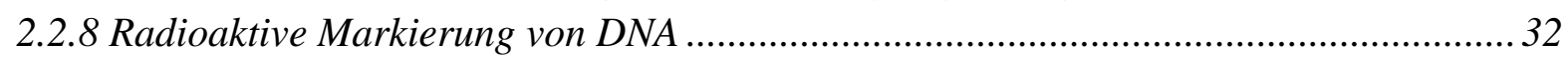

2.2.8.1 Radioaktive Markierung von DNA-Fragmenten mit dem Megaprime-System ..... 32

2.2.8.2 Abtrennung nicht inkorporierter Radionukleotide............................................... 33

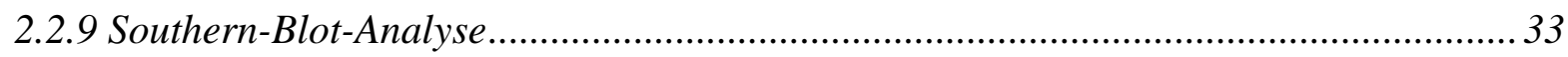

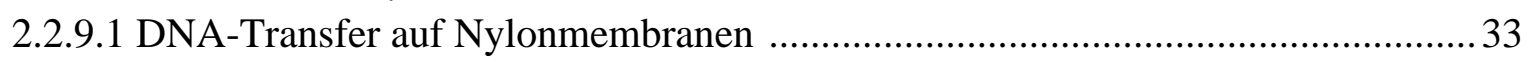

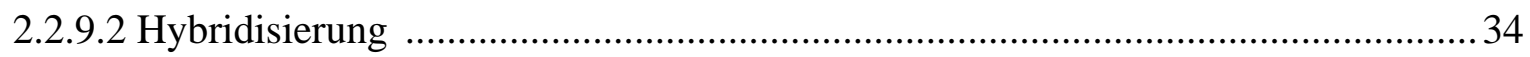

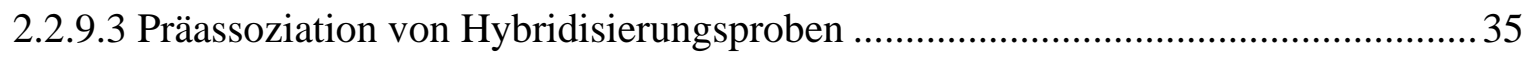

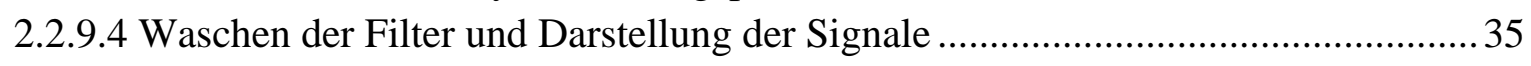

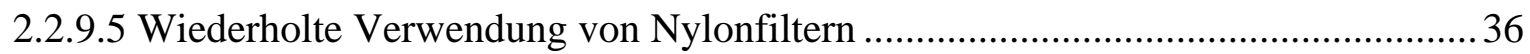

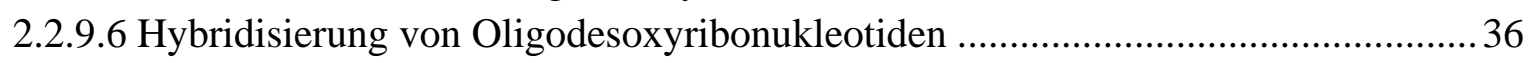

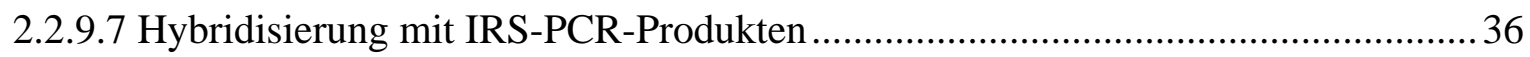

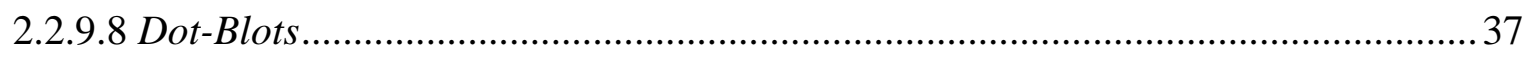

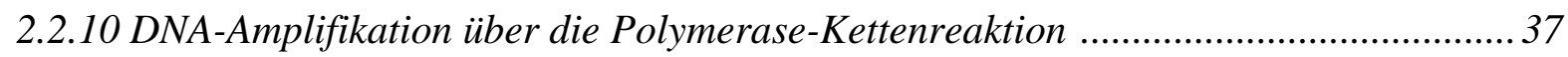

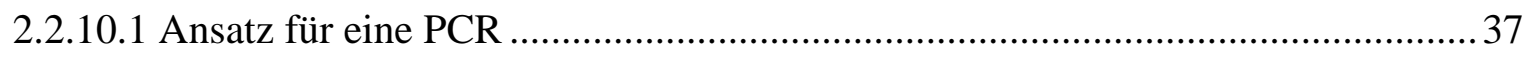

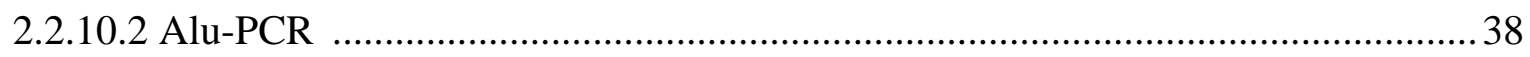

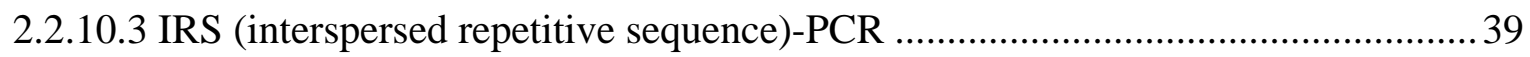

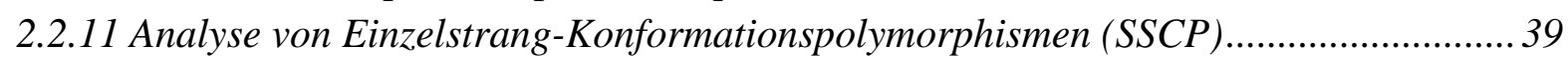

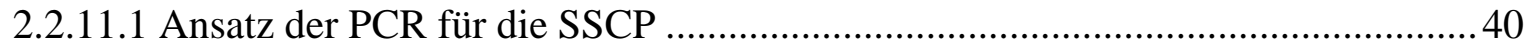

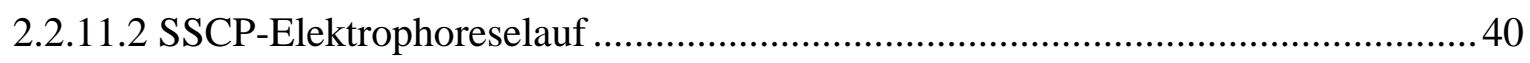

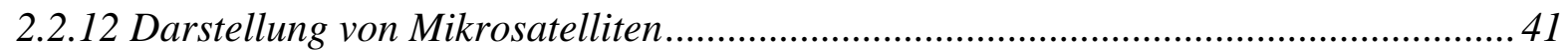

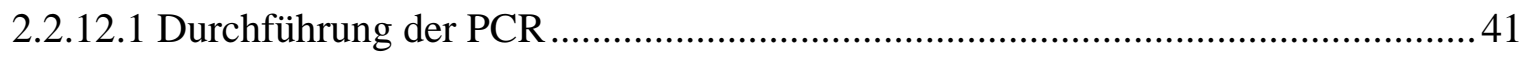

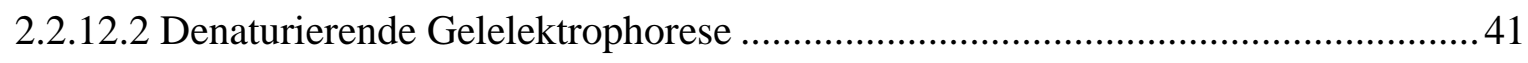

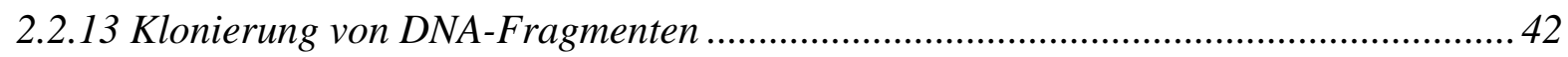

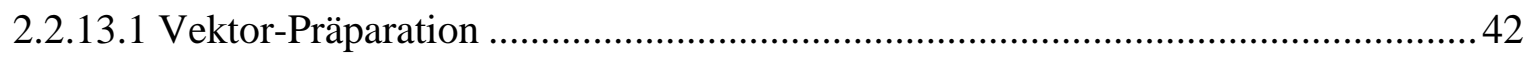

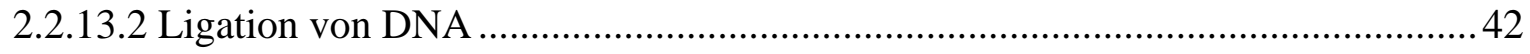

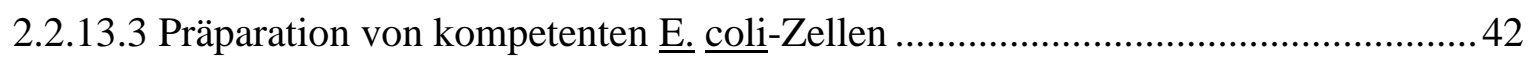

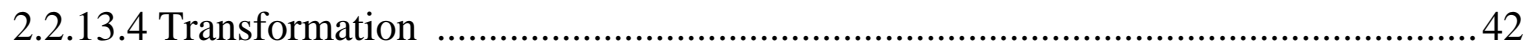

2.2.14 Dye-Terminator-Fluoreszenz-Sequenzierung ........................................................... 43

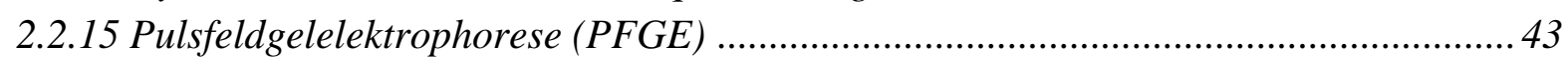

2.2.15.1 Restriktionsspaltung von DNA in Agaroseblöckchen ...................................... 44 
2.2.15.2 Partielle Restriktion von DNA in Blöckchen ...................................................... 44

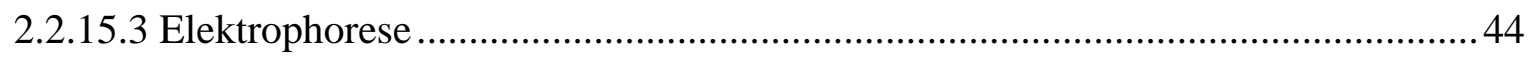

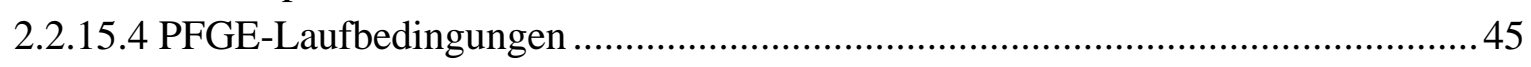

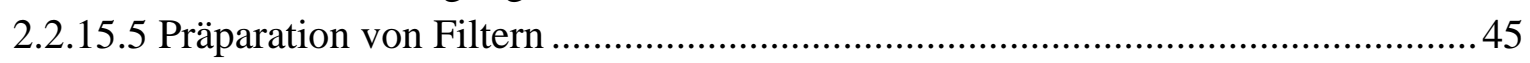

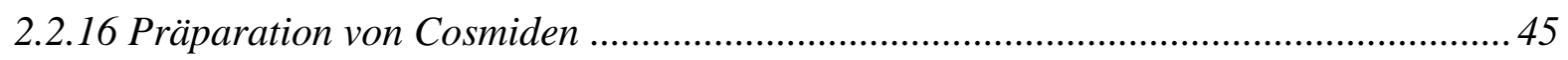

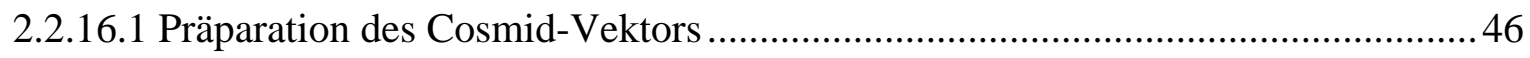

2.2.16.2 Isolierung und partielle Spaltung der YAC-DNA ............................................. 46

2.2.16.3 Ligation der partiell geschnittenen YAC-DNA in den Cosmid-Vektor ................ 47

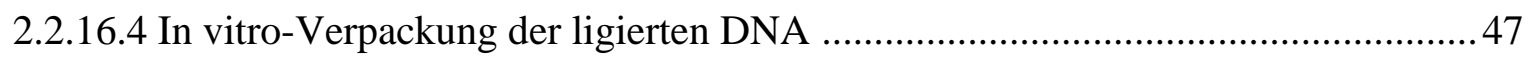

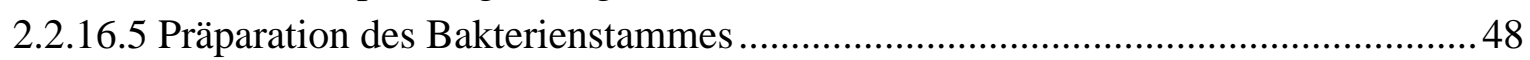

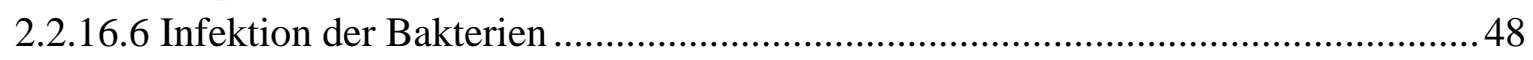

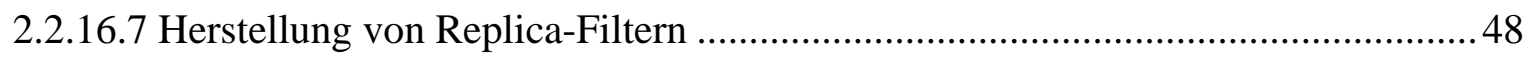

2.2.16.8 Transfer humaner Cosmide auf Filter mit Hilfe einer automatischen

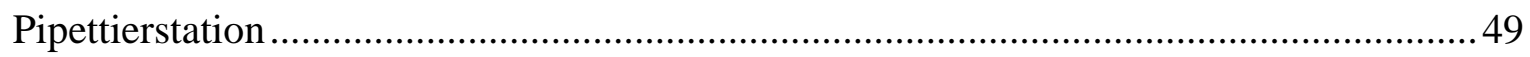

2.2.16.9 Markierung von Cosmid-Enden durch lineare PCR ............................................. 49

2.2.17 Herstellung der Chromosomenpräparate ..................................................................50

2.2.17.1 Chromosomenpräparation aus Lymphozyten .................................................5 50

2.2.17.2 Chromosomenpräparation aus EBV-transformierten B-Lymphozyten .................51

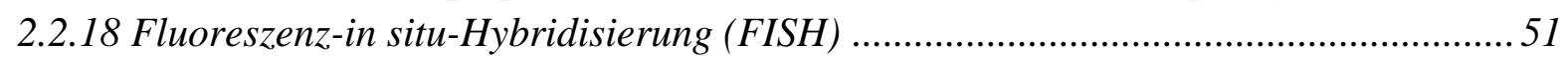

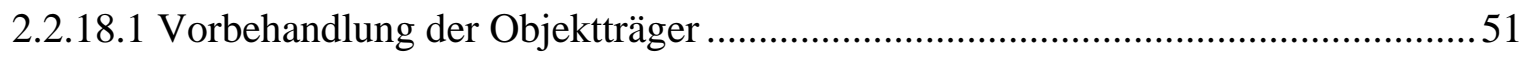

2.2.18.1.1 RNase-Behandlung der Objektträger.................................................... 51

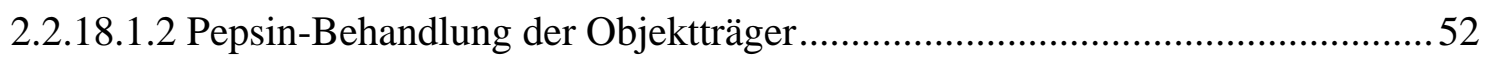

2.2.18.1.3 Denaturierung der Chromosomenpräparate.................................................52

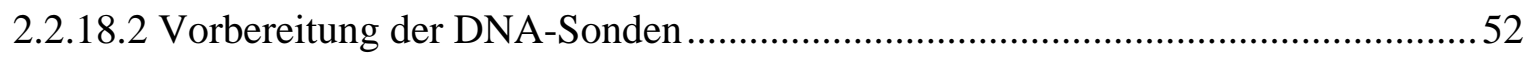

2.2.18.2.1 Markierung der DNA-Sonden mittels Nicktranslation ..................................52

2.2.18.2.2 Kontrolle des Biotin-Einbaus mittels Dot-Blot ..........................................53

2.2.18.2.3 Suppression unspezifischer Hybridisierung ..............................................5

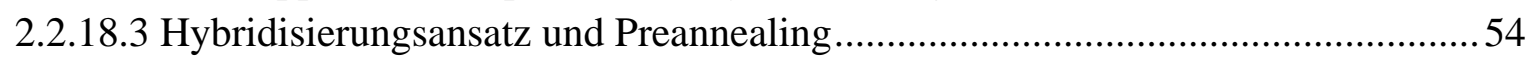

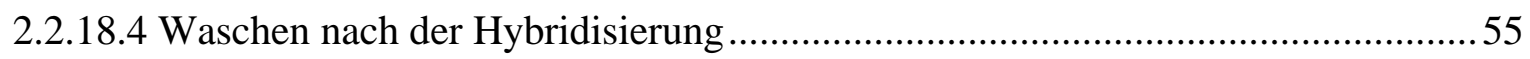

2.2.18.5 Detektion und Amplifikation von Biotin-markierten Sonden ..............................55

2.2.18.6 Detektion und Amplifikation von Digoxigenin-markierten Sonden ....................56

2.2.18.7 Zweifarbige FISH: Avidin-FITC- und Digoxigenin-Cy3-Detektion .....................57

2.2.18.8 Gegenfärbung der Chromosomen mit Propidiumiodid und DAPI.......................57

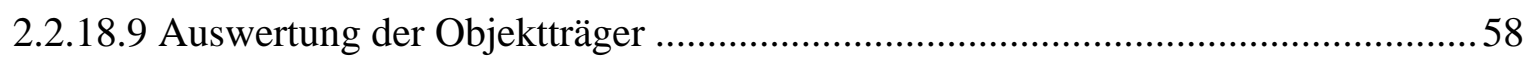

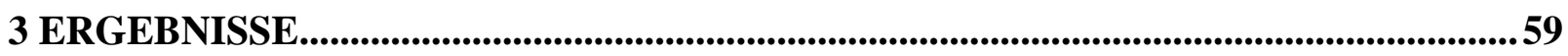

3.1 ERSTELLUNG EINES HOCHAUFLÖSENDEN YAC-CONTIGS FÜR DIE REGION EINES MIT RUSSELLSILVER-SYNDROM EINHERGEHENDEN TRANSLOKATIONSBRUCHPUNKTES AUF CHROMOSOM 17Q

3.1.1 Analyse des YAC-Contigs auf die Anwesenheit von Genen......

3.1.2 Zuordnung von ESTs (expressed sequence tags) zu dem YAC-Contig der Region

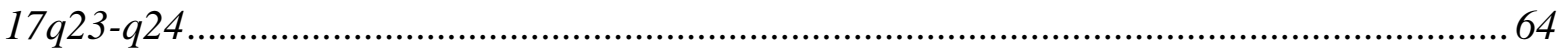

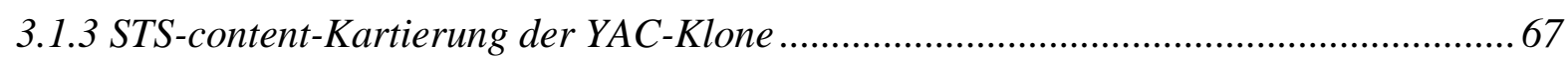

3.1.4 FISH-Analyse mit YACs für das Chromosomensegment 17q23-q24............................67 
3.1.4.1 FISH-Analyse der YAC-Klone 853F8, 963C7 und 765F4 67

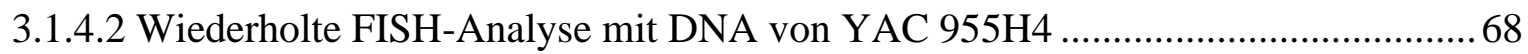

3.1.5 Identifizierung duplizierter Segmente innerhalb der Region 17q23-q24 ..................... 71

3.2 RESTRIKTIONSKARTIERUNG VON YACS DER BRUCHPUNKTREGION....................................... 71

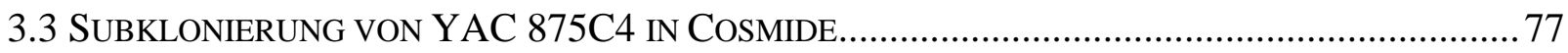

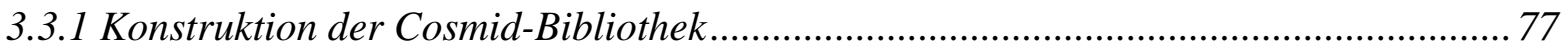

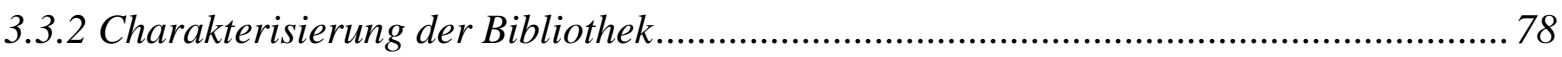

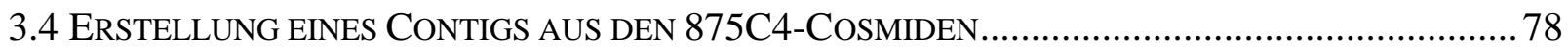

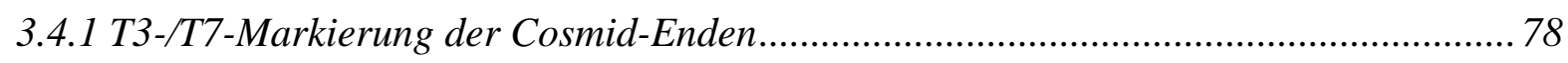

3.4.2 Erstellung einer EcoRI-Restriktionskarte von Cosmiden .............................................. 79

3.4.3 Detektion von randständigen Cosmiden des Contigs .................................................... 83

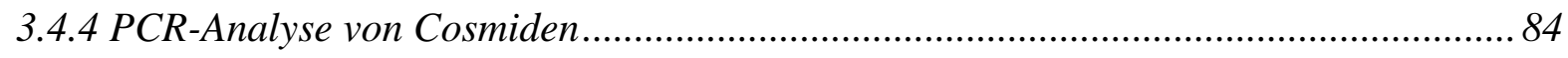

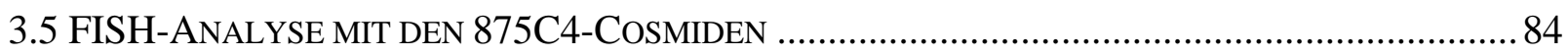

3.6 ISOLIERUNG VON PAC-KLONEN FÜR DIE BRUCHPUNKTREGION VON AS AUF CHROMOSOM 17.

.88

3.6.1 Entwicklung von neuen sequence tagged sites (STS) .............................................. 88

3.6.1.1 Generierung von STS-Stellen für die Insert-Enden von YAC 875C4 .................... 88

3.6.1.2 Sequenzierung des T7-Endes von Cosmid 1B11 .............................................. 90

3.6.1.3 Sequenzierung des T7-Endes von Cosmid 2H8 ............................................... 90

3.6.1.4 Sequenzierung des T3- und T7-Endes von Cosmid 2A3 .................................... 90

3.6.1.5 Sequenzierung des T7-Endes von Cosmid CF58 …........................................... 91

3.6.1.6 Sequenzierung des T7-Endes von Cosmid CF20b ............................................. 91

3.6.2 Identifizierung von PAC-Klonen durch PCR-Analyse ............................................... 92

3.6.3 Identifizierung von PAC-Klonen durch Hybridisierung auf PAC-Filter....................... 95

3.6.4 Identifizierung von PAC-Klonen anhand veröffentlichter Daten .................................96

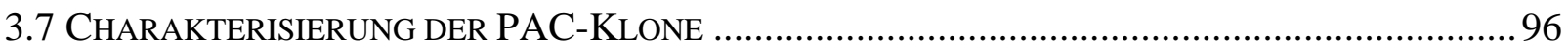

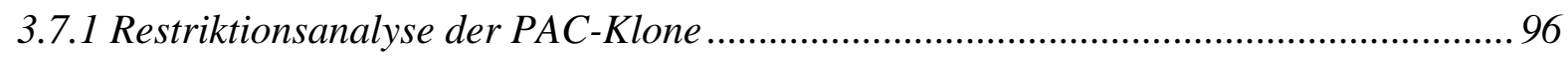

3.7.2 Größenbestimmung der PAC-Inserts.......................................................................... 98

3.7.3 Kartierung der PACs mit Hilfe der Fluoreszenz-in situ-Hybridisierung (FISH)......... 99

3.8 ISOLIERUNG VON PAC-ENDFRAGMENTEN UND ERZEUGUNG NEUER STS-STELLEN.............. 103

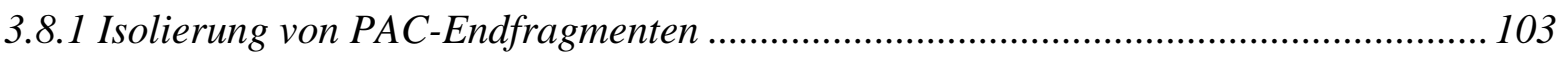

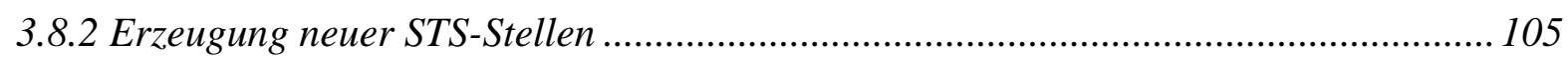

3.8.2.1 Generierung von STS-Stellen für die Insert-Enden von PAC 188D1 .................. 105

3.8.2.2 Generierung von STS-Stellen für die Insert-Enden von PAC 306O9-2 ................ 106

3.8.2.3 Generierung von STS-Stellen für die Insert-Enden von PAC 209I3-1................. 106

3.8.2.4 Generierung von STS-Stellen für die Insert-Enden von PAC58J13 .................... 107

3.8.2.5 Generierung von STS-Stellen für die Insert-Enden von PAC 112L5 ................... 107

3.8.2.6 Generierung von STS-Stellen für die Insert-Enden von PAC 120O4 .................. 108

3.8.2.7 Generierung von STS-Stellen für die Insert-Enden von PAC 7B12 .................... 109

3.8.2.8 Generierung von STS-Stellen für die Insert-Enden von PAC 293H13 ................ 109

3.8.2.9 Generierung von STS-Stellen für die Insert-Enden von PAC 241A12 ................. 110

3.8.2.10 Generierung von STS-Stellen für die Insert-Enden von PAC 83D4 ................... 110

3.8.2.11 Generierung von STS-Stellen für die Insert-Enden von PAC 81B9 .................. 111 
3.9 STS- UND EST-CONTENT-KARTIERUNG DER PAC-KLONE ................................................ 112

3.10 SEQUENZIERUNG VON PCR-PRODUKTEN VON KLONEN DER REGION 17Q23-Q24...............115

3.10.1 Sequenzierung von PCR-Produkten der EST WI-9461 ........................................... 115

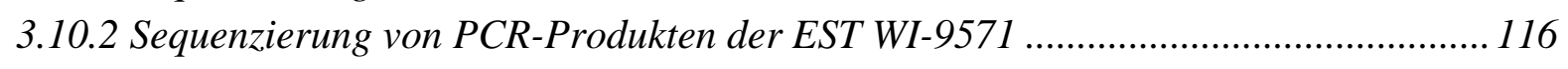

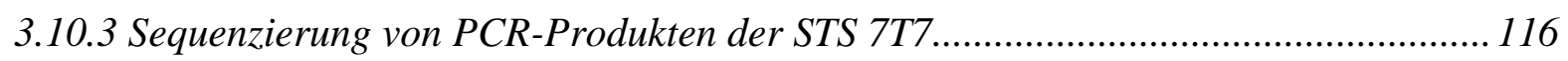

3.10.4 Sequenzierung von PCR-Produkten der STS 293T7.............................................. 117

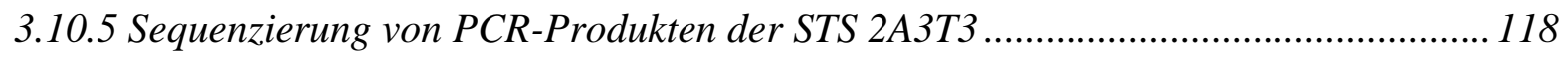

3.10.6 Sequenzierung von PCR-Produkten der STS 293SP6 ............................................ 119

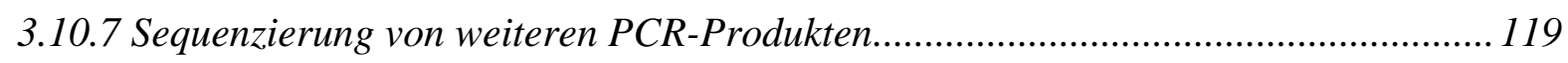

3.11 CHARAKTERISIERUNG VON ZWEI EXPRESSED SEQUENCE TAGS AUS DER BRUCHPUNKTREGION

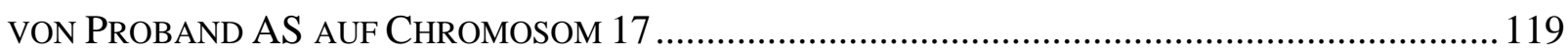

3.11.1 Sequenzierung des cDNA-Klons 312967 (EST WI-9461)....................................... 120

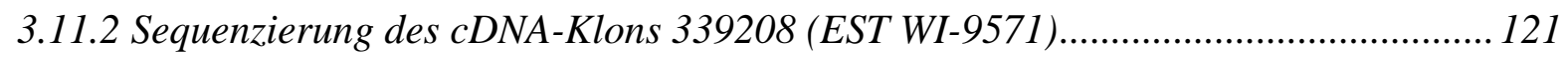

3.12 ZUORDNUNG VON BACS ZU DER REGION 17Q23-Q24 ANHAND VON DATENBANK-ANALYSEN

3.12.1 Identifizierung von hRPK.147L13 (Accession-Nr. AC005332)............................... 126

3.12.2 Identifizierung von hRPK.557B23 (Accession-Nr. AC006534).................................. 127

3.12.3 Identifizierung von hRPK.346K10 (Accession-Nr. AC006120) ................................. 128

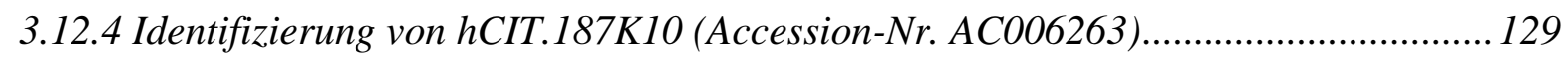

3.12.5 Identifizierung von hRPK.115C3 (Accession-Nr. AC006947) ................................... 130

3.12.6 Identifizierung von hRPK.74H8 (Accession-Nr. AC005918) .................................... 131

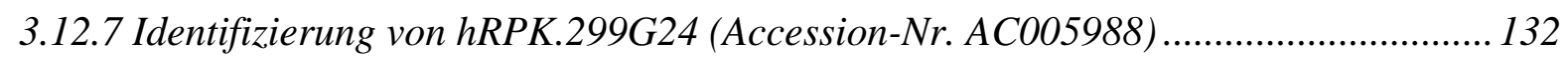

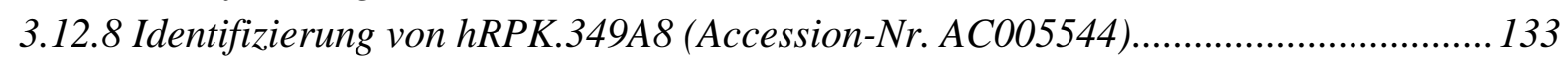

3.12.9 Identifizierung von hRPK.62F10 (Accession-Nr. AC005799).................................... 134

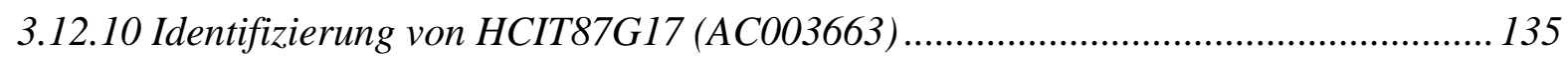

3.12.11 Identifizierung von hRPK.115N5 (Accession-Nr. AC006440) ............................... 136

3.13 KARTIERUNG UND CHARAKTERISIERUNG DES GENS VON KARYOPHERIN ALPHA 2 (KPNA2)

UND SUCHE NACH MUTATIONEN IN PROBANDEN MIT RSS .................................................... 137

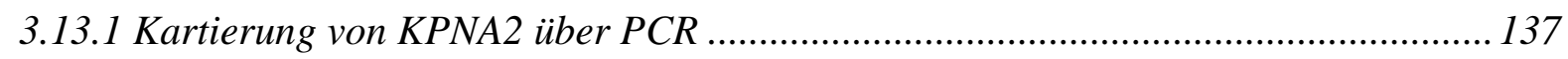

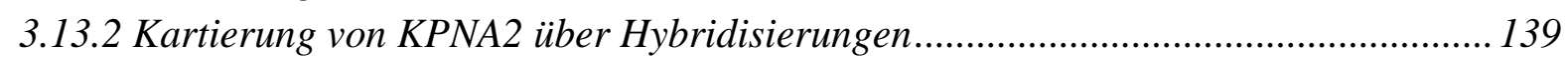

3.13.4 Detektion von abnormen KPNA2-Fragmenten bei Proband AS ............................... 143

3.13.4 Bestimmung der Exon-Intron-Struktur von Karyopherin alpha 2 (KPNA2)............. 144

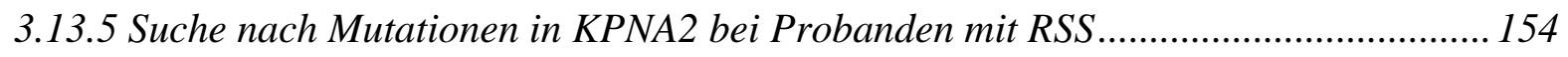

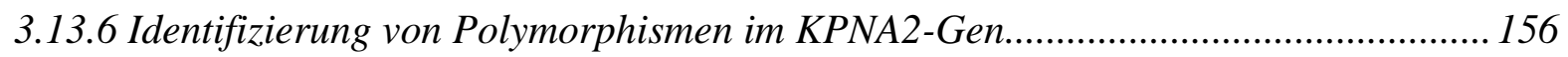

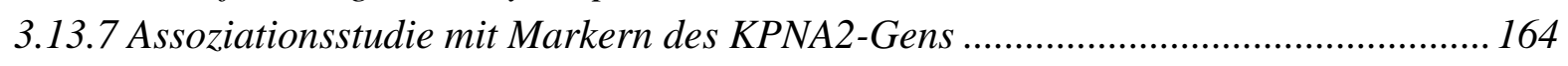

3.14 Analyse von Mikrosatelliten des Chromosoms 17 Bei Probanden Mit RSS ........ 165

3.15 FISH-ANALYSE VON PROBANDEN MIT RSS ZUR SUCHE NACH DELETIONEN AUF

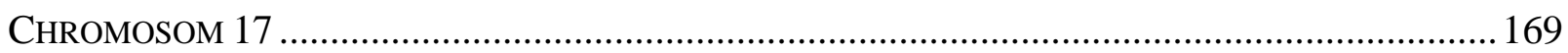

3.16 DETEKTION VON ALLELISCHER NICHT-AMPLIFIKATION DES MARKERS D17S1870 ............ 170

3.17 CHARAKTERISIERUNG EINES MIT RUSSELL-SILVER-SYNDROM EINHERGEHENDEN

TRANSLOKATIONSBRUCHPUNKTES IN DER REGION 17Q25 .............................................. 172

3.18 CHARAKTERISIERUNG EINES MIT RUSSELL-SILVER-SYNDROM EINHERGEHENDEN

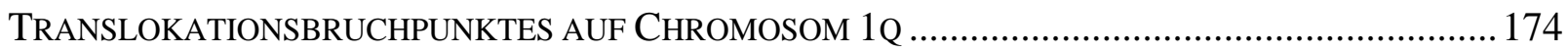


4.1 ERSTELLUNG EINES DETAILLIERTEN YAC-CONTIGS FÜR DIE REGION 17Q23-Q24 183

4.2 RESTRIKTIONSKARTIERUNG DER REGION REGION 17Q23-Q24.

4.3 GENERIERUNG UND CHARAKTERISIERUNG VON COSMID-KLONEN ..................................... 194

4.4 ISOLIERUNG UND CHARAKTERISIERUNG VON PAC-KLONEN DER REGION 17Q23-Q24 ........ 198

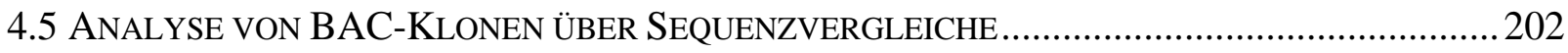

4.6 KARYOPHERIN $\alpha 2$ (KPNA2) ALS KANDIDATENGEN FÜR DAS RSS ................................205

4.7 Analyse von Mikrosatelliten des Chromosoms 17 Bei Probanden mit RSS .......... 211

4.8 CHARAKTERISIERUNG EINES MIT RUSSELL-SILVER-SYNDROM EINHERGEHENDEN

TRANSLOKATIONSBRUCHPUNKTES IN DER REGION 17Q25

4.9 CHARAKTERISIERUNG EINES MIT RSS EINHERGEHENDEN TRANSLOKATIONSBRUCHPUNKTES

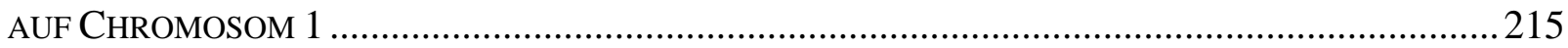

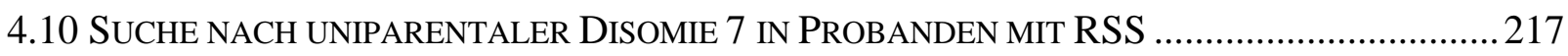

4.10.1 Entstehungsmechanismen von uniparentalen Disomien ........................................ 217

4.10.2 Phänotypische Konsequenzen von uniparentalen Disomien ...................................... 219

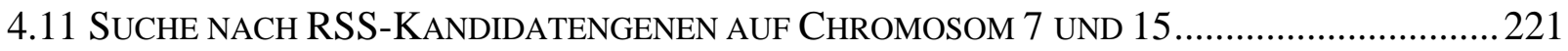

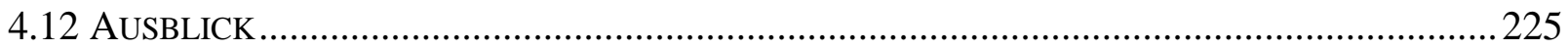

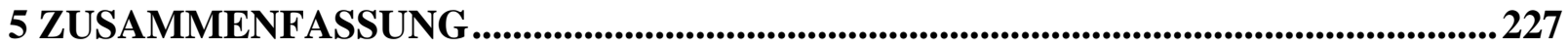

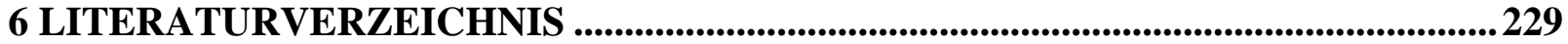




\section{Abkürzungen}

Abb.

abs.

Ac

APS

bp

BAAD

BCIP

Bio-UTP

BSA

cDNA

$\mathrm{Ci}$

CIP

$\mathrm{cM}$

cos-sites

DAPI

d

dATP

dCTP

dd

ddNTP

dGTP

DMSO

dNTP

dITP

DTT

dTTP

EBV

E.coli

EDTA

EGTA

EMBL

EST

et al.

$\mathrm{EtBr}$

$\mathrm{EtOH}$

FISH

$\mathrm{g}$

h

IPTG

$\mathrm{kb}$

1

LB-Medium

$L M P$

$\mathrm{M}$

$\mathrm{m}$
Abbildung

absolut

Acetat

Ammoniumperoxidsulfat

Basenpaare

biotinyliertes Anti-Avidin

5-Bromo-4-Chloro-3-Indoyl-Phosphat-p-Toluidinsalz

biotinyliertes Desoxyuraciltriphosphat

Rinderserumalbumin

komplementäre DNA

Curie

Calf intestinal phosphatase

Centimorgan

cohesive ends

4,6-diamidino-2'phenylindol

$2^{\prime}$-desoxy-

2'-Desoxy-adenosin-5'-triphosphat

$2^{\prime}$-Desoxy-cytosin-5'-triphosphat

2',3'-didesoxy-

Didesoxynukleosid-5'-triphosphat

2'-Desoxy-guanosin-5'-triphosphat

Dimethylsulfoxid

2'-Desoxy-nukleosid-5'-triphosphat

2'-Desoxy-inosin-5'-triphosphat

Dithiothreitol

2'-Desoxy-thymidin-5'-triphosphat

Epstein-Barr-Virus

Escherichia coli

Ethylendiamin-N,N, $\mathrm{N}^{\prime}, \mathrm{N}^{\prime}$-tetraessigsäure

Ethylenglycol-bis(ß-aminoethylether)-

$\mathrm{N}, \mathrm{N}, \mathrm{N}^{\prime}, \mathrm{N}^{\prime}$-tetraacetat

European Molecular Biology Laboratory

expressed sequence tag

et altera

Ethidiumbromid

Ethanol

Fluoreszenz-in situ-Hybridisierung

Gramm

Stunde

Isopropyl-3-D-thiogalaktopyranosid

Kilobasen

Liter

Luria-Bertani-Medium

low-melting-point

Molarität

milli- 
$\mu$

$\mathrm{Mb}$

min

mRNA

$\mathrm{n}$

NBT

OD

OMIM

$\mathrm{p}$

p-Arm

PAC

PAGE

PBS

PCR

PFGE

PIC

q-Arm

rpm

RT

$\mathrm{S}$

SDS

SSCP

STS

Tab.

TEMED

Tris

tRNA

$\mathrm{U}$

ÜN

UV

V

Vol.

$\mathrm{X}-\mathrm{Gal}$

YAC mikro-

Megabasen

Minute

messenger RNA

nano-

Nitroblau-Tetrazoliumchlorid

Optische Dichte

Online Mendelian Inheritance in Man

pico-

kurzer Arm eines Chromosoms

P1-derived artificial chromosome

Polyacrylamidgelelektrophorese

phosphate buffered saline

polymerase chain reaction

Pulsfeldgelelektrophorese

polymorphism information content

langer Arm eines Chromosoms

Umdrehungen pro Minute

Raumtemperatur

Sekunde

Natriumdodecylsulfat

single-strand conformational polymorphism analysis

sequence tagged site

Tabelle

$\mathrm{N}, \mathrm{N}, \mathrm{N}^{\prime}, \mathrm{N}^{\prime}$-Tetramethylethylendiamin

Tris(hydroxymethyl)-aminomethan

transfer-RNA

Unit (Enzymaktivität)

Über Nacht

ultraviolett

Volt

Volumen

5-bromo-4-chloro-3-indolyl-ß-D-Galaktosid

yeast artificial chromosome 


\section{Einleitung}

\subsection{Kartierung des menschlichen Genoms}

Die Verfügbarkeit detaillierter genetischer und physikalischer Karten für das humane Genom ist Voraussetzung für die Identifizierung von Genen über die positionelle Klonierung und positionelle Kandidatengenverfahren. Daher ist die Erstellung dieser Karten ein wichtiges Ziel, welches im Rahmen des 1988 gegründeten Human Genome Project verfolgt wird (Watson, 1989; McKusick, 1989).

Genetische Karten geben die relative Anordnung und die genetischen Abstände von Loci aufgrund beobachteter Rekombinationen zwischen ihnen wieder. Die Rekombinationshäufigkeit ist ein $\mathrm{Ma} \beta$ für den genetischen Abstand zwischen zwei Loci; je weiter diese auf einem Chromosom voneinander entfernt sind, desto größer ist die Wahrscheinlichkeit, daß sie durch ein Crossing-over in der Meiose getrennt werden. Per Definition beträgt der Abstand zwischen zwei Loci, die eine Rekombination von einem Prozent zeigen, 1 Centimorgan (cM). Eine genetische Distanz von $1 \mathrm{cM}$ entspricht bei Berücksichtigung des gesamten humanen Genoms durchschnittlich einer physikalischen Länge von etwa 1 x $10^{6}$ bp (Stephens et al., 1990). Dabei ist jedoch zu berücksichtigen, daß genetische und physikalische Abstände nicht linear verknüpft sind, da die Rekombinationsereignisse vom Geschlecht und der Chromosomenregion abhängen (Donis-Keller et al., 1987; Murray et al., 1994). Um eine genetische Karte aufgrund von Kopplungsanalysen in Familien erstellen zu können, werden geeignete polymorphe Marker benötigt. Diese stehen mit den DNA-Polymorphismen, die sich über das gesamte Genom verteilen, in ausreichender Anzahl zur Verfügung.

Bis 1988 waren die DNA-Marker für Kopplungsanalysen im wesentlichen begrenzt auf Restriktionsfragment-Längenpolymorphismen (RFLPs), die auf RestriktionsschnittstellenPolymorphismen beruhen (Botstein et al., 1980; White et al., 1985). Die ersten RFLPs wurden charakterisiert, indem Southern-Blots von Restriktionsspaltungen mit radioaktiv markierten Sonden hybridisiert wurden. Dieses Verfahren ist jedoch sehr arbeitsintensiv und erfordert den Einsatz großer DNA-Mengen. Zudem besitzen RFLPs, die dadurch entstehen, daß eine Schnittstelle zerstört oder neu geschaffen wird, nur zwei Allele (Schnittstelle vorhanden oder nicht vorhanden) und somit einen geringen Informationsgehalt. Eine neue Familie von Markern, die Minisatellitenmarker (variable number of tandem repeats, VNTRs) mit Tandemwiederholungen variabler Anzahl, wurden erstmals von Nakamura et al. (1987) beschrieben. Im Gegensatz zu Markern, mit denen der Austausch eines einzigen Basenpaares erkannt wird, können diese Marker sehr informativ sein und hohe Polymorphismus-Informationsgehalte (polymorphism information content, PIC) aufweisen (Nakamura et al., 1987). Minisatellitenmarker sind jedoch ungleichmäßig im Genom verteilt und treten gehäuft in der Nähe von Telomeren auf (Royle et al., 1988). Methodische Probleme stellten jedoch auch nach Einführung der Minisatellitenmarker im Hinblick auf eine einfache Kartierung immer noch ein Hindernis dar, da auch diese Marker über radioaktive Hybridisierungen auf Southern-Blots charakterisiert wurden. Eine genetische Karte mit geringer Auflösung, die mit Hilfe von RFLPs und Minisatelliten erstellt worden war, wurde 1987 von Donis-Keller et al. vorgestellt.

Mit Einführung der Polymerase-Kettenreaktion (PCR) (Saiki et al., 1988) wurden Kartierungen schnell und einfach möglich. Auch RFLPs werden inzwischen in der Regel zunächst mit 
geeigneten Primern amplifiziert. Anschließend wird das PCR-Produkt mit dem entsprechenden Restriktionsenzym inkubiert und mittels einer Gelelektrophorese überprüft, ob das entsprechende Fragment gespalten wurde. Minisatelliten sind für Standard-PCR-Verfahren jedoch weniger gut geeignet, da sich große Allele oft schlecht amplifizieren lassen. Die rasche Erweiterung der genetischen Karten konnte durch den Einsatz einer neuen Art von polymorphen Markern, den sogenannten Mikrosatellitenmarkern (short tandem repeat polymorphism, STRPs) erreicht werden. Dabei handelt es sich um tandemförmig wiederholte Sequenzelemente von häufig 2 bis 5 Basen (Weber \& May, 1989), die aufgrund ihrer Variabilität in der Anzahl der Repeats ebenfalls als genetische Marker geeignet sind (Zuliani und Hobbs, 1990). Mikrosatellitenmarker sind in großer Zahl vorhanden und gleichmäßig über das gesamte Genom verteilt. Zudem besitzen sie einen hohen Informationsgehalt und sind über PCR leicht zu analysieren (Weber et al., 1990).

Eine Kopplungskarte mit Mikrosatellitenmarkern wurde 1992 von Weissenbach et al. vorgestellt. Geeignete Marker wurden mit Hilfe von somatischen Mensch/Nagetier-Hybridzellinien den spezifischen Chromosomen zugeordnet, anschließend wurden Kopplungsanalysen durchgeführt, um die Positionen der Marker zu bestimmen. Die so erstellte Karte beinhaltete 813 Marker. Später erstellte genetische Karten enthielten weitere genetische Marker (vor allem Mikrosatelliten) und zeigten eine zunehmend höhere Auflösung. Die 1994 vorgestellte comprehensive human linkage map (Murray et al., 1994) beinhaltete 5826 Loci mit einer durchschnittlichen Distanz von 0,7 cM. Die von Dib et al. (1996) erstellte Karte enthielt 5264 polymorphe Marker mit einem durchschnittlichen Abstand von 1,6 cM. Die Auflösung genetischer Karten hat sich seitdem kaum verbessert, da sich allgemein die Ansicht durchsetzte, daß die vorhandene Markerauflösung ausreicht, um als Grundlage für die Erstellung einer umfassenden physikalischen Karte des menschlichen Genoms zu dienen (Collins et al., 1998).

Physikalische Karten geben den Abstand zwischen einzelnen Loci in absoluten Werten, ausgedrückt in Basenpaaren (bp), an. In cytogenetischen Karten werden DNA-Marker in Bezug zum Bandenmuster des Chromosoms nach differentieller Färbung oder basierend auf ihrer relativen Position auf einem Chromosom angeordnet. Dies kann über die Analyse von somatischen Zellhybriden (Weiss und Green, 1967) oder mittels der Fluoreszenz-in situ-Hybridisierung (FISH) (Pinkel et al., 1986; Lichter et al., 1988) erfolgen.

Somatische Zellhybride werden hergestellt, indem humane Zellen mit Nagetierzellen fusioniert werden. Da in den anschließenden Teilungszyklen humane Chromosomen verloren gehen, können auf diese Weise Hybridklone erhalten werden, die nur einzelne humane Chromosomen enthalten. Indem diese Hybridzellen auf die An- bzw. Abwesenheit von Markern analysiert werden, läßt sich die Zuordnung einer humanen Sequenz zu einem bestimmten Chromosom indirekt ermitteln. Die subchromosomale Kartierung einer Sonde kann über die Analyse von strahlungsinduzierten Hybriden (radiation hybrid map, $\mathrm{RH}$ ) ermittelt werden. Zur Herstellung der strahlungsinduzierten Hybride werden entweder Mensch/Nagetier-Hybridzellinien, die ein oder mehrere menschliche Chromosomen enthalten, oder diploide humane Zellen mit Röntgenstrahlung behandelt und somit die Chromosomen fragmentiert. Diese Zellen werden mit normalen Nagetierzellen fusioniert. Ein Selektionssystem sorgt dafür, daß nur Hybridzellen überleben. Die entstandenen strahlungsinduzierten Hybride enthalten das selektierbare Marker- 
gen und verschiedene Fragmente der menschlichen Chromosomen, die an beliebigen Stellen in die Nagetierchromosomen integriert wurden. Da die Röntgenstrahlung umso häufiger einen Bruch zwischen zwei Loci induziert, je größer der Abstand zwischen ihnen ist, lassen sich die Abstände zwischen Markern anhand der Bruchfrequenz messen. Die Maßeinheit für Bestrahlungskarten ist centiRay (cR). Eine Entfernung von $1 \mathrm{cR}_{\mathrm{x}}$ zwischen zwei Loci entspricht 1 $\%$ Bruchfrequenz nach einer Bestrahlung mit x rad Röntgenstrahlung. Die Hybridklone werden anschließend auf die An- bzw. Abwesenheit von Markern getestet. Die Auflösung der auf diese Weise konstruierten Karten ist von der Bestrahlungsdosis abhängig. Die bisher detaillierteste RH-Karte des gesamten humanen Genoms wurde von Deloukas et al. (1998) veröffentlicht. Diese Karte beinhaltet 41664 Loci. Da auch Mikrosatelliten-Marker der genetischen Karte von Dib et al. (1996) in die RH-Karte integriert wurden, ist auch ein direkter Bezug zur genetischen Karte hergestellt.

Im Gegensatz zur indirekten Kartierung mittels somatischer Zellhybride erlaubt die FISH den direkten Nachweis einer zu einer Sonde komplementären Sequenz auf einem Chromosom. Dabei wird eine DNA-Sonde nach Markierung mit einem Reportermolekül auf Chromosomenpräparate hybridisiert. Anschließend wird das Reportermolekül durch Bindung an ein fluoreszenzmarkiertes Nachweisreagenz und anschließende optische Anregung sichtbar gemacht. Der Gebrauch verschiedener Fluoreszenzfarbstoffe erlaubt die gleichzeitige Detektion von mehreren DNA-Sonden. Bei Hybridisierung auf Metaphasechromosomen können DNA-Sonden jedoch nur dann als getrennt voneinander nachgewiesen werden, wenn sie mehr als ca. $3 \mathrm{Mb}$ auseinanderliegen (Lichter et al., 1990; Lawrence et al., 1990). Bei Hybridisierung an Prometaphasechromosomen erhöht sich die Auflösung auf ca. $1 \mathrm{Mb}$. Die erzielte Auflösung der FISH-Kartierung läßt sich durch Hybridisierung auf künstlich entspiralisierte Chromatin- oder DNA-Fasern weiter verbessern. Auf diese Weise ist eine Auflösung von bis zu $5 \mathrm{~kb}$ zu erreichen (Tocharoentanaphol et al., 1994). Bray-Ward et al. (1996) hybridisierten mittels der FISH über 950 YAC-Klone der CEPH-YAC-Bibliothek auf humane Metaphasechromosomen und ordneten die YACs aufgrund ihrer relativen Position auf den Chromosomen an. Zudem wurden 337 dieser Klone spezifischen Regionen bzw. Banden zugeordnet. Da die meisten von BrayWard et al. (1996) kartierten Klone für ein oder mehrere polymorphe Marker positiv getestet wurden, ist mittels der erhaltenen FISH-Ergebnisse eine Integration von cytogenetischen, genetischen und physikalischen Karten möglich.

Zunehmend stehen für einzelne chromosomale Regionen physikalische Karten in Form von überlappenden Klonen genomischer Art, sog. Contigs, zur Verfügung. Ein wichtiges Zwischenziel des Human Genome Project, welches bis zum Ende des Jahres 2001 erreicht sein soll, ist die Erstellung einer Contig-Karte, die $90 \%$ des menschlichen Genoms abdeckt (Collins et al., 1998; Goodman, 1998). Überlappungen zwischen den Klonen lassen sich beispielsweise über das sogenannte STS content mapping feststellen. Dabei werden verschiedene Klone auf die An- bzw. Abwesenheit verschiedener sequence tagged sites (STSs) untersucht, die als beliebige, mittels der PCR nachweisbare Sequenzabschnitte definiert sind (Olson et al., 1989). Klone mit mehr oder weniger gleichem STS-Gehalt können auf diese Weise als überlappend identifiziert werden. Über STS content mapping läßt sich somit auch die wahrscheinliche Anordnung von Markern auf genomischer Ebene bestimmen. Die Auflösung der Contig-Karten hängt davon $a b$, welche Vektoren für die Erstellung eines Contigs eingesetzt werden (YACs, 
BACs, PACs, P1-Klone, Cosmide, Plasmide), und wie groß der Abstand zwischen den einzelnen Markern ist. YAC-Klone können Inserts mit einer Größe von bis zu $2000 \mathrm{~kb}$ tragen (Burke et al., 1987; Cohen et al., 1993). Daher eignen sich YAC-Contigs gut zur Klonierung großer genomischer Bereiche. Ein besonderer Nachteil von YACs besteht jedoch in dem häufigen Auftreten chimärer Klone (Green et al., 1991; Nagaraja et al., 1994). Da zudem Deletionen oder Umordnungen im YAC-Insert auftreten können, enthalten nahezu 50 \% aller YAC-Klone als Artefakte DNA-Abschnitte, die im Genom nicht zusammenhängen (Larionov et al., 1994). Eine YAC-Contig-Karte, die 75 \% des humanen Genoms mit 225 Contigs abdeckt, wurde 1995 von Chumakov et al. veröffentlicht. Zudem sind in der Datenbank des Whitehead Institute YAC-Contigs für große Bereiche des humanen Genoms verfügbar. Detailliertere physikalische Karten wurden mit Hilfe von genomischen Klonen wie BACs, PACs oder Cosmiden für zahlreiche kleinere genomische Regionen erstellt. Beispielsweise stellten Vollrath und JaramilloBabb (1999) ein BAC-Contig für die Chromosomenregion 1q24 vor, welches 2,2 Mb umfaßt.

Die Restriktionskartierung ist eine physikalische Kartierung, deren Auflösung von der Häufigkeit der ausgewählten Schnittstellen abhängt. DNA-Bereiche werden durch diese Karten über die relative Anordnung der Restriktionsschnittstellen charakterisiert. Restriktionskarten selten schneidender Endonukleasen lassen sich erstellen, indem die Fragmente mit Hilfe der Pulsfeldgelelektrophorese (Carle et al., 1986) aufgetrennt werden.

Die endgültige physikalische Karte des menschlichen Genoms ist die vollständige DNASequenz. Diese soll bis zum Jahr 2003 im Rahmen des Human Genome Project (HGP) über die Sequenzierung von kartierten Klonen ermittelt werden (Collins et al., 1998; Goodman, 1998). Die Sequenzierung dieser Klone erfolgt in 2 Phasen. In der ersten Phase wird der größte Teil der Sequenz eines kartierten Klons (vorwiegend BACs und PACs) generiert, indem 1,4 bis 2,2 kb lange DNA-Fragmente des Klons in M13- oder Plasmid-Vektoren subkloniert und diese Subklone von beiden Enden her ansequenziert werden. Die auf diese Weise erhaltenen Sequenzen werden miteinander verbunden und eine sogenannte "working draft"-Sequenz erhalten, die den größten Teil des zu sequenzierenden Klons abdeckt. In der zweiten Phase werden durch gezielte Sequenzierungen Lücken geschlossen und Unstimmigkeiten beseitigt (The Sanger Centre and the Washington University Genome Sequencing Center, 1998). Ein Zwischenziel des HGP ist es, bis zum Ende 2001 mindestens $90 \%$ des Genoms mit sogenannten "working draft"-Sequenzen kartierter Klone abzudecken. Zudem soll bereits ein Drittel der humanen Sequenz bis Ende 2001 vollständig verfügbar sein und als komplette Sequenz hoher Qualität vorliegen (Collins et al., 1998). Von Venter et al. (1998) wird dagegen eine Strategie zur Sequenzierung großer Teile des humanen Genoms verfolgt, die auf der shotgun Subklonierung des gesamten humanen Genoms und der anschließenden Sequenzierung dieser Klone beruht. Das Zusammenfügen dieser Daten zu einer durchgehenden Sequenz hoher Qualität dürfte jedoch durch das Vorhandensein von repetitiven Sequenzen im Genom nur mit Hilfe der vom HGP öffentlich zur Verfügung gestellten Information möglich sein (Collins et al., 1998).

\subsection{Isolierung von Krankheitsgenen}

Die Identifizierung von Genen ist Voraussetzung für eine Mutationsanalyse und ermöglicht die molekulare Diagnose genetisch bedingter Erkrankungen. Zudem besitzt die Klonierung krank- 
heitsverursachender Gene und die Erforschung der Funktion ihrer Genprodukte ein großes Potential für die Entwicklung gezielter medizinischer Therapien für genetische Erkrankungen. Zur Identifizierung von Krankheitsgenen können verschiedene Strategien angewendet werden (Wicking und Williamson, 1991; Collins, 1992; Stubbs, 1992; Ballabio, 1993; Collins, 1995). Die Vorgehensweise hängt vom Informationsstand über die jeweilige Erkrankung ab, beispielsweise davon, ob Tiermodelle vorhanden sind oder chromosomale Anomalien mit der jeweiligen Erkrankung in Zusammenhang gebracht werden können.

Bei der funktionsspezifischen Klonierung (Collins, 1992; Ballabio, 1993; Collins, 1995) werden Informationen über die Funktion eines Gens genutzt, um dieses zu klonieren. Somit ist die funktionsspezifische Klonierung nur möglich, wenn bekannt ist, welcher biochemische Basisdefekt einer Erkrankung zugrunde liegt. Die Klonierung des Gens kann beispielsweise erreicht werden, indem Proben, die aufgrund der Aminosäuresequenz eines Proteins hergestellt wurden, zum Durchsuchen von cDNA-Bibliotheken eingesetzt werden. Mit Hilfe der cDNASequenz können anschließend genomische Klone für eine vollständige Charakterisierung des Gens isoliert werden. Diese ermöglichen zudem die Kartierung des Gens. Durch funktionsspezifische Klonierung wurde beispielsweise die Klonierung des Faktor IX-Gens, dessen Defekt zu Hämophilie B führt, erreicht (Giannelli et al., 1983; Camerino et al., 1984).

Bei Erkrankungen, deren biochemische Grundlagen unbekannt sind, kann das verantwortliche Gen über seine genetische oder physikalische Lokalisierung im Genom isoliert werden. Diese Strategie wird als positionelle Klonierung bezeichnet (Collins, 1992). Durch Einschränkung der Region, die das gesuchte Gen enthält, ist dieses schließlich zu identifizieren. Anschließend kann die Funktion des Gens geklärt werden (Wicking und Williamson, 1991; Collins, 1992; Stubbs, 1992; Ballabio, 1993; Collins, 1995). Ein Beispiel für diese Vorgehensweise ist die Klonierung des für die Cystische Fibrose verantwortlichen CFTR-Gens (Kerem et al., 1989; Riordan et al., 1989; Rommens et al.,1989).

Die chromosomale Lokalisierung des mutierten Gens kann über Kopplungsanalysen in Familien, in denen die Erkrankung segregiert, eingeleitet werden. Dazu werden die Familien mit über das ganze Genom verteilten polymorphen Markern analysiert, bis eine genetische Kopplung mit ein oder mehreren chromosomal lokalisierten Markern gefunden und so die chromosomale Lokalisierung des mutierten Gens ermittelt wird. Nachdem eine Kopplung mit DNAMarkern nachgewiesen ist, wird versucht die verantwortliche Region über eine Feinkartierung weiter einzugrenzen. Limitierend dabei ist jedoch die Anzahl der verfügbaren informativen Meiosen der betroffenen Familien.

In einigen Fällen treten bei Probanden mit einer genetischen Erkrankung cytogenetisch sichtbare Chromosomenveränderungen, wie Deletionen, Duplikationen oder Translokationen auf, die Hinweise auf die Position des verantwortlichen Gens geben. Dies kann den Prozeß der Genlokalisierung erheblich beschleunigen, da die veränderten Segmente gezielt als Kandidatenregionen untersucht werden können (Collins, 1992). Beispiele für die Lokalisierung einer vererbbaren Krankheit durch Analyse von kleinen Deletionen beinhalten die Identifizierung des Retinoblastoms auf Chromosom 13q14.1-q14.2 (Oryne et al., 1971; Grace et al., 1971; Wilson et al., 1973; Riccardy et al., 1979; Balaban-Mahlenbaum et al., 1981; Fukushima et al.,1987), 
der Muskeldystrophie Duchenne auf Xp21.2 (Kunkel et al., 1986; Koenig et al.,1987) und der Polyposis coli auf Chromosom 5q21-q22 (Hockey et al., 1989; Cross et al., 1992). In diesen drei Fällen lieferten die Deletionen den wichtigsten Hinweis für die spätere Isolierung der Gene.

De novo entstehende, reziproke Translokationen können ebenso zur Isolierung eines Gens beitragen (McKusik, 1994). Bei Translokationen kann die Krankheit entweder dadurch entstehen, daß ein Gen oder eine regulatorische Region durch ein Bruchereignis unterbrochen oder durch Bildung eines sogenannten Fusionsgens ein neuer Phänotyp verursacht wird (McKusik, 1994; Wagner et al., 1994). Kontrollelemente eines Gens können zudem kodierende Elemente eines anderen Gens beeinflussen.

Bei einer Reihe von X-chromosomalen Erkrankungen lieferten balancierte X-autosomale Translokationen bei betroffenen Probanden einen wichtigen Hinweis auf die Lokalisierung des Gens auf dem X-Chromosom. Bei reziproken Translokationen zwischen Autosomen kann der Locus des zu klonierenden Gens definiert werden, indem bei Probanden mit derselben Diagnose unabhängige Translokationsereignisse identifiziert werden, die jeweils das gleiche Chromosom bzw. die gleiche Chromosomenbande betreffen. Im Fall der Typ II hereditären Sphärozytose wurde die Krankheit durch zwei Familien mit balancierten Translokationen der Chromosomenregion 8p11 zugeordnet. In einer Familie wurde eine Translokation zwischen den Chromosomen 8 und 12 gefunden (Kimberling et al., 1975 und 1978) und in einer anderen eine Translokation zwischen Chromosom 3 und 8 (Bass et al., 1983). In beiden Familien segregierte die Sphärozytose mit der balancierten Translokation, wobei der Bruchpunkt innerhalb von 8p sich jeweils in der Bande 8p11 befand. Später wurde gezeigt, daß diese Krankheit durch einen Defekt im Ankyrin-Gen entsteht (Lux et al., 1990).

Weitere Beispiele, bei denen die Identifizierung eines Krankheitsgens durch reziproke autosomale Translokationen ermöglicht wurde, sind die Blepharophimose (BPES) im Bereich 3q22q23, die Greig-Cephalopolysyndactylie auf 7q13, das Williams-Beuren-Syndrom auf 7q11.2, die Aniridie auf 11p13 und das Rubinstein-Taybi-Syndrom im Bereich 16p13.3 (McKusik, 1994).

Um die Genregion einer Erkrankung, welche bereits über Kopplungsanalyse oder cytogenetische Auffälligkeiten einem chromosomalen Segment zugeordnet wurde, weiter einzugrenzen, erfolgt in der Regel die physikalische Kartierung und Klonierung des relevanten Bereichs. Mit Sonden der Region werden z. B. YAC-Klone identifiziert und aus diesen Contigs aufgebaut. Die weitere Analyse erfolgt dann in der Regel mit kleineren genomischen Klonen wie BACs, PACs und Cosmiden, die überlappend angeordnet auf exprimierte Sequenzen untersucht werden. Nach der Identifizierung transkribierter Sequenzen im klonierten DNA-Abschnitt wird geprüft, ob das entsprechende Gen bei erkrankten Personen Mutationen aufweist. Wenn solche Mutationen festgestellt werden, ist der Nachweis erbracht, daß es sich bei der exprimierten Sequenz um das krankheitsverursachende Gen handelt.

Bei positionsunabhängigen Kandidatengenverfahren werden Gene mit einer bestimmten Erkrankung in Zusammenhang gebracht, ohne daß die Position des Gens bekannt ist. Dies kann beispielsweise dann der Fall sein, wenn der Phänotyp einer Krankheit dem einer Erkrankung bei Menschen oder Tieren ähnlich ist, für die das zugrundeliegende Gen bekannt ist. 
Ist die verantwortliche chromosomale Region eingeengt, so kann auch ein positioneller Kandidatengen-Versuch unternommen werden, bei dem Gene, die aufgrund ihrer Lokalisation und ihrer Funktion mögliche Kandidatengene sind, nach spezifischen Mutationen durchsucht werden (Collins, 1992; Ballabio, 1993; Collins, 1995). Beispielsweise wurde im Fall der Retinitis pigmentosa zunächst eine Kopplung mit Markern des langen Arms von Chromosom 3 festgestellt (Donis-Keller et al., 1987; McWilliam et al, 1989). Da das für Rhodopsin kodierende Gen ebenfalls dem langen Arm von Chromosom 3 zugeordnet worden war (Nathans et al.,1986), wurde in Patienten mit Retinitis pigmentosa nach Mutationen innerhalb des Rhodopsin-Gens gesucht. Dadurch, daß bei einem Teil der Patienten Mutationen innerhalb dieses Gens gefunden wurden, konnte gezeigt werden, daß eine Mutation im Rhodopsin-Gen die Ursache für eine Form der Retinitis pigmentosa ist (Dryja et al., 1990).

Da im Rahmen des humanen Genomprojektes die Anzahl kartierter Gene drastisch zunimmt, gewinnt der positionelle Kandidatengenversuch zunehmend an Bedeutung. Im Dezember 1999 waren bereits 5849 Gene einem spezifischen Chromosom zugeordnet (OMIM). In Anbetracht der Tatsache, daß die Anzahl der humanen Gene auf 65000 bis 80000 geschätzt wird (Antequera \& Bird, 1994; Fields et al., 1994), ist dies zwar nur ein kleiner Teil, trotzdem kann mit einer relativ raschen Kartierung gerechnet werden, da ein großer Teil der Gene bereits als sogenannte expressed sequence tag (EST) vorliegt. Dabei handelt es sich um sequenzierte Abschnitte von cDNA-Klonen, die unter Verwendung spezifischer Primer als exprimierte STS darstellbar sind (Adams et al., 1991). Kartiert eine EST in die Kandidatenregion, so kann der entsprechende cDNA-Klon für weitere Analysen herangezogen werden.

Eine physikalische RH-Karte des humanen Genoms, die 30181 Gene bzw. ESTs enthält, wurde 1998 von Deloukas et al. vorgestellt. Somit ist inzwischen mehr als ein Drittel der humanen Gene zumindest in Form von ESTs kartiert. Ein Jahr nach dem Erscheinen der Vorgängerkarte (Schuler et al., 1996), welche ungefähr 16000 Gene bzw. ESTs enthält, wurden 16 Gene über positionelle Klonierung bzw. positionelle Kandidatengenversuche kloniert. Von diesen Genen waren zur Zeit ihrer Klonierung bereits 7 als ESTs kartiert (Deloukas et al., 1998).

Sind keine Kandidatengene verfügbar, können mit den im Rahmen des positionellen Klonierens gewonnenen rekombinanten Klonen transkribierte Sequenzen für eine kritische Region isoliert werden. Um Transkripte in einer großen genomischen Region zu identifizieren, gibt es verschiedene Möglichkeiten.

Zoo-Blots identifizieren in der Evolution konservierte Bereiche, indem DNA-Sonden auf Filter mit DNA verschiedener Spezies hybridisiert werden. Da kodierende Sequenzen in der Evolution zum großen Teil konserviert bleiben, deutet das Vorhandensein konservierter Sequenzen auf die Anwesenheit von Genen hin (Monaco et al., 1986; Wicking und Williamson, 1991). Im 5'-Bereich von Genen sind zudem häufig CpG-Inseln ( $C p G$ islands), d.h. kurze, wenig methylierte CG-reiche Sequenzen zu finden, die durch eine Anhäufung von Restriktionsschnittstellen von selten schneidenden Restriktionsenzymen mit einer CG-reichen Schnittsequenz entdeckt werden können (Bird, 1987; Lindsay und Bird, 1987).

Wird auf Northern-Blots hybridisiert, so kann dies zur Entdeckung von transkribierten Sequenzen führen. Anschließend können cDNA-Klone isoliert und sequenziert werden (Wicking und Williamson, 1991). Außerdem können cDNA-Bibliotheken z.B. mit Cosmiden (Herrmann et 
al., 1990; Verkerk et al., 1991; Joslyn et al., 1991) oder YACs (Rommens et al.,1989) durchmustert werden.

Zusätzlich lassen sich Gene durch Exon-Trapping (Duyk et al., 1990) oder der aus dieser Technik modifizierten Exonamplifikation (Buckler et al., 1991; Church et al., 1994) identifizieren. Bei diesen Methoden wird die Fähigkeit von retroviralen Vektoren genutzt, RNAKopien klonierter Sequenzen korrekt zu spleißen (Duyk et al., 1990; Buckler et al., 1991). Es kann auch der gesamte Bereich sequenziert und die erhaltene Sequenz mit der anderer Spezies verglichen oder eine Exon-Vorhersage (Uberbacher und Mural, 1991) durchgeführt werden.

Verschiedene Verfahren sind verfügbar, mit deren Hilfe krankheitsverursachende Gene identifiziert und darin kausale Mutationen nachgewiesen werden können. $\mathrm{Zu}$ den gebräuchlichen gehören beispielsweise die Analyse von Einzelstrang-Konformationspolymorphismen (singlestrand conformational polymorphism analysis, SSCP) (Orita et al., 1989), die Analyse der Mobilität von Heteroduplexsträngen (Keen et al., 1991), Gelelektrophorese mit einem Denaturierungsgradienten (denaturing gradient gel electrophoresis, DGGE) (Cariello und Skopek, 1993) und chemische bzw. enzymatische Spaltung an Fehlpaarungsstellen (Dean, 1995). Mutationen können auch über den Nachweis verkürzter Proteine (protein truncation test, PTT) festgestellt werden (Roest et al., 1993). Eine weitere Möglichkeit Mutationen in einem Gen zu identifizieren, besteht darin, die codierenden Bereiche und angrenzende Spleißstellen eines Gens zu sequenzieren. Bei dieser Methode werden in der Regel sämtliche Veränderungen, die nicht ganze Exons betreffen, erkannt. Ein Nachteil dieser Methode ist darin zu sehen, daß das Verfahren relativ arbeitsaufwendig ist (Ballhausen, 1998).

\subsection{Das Russell-Silver-Syndrom (RSS)}

Das Russell-Silver-Syndrom (RSS) wurde unabhängig voneinander erstmals von Silver et al. (1953) und Russell (1954) beschrieben. Black (1961) und Rimoin (1969) erkannten gemeinsame Merkmale der Probanden und schlugen vor, solche mit ähnlichem Phänotyp unter dem Russell-Silver-Syndrom zusammenzufassen.

$\mathrm{Zu}$ den Hauptmerkmalen des RSS zählen eine prä- und postnatale Wachstumsretardierung sowie ein charakteristisches kleines dreiecksförmiges Gesicht mit relativ großer, vorgewölbter Stirn (Wollmann et al., 1995). Das Auftreten weiterer Symptome kann die Diagnose bestätigen, wird jedoch nicht als obligatorisch vorausgesetzt. Die Geburtslänge von Jungen und Mädchen liegt bei etwa 43,2 $\pm 3,7 \mathrm{~cm}$. Das Geburtsgewicht von Jungen beträgt $1940 \pm 353 \mathrm{~g}$ und das von Mädchen $1897 \pm 325$ g. Die Endgröße der männlichen Probanden liegt bei 151,2 \pm 7,8 cm und die von weiblichen Probanden bei 139,7 \pm 7,4 cm (Wollmann et al., 1995). Neben den Hauptmerkmalen des Syndroms weisen $68 \%$ der Probanden eine Klinodactylie der fünften Finger auf, relative Makrocephalie ist bei $64 \%$ der Probanden festzustellen, Anomalien der Ohren zeigen $53 \%$ der Probanden und skeletale Asymmetrien werden bei $51 \%$ der Probanden beobachtet. Andere, bei weniger als $50 \%$ der Probanden auftretende Merkmale sind Brachydactylie der fünften Finger (48 \%), abwärts gerichtete Mundwinkel (46 \%), muskuläre Hypotrophie/-tonie (45\%), psychomotorische Retardierung (37\%), schiefe Zähne (28\%), hohe piepsige Stimme (22\%), Syndactylien (19\%), Café-au-lait Flecken (19\%) und eine früh 
einsetzende Pubertät (8 \%) (Wollmann et al., 1995). Wollmann et al. (1995) gaben keine Frequenz für das Auftreten eines reduzierten Knochenalters an, zeigten jedoch, daß das Knochenalter von 111 Probanden bis zum Alter von etwa 10 Jahren deutlich unter dem chronologischen Alter lag. Nach Escobar et al. (1978) ist das Knochenalter bei 50 \% der Probanden reduziert. Die Symptome sind bei einzelnen Probanden unterschiedlich stark ausgeprägt, die Expressivität ist sehr variabel (Tanner et al., 1975; Escobar et al., 1978).

Die Häufigkeit des RSS ist unbekannt, seit der ersten Beschreibung 1953 wurden jedoch ungefähr 350 Probanden beschrieben (Wollmann et al., 1995). Meistens entsteht das RSS sporadisch. Es wurden jedoch auch Familien mit ein oder mehreren betroffenen Geschwistern beschrieben (Rimoin, 1969; Fuleihan et al., 1971; Robichaux et al., 1981; Nair und Sabarinathan, 1984; Davies et al., 1988; Teebi, 1992) was auf eine genetische Ursache des RSS und auf einen autosomal rezessiven Erbgang in einigen Familien schließen läßt (Teebi, 1992; Wollmann et al., 1995). In anderen Fällen ließen phänotypische Ähnlichkeiten zwischen dem betroffenen Kind und der Mutter auf einen dominanten Erbgang schließen (Duncan et al., 1990; Zanchetta et al., 1990; Al-Fifi et al., 1996). Bei genetischen Analysen von 150 Personen beobachteten Escobar et al. (1978) 4 Familien, in denen Geschwister betroffen waren, und 5 Familien, in denen ein anderes Familienmitglied Symptome des RSS zeigte. Die Autoren vermuteten daher einen autosomal dominanten Erbgang mit unvollständiger Penetranz und einer hohen Frequenz an Neumutationen. Nach Patton (1988) hätten jedoch mehr Familien mit mehreren Betroffenen identifiziert werden müssen, wenn das RSS dominant vererbt wird, zumal das Syndrom nicht tödlich verläuft und die Probanden nicht infertil sind. Von Partington et al. (1986) wurde eine Familie mit RSS vorgestellt und ein X-chromosomaler Erbgang vorgeschlagen. In drei Fällen waren die Kinder einer betroffenen Mutter unauffällig (Abramowicz und Nitowsky, 1977; Tapia et al., 1983, Wollmann et al., 1995).

In Zusammenhang mit dem RSS wurden verschiedene Chromosomenaberrationen beobachtet, die die Chromosomen 1 (Kennerknecht und Rodens, 1991), 8 (Schinzel et al., 1994), 13 (Wahlström et al., 1989), 15 (Wilson et al., 1985; Francke et al, 1988; Roback et al., 1991; Dolon, 1993; Tamura et al., 1993; Rogan et al., 1996) und 18 (Christensen und Nielsen, 1978; Niklaus et al., 1992) betreffen. Kleczkowska et al. (1986) berichteten zudem über einen Fall mit einer Translokation $\mathrm{t}(5 \mathrm{p} 7 \mathrm{p} ; 5 \mathrm{q} 7 \mathrm{q})$. Weiterhin wurden inzwischen 16 RSS-Probanden mit einer maternalen uniparentalen Disomie von Chromosom 7 (mUPD7) beschrieben (Spence et al., 1988; Voss et al., 1989; Spotila et al., 1992; Kotzot et al., 1995; Langlois et al., 1995; Shuman et al., 1996; Preece et al., 1997; Eggermann et al., 1997; Cuisset et al., 1997), von denen mindestens 12 die Symptome des RSS zeigten.

Da in Verbindung mit dem RSS sowohl über verschiedene Erbgänge als auch über Aberrationen verschiedener Chromosomen berichtet wurde, vermuten viele Autoren, daß das RSS genetisch heterogen ist (Escobar et al., 1978; Goodmann und Gorlin, 1983; Saal et al., 1985; Partington, 1986; Wahlström et al., 1989, Kotzot et al., 1995, Preece et al., 1999). Andere Autoren vermuten, daß sich hinter der Diagnose RSS verschiedene bisher nicht unterscheidbare Entwicklungsstörungen verbergen (Graham et al., 1981; Wilson et al., 1985; Rogan et al., 1996).

Eine Probandin mit RSS und einer familiären Translokation t(17;20)(q25;q13) wurde 1992 von Ramirez-Dueñas et al. beschrieben. Midro et al. beschrieben 1993 einen Probanden mit einer 
de novo entstandenen Translokation $\mathrm{t}(1 ; 17)(\mathrm{q} 31 ; \mathrm{q} 25)$. Da der Translokationsbruchpunkt auf Chromosom 17 bei diesen Translokationsprobanden cytogenetisch übereinstimmt, wurde als Grundlage für diese Arbeit angenommen, daß die Translokationsbruchpunkte der Chromosomenregion 17q25 mit dem RSS assoziiert sind.

Im Rahmen einer vorangegangenen Arbeit (Dörr, 1995) wurde der Translokationsbruchpunkt des von Midro et al. (1993) beschriebenen Probanden über FISH-Analyse mit cytogenetisch kartierten Cosmiden (Inazawa et al., 1989) abweichend von der cytogenetischen Analyse von Midro et al. in der Region 17q23-q24 kartiert. Es wurden erste YAC-Klone für die Region des Translokationsbruchpunktes isoliert und diese in einem vorläufigen Contig (s. Abb. 1) angeordnet (Dörr, 1995).

\subsection{Ziel der Arbeit}

Im Rahmen der vorliegenden Arbeit sollte ausgehend von dem bestehenden YAC-Contig eine hochauflösende physikalische Karte der Region des Translokationsbruchpunktes des von Midro et al. (1993) beschriebenen RSS-Probanden auf Chromosom 17 erstellt werden. Zudem sollte die Bruchpunktregion über die Isolierung von kleineren genomischen Klonen wie Cosmiden oder PACs weiter eingegrenzt werden, um in der Region des Translokationsbruchpunktes mögliche Kandidatengene für das RSS identifizieren $\mathrm{zu}$ können. Schließlich sollte in möglicherweise vorhandenen RSS-Kandidatengenen nach Mutationen in RSS-Probanden gesucht werden. 


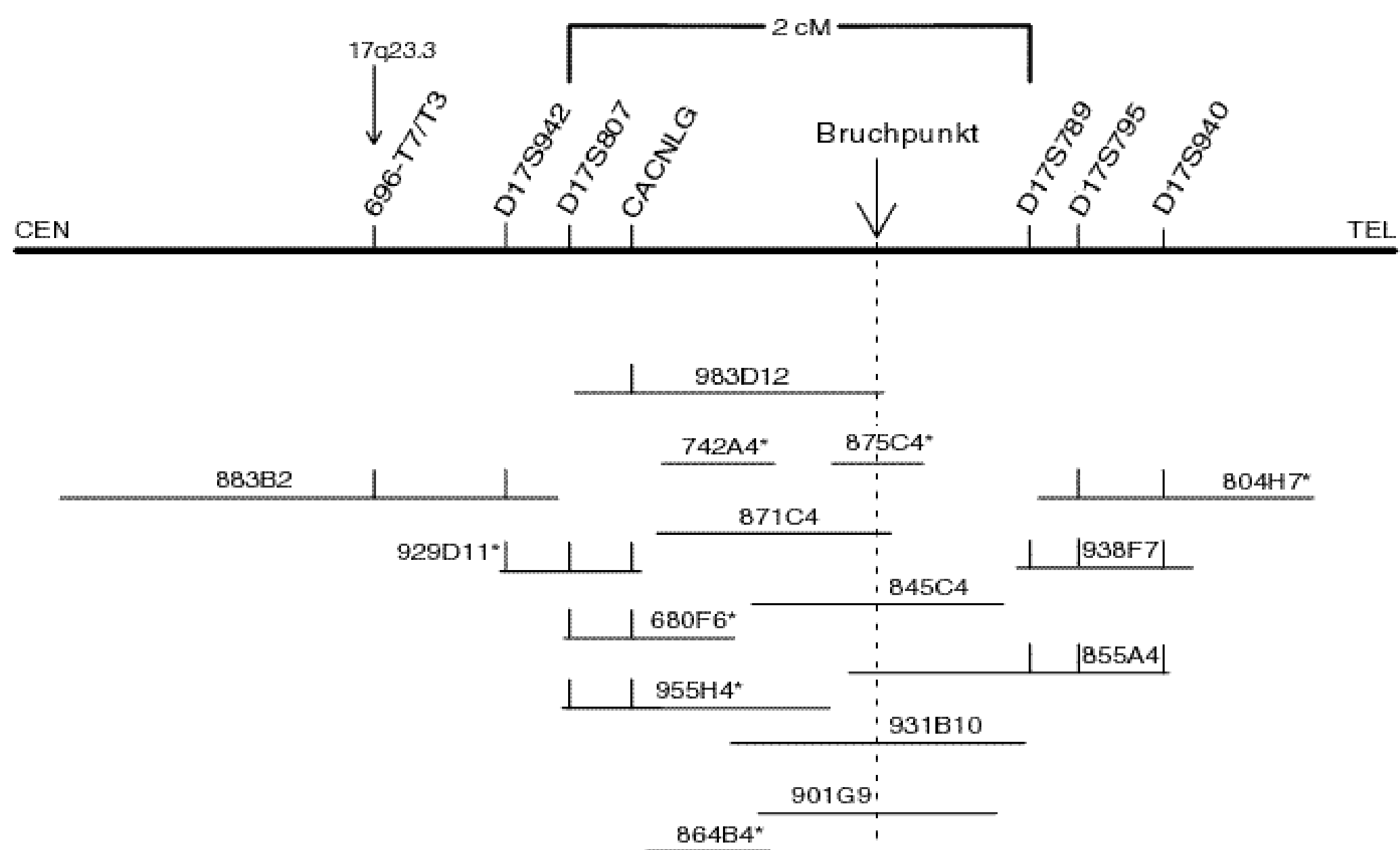

Abb. 1: Physikalische Kartierung der für das Russell-Silver-Syndrom kritischen Chromosomenregion 17q23-q24 mit Hilfe von YAC-Klonen. YACs, die nicht maßstabsgerecht eingezeichnet wurden, sind mit einem Stern markiert. Bei diesen YACs handelt es sich um solche, die entweder chimärisch sind, oder die entsprechenden Hefezellen enthalten mehr als einen YAC, so daß nicht entschieden werden kann, wie groß die Chromosom 17-spezifische Region dieser Klone ist (nach Dörr, 1995). 


\section{Material und Methoden}

\subsection{Material}

\subsubsection{Chemikalien}

\subsubsection{Allgemeine Chemikalien}

Nicht gesondert aufgeführte Chemikalien wurden von den Firmen Merk (Darmstadt), Baker (Deventer, Niederlande) oder Serva (Heidelberg) in p.A. Qualität bezogen.

Acrylamid

Acrylamid (40\%), inkl. $50 \%$ Harnstoff

Acrylamidlösung (40 \%)

Agarose

Ammoniumperoxodisulfat

Ampicillin

Ampuwa

Bacto-Agar

Bacto-Hefeextrakt

Bacto-Trypton

BCIP

Colcemid

DAPI

Dextransulfat

Dithiothreitol

Ethidiumbromid

Ethylendiamin-N,N,N',N'-tetraessigsäure

Ficoll 400

Fötales Kälberserumalbumin

Formamid

Glycerin

Guanidinhydrochlorid

Hanks Salzlösung

Harnstoff

ISCOVES-Medium

Isopropyl- $\beta$-D-thiogalaktopyranosid

Kanamycin

Lambda-DNA

Laurylsarcosin

L-Glutamin

Lithiumdodecylsulfat

Low-melting-point-Agarose

MDE-Fertiglösung
Pharmacia, Freiburg

Serva, Heidelberg

Amresco, Solon, USA

Gibco BRL, Eggenstein

Serva, Heidelberg

Boehringer, Mannheim

Fresenius AG, Bad Homburg

Difco-Laboratories, Detroit, USA

Difco-Laboratories, Detroit, USA

Difco-Laboratories, Detroit, USA

Gibco BRL, Eggenstein

Calbiochem, Bad Soden

Serva, Heidelberg

Pharmacia, Freiburg

Sigma, Deisenhofen

Merck, Darmstadt

Merck, Darmstadt

Sigma, Deisenhofen

Biochrom, Berlin

Fluka, Neu-Ulm

Serva, Heidelberg

Stratagene, Heidelberg

Biochrom, Berlin

Serva, Heidelberg

Gibco BRL, Eggenstein

Boehringer, Mannheim

Boehringer, Mannheim

New England Biolabs

Sigma, Deisenhofen

Serva, Heidelberg

Sigma, Deisenhofen

Gibco BRL, Eggenstein

Biozym, Hamburg 
Natriumdodecylsulfat

NBT

PBS

Penicillin/Streptomycin

Phenol

Phytohämagglutinin

Polyethylenglycol

Polyvinylpyrrolidon

p-Phenylendiamin

Propidiumiodid

Rapid-hyb buffer

ReproGel $^{\mathrm{TM}}$

Sea-Plaque-GTG-LMP-Agarose

Sorbitol

Tetramethylethylendiamin

Triton-X 100

Tween 20

Vectashield

$\mathrm{X}-\mathrm{GAL}$

Yeast nitrogen base

\subsubsection{Radiochemikalien}

$\left[\alpha-{ }^{32} \mathrm{P}\right]-\mathrm{dCTP},\left[\gamma^{32} \mathrm{P}\right]-\mathrm{ATP}$

\subsubsection{Biochemikalien und Enzyme}

Agarase

Aminosäuren

Biotin-16-dUTP

Biotinyliertes Anti-Avidin D

Cot-1-DNA, human

Digoxigenin-11-dUTP

DNA-Polymerase I

DNase I

dNTPs

Fluorescein Avidin DCS

Kaninchen-Anti-Maus IgG konj. Cy3

Lachssperm-DNA

Lysozym

Lytikase

Maus-Anti-Digoxigenin IgG

Megaprime $^{T M}$ DNA labelling system
Serva, Heidelberg

Gibco BRL, Eggenstein

Biochrom, Berlin

Biochrom, Berlin

Gibco BRL, Eggenstein

Wellcome Diagnostics

Serva, Heidelberg

Sigma, Deisenhofen

Sigma, Deisenhofen

Sigma, Deisenhofen

Amersham LIFE SCIENCE, Braunschweig

Pharmacia, Freiburg

FMC BioProducts, Rockland, USA

Merck, Darmstadt

Sigma, Deisenhofen

Merck, Darmstadt

Sigma, Deisenhofen

Vector Lab., über Serva, Heidelberg

Sigma, Deisenhofen

Difco, Detroit, USA

Amersham Buchler, Braunschweig

Boehringer, Mannheim

Serva, Heidelberg

Boehringer, Mannheim

Vector Lab., über Serva, Heidelberg

Gibco BRL, Eggenstein

Boehringer, Mannheim

Boehringer, Mannheim

Serva, Heidelberg

Boehringer, Mannheim

Vector Lab., über Serva, Heidelberg

Jackson Immuno Research Lab. (USA), über Dianova

Sigma, Deisenhofen

Sigma, Deisenhofen

Boehringer, Mannheim

Boehringer, Mannheim

Amersham, Braunschweig 
Plazenta-DNA

Proteinase $\mathrm{K}$

Restriktionsendonukleasen

Rinderserumalbumin

RNase A

Spermidin

Spermin

Streptavidin alkaline Phosphatase

Taq-DNA-Polymerase

T4-DNA-Ligase

Thermo Sequenase dye terminator

Ziege-Anti-Kaninchen IgG konj. Cy3
Sigma, Deisenhofen

Serva, Heidelberg

NEB/Schwalbach/Taunus

Boehringer, Mannheim

Biomol, Ilvesheim

Sigma, Deisenhofen

Sigma, Deisenhofen

Sigma, Deisenhofen

Gibco BRL, Eggenstein

MBI Fermentas, St. Leon-Rot

Boehringer, Mannheim

NEB/Schwalbach/Taunus

Amersham LIFE SCIENCE, Braunschweig Jackson Immuno Research Lab. (USA), über Dianova

\subsubsection{Oligodesoxyribonukleotide}

Die verwendeten Oligodesoxyribonukleotide wurden von folgenden Firmen bezogen:

NAPS, Göttingen

Kits \& Probes GmbH, Göttingen

Eurogentec, Seraing, Belgien

Pharmacia, Freiburg

Metabion, Martinsried

\subsubsection{DNA-Längenstandards}

$1 \mathrm{~kb}$-Leiter

Lambda-DNA-Eco130I

Lambda-DNA-HindIII

Lambda-DNA-HindIII/EcoRI

Lambda-Mix 19

Lambda-Konkatamere

low-range-PFGE-Marker

pBluescript-DNA-HpaII

pUC-Mix Marker, 8

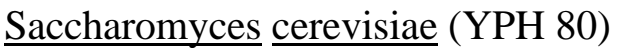

Boehringer, Mannheim

MBI Fermentas, St. Leon-Rot

NEB, Schwalbach/Taunus

NEB, Schwalbach/Taunus

MBI Fermentas, St. Leon-Rot

NEB, Schwalbach/Taunus

NEB, Schwalbach/Taunus

eigene Präparation

MBI Fermentas, St. Leon-Rot

NEB, Schwalbach/Taunus 


\subsubsection{Gebrauchswaren}

Gebrauchswaren, die nicht gesondert aufgeführt sind, wurden von den Firmen Schütt bzw. Krannich, Göttingen, bezogen.

Deckgläser $(24 \times 60 \mathrm{~mm}$ oder $24 \times 32 \mathrm{~mm}) \mathrm{AL}$

Dia-Farbfilme (Scotch Chrome 640T) Scotch

Filterpapier

Schleicher \& Schüll, Dassel

Fixogum

Marabu, Hamm

Gewebekulturflaschen, $50 \mathrm{ml}$

Hyperfilm $^{\mathrm{TM}}$-MP-Röntgenfilm

Greiner, Nürtingen

Küvetten

MicroSpin ${ }^{T M} G-50$ Columns

Amersham, Braunschweig

Hellma

MicroSpin ${ }^{T M}$ S-300 HR Columns

Pharmacia Biotech

Pharmacia Biotech

Nitrozellulosefilter

Schleicher \& Schüll, Dassel

Nylonmembran (Hybond N \& N+)

Amersham, Braunschweig

Objektträger, $76 \times 26 \mathrm{~mm}$

Menzel-Gläser

Pasteurpipetten, $150 \mathrm{~mm}$

Brand

Pipettenspitzen

Eppendorf, Hamburg

Plastikwaren

Greiner, Nürtingen und Sarstedt

Reaktionsgefäße

Eppendorf, Hamburg

Skalpelle, steril

Swann-Morton, Sheffield

Whatman-Papier

Schleicher \& Schüll, Dassel

\subsubsection{Puffer und Stammlösungen}

Für alle Lösungen wurde Milli-Q-Wasser (Milli-Q-Water-System von Millipore) verwendet. Hitzestabile Lösungen wurden bei $121^{\circ} \mathrm{C}$ und 2 bar im Dampfdruck-Autoklaven autoklaviert. Hitzeempfindliche Lösungen wurden sterilfiltriert (Porengröße 0,25 $\mu$ m oder $0,45 \mu \mathrm{m}$ ).

10 x Aminosäure-Stock

$200 \mu \mathrm{g} / \mathrm{ml}$ Adenin

$200 \mu \mathrm{g} / \mathrm{ml}$ Arginin

$200 \mu \mathrm{g} / \mathrm{ml}$ Isoleucin

$200 \mu \mathrm{g} / \mathrm{ml}$ Histidin

$600 \mu \mathrm{g} / \mathrm{ml}$ Leucin

$200 \mu \mathrm{g} / \mathrm{ml}$ Lysin

$200 \mu \mathrm{g} / \mathrm{ml}$ Methionin

$500 \mu \mathrm{g} / \mathrm{ml}$ Phenylalanin

$300 \mu \mathrm{g} / \mathrm{ml}$ Tyrosin (in verdünnter $\mathrm{NaOH}$ lösen)

$1.5 \mathrm{mg} / \mathrm{ml}$ Valin

\section{Elektrophorese-Ladepuffer}

0,1\% Bromphenolblau

$15 \%$ Ficoll 400

Formamid-Ladepuffer

$85 \%$ Formamid

$0,1 \%$ Dextranblau

\section{LB-Medium \& -platten}

$1 \%$ Bacto-Trypton

$0.5 \%$ Bacto-Hefeextrakt

$1 \% \mathrm{NaCl}$

$\mathrm{pH} 7,5$, autoklavieren

1,5\% Agar für Nährmedienplatten 
Phosphatgepufferte Salzlösung (PBS)

$137 \mathrm{mM} \mathrm{NaCl}$

2,7 $\mathrm{mM} \mathrm{KCl}$

$10 \mathrm{mM} \mathrm{Na}_{2} \mathrm{HPO}_{4}$

$1,8 \mathrm{mM} \mathrm{KH}_{2} \mathrm{PO}_{4}$

$\mathrm{pH} 7,2$, sterilfiltrieren

$50 \times$ TAE

$2 \mathrm{M}$ Tris

$0.25 \mathrm{M}$ Natriumacetat

$50 \mathrm{mM}$ EDTA

pH 7.8, autoklavieren

$10 \times$ TE

$100 \mathrm{mM}$ Tris- $\mathrm{HCl}, \mathrm{pH}$ 7,6

10 mM EDTA, $\mathrm{pH} 8,0$
$20 \times \mathrm{SSC}$

$3 \mathrm{M} \mathrm{NaCl}$

0,3 M Tri-Natriumcitrat-2-hydrat

pH 7,0
YAC-Medium \& -platten

$2 \%$ Glukose

$0,67 \%$ Yeast Nitrogen Base

$1 \mathrm{x}$ Aminosäure-Stock

$2 \%$ Agar für Platten

\subsubsection{Art und Herkunft des verwendeten Untersuchungsmaterials}

\subsubsection{Herkunft menschlicher genomischer DNA}

Menschliche genomische DNA wurde aus peripheren Blutzellen klinisch unauffälliger Kontrollpersonen der mitteleuropäischen Bevölkerung gewonnen. Diese DNA wurde als Kontolle bei PCR- und Hybridisierungsanalysen eingesetzt. Zur Herstellung von Kontrollobjektträgern mit Metaphasechromosomen diente heparinisiertes Vollblut von klinisch unauffälligen Personen.

\subsubsection{Probanden mit Russell-Silver-Syndrom}

In Zusammenarbeit mit verschiedenen Kliniken und Ärzten wurde ein Untersuchungskollektiv von 34 Probanden mit Russell-Silver-Syndrom (RSS) etabliert. Die klinische Diagnose RSS wurde von den betreuenden Ärzten gestellt. Bei einem dieser Probanden (AS) wurde cytogenetisch eine de novo Translokation $\mathrm{t}(1 ; 17)(\mathrm{q} 31 ; \mathrm{q} 25)$ festgestellt (Midro et al., 1993), bei einer Probandin (GR) eine Translokation $\mathrm{t}(17 ; 20)(\mathrm{q} 25 ; \mathrm{q} 13)$, die die Probandin von ihrem unauffälligen Vater geerbt hatte (Ramirez-Dueñas et al., 1992). Bei den verbleibenden 32 RSS-Probanden lieferte die cytogenetische Analyse keinen Hinweis auf eine Chromosomenanomalie. Bei einem Probanden (MA) wurden jedoch neben dem RSS die Symptome der Cystischen Fibrose nachgewiesen (Hehr et al.,1999).

Von den Probanden und in den meisten Fällen von deren Familienangehörigen wurde durch die betreuenden Ärzte EDTA- bzw. Heparin-Blut zur DNA- und Chromosomenpräparation, bzw. zur Etablierung permanenter Zellinien nach EBV-Transformation zugesandt. Die Zellinien 
wurden durch das Labor der postnatalen Cytogenetik am Institut für Humangenetik der Universität Göttingen hergestellt und betreut.

\subsubsection{YACs (Yeast artificial chromosomes)}

Die in dieser Arbeit verwendeten YAC-Klone entstammen der YAC-Bibliothek von CEPH, Paris. In Tabelle 1 sind die YAC-Klone des Chromosoms 17 enthalten, die bereits zur Verfügung standen. Tabelle 2 enthält die in dieser Arbeit isolierten YACs des Chromosoms 17 und Tabelle 3 die des Chromosoms 1.

Die in Tabelle 1 aufgeführten YAC-Klone wurden in einer vorangegangenen Arbeit (Dörr, 1995) isoliert und mittels der Pulsfeldgelelektrophorese und der Southern-Blot-Analyse hinsichtlich ihrer Größe und Zahl der enthaltenden YACs charakterisiert. Die Loci D17S942, D17S807, D17S789, D17S795 und D17S940 und das Gen CACNLG (calcium channel, L type, gamma polypeptid) wurden über PCR-Analysen auf den YACs lokalisiert. Weitere Loci wurden den YACs aufgrund von Daten des Whitehead Institue oder des CEPH zugeordnet. Die chromosomale Lokalisierung der YAC-Klone erfolgte über Fluoreszenz-in situ-Hybridisierung (FISH) an Metaphasepräparate von unauffälligen Kontrollpersonen. Signale, die nicht auf Chromosom 17 auftraten, kamen dabei entweder durch chimärische YACs oder durch Klone, die mehr als einen YAC enthalten, zustande. Nach Hybridisierung auf Metaphasepräparate des Probanden AS mit 1;17 Translokation wurden die Chromosom 17-spezifischen YACs proximal (Signal auf der(17)) oder distal (Signal auf der(1)) zum Translokationsbruchpunkt des Probanden kartiert. Zudem wurden 7 YACs identifiziert, die den Translokationsbruchpunkt des Probanden AS auf Chromosom 17 überspannen (Signal auf der(17) und der(1)).

Traten aufgrund des chimärischen Charakters oder wegen der Koklonierung von mehreren YACs bei der Hybridisierung auf normale Chromosomen zusätzliche Signale auf den Chromosomen 1 bzw. 17 auf, war auf einem der derivativen Chromosomen neben einem Signal in der Bruchpunktregion ein weiteres Signal an einem anderen Chromosomensegment vorhanden.

Tab. 1: Übersicht über die YAC-Klone des Chromosoms 17, die bereits zur Verfügung standen

\begin{tabular}{|c|c|c|c|c|}
\hline $\begin{array}{l}\text { YAC- } \\
\text { Klon }\end{array}$ & $\begin{array}{l}\text { YAC-Größe } \\
(\mathrm{kb}) \\
\text { (eigene } \\
\text { Daten) }\end{array}$ & $\begin{array}{l}\text { Loci } \\
\text { (Whitehead/ CEPH/ } \\
\text { eigene Daten) }\end{array}$ & $\begin{array}{l}\text { FISH-Signale an } \\
\text { normalen } \\
\text { Chromosomen }\end{array}$ & $\begin{array}{l}\text { FISH-Signale an den } \\
\text { Translokations- } \\
\text { chromosomen von } \\
\text { Proband AS }\end{array}$ \\
\hline $895 \mathrm{~F} 2$ & $\begin{array}{l}>1600,400, \\
330\end{array}$ & D17S790 & $17 q 21.3-q 22,3 q$ & $\operatorname{der}(17)$ \\
\hline $751 \mathrm{C} 12$ & 1090 & D17S923 & $17 q 22-q 23,17 q 1$ & $\operatorname{der}(17), \operatorname{der}(17)$ \\
\hline 967D10 & 1130 & D17S792 & $17 q 22-q 23,17 q 1$ & $\operatorname{der}(17), \operatorname{der}(17)$ \\
\hline $868 \mathrm{~F} 12$ & $>1600,580$ & D17S808 & $17 q 22-23,2 q, 2 q$ & $\operatorname{der}(17)$ \\
\hline $923 \mathrm{H} 8$ & 630 & D17S944 & $17 q 22-q 23$ & $\operatorname{der}(17)$ \\
\hline $813 \mathrm{~B} 7$ & 1260 & D17S948 & 17q22-q23, 17q1 & $\operatorname{der}(17), \operatorname{der}(17)$ \\
\hline 796C1 & $>1600$ & D17S794 & $17 q 22-q 23,17 q 1, C p$ & $\operatorname{der}(17), \operatorname{der}(17)$ \\
\hline
\end{tabular}


Tab. 1: Fortsetzung

\begin{tabular}{|c|c|c|c|c|}
\hline $\begin{array}{l}\text { YAC- } \\
\text { Klon }\end{array}$ & $\begin{array}{l}\text { YAC-Größe } \\
(\mathrm{kb}) \\
\text { (eigene } \\
\text { Daten) }\end{array}$ & $\begin{array}{l}\text { Loci } \\
\text { (Whitehead/ CEPH/ } \\
\text { eigene Daten) }\end{array}$ & $\begin{array}{l}\text { FISH-Signale an } \\
\text { normalen } \\
\text { Chromosomen }\end{array}$ & $\begin{array}{l}\text { FISH-Signale an den } \\
\text { Translokations- } \\
\text { chromosomen von } \\
\text { Proband AS }\end{array}$ \\
\hline $883 \mathrm{~B} 2$ & $>1600$ & D17S942 & $17 q 23$ & $\operatorname{der}(17)$ \\
\hline 929D11 & 500 & $\begin{array}{l}\text { D17S942, D17S807, } \\
\text { CACNLG }\end{array}$ & 17q23-q24, Cq, Dq, 3p & $\operatorname{der}(17)$ \\
\hline 680F6 & $>1600$ & D17S807, CACNLG & $17 q 23-q 24,2 q$ & $\operatorname{der}(17)$ \\
\hline $955 \mathrm{H} 4$ & 1290 & D17S807, CACNLG & $17 q 23-q 24, \mathrm{Cq}$ & $\operatorname{der}(17)$ \\
\hline 742A4 & n.b. & - & $\begin{array}{l}17 q 23-q 24,6 q, F q, \\
(B q)\end{array}$ & $\operatorname{der}(17)$ \\
\hline 864B4 & 720,440 & - & 17q22-q24, 1q31-q32 & $\begin{array}{l}\text { der(17), Signal aus } \\
\text { 1q auf } \operatorname{der}(17)\end{array}$ \\
\hline 450A9 & 350 & - & $17 q 23-q 24, C q, 2 q$ & $\operatorname{der}(17)$ \\
\hline 983D12 & 1100 & CACNLG & $17 q 23$ & $\operatorname{der}(17), \operatorname{der}(1)$ \\
\hline 901G9 & 850 & - & $17 q 23-q 24$ & $\operatorname{der}(17), \operatorname{der}(1)$ \\
\hline $871 \mathrm{C} 4$ & 840 & - & $17 q 23-q 24$ & $\operatorname{der}(17), \operatorname{der}(1)$ \\
\hline $875 \mathrm{C} 4$ & 380 & - & $17 q 23-q 24,4 q$ & $\operatorname{der}(17), \operatorname{der}(1)$ \\
\hline $845 C 6$ & 900 & - & $17 q 23-q 24$ & $\operatorname{der}(17), \operatorname{der}(1)$ \\
\hline 931B 10 & 1050 & - & $17 q 23-q 24$ & $\operatorname{der}(17), \operatorname{der}(1)$ \\
\hline $855 \mathrm{~A} 4$ & 1090 & $\begin{array}{l}\text { D17S789, D17S795, } \\
\text { D17S940 }\end{array}$ & $17 q 23-q 24$ & $\operatorname{der}(17), \operatorname{der}(1)$ \\
\hline 938F7 & 620 & $\begin{array}{l}\text { D17S789, D17S795, } \\
\text { D17S940 }\end{array}$ & $17 q 23-q 24$ & $\operatorname{der}(1)$ \\
\hline $804 \mathrm{H} 7$ & $>1600,980$ & D17S795, D17S940 & $17 q 23-q 24,2 q, 7 p$ & $\operatorname{der}(1)$ \\
\hline $723 \mathrm{H} 7$ & 820 & D17S840 & $17 q 23-q 24$ & $\operatorname{der}(1)$ \\
\hline $805 \mathrm{G} 6$ & $>1600,910$ & D17S840, D17S949 & $17 q 23-q 24$ & $\operatorname{der}(1)$ \\
\hline 915A11 & n.b. & D17S840, D17S949 & $17 q 24, D q$ & $\operatorname{der}(1)$ \\
\hline 893D11 & 890 & D17S949 & $17 q 23-q 24,17 q 1, \mathrm{Cq}$ & $\begin{array}{l}\text { der(1), Signal aus } \\
17 q 1 \text { auf } \operatorname{der}(17)\end{array}$ \\
\hline 954G3 & 890,680 & D17S785 & $17 \mathrm{q} 23-\mathrm{q} 25, \mathrm{Cq}, \mathrm{Cq}$ & $\operatorname{der}(1)$ \\
\hline 716B9 & 440,150 & D17S785 & $17 q 24-q 25$ & $\begin{array}{l}\text { der(1), Signal aus } \\
\text { 17q1 auf } \operatorname{der}(17)\end{array}$ \\
\hline $738 \mathrm{E} 4$ & $\begin{array}{l}440,350 \\
230,150\end{array}$ & D17S785 & $17 \mathrm{q} 25, \mathrm{Cq}$ & $\operatorname{der}(1)$ \\
\hline
\end{tabular}


Tab. 2: Übersicht über die in dieser Arbeit isolierten YAC-Klone des Chromosoms 17

\begin{tabular}{lll}
\hline YAC-Klon & Insert-Größe $(\mathrm{kb})($ nach CEPH $)$ & Loci $(\mathrm{CEPH})$ \\
\hline $764 \mathrm{~F} 4$ & 1050 & D1S444, D1S240 \\
$963 \mathrm{C} 7$ & 1480 & D17S113, D5S662 \\
$853 \mathrm{~F} 8$ & 730 & D17S1309 \\
\hline
\end{tabular}

Tab. 3: Übersicht über die in dieser Arbeit isolierten YAC-Klone des Chromosoms 1

\begin{tabular}{lcl}
\hline YAC-Klon & $\begin{array}{l}\text { Insert-Größe }(\mathrm{kb}) \\
(\text { Whitehead/CEPH })\end{array}$ & Loci für Chromosom 1 (Whitehead Institute $)$ \\
\hline 918H5 & 1240 & D1S431, D1S445, WI-6347, D1S2799, WI-6381, D1S2658 \\
895F3 & 1730 & D1S1569, WI-7045, WI-9125, WI-6302 \\
$792 \mathrm{D} 9$ & 1640 & D1S452, D1S210, WI-10286 \\
874B11 & 810 & D1S2815, CHLC.ATA14D03, NIB1475, WI-6210, NIB1951 \\
941F11 & 1270 & NIB1475, WI-6210, NIB1951, WI-5780 \\
854B9 & 1060 & WI-3774, D1S2790, WI-5545, WI-7792, WI-7237 \\
744A9 & 1550 & WI-9787, D1S2786, AFM296WF1, D1S212, D1S2791, \\
& & WI-3070, WI-5460 \\
920B6 & 1730 & D1S215, D1S2883, WI-9721, WI-6293, WI-9655, D1S2640 \\
789H12 & 930 & WI-2775; WI-9007, STSG-10176, D1S2818, D1S466, \\
& & D1S2619 \\
940F12 & 190 & WI-8876, WI-6860, WI-7043, CHLC.GATA12F10 \\
765F4 & 1050 & WI-5858, D1S240, WI-6876 \\
864B4 & 400 & D1S444, D1S254 \\
\hline
\end{tabular}

\subsubsection{Cosmid-Marker}

Die Cosmid-Marker wurden von INAZAWA et al., Japan in Form von Agar-Kulturen bezogen. Sie sind Bestandteil der von diesen Autoren konstruierten, hoch auflösenden cytogenetischen Karte des Chromosoms 17, welche 342 Cosmid-Marker beinhaltet (INAZAWA et al., 1993). Die einzelnen Cosmide stammen aus einer Cosmid-Bibliothek, deren Grundlage eine monochromosomale Mensch-Maus-Hybrid-Zellinie von Chromosom 17 war. 
Tab. 4: Überblick über die verwendeten Cosmid-Klone

\begin{tabular}{lll}
\hline Proben-Name & Insert-Größe & chromosomale Lokalisierung \\
\hline cCI17-696 & $38 \mathrm{~kb}$ & $17 \mathrm{q} 23.3$ \\
cCI17-591 & $38 \mathrm{~kb}$ & $17 \mathrm{q} 24$ \\
$\mathrm{cCI} 17-464$ & $30 \mathrm{~kb}$ & $17 \mathrm{q} 24.3-\mathrm{q} 25.1$ \\
$\mathrm{cCI} 17-546$ & $38 \mathrm{~kb}$ & $17 \mathrm{q} 24.3-\mathrm{q} 25.1$ \\
$\mathrm{cCI} 17-469$ & $15 \mathrm{~kb}, 13 \mathrm{~kb}, 12 \mathrm{~kb}, 11 \mathrm{~kb}$ & $17 \mathrm{q} 25.2-\mathrm{q} 25.3$ \\
\hline
\end{tabular}

\subsubsection{5 cDNA-Klone}

Die in dieser Arbeit verwendeten cDNA-Klone wurden von der American Type Culture Collection (ATCC) oder vom RZPD, Berlin bezogen. Die Daten der Klone sind in der folgenden Tabelle angegeben.

Tab. 5: Übersicht über die verwendeten, humanen cDNA-Klone

\begin{tabular}{|c|c|c|c|c|}
\hline Clone ID & $\begin{array}{l}\text { Accession ID } \\
\text { (Genbank/EMBL) }\end{array}$ & EST/Gen & Gewebe & Insertgröße (kb) \\
\hline 65978 (ATCC) & X52479 & PRKCA & $\begin{array}{l}\text { akute T-Zell Leukä- } \\
\text { mie, Jurkat cell line }\end{array}$ & 2,245 \\
\hline $\begin{array}{l}73134 \text { (I.M.A.G.E.) } \\
312967 \text { (ATCC) }\end{array}$ & T56592 + T57277 & WI-9461 & fetale Milz & 0,814 \\
\hline $\begin{array}{l}117423 \text { (I.M.A.G.E.) } \\
339208 \text { (ATCC) }\end{array}$ & $\mathrm{T} 89723+\mathrm{T} 89821$ & WI-9571 & Lunge & keine Angabe \\
\hline 147454 (I.M.A.G.E.) & $\mathrm{R} 81372+\mathrm{R} 81373$ & KPNA2 & Plazenta & 2,599 \\
\hline 531850 (I.M.A.G.E.) & AA 134708 + AA126274 & KPNA2 & Neuroepithel & 2,033 \\
\hline 151572 (I.M.A.G.E.) & H03125 + H03937 & KPNA2 & Plazenta & 1,294 \\
\hline 233334 (I.M.A.G.E.) & H78874 + H80114 & KPNA2 & fötale Leber \& Milz & 1,528 \\
\hline
\end{tabular}

\subsubsection{PAC-Bibliothek}

Die im Rahmen dieser Arbeit verwendete humane genomische PAC-(P1-derived artificial chromosome) Bibliothek wurde von Pieter de Jong und Kollegen konstruiert und vom UK HGMP Resource Centre bezogen. Die Bibliothek besteht aus etwa 115200 Klonen mit einer durchschnittlichen Insert-Größe von $110 \mathrm{~kb}$ und wird in 315 Mikrotiterplatten (384-well) aufbewahrt. Nach Angaben des Herstellers sind $25 \%$ der Klone ohne Insert. Die Bank wurde in Form von PAC-Pools in Glycerin für PCR-Analysen erhalten. 


\subsubsection{Sequenzen und Herkunft der verwendeten Primer}

\subsubsection{Mikrosatellitenmarker und anonyme Sonden für Chromosom 17}

Tab. 6: Übersicht über die eingesetzten Primer von anonymen DNA-Loci des Chromosoms 17

\begin{tabular}{|c|c|c|c|}
\hline Locus (Marker) & Primer $\left(5^{\prime} \rightarrow 3^{\prime}\right)$ & $\begin{array}{l}\text { Produkt- } \\
\text { größe (bp) }\end{array}$ & Referenz \\
\hline D17S1566 & $\begin{array}{l}\text { AAAGATCCTTATTGCCACTTTACTG } \\
\text { CTCTTACCTTGCTGGTGAGATTG }\end{array}$ & $179-209$ & GDB: 461128 \\
\hline D17S948 & $\begin{array}{l}\text { GTCTCTGTCCTTAGGGAGTTTA } \\
\text { TATCTTTGCCCATTTCTTG }\end{array}$ & $125-149$ & Gyapay et al. (1994) \\
\hline D17S1557 (MR11749) & $\begin{array}{l}\text { CCTCTCTTtCCTGGCCTTG } \\
\text { TTGGAGCAATGAAGATGCAG }\end{array}$ & 175 & Whitehead/ MIT (1994) \\
\hline D17S1695 (WI-5110) & $\begin{array}{l}\text { CCCCCAAAGTGAGTGACTGT } \\
\text { GAACTCCCTTCCTTACTTGGTAA }\end{array}$ & 250 & Whitehead/ MIT (1995) \\
\hline $696 \mathrm{~T} 3$ & $\begin{array}{l}\text { GTGGCTTTCAAAGCTCTTGG } \\
\text { ACTATTCCACCCAGTACATGGG }\end{array}$ & 172 & Dörr (1995) \\
\hline $696 \mathrm{~T} 7$ & $\begin{array}{l}\text { GCTTAACCTGGGATTGGTCA } \\
\text { TCTTGACTGGATGGTTCTACCC }\end{array}$ & 193 & Dörr (1995) \\
\hline D17S942 (AFM269YF1) & $\begin{array}{l}\text { CTGATGCCAAGATTTTTTAC } \\
\text { TGATTCTATTTCCCTAATATACTG }\end{array}$ & $168-176$ & Gyapay et al. (1994) \\
\hline D17S1524 (MR10529) & $\begin{array}{l}\text { ACGTGTTATCCTGGTATCCTGC } \\
\text { GAAAGGAACGAGGTGCTCC }\end{array}$ & 125 & Whitehead/ MIT (1994) \\
\hline D17S807 (AFM234XC9) & $\begin{array}{l}\text { TCCACCTGTAGACCTGGTAAA } \\
\text { AGTGCTGCGTCTACAACCT }\end{array}$ & $114-138$ & Weissenbach et al. (1992) \\
\hline GAAT1E12 (GAAT-P7946) & $\begin{array}{l}\text { TCCGTCTTACTCAGACTGGC } \\
\text { CAATCATTCATTGCTCGACA }\end{array}$ & $144-$ & CHLC \\
\hline D17S1813 (AFMA300XA5) & $\begin{array}{l}\text { AGCTCCAAAGTTACATAATGC } \\
\text { AAGTGATCCATCCCCC }\end{array}$ & $211-229$ & Dib et al. (1996) \\
\hline D17S1870 (AFM323TB1) & $\begin{array}{l}\text { TGTTGCCCCTTAGATTCA } \\
\text { CGCCTGGCTAATTTTG }\end{array}$ & $218-240$ & Dib et al. (1996) \\
\hline D17S789 (AFM107YB8) & $\begin{array}{l}\text { ACTCCAAATCAAGTTTGTACTGAGA } \\
\text { CTGCATACGAAGGGTAGGAC }\end{array}$ & $154-170$ & Weissenbach et al. (1992) \\
\hline D17S795 (AFM175XG3) & $\begin{array}{l}\text { TTTTCATGCGCTATCTCCAG } \\
\text { TGAGTTGTTAGCAATACTCGTAGG }\end{array}$ & $105-121$ & Weissenbach et al. (1992) \\
\hline D17S940 & $\begin{array}{l}\text { CCTGTTTTTTGATGTACTTATCTC } \\
\text { TCTTTAATGGAATTTCATACC }\end{array}$ & $207-215$ & Gyapay et al. (1994) \\
\hline
\end{tabular}




\subsubsection{Mikrosatellitenmarker für Chromosom 7, 18 und 20}

Tab. 7: Eingesetzte Primer von anonymen DNA-Loci der Chromosomen 7, 18 und 20

\begin{tabular}{|c|c|c|c|}
\hline Locus (Marker) & Primer $\left(5^{\prime} \rightarrow 3^{\prime}\right)$ & $\begin{array}{l}\text { Produkt- } \\
\text { größe (bp) }\end{array}$ & Referenz \\
\hline D7S493 & $\begin{array}{l}\text { GGAAGTTCCCAGCCATAGTT } \\
\text { GAAAGCACTTACCTACTGAGGATTT }\end{array}$ & $194-224$ & Weissenbach et al. (1992) \\
\hline D7S502 & $\begin{array}{l}\text { GGAAGGTATGTTGCGG } \\
\text { TAAGCCACCAAGAACACC }\end{array}$ & $273-291$ & Weissenbach et al. (1992) \\
\hline D7S527 & $\begin{array}{l}\text { CATTGCAAACTCAGGAGATA } \\
\text { TAACAGAGGCATGAAAACCA }\end{array}$ & $273-297$ & Weissenbach et al. (1992) \\
\hline D7S483 & $\begin{array}{l}\text { AGTGGTCATTAGCCTTGGCAAAATC } \\
\text { AACCAGAGTTGTAAGCCATGAAAGT }\end{array}$ & $166-188$ & Weissenbach et al. (1992) \\
\hline D7S684 & $\begin{array}{l}\text { GCTTGCAGTGAGCCGAC } \\
\text { GATGTTGATGTAAGACTTTCCAGCC }\end{array}$ & $169-187$ & Gyapay et al. (1994) \\
\hline D18S1009 & $\begin{array}{l}\text { CCCTTATCATGCTCTATCCA } \\
\text { CTGGTGTGGGAGACAAAT }\end{array}$ & $144-154$ & Dib et al. (1996) \\
\hline D18S554 & $\begin{array}{l}\text { TAACTGAGACCNTGAGTCGTGA } \\
\text { GCTGCATTTGGCTTGG }\end{array}$ & $212-228$ & Gyapay et al. (1994) \\
\hline D20S1154 & $\begin{array}{l}\text { ACTTGCATTTTAAACACAATCCCTG } \\
\text { CTAAGACCGCTTTCCCTGTTGA }\end{array}$ & $205-$ & GDB: 6053909 \\
\hline
\end{tabular}

\subsubsection{EST-Marker}

Tab. 8: Übersicht über die eingesetzten Primer von expressed sequence tags

\begin{tabular}{|c|c|c|c|}
\hline EST & Primer $\left(5^{\prime} \rightarrow 3^{\prime}\right)$ & $\begin{array}{l}\text { Produkt- } \\
\text { größe (bp) }\end{array}$ & Referenz \\
\hline WI-9571 & $\begin{array}{l}\text { TTCAATTCAGGTACTTGAAAGAAGG } \\
\text { TCTTCTGGCACACCTGGAG }\end{array}$ & 278 & Whitehead/ MIT (1996) \\
\hline WI-9269 & $\begin{array}{l}\text { ATCTTAGTACTTTTTCTGCGGCC } \\
\text { GGGTGAAACAGATCAAAGCC }\end{array}$ & 99 & Whitehead/ MIT (1996) \\
\hline WI-8032 & $\begin{array}{l}\text { TATTATCTCCACAAGAAAACAACCA } \\
\text { GGCATCTGTAGAAATTTTTGTCA }\end{array}$ & 204 & Whitehead/ MIT (1996) \\
\hline stSG2005 & $\begin{array}{l}\text { TTGCTGCTATATCCAAGAGCTG } \\
\text { GTGATGAGCCATTTTTCAAATG }\end{array}$ & 219 & Sanger Centre (1996) \\
\hline stSG3721 & $\begin{array}{l}\text { GGAAGAAAAACACAGAACAGCC } \\
\text { ACCACTGCCACTGCTGAAG }\end{array}$ & 132 & Sanger Centre (1996) \\
\hline stSG2549 & $\begin{array}{l}\text { TTGCAGGCTTGTATTCCACA } \\
\text { AGTTAAAAAGGGGGTGGGTG }\end{array}$ & 166 & Sanger Centre (1996) \\
\hline WI-9461 & $\begin{array}{l}\text { CACCAACTTCATGACTTCTAAAATG } \\
\text { TCTTGGGGAGAAGGGAATAA }\end{array}$ & 178 & Whitehead/ MIT (1996) \\
\hline
\end{tabular}


Tab. 8: Fortsetzung

\begin{tabular}{|c|c|c|c|}
\hline EST & Primer $\left(5^{\prime} \rightarrow 3^{\prime}\right)$ & $\begin{array}{l}\text { Produkt- } \\
\text { größe (bp) }\end{array}$ & Referenz \\
\hline WI-7618 & $\begin{array}{l}\text { AAATGTCTGTTTTTCATAATTGCTC } \\
\text { TCAAATATTTTTTATTGGAAGGCC }\end{array}$ & 276 & Whitehead/ MIT (1996) \\
\hline WI-15726 (ICAM2) & $\begin{array}{l}\text { CAGGTGTTTGTATTCGGGCT } \\
\text { ACACCACGGTGGTCACTG }\end{array}$ & 126 & Whitehead/ MIT (1996) \\
\hline
\end{tabular}

\subsubsection{Gen-Primer}

Tab. 9: Übersicht über die verwendeten Gen-Primer

\begin{tabular}{|c|c|c|c|}
\hline Locus & Primer $\left(5^{\prime} \rightarrow 3^{\prime}\right)$ & $\begin{array}{l}\text { Produkt- } \\
\text { größe (bp) }\end{array}$ & Referenz \\
\hline ACOX 1 & $\begin{array}{l}\text { CAGTTGGAAAGACTTCA } \\
\text { CCTGGGCATACTTCATC }\end{array}$ & 420 & Varanasi et al. (1994) \\
\hline $\mathrm{ACE}$ & $\begin{array}{l}\text { GCTTCAGTAGGCCGTGG } \\
\text { ATGCAGCTCGTTCTCCG }\end{array}$ & 125 & Genethon (1996) \\
\hline DCP1 & $\begin{array}{l}\text { CTGGAGACCACTCCCATCCTTTCT } \\
\text { GATGTGGCCATCACATTCGTCAGAT }\end{array}$ & $190 / 490$ & Rigat et al. (1992) \\
\hline $\mathrm{APOH}$ & $\begin{array}{l}\text { GTGTAGGTGTACTCATCTACTGTGT } \\
\text { CTCTCCTTGGTACACCACAGTGG }\end{array}$ & 147 & $\begin{array}{l}\text { Steinkasserer et al. } \\
\text { (1993) }\end{array}$ \\
\hline GAA & $\begin{array}{l}\text { TGGTGACCGATGCCAGGAACAGAGGAT } \\
\text { GTGCACTCTGCCCTTTCGTGTACACAGA }\end{array}$ & $\begin{array}{l}\text { keine } \\
\text { Angabe }\end{array}$ & Huie et al. (1994) \\
\hline PECAM1 & $\begin{array}{l}\text { TAATACAACATCCACGAGGGTC } \\
\text { CTGACAGTGTCTTGAGTGGG }\end{array}$ & 142 & $\begin{array}{l}\text { NCBI; Accession-Nr. } \\
\text { RH17926 }\end{array}$ \\
\hline G6PDL & $\begin{array}{l}\text { GATTAGAGGTTATACAAACTGAA } \\
\text { CTTCTGTATAAGCACCTACTG }\end{array}$ & 132 & $\begin{array}{l}\text { NCBI; Accession-Nr. } \\
\text { RH26351 }\end{array}$ \\
\hline D17S1977 (PRKCA) & $\begin{array}{l}\text { CTCACCAGCGAGAACAAACA } \\
\text { AAGCCGTGGCCTTAAAATTT }\end{array}$ & 90 & $\begin{array}{l}\text { Stanford Human } \\
\text { Genome Center (1995) }\end{array}$ \\
\hline ITGA2B & $\begin{array}{l}\text { TCTCCGTCTTCTGTTACACCTACCA } \\
\text { TGATGGTGCAGCCTACACTATTCTA }\end{array}$ & 372 & GDB (1991) \\
\hline ITGB3 & $\begin{array}{l}\text { AGCCATTGCTCCTAGTGGAG } \\
\text { GCTAAATCATCCTTAGCCTTC }\end{array}$ & $166-184$ & Stoffel und Bell (1992) \\
\hline TBX2 & $\begin{array}{l}\text { AGCTGAGGAGAAGTCGTGC } \\
\text { ACTGTCTGTCTGCACCACCAG }\end{array}$ & 320 & $\begin{array}{l}\text { Campbell } \\
\text { (pers. Mitteilung) }\end{array}$ \\
\hline ICAM2 & $\begin{array}{l}\text { TTTATCAGCAGCTTCCCAG } \\
\text { TAGCCTTCTGCAAACTGATG }\end{array}$ & 135 & selbst gewählt \\
\hline CACNLG-5, & $\begin{array}{l}\text { CATCATGCATGTGTATCAGT } \\
\text { CTGCCTGCTCCCAGACAGCT }\end{array}$ & 190- & Powers et al. (1993) \\
\hline CACNLG-3', & $\begin{array}{l}\text { GAAGCCTGAGGGTCGCTAGG } \\
\text { GGATGGGGCTGGTGGCTACG }\end{array}$ & $324-$ & Olkers et al. (1993) \\
\hline
\end{tabular}




\subsubsection{Vektorspezifische Primer}

Tab. 10: Bezeichnung und Sequenzen der vektorspezifischen Primer

\begin{tabular}{lll}
\hline Bezeichnung & Sequenz & Referenz \\
\hline URA & CGATATAGGCGCCAGCAACCGCACCTGTGG & Bates et al. (1992) \\
TRP & CGCACCCGTTCTCGAGCACTGTCCGACC & Bates et al. (1992) \\
T3 & AATTAACCTCACTAAAGGG & nach Stratagene \\
T7 & GTAATACGACTCACTATAGGGC & nach Stratagene \\
Cos1-T3 & AATTAACCCTCACTAAAGG & Giannakudis (pers. Mitteilung) \\
Cos1-T7 & CATAATACGACTCACTATAGG & Giannakudis (pers. Mitteilung) \\
PAC-Sp6 & GGCCGTCGACATTTAGGTGACAC & selbst gewählt \\
PAC-T7 & CCGCTAATACGACTCACTATAGGG & selbst gewählt \\
\hline
\end{tabular}

\subsubsection{Alu- und LINE-Primer}

Tab. 11: Bezeichnung und Sequenzen der verwendeten Alu- und LINE-Primer

\begin{tabular}{|c|c|c|}
\hline Bezeichnung & Sequenz & Referenz \\
\hline $5^{\prime}$ & GGATTACAGGCGTGAGCCAC & Tagle \& Collins (1992) \\
\hline $3^{\prime}$ & GATCGCGCCACTGCACTCC & Tagle \& Collins (1992) \\
\hline 450 & AAAGTGCTGGGATTACAGG & Breen et al. (1992) \\
\hline 451 & GTGAGCCGAGATCGCGCCACTGCACT & Breen et al. (1992) \\
\hline 153 & GGGATTACAGGCGTGAGCCAC & Breen et al. (1992) \\
\hline 154 & TGCACTCCAGCCTGGGCAACA & Breen et al. (1992) \\
\hline CL1 & TCCCAAAGTGCTGGGATTACAG & Lengauer et al. (1992) \\
\hline CL2 & CTGCACTCCAGCCTGGG & Lengauer et al. (1992) \\
\hline CL3 & GTTGGCCAGGCTGGTCT & Lengauer et al. (1992) \\
\hline ALE1 & GCCTCCCAAAGTGCTGGGATTACAG & Cole et al. (1991) \\
\hline ALE3 & CCA $(\mathrm{C} / \mathrm{T}) \mathrm{TGCACTCCAGCCTGGG}$ & Cole et al. (1991) \\
\hline LINE1 & CATGGCACATGTATACATATGTAAC (A/T) AACC & Scott et al. (1987) \\
\hline AGK34 & GCCGAGATCG (C/T) GCCACTGCACTCCAGCCTGGG & Baldini et al. (1992) \\
\hline
\end{tabular}




\subsubsection{Vektoren}

Folgende Vektoren wurden für Klonierungen bzw. Hybridisierungen verwendet:

Tab. 12: Vektoren

\begin{tabular}{ll}
\hline Vektor & Referenz \\
\hline pBluescript SK & Short et al. (1988) \\
pBR322 & Bolivar et al. (1978) \\
pGEM-T-Vektor & Marchuk et al. (1991) \\
pZErO-2 & Invitrogen Nr. 45-0448 \\
SuperCos-1 & Evans et al. (1989) \\
\hline
\end{tabular}

\subsubsection{Bakterienstämme}

Folgende E. coli K12 Stämme wurden im Rahmen dieser Arbeit verwendet:

Tab. 13: Bakterienstämme

\begin{tabular}{ll}
\hline Stamm & Referenz \\
\hline DH5 $\alpha$ & Hanahan (1983) \\
XL1-blue-MR & Bullock et al. (1987) \\
\hline
\end{tabular}

\subsubsection{Antibiotika und Selektivplatten}

Es wurden Stammlösungen der Antibiotika Ampicillin (50 mg/ml) und Kanamycin (30 mg/ml) angesetzt, sterilfiltriert und bis zum Gebrauch bei $-20^{\circ} \mathrm{C}$ gelagert. Der Zusatz der Antibiotika zu den autoklavierten Medien erfolgte nach Abkühlung auf etwa $55^{\circ} \mathrm{C}$ im Verhältnis $1: 1000$ (50 bzw. $30 \mu \mathrm{g} / \mathrm{ml}$ Endkonzentration). Zur Herstellung von selektiven Platten mit X-Gal wurden dem abgekühlten LB-Agar Ampicillin, 1mM IPTG (Stammlösung $100 \mathrm{mM}$ in $\mathrm{H}_{2} \mathrm{O}$ ) und $0,0004 \% \mathrm{X}-\mathrm{Gal}$ (Stammlösung $2 \%$ in N-N-Dimethylformamid) zugegeben, gemischt und steril in Petrischalen gegossen. Die Platten wurden bei $4^{\circ} \mathrm{C}$ gelagert. 


\subsection{Methoden}

Die Methoden wurden, soweit nicht anders angegeben, nach Sambrook et al. (1989) durchgeführt.

\subsubsection{Isolierung von DNA aus Bakterien}

\subsubsection{Alkalische Minipräparation von Plasmid-, Cosmid- und PAC-DNA}

Alkalischer Lysispuffer 1:

$50 \mathrm{mM}$ Glukose

$25 \mathrm{mM}$ Tris-HCI, $\mathrm{pH} 8,0$

$10 \mathrm{mM}$ EDTA, pH 8,0

$5 \mathrm{mg} / \mathrm{ml}$ Lysozym

Alkalischer Lysispuffer 2:

$0,2 \mathrm{~N} \mathrm{NaOH}$

$1 \%$ SDS

Alkalischer Lysispuffer 3:

3 M Kaliumacetat, $\mathrm{pH}$ 5,5

$5 \mathrm{ml}$ LB-Medium mit Kanamycin $(30 \mu \mathrm{g} / \mathrm{ml})$ bzw. Ampicillin $(50 \mu \mathrm{g} / \mathrm{ml})$ wurden mit rekombinanten Bakterienzellen einer Einzelkolonie angeimpft und ÜN im Rundschüttler bei $37^{\circ} \mathrm{C}$ inkubiert. $1,5 \mathrm{ml}$ der Bakteriensuspension wurden in einem Reaktionsgefäß für $5 \mathrm{~min}$ bei $13.000 \mathrm{rpm}$ und RT abzentrifugiert (Biofuge pico, Heraeus, Osterode). Der Überstand wurde verworfen und erneut $1,5 \mathrm{ml}$ der gleichen Bakterienkultur zugegeben. Nach wiederholter Zentrifugation wurden die Bakterien in $100 \mu$ l Lysispuffer 1 resuspendiert und 5 min bei RT stehengelassen. Nach Zugabe von $200 \mu$ l Lysispuffer 2 wurde vorsichtig gemischt und 5 min bei RT inkubiert. Die Ausfällung der Proteine erfolgte durch Zugabe von $150 \mu 1$ Lysispuffer 3. Nach einer Inkubation von mindestens 5 min auf Eis wurde für 20 min bei $13.000 \mathrm{rpm}$ und RT zentrifugiert. Der Überstand wurde in ein neues Reaktionsgefäß überführt und $1 \mathrm{x}$ mit Phenol und $1 \mathrm{x}$ mit Ether extrahiert. Anschließend wurde die DNA durch Zugabe von 2,5 Vol. absolutem Ethanol für $20 \mathrm{~min}$ bei RT gefällt und dann $20 \mathrm{~min}$ bei $13.000 \mathrm{rpm}$ und RT abzentrifugiert. Das DNA-Pellet wurde mit $70 \%$ Ethanol gewaschen, wie oben zentrifugiert, getrocknet und in einem definierten $\mathrm{Vol} . \mathrm{H}_{2} \mathrm{O}$ aufgenommen.

\subsubsection{Alkalische Maxipräparation von Plasmid-, Cosmid- und PAC-DNA}

(modifiziert nach Birnboim \& Doly, 1979 und Ish-Horowicz \& Burke, 1981)

Lösungen siehe 2.2.1.1.

$50 \mathrm{ml}$ LB-Medium mit Kanamycin $(30 \mu \mathrm{g} / \mathrm{ml})$ bzw. Ampicillin $(50 \mu \mathrm{g} / \mathrm{ml})$ wurden mit rekombinanten Bakterienzellen einer Einzelkolonie von einer Agarplatte angeimpft und ÜN unter Schütteln bei $37^{\circ} \mathrm{C}$ inkubiert. Die Bakterien wurden $15 \mathrm{~min}$ bei $4.000 \mathrm{rpm}$ und $4{ }^{\circ} \mathrm{C}$ abzentrifugiert (Megafuge 1,0 R, Herolab, Wiesloch), in 2,5 ml Alkalischem Lysispuffer 1 
resuspendiert und 5 min bei RT inkubiert. Anschließend wurden $10 \mathrm{ml}$ Alkalischer Lysispuffer 2 zugegeben und erneut 5 min bei RT inkubiert. Es wurden 7,5 ml Alkalischer Lysispuffer 3 zupipettiert, nach Mischen mindestens 5 min auf Eis inkubiert und die Zelltrümmer sowie die genomische DNA wie oben beschrieben abzentrifugiert. Die DNA wurde in einem neuen Reaktionsgefäß aus dem Überstand mit 1 Vol. Isopropanol gefällt. Das Präzipitat wurde nach erneuter Zentrifugation in $500 \mu \mathrm{l} \mathrm{H}_{2} \mathrm{O}$ aufgenommen. Nach Zugabe von $10 \mu \mathrm{g}$ RNase A wurde 30 min bei $37^{\circ} \mathrm{C}$ inkubiert. Die DNA wurde $2 \mathrm{x}$ mit Phenol und $1 \mathrm{x}$ mit Ether extrahiert. Durch Zugabe von 2 Vol. absolutem Ethanol wurde die DNA bei RT gefällt und anschließend 20 min bei $13.000 \mathrm{rpm}$ und RT abzentrifugiert (Biofuge pico, Heraeus, Osterode). Die DNA wurde mit $70 \%$ Ethanol gewaschen, abzentrifugiert, getrocknet und in einem definierten $\mathrm{Vol} . \mathrm{H}_{2} \mathrm{O}$ aufgenommen.

\subsubsection{Herstellung von Stammkulturen}

$\mathrm{Zu} 500 \mu \mathrm{l}$ einer ÜN-Kultur wurde das gleiche Vol. steriles Glycerin in ein Reaktionsgefäß pipettiert. Nach kurzem Vortexen wurden die Glycerinstocks sofort auf Trockeneis oder in flüssigem Stickstoff eingefroren und bei $-70^{\circ} \mathrm{C}$ gelagert.

\subsubsection{Präparation von YAC-DNA}

2.2.2.1 Präparation von YAC-DNA in Lösung (nach Burke et al., 1987; The Fifth Wellcome Summer School, London, 1990)

$\begin{array}{clrl}\text { Guanidin-HCl-Lösung, } \mathrm{pH} 8,0: & 4,5 \mathrm{M} \mathrm{GuHCl} & \text { Sorbitol-Puffer, } \mathrm{pH} 7,5: & 0,9 \mathrm{M} \text { Sorbit } \\ & 0,1 \mathrm{M} \mathrm{EDTA} & & 20 \mathrm{mM} \text { EDTA } \\ & 0,15 \mathrm{M} \mathrm{NaCl} & \\ & 0,05 \% \text { Sarkosyl } & \end{array}$

Durch die hier dargestellte Präparation wurden DNA-Fragmente in einem Größenbereich von 50-200 kb erhalten. Die so erhaltene DNA wurde für PCR-Analysen eingesetzt. $5 \mathrm{ml}$ YACMedium wurden mit einer Hefekolonie angeimpft und 1 Tag bei $30^{\circ} \mathrm{C}$ und $160 \mathrm{rpm}$ geschüttelt. Nach Zugabe von $50 \mathrm{ml}$ YAC-Medium erfolgte eine erneute Inkubation im Schüttelinkubator für 2 Tage. Die Hefezellen wurden für $15 \mathrm{~min}$ bei $4000 \mathrm{rpm}$ und $10^{\circ} \mathrm{C}$ abzentrifugiert (Megafuge 1,0 R, Heraeus, Osterode) und das Pellet in $5 \mathrm{ml}$ Sorbitol-Puffer resuspendiert. Der Ansatz wurde nach Zugabe von $70 \mu$ DTT $(1 \mathrm{M})$ und $20 \mu$ l Lyticase $(10 \mathrm{mg} / \mathrm{ml})$ für $1 \mathrm{~h}$ bei $37^{\circ} \mathrm{C}$ inkubiert. Die Sphäroblasten wurden für $15 \mathrm{~min}$ bei $2000 \mathrm{rpm}$ abzentrifugiert, in $5 \mathrm{ml}$ Guanidin-HCI-Lösung aufgenommen und $10 \mathrm{~min}$ bei $65^{\circ} \mathrm{C}$ erhitzt. Nach Abkühlung auf RT wurde die DNA durch Zugabe von 1 Vol. absolutem Ethanol gefällt, durch 15 min Zentrifugation bei $4000 \mathrm{rpm}$ präzipitiert und schließlich in $500 \mu \mathrm{TE}, \mathrm{pH}$ 7,4 gelöst. Es folgten eine RNase-Behandlung mit $200 \mu \mathrm{g}$ RNase A für 30 min bei $37^{\circ} \mathrm{C}$ sowie eine Proteinase K-Behandlung mit $200 \mu \mathrm{g}$ Proteinase K für $1 \mathrm{~h}$ bei $65^{\circ} \mathrm{C}$. Anschließend wurden zwei Phenolextraktionen und eine Chloroformextraktion durchgeführt und die Hefe-DNA durch Zugabe von 0,1 Vol. $\mathrm{NaAc}$ und 2,5 Vol. $100 \%$ Ethanol bei $-20^{\circ} \mathrm{C}$ gefällt und bei $13.000 \mathrm{rpm}$ für $20 \mathrm{~min}$ abzentri- 
fugiert (Biofuge pico, Heraeus, Osterode). Das DNA-Pellet wurde mit $70 \%$ Ethanol gewaschen, getrocknet und in einem definierten Vol. $\mathrm{H}_{2} \mathrm{O}$ aufgenommen.

2.2.2.2 Präparation von Hefe-DNA in Agaroseblöckchen (The Fifth Wellcome Summer School, London, 1990)

Sorbitol-Puffer: $\quad 1$ M Sorbit $20 \mathrm{mM}$ EDTA

$\mathrm{pH} \mathrm{7,5}$

\author{
Sorbitol-Tris-Puffer: 1 M Sorbitol \\ $10 \mathrm{mM}$ Tris- $\mathrm{HCl}, \mathrm{pH} 7,5$ \\ $20 \mathrm{mM}$ EDTA
}

Hefe-Lysis-Lösung: $1 \%$ Lithiumdodecylsulfat

$100 \mathrm{mM}$ EDTA, $\mathrm{pH} 8,0$

$10 \mathrm{mM}$ Tris-HCl, $\mathrm{pH} 8,0$

Um hochmolekulare YAC-DNA gegen mechanische Zerstörung zu schützen und damit eine Präparation vollständiger Chromosomen zu gewährleisten, wurden die Hefezellen in LMPAgarose eingebettet, bevor deren Zellwand gespalten, die Sphäroblasten lysiert und Proteine entfernt wurden. $5 \mathrm{ml}$ YAC-Medium wurden mit einer Hefekolonie von einer Agarplatte angeimpft und einen Tag bei $30^{\circ} \mathrm{C}$ bei $160 \mathrm{rpm}$ im Rundschüttler inkubiert. Nach Zugabe von $50 \mathrm{ml}$ YAC-Medium erfolgte eine erneute Inkubation im Rundschüttler für 2 Tage. Die Zellen wurden durch eine $15 \mathrm{~min}$ Zentrifugation bei $10^{\circ} \mathrm{C}$ bei $4000 \mathrm{rpm}$ (Megafuge 1,0 R, Heraeus, Osterode) geerntet und der Überstand verworfen. Das Pellet wurde in $25 \mathrm{ml} 50 \mathrm{mM}$ EDTA, pH 8,0 resuspendiert und wie oben zentrifugiert. Das Zellpellet wurde in $250 \mu$ l Sorbitol-Puffer resuspendiert, mit $70 \mathrm{U}$ Lyticase und $7 \mu \mathrm{l}$ DTT $(1 \mathrm{M})$ versetzt und mit $250 \mu \mathrm{l}$ auf $50^{\circ} \mathrm{C}$ erwärmter, verflüssigter $2 \%$ LMP-Agarose (in Sorbitol-Puffer) gemischt. Jeweils 50-100 $\mu 1$ (je nach Art der verwendeten Blöckchenformer) der obigen Mischung wurden in mit Klebeband abgedichtete Blöckchenformer pipettiert und mindestens $30 \mathrm{~min}$ auf Eis gekühlt. Mit einer sterilen Impföse wurden die Blöckchen aus den Formern herausgeschoben und $1 \mathrm{~h}$ bei $37^{\circ} \mathrm{C}$ in $10 \mathrm{ml}$ Sorbitol-Tris-Puffer mit $140 \mu \mathrm{LTT}(1 \mathrm{M})$ und $700 \mathrm{U}$ Lyticase inkubiert. Anschließend wurden die Blöckchen für $1 \mathrm{~h}$ bei $37^{\circ} \mathrm{C}$ in $10 \mathrm{ml}$ Hefe-Lysis-Lösung stehengelassen. Die HefeLysis-Lösung wurde durch frische ersetzt und die Hefezellen in dieser Lösung ÜN bei $37^{\circ} \mathrm{C}$ inkubiert. Nach dreimaligem Waschen in 1 x TE, pH 8,0 bei RT wurden die Blöckchen in 0,05 M EDTA, pH 8,0 bei $4^{\circ} \mathrm{C}$ aufbewahrt.

2.2.2.3 Isolierung von YAC-DNA aus Agaroseblöckchen (modifiziert nach Protokoll der Firma Boehringer)

Um YAC-DNA in hochmolekularer Form in Lösung verfügbar zu haben, wurde die Hefe-DNA aus Agaroseblöckchen isoliert. Ein YAC-DNA-Blöckchen wurde zweimal für 30 min bei RT in sterilem $1 \mathrm{x}$ TAE-Puffer equilibriert und anschließend für $10 \mathrm{~min}$ bei $65^{\circ} \mathrm{C}$ aufgeschmolzen. Nach 5 min Abkühlung auf $45^{\circ} \mathrm{C}$ wurde $2 \mathrm{U}$ Agarase/100 $\mu$ l aufgeschmolzener Agarose zugegeben, für mindestens $1 \mathrm{~h}$ bei $45^{\circ} \mathrm{C}$ inkubiert und anschließend ein bis zwei Phenolextraktionen und eine Ether-Extraktion durchgeführt. Die DNA wurde durch Zugabe von 0,1 Vol. NaAc und 2,5 Vol. $100 \%$ Ethanol gefällt und für 20 min bei 13.000 abzentrifugiert. Das DNA-Pellet 
wurde mit $70 \%$ Ethanol gewaschen, getrocknet und in einem definierten $\mathrm{Vol} . \mathrm{H}_{2} \mathrm{O}$ aufgenommen.

\title{
2.2.3 Präparation hochmolekularer genomischer DNA
}

2.2.3.1 DNA-Isolierung aus Blut mit Proteinaussalzung (nach Baas et al., 1984 und Miller et al., 1988)

$\begin{array}{ll}\text { Lysispuffer: } & 155 \mathrm{mM} \mathrm{NH}_{4} \mathrm{Cl} \\ & 10 \mathrm{mM} \mathrm{KHCO}_{3} \\ & 0,1 \mathrm{mM} \mathrm{EDTA} \\ & \mathrm{pH} 7,4\end{array}$

\author{
SE-Puffer: $\quad 75 \mathrm{mM} \mathrm{NaC1}$ \\ 1 mM EDTA \\ $\mathrm{pH} 8,0$
}

$10 \mathrm{ml}$ Vollblut wurden mit $30 \mathrm{ml}$ kaltem Lysispuffer in einem $50 \mathrm{ml}$-Röhrchen vermengt und unter mehrmaligem Mischen mindestens $30 \mathrm{~min}$ auf Eis inkubiert. Anschließend wurden die Lymphozyten für $15 \mathrm{~min}$ bei $2000 \mathrm{rpm}$ und $4^{\circ} \mathrm{C}$ pelletiert (Megafuge 1,0 R, Heraeus, Osterode), in $10 \mathrm{ml}$ Lysispuffer resuspendiert und für weitere $15 \mathrm{~min}$ auf Eis inkubiert. Die Lymphozyten wurden erneut wie oben beschrieben abzentrifugiert. Dieser Schritt wurde so lange wiederholt, bis das Lymphozytenpellet weißlich erschien. Zur Proteolyse der Lymphozyten wurde das Pellet in $5 \mathrm{ml}$ SE-Puffer vollständig resuspendiert und nach Zugabe von $25 \mu \mathrm{l}$ Proteinase K $(10 \mathrm{mg} / \mathrm{ml})$ und $500 \mu 110 \%$ SDS ÜN bei $55^{\circ} \mathrm{C}$ inkubiert. Nach Abkühlung auf RT wurden 1,5 ml gesättigte Kochsalzlösung hinzugegeben, die Mischung 15 s gevortext und dann für 15 min bei 4000 rpm und RT zentrifugiert. Die DNA wurde durch Zugabe von 2 Vol. absolutem Ethanol aus dem Überstand ausgefällt und das geknäuelte DNA-Präzipitat mit Hilfe einer Pipettenspitze in ein Reaktionsgefäß überführt. Die DNA wurde 10 min bei $12000 \mathrm{rpm}$ und RT in einer Tischzentrifuge (Biofuge pico, Heraeus, Osterode) pelletiert und mit $70 \%$ Ethanol gewaschen. Anschließend wurde die DNA nur angetrocknet, in $\mathrm{H}_{2} \mathrm{O}$ aufgenommen und bis zur Verwendung bei $4^{\circ} \mathrm{C}$ aufbewahrt.

\subsubsection{DNA-Präparation aus transformierten EBV-Lymphozyten}

$30 \mathrm{ml}$ Medium mit den darin enthaltenen Zellen wurden in $50 \mathrm{ml}$ Röhrchen überführt, die Kulturflaschen mit $5 \mathrm{ml}$ PBS gespült, dieses ebenfalls dazugegeben und die Zellen für 10 min bei $2000 \mathrm{rpm}$ sedimentiert (Megafuge 1,0 R, Heraeus, Osterode). Anschließend wurde das Pellet in $5 \mathrm{ml}$ SE-Puffer resuspendiert. Die weitere Vorgehensweise war wie unter 2.2.3.1. beschrieben.

\subsubsection{Präparation von hochmolekularer Lymphozyten-DNA in Agaroseblöckchen (nach} Herman et al., 1987)

RBC-Lysis-Puffer:

$0,83 \% \mathrm{NH}_{4} \mathrm{Cl}$-Lösung

$1,03 \mathrm{~g}$ Tris/1

vor Gebrauch 9 Teile $\mathrm{NH}_{4} \mathrm{Cl}$-Lösung und 1 Teil Tris-Puffer mischen 
ESP:

0,5 M EDTA, $\mathrm{pH} 8,0$

$1 \%$ Lauroylsarkosin

$2 \mathrm{mg} / \mathrm{ml}$ Proteinase K

PMSF:

$40 \mathrm{ng} / \mathrm{ml}$ in Isopropanol

Durch die Einbettung vollständiger Zellen in $L M P$-Agarose und die nachfolgende Aufarbeitung der DNA in der Agarose blieb die hochmolekulare genomische DNA im Idealfall in ihrer ursprünglich im Chromosom vorhandenen Länge in der Agarose zurück.

$10 \mathrm{ml}$ Vollblut wurden mit $40 \mathrm{ml} \mathrm{RBC-Lysis-Puffer} \mathrm{in} \mathrm{einem} 50$ ml-Röhrchen vermischt und 30 min auf Eis inkubiert, wobei zwischenzeitlich mehrmals geschwenkt wurde. Die Lymphozyten wurden $15 \mathrm{~min}$ bei $1500 \mathrm{rpm}$ und $4^{\circ} \mathrm{C}$ abzentrifugiert (Megafuge 1,0 R, Heraeus, Osterode) und in $25 \mathrm{ml}$ RBC-Lysis-Puffer resuspendiert. Nach einer Inkubationszeit von 5-10 min auf Eis wurden die Lymphozyten erneut wie oben beschrieben abzentrifugiert und anschließend in $20 \mathrm{ml} \mathrm{RBC-Lysis-Puffer} \mathrm{resuspendiert.} \mathrm{Nach} \mathrm{erneuter} 5$ min Inkubation auf Eis wurden die Zellen abzentrifugiert, in $20 \mathrm{ml}$ kaltem PBS resuspendiert, 10 min bei $2500 \mathrm{rpm}$ und $4^{\circ} \mathrm{C}$ zentrifugiert und schließlich in 1,5 ml PBS resuspendiert. Es wurden $1,7 \mathrm{ml}$ auf $50^{\circ} \mathrm{C}$ erwärmte, verflüssigte $1 \%$ LMP-Agarose (in PBS) zugegeben und jeweils $100 \mu 1$ der AgaroseZell-Mischung in mit Klebeband abgedichtete Blöckchenformer pipettiert. Nach 30 min Inkubation auf Eis wurden die Blöckchen mit einer sterilen Impföse aus den Formern herausgeschoben und in $10 \mathrm{ml}$ ESP aufgefangen. Die Blöckchen wurden zur vollständigen Entfernung der Proteine $48 \mathrm{~h}$ bei $56^{\circ} \mathrm{C}$ im Wasserbad inkubiert. Die Blöckchen wurden 3 x 30 min in $1 \mathrm{x}$ TE geschwenkt und anschließend zweimal in $10 \mathrm{ml}$ TE-Puffer mit $10 \mu 1$ PMSF für jeweils 30 min bei $56^{\circ} \mathrm{C}$ inkubiert, um die Restaktivität der Proteinase $\mathrm{K}$ zu entfernen. Die Aufbewahrung der Blöckchen erfolgte in $0,5 \mathrm{M}$ EDTA, $\mathrm{pH} 8,0$ bei $4^{\circ} \mathrm{C}$.

\subsubsection{Präparation von hochmolekularer Lymphoblasten-DNA in Agaroseblöckchen}

(Schnittger, pers. Mitteilung)

$30 \mathrm{ml}$ Medium mit den darin enthaltenen Zellen wurden in ein $50 \mathrm{ml}$-Röhrchen überführt. Die Zellkulturflasche wurde mit $5 \mathrm{ml}$ PBS-Puffer ausgespült und die Zellen bei $1500 \mathrm{rpm} 10 \mathrm{~min}$ abzentrifugiert (Megafuge 1,0 R, Heraeus, Osterode). Die Zellen wurden in $20 \mathrm{ml}$ PBS-Puffer resuspendiert, $10 \mathrm{~min}$ bei $1500 \mathrm{rpm}$ zentrifugiert und anschließend in $25 \mathrm{ml}$ RBC-Lysis-Puffer resuspendiert. Die weitere Vorgehensweise war wie unter 2.2.3.3. beschrieben.

\subsubsection{Konzentrationsbestimmung von DNA}

Anhand der Extinktion wurde die Konzentration der DNA mit einem Spektralphotometer (LKB Ultrospec III, Pharmacia, Freiburg) bestimmt. Es wurde eine Quarzküvette mit $1 \mathrm{~cm}$ Schichtdicke verwendet. Nach Abgleich des Photometers wurde die in $\mathrm{H}_{2} \mathrm{O}$ gelöste DNA bei den Wellenlängen 260 und $280 \mathrm{~nm}$ gemessen. Eine $\mathrm{OD}_{260}$ von 1 entspricht bei einer Schichtdicke

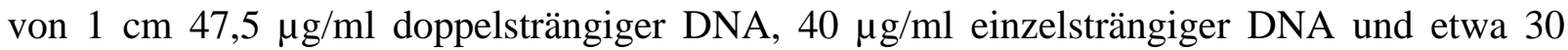
$\mu \mathrm{g} / \mathrm{ml}$ einzelsträngiger Oligonukleotide. Das Verhältnis zwischen den Extinktionen bei 260 
und $280 \mathrm{~nm}\left(\mathrm{OD}_{260} / \mathrm{OD}_{280}\right)$ gibt ein $\mathrm{Ma}$ für die Reinheit der Nukleinsäuren an und sollte 2,0 $+/-0,2$ betragen.

\subsubsection{Restriktionsenzymatische Spaltung von DNA}

Die Spaltung von DNA mit unterschiedlichen Restriktionsendonukleasen erfolgte in den vom Hersteller mitgelieferten Restriktionspuffern bei den angegebenen Reaktionsbedingungen. In der Regel wurden pro $\mu \mathrm{g}$ DNA 10 Units des jeweiligen Enzyms eingesetzt, die Spaltung erfolgte für 2-5 h bei entsprechender Temperatur. Bei Spaltung von genomischer DNA wurde zur Stabilisierung der DNA Spermidin in einer Endkonzentration von 2,5 mM hinzugefügt. Für gleichzeitige Spaltungen mit zwei verschiedenen Enzymen wurden vom Hersteller empfohlene Bedingungen gewählt.

\subsubsection{Elektrophoretische Auftrennung von DNA-Fragmenten}

\subsubsection{Polyacrylamid-Gelelektrophorese (PAGE)}

Die nicht-denaturierende native Polyacrylamid-Gelelektrophorese (PAGE) wurde zur Analyse von PCR-Produkten mit einer maximalen Länge von 800 bp eingesetzt. Die Auftrennung dieser DNA-Fragmente erfolgte in 12,8 \% Polyacrylamidgelen mit $1 \times$ TBE als Laufpuffer.

Die beiden Glasplatten wurden gründlich mit Wasser gereinigt, die Abstandhalter zwischen diese gelegt und mit Metallklammern befestigt. In einem $50 \mathrm{ml}$ Röhrchen wurden $4 \mathrm{ml}$ Bisacrylamid-Acrylamid-Lösung (40\%), 8,5 ml 1 x TBE und $150 \mu 110 \%$ APS vermischt. Nach Zugabe von $20 \mu$ TEMED wurde die Lösung luftblasenfrei zwischen die Glasplatten gegossen und der Kamm eingesetzt. Die Gele waren nach 20 min polymerisiert. Die Proben wurden mit 1/10 Ladungspuffer versetzt und in die Geltaschen pipettiert. Als Längenstandard diente mit HpaII gespaltene DNA des Plasmids Bluescript. Die Elektrophorese wurde für 1 - 2 h bei $100 \mathrm{~V}$ durchgeführt. Das Gel wurde anschließend mit einem Spatel vorsichtig von den Glasplatten gelöst, 10 min in 1 x TBE mit EtBr-Lösung ( $3 \mu 110 \mathrm{mg} / \mathrm{ml}$ EtBr-Lösung auf 100 ml Puffer) angefärbt und unter Verwendung des Videoprinter-Systems (E.A.S.Y., Herolab, Wiesloch) dokumentiert.

\subsubsection{Agarose-Gelektrophorese}

Durch eine Elektrophorese in Agarosegelen können DNA-Moleküle in einem Größenbereich von $0,1-30 \mathrm{~kb}$ aufgetrennt werden. Je nach Größe der aufzutrennenden DNA-Fragmente wurden 0,5 - 2 \%ige Agarosegele verwendet. Für einige präparative Anwendungen (s. 2.2.7.2.) wurden LMP-Agarose-Gele gefertigt. Die jeweils benötigte Agarosemenge wurde in $1 \mathrm{x}$ TBEbzw. TAE-Puffer gegeben, durch Aufkochen gelöst und nach Abkühlung auf etwa $50^{\circ} \mathrm{C}$ in einen Gelträger (EASY-CAST ${ }^{\mathrm{TM}}$, peQLab, Erlangen) gegossen. Für einige Anwendungen wurde die abgekühlte Agarose mit EtBr-Lösung $(10 \mathrm{mg} / \mathrm{ml})$ bis zu einer Endkonzentration von $0,2 \mu \mathrm{g} / \mathrm{ml}$ versetzt. Die DNA-Proben wurden mit $1 / 10$ Ladepuffer versetzt und in die Geltaschen pipettiert. Als Längenstandard diente eine DNA mit bekannten Fragmentgrößen. Als Laufpuffer wurde 1 x TBE bzw. 1 x TAE verwendet. Die Elektrophoresen wurden in der Regel 
bei 70 - $90 \mathrm{~V}$ durchgeführt. Nach Ablauf der Elektrophorese wurden die Gele in EtBr-Lösung (3 $\mu 110$ mg/ml EtBr-Lösung auf $100 \mathrm{ml}$ Puffer) angefärbt, wenn kein EtBr zur Agarose zugegeben wurde. Die Gele wurde mit Hilfe des Videoprinter-Systems (E.A.S.Y., Herolab, Wiesloch) dokumentiert.

\subsubsection{Isolierung von DNA aus Gelen}

\subsubsection{Extraktion von DNA-Fragmenten aus Agarosegelen}

Die Auftrennung der DNA-Fragmente erfolgte wie unter 2.2.6.2. beschrieben. Agaroseblöckchen, welche die gewünschten DNA-Banden enthielten, wurden unter UV-Licht (305 nm) (Transilluminator, Herolab, Wiesloch) mit einem sterilen Skalpell aus den präparativen Gelen ausgeschnitten und in ein Filterpapier überführt, welches sich in einem 1,5 ml-Reaktionsgefäß mit abgeschnittenem Boden befand. Dieses Reaktionsgefäß wurde in ein weiteres 1,5 mlReaktionsgefäß gestellt, so daß es nach Zentrifugation in einer Tischzentrifuge für $45 \mathrm{~s}$ bei $12.000 \mathrm{rpm}$ (Biofuge pico, Heraeus, Osterode) möglich war, die DNA frei von Agarose im unteren Gefäß aufzufangen. Die so isolierte DNA konnte direkt für Sequenzierungen oder Hybridisierungen eingesetzt werden.

\subsubsection{Extraktion von DNA-Fragmenten aus LMP-Agarose}

Die zu isolierende DNA-Bande wurde wie unter 2.2.7.1. beschrieben mittels eines sterilen Skalpells aus einem Low-melting-point-Agarosegel ausgeschnitten, in ein Reaktionsgefäß überführt und gewogen. Dabei entsprechen $100 \mathrm{mg}$ Gel etwa einem Vol. von $100 \mu \mathrm{l}$. Anschließend wurde die DNA wie unter 2.2.2.3. beschrieben aus den Agaroseblöckchen isoliert.

\subsubsection{Extraktion von DNA-Fragmenten aus Polyacrylamidgelen}

Zur Isolierung von DNA aus Polyacrylamidgelen wurde die entsprechende Bande unter UVLicht (305 nm) (Transilluminator, Herolab, Wiesloch) mit einem sterilen Skalpell aus dem Gel herausgeschnitten und in ein $1,5 \mathrm{ml}$ Reaktionsgefäß überführt. Die Polyacrylamidstücke wurden mit einer Pipettenspitze zerkleinert. Nach Zugabe von $500 \mu \mathrm{l}$ TE, pH 8,0 erfolgte die Eluierung der DNA $1 \mathrm{~h}$ bei $65^{\circ} \mathrm{C}$. Anschließend wurden die Gelreste durch eine Zentrifugation bei $13.000 \mathrm{rpm}$ für $10 \mathrm{~min}$ bei RT pelletiert (Biofuge pico, Heraeus, Osterode). Danach wurde die im Überstand enthaltene DNA durch Zugabe von 1/10 Vol. NaAc und 2,5 Vol. $100 \%$ EtOH präzipitiert, in $10 \mu \mathrm{l}$ Ampuwa gelöst und ein Aliquot auf einem 12,8 \% Polyacrylamidgel (s. 2.2.6.1.) analysiert.

2.2.8 Radioaktive Markierung von DNA (modifiziert nach Feinberg und Vogelstein, 1984)

\subsubsection{Radioaktive Markierung von DNA-Fragmenten mit dem Megaprime-System}

Für die radioaktive Markierung der DNA-Sonden mit $\left[\alpha-{ }^{32} \mathrm{P}\right] \mathrm{dCTP}$ wurden Kits von AMERSHAM (Kat.-Nr. RPN 1607) eingesetzt. Die Kits beinhalten Primerlösung mit random 
Nonamer-Primern in wässriger Lösung, konzentrierten Megaprime Reaktionspuffer mit dATP, dGTP und dTTP sowie Enzym-Lösung mit 1U DNA-Polymerase I Klenow-Fragment/ $\mu$ l. 20 - 100 ng der zu markierenden DNA wurden mit Ampuwa auf ein Volumen von $28 \mu 1$ aufgefüllt, dazu wurden $5 \mu$ l Primerlösung pipettiert. Der Ansatz wurde 10 min gekocht, abzentrifugiert und anschließend sofort für 5 min auf Eis abgekühlt. Es folgte die Zugabe von $10 \mu 1$ Reaktionspuffer, $2 \mu \mathrm{l}$ Klenow-Enzym $(1 \mathrm{U} / \mu \mathrm{l})$ und $5 \mu \mathrm{l}(50 \mu \mathrm{Ci})\left[\alpha_{-}{ }^{32} \mathrm{P}\right] \mathrm{dCTP}(3000$ $\mathrm{Ci} / \mathrm{mmol}$ ). Der Ansatz wurde kurz gemischt, abzentrifugiert und mindestens $1 \mathrm{~h}$ bei $37^{\circ} \mathrm{C}$ inkubiert.

Die radioaktive Markierung von PCR-Produkten erfolgte wie oben beschrieben, wobei jedoch neben den random Primern jeweils 1,5 pmol der spezifischen PCR-Primer zugesetzt wurden.

\subsubsection{Abtrennung nicht inkorporierter Radionukleotide}

Zur Reduktion des Hintergrunds und zur Bestimmung der Effizienz der Markierung mußten die nicht eingebauten Nukleotide abgetrennt werden. Dazu wurde die DNA durch Zugabe von $6 \mu 1$ tRNA (10 mg/ml), $15 \mu 13 \mathrm{M} \mathrm{NaAc}, \mathrm{pH} 5,3$ und $40 \mu 1$ Isopropanol und anschließende $30 \mathrm{~min}$ Inkubation auf Eis aus dem Ansatz ausgefällt. Nach einer 10 min Zentrifugation bei 13.000 rpm bei RT (Biofuge pico, Heraeus, Osterode) wurde der Überstand in ein neues Reaktionsgefäß überführt und das DNA-Pellet in $200 \mu \mathrm{l}$ TE, pH 8,0 gelöst. Die Aktivität des Überstands sowie des Pellets wurden mit Hilfe eines Geiger-Müller-Zählrohrs bestimmt. Erfahrungsgemäß sollten dabei mehr als $40 \%$ der Radioaktivität im DNA-Pellet sein. Anschließend wurde die DNA 30 min auf Eis gelöst und bis zur Hybridisierung bei $4^{\circ} \mathrm{C}$ aufbewahrt.

Alternativ dazu wurden nicht eingebaute Nukleotide mit Hilfe von MicroSpin ${ }^{\mathrm{TM}}$ G-50 Columns (Pharmacia, Freiburg) abgetrennt. Bei Anwendung dieses Verfahrens wurden die Säulchen zunächst resuspendiert und der Deckel etwas geöffnet. Nach Abbrechen des unteren Endes wurden die Säulchen in ein leeres 1,5 ml Reaktionsgefäß gestellt und 1 min bei $2800 \mathrm{rpm}$ zentrifugiert (Biofuge pico, Heraeus, Osterode). Das Reaktionsgefäß wurde geleert, anschließend wurde die Probe aufgetragen und $2 \mathrm{~min}$ wie oben zentrifugiert. Die markierte Sonde befand sich daraufhin im Reaktionsgefäß. Anschließend wurde die Aktivität der Säule sowie die der Sonde wie oben mit Hilfe eines Geiger-Müller-Zählrohrs bestimmt. Auch bei dieser Methode sollte die markierte Sonde mehr als $40 \%$ der eingesetzten Radioaktivität beinhalten.

\subsubsection{Southern-Blot-Analyse}

2.2.9.1 DNA-Transfer auf Nylonmembranen (modifiziert nach Southern, 1975)

Denaturierungslösung: $0,5 \mathrm{M} \mathrm{NaOH}$ $1,5 \mathrm{M} \mathrm{NaC} 1$
Neutralisierungslösung: $1 \mathrm{M} \mathrm{NH}_{4} \mathrm{Ac}$ $0.02 \mathrm{M} \mathrm{NaOH}$

Nach Färbung und Fotografie des Gels wurde die DNA in einer Fotoschale für 15 min in 0,25 M HCl-Lösung depuriniert. Nach Abgießen der HCl-Lösung wurde das Gel kurz mit deionisiertem Wasser abgespült und 45 min in Denaturierungslösung geschwenkt. Nach erneutem 
Abspülen des Gels mit Aqua bidest. folgte eine Inkubationszeit von 30-60 min in Neutralisierungslösung. Danach wurde das Gel mit der Oberseite nach oben auf zwei Lagen Whatman 3MM Papier gelegt, die zuvor mit 20 x SSC getränkt wurden. Diese tauchten von einer Glasplatte in ein Reservoir von 20 x SSC und ermöglichten so den Kapillarfluß. Als Verdunstungsschutz für den Transferpuffer und für eine gerichtete Saugkraft durch das Gel wurde zur Abdichtung Frischhaltefolie um das Gel gelegt. Auf das Gel wurde eine in 2 x SSC getränkte, auf Gelgröße geschnittene Nylonmembran, zwei Lagen in 2 x SSC getränktes Whatman 3MM Papier und ein Stapel Papierhandtücher gelegt. Auf die Papierhandtücher wurde eine Glasplatte plaziert, auf die zur Beschwerung ein Gewicht von etwa $500 \mathrm{~g}$ gestellt wurde. Nach zwei Tagen Transfer wurde die Lage der Geltaschen auf der Nylonmembran markiert. Der Filter wurde kurz in 2 x SSC gespült und an der Luft getrocknet, bis keine Flüssigkeitsreste mehr zu erkennen waren. Anschließend wurde die DNA durch UV-LichtBestrahlung im UV-Crosslinker (Typ 1800, Stratagene, Heidelberg) kovalent an die Nylonmembran gebunden.

Alternativ dazu wurde bei einem alkalischen Southern-Blot auf die Neutralisierung des Gels verzichtet und das Gel mit Denaturierungslösung $(0,4 \mathrm{M} \mathrm{NaOH}, 1,5 \mathrm{M} \mathrm{NaCl})$ als Transferpuffer geblottet. Im Anschluß daran wurde die Membran wie oben erläutert behandelt.

2.2.9.2 Hybridisierung (nach Denhardt, 1966)

Denhardt's-Lösung, $50 \mathrm{x}$ : $\quad 1 \%$ Rinderserumalbumin

$1 \%$ Ficoll 400

$1 \%$ Polyvinylpyrrolidon

Hybridisierunglösung I: $\quad 6$ x SSC

5 x Denhardt's-Lösung

$0,5 \%$ SDS

$10 \%$ Dextransulfat

Hybridisierungslösung II: Rapid-hyb buffer (Amersham LIFE SCIENCE, NIF939)

Die zu hybridisierenden DNA-Filter wurden aufgerollt in einen mit 2 x SSC gefüllten Hybridisierungszylinder geschoben. Dabei wurde der Filter mit der beschrifteten DNA-Seite nach innen so eingelegt, daß er luftblasenfrei direkt an der Zylinderwand anlag. Die 2 x SSC-Lösung wurde abgegossen und durch $6 \mathrm{ml}$ auf $68^{\circ} \mathrm{C}$ erhitzte Hybridisierungslösung I oder II ersetzt. Bei Verwendung von Hybridisierungslösung I wurden $60 \mu \mathrm{l}$ Lachssperm-DNA $(10 \mathrm{mg} / \mathrm{ml}) 5 \mathrm{~min}$ bei $95^{\circ} \mathrm{C}$ denaturiert, 5 min auf Eis gestellt und zur Vermeidung unspezifischer Bindungen der Sonde an die Membran zur Hybridisierunglösung pipettiert. Der Filter wurde daraufhin mindestens $30 \mathrm{~min}$ im Rollerapparat bei $68^{\circ} \mathrm{C}$ vorhybridisiert. Die markierte Sonde wurde nach Denaturierung im Wasserbad für 5 min bei $95^{\circ} \mathrm{C}$, für 2 min auf Eis gestellt, abzentrifugiert und zur Hybridisierungslösung pipettiert. Die Hybridisierung erfolgte ÜN bei $68^{\circ} \mathrm{C}$ im Rollerschrank. 


\subsubsection{Präassoziation von Hybridisierungsproben}

Die Präassoziation von Hybridisierungssonden dient der Absättigung derjenigen Sondenanteile, mit denen eine Hybridisierung mit der auf dem Filter gebundenen DNA verhindert werden soll. Bei der Hybridisierung mit Sonden, die einen großen Anteil an repetitiven Sequenzbereichen beinhalten, wurde die markierte DNA mit humaner Plazenta-DNA präassoziert. Dazu wurde die Sonde nach der radioaktiven Markierung (s. 2.2.8.) zusammen mit $50 \mu 1$ humaner PlazentaDNA $(10 \mathrm{mg} / \mathrm{ml})$ für $10 \mathrm{~min}$ im Wasserbad denaturiert. Der Ansatz wurde kurz abzentrifugiert, 15 min bei $65^{\circ} \mathrm{C}$ inkubiert und anschließend zu der Hybridisierungslösung pipettiert.

\subsubsection{Waschen der Filter und Darstellung der Signale}

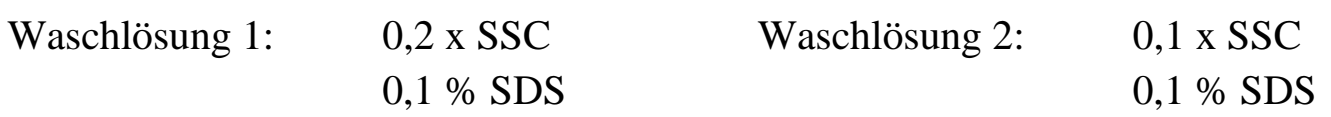

Die Hybridisierungslösung wurde in den radioaktiven Abfall verworfen, bzw. in einem Plastikgefäß zur weiteren Verwendung bei $4^{\circ} \mathrm{C}$ gelagert. Der Hybridisierungszylinder wurde mit $2 \mathrm{x}$ SSC gefüllt, der Filter wurde in die auf $65^{\circ} \mathrm{C}$ vorgeheizte Waschlösung 1 überführt und zunächst 10 min gewaschen, zwischenzeitlich wurde die Aktivität des Filters mit dem Proportionalzähler gemessen. Es folgte ein erneuter Waschvorgang für $10 \mathrm{~min}$ in Waschlösung 1 oder 2. Die Filterwaschung wurde solange fortgesetzt, bis eine Restaktivität auf dem Filter verblieb, die sich nach der Größe des Filters und zu erwartender Bandenzahl richtete, jedoch ungefähr $30-100 \mathrm{~Bq} / \mathrm{cm}^{2}$ betrug. Der noch leicht feuchte Filter wurde in Frischhaltefolie gewickelt, in eine Autoradiografiekassette mit Verstärkerfolie eingelegt und bei Rotlicht ein Röntgenfilm aufgelegt. Der Film wurde zunächst für einen Tag bei $-70^{\circ} \mathrm{C}$ exponiert und anschließend entwickelt, um die Signalintensität abschätzen zu können. Ein weiterer Film wurde entsprechend der Signalintensität bis zu 10 Tagen exponiert. Alternativ dazu konnte der in Frischhaltefolie eingewickelte Filter in einer Expositionskassette mit aufgelegtem Phosphor screen von Molecular Dynamics bei RT exponiert werden. Die Strahlungsenergie der hybridisierten Sonden wurde dabei in der Kristallstruktur der screens gespeichert. Die Expositionszeit verkürzte sich bei dieser Vorgehensweise erheblich, so daß die screens schon nach $1 \mathrm{~h}$ vom Storm 860 PhosphorImager (Molecular Dynamics) mit rotem Licht $(635 \mathrm{~nm})$ gescannt werden konnten. Während der Exposition durch die Strahlung angeregte Elektronen fallen dadurch in den Grundzustand, wobei blaues Licht emitiert wird, dieses wird vom Storm gemessen, in ein elektrisches Signal umgewandelt und als digitale Information am angeschlossenen Computer gespeichert. Die Auswertung der vom Storm gesammelten Daten erfolgte mit dem Computerprogramm ImageQuant (Molecular Dynamics). Anschließend wurden die screens durch Bestrahlung mit Licht bestimmter Wellenlängen im Image Eraser (Molekular Dynamics) gelöscht und erneut für 1-3 Tage exponiert. 


\subsubsection{Wiederholte Verwendung von Nylonfiltern}

Strip-Lösung: $\quad 0,1 \times \mathrm{TE}, \mathrm{pH} 8,0$

$0,1 \%$ SDS

In der Regel wurde jeder DNA-Filter für aufeinander folgende Hybridisierungen mit verschiedenen DNA-Sonden verwendet. Entweder wurde die nächste Hybridisierung erst durchgeführt, wenn auf dem Filter keine Restaktivität mehr festzustellen war oder die vorher verwendete Sonde wurde vor der erneuten Hybridisierung des Filters entfernt. Dazu wurde die StripLösung auf $80^{\circ} \mathrm{C}$ erhitzt und die Filter zweimal für 15 min darin gewaschen.

\subsubsection{Hybridisierung von Oligodesoxyribonukleotiden}

Oligodesoxyribonukleotide mit einer Länge von 17 - 30 bp wurden im Rahmen dieser Arbeit auf Southern geblottete genomische Klone hybridisiert. Die Oligonukleotide wurden dazu über eine Kinasierungsreaktion radioaktiv markiert, wobei der $\gamma$-Phosphatrest des $\left(\gamma_{-}{ }^{32} \mathrm{P}\right)$-ATPs durch die T4-Polynukleotid-Kinase auf das 5'-Ende des Oligonukleotids übertragen wurde.

Für den Einsatz bei der Southern-Hybridisierung wurden 300 ng Oligonukleotid, 2,5 $\mu$ l Kinasierungspuffer $(10 \mathrm{x}), 3 \mu \mathrm{l}\left[\gamma_{-}{ }^{32} \mathrm{P}\right]$-ATP $(3000 \mathrm{Ci} / \mathrm{mmol})$ und $1 \mu \mathrm{l}$ T4-Polynukleotid-Kinase (10 $\mathrm{U} / \mu \mathrm{l})$ in ein Reaktionsgefäß pipettiert und mit Ampuwa auf ein Gesamtvolumen von $25 \mu \mathrm{l}$ aufgefüllt. Nach Inkubation für $30 \mathrm{~min}$ bei $37^{\circ} \mathrm{C}$ wurde der Ansatz ohne weitere Behandlung für die Hybridisierung (s. 2.2.9.2.) eingesetzt.

Die Hybridisierung erfolgte bei Temperaturen zwischen $55^{\circ} \mathrm{C}$ und $60^{\circ} \mathrm{C}$. Die anschließenden Waschungen der Filter wurden, wie in 2.2.9.4. beschrieben, durchgeführt, jedoch bei der entsprechenden Hybridisierungstemperatur in 2 x SSC/0,1 \% SDS.

\subsubsection{Hybridisierung mit IRS-PCR-Produkten}

IRS-PCR-Produkten wurden im Verlauf dieser Arbeit auf PAC-Filter der Bibliothek von Pieter de Jong hybridisiert, um PAC-Klone über Hybridisierungen mit YAC-Sonden identifizieren zu können. Dafür wurden die über IRS-PCR (s. 2.2.10.3) generierten PCR-Produkte, welche mit den Primer-Kombinationen Ale 1/Ale 3, Ale 1/LINE 1, Ale 3/LINE 1 und AGK/LINE 1 erhalten wurden, über MicroSpin ${ }^{\mathrm{TM}}$ S-300 HR Columns (Pharmacia, Freiburg) aufgereinigt. Dies erfolgte wie unter 2.2.8.2 für MicroSpin ${ }^{\mathrm{TM}}$ G-50 Columns beschrieben. Anschließend wurden 2-3 $\mu 1$ der gepoolten PCR-Produkte durch Random primed labelling (s.2.2.8.1.) mit $25 \mu \mathrm{Ci}$ alpha dCTP radioaktiv markiert. Die Präassoziation (s. 2.2.9.3.) der Sonden erfolgte mit $12 \mu 1$ Cot-1-DNA $(1 \mu \mathrm{g} / \mu \mathrm{l}), 50 \mu \mathrm{l}$ Plazenta-DNA $(5 \mathrm{mg} / \mathrm{ml}$ in $4 \mathrm{x}$ SSC) und $10 \mu \mathrm{l}$ Alu-PCR-Produkten (von einer PCR mit humaner Gesamt-DNA mit den Primern Ale 1 und Ale 3) für $4 \mathrm{~h}$ bei $68^{\circ} \mathrm{C}$. Anschließend erfolgte die Hybridisierung (s. 2.2.9.2) auf die 7 Filter der PAC-Bibliothek. Die anschließenden Waschschritte wurden wie in 2.2.9.4. beschrieben, durchgeführt. 


\subsubsection{Dot-Blots}

100 - 300 ng der zu untersuchenden DNA wurden für 10 min in kochendem Wasser denaturiert und sofort für 5 min auf Eis abgekühlt. Die DNA wurde auf eine Nylonmembran pipettiert und der Auftragungsort markiert. Schließlich wurde die DNA durch UV-Licht-Bestrahlung im Crosslinker (Typ 1800, Stratagene, Heidelberg) kovalent an die Nylonmembran gebunden. Die Filter wurden als Kontrollen bei Hybridisierungen (s. 2.2.9.2.) mitgeführt.

\subsubsection{DNA-Amplifikation über die Polymerase-Kettenreaktion (nach Saiki et al., 1988)}

Die Polymerase-Kettenreaktion (PCR) ermöglicht die Amplifikation spezifischer DNA-Bereiche in vitro selbst bei Vorhandensein sehr geringer Ausgangsmengen an DNA. Die Methode basiert auf einer Abfolge von Denaturierung der template-DNA, Anlagerung sequenzspezifischer Primer und Synthese einer komplementären DNA-Kopie durch die aus Thermus aquaticus isolierte, bis $\mathrm{zu} 95^{\circ} \mathrm{C}$ thermostabile Taq-DNA-Polymerase. Über eine zyklische Wiederholung dieser Schritte in einem programmierbaren Thermocycler bei kontrollierter Temperatur kommt es zu einer exponentiellen Vervielfältigung der Zielsequenz im Reaktionsansatz.

\subsubsection{Ansatz für eine PCR}

Zur Durchführung einer nicht-radioaktiven PCR wurden folgende Komponenten in einem Reaktionsgefäß vereinigt:

$\begin{array}{ll}\text { template-DNA }(100 \mathrm{ng} / \mu \mathrm{l}) & 1,0 \mu \mathrm{l} \\ \text { dNTPs }(10 \mathrm{mM}) & 0,5 \mu \mathrm{l} \\ 10 \mathrm{x} \text { Taq-Polymerase-Puffer } & 2,5 \mu \mathrm{l} \\ \text { forward } \text { Primer }(15 \mathrm{pmol} / \mu \mathrm{l}) & 1,0 \mu \mathrm{l} \\ \text { reverse } \text { Primer }(15 \mathrm{pmol} / \mu \mathrm{l}) & 1,0 \mu \mathrm{l} \\ \text { Taq-Polymerase }(1 \mathrm{U} / \mu \mathrm{l}) & 0,1-0,75 \mu \mathrm{l} \\ \mathrm{H}_{2} \mathrm{O} & \mathrm{ad} 25 \mu \mathrm{l}\end{array}$

Bei jeder PCR wurden eine Negativkontrolle, in dem alle Komponenten bis auf die DNA enthalten waren, sowie eine Positivkontrolle mit genomischer DNA mitgeführt. Zudem wurde bei einigen PCR-Ansätzen Dimethylsulfoxid (DMSO) oder Formamid zur Erhöhung der Spezifität durch partielle Denaturierung dazugegeben (Hung et al., 1990; Sarkar et al., 1990). Die einzelnen Temperatur- und Zeitparameter richten sich nach den jeweiligen Oligonukleotidzusammensetzungen und den $\mathrm{zu}$ amplifizierenden Fragmentlängen. Im folgenden sind die am häufigsten verwendeten Amplifikationsprogramme aufgelistet. Alle Programme beginnen mit einem 3 min Denaturierungsschritt bei $94^{\circ} \mathrm{C}$ und endeten mit einer 5 min Elongation der DNAStränge bei $72^{\circ} \mathrm{C}$. Die Reaktionen wurden entweder im Thermocycler GeneAmp 9600 von Perkin Elmer Cetus, Weiterstadt oder im Mastercycler Gradient von Eppendorf, Hamburg durchgeführt. 
Tab. 14: Verwendete PCR-Programme

\begin{tabular}{llllll}
\hline & Programm 1 & Programm 2 & Programm 3 & Programm 4 & Programm 5 \\
\hline $\begin{array}{l}\text { 1. Denaturierung } \\
\text { 2. Anlagerung der }\end{array}$ & $94^{\circ} \mathrm{C} / 60 \mathrm{~s}$ & $94^{\circ} \mathrm{C} / 60 \mathrm{~s}$ & $94^{\circ} \mathrm{C} / 60 \mathrm{~s}$ & $94^{\circ} \mathrm{C} / 30 \mathrm{~s}$ & $94^{\circ} \mathrm{C} / 45 \mathrm{~s}$ \\
$\begin{array}{l}\text { Primer } \\
\text { 3. Elongation }\end{array}$ & $75^{\circ} \mathrm{C} / 60 \mathrm{~s}$ & $55^{\circ} \mathrm{C} / 60 \mathrm{~s}$ & $60^{\circ} \mathrm{C} / 60 \mathrm{~s}$ & $60^{\circ} \mathrm{C} / 30 \mathrm{~s}$ & $60^{\circ} \mathrm{C} / 45 \mathrm{~s}$ \\
Anzahl der Zyklen & 32 & $72^{\circ} \mathrm{C} / 2 \mathrm{~min}$ & $72^{\circ} \mathrm{C} / 4 \mathrm{~min}$ & $72^{\circ} \mathrm{C} / 3 \mathrm{~min}$ & $70^{\circ} \mathrm{C} / 45 \mathrm{~s}$ \\
\hline
\end{tabular}

Für eine Erhöhung der Spezifität unspezifisch bindender Primer wurde eine sog. touch down$P C R$ (Programm 6) durchgeführt. Dabei wurde die Anlagerungstemperatur sukzessive um $1{ }^{\circ} \mathrm{C}$ herabgesetzt.

Tab. 15: PCR-Programm 6

\begin{tabular}{llll}
\hline Zyklen & Denaturierung & Anlagerung & Elongation \\
\hline insgesamt 12 & $94^{\circ} \mathrm{C} / 60 \mathrm{~s}$ & $68-57^{\circ} \mathrm{C} / 60 \mathrm{~s}$ & $72^{\circ} \mathrm{C} / 60 \mathrm{~s}$ \\
20 & $94^{\circ} \mathrm{C} / 60 \mathrm{~s}$ & $57^{\circ} \mathrm{C} / 60 \mathrm{~s}$ & $72^{\circ} \mathrm{C} / 60 \mathrm{~s}$ \\
\hline
\end{tabular}

2.2.10.2 Alu-PCR (nach Nelson et al., 1989)

Bei der Alu-PCR wurden Primer verwendet, die spezifisch an humane Alu-repeat-Sequenzen binden (Hwu et al., 1986). Da Alu-repeats durchschnittlich alle 3-4 kb im menschlichen Genom vorkommen sind auch in humanen YAC-, PAC- und Cosmid-Inserts viele dieser Sequenzwiederholungen vorhanden, so daß Endfragmente dieser Klone durch die Kombination spezifischer Primer aus den Vektorenden mit jeweils einem Alu-Primer dargestellt werden konnten. Je nach Abstand der Alu-Sequenz von der Vektorsequenz wurden dabei unterschiedlich große Endfragmente erhalten. Um die Amplifikation eines internen Alu-Alu-Produkts zu erkennen, wurde als Kontrolle ein PCR-Ansatz ohne den jeweiligen Vektorprimer mitgeführt. Die Amplifikate wurden in einem 1,5\%-Agarosegel aufgetrennt und die Fragmentgrößen des Testansatzes mit denen des Kontrollansatzes ohne Vektorprimer verglichen. Fragmente, die sowohl im Testansatz als auch im Kontrollansatz auftraten, stellten wahrscheinlich interne AluFragmente dar, während die ausschließlich im Testansatz entstandenen PCR-Produkte mit großer Wahrscheinlichkeit spezifische Endfragmente darstellten. Nach Isolierung aus dem Gel wurden die Endfragmente sequenziert und durch Wahl geeigneter Primer neue STSs generiert. Diese neuen Marker konnten für die Durchmusterung einer PAC-Bibliothek und für die Contig-Bildung eingesetzt werden.

Die von der Alu-Konsensus-Sequenz (Kariya et al., 1987) abgeleiteten Primer, die im Rahmen dieser Arbeit zum Einsatz kamen, sind in Tabelle 11 aufgelistet. Für die Alu-PCR wurde PCRProgramm 3 (s. Tab. 14) benutzt, wobei eine Elongationszeit von 4 min eine Amplifikation von DNA-Fragmenten bis zu $3 \mathrm{~kb}$ ermöglichte. Um YAC-Endfragmente darstellen zu können, 
wurden die vektorspezifischen Primer URA und TRP mit den verschiedenen Alu-Primern in einem wie unter 2.2.10.1. beschriebenen PCR-Ansatz kombiniert, wobei jedoch jeweils 30 pmol Primer eingesetzt wurden. Die Darstellung von PAC- bzw. Cosmid- Endfragmenten erfolgte analog, wobei jedoch die vektorspezifischen Primer Sp6 und T7 bzw. T3 und T7 mit verschiedenen Alu-Primern kombiniert wurden.

\subsubsection{IRS (interspersed repetitive sequence)-PCR}

Mit der IRS-PCR konnten DNA-Sequenzen, die zwischen häufig vorkommenden, repetitiven Elementen lokalisiert sind, amplifiziert werden. Diese Methode wurde eingesetzt, um YACSonden zu generieren, die sich für die Hybridisierung auf PAC-Filter eigneten. Dabei erfolgte eine spezifische Anreicherung der humanen Insert-Sequenzen der YACs. Vektor-Sequenzen wurden nicht angereichert, diese waren daher nur in sehr geringer Konzentration in der Hybridisierungssonde enthalten, so daß eine Kreuzhybridisierung über den Vektor-Anteil der Klone stark reduziert werden konnte. Um IRS-PCR-Fragmente zu erzeugen, wurde die YAC-DNA für eine PCR mit den Primern Ale 1, Ale 3, AGK und LINE 1 (s. Tab. 11) in den Kombinationen Ale 1/Ale 3, Ale 1/LINE 1, Ale 3/LINE 1 und AGK/LINE 1 eingesetzt. Bei Einsatz des LINE 1-Primers wurde die PCR mit einer Annealing-Temperatur von $65^{\circ} \mathrm{C}$ durchgeführt, ansonsten betrug diese $55^{\circ} \mathrm{C}$. Der Ansatz setzte sich wie folgt zusammen:

$\begin{array}{ll}\text { template-DNA }(100 \mathrm{ng} / \mu \mathrm{l}) & 1,0 \mu \mathrm{l} \\ \text { dNTPs }(25 \mathrm{mM}) & 0,3 \mu \mathrm{l} \\ 10 \mathrm{x} \text { Taq-Polymerase-Puffer } & 5,0 \mu \mathrm{l} \\ \text { forward } \text { Primer }(15 \mathrm{pmol} / \mu \mathrm{l}) & 1,0 \mu \mathrm{l} \\ \text { reverse } \text { Primer }(15 \mathrm{pmol} / \mu \mathrm{l}) & 1,0 \mu \mathrm{l} \\ \text { Taq-Polymerase }(1 \mathrm{U} / \mu \mathrm{l}) & 1,0 \mu \mathrm{l} \\ \mathrm{H}_{2} 0 & \mathrm{ad} 50 \mu \mathrm{l}\end{array}$

Die Reaktion wurde in einem Thermocycler (PE 9600) mit folgendem Cycling-Programm 3035 x inkubiert: $94^{\circ} \mathrm{C}$ für $10 \mathrm{~s}, 65 / 55^{\circ} \mathrm{C}$ für $20 \mathrm{~s}$ und $72^{\circ} \mathrm{C}$ für 3 min. Das Programm begann mit einem 5 min Denaturierungsschritt bei $94^{\circ} \mathrm{C}$ und endete mit einer 10 min Elongation der DNAStränge bei $72^{\circ} \mathrm{C}$.

\subsubsection{Analyse von Einzelstrang-Konformationspolymorphismen (single-strand confor- mational polymorphism analysis, SSCP) (nach Orita et al., 1989)}

Für SSCP-Analysen wurde ein Abschnitt der DNA mit Fluoreszenz-markierten Primern durch PCR amplifiziert. Die PCR-Produkte wurden anschließend denaturiert und die Einzelstränge durch nichtdenaturierende Polyacrylamidgelelektrophorese in einem Alf-express Sequenzierautomat (Pharmacia, Freiburg) aufgetrennt, wobei die Fluoreszenzsignale der PCR-Produkte durch einen Laserstrahl induziert und einem computergesteuerten Auswertungsprogramm übermittelt wurden. 


\subsubsection{Ansatz der PCR für die SSCP}

Die PCR wurde wie unter 2.2.10.1. beschrieben durchgeführt, wobei sowohl die verwendeten forward-als auch die reverse-Primer mit Cy5-Fluoreszenzfarbstoff markiert waren. Es wurde Thermocycler-Programm 5 (s. 2.2.10.1.) verwendet. Anschließend wurde $1 \mu 1$ des PCR-Ansatzes mit $19 \mu$ l Formamid-Ladepuffer gemischt und 3 min bei $85^{\circ} \mathrm{C}$ denaturiert. Die Proben wurden auf Eis gestellt und verblieben dort bis zum Auftragen auf das Gel.

\subsubsection{SSCP-Elektrophoreselauf}

Die Elektrophoreseplatten wurden mit deionisiertem Wasser gereinigt, mit Isopropanol abgespült und getrocknet. Die beiden Platten wurden übereinander gelegt, wobei durch seitliche Abstandhalter ein Abstand von 0,5 mm zwischen den Platten erhalten blieb, und durch Metallklammern fest zusammengehalten. Anschließend wurde der Kamm eingeschoben und die Glasplatten am Kamm mit Metallklammern zusammengedrückt.

Für die SSCP-Analysen diente eine $2 \mathrm{x}$-MDE-Fertiglösung von Biozym als Grundmatrix. 7,5 ml der 2 x MDE-Gellösung wurden mit 3,6 ml 5 x TBE versetzt und mit deionisiertem Wasser auf auf ein Volumen von $30 \mathrm{ml}$ aufgefüllt. Anschließend wurde die Lösung 5 min mit einer Wasserstrahlpumpe entgast. Nach Zugabe von $120 \mu 10 \%$ APS und $12 \mu 1$ TEMED wurde die Gellösung mit einer $50 \mathrm{ml}$-Spritze zügig und luftblasenfrei zwischen die präparierten Glasplatten gegossen. Nach mindestens 2 h Polymerisation des Gels wurden die Elektrophoresekammern in den Sequenzierautomaten eingebaut und 0,6 x TBE als Laufpuffer in die Pufferkammer gegeben. Vor der SSCP-Analyse wurden die Glasplatten, die mittels einer inneren Zirkulationsschleife temperiert wurden, über einen externen Thermostaten auf die entsprechende Lauftemperatur $\left(10^{\circ} \mathrm{C}\right.$ oder $\left.18^{\circ} \mathrm{C}\right)$ vorgekühlt.

In die mit Puffer gespülten Geltaschen wurden $2 \mu 1$ der mit Ladepuffer versetzten, denaturierten Proben (siehe 2.2.11.1.) pipettiert. Als Längenstandard dienten PCR-Produkte mit bekannten Fragmentgrößen. An dem angeschlossenen Computer wurde das Programm Alfwin gestartet, welches die Verbindung zwischen Alf-express und dem Computer herstellt und die gewonnenen Daten sammelt.

Für die Elektrophorese wurden folgende Laufbedingungen gewählt:

$$
\begin{aligned}
& -1500 \text { Volt } \\
& -150 \mathrm{~mA} \\
& -15 \text { Watt } \\
& -540 \mathrm{~min} \\
& \text { - Heizung: aus } \\
& \text { - Sample intervall: } 2 \mathrm{~s}
\end{aligned}
$$

Die Auswertung der Elektrophoreseläufe erfolgte mit dem Computerprogramm Allelink der Firma Pharmacia. 


\subsubsection{Darstellung von Mikrosatelliten}

Zur Darstellung von Mikrosatelliten wurden fluoreszenzmarkierte PCR-Produkte denaturiert und die Einzelstränge durch denaturierende Polyacrylamidgelelektrophorese in einem Alf-express Sequenzierautomat der Firma Pharmacia aufgetrennt.

\subsubsection{Durchführung der PCR}

Die PCR wurde wie unter 2.2.10.1. beschrieben mit 0,7 U Enzym durchgeführt, wobei nur einer der verwendeten Primer, in der Regel der forward-Primer, mit Cy5 fluoreszenzmarkiert war. Die Amplifikation erfolgte mit dem unter 2.2.10.1. beschriebenem Programm 1. Nach Ablauf der PCR wurde $1 \mu \mathrm{l}$ des PCR-Ansatzes mit $16 \mu$ l Formamid-Ladepuffer und $3 \mu 1$ eines Marker-Mix gemischt. Der Marker-Mix beinhaltete Fragmente bekannter Größe und ermöglichte die Linearisierung des Gels. Anschließend wurden die Proben 3 min bei $94^{\circ} \mathrm{C}$ denaturiert und bis zum Auftragen auf das Gel auf Eis gestellt.

\subsubsection{Denaturierende Gelelektrophorese}

Mit deionisiertem Wasser gereinigte Elektrophoreseplatten wurden mit Isopropanol abgespült und getrocknet. Die beiden Platten wurden mit 0,3 mm Abstandhaltern übereinander gelegt und durch Metallklammern fest zusammengehalten. Anschließend wurde der Kamm eingeschoben und die Glasplatten am Kamm mit Metallklammern zusammengedrückt.

Für ein $8 \%$ denaturierendes Gel wurden $3 \mathrm{ml}$ Acrylamid-Bisacrylamid-Lösung (19:1, Serva), 2 ml 10 x TBE/Harnstoff-Puffer (Serva), 15 ml $50 \%$ Harnstoff-Lösung (Serva) und $70 \mu 110 \%$ APS vermischt. Nach Zugabe von 16,7 $\mu \mathrm{l}$ TEMED wurde die Lösung mit einer 50 ml-Spritze luftblasenfrei zwischen die Glasplatten gefüllt. Nach $1 \mathrm{~h}$ waren die Gele polymerisiert. Alternativ dazu wurden $8 \%$ denaturierende Gele mit ReproGel ${ }^{\mathrm{TM}}$ von Pharmacia hergestellt. ReproGel $^{\mathrm{TM}}$ beinhaltet die Fertiglösungen A (Acrylamid/Bisacrylamid) und B (TBE, denaturierendes Agens und UV-Initiator), die vor der Verwendung gemischt wurden. Anschließend konnte die Lösung zwischen die vorbereiteten Elektrophoreseplatten gegossen werden. Die Polymerisation erfolgte für 10 min unter UV-Licht im ReproSet ${ }^{\mathrm{TM}}$ von Pharmacia.

Die Elektrophoresekammern wurden in den Sequenzierautomaten eingebaut und 0,5 x TBE als Laufpuffer in die Pufferkammer gegeben. Anschließend wurden $3 \mu 1$ der mit Ladepuffer versetzten, denaturierten Proben (s. 2.2.12.1.) in die mit Puffer gespülten Geltaschen pipettiert. An dem angeschlossenen Computer wurde das Programm Alfwin gestartet. Für die Elektrophorese wurden folgende Laufbedingungen gewählt:

$$
\begin{aligned}
& -1500 \text { Volt } \\
& -65 \mathrm{~mA} \\
& -30 \mathrm{Watt} \\
& -300 \mathrm{~min} \\
& - \text { Heizung: } 55^{\circ} \mathrm{C}
\end{aligned}
$$


Die Auswertung der Elektrophoreseläufe erfolgte mit dem Computerprogramm Allelink der Firma Pharmacia.

\subsubsection{Klonierung von DNA-Fragmenten}

\subsubsection{Vektor-Präparation}

Für die Subklonierungen von DNA-Fragmenten wurden die Vektoren pBluescript oder pZErO2 verwendet. PCR-Produkte wurden in den pGEM-T-Vektor ligiert.

$1 \mu \mathrm{g}$ Vektor-DNA wurde mit $20 \mathrm{U}$ des entsprechenden Klonierungsenzyms gespalten (s. 2.2.5.). Nach einer Ethanolfällung wurde die DNA in $10 \mu \mathrm{TE}, \mathrm{pH} 8,0$ aufgenommen, ein Aliquot auf einem $1 \%$ Agarosegel analysiert und der Rest mit alkalischer Phosphatase aus Kälberdarm (Calf Intestinal Phosphatase, CIP) behandelt. Dazu wurde zu $1 \mu \mathrm{g}$ gespaltener VektorDNA in einem Gesamtvolumen von $50 \mu 11$ x Phosphatase-Puffer 1 U CIP gegeben. Nach einer 30 min Inkubation bei $37^{\circ} \mathrm{C}$ wurde das Enzym durch $10 \mathrm{~min}$ Erhitzen auf $65^{\circ} \mathrm{C}$ inaktiviert. Der Vektor wurde mit Phenol extrahiert, durch Ethanol gefällt, in $10 \mu \mathrm{l}$ TE, pH 8,0 aufgenommen und bis zur weiteren Verwendung bei $-20^{\circ} \mathrm{C}$ gelagert.

\subsubsection{Ligation von DNA}

Das zu ligierende DNA-Fragment wurde nach einer Spaltung mit dem entsprechenden Enzym wie unter 2.2.7. beschrieben aus einem Agarosegel isoliert. Anschließend wurde das DNAFragment in einem Gesamtvolumen von $20 \mu \mathrm{l}$ in 1 x Ligase-Puffer unter Zusatz von 1 U T4 DNA-Ligase ÜN bei $14^{\circ} \mathrm{C}$ in die Klonierungsschnittstelle des Vektors ligiert. Die zu ligierenden DNA-Fragmente befanden sich dabei in einem 3-fachen molaren Überschuß im Ansatz. Die Ligation wurde bis zur weiteren Verwendung bei $-20^{\circ} \mathrm{C}$ gelagert.

\subsubsection{Präparation von kompetenten E. coli-Zellen}

Zur Aufnahme von rekombinanten Plasmidmolekülen wurde die Zellwand der Bakterien durch die Inkubation mit $\mathrm{CaCl}_{2}$ für DNA durchlässig gemacht. $50 \mathrm{ml} \mathrm{LB}-M e d i u m$ wurden mit $200 \mu \mathrm{l}$ einer Vorkultur eines E. coli Stammes, z.B. DH5 $\alpha$, inokuliert und bei $37^{\circ} \mathrm{C}$ und $160 \mathrm{rpm}$ bis zu einer $\mathrm{OD}_{650}$ von 0,2 inkubiert. Anschließend wurden die Zellen 10 min auf Eis gestellt und bei $4^{\circ} \mathrm{C}$ für $10 \mathrm{~min}$ bei $2500 \mathrm{rpm}$ pelletiert (Megafuge 1,0 R, Heraeus, Osterode). Das Pellet wurde bei $4^{\circ} \mathrm{C}$ in $30 \mathrm{ml} 100 \mathrm{mM} \mathrm{CaCl}_{2}$ resuspendiert und erneut $20 \mathrm{~min}$ auf Eis gestellt. Nach einer weiteren Zentrifugation für $10 \mathrm{~min}$ bei $2500 \mathrm{rpm}$ wurden die Zellen in 2,5 ml eiskalter $\mathrm{CaCl}_{2}$ Lösung aufgenommen, der zuvor 0,1 Vol. Glycerin zugefügt wurde. Die Zellen wurden in 100 $\mu 1$ Aliquots in flüssigem Stickstoff eingefroren und bei $-70^{\circ} \mathrm{C}$ gelagert.

\subsubsection{Transformation (nach Hanahan, 1983)}

Für die Transformation eines Ligationsansatzes wurden $100 \mu l$ kompetente Bakterienzellen auf Eis aufgetaut, mit 10-50 ng DNA aus dem Ligationsansatz gemischt und 20 min auf Eis inkubiert. Nach einem Hitzeschock für $90 \mathrm{~s}$ bei $42^{\circ} \mathrm{C}$ wurde der Ansatz 2 min auf Eis gestellt und 
nach Zugabe von $500 \mu \mathrm{l}$ LB-Medium für $1 \mathrm{~h}$ bei $37^{\circ} \mathrm{C}$ im Schüttler inkubiert. Anschließend wurden die Zellen auf LB-Agarplatten mit $50 \mu \mathrm{g} / \mathrm{ml}$ Ampicillin (pBluescript) bzw. $30 \mu \mathrm{g} / \mathrm{ml}$ Kanamycin (pZErO-2) ausplattiert. Die Platten wurden ÜN bei $37^{\circ} \mathrm{C}$ inkubiert.

2.2.14 Dye-Terminator-Fluoreszenz-Sequenzierung (nach Sanger et al., 1977)

Die Sequenzierungen wurden mit dem Thermo Sequenase dye terminator cycle sequencing premix Kit der Firma Amersham durchgeführt. In diesem Kit fanden sich ein gebrauchsfertiger Prämix bestehend aus Thermo Sequenase-DNA-Polymerase, dNTPs, dITP, mit Fluoreszensfarbstoffen markierten ddNTPs und Puffer. Die Verwendung dieses Sequenzierungskits ermöglicht die Durchführung der vier Reaktionen in einem Gefäß. Der Einbau eines der vier fluoreszenzmarkierten Didesoxynukleotide ddGTP, ddATP, ddTTP und ddCTP terminiert die Verlängerung der DNA-Kette, wobei Fragmente unterschiedlicher Länge mit einem Didesoyxanalogon am 3'-Ende entstehen. Der Zusatz von dITP verringerte Bandenkompressionen. Die Auswertung der Reaktionen erfolgte auf einer automatischen Sequenzieranlage (ABI 377) der Firma Applied Biosystems.

Der Sequenzierungsansatz setzte sich wie folgt zusammen:

$\begin{array}{ll}\text { Prämix: } & 8 \mu \mathrm{l} \\ \text { Matrizen DNA: } & \\ \text { ds DNA Matrize } & 0,5-5 \mu \mathrm{g} \\ \quad \text { oder } & \\ \text { PCR-Produkte } & 10-100 \mathrm{ng} \\ \text { Primer } & 3,2 \mathrm{pmol}\end{array}$

ad $20 \mu \mathrm{l} \mathrm{H}_{2} \mathrm{O}$

Die Reaktion wurde in einem Thermocycler (GeneAmp 9600, Perkin Elmer Cetus, Weiterstadt oder Mastercycler Gradient, Eppendorf, Hamburg) mit folgendem Cycling-Programm $30 \mathrm{x}$ inkubiert: $96^{\circ} \mathrm{C}$ für $30 \mathrm{~s}, 50^{\circ} \mathrm{C}$ für $15 \mathrm{~s}$ und $60^{\circ} \mathrm{C}$ für $4 \mathrm{~min}$. Nach Abschluß der Sequenzierung wurde die DNA durch Zugabe von $2 \mu 12 \mathrm{M} \mathrm{NaAc}$ und $55 \mu 1100 \%$ EtOH gefällt. Es wurde für 15 min bei $12.000 \mathrm{rpm}$ bei RT zentrifugiert (Biofuge pico, Heraeus, Osterode), die Pellets in 70 $\% \mathrm{EtOH}$ gewaschen und anschließend getrocknet. Anschließend wurden die Pellets in $4 \mu \mathrm{l}$ Formamid-Ladepuffer aufgenommen. Vor dem Auftragen wurden die Proben denaturiert und auf Eis abgekühlt.

2.2.15 Pulsfeldgelelektrophorese (PFGE) (nach Schwartz und Cantor, 1984; modifiziert nach Carle et al., 1986)

Die PFGE-Technik ermöglicht die Auftrennung von hochmolekularer DNA bis zu einer Größe von ungefähr $5 \mathrm{Mb}$ und wurde im Rahmen dieser Arbeit für die Konstruktion einer long-rangeRestriktionskarte, die ein direktes Maß der physikalischen Abstände auf einem Chromosom 
darstellt, verwendet. Außerdem wurde die PFGE zur Größenbestimmung von PAC-Klonen eingesetzt.

Bei der PFGE wurde nicht nur die Größe als Funktion des Siebeffekts in der Agarosematrix für die Laufeigenschaften der DNA genutzt, sondern darüber hinaus die Art und Weise ihres Streckungsvermögens im elektrischen Feld. Durch zwei an ein Gel angelegte alternierende, in ihrer Stärke veränderbare, Spannungsfelder wird die DNA permanent zu Konformationsänderungen veranlaßt, die im Falle kürzerer Fragmente früher, im Falle längerer Ketten später die Reorientierung, Streckung und Wanderung in Richtung des angelegten Feldes zuläßt. Die Auftrennung der Fragmente ist dabei abhängig von Pulszeit, Feldstärke, Temperatur, Pufferzusammensetzung, Typ und Konzentration der Agarose und dem Winkel der Spannungsfelder zueinander. Größere Fragmente wurden dabei durch längere Pulszeiten, kleinere Fragmente durch niedrige Pulszeiten separiert.

\subsubsection{Restriktionsspaltung von DNA in Agaroseblöckchen (modifiziert nach The Fifth}

Wellcome Summer School, London, 1990)

Agaroseblöckchen mit YAC-DNA (s. 2.2.2.2.) oder genomischer DNA (s. 2.2.3.3. bzw. 2.2.3.4.) wurden vor der Restriktionsspaltung zweimal 20 min bei $\mathrm{RT}$ in $\mathrm{H}_{2} \mathrm{O}$ äquilibriert. Anschließend wurde jeweils ein halbes Blöckchen in ein 1,5 ml Reaktionsgefäß überführt und dort in einem Gesamtvolumen von $200 \mu \mathrm{l}$ in $0,5 \mathrm{mg} / \mathrm{ml}$ BSA, $2 \mathrm{mM}$ Spermidin und dem entsprechenden Restriktionspuffer 30 min bei der für das Enzym optimalen Temperatur vorinkubiert. Nach Zugabe von 40 U Enzym wurde $4 \mathrm{~h}$ bei der jeweiligen Temperatur gespalten. Die Blöckchen wurden bis zum Laden des Pulsfeldgels bei $4^{\circ} \mathrm{C}$ aufbewahrt.

2.2.15.2 Partielle Restriktion von DNA in Blöckchen (modifiziert nach The Fifth Wellcome Summer School, London, 1990)

Ziel der partiellen Restriktion von Hefe-DNA mit darin enthaltenem YAC war es, eine grobe Restriktionskarte eines YAC-Inserts bzw. einer in YACs klonierten Chromosomenregion zu erstellen. Um unvollständig geschnittene DNA zu erhalten, wurden in mehreren Ansätzen unterschiedliche Enzymkonzentrationen bei begrenzter Inkubationszeit eingesetzt. Die halben Blöckchen wurden wie unter 2.2.15.1. beschrieben in $\mathrm{H}_{2} \mathrm{O}$ äquilibriert und vorinkubiert. Für jeden YAC wurde je ein Ansatz mit $1 \mathrm{U}$ Enzym, 0,2 U Enzym und 0,1 U Enzym versetzt. Für eine vollständige Spaltung wurde ein Ansatz mit $40 \mathrm{U}$ Enzym mitgeführt. Nach Zugabe des Enzyms wurden die Blöckchen 30 min auf Eis gestellt, damit das Enzym in das Agaroseblöckchen diffundieren konnte. Nach einer Inkubationszeit von $1 \mathrm{~h}$ wurde die Reaktion durch Zugabe von $5 \mu \mathrm{l}$ 0,5 M EDTA abgestoppt und das Reaktionsgefäß auf Eis gestellt. Anschließend konnte das Pulsfeldgel geladen werden.

\subsubsection{Elektrophorese}

Die PFGE erfolgte mit dem BIOMETRA-System Rotaphor bzw. mit dem CHEF MAPPER von BIO RAD. Für die Elektrophorese wurden $1 \%$ Agarose-Gele in 0,25 x TBE (BIOMETRASystem) bzw. 0,5 x TBE (CHEF MAPPER) verwendet. Zur Ladung der Proben wurden die 
Spitzen zweier Pasteurpipetten über dem Bunsenbrenner haarnadelförmig abgerundet und mit deren Hilfe die Agaroseblöckchen in die Geltaschen transferiert und mit $1 \%$ LMP-Agarose in 0,25 x/ 0,5 x TBE eingegossen. Das beladene Gel wurde in die bereits mit 21 0,25 x/0,5 x TBE gefüllte, vorgekühlte Gelkammer gelegt auf Betriebstemperatur gebracht.

\subsubsection{PFGE-Laufbedingungen}

Zur Auftrennung von DNA-Fragmenten mit dem BIOMETRA-System Rotaphor galten folgende Laufbedingungen:

Tab. 16: PFGE-Laufbedingungen I

\begin{tabular}{llllll}
\hline $\begin{array}{l}\text { Fragmente } \\
(\mathrm{kb})\end{array}$ & $\begin{array}{l}\text { Pulszeit } \\
(\mathrm{s})\end{array}$ & $\begin{array}{l}\text { Gradient } \\
(\mathrm{V} / \mathrm{cm})\end{array}$ & $\begin{array}{l}\text { Winkel } \\
(\mathrm{Grad})\end{array}$ & $\begin{array}{l}\text { Laufzeit } \\
(\mathrm{h})\end{array}$ & $\begin{array}{l}\text { Temperatur } \\
\left({ }^{\circ} \mathrm{C}\right)\end{array}$ \\
\hline $10-1000$ & $90-3 \log$ & 9 & $110-120$ & 35 & 13 \\
$20-800$ & $60-5 \log$ & 10 & 120 & 42 & 12 \\
$200-1800$ & $150-25 \log$ & 9 & 120 & 60 & 12 \\
$400-2500$ & $200-50 \log$ & 9 & 120 & 70 & 12 \\
\hline
\end{tabular}

Der CHEF MAPPER von BIO RAD wurde eingesetzt, um die Größenbestimmung von PACKlonen durchzuführen. Dazu wurden folgende Bedingungen gewählt:

Tab. 17: PFGE-Laufbedingungen II

\begin{tabular}{llllll}
\hline $\begin{array}{l}\text { Fragmente } \\
(\mathrm{kb})\end{array}$ & $\begin{array}{l}\text { Pulszeit } \\
(\mathrm{s})\end{array}$ & $\begin{array}{l}\text { Gradient } \\
(\mathrm{V} / \mathrm{cm})\end{array}$ & $\begin{array}{l}\text { Winkel } \\
(\mathrm{Grad})\end{array}$ & $\begin{array}{l}\text { Laufzeit } \\
(\mathrm{h})\end{array}$ & $\begin{array}{l}\text { Temperatur } \\
\left({ }^{\circ} \mathrm{C}\right)\end{array}$ \\
\hline $5-150$ & $1,69-7,35$ & 6 & 120 & 16 & 14 \\
\hline
\end{tabular}

\subsubsection{Präparation von Filtern}

Nach der PFGE wurde das Gel 30 min in $0,25 \times$ TBE mit EtBr $(0,4 \mu \mathrm{g} / \mathrm{ml})$ gefärbt und mit Hilfe des Videoprinter-Systems (E.A.S.Y., Herolab, Wiesloch) dokumentiert. Die weitere Behandlung der Gele erfolgte wie unter 2.2.9 beschrieben.

\subsubsection{Präparation von Cosmiden (nach Protokoll der Firma Stratagene)}

Cosmide besitzen eine Klonierungskapazität bis $\mathrm{zu} 46 \mathrm{~kb}$ und sind geeignete genomische Klone für die strukturelle und funktionelle Analyse von interessanten Regionen im Genom. Sie bieten gegenüber YACs u.a. den Vorteil einer leichteren Handhabung sowie einer größeren Stabilität. Für die Subklonierung von YAC-DNA in Cosmide wurde die YAC-DNA partiell gespalten, so daß bevorzugt Restriktionsfragmente zwischen 40 und $50 \mathrm{~kb}$ Länge entstanden. Diese konnten mit einem Cosmid-Vektor ligiert und nach Verpackung mit einem $\lambda$-Verpackungssystem in E. coli-Zellen transfiziert werden. 
Im Rahmen dieser Arbeit wurde der Cosmid-Vektor SuperCos-1 der Firma Stratagene verwendet. Dabei handelt es sich um einen Vektor, der flankierend zu der Klonierungsstelle Promotorsequenzen der Bakteriophagen T3 bzw. T7 beinhaltet, über die z.B. eine spezifische Markierung der Cosmid-Enden ermöglicht werden konnte. Zusätzlich besitzt sCos-1 zwei NotISchnittstellen, wodurch das Insert aus dem Konstrukt herausgeschnitten werden kann (Evans et al., 1989).

\subsubsection{Präparation des Cosmid-Vektors}

$10 \mu \mathrm{g}$ Cosmid-Vektor SuperCos-1 wurden mit $100 \mathrm{U}$ XbaI (Restriktionspuffer II) in einem Gesamtvolumen von $100 \mu \mathrm{l}$ für $2 \mathrm{~h}$ bei $37^{\circ} \mathrm{C}$ gespalten (s. 2.2.5.). Zur Überprüfung der Restriktion wurde ein Aliquot auf einem $1 \%$ Agarosegel analysiert (s. 2.2.6.2.). Die restliche DNA wurde ÜN bei $-20^{\circ} \mathrm{C}$ ausgefällt und bei $13.000 \mathrm{rpm}$ abzentrifugiert (Biofuge pico, Heraeus, Osterode). Anschließend wurde das DNA-Pellet mit $70 \%$ Ethanol gewaschen, getrocknet, in $20 \mu \mathrm{TE}, \mathrm{pH} \mathrm{8,0}$ aufgenommen und anschließend mit alkalischer Phosphatase behandelt (s. 2.2.13.1.). $\mathrm{Zu} 10 \mu \mathrm{g}$ mit $\mathrm{XbaI}$ gespaltenem sCos-1 wurden in $50 \mu \mathrm{l}$ Gesamtvolumen Phosphatase-Puffer und $10 \mathrm{U}$ alkalische Phosphatase (CIP) gegeben. Die Reaktion wurde nach 30 min Inkubation bei $37^{\circ} \mathrm{C}$ mit $3 \mu \mathrm{l}$ EGTA, pH 8,0 sowie durch Inkubation für $10 \mathrm{~min}$ bei $65^{\circ} \mathrm{C}$ gestoppt. Der Vektor wurde mit Phenol extrahiert und anschließend durch Zugabe von 0,1 Vol. NaAc und 2,5 Vol. Ethanol ÜN bei $-20^{\circ} \mathrm{C}$ gefällt, abzentrifugiert, einmal mit $70 \%$ Ethanol gewaschen und in $20 \mu \mathrm{TE}, \mathrm{pH}$ 8,0 aufgenommen. Anschließend wurde der mit XbaI und CIP behandelte Vektor in einem Gesamtvolumen von 50 $\mu \mathrm{l}$ in $0,1 \mu \mathrm{g} / \mu \mathrm{l}$ BSA, 2,5 mM Spermidin und Reaktionspuffer III mit $40 \mathrm{U}$ BamHI für $2 \mathrm{~h}$ bei $37^{\circ} \mathrm{C}$ gespalten. Ein Aliquot wurde auf einem $1 \%$ Agarosegel analysiert. Die restliche DNA wurde zweimal mit Phenol extrahiert, durch Ethanolfällung wie oben ÜN bei $-20^{\circ} \mathrm{C}$ präzipitiert, abzentrifugiert, gewaschen und schließlich in $10 \mu \mathrm{lE}, \mathrm{pH}$ 8,0 aufgenommen. Der Vektor wurde bis zur weiteren Verwendung bei $-20^{\circ} \mathrm{C}$ aufbewahrt.

\subsubsection{Isolierung und partielle Spaltung der YAC-DNA}

Äquilibrierungspuffer:

$$
\begin{aligned}
& 1 \times \mathrm{TAE} \\
& 100 \mathrm{mM} \mathrm{NaCl} \\
& 30 \mu \mathrm{M} \text { Spermin } \\
& 70 \mu \mathrm{M} \text { Spermidin }
\end{aligned}
$$

Die in den Cosmid-Vektor zu klonierende YAC-DNA wurde wie unter 2.2.2.2. beschrieben in Agaroseblöckchen präpariert. Anschließend wurde die YAC-DNA durch ein präparatives LMP (Seaplaque GTG)-Pulsfeldgel von den endogenen Hefechromosomen abgetrennt. Die YACDNA wurde ausgeschnitten und durch enzymatischen Abbau der Agarose freigesetzt. Um die DNA in die BamHI-Schnittstelle des Vektors SuperCos-1 klonieren zu können, wurde die YAC-DNA partiell mit MboI geschnitten, das zur BamHI-Schnittstelle kompatible DNA-Enden generierte. Zur Erzeugung von YAC-DNA-Fragmenten mit Längen zwischen 40 und $50 \mathrm{~kb}$ wurde eine partielle $M b o I-S p a l t u n g$ durchgeführt, wobei sowohl über die Enzymkonzentration als auch über die Zeit Einfluß auf den Grad der Spaltung genommen wurde. 
44 Blöckchen (jeweils $100 \mu \mathrm{l}$ ) des zu klonierenden YACs wurden durch PFGE bei Laufbedingungen, die unter 2.2.15.4. zur Auftrennung von Fragmenten von 20-800 kb beschrieben sind, von den endogenen Hefechromosomen getrennt. Nach Anfärben des Gels mit EtBr wurden die DNA-Banden, die die YAC-DNA enthielten, unter UV-Licht ausgeschnitten, gewogen und 3 x 20 min in Äquilibrierungpuffer geschwenkt. Nach Zugabe von 1 Volumen 1 x TAE wurde die Agarose für $15 \mathrm{~min}$ bei $65^{\circ} \mathrm{C}$ geschmolzen und auf $45^{\circ} \mathrm{C}$ abgekühlt. Es wurden $5 \mathrm{U}$ Agarase $/ 100 \mu \mathrm{l}$ aufgeschmolzener Agarose zugegeben und ÜN bei $45^{\circ} \mathrm{C}$ inkubiert. Die DNA wurde $1 \mathrm{x}$ mit Phenol und $1 \mathrm{x}$ mit Chloroform extrahiert und durch Zugabe von 0,2 Vol. NaAc, pH 5,3 und 1 Vol. Isopropanol für $3 \mathrm{~h}$ bei RT gefällt. Die DNA wurde 20 min bei $15.000 \mathrm{rpm}$ und $4^{\circ} \mathrm{C}$ abzentrifugiert (3K20-Zentrifuge, Sigma, Deisenhofen) und das Pellet mit $70 \% \mathrm{EtOH}$ gewaschen. Anschließend wurde die DNA in $1 \mathrm{x}$ TE aufgenommen und ein Aliquot auf einem 0,4\% Agarosegel analysiert. Die Restriktionen der DNA wurden in einem Gesamtvolumen von $150 \mu 11$ x Restriktionspuffer bei $37^{\circ} \mathrm{C}$ durch Zugabe von $0,05 \mathrm{U} M b o \mathrm{I}$ gestartet. Nach 5, 10, 20 und 40 min wurden 37,5 $\mu$ l Aliquots entnommen und die Reaktionen jeweils mit $1 \mu \mathrm{l}$ 0,5 mM EDTA, pH 8,0 abgestoppt. Jeweils $10 \mu \mathrm{l}$ dieser Aliquots wurden auf einem 0,4 \% Agarosegel analysiert. Alle Ansätze der partiellen Restriktion wurden vereinigt und ÜN präzipitiert. Für die Behandlung mit alkalischer Phosphatase (CIP) wurde die DNA in $100 \mu 11$ x CIP-Puffer aufgenommen und unter Zusatz von $80 \mathrm{U}$ CIP für 30 min bei $37^{\circ} \mathrm{C}$ inkubiert. Die Phosphatase wurde für 15 min bei $68^{\circ} \mathrm{C}$ inaktiviert und der Ansatz zweimal mit Phenol extrahiert. Nach einer Ethanolfällung wurde die DNA in $6 \mu 1$ Ampuwa aufgenommen und bei $4^{\circ} \mathrm{C}$ aufbewahrt.

\title{
2.2.16.3 Ligation der partiell geschnittenen YAC-DNA in den Cosmid-Vektor
}

Die Ligation der partiell mit $\mathrm{MboI}$ geschnittenen YAC-DNA in die BamHI-Schnittstelle des Cosmid-Vektors sCos-1 wurde in einem Gesamtvolumen von $20 \mu$ wie unter 2.2.13.2 beschrieben durchgeführt.

\subsubsection{In vitro-Verpackung der ligierten DNA (nach Protokoll der Firma Stratagene)}

SM-Puffer:

\author{
$100 \mathrm{mM} \mathrm{NaCl}$ \\ $8 \mathrm{mM} \mathrm{MgSO}_{4}$ \\ $50 \mathrm{mM}$ M Tris-HCl, $\mathrm{pH} 7,5$ \\ $0,01 \%$ Gelatine
}

In der vorliegenden Arbeit wurde die Verpackung der rekombinanten Lambda-DNA mit Hilfe des GIGAPACK II XL Packaging Extract (Stratagene) nach den Angaben des Herstellers durchgeführt. Dieser in vitro-Verpackungsextrakt eignet sich besonders gut für die Herstellung einer Cosmid-Bibliothek, da er bevorzugt sehr lange Inserts mit sehr hoher Effizienz verpackt. Er besteht aus einem sonic extract sowie einem freeze-thaw extract, welche alle für die Verpackung notwendigen Bestandteile enthält. Für die Verpackungsreaktion wurde 1/3 des gesamten Ligationsansatzes (s. 2.2.16.3) verwendet. Dazu wurden dem Gesamtpaket jeweils ein sonic extract und ein freeze-thaw extract entnommen. Der freeze-thaw extract wurde schnell zwischen den Fingern erwärmt, bis er gerade begann aufzutauen. Es wurden sofort $4 \mu 1$ des 
Ligationsansatzes hinzupipettiert, die Mischung auf Eis gestellt und zügig $15 \mu 1$ sonic extract zugegeben. Der Ansatz wurde vorsichtig gemischt, für $2 \mathrm{~h}$ bei RT inkubiert und anschließend $500 \mu \mathrm{l}$ SM-Puffer und $20 \mu \mathrm{l}$ Chloroform dazugegeben. Die Zelltrümmer wurden durch eine kurze Zentrifugation sedimentiert, der Überstand in ein neues Reaktionsgefäß überführt und bis zur weiteren Verwendung bei $4^{\circ} \mathrm{C}$ gelagert.

\subsubsection{Präparation des Bakterienstammes}

$50 \mathrm{ml}$ LB-Medium, das zusätzlich 0,2\% Maltose und $10 \mathrm{mM} \mathrm{MgS0}_{4}$ enthielt, wurde mit einer Kolonie des E. coli-Stammes XL1-blue-MR inokuliert und ÜN bei $30^{\circ} \mathrm{C}$ im Schüttler mit 200 rpm angezogen. Die gemessene Zelldichte sollte eine $\mathrm{OD}_{600}$ von 1 nicht überschreiten. Dabei dient die Maltose der Induktion des entsprechenden Rezeptors bei E. coli über den auch die Adsorption des Phagen $\lambda$, vermittelt wird. Die Bakterien wurden anschließend durch eine 10 min Zentrifugation bei $2000 \mathrm{rpm}$ sedimentiert (Megafuge 1,0 R, Heraeus, Osterode) und vorsichtig in 12,5 ml $10 \mathrm{mM} \mathrm{MgSO}_{4}$ resuspendiert. Anschließend wurde die $\mathrm{OD}_{600}$ der Zellen mit $10 \mathrm{mM} \mathrm{MgSO}_{4}$ auf 0,6 eingestellt. Die Bakterien wurden höchstens $48 \mathrm{~h}$ bis zum weiteren $\mathrm{Ge}-$ brauch bei $4^{\circ} \mathrm{C}$ aufbewahrt.

\subsubsection{Infektion der Bakterien}

Es wurden 1:5, 1:10 und 1:50 Verdünnungen der verpackten Cosmid-DNA (s. 2.2.16.4.) in SM-Puffer hergestellt. Jeweils $25 \mu 1$ dieser Verdünnungen wurden mit $25 \mu 1$ des aufbereiteten Bakterienstammes vermischt und für $30 \mathrm{~min}$ bei RT zur Adsorption der Phagen stehengelassen. Nach Zugabe von $200 \mu \mathrm{LB}$ L-Medium wurden die Zellen für $1 \mathrm{~h}$ bei $37^{\circ} \mathrm{C}$ inkubiert, wobei alle 15 min vorsichtig gemischt wurde. Anschließend wurde der Ansatz 1 min bei $10.000 \mathrm{rpm}$ abzentrifugiert (Biofuge pico, Heraeus, Osterode), in $50 \mu 1$ frischem LB-Medium resuspendiert und anschließend auf Agarplatten (10 x $10 \mathrm{~cm}$ Petrischalen) mit $25 \mu \mathrm{g} / \mathrm{ml}$ Kanamycin ausplattiert. Die Platten wurden ÜN bei $37^{\circ} \mathrm{C}$ im Brutschrank inkubiert. Zur Herstellung weiterer Platten der Cosmid-Bibliothek wurde diejenige Verdünnung gewählt, die ca. 100 Kolonien/Platte ergab.

\subsubsection{Herstellung von Replica-Filtern}

Für die Charakterisierung und spätere Durchmusterung der Cosmid-Bibliotheken waren sowohl die PCR als auch die Hybridisierungstechnik geeignet. Für Hybridisierungen wurden ReplicaFilter der Kultur-Platten angefertigt, wobei die Cosmide von der Agarplatte auf Nitrozellulosefilter übertragen und anschließend dort lysiert wurden.

Für den Transfer der Cosmid-Klone auf die Nitrozellulosefilter wurden entsprechend der Anzahl an Agarplatten 10 x $10 \mathrm{~cm}$ große Filter vorbereitet. Die Membran wurde vorsichtig ohne Luftblasen auf die Bakterienkolonien gelegt und dort für 2 min belassen. Zur Markierung wurde der Filter noch auf der Platte liegend mit Hilfe einer heißen Nadel mit drei Löchern versehen. Durch einen Vergleich des Lochmusters auf dem Filter mit dem auf der Agarplatte konnten beide nach der Hybridisierung zur Deckung gebracht und entsprechende positive Klone identifiziert werden. Der Filter wurde mit den an der Unterseite anhaftenden Kolonien 
vorsichtig von der Platte abgezogen, indem in einer Ecke mit Hilfe einer Pinzette mit dem Ablösen begonnen und dann diagonal fortgefahren wurde. Zur anschließenden Lyse der Bakterien wurde ein mit Denaturierungslösung (s. 2.2.9.1) getränktes Blotting-Papier in einer $20 \mathrm{x}$ $20 \mathrm{~cm}$ Petrischale vorbereitet, auf dem der Replica Filter mit der Kolonieseite nach oben für 5 min inkubiert wurde. Der Filter wurde dann zur Neutralisierung für 2 min auf ein mit Neutralisierungs-Lösung (s. 2.2.9.1.) getränktes Blotting-Papier gelegt, kurz in 2 x SSC gespült, an der Luft getrocknet, wonach die DNA unter UV-Licht im Crosslinker (Typ 1800, Stratagene, Heidelberg) an die Membran gebunden wurde. Bis zur Hybridisierung wurden die Filter trocken bei RT gelagert.

\subsubsection{Transfer humaner Cosmide auf Filter mit Hilfe einer automatischen Pipettier- station}

Durch eine Hybridisierung der Replica-Filter mit Cot-1-DNA sollten Cosmide mit humanen Inserts identifiziert werden. Cot-1-DNA, welche eine mit repetitiven Sequenzen angereicherte genomische DNA des Menschen darstellt, wurde wie unter 2.2.8 beschrieben radioaktiv markiert. Die weitere Vorgehensweise erfolgte wie unter 2.2.9.2 bzw. 2.2.9.4. dargestellt. Zur Identifizierung der humanen Cosmide wurde das auf den Filtern zu erkennende Lochmuster mit den Nadeleinstichen auf den Agarplatten verglichen und zur Deckung gebracht. Dabei identifizierte positive Cosmide wurden von den Agarplatten in 96-well Mikrotiterplatten überführt, ÜN bei $37^{\circ} \mathrm{C}$ inkubiert und bei $-70^{\circ} \mathrm{C}$ gelagert.

Für eine weitere Durchmusterung und nähere Charakterisierung der Cosmide wurden 192 Klone (2 Mikrotiterplatten) als geordnete Bakterienkolonien (Grid) auf Nitrozellulosemembranen mit Hilfe der Pipettierstation Biomek 1000 der Firma Beckman Instruments (Palo Alto, USA) übertragen. Die bei $-70^{\circ} \mathrm{C}$ in den Mikrotiterplatten gelagerten Cosmide wurden langsam auf Eis aufgetaut und anschließend mittels eines mit 96 Nadeln bestückten Zubehörs der Pipettierstation automatisch auf die Filter transferiert. Auf diese Weise wurden auf jeden Filter jeweils 96 oder 192 Cosmid-Klone überführt, die ÜN auf LB-Platten mit $25 \mu \mathrm{g} / \mathrm{ml} \mathrm{Kanamycin}$ bei $37^{\circ} \mathrm{C}$ inkubiert und im Anschluß daran wie unter 2.2.16.7 beschrieben lysiert wurden.

\subsubsection{Markierung von Cosmid-Enden durch lineare PCR}

Zur schnellen Anordnung der Cosmide in einem Contig wurden die Enden von mehreren unabhängigen Cosmiden unter Verwendung der vektorspezifischen Primer T3 und / oder T7 radioaktiv markiert. Auf diese Weise wurden spezifische Sonden für die Cosmid-Enden erhalten, diese wurden auf die gesamte Bibliothek hybridisiert. Für die radioaktive Markierung der Cosmid-Enden wurden 0,1 bis $1 \mu \mathrm{g}$ Cosmid-DNA in einem Gesamtvolumen von $20 \mu \mathrm{l}$ in EcoRI-Restriktionspuffer, 2,5 mM Spermidin mit $20 \mathrm{U}$ EcoRI für $2 \mathrm{~h}$ bei $37^{\circ} \mathrm{C}$ gespalten. Zur Überprüfung der Vollständigkeit der Restriktion wurden $15 \mu 1$ auf einem $1 \%$ Agarosegel analysiert (2.2.6.2.). Die anschließende lineare PCR wurde in folgendem Ansatz durchgeführt.

$1 \mu \mathrm{l}$ der mit EcoRI gespaltenen DNA

$5 \mu 110$ x PCR-Puffer

$1 \mu \mathrm{ldNTP}$ Mix (jeweils 5 mM dATP, dTTP, dGTP) 
$0,5 \mu 11 \% \mathrm{BSA}$

200 ng T3-Primer und / oder 200 ng T7-Primer

2,5 U Taq-Polymerase

$2 \mu \mathrm{l}\left(\alpha-{ }^{32} \mathrm{P}\right)-\mathrm{dCTP}$

ad $50 \mu \mathrm{lmit} \mathrm{H}_{2} \mathrm{O}$

Die Amplifikation wurde mit Thermocycler-Programm 4 (s. 2.2.10.1) durchgeführt. Vor der Hybridisierung wurde der Ansatz wie unter 2.2.9.3. beschrieben mit $50 \mu 1$ humaner PlazentaDNA $(10 \mathrm{mg} / \mathrm{ml})$ versetzt, für $10 \mathrm{~min}$ in kochendem Wasser denaturiert und anschließend für 20 min bei $65^{\circ} \mathrm{C}$ inkubiert. Die Hybridisierung und nachfolgende Waschung der Filter erfolgte wie unter 2.2.9.2. bzw. 2.2.9.4. erläutert.

\subsubsection{Herstellung der Chromosomenpräparate}

2.2.17.1 Chromosomenpräparation aus Lymphozyten (modifiziert nach Francke und Oliver, 1978)

Lymphozyten-Gebrauchslösung:

$100 \mathrm{ml}$ ISCOVES-Medium

$10 \mathrm{ml} \mathrm{FKS}$

$1 \mathrm{ml}$ Glutaminlösung

$1 \mathrm{ml}$ Penicillin/Streptomycin

Colcemid-Stammlösung:

$0,1 \mathrm{mg} / \mathrm{ml} \mathrm{Hanks}$

Fixativ:

3 Teile Methanol

1 Teil Eisessig

frisch ansetzen

Hypotone Lösung:

$2 \mathrm{~g} / 1$ Natriumcitrat

2,96 g/ 1 Kaliumchlorid

Der Kulturansatz, bestehend aus $1 \mathrm{ml}$ heparinisiertem Vollblut, $150 \mu 1$ Phytohämagglutinin und $10 \mathrm{ml}$ Lymphocyten-Gebrauchslösung, wurde unter sterilen Bedingungen pipettiert und für 72 $\mathrm{h}$ bei $37^{\circ} \mathrm{C}$ im Brutschrank inkubiert. Eine Stunde vor Kulturende wurden 0,5 ml ColcemidStammlösung zur Arretierung der Zellen in der Mitose zugesetzt. Nach Ablauf der Kulturzeit wurden die Zellen durch $10 \mathrm{~min}$ Zentrifugation bei $1000 \mathrm{rpm}$ (Megafuge 1,0 R, Heraeus, Osterode) sedimentiert und in $10 \mathrm{ml}$ auf $37^{\circ} \mathrm{C}$ temperierter hypotoner Lösung schrittweise aufgenommen. Es folgte eine Inkubation von 18 min bei RT, wobei zwischendurch $1 \mathrm{x}$ gemischt wurde. Anschließend wurde wie zuvor zentrifugiert, der Überstand bis auf $500 \mu 1$ abgenommen und das Pellet darin resuspendiert. Es wurde tropfenweise eiskaltes Fixativ zugegeben, dann wurde das Röhrchen mit Fixativ aufgefüllt und erneut gemischt. Nach Inkubation für 15 min bei RT wurden die Zellen abermals abzentrifugiert und fixiert und für 10 min bei RT inkubiert. 
Nach erneuter Zentrifugation wurde ein letzter Fixierungschritt angeschlossen und die Zellen ohne Inkubation direkt pelletiert. Der Überstand wurde bis auf $1,5 \mathrm{ml}$ abgenommen und die Zellen darin resuspendiert. Zur Entfernung von Staubpartikeln wurden die Objektträger unter fließendem demineralisierten Wasser gespült und bis zur Verwendung in Milli-Q-Wasser bei $4^{\circ} \mathrm{C}$ in Küvetten gelagert. 1-2 Tropfen der Zellsuspension wurden dann aus einer Höhe von 10 $\mathrm{cm}$ auf einen vorbehandelten, nassen Objektträger getropft. Bei 100-250facher Vergrößerung wurden dann die Zell- und Metaphasendichte sowie die Spreitungsqualität der Chromosomen im Phasenkontrastmikroskop kontrolliert. Die Chromosomenpräparate sollten vor der Hybridisierung etwa 1 Woche alt sein. Durch Inkubation der Objektträger bei $37^{\circ} \mathrm{C}$ ÜN konnte die Alterung jedoch beschleunigt werden. Eine längere Lagerung erfolgte bei $-20^{\circ} \mathrm{C}$.

\subsubsection{Chromosomenpräparation aus EBV-transformierten B-Lymphozyten}

Die EBV-Kulturen wurden im Labor der postnatalen Cytogenetik, Institut für Humangenetik der Universität Göttingen, etabliert und für die Untersuchungen zur Verfügung gestellt.

Nach einer Inkubation von $24 \mathrm{~h}$ nach dem letzten Mediumwechsel wurde die Kultur leicht geschüttelt, um die Zellen zu suspendieren und $0,5 \mathrm{ml}$ Colcemid-Stammlösung (s. 2.2.17.1.) pro $10 \mathrm{ml}$ Medium hinzugegeben. Danach wurde die Kultur noch 90 min lang im Brutschrank bei $37^{\circ} \mathrm{C}$ und unter einer Atmosphäre von $9 \%$ Kohlendioxid weiterinkubiert. Nach Ablauf dieser Zeit wurden die Zellen $10 \mathrm{~min}$ bei $1000 \mathrm{rpm}$ pelletiert und der Überstand bis auf $500 \mu 1$ abgenommen. Darin wurden die Zellen durch Aufklopfen des Röhrchens resuspendiert und das Röhrchen anschließend mit auf $37^{\circ} \mathrm{C}$ vorgewärmter hypotoner Lösung (s. 2.2.17.1.) aufgefüllt und gemischt. Die weitere Aufarbeitung der Zellen erfolgte wie unter 2.2.17.1. beschrieben.

2.2.18 Fluoreszenz-in situ-Hybridisierung (FISH) (modifiziert nach Lichter et al., 1988)

\subsubsection{Vorbehandlung der Objektträger}

Eine Vorbehandlung der Objektträger vor Einsatz in der FISH hat sich für die Qualität des Fluoreszenzpräparates in bestimmten Fällen als günstig erwiesen. Durch die RNase A-Behandlung wurde auf 1-3 Wochen gelagerten Objektträgern die auf dem Objektträger fixierte RNA entfernt. Auf diese Weise wurde eine unspezifische Bindung der markierten DNA-Sonde an endogene RNA verhindert. Dies führte zu einer Erhöhung der Spezifität der Hybridisierung in bezug auf Signal und Hintergrund. Bei länger gelagerten Objektträgern war diese Behandlung nicht erforderlich. War auf den Objektträgern viel Cytoplasma zu erkennen, wurden durch eine Pepsin-Behandlung proteinhaltige Zellbestandteile entfernt.

\subsection{RNase-Behandlung der Objektträger}

RNase A-Lösung: $\quad 0,1 \mathrm{mg} / \mathrm{ml}$ RNase A in 2 x SSC 
Vor dem Gebrauch der RNase A-Lösung wurde diese 15 min im Wasserbad gekocht, um möglicherweise darin enthaltene DNasen zu zerstören. Nach Abkühlung der Lösung wurden jeweils $200 \mu \mathrm{l}$ pro Objektträger aufgetragen, diese dann blasenfrei mit einem 24 x $60 \mathrm{~mm}$ Deckglas abgedeckt und die Präparate dann $1 \mathrm{~h}$ bei $37^{\circ} \mathrm{C}$ in einer feuchten Kammer inkubiert. Anschließend wurden die Objektträger zweimal 15 min bei RT in einer Küvette mit 2 x SSC inkubiert, was der Entfernung der RNase A-Lösung und der Alterung der Objektträger diente.

\subsection{Pepsin-Behandlung der Objektträger}

Pepsin-Lösung: $\quad 4 \mu \mathrm{l}$ Pepsin $(100 \mathrm{mg} / \mathrm{ml})$

$40 \mu 10,1 \mathrm{M} \mathrm{HCl}$

ad $40 \mathrm{ml}$ Aqua dest.

Die Objektträger wurden in eine Küvette mit auf $37^{\circ} \mathrm{C}$ vorgewärmter Pepsinlösung überführt und darin 4-6 min inkubiert.

\subsection{Denaturierung der Chromosomenpräparate}

Denaturierungslösung:

$70 \%$ Formamid in $2 \times$ SSC

$\mathrm{pH} 7,0$

Vor der Denaturierung wurden die Objektträger in einer aufsteigenden EtOH-Reihe (je $1 \mathrm{~min}$ in $70 \%, 80 \%, 90 \%$ und $2 \times 1$ min in $99 \%$ ) dehydriert. Die frisch angesetzte Denaturierungslösung wurde in einer Küvette auf $70^{\circ} \mathrm{C}$ vorgewärmt und die Chromosomenpräparate darin 2,53 min denaturiert. Anschließend wurden die Objektträger direkt durch eine auf $-20^{\circ} \mathrm{C}$ gekühlte aufsteigende EtOH-Reihe (je 1 min in $70 \%, 80 \%, 90 \%$ und $2 \times 1$ min in $99 \%$ ) geführt und aufrecht an der Luft getrocknet. Die so behandelten Präparate wurden noch am selben Tag für eine Hybridisierung eingesetzt.

\subsubsection{Vorbereitung der DNA-Sonden}

2.2.18.2.1 Markierung der DNA-Sonden mittels Nicktranslation (nach Rigby et al., 1977)

Sowohl YAC-DNA als auch PAC-, Cosmid- und Plasmid-DNA wurden mit Hilfe der Nicktranslation mit Biotin-16-dUTP bzw. Digoxigenin-11-dUTP markiert. Diese Reaktion ermöglichte eine gezielte Beeinflussung der Fragmentgrößen der markierten Sonden. Über die Variation der Nicktranslationsbedingungen, vornehmlich der DNase-Konzentration und der Inkubationsdauer, konnte die für eine erfolgreiche Hybridisierung optimale Fragmentgröße der Sonden von 200 bis 400 Basenpaaren erreicht werden.

Nicktranslationspuffer, $10 \mathrm{x}$ :

$$
\begin{aligned}
& \text { 0,5 M Tris- } \mathrm{HCl}, \mathrm{pH} 7,5 \\
& 0,1 \mathrm{M} \mathrm{MgSO}_{4} \\
& 1 \mathrm{mM} \text { Dithiothreitol } \\
& 500 \mu \mathrm{g} / \mathrm{ml} \mathrm{BSA}
\end{aligned}
$$


DNase I-Lösung:

$1 \mu \mathrm{l}$ DNase I (1 mg/ml)

ad $1 \mathrm{ml}$ Ampuwa

200 ng einer PAC-, Cosmid- oder Plasmid-DNA wurden in einem $40 \mu$ l Ansatz wie folgt markiert:

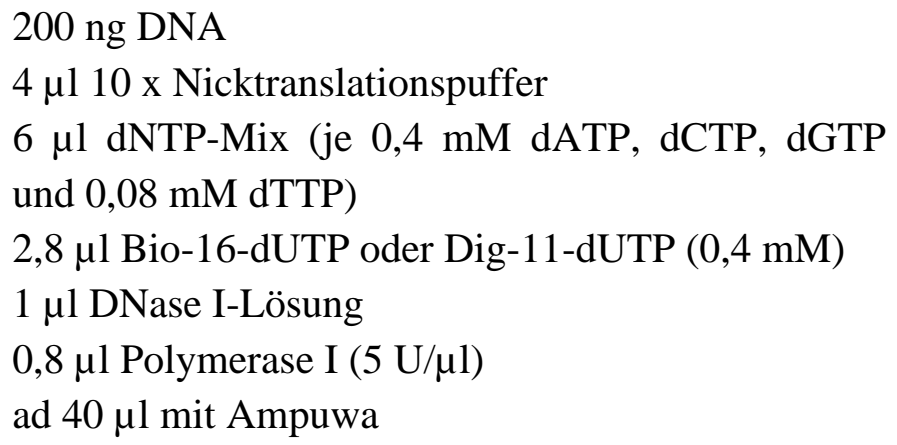

YAC-DNA wurde in Form von Gesamt-DNA, also Hefe- einschließlich Insert-DNA, markiert. Der Nicktranslationsansatz betrug $200 \mu \mathrm{l}$ und sah wie folgt aus:

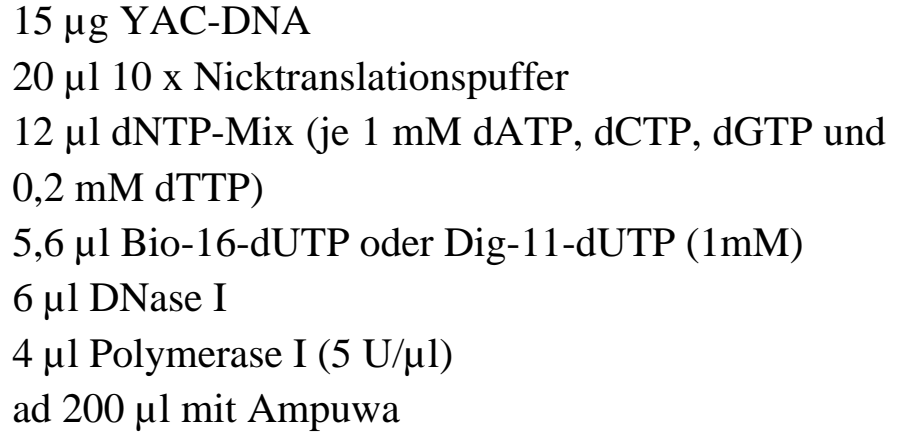

Der Nicktranslationsansatz wurde $2 \mathrm{~h}$ bei $14^{\circ} \mathrm{C}$ inkubiert und die Markierung dann durch Zugabe von 0,1 Vol. $3 \mathrm{M}$ NaAc und 2,5 Vol. $100 \%$ EtOH gestoppt. Die markierte DNA wurde durch 30 min Inkubation bei $-70^{\circ} \mathrm{C}$ oder ÜN bei $-20^{\circ} \mathrm{C}$ ausgefällt.

\subsection{Kontrolle des Biotin-Einbaus mittels Dot-Blot}

Puffer 1: $25 \mathrm{mM}$ Tris-HCl, $\mathrm{pH} 7,5$

$50 \mathrm{mM} \mathrm{NaCl}$

$0,05 \%$ Triton $\mathrm{X}-100$
Puffer 2: 25 mM Tris-HCl, pH 9,5

$50 \mathrm{mM} \mathrm{NaCl}$

Nach der Nicktranslation konnte die Effizienz der Reaktion über eine Farbreaktion abgeschätzt werden. Dazu wurde die markierte PAC-, Cosmid- oder Plasmid-DNA in $100 \mu 1$ Ampuwa bzw. markierte YAC-DNA in $300 \mu$ gelöst. Es wurde eine 1:10, 1:100 und 1:1000 Verdünnung angesetzt und je $1 \mu$ l dieser Verdünnungen und der Ausgangslösung auf einen mit 2 x SSC befeuchteten Nitrocellulosefilter aufgetropft. Alternativ dazu wurde in einigen Fällen auch ein beschleunigtes Verfahren angewendet, bei dem direkt 1/100 der markierten, noch nicht gefäll- 
ten DNA bzw. eine 1:10 und 1:100 Verdünnung dieser Menge auf den Filter aufgetragen wurde. Die DNA wurde anschließend durch UV-Bestrahlung im Crosslinker (Typ 1800, Stratagene, Heidelberg) kovalent an die Filter gebunden. Um unspezifische Bindungen des später zugesetzten Streptavidin an die Filter zu verhindern, wurde der Filter $30 \mathrm{~min}$ in $7 \mathrm{ml}$ Puffer 1 und $3 \mathrm{ml} 10 \%$ igem BSA bei $37^{\circ} \mathrm{C}$ inkubiert. Zur Detektion des Biotins wurde der Filter dann $30 \mathrm{~min}$ in 9,5 ml Puffer 1 mit 0,3 ml $10 \%$ BSA unter Zusatz von $5 \mu 1$ alkalischer StreptavidinPhosphatase $(0,8 \mathrm{mg} / \mathrm{ml})$ bei RT und unter Schwenken inkubiert. Der Filter wurde dann 3 x 5 min in Puffer 1 und 2 x 5 min in Puffer 2 gewaschen, bevor sich die eigentliche Farbreaktion anschloß. Für diese wurde der Filter $1 \mathrm{~h}$ in $5 \mathrm{ml}$ Puffer 2 mit jeweils $4 \mu \mathrm{l} / \mathrm{ml}$ BCIP und NBT unter Lichtabschluß auf dem Schüttler inkubiert. Eine deutliche Blaufärbung der 1:10- und eine noch erkennbare Blaufärbung der 1:100-Verdünnung zeigten einen sehr guten Biotin-Einbau an. Nach erfolgtem Dot-Blot wurde die Ausgangslösung durch 1/10 Vol. 3 M NaAc und 2,5 Vol. $100 \%$ EtOH gefällt.

\subsection{Suppression unspezifischer Hybridisierung (nach Pinkel et al., 1988)}

Rekombinante DNA, die ihren Ursprung in eukaryotischer DNA hat, enthält oft repetitive Sequenzen wie z.B. Alu- und alphoide Sequenzen. Eine in situ Hybridisierung auf menschlichen Chromosomen mit einer Sonde, die solche Sequenzen beinhaltet, würde zu einer unspezifischen Markierung vieler Chromosomen führen. Um derartige Kreuzhybridisierungen zu verhindern, wurde der markierten Sonde sog. Kompetitions-DNA zugesetzt, die sich vor der eigentlichen Hybridisierung an die entsprechenden Sequenzen der Sonde anlagerte. Als Kompetitions-DNA diente Lachssperm-DNA (zur Absättigung von unspezifischen Sequenzen), deren Fragmentlängen im Sonikator auf 250-500 bp eingestellt wurden, und Cot-1-DNA (zur Absättigung von hochrepetitiven Sequenzen). Je größer die eingesetzte DNA-Sonde war (Plasmid < Cosmid < PAC < YAC), desto mehr Kompetitions-DNA wurde zugesetzt. Für Plasmide wurden in der Regel $3 \mu \mathrm{l}$ Cot-1-DNA $(1 \mathrm{mg} / \mathrm{ml})$ und $2 \mu l$ Lachssperm-DNA (10 $\mathrm{mg} / \mathrm{ml}$ ), für Cosmide und PACs $9 \mu 1$ Cot-1-DNA und $6 \mu 1$ Lachssperm-DNA und für YACs entsprechend $20 \mu \mathrm{l}$ Cot-1-DNA und $5 \mu \mathrm{l}$ Lachssperm-DNA zugesetzt. Die Kompetitions-DNA wurde der markierten Sonde nach dem Dot-Blot zugesetzt und mit ihr ausgefällt.

\subsubsection{Hybridisierungsansatz und Preannealing}

Mastermix:

Hybridisierungslösung:
$20 \%$ Dextransulfat in $2 \times$ SSC

1 Vol. $100 \%$ deion. Formamid

1 Vol. Mastermix

Pro Objektträger wurden 200 ng markierte Plasmid-, Cosmid- oder PAC-DNA bzw. etwa 15 $\mu \mathrm{g}$ YAC-DNA in $10 \mu \mathrm{l}$ Hybridisierungslösung eingesetzt. Dafür wurde die markierte und mit Kompetitions-DNA versetzte DNA mit 0,1 Vol. NaAc/2,5 Vol. EtOH gefällt, mit $70 \% \mathrm{EtOH}$ gewaschen und das getrocknete Pellet anschließend in $5 \mu 1100 \%$ deion. Formamid 30 min bei $37^{\circ} \mathrm{C}$ gelöst. Nach Zugabe von $5 \mu 1$ Mastermix erfolgte die Denaturierung der DNA durch 5minütiges Kochen des Hybridisierungsansatzes. Anschließend wurde der Hybridisierungansatz 
15 min bei $37^{\circ} \mathrm{C}$ inkubiert. Durch dieses sogenannte Preannealing wurde der zugesetzten Kompetitions-DNA Gelegenheit gegeben, die repetitiven Sequenzen der markierten Sonde vor der eigentlichen Hybridisierung abzusättigen. Nach dem Preannealing wurden pro Objektträger $10 \mu \mathrm{l}$ dieses Hybridisierungsansatzes auf den denaturierten Objektträger (s. 2.2.18.1.3.) pipettiert, mit einem 24 x $32 \mathrm{~mm}$ Deckglas blasenfrei abgedeckt und die Ränder mit Fixogum versiegelt. Die Hybridisierung erfolgte ÜN in einer feuchten Kammer bei $37^{\circ} \mathrm{C}$.

\subsubsection{Waschen nach der Hybridisierung}

Die während der Hybridisierung nicht oder nur unspezifisch gebundenen Sondenmoleküle wurden durch anschließende Waschschritte verschiedener Stringenz entfernt, um unspezifische Signale und mögliche Hintergrundprobleme auf dem Objektträger zu verringern. Alle Waschschritte erfolgten unter Schütteln in der bei der angegebenen Temperatur vorgewärmten Waschlösung. Pro Objektträger wurde die Temperatur aller Lösungen um $1^{\circ} \mathrm{C}$ erhöht, um die Stringenz der Waschschritte zu gewährleisten.

Waschlösung I: $\quad 50 \%$ Formamid in 2 x SSC $\mathrm{pH} 7,0$ $42^{\circ} \mathrm{C}$

Waschlösung III: $\quad 0,1$ x SSC $62^{\circ} \mathrm{C}$

\section{Waschlösung II: 2 x SSC \\ $42^{\circ} \mathrm{C}$}

Waschlösung IV: 4 x SSC

$0,1 \%$ Tween 20

$42^{\circ} \mathrm{C}$

Mit einer Pinzette wurde das Fixogum von den Objektträgern abgezogen und die Deckgläser vorsichtig entfernt. Anschließend wurden die Objektträger 3 x 5 min in einer Küvette mit Waschlösung I, 5 x 2 min in Waschlösung II, 3 x 5 min in Waschlösung III sowie 1 x 5 min in Waschlösung IV gewaschen.

\subsubsection{Detektion und Amplifikation von Biotin-markierten Sonden}

Blocking-Lösung: $\quad 5 \%$ BSA in 4 x SSC

Waschlösung: $\quad 4$ x SSC

$0,1 \%$ Tween 20

$42^{\circ} \mathrm{C}\left(+1{ }^{\circ} \mathrm{C} /\right.$ Objektträger $)$

Avidin-FITC-Lösung: $\quad 2,5 \mu \mathrm{l}$ Avidin-FITC $(1 \mathrm{mg} / \mathrm{ml})$

$1 \mathrm{ml}$ Blocking-Lösung

BAAD-Lösung: $\quad 5 \mu 1$ BAAD $(0,5 \mathrm{mg} / \mathrm{ml})$

$1 \mathrm{ml}$ Blocking-Lösung 
Biotin wurde durch spezifische Bindung von FITC-gekoppeltem Avidin (Fluorescein Avidin) detektiert. Anschließend wurde eine Amplifikation durch Einsatz eines biotinylierten Antikörpers gegen Avidin (Biotinyliertes Anti-Avidin D) und erneute Inkubation mit FITC-gekoppeltem Avidin angeschlossen. Für die meisten eingesetzten Sonden erwies es sich als sinnvoll, eine zweite Amplifikation nach diesem Muster durchzuführen. Alle Inkubationsschritte in der feuchten Kammer erfolgten unter Lichtabschluß und, mit Ausnahme des Blocking-Schritts, unter einem Deckglas. Die Waschschritte erfolgten auf dem Schüttler unter Lichtabschluß.

Nach den Waschschritten wurden die Objektträger in eine feuchte Kammer gelegt und mit 500 $\mu 1$ Blocking-Lösung benetzt. Nach 10 min Inkubation bei RT wurde die Blocking-Lösung durch kurzes Aufstellen der Objektträger entfernt und $100 \mu 1$ der Avidin-FITC-Lösung aufgetragen. Nach 30 min Inkubation bei $37^{\circ} \mathrm{C}$ wurden die Objektträger 3 x 5 min in der Waschlösung gewaschen. Es folgte ein weiterer Blocking-Schritt und eine Inkubation mit $100 \mu \mathrm{l}$ BAAD-Lösung bei $37^{\circ} \mathrm{C}$. Nach 30 min wurden die Objektträger erneut wie oben gewaschen. Es folgte ein erneuter Blocking-Schritt, gefolgt von einer 30 min Inkubation mit Avidin-FITCLösung und anschließendem Waschschritt. In der Regel wurde zur Amplifikation der Signale noch $1 \mathrm{x}$ durch Inkubation mit Avidin-FITC-Lösung und BAAD-Lösung wie beschrieben verstärkt.

\subsubsection{Detektion und Amplifikation von Digoxigenin-markierten Sonden}

Die Detektion von Digoxigenin erfolgte über eine mit Cy3-gekoppelte Antikörperreihe. Im ersten Schritt wurden die Digoxigeninmoleküle durch den monoklonalen Anti-DigoxigeninAntikörper aus der Maus gebunden. Auf diesen folgte dann der Cy3-konjugierte Anti-MausAntikörper vom Kaninchen, der wiederum mittels eines Cy3-konjugierten Anti-KaninchenAntikörpers aus der Ziege detektiert wurde.

Blocking-Lösung und Waschlösungen siehe unter 2.2.18.5.

Anti-Digoxigenin-Lösung:

Anti-Maus-Cy3:

Anti-Kaninchen-Cy3:
$1 \mu \mathrm{l}$ Anti-Digoxigenin (Maus) $(100 \mu \mathrm{g} / \mathrm{ml})$

$500 \mu 1$ Blocking-Lösung

$1 \mu \mathrm{l}$ Anti-Maus-Cy3 (Kaninchen) $(200 \mu \mathrm{g} / \mathrm{ml})$

$250 \mu$ l Blocking-Lösung

$1 \mu \mathrm{l}$ Anti-Kaninchen-Cy3 (Ziege) $(200 \mu \mathrm{g} / \mathrm{ml})$

$250 \mu$ l Blocking-Lösung

Nach den Waschschritten wurden die Objektträger in eine feuchte Kammer gelegt, mit $500 \mu 1$ Blocking-Lösung benetzt und für 10 min bei RT inkubiert. Anschließend wurde die BlockingLösung entfernt und $100 \mu$ l Maus-Anti-Digoxigenin-Antikörper aufgetragen. Nach $30 \mathrm{~min}$ Inkubation bei $37^{\circ} \mathrm{C}$ wurden die Objektträger 3 x 5 min in der Waschlösung gewaschen. Es folgte ein weiterer Blocking-Schritt und eine Inkubation mit $100 \mu$ l Anti-Maus konjugiertem $\mathrm{Cy} 3$ bei $37^{\circ} \mathrm{C}$. Nach 30 min wurden die Objektträger erneut gewaschen. Es folgte ein erneuter 
Blocking-Schritt, gefolgt von einer 30 min Inkubation mit Anti-Kaninchen konjugiertem Cy3 und anschließendem Waschschritt.

\subsubsection{Zweifarbige FISH: Avidin-FITC- und Digoxigenin-Cy3-Detektion}

Bei der zweifarbigen FISH wurden zwei unterschiedlich markierte DNA-Sonden gleichzeitig für eine Hybridisierung eingesetzt. Eine Sonde wurde wie unter 2.2.18.2.1. beschrieben biotinyliert, die zweite wurde mit Digoxigenin markiert. Der Hybridisierungansatz gleicht dem der Hybridisierung mit einer einzigen Sonde, wobei die bis zum Preannealing getrennt behandelten Sonden direkt vor der Hybridisierung vermischt und gemeinsam auf das denaturierte Chromosomenpräparat aufgetragen wurden. Nach der Hybridisierung wurde wie unter 2.2.18.4. beschrieben gewaschen.

Nach den Waschschritten wurde 10 min bei RT geblockt. Anschließend erfolgte eine Inkubation mit Avidin-FITC-Lösung wie unter 2.2.18.5. beschrieben. Die Objektträger wurden $3 \mathrm{x}$ 5 min in Waschlösung gewaschen und 10 min geblockt. Es folgte eine gleichzeitige Inkubation mit biotinyliertem Anti-Avidin-Antikörper und Maus-Anti-Digoxigenin-Antikörper für 30 min bei $37^{\circ} \mathrm{C}$. Es folgte ein erneuter Waschschritt, ein Blocking-Schritt und eine Inkubation in Avidin-FITC und Anti-Maus konjugiertem Cy3 für 30 min bei $37^{\circ} \mathrm{C}$. Nach erneutem Waschen und Blocken folgte eine Inkubation mit biotinyliertem Anti-Avidin-Antikörper und AntiKaninchen konjugiertem Cy3 für 10 min bei $37^{\circ} \mathrm{C}$. Nach erneutem Wasch- und BlockingSchritt wurde eine letzte Inkubation mit Avidin-FITC angeschlossen und die Objektträger abschließend in Waschlösung gewaschen.

\subsubsection{Gegenfärbung der Chromosomen mit Propidiumiodid und DAPI}

Propidiumiodid-DAPI-Färbelösung:

$$
\begin{aligned}
& 0,1 \mathrm{mg} / \mathrm{ml} \text { Propidiumiodid } \\
& 0,002 \mathrm{mg} / \mathrm{ml} \text { DAPI } \\
& \text { in Vectashield }
\end{aligned}
$$

DAPI-Färbelösung:

$$
\begin{aligned}
& 0,002 \mathrm{mg} / \mathrm{ml} \text { DAPI } \\
& \text { in Vectashield }
\end{aligned}
$$

Für Biotin markierte Sonden wurde die Propidiumiodid-DAPI-Färbelösung zum Eindeckeln verwendet, bei Digoxigen-markierten Sonden bzw. bei der zweifarbigen FISH wurde der Färbelösung nur DAPI zugesetzt. Auf die Objektträger wurden $30 \mu 1$ der Färbelösung aufgetragen, ein Deckglas blasenfrei aufgelegt und mit Nagellack umrandet. 


\subsubsection{Auswertung der Objektträger}

Die Präparate wurden zunächst mit einem Zeiss Axiophot-Fluoreszenzmikroskop und nach Anschaffung eines Zeiss Axioplan-Fluoreszenzmikroskop mit diesem ausgewertet. Die Mikroskope waren mit folgenden Filtersystemen ausgestattet:

- Propidiumiodid-Anregung: Filter 450-490, FT510, LP 520 (Zeiss, Göttingen):

- FITC-Anregung: Filter F41-001 (AF Analysentechnik, Tübingen)

- DAPI-Anregung: Filter F31-000 (AF Analysentechnik, Tübingen)

- Anregung von Propidiumiodid und FITC: Filter BP564, FT580, LP 590 (Zeiss, Göttingen):

- Anregung von DAPI/FITC/Texas Red: Filter F61-002 (AF Analysentechnik, Tübingen)

Geeignete Metaphasen wurden bis zur Anschaffung einer CCD-Camera und des MetasystemsDokumentationssystems zunächst bei 160facher Vergrößerung fotografiert. Hierzu wurden Scotch 640T-Diafilme verwendet. Nachdem das Metasystems-Dokumentationssystem zur Verfügung stand, wurden geeignete Metaphasen digital gespeichert. 


\section{Ergebnisse}

\subsection{Erstellung eines hochauflösenden YAC-Contigs für die Region eines mit Russell-Silver-Syndrom einhergehenden Translokationsbruchpunktes auf Chromosom 17q}

$\mathrm{Zu}$ Beginn dieser Arbeit stand ein vorläufiges YAC-Contig für die Region 17q23-q24 des Translokationsbruchpunktes von Proband AS zur Verfügung (Dörr, 1995; s. Abb. 1). Die Kartierung der YAC-Klone in bezug zum Translokationsbruchpunkt des Probanden AS war über eine Fluoreszenz-in situ-Hybridisierung (FISH) an Metaphasen des Probanden erfolgt (Dörr, 1995; s. Tab. 1), wobei 7 YACs (983D12, 875C4, 871C4, 845C6, 855A4, 931B10, 901G9) Signale an beiden derivativen Chromosomen des Probanden AS zeigten. Daher wurde angenommen, daß diese YACs den Bruchpunkt des Probanden überspannen. In Abbildung 2 ist ein Ideogramm gezeigt, welches die reziproke Translokation von Proband AS darstellt.

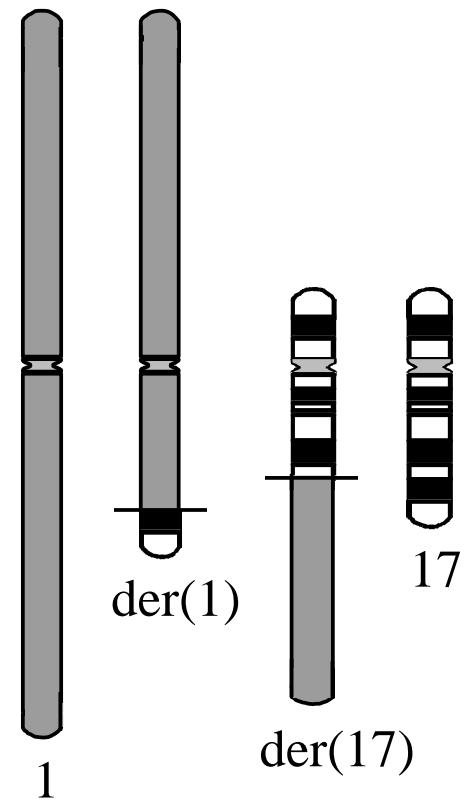

Abb. 2: Ideogramm zur Darstellung der reziproken 1;17 Translokation des von Midro et al. (1993) beschriebenen Probanden AS. Aus Gründen der Übersichtlichkeit wurde Chromosom 1 nicht gebändert dargestellt.

Um eine möglichst detaillierte Karte der Bruchpunktregion des Probanden AS auf Chromosom 17 erstellen zu können, war es erforderlich dem bereits bestehenden YAC-Contig dieser Region weitere Marker zuzuordnen. Bei diesen Markern handelt es sich um Genloci, ESTs (expressed sequence tags) und STSs (sequence-tagged sites). Mit Ausnahme der Lokalisierung der Protein-Kinase $\mathrm{C} \alpha$ (PRKCA) erfolgte die Zuordnung dieser Loci ausschließlich über PCRAnalysen. Dazu wurden bis zu 31 YACs der Bruchpunktregion mit locusspezifischen Primern auf die Anwesenheit von 28 Loci für Gene/ESTs und 23 STSs untersucht. Für jedes eingesetzte Primerpaar wurde eine Positivkontrolle mit genomischer DNA und eine Negativkontrolle ohne DNA mitgeführt. Um Amplifikationen der Hefe-DNA auszuschließen, wurde zudem ein 
Ansatz mit DNA des Hefe-Stamms AB1380 analysiert. Jede PCR-Analyse wurde mindestens zweimal pro Locus durchgeführt.

Über die PCR-Analyse konnten dem in Vorarbeiten erstellten YAC-Contig (s. Abb. 1) der Region 17q23-q24, welches einen Bereich von etwa 4-5 Mb mit überlappenden YACs abdeckt, 8 Loci für 3 bereits beschriebene Gene (APOH, PRKCA und KPNA2) und ein Gen oder Pseudogen (G6PDL) sowie 7 ESTs und 23 STS-Stellen zugeordnet werden (s. Abb. 5). Die lineare Anordnung der Loci von proximal nach distal ergab sich z.T. jedoch erst nach Analyse von kleineren genomischen Klonen, wie Cosmiden und PACs. Zudem konnte der Translokationsbruchpunkt erst nach Analyse der PACs exakt lokalisiert werden.

Neben neuen Markern wurden auch 3 weitere YACs (765F4, 853F8 und 963C7) proximal zum Translokationsbruchpunkt in das Contig eingeordnet. Die Einordnung dieser YACs ermöglichte es, Bereiche mit duplizierten Segmenten mit nahezu konservierter Sequenzhomologie in zwei verschiedenen Bereichen innerhalb des Contigs zu identifizieren (s. 3.1.5).

Die im Verlauf dieser Arbeit analysierten Loci werden im folgenden beschrieben. Die Ergebnisse der PCR-Analysen mit Genen/ESTs sind in Tabelle 18 dargestellt. Tabelle 19 gibt eine Übersicht über die PCR-Ergebnisse aller analysierten Loci.

\subsubsection{Analyse des YAC-Contigs auf die Anwesenheit von Genen}

Eine Reihe von Genen des Chromosoms 17 sind in den verschiedenen genetischen und physikalischen Karten dieses Chromosoms enthalten und stellen damit wichtige Orientierungspunkte in diesen Karten dar. Es sollte überprüft werden, welche dieser Gene, die aufgrund ihrer chromosomalen Zuordnung in Frage kamen, im Bereich des YAC-Contigs kartieren.

Bereits in einer vorangegangenen Arbeit (Dörr, 1995) war die Zuordnung von Loci folgender 11 Gene zu den YACs des Contigs über PCR-Analysen überprüft worden: MYL4 (myosin, light polypeptide 4), MPO (myeloperoxidase), GH1 (growth hormone 1), ZNF147 (estrogenresponsive finger protein), SCN4A (sodium channel, voltage-gated, type IV), PRKAR1A (human cAMP-dependent protein kinase type I-alpha subunit), TK1 (thymidine kinase 1), CACNLG (calcium channel, L type, gamma polypeptid), SSTR2 (somatostatin receptor 2), FDXR (ferredoxin reductase), RPL27 (ribosomal protein 27). Durch diese Analysen konnten 2 Loci für das Gen CACNLG der Region des Translokationsbruchpunktes von Proband AS zugeordnet werden, alle anderen getesteten Gene befanden sich jedoch nicht innerhalb des YAC-Contigs der Bruchpunktregion. Das Gen GRB2 (growth factor receptor bound protein 2) wurde durch FISH-Analyse distal des Contigs kartiert.

Um neben CACNLG weitere Gene im Bereich der Bruchpunktregion des Probanden AS kartieren zu können, wurden die YACs dieser Region über PCR-Analysen auf die Anwesenheit weiterer Chromosom 17q-spezifischer Gene untersucht. Die Lokalisierung der PRKCA erfolgte zudem auch über Southern-Blot-Analysen. Die Ergebnisse der einzelnen Analysen sind in Tab. 18 zusammengefaßt. In der Region 17q23-q24 kartierte Gene sind zudem in der erstellten physikalischen Karte dieser Region (s. Abb. 5) enthalten. Folgende Genloci wurden getestet: 


\section{Apolipoprotein $\mathrm{H}$ (APOH)}

APOH ist ein Glycoprotein, das mit Lipoproteinen des Plasmas assoziiert ist (Polz \& Kostner, 1979). Nakaya et al. (1980) zeigten, daß APOH Lipoprotein-Lipasen aktivieren kann. Nimpf et al. (1986) postulierten, daß APOH die Prothrombinase-Aktivität und die Aggregation von Blutplättchen hemmt. Ein Komplex von APOH und negativ geladenen Phospholipiden bildet zudem ein Autoantigen, welches durch Antikörper, die bei Autoimmunerkrankungen wie Lupus erythematodes vorkommen, erkannt wird (Galli et al., 1990; McNeil et al., 1990). Probanden ohne zirkulierendes APOH wurden von Hoeg et al. (1985) beschrieben, jedoch weisen diese Probanden keine Auffälligkeiten auf. Haagerup et al. (1991) ordneten das APOH-Gen über Kopplungsanalysen dem Chromosom 17q zu. Steinkasserer et al. (1992) kartierten das Gen durch Southern-Blot-Analysen von DNA aus somatischen Zellhybriden in die Region 17q23-qter.

Über PCR-Analyse mit spezifischen Primern für APOH konnte dieses Gen dem YAC-Klon 883B2 zugeordnet werden. Dieses Gen liegt somit distal des Translokationsbruchpunktes von Proband AS, aber innerhalb des für die Bruchpunktregion erstellten Contigs.

\section{Protein kinase $C$, alpha (PRKCA)}

Die Aktivierung der PRKCA durch Calciumionen und den second messenger Diacylglycerin spielt eine wichtige Rolle bei der Induktion von Zellantworten einer Vielzahl von LigandRezeptor-Systemen und bei der Regulation von Zellantworten auf externe Stimuli. Zudem ist die PRKCA der wichtigste Phorbolester-Rezeptor. Linnenbach et al. (1988) fanden in einer primären Melanom-Zellinie eine Tumor-spezifische Deletion innerhalb des PRKCA-Gens. Durch Southern-Blot-Analyse von somatischen Zellhybriden und in situ Hybridisierung ordneten Coussens et al. (1986) das PRKCA-Gen der Region 17q22-q24 zu. Durch in situ Hybridisierung an Translokationschromosomen grenzten Latos-Bielenska et al. (1991) die Region des Gens auf den Bereich 17q22-23.2 ein.

Durch Hybridisierung des Inserts eines cDNA-Klons der PRKCA (s. Tab. 5) auf EcoRISouthern-Blots von YAC-DNA konnte dieses Gen auf den YACs 883B2, 929D11 und 955H4 lokalisiert werden. Über PCR mit den Primern für D17S1977, die innerhalb des PRKCA-Gens lokalisiert sind, wurden die YACs 929D11 und 955H5 positiv getestet.

\section{Glucose-6-phosphate dehydrogenase-like (G6PDL)}

Yoshida et al. (1986) hybridisierten eine cDNA-Probe für die X-gekoppelte Glucose-6-Phosphat-Dehydrogenase (G6PD) auf DNA, die ausgehend von durchflußsortierten Chromosomen erhalten worden war. Auf diese Weise wurde festgestellt, daß nicht nur das X-Chromosom, sondern auch das Chromosom 17, Sequenzen enthält, die mit der cDNA der G6PD hybridisieren. Die Autoren vermuten, daß es sich bei dem G6PDL-Locus entweder um ein Pseudogen, um ein Gen für das fetale, gehirnspezifische Isozym der G6PD oder um ein anderes Gen handelt.

Mit spezifischen Primern für G6PDL konnte dieser Locus auf den YACs 929D11 und 955H4 nachgewiesen werden, dieses Gen oder Pseudogen ist somit im Bereich der Bruchpunktregion lokalisiert. 


\section{Integrin alpha $2 b$ (ITGA2B, GPIIb) /Integrin beta 3 (ITGB3, GPIIIa)}

Die Integrine, eine Familie von Membranrezeptoren, die an Zell-Zell- und Zell-Matrix-Interaktionen beteiligt sind, sind heterodimerische Komplexe aus alpha- und beta-Untereinheiten. Mutationen in ITGA2B und ITGB3 führen zur Glanzmann Thrombasthenie (OMIM *273800 und *173470). Dabei handelt es sich um eine in der Regel rezessive Erkrankung, die durch eine unzureichende Blutgerinnung und morphologisch abnormale Blutplättchen charakterisiert ist.

Die Gene ITGA2B und ITGB3 wurden durch Analyse von somatischen Zellhybriden und in situ Hybridisierung der Region 17q21-23 (Sosnoski et al., 1988). bzw. 17q21-22 (Bray et al., 1988) zugeordnet. Luo et al. (1989) und Van Cong et al. (1989) ordneten diese Gene durch in situ Hybridisierung der Region 17q21 zu. In der genetischen Karte des entsprechenden Chromosoms 11 der Maus (The Jackson Laboratory) befinden sich diese Gene jedoch in unmittelbarer Nähe der PRKCA. Da die PRKCA innerhalb des YAC-Contigs kartiert werden konnte, wurden die YACs der Bruchpunktregion auf die Anwesenheit von ITGA2B und ITGB3 überprüft. Über PCR-Analyse mit spezifischen Primern ließen sich die Gene jedoch auf keinem der getesteten YACs nachweisen.

\section{T-box 2 (TBX2)}

Das T-Box-Motiv (Tbx) kommt in einer Genfamilie vor, deren strukturelle Merkmale und Expressionsmuster auf ihre Beteiligung an der prä- und postnatalen Genregulation schließen lassen (Law et al., 1995).

Durch Analyse von somatischen Zellhybriden wurde das Gen für TBX2 von Campbell et al. (1995) zwischen den Markern D17S792 und D17S789 lokalisiert. Durch FISH-Analyse wurde dieses Gen der Region 17q23-q24 zugeordnet (Campbell et al., 1995). Aufgrund dieser Lokalisierung wurden die YACs der Bruchpunktregion mit spezifischen Primern für TBX2 analysiert. Dieses Gen ließ sich jedoch nicht auf den getesteten YACs der Bruchpunktregion nachweisen. Übereinstimmend damit kartierten Law et al. (1995) TBX2 schließlich auf einem YAC-Contig, welches die Mikrosatelliten-Marker D17S792, D17S794 und D17S948 beinhaltet. Somit ist TBX2 proximal zu dem Translokationsbruchpunkt des Probanden AS lokalisiert.

\section{Dipeptidyl carboxipeptidase 1 (DCP1) = Angiotensin I converting enzyme (ACE)}

DCP1 katalysiert die Umwandlung von Angiotensin I in Angiotensin II und spielt eine wichtige Rolle bei der Regulation des Blutdrucks und des Wasserhaushalts.

Durch in situ Hybridisierung wurde das DCP1-Gen von Mattei et al. (1989) der Bande 17q23 zugeordnet.

Da kein getesteter YAC nach PCR mit spezifischen Primern für DCP1/ACE ein Amplifikat aufwies, konnte dieses Gen nicht in der Bruchpunktregion lokalisiert werden.

\section{Platelet-endothelial cell adhesion molecule (PECAM1)}

PECAM1 ist ein Mitglied der Immunoglobulin (Ig) Superfamilie. Es ist auf der Oberfläche von zirkulierenden Bluplättchen, Monozyten, Neutrophilen und einzelnen T-Zell-Untereinheiten vorhanden. Ein Polymophismus in der extrazellulären Domäne von PECAM1 wurde von Behar et al. (1996) identifiziert. Bei $71 \%$ von Probanden, die nach Knochenmarkstransplantationen 
Graft-versus-host disease (GVHD) entwickelten, stimmte der Genotyp der Spender an dieser Stelle nicht mit dem der Empfänger überein (Behar et al., 1996). Durch PCR-Analyse von somatischen Zellhybriden und FISH ordneten Gumina et al. (1996) das PECAM1-Gen der Region 17q23 zu.

Über PCR-Analyse mit spezifischen Primern für PECAM1 konnte dieses Gen jedoch nicht auf YACs der Bruchpunktregion nachgewiesen werden.

\section{Intercellular adhesion molecule 2 (ICAM2)}

Das interzelluläre Adhäsionsmolekül ICAM2 ist ein Zelloberflächenligand des Rezeptors LFA1. Es wird vermutet, daß ICAM2 bei Zell-Zell-Interaktionen des Immunsystems vermittelt (Sansom et al., 1991). Durch Hybridisierung auf Southern-Blots von DNA somatischer Zellhybriden kartierten Sansom et al. (1991) das ICAM2-Gen in die Region 17q23-25.

Dieses Gen konnte durch PCR-Analyse mit spezifischen Primern nicht auf den getesteten YACs nachgewiesen werden.

\section{Galaktokinase 1 (GALK1)}

Die GALK1 ist an der Umwandlung von Galaktose in Glukose beteiligt und katalysiert die Phosphorylierung von Galaktose zu Galaktose-1-phosphat. Das Fehlen dieses Enzyms führt zu Galaktokinase-Mangel Galaktosämie (OMIM *230200). Dabei handelt es sich um eine autosomal rezessiv vererbte Erkrankung, die mit Katarakten einhergeht (Stambolian et al., 1995).

Elsevier et al. (1975) lokalisierten das Gen für die GALK1 in der Region 17q21-22. Stambolian et al. (1995) ordneten die GALK1 später über FISH der Bande 17q24 zu.

Mit spezifischen Primern für die GALK1 wurden die YACs der Bruchpunktregion auf die Anwesenheit dieses Gens getestet, mit diesen YACs wurde jedoch kein Amplifikat erhalten. Daher ist anzunehmen, daß die GALK1 nicht in der Bruchpunktregion lokalisiert ist.

\section{Peroxisomal acyl-CoA oxidase (ACOX1)}

ACOX1 ist das erste Enzym der peroxisomalen $\beta$-Oxidation von Fettsäuren und katalysiert die Oxidation von Acyl-CoAs zu 2-trans-Enoyl-CoAs, wobei Elektronen direkt auf molekularen Sauerstoff übertragen werden. Auf diese Weise entsteht $\mathrm{H}_{2} \mathrm{O}_{2}$. Eine letale Erkrankung, die durch ein Fehlen von peroxisomaler ACOX1 charakterisiert wird, ist die pseudoneonatale Adrenoleukodystrophie (s. OMIM *264470). Probanden mit dieser Erkrankung entwickeln im Alter von 2-3 Jahren eine fortschreitende Leukodystrophie, die zu Blindheit, Taubheit und Spasmus führt.

ACOX1 wurde von Varanasi et al. (1994) durch FISH-Analyse im Bereich 17q25.1 kartiert. Durch PCR-Analyse von somatischen Zellhybriden kartierten Moghrabi et al. (1995) dieses Gen in die Region 17q23-qter.

Über PCR-Analyse mit spezifischen Primern für ACOX1 konnte dieses Gen nicht auf den YACs der Bruchpunktregion lokalisiert werden.

\section{Acid alpha-glucosidase (GAA)}

Bei der GAA handelt es sich um ein lysosomales Enzym. Das Fehlen dieses Enzyms verursacht eine autosomal rezessiv vererbte Glycogenspeicherkrankheit (Glycogen storage disease type II, 
OMIM *232300). Das klinische Spektrum dieser Erkrankung reicht von einer schweren Form (Pompe disease), die bereits im Kindesalter auftritt und durch Kardiomegalie und Hypotonie charakterisiert ist, bis zu einer langsam fortschreitenden Krankheit mit adultem Auftreten, die beschränkt ist auf die Skelettmuskeln.

Durch Analyse von somatischen Zellhybriden ordneten D'Ancona et al. (1979) und Solomon et al. (1979) das GAA-Gen dem Chromosom 17 zu. Sandison et al. (1982) grenzten die Region des GAA-Locus auf die Region 17q22-qter ein. Durch in situ Hybridisierung wurde GAA von Halley et al. (1984) der Region 17q23-q25 zugeordnet, während Martinuk et al. (1985) GAA in der Region 17q21.2-q23 lokalisierten. Daher wurde angenommen, daß GAA in der kleinsten Überlappungsregion der verschiedenen Lokalisierungen, also in 17q23 lokalisiert ist.

Mittels PCR mit spezifischen Primern für die GAA wurden die YACs der Bruchpunktregion des Probanden AS auf die Anwesenheit dieses Gens überprüft. Die Analyse ergab jedoch keinen Nachweis des Gens auf den getesteten YACs. Schließlich lokalisierten Kuo et al. (1996) das GAA-Gen durch FISH in der Region 17q25.2-q25.3, so daß anzunehmen ist, daß GAA distal des Translokationsbruchpunktes von Proband AS lokalisiert ist.

\subsubsection{Zuordnung von ESTs (expressed sequence tags) zu dem YAC-Contig der Region 17q23-q24}

Für die EST-content Kartierung wurde die DNA der einzelnen YAC-Klone mittels PCR auf die An- bzw. Abwesenheit der jeweiligen ESTs untersucht. Die Ergebnisse der einzelnen Analysen sind in Tab. 18 zusammengefaßt. Abbildung 3 zeigt beispielhaft die Ergebnisse der PCR-Analyse für den Locus WI-9571. Die YACs wurden auf die Anwesenheit folgender ESTs überprüft:

\section{WI-9461}

Über Analysen des Whitehead Institute/MIT Center for Genome Research wurde die EST WI9461 auf den YAC-Klonen 711E2, 902C10, 730A2, 824E7 sowie auf den YACs 931B10 und 845C6, die im Contig der Bruchpunktregion enthalten sind, lokalisiert. Durch die im Rahmen dieser Arbeit durchgeführte PCR-Analyse wurde die Anwesenheit von WI-9461 auf den YACs 931B10, 845C6 und 871C4 nachgewiesen. Somit wurden die Angaben des Whitehead Institute für die Klone 931B10 und 845C6 bestätigt und zusätzlich WI-9461 auf YAC 871C4 nachgewiesen. Die erst später in das Contig eingeordneten YACs 963C7 und 765F4 wurden ebenfalls positiv für WI-9461 getestet.

\section{WI-9571}

Die EST WI-9571 wurde nach Angaben des Whitehead Institute/MIT Center for Genome Research auf den YAC-Klonen 853F8, 963C7, 765F4, 895B2, 886E11, 901H9, 711E2 sowie auf den im YAC-Contig der Bruchpunktregion enthaltenen YACs 845C6 und 931B10 positioniert. Über eine PCR-Analyse mit YAC-Klonen der Bruchpunktregion konnte die Anwesenheit dieser EST auf den YACs 845C6 und 931B10 bestätigt werden, zudem wurde diese EST auf den YAC-Klonen 871C4 und 901G9 nachgewiesen. Auf den erst später in das Contig eingeordneten YACs 853F8, 963C7 und 765F4 wurde EST WI-9571 ebenfalls lokalisiert. 


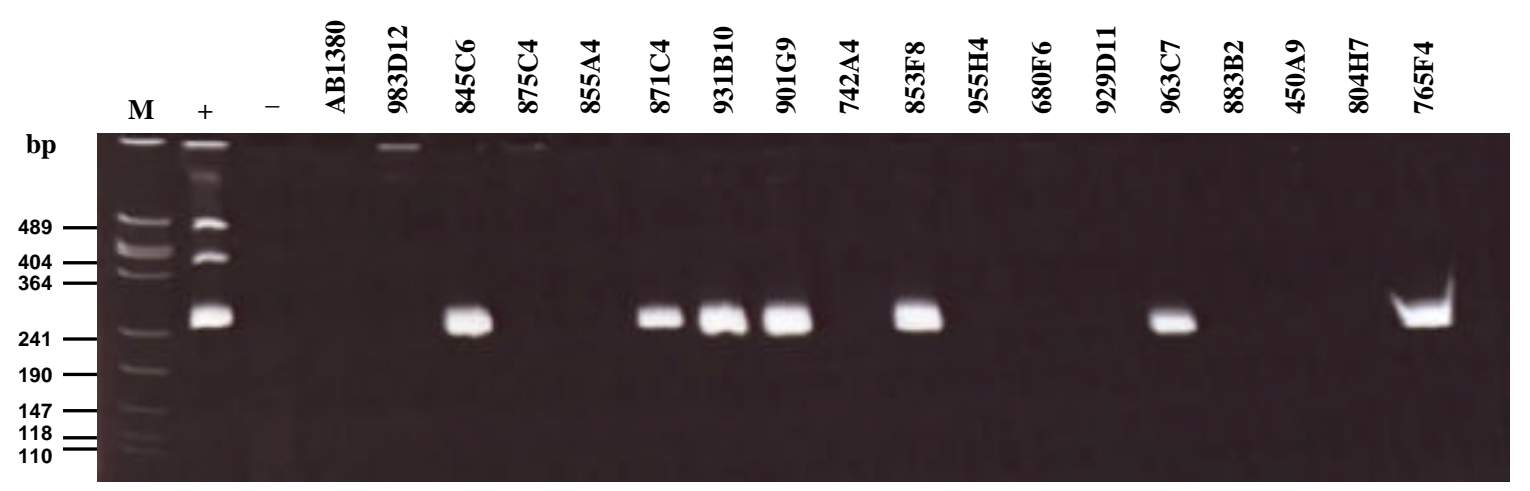

Abb. 3: STS-content-Kartierung von YAC-Klonen mittels PCR-Analyse für den Locus WI-9571. (M: Längenstandard pBluescript, HpaII-geschnitten; +: Positivkontrolle mit humaner genomischer DNA; -: Negativkontrolle ohne DNA; AB1380: Negativkontrolle mit HefeDNA des Stamms AB1380).

\section{WI-8032}

EST WI-8032 wurde vom Whitehead Institute/MIT Center for Genome Research auf den YACKlonen 915F8, 883B1, 721G5, 944A10, 735D1 sowie auf dem im Contig enthaltenen YAC 883B2 nachgewiesen. Die Anwesenheit von WI-8032 konnte auf dem Klon 883B2 bestätigt werden, weitere positive YACs wurden jedoch nicht identifiziert.

\section{WI-9269}

EST WI-9269 ist für ein humanes guanine nucleotide regulatory protein (G13) spezifisch. Das Whitehead Institute/MIT Center for Genome Research kartierte EST WI-9269 auf den YACKlonen 853F8, 963C7 und 765F4. Diese YACs wurden daher in die Analysen zur Generierung des Contigs einbezogen. Die Anwesenheit der EST WI-9269 auf diesen YACs ließ sich über PCR-Analyse bestätigen. Dieser Locus war jedoch nicht auf weiteren YACs nachweisbar.

\section{WI-7618}

EST WI-7618 ist für das humane nukleäre Protein p68 spezifisch. Vom Whitehead Institute/MIT Center for Genome Research wurde dieser Locus auf dem YAC-Klon 789B1 nachgewiesen. EST WI-7618 konnte jedoch auf keinem der getesteten YACs des Contigs nachgewiesen werden, daher ist anzunehmen, daß WI-7618 außerhalb der Bruchpunktregion von Proband AS kartiert.

\section{WI-15726}

EST WI-15726 ist spezifisch für ICAM2 (s. auch 3.1.1.1). Dieser Locus konnte vom Whitehead Institute/MIT Center for Genome Research auf keinem YAC-Klon nachgewiesen werden. Durch die im Rahmen dieser Arbeit durchgeführte PCR-Analyse konnte ebenfalls kein YAC identifiziert werden der WI-15726 aufweist.

\section{stSG3721 / stSG2549 / stSG2005/ stSG9224}

Die ESTs stSG3721, stSG2549, stSG2002 und stSG9224 sind in der Strahlungshybridkarte GB4 des National Center for Biotechnology Information (NCBI) enthalten. Vom Sanger 
Centre wurden diese ESTs zwischen den Markern D17S794 und D17S795 kartiert. Über eine PCR-Analyse mit den YACs der Bruchpunktregion konnte EST stSG3721 auf den 8 YACs 955H4, 983D12, 871C4, 845C6, 931B10, 901G9, 875C4 und 855A4 lokalisiert werden. EST stSG2549 konnte auf den 7 YAC-Klonen 955H4, 871C4, 845C6, 931B10, 901G9, 875C4 und $855 \mathrm{~A} 4$ nachgewiesen werden. EST stSG2005 ist für eine $26 \mathrm{~S}$ proteasome subunit p55 spezifisch. Dieser Locus wurde auf den 7 YACs 955H4, 680F6, 983D12, 742A4, 871C4, 845C6 und 931B10 nachgewiesen. Für EST stSG9224 wurde der YAC-Klon $901 \mathrm{G} 9$ positiv getestet. Da stSG9224 jedoch nur auf diesem einen YAC kartiert wurde und sich zudem im folgenden herausstellte, daß YAC 901G9 komplex umgebaut ist, wurde stSG9224 nicht in die erstellte physikalische Karte integriert.

Tab. 18: Ergebnisse der STS-content-Kartierung von Genen/ESTs

(+: positiv, -: negativ, o: positiv aufgrund duplizierter Regionen)

\begin{tabular}{|c|c|c|c|c|c|c|c|c|c|c|c|c|c|c|c|c|c|c|c|c|c|c|c|c|c|}
\hline & $\begin{array}{l}\check{D} \\
0 \\
\end{array}$ & $\begin{array}{l}\nwarrow \\
0 \\
0\end{array}$ & $\begin{array}{l}\nwarrow \\
\mathbb{D} \\
0\end{array}$ & $\begin{array}{l}\bar{D} \\
0 \\
0\end{array}$ & $\begin{array}{l}\nwarrow \\
\mathbb{D} \\
0\end{array}$ & $\stackrel{\leftarrow}{\varpi}$ & $\begin{array}{l}5 \\
0 \\
0\end{array}$ & 占 & 占 & 占 & $\begin{array}{r}\qquad \\
\uplus \\
\end{array}$ & $\begin{array}{r}\leftarrow \\
\uplus \\
\end{array}$ & $\begin{array}{l}\bar{D} \\
0 \\
0\end{array}$ & $\begin{array}{l}\nwarrow \\
0 \\
0\end{array}$ & $\stackrel{\leftarrow}{\varpi}$ & 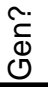 & $\stackrel{\leftarrow}{\varpi}$ & \begin{tabular}{|l}
$\leftarrow$ \\
$\omega$ \\
\end{tabular} & $\begin{array}{r}\leftarrow \\
\uplus \\
\end{array}$ & $\begin{array}{r}\llcorner \\
\uplus \\
\end{array}$ & 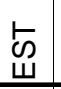 & 卢 & $\begin{array}{l}\bar{D} \\
\mathbb{0} \\
0\end{array}$ & $\begin{array}{l}\check{\Phi} \\
\mathbb{0}\end{array}$ & $\begin{array}{l}\nwarrow \\
\mathbb{d} \\
0\end{array}$ \\
\hline YACs & 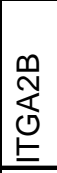 & 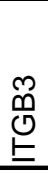 & $\begin{array}{l}\underset{x}{x} \\
\text { 岸 }\end{array}$ & \begin{tabular}{|l|} 
\\
0 \\
0 \\
$\Delta$ \\
0 \\
0 \\
0 \\
\end{tabular} & 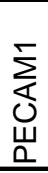 & $\begin{array}{l}\stackrel{2}{N} \\
\hat{n} \\
\frac{1}{1} \\
\stackrel{1}{3}\end{array}$ & $\sum_{\underline{\delta}}^{N}$ & $\begin{array}{l}\frac{\infty}{6} \\
\frac{1}{3} \\
\frac{1}{3}\end{array}$ & 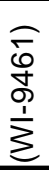 & $\begin{array}{l}\overline{\hat{N}} \\
\text { م⿱ } \\
\frac{1}{3}\end{array}$ & 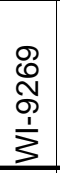 & $\begin{array}{l}N \\
\text { ల్ } \\
\infty \\
1 \\
3\end{array}$ & 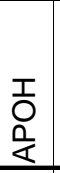 & 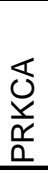 & 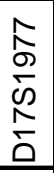 & $\begin{array}{l}\overrightarrow{1} \\
0 \\
0 \\
0 \\
0\end{array}$ & 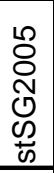 & $\begin{array}{l}\bar{N} \\
N \\
心 \\
心 \\
\tilde{N} \\
\tilde{c}\end{array}$ & 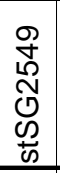 & $\begin{array}{l}\overline{0} \\
5 \\
\frac{1}{1} \\
⿱ 亠 䒑\end{array}$ & 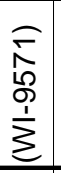 & 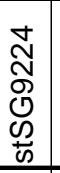 & $\frac{\bar{x}}{\frac{1}{\Delta}}$ & $\begin{array}{l}\bar{x} \\
\text { Oુ } \\
\text { ¿্র }\end{array}$ & $\underset{0}{\mathbb{d}}$ \\
\hline $895 F 2$ & - & - & - & & & & & & & & - & - & - & & & & & & & & & & & & \\
\hline $751 \mathrm{C} 12$ & - & - & - & & & & & & & & - & - & - & & & & & & & & & & & & \\
\hline 967D10 & - & - & - & & & & & & & & - & - & - & & & & & & & & & & & & \\
\hline $868 \mathrm{~F} 12$ & - & - & - & & & & & & & & - & - & - & - & & & & & & & & & & & \\
\hline $813 \mathrm{~B} 7$ & - & - & - & & & & & & & & - & - & - & - & & & & & & & & & & & \\
\hline $796 C 1$ & - & - & - & & & & & & & & - & - & - & - & & & & & & & & & & & \\
\hline $923 \mathrm{H} 8$ & - & - & - & - & - & - & & - & - & - & - & - & - & - & & - & & & & - & - & & & & \\
\hline 864B4 & - & - & - & - & & & & - & - & - & - & - & - & - & & & & & & - & - & & - & - & - \\
\hline 450A9 & - & - & - & - & & & & - & - & - & - & - & - & - & & & & & & - & - & & - & - & - \\
\hline $765 F 4$ & & & & - & - & - & - & & + & + & + & - & - & & - & - & - & - & - & 0 & 0 & - & & & \\
\hline $963 C 7$ & & & & - & - & - & - & & + & + & + & - & - & & - & - & - & - & - & 0 & 0 & - & & & \\
\hline $853 F 8$ & & & & - & - & - & - & & - & + & + & - & - & & - & - & - & - & - & - & 0 & - & & & \\
\hline 883B2 & - & - & - & - & - & - & - & - & - & - & - & + & + & + & - & - & - & - & - & - & - & - & - & - & - \\
\hline 929D11 & - & - & - & - & - & - & - & - & - & - & - & - & - & + & + & + & - & - & - & - & - & - & - & - & - \\
\hline $680 \mathrm{F6}$ & - & - & - & - & - & - & - & - & - & - & - & - & - & - & - & - & + & - & - & - & - & - & - & - & - \\
\hline 983D12 & - & - & - & - & - & - & - & - & - & - & - & - & - & - & - & - & + & + & - & - & - & - & - & - & - \\
\hline 742A4 & - & - & - & - & - & - & - & - & - & - & - & - & - & - & - & - & + & - & - & - & - & - & - & - & - \\
\hline $955 \mathrm{H} 4$ & - & - & - & - & - & - & - & - & - & - & - & - & - & + & + & + & + & + & + & - & - & - & - & - & - \\
\hline $871 C 4$ & - & - & - & - & - & - & - & - & 0 & 0 & - & - & - & - & - & - & + & + & + & + & + & - & - & - & - \\
\hline $845 \mathrm{C} 6$ & - & - & - & - & - & - & - & - & 0 & 0 & - & - & - & - & - & - & + & + & + & + & + & - & - & - & - \\
\hline 931B10 & - & - & - & - & - & - & - & - & 0 & 0 & - & - & - & - & - & - & + & + & + & + & + & - & - & - & - \\
\hline 901G9 & - & - & - & - & - & - & - & - & - & 0 & - & - & - & - & - & - & - & + & + & - & + & + & - & - & - \\
\hline $875 \mathrm{C} 4$ & - & - & - & - & - & - & - & - & - & - & - & - & - & - & - & - & - & + & + & - & - & - & - & - & - \\
\hline $855 A 4$ & - & - & - & - & - & - & - & - & - & - & - & - & - & - & - & - & - & + & + & - & - & - & - & - & - \\
\hline 938F7 & - & - & - & - & & & - & - & - & - & - & - & - & - & - & & - & - & - & - & - & - & - & - & - \\
\hline $804 \mathrm{H} 7$ & - & - & - & - & - & - & - & - & - & - & - & - & - & & - & & - & - & - & - & - & - & - & - & - \\
\hline 921C6 & - & & & - & & & & & & & - & & - & & & & & & & & & & & - & - \\
\hline $723 \mathrm{H} 7$ & - & & & & & & & & & & - & & & & & & & & & & & & & & \\
\hline $144 \mathrm{H} 7$ & - & & & & & & & & & & - & & & & & & & & & & & & & & \\
\hline $805 \mathrm{G} 6$ & - & & & & & & & & & & - & & & - & - & & & & & & & & & & \\
\hline 893D11 & - & & & & & & & & & & - & & & & & & & & & & & & & & \\
\hline 954G3 & - & & & & & & & & & & - & & & & & & & & & & & & & & \\
\hline 915A11 & - & & & & & & & & & & - & & & & & & & & & & & & & & \\
\hline 716B9 & - & & & & & & & & & & - & & & & & & & & & & & & & & \\
\hline
\end{tabular}




\subsubsection{STS-content-Kartierung der YAC-Klone}

Die anonymen Marker D17S1557, D17S1695, D17S1524, GAAT1E12, D17S1813 und D17S1870 wurden vom Whitehead Institute/MIT Center for Genome Research im Bereich der Bruchpunktregion des Probanden AS kartiert (Contig WC17.9). Daher wurden die YACs der Region des Translokationsbruchpunktes über PCR-Analysen auf die Anwesenheit dieser STSs überprüft. Zudem wurden die YACs auch auf die Anwesenheit der im Rahmen der vorliegenden Arbeit generierten STS-Stellen (s. 3.2, 3.6.1, 3.8.2 und 3.13.1) analysiert. Die Ergebnisse dieser PCR-Analysen sind Tab. 19 und Abb. 5 zu entnehmen.

\subsubsection{FISH-Analyse mit YACs für das Chromosomensegment 17q23-q24}

Im Verlauf dieser Arbeit wurden dem YAC-Contig drei weitere YACs (853F8, 963C7 und 765F4) zugeordnet. Die Ergebnisse der FISH-Analysen dieser YACs werden im folgenden dargestellt. Zudem wurden bei einer wiederholten FISH mit DNA des YACs 955H4 neue Ergebnisse erhalten, die ebenfalls beschrieben werden.

\subsubsection{FISH-Analyse der YAC-Klone 853F8, 963C7 und 765F4}

Auf den YACs 853F8, 963C7 und 765F4 wurden nach Angaben des Whitehead Institute die ESTs WI-9571 und WI-9269 nachgewiesen. Somit wurde angenommen, daß diese YACs in der Region des YAC-Contigs lokalisiert sind. Daher wurden die Klone 853F8, 963C7 und 765F4 vom CEPH-Institut bezogen und über eine FISH an Metaphasechromosomen des Probanden AS hybridisiert, die ausgehend von EBV-Zellen präpariert worden waren. Nach Auswertung von mindestens 15 Metaphasen pro YAC-Klon zeigte sich, daß diese Klone nur Signale auf dem derivativen Chromosom 17, aber nicht auf dem derivativen Chromosom 1 zeigten. Diese YACs wurden somit proximal zum Translokationsbruchpunkt des Probanden AS auf Chromosom 17 positioniert. Beispiele für die FISH mit diesen YACs sind in Abb. 4 dargestellt.

YAC 765F4 wies neben Signalen, die spezifisch für Chromosom 17 waren, auch Signale auf Chromosom 1q und auf Chromosom 5q auf (s. Abb. 4). Bei diesem YAC handelt es sich somit vermutlich um einen chimärischen Klon, dessen Insert sich aus Chromosomensegmenten von Chromosom 17, 1 und 5 zusammensetzt. Andererseits ist es möglich, daß der entsprechende Hefestamm mehr als einen YAC enthält.

Da YAC 765F4 auch Sequenzen von Chromosom 1q enthält, konnte mit Hilfe dieses YACs nicht nur der Bruchpunkt auf Chromosom 17, sondern auch der Bruchpunkt auf Chromosom 1q kartiert werden. Auf den Translokationschromosomen war das Chromosom 1-spezifische Signal auf dem derivativen Chromosom 17 lokalisiert. Der Chromosom 1 spezifische Anteil dieses YACs wurde somit distal zu dem Bruchpunkt von Chromosom 1q kartiert (s. auch unter 3.18). Da der Chromosom 17-Anteil von YAC 765F4 und der Chromosom 1-Anteil dieses YACs auf dem der(17) nahe beieinanderliegen, ist auf diesem Chromosom jedoch nur ein Signal zu erkennen. 


\subsubsection{Wiederholte FISH-Analyse mit DNA von YAC 955H4}

Die Ergebnisse der PCR-Analyse mit den distal vom Translokationsbruchpunkt von Proband AS kartierten Loci KPNA2-E1, KPNA2-E2, CF20b und KPNA2-3' deuteten darauf hin, daß YAC 955H4 neben Sequenzen, die proximal zu diesem Bruchpunkt lokalisiert sind, auch solche distal zu diesem Bruchpunkt enthält. YAC 955H4 hatte jedoch nach FISH-Analysen an Metaphasen des Probanden AS, die im Rahmen der vorangegangenen Arbeit durchgeführt worden waren, nur Signale am derivativen Chromosom 17 und nicht am derivativen Chromosom 1 gezeigt. Daher war davon ausgegangen worden, daß dieser YAC proximal zum Translokationsbruchpunkt kartiert (Dörr, 1995). Bei einer erneut durchgeführten FISH an Metaphasechromosomen des Probanden AS aus EBV-Kulturen zeigte YAC 955H4 jedoch nicht nur Signale am derivativen Chromosom 17, sondern auch am derivativen Chromosom 1 (s. Abb. 4). Daher wurde angenommen, daß auch YAC 955H4 den Translokationsbruchpunkt des Probanden AS überspannt. Neben Signalen, die dem Chromosom 17-Anteil dieses YACs entsprechen, zeigte YAC 955H4 aufgrund des chimärischen Charakters des YACs, wie auch bei zuvor durchgeführten FISH-Analysen, Signale auf Chromosom 11.
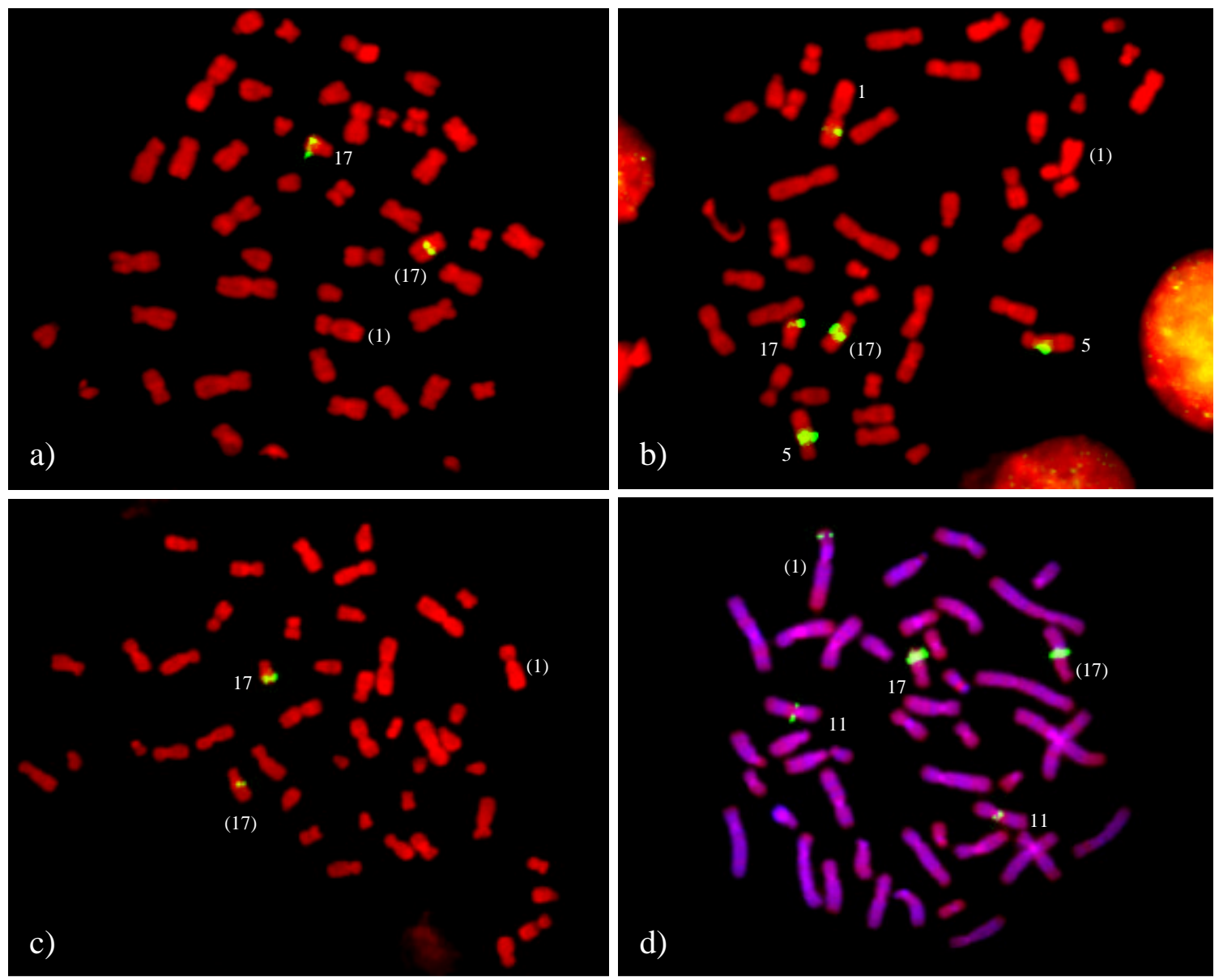

Abb. 4: Beispiele für FISH-Analysen mit YAC-Klonen an Metaphasen von Proband AS. a) $963 \mathrm{C} 7$; b) $765 \mathrm{~F} 4$; c) $853 \mathrm{~F} 8$; d) $955 \mathrm{H} 4$. In a), b) und c) sind die Chromosomen mit Propidiumiodid gegengefärbt, in d) mit Propidiumiodid und DAPI. Es tragen jeweils das normale Chromosom 17 und das der(17) [(17)] Signale. In b) tragen aufgrund des chimärischen Charakters des YACs zudem das Chromosom 5 und das Chromosom 1 Signale. In d) sind zusätzlich Signale auf dem der(1) [(1)] und Chromosom 11 vorhanden. 
Tab. 19: Ergebnisse der STS-/EST-/Gen-content-Kartierung von 34 YAC-Klonen. (+: positiv, -: negativ, o: positiv aufgrund duplizierter Regionen, ? :STSAnalyse unklar, ( ): schwache Signale). Die Reihenfolge der Loci ergab sich z. T. erst nach Analyse von PAC- oder Cosmid-Klonen. Genloci sind in blau, ESTs in grün, in der Literatur beschriebene STSs in schwarz und in dieser Arbeit generierte STSs (sofern sie nicht gleichzeitig Genloci darstellen) in rot dargestellt.

\begin{tabular}{|c|c|c|c|c|c|c|c|c|c|c|c|c|c|c|c|c|c|c|c|c|c|c|c|c|c|c|c|c|c|c|c|c|c|c|c|c|c|c|c|c|c|c|c|c|c|c|c|c|c|c|c|c|c|c|c|c|c|}
\hline & $\stackrel{\infty}{\infty}$ & $\begin{array}{l}\infty \\
\omega \\
\infty\end{array}$ & $\begin{array}{l}\infty \\
\omega \\
\omega\end{array}$ & $\begin{array}{l}\infty \\
\omega \\
\end{array}$ & $\begin{array}{l}\infty \\
\omega \\
\infty\end{array}$ & $\begin{array}{l}\infty \\
\qquad \\
\infty\end{array}$ & \begin{tabular}{|l} 
\\
$w$ \\
\end{tabular} & $\begin{array}{ll}\infty \\
\omega \\
\omega\end{array}$ & $\begin{array}{l}\infty \\
\omega \\
\omega\end{array}$ & $\stackrel{\varpi}{\underline{w}}$ & $\stackrel{0}{\infty}$ & 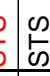 & $\begin{array}{l}\infty \\
0 \\
0\end{array}$ & 5 & $\frac{n}{b}$ & $\underline{\omega}$ & $\begin{array}{l}\bar{D} \\
0 \\
\end{array}$ & $\begin{array}{l}\infty \\
\stackrel{\infty}{\infty} \\
\end{array}$ & $\begin{array}{l}c \\
\mathbb{D} \\
\mathbb{0} \\
\end{array}$ & $\begin{array}{l}\infty \\
\infty \\
\infty\end{array}$ & \begin{tabular}{|l|} 
\\
$\mathbb{D}$ \\
0 \\
\end{tabular} & $\begin{array}{l}\widetilde{c} \\
\tilde{D} \\
0 \\
0\end{array}$ & $\begin{array}{l}\infty \\
\stackrel{\omega}{\infty} \\
\end{array}$ & 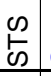 & \begin{tabular}{|l|} 
\\
0 \\
0 \\
\end{tabular} & \begin{tabular}{l}
\multicolumn{1}{c}{} \\
$\mathbb{0}$
\end{tabular} & \begin{tabular}{|l|} 
\\
$w$ \\
\end{tabular} & $\begin{array}{l}\infty \\
\omega \\
\end{array}$ & $\begin{array}{l}\infty \\
\stackrel{\infty}{\infty} \\
\end{array}$ & $\begin{array}{l}\infty \\
\omega \\
\omega\end{array}$ & $\begin{array}{l}\infty \\
\qquad \\
\infty\end{array}$ & $\begin{array}{l}\infty \\
\bullet \\
\infty\end{array}$ & $\begin{array}{l}\infty \\
\infty \\
\infty\end{array}$ & \begin{tabular}{|l|}
\llcorner \\
\\
\end{tabular} & 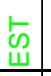 & \begin{tabular}{|l|} 
\\
\\
\end{tabular} & 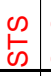 & $\begin{array}{l}\infty \\
\infty \\
\infty\end{array}$ & $\begin{array}{c}\infty \\
\infty \\
\infty\end{array}$ & $\begin{array}{l}c \\
\Phi \\
\mathbb{0}\end{array}$ & $\begin{array}{l}c \\
\mathbb{D} \\
\mathbb{0}\end{array}$ & $\begin{array}{l}c \\
\Phi \\
\mathbb{0}\end{array}$ & $\begin{array}{l}c \\
\mathbb{D} \\
\mathbb{0}\end{array}$ & $\stackrel{\infty}{\infty}$ & \begin{tabular}{|l}
$\infty$ \\
$\qquad$ \\
\end{tabular} & $\stackrel{\leftarrow}{w}$ & $\begin{array}{l}\stackrel{\infty}{E} \\
\stackrel{\infty}{\circ} \\
\end{array}$ & $\begin{array}{l}\omega \\
\omega \\
\omega\end{array}$ & $\begin{array}{l}\infty \\
\qquad \infty \\
\end{array}$ & $\begin{array}{l}\infty \\
\infty \\
\infty\end{array}$ & \begin{tabular}{|l}
$\infty$ \\
$\qquad$ \\
\end{tabular} & $\begin{array}{l}\infty \\
\qquad \infty \\
\infty\end{array}$ & $\begin{array}{l}\infty \\
\omega \\
\end{array}$ & \begin{tabular}{|l|} 
\\
$\omega$ \\
\end{tabular} & \begin{tabular}{|l|} 
\\
0 \\
0 \\
\end{tabular} & $\stackrel{\infty}{\infty}$ & $\infty$ \\
\hline YACs & 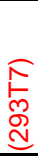 & 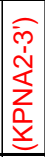 & 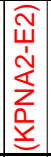 & & $\mid \begin{array}{c}\overline{\overline{0}} \\
\dot{0} \\
\frac{1}{1} \\
\stackrel{3}{3}\end{array}$ & $\begin{array}{l}F \\
\infty \\
\infty\end{array}$ & $\begin{array}{l}\overline{1} \\
\text { L } \\
0 \\
1 \\
\stackrel{1}{3} \\
\end{array}$ & 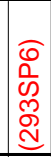 & $\widehat{E}$ & 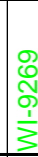 & $\begin{array}{l}\infty \\
\infty \\
\infty \\
\infty \\
\infty\end{array}$ & & \begin{tabular}{|l} 
\\
0 \\
\\
8 \\
0 \\
0
\end{tabular} & $\left\{\begin{array}{l}1 \\
0 \\
8 \\
8\end{array}\right.$ & & & 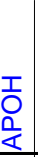 & 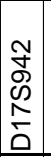 & 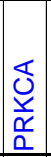 & 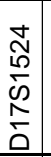 & $\begin{array}{l}\hat{N} \\
\sigma \\
\frac{D}{D} \\
\hat{N} \\
\bar{D} \\
\end{array}$ & $\begin{array}{l} \\
\overrightarrow{0} \\
0 \\
0 \\
0\end{array}$ & $\begin{array}{l}\hat{0} \\
0 \\
0 \\
N \\
\hat{D} \\
\end{array}$ & 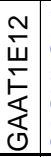 & \begin{tabular}{|l|}
\multicolumn{1}{|c}{} \\
0 \\
0 \\
2 \\
0 \\
0 \\
0 \\
\end{tabular} & 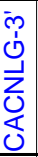 & & $\begin{array}{l}\frac{m}{\infty} \\
\infty \\
\frac{\infty}{\infty} \\
N \\
\frac{1}{0}\end{array}$ & & $\mid \begin{array}{l}R \\
\infty \\
\infty \\
\mathcal{D} \\
N \\
\bar{D}\end{array}$ & & $\begin{array}{l}10 \\
\infty \\
\infty \\
\underline{\alpha} \\
\underline{\underline{F}} \\
\end{array}$ & $\begin{array}{l}0 \\
0 \\
\infty \\
\infty \\
\infty \\
\end{array}$ & \begin{tabular}{|l|}
$\bar{N}$ \\
$N$ \\
$\tilde{N}$ \\
$\bar{N}$ \\
$\bar{\omega}$ \\
\end{tabular} & & $\begin{array}{l}\stackrel{N}{\circ} \\
\stackrel{N}{*} \\
\end{array}$ & 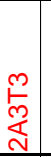 & $\begin{array}{l}F \\
\infty \\
0 \\
0\end{array}$ & $\underset{\mathrm{N}}{\stackrel{5}{\tau}}$ & $\begin{array}{l}\bar{u} \\
\dot{\sim} \\
\stackrel{\mathbf{x}}{z} \\
\underline{\mathbf{z}} \\
\underline{\underline{y}}\end{array}$ & 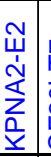 & 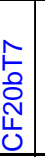 & 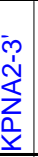 & $\underset{\infty}{E}$ & $\begin{array}{l}\text { F } \\
\underset{N}{\text { N }} \\
\end{array}$ & $\begin{array}{l}\overline{6} \\
5 \\
0 \\
\frac{1}{3} \\
\end{array}$ & 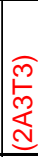 & $\frac{E}{E}$ & \begin{tabular}{|l}
$\hat{L}$ \\
$\infty$ \\
$\omega$ \\
$\mathrm{L}$ \\
$\mathrm{v}$ \\
\end{tabular} & 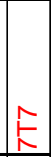 & \begin{tabular}{|c}
0 \\
0 \\
$\infty$ \\
$\tilde{N}$ \\
$\tilde{N}$
\end{tabular} & $\begin{array}{l}\widehat{N} \\
\hat{L} \\
o \\
\frac{1}{3} \\
3\end{array}$ & & 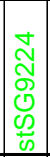 & $\mid \begin{array}{l}\frac{\pi}{\alpha} \\
\frac{\alpha}{\alpha} \\
\frac{\alpha}{\alpha} \\
\frac{\alpha}{\alpha} \\
\end{array}$ & $\begin{array}{l}8 \\
\infty \\
N \\
N \\
\frac{1}{0} \\
0\end{array}$ & 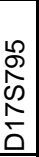 \\
\hline $895 \mathrm{~F} 2$ & & & & & & & & & & - & & - & & & & - & - & & & & & & & & & & & & & & & & & & & & & & & & & & & & & & & & & & & & & & & & \\
\hline 751C12 & & & & & & & & & & - & & - & & & & - & - & & & & & & & & & & & & & & & & & & & & & & & & & & & & & & & & & & & & & & & & \\
\hline 967D10 & & & & & & & & & & - & & - & & & & - & - & & & & & & & & & & & & & & & & & & & & & & & & & & & & & & & & & & & & & & & & \\
\hline $868 \mathrm{~F} 12$ & & & & & & & & & & - & & - & & & & - & - & & - & & & & & & & & & & & & & & & & & & & & & & & & & & & & & & & & & & & & & & \\
\hline 813B7 & & & & & & & & & & - & & - & & & & - & - & & - & & & & & & & & & & & & & & & & & & & & & & & & & & & & & & & & & & & & & & \\
\hline $796 \mathrm{C} 1$ & & & & & & & & & & - & & - & & & & - & - & & - & & & & & & & & & & & & & & & & & & & & & & & & & & & & & & & & & & & & & & \\
\hline $923 \mathrm{H} 8$ & & & & - & - & & - & & & - & & - & - & 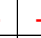 & - & - & - & - & - & - & & - & - & - & - & - & & & & - & & & & & & & & & & & & & & & & - & & & & & & - & & & - & - & - \\
\hline 864B4 & & & & - & - & & - & & & - & & - & - & 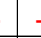 & - & - & - & - & - & - & & & - & - & - & - & & - & & - & & & & & & & & & & & & & & & & - & & & & & & - & & & -1 & - & - \\
\hline 450A9 & & & & - & - & & - & & & - & & - & - & - & - & - & - & - & - & - & & & - & - & - & - & & - & & - & & & & & & & & & & & & - & & - & & - & & & - & & & - & & & -1 & - & - \\
\hline 765F4 & - & + & + & + & + & + & + & + & + & + & + & - & - & - & - & - & - & - & & - & - & - & - & - & - & - & - & - & & - & & - & & - & - & - & & & - & - & 0 & - & 0 & - & - & 0 & & - & - & 0 & (o) & 0 & - & - & & - & \\
\hline $963 \mathrm{C} 7$ & $\begin{array}{llll}+ & & \end{array}$ & + & + & + & + & + & + & + & + & + & + & + & + & +1 & + & - & - & - & & - & - & - & - & - & - & - & - & - & & - & & - & & - & - & - & - & & - & - & 0 & - & 0 & - & 0 & 0 & - & - & - & 0 & (o) & 0 & - & - & & - & \\
\hline $853 \mathrm{~F} 8$ & - & - & - & - & - & - & + & + & + & \pm & \pm & + & \pm & +1 & + & - & - & - & & - & - & - & - & - & - & - & - & - & & - & & - & & - & -1 & - & & & - & - & - & - & - & - & - & - & & - & - & 0 & (o) & 0 & - & - & & - & \\
\hline $883 \mathrm{~B} 2$ & - & - & - & - & - & - & - & - & - & 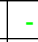 & - & + & + & +1 & + & + & + & + & + & -1 & - & - & -1 & - & -1 & - & - & - & & - & & - & & - & - & -1 & & & - & - & - & - & - & - & - & - & 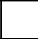 & - & - & - & - & - & - & - & \begin{tabular}{|l|} 
\\
\end{tabular} & - & - \\
\hline 929D11 & - & - & - & - & - & - & - & - & - & - & - & - & - & - & - & - & - & + & + & + & + & + & + & + & + & + & - & - & -1 & - & -4 & - & -1 & - & - & - & - & - & - & - & - & - & - & - & - & - & - & - & - & - & - & - & - & - & -1 & - & - \\
\hline 680F6 & - & - & - & - & - & - & - & - & - & - & - & - & - & - & - & - & - & - & - & \begin{tabular}{|l|}
- \\
\end{tabular} & - & - & + & + & + & + & + & + & + & - & - & - & \begin{tabular}{|l|}
- \\
\end{tabular} & - & - & - & - & \begin{tabular}{|l|}
- \\
\end{tabular} & - & - & - & - & - & - & - & - & - & - & $?$ & - & ? & - & - & - & \begin{tabular}{|l|}
- \\
\end{tabular} & - & - \\
\hline 983D12 & - & - & - & - & - & - & - & - & - & - & - & - & - & - & - & - & - & -1 & - & \begin{tabular}{l|l} 
\\
\end{tabular} & - & \begin{tabular}{l|l}
- \\
\end{tabular} & - & + & + & + & + & + & - & - & -4 & + & \begin{tabular}{|l|} 
\\
\end{tabular} & + & - & - & - & \begin{tabular}{|l|} 
\\
\end{tabular} & - & - & - & - & - & - & - & - & - & - & - & - & - & - & - & - & -1 & - & - \\
\hline $742 \mathrm{~A} 4$ & - & - & - & - & - & - & - & - & - & - & - & - & - & -1. & - & - & - & - & - & - & - & \begin{tabular}{l|l} 
\\
\end{tabular} & - & + & - & - & + & + & + & - & -1 & - & - & -4 & - & - & - & - & - & - & - & - & - & - & - & - & - & - & - & - & - & - & - & - & -1 & - & - \\
\hline $955 \mathrm{H} 4$ & - & 0 & 0 & - & - & - & - & - & - & - & - & - & - &. & - & - & - & - & + & + & + & + & + & + & + & + & + & - & - & + & + & + & + & + & + & + & + & + & + & + & + & + & + & - & - & - & * & - & - & - & - & - & - & - & -1 & - & - \\
\hline $871 \mathrm{C} 4$ & 0 & 0 & 0 & - & 0 & - & 0 & 0 & 0 & - & - & - & - & - & - & - & - & - & - & - & - & - & - & - & - & - & + & + & + & + & + & + & + & + & + & + & + & + & + & + & + & + & + & + & + & + & + & + & + & + & + & + & - & - & - & - & - \\
\hline $845 \mathrm{C} 6$ & 0 & 0 & 0 & - & 0 & - & 0 & 0 & 0 & - & - & - & - & - & - & - & - & - & - & - & - & - & - & - & - & - & + & + & + & + & + & + & + & + & + & + & + & + & + & + & + & + & + & - & + & + & + & + & + & + & + & + & + & - & - & - & - \\
\hline 931B10 & 0 & 0 & 0 & - & 0 & - & 0 & 0 & 으 & - & - & - & - & - & - & - & - & - & - & - & - & - & - & - & - & - & + & + & + & + & + & + & + & + & + & + & + & + & + & + & + & + & + & + & + & + & + & + & + & + & + & + & (+) & - & -1 & - & - \\
\hline $901 \mathrm{G} 9$ & \begin{tabular}{|l}
- \\
\end{tabular} & 0 & 0 & - & 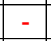 & - & 0 & 0 & 0 & - & - & - & - & -1 & - & - & - & - & - & \begin{tabular}{l|}
- \\
\end{tabular} & - & - & - & - & $\begin{array}{ll}- \\
\end{array}$ & - & - & -1 & + & - & $\begin{array}{ll}- \\
\end{array}$ & -4 & + & + & +1 & + & + & + & + & + & + & + & + & + & - & - & + & + & + & + & + & + & - & + & \begin{tabular}{l|}
- \\
\end{tabular} & - & - \\
\hline $875 \mathrm{C} 4$ & - & - & - & - & - & - & - & - & - & - & - & - & - & - & - & - & - & - & - & - & - & - & - & - & - & - & - & - & - & - & - & + & + & + & + & + & + & - & - & - & - & - & - & - & - & - & * & - & - & - & - & - & - & - & - & - & - \\
\hline $855 \mathrm{~A} 4$ & - & - & - & - & - & - & - & - & - & - & - & - & - &. & - & - & - & - & - & - & - & - & - & - & - & - & - & - & - & - & - & - & - & + & + & + & + & - & - & - & - & - & - & - & - & - & & - & - & - & - & - & - & - & -1 & + & + \\
\hline $938 \mathrm{~F} 7$ & - & - & - & - & - & - & - & - & - & - & - & - & - & - & - & - & - & - & - & - & - & & - & - & - & - & - & - & & - & 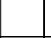 & - & 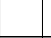 & - & -1 & - & & 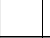 & - & - & - & & - & 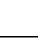 & - & - & & - & 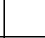 & - & - & - & - & - & -1 & + & + \\
\hline $804 \mathrm{H} 7$ & - & - & - & - & - & - & - & - & - & - & - & - & - & - & - & - & - & - & & - & - & - & - & - & - & - & - & - & - & - & - & - & - & - & - & - & & - & - & - & - & - & - & - & - & - & & - & - & - & - & - & - & - & -1 & - & + \\
\hline $921 \mathrm{C} 6$ & & & & & & & & & & - & & & & & & & - & & & & & & & & & & & - & & & & & & & & & & & & & & & & & & & & & & & & & & & & & \\
\hline $723 \mathrm{H} 7$ & & & & & & & & & & - & & & & & & & & & & & & & & & & & & & & & & & & & & & & & & & & & & & & & & & & & & & & & & & \\
\hline $144 \mathrm{H} 7$ & & & & & & & & & & - & & & & & & & & & & & & & & & & & & & & & & & & & & & & & & & & & & & & & & & & & & & & & & & \\
\hline $805 \mathrm{G} 6$ & & & & & & & & & & - & & & & & & & & & - & & & & & & & & & & & & & & & & & & & & & & & & & & & & & & & & & & & & & & \\
\hline 893D11 & & & & & & & & & & - & & & & & & & & & & & & & & & & & & & & & & & & & & & & & & & & & & & & & & & & & & & & & & & \\
\hline 954G3 & & & & & & & & & & - & & & & & & & & & & & & & & & & & & & & & & & & & & & & & & & & & & & & & & & & & & & & & & & \\
\hline 915A11 & & & & & & & & & & - & & & & & & & & & & & & & & & & & & & & & & & & & & & & & & & & & & & & & & & & & & & & & & & \\
\hline 716B9 & & & & & & & & & & - & & & & & & & & & & & & & & & & & & & & & & & & & & & & & & & & & & & & & & & & & & & & & & & \\
\hline
\end{tabular}




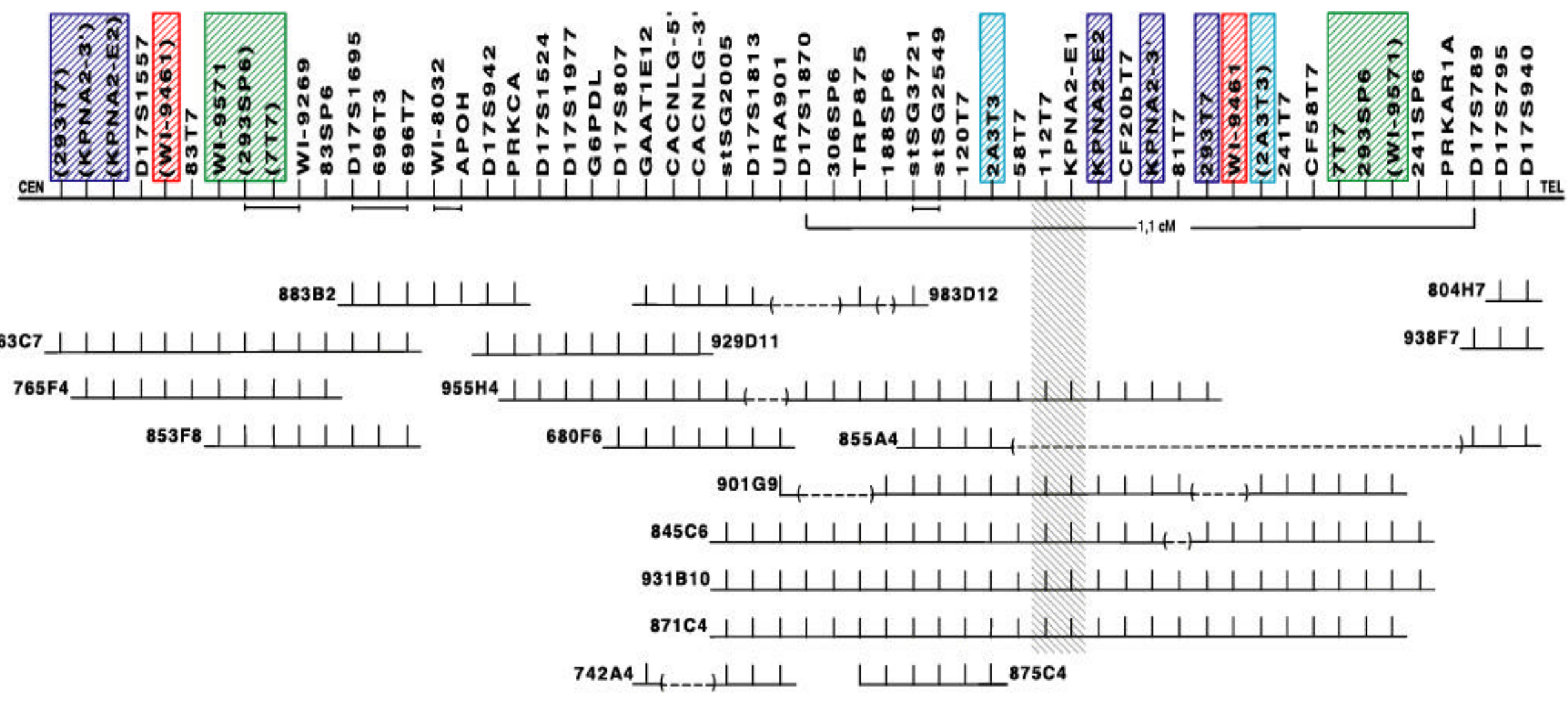

Abb. 5: Mit Hilfe von YAC-Klonen erstellte hochauflösende physikalische Karte der RSS-kritischen Chromosomenregion 17q23-q24. Die Region des Translokationsbruchpunktes von Proband AS ist durch einen schraffierten Balken symbolisiert. Beiderseits dieses Bruchpunktes identifizierte dupliziert vorliegende Loci sind durch farbige Kästen hervorgehoben. Die lineare Anordnung der Loci ergab sich z. T. erst nach Analyse von kleineren genomischen Klonen (s. auch Abb. 22). - : Anordnung der Loci nicht festgelegt; (---): deletierte Regionen von YACs. 


\subsubsection{Identifizierung duplizierter Segmente innerhalb der Region 17q23-q24}

Im Verlauf der Erstellung des YAC-Contigs wurden in der Region 17q23-q24, beiderseits des Translokationsbruchpunktes von Proband AS, duplizierte Regionen identifiziert. Dies war möglich, da bei der Kartierung einiger Loci YAC-Klone positiv getestet wurden, die aufgrund ihrer Anordnung im YAC-Contig keinen gemeinsamen Bereich aufweisen. Beispielsweise wiesen mit der EST WI-9571 sowohl die proximal zum Translokationsbruchpunkt des Probanden AS kartierten Klone 765F4, 963C7 und 853F8 als auch die diesen Bruchpunkt überspannenden Klone 871C4, 845C6, 931B10 und 901G9 positive Signale auf (s. Abb. 3). Um zu überprüfen, ob sich die Sequenzen dieser Loci unterscheiden, wurde eine Sequenzierung der entsprechenden PCR-Produkte verschiedener Klone angeschlossen (s. unter 3.10). Durch diese Analysen konnte schließlich eindeutig gezeigt werden, daß sich die duplizierten Loci der proximalen Region des Contigs von denen der distalen Region unterscheiden lassen. Im Verlauf der Kartierung der Region wurden insgesamt 8 Loci (WI-9461, WI-9571, 7T7, 293SP6, 293T7, 2A3T3, KPNA2-E2 und KPNA2-3') identifiziert, mit deren Primern sich jeweils 2 verschiedene Bereiche der erstellten Karte der Region 17q23-q24 amplifizieren lassen. Diese Loci wurden jeweils zweifach in die Karten dieser Region integriert.

\subsection{Restriktionskartierung von YACs der Bruchpunktregion}

Mit Hilfe seltenschneidender Restriktionsenzyme und der Auftrennung hochmolekularer DNA mit der Pulsfeldgelelektrophorese (PFGE) ist es möglich, sogenannte long range maps zu erstellen (Van Ommen et al., 1986; Bickmore \& Bird, 1992). Die Kartierung von YAC-DNA bietet gegenüber der Kartierung gesamtgenomischer, nicht klonierter DNA den Vorteil nicht methylierte, klonierte und wenig komplexe DNA schneiden und analysieren zu können. $\mathrm{Zu}$ berücksichtigen sind dabei jedoch Coklonierungsereignisse und der z.T. chimärische Charakter der Klone. Weiterhin können in der Struktur veränderte YAC-Inserts, wie sie z.B. durch Deletionen, Inversionen und Duplikationen entstehen, die Befunde verfälschen.

Zur Einschätzung der physikalischen Abstände in der Bruchpunktregion wurde eine Restriktionskartierung von 6 den Translokationsbruchpunkt des Probanden AS auf Chromosom 17 überspannenden YAC-Klonen vorgenommen. Die YAC-Klone 845C6, 901G9 931B10, 855A4, 875C4 und 983D12 wurden zunächst auf ihren Gehalt an Schnittstellen überprüft. Dazu wurde die in Agaroseblöckchen präparierte DNA dieser Klone mit den Enzymen BssHII, XhoI, MluI und NotI geschnitten und mit Hilfe der PFGE aufgetrennt, wobei Bedingungen für $10-1000 \mathrm{~kb}$ große Fragmente gewählt wurden (s. Tab. 16). Anschließend wurde die DNA auf eine Nylonmembran transferiert und mit radioaktiv markierter Cot-1-DNA hybridisiert. Dabei zeigte sich, daß mit den seltenschneidenden Enzymen BssHII, XhoI und MluI relativ viele Restriktionsfragmente mit einer durchschnittlichen Größe von $50 \mathrm{~kb}$ erhalten wurden. Das Auftreten von vielen relativ kleinen Fragmenten mit nahezu identischer Größe erschwert jedoch die lineare Anordnung der einzelnen Fragmente. Für eine Restriktionskartierung der Klone wurde daher NotI eingesetzt, da mit diesem Enzym im Durchschnitt größere Fragmente erhalten wurden. Die in Agaroseblöckchen enthaltene DNA der YACs 845C6, 901G9 931B10, 855A4, 875C4 und 983D12 wurde für diese Kartierung sowohl vollständig als auch partiell mit NotI geschnitten. Dazu wurde die DNA mit einer aufsteigenden Reihe an Enzymverdünnungen in 
einer vorgegebenen Zeit gespalten, nebeneinander auf ein Pulsfeldgel geladen und mittels der PFGE aufgetrennt. In Abb. 6 werden Beispiele von PFGE-Auftrennungen gezeigt, wobei neben den natürlichen Hefechromosomen z.B. bei Klon 875C4 ein YAC mit einer Größe von $370 \mathrm{~kb}$ und bei Klon 855A4 ein YAC mit einer Größe von $1080 \mathrm{~kb}$ zu sehen sind.
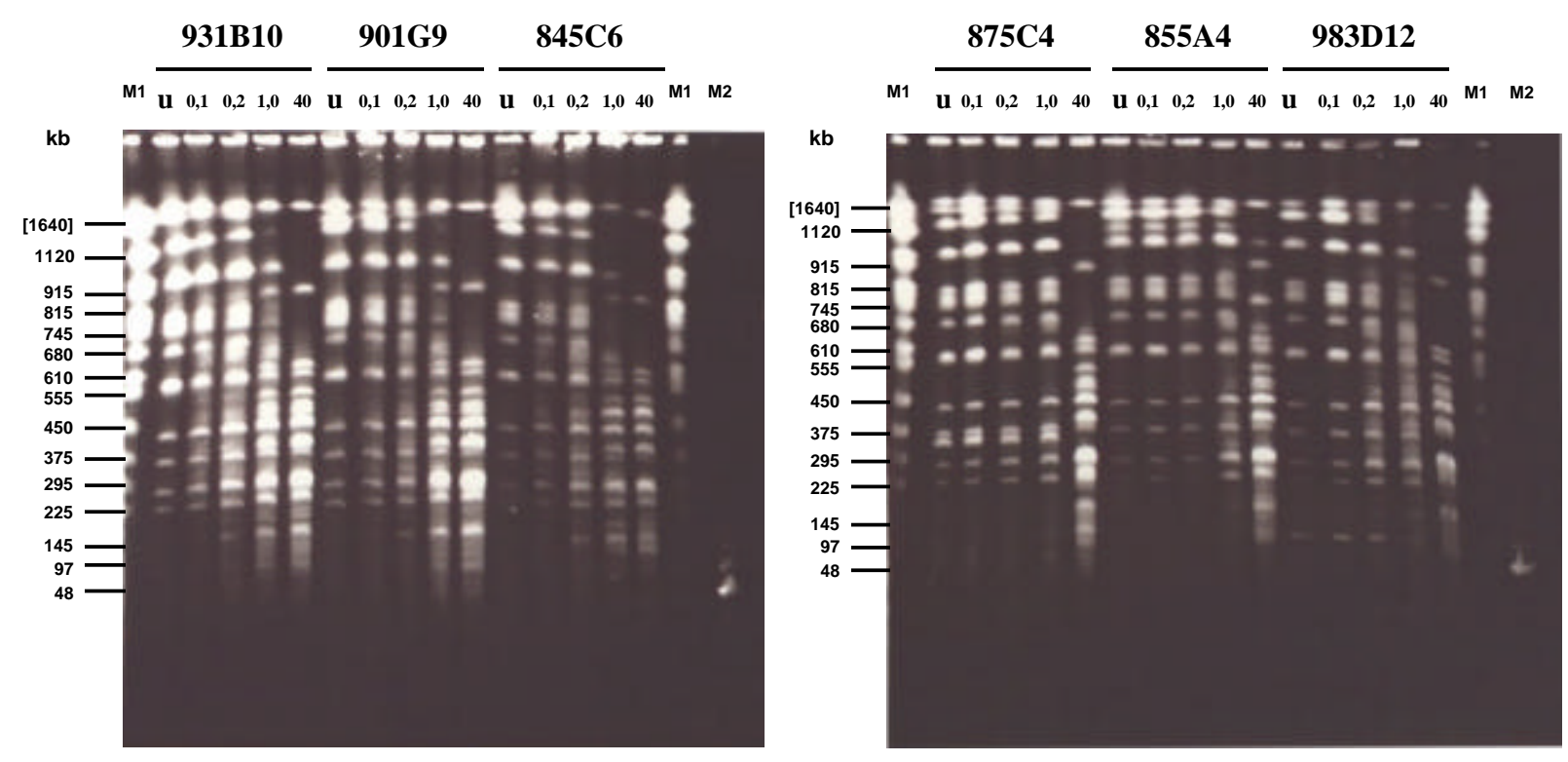

Abb. 6: Partielle Spaltungen der DNA von 6 verschiedenen YAC-Klonen mit dem Enzym NotI. Die DNA wurde mit 0,1;0,2;1,0 bzw. $40 \mathrm{U}$ NotI gespalten, zudem wurde ungespaltene DNA (u) aufgetragen. Nach der PFGE wurde das Gel mit Ethidiumbromid gefärbt. (M1: Längenstandard Saccharomyces cerevisiae, YPH 80; M2: Low range marker).

Die aufgetrennte DNA wurde durch Southern-Blotting auf Nylonmembranen übertragen und mit verschiedenen Sonden hybridisiert.

Für die Bestimmung der Endfragmente wurden Sonden für den URA- bzw. für den TRP-Arm des YAC-Vektors pYAC4 eingesetzt. Die Sonden für die Vektorarme wurden aus dem 4,36 kb langen Plasmidvektor pBR322 (Watson et al., 1988) gewonnen. Bei Restriktion von pBR322 mit SalI und $P v u I I$ entstand ein 1,4 kb langes Fragment, mit dem der URA-Arm spezifisch detektiert wurde. Die Spaltung des Vektors mit den Enzymen EcoRI, PstI und PvuII ergab drei Fragmente von $0,677 \mathrm{~kb}, 2,22 \mathrm{~kb}$ und 1,54 kb. Zur Identifizierung des TRP-Arms wurde das $1,54 \mathrm{~kb}$-Fragment verwendet.

Über die Hybridisierung mit den Sonden für den URA- und den TRP-Arm der YACs wurden die jeweiligen Endfragmente des YACs detektiert (s. Abb. 7). Bei unvollständig gespaltener DNA wurden zudem größere Fragmente detektiert, die sich aus dem Endfragment und davon nicht abgespaltenen Fragmenten zusammensetzen. Die lineare Anordnung der einzelnen Fragmente war durch einen Größenvergleich möglich. Die Hybridisierung mit genomischer DNA ergab außer den Endfragmenten zusätzlich interne partiell oder vollständig gespaltene Fragmente (s. Abb. 7).

Die nach vollständiger Spaltung mit NotI erhaltenen Fragmentgrößen der untersuchten YACKlone sind in Tabelle 20 dargestellt. Tabelle 21 gibt einen Überblick über die nach unvollständiger Spaltung erhaltenen Fragmentgrößen. 

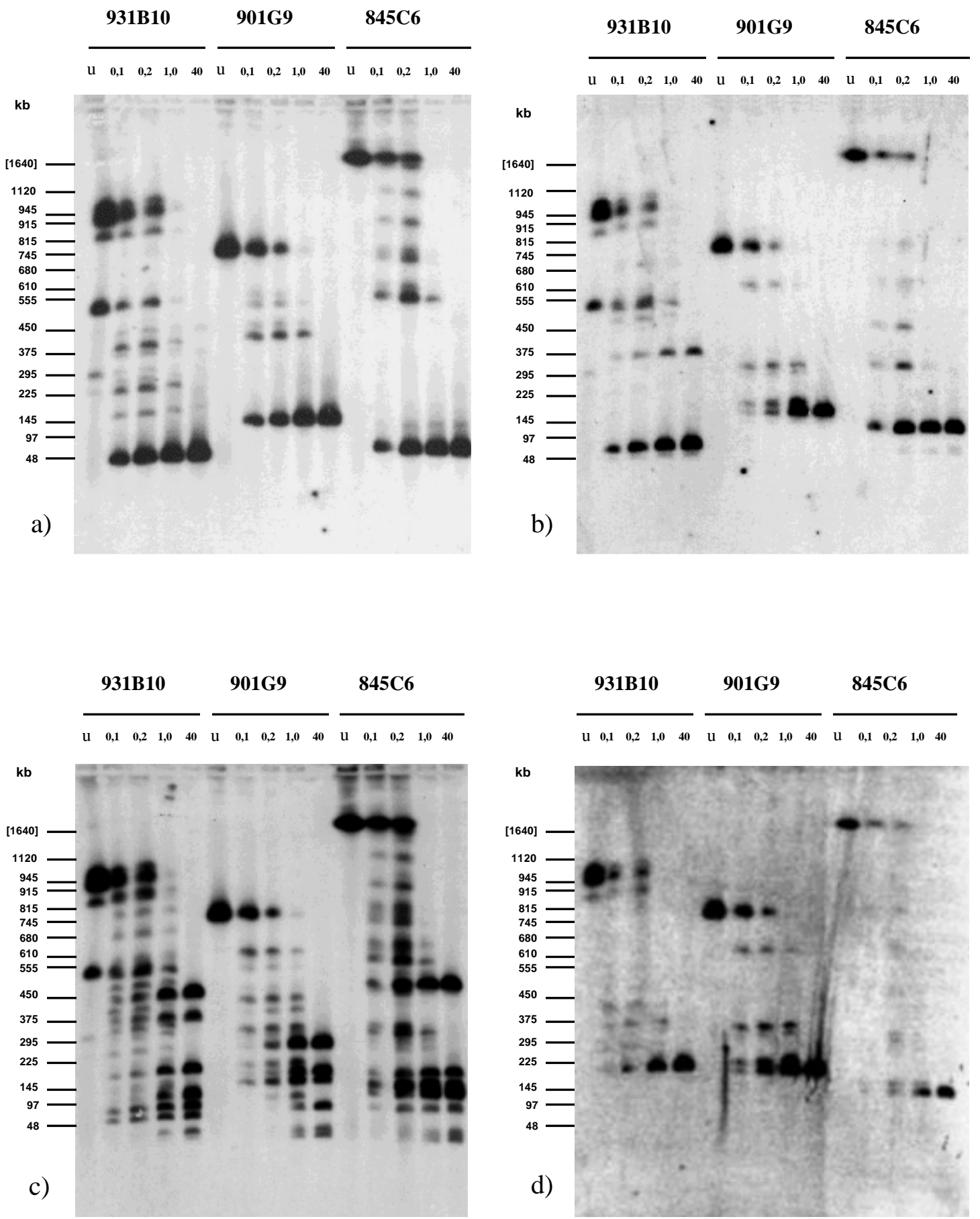

Abb. 7: Southern-Blot-Hybridisierung verschiedener Sonden auf einen Filter mit NotI partiell bzw. vollständig gespaltener YAC-DNA. a) Hybridisierung mit einer Sonde für den URA-Vektorarm; b) Hybridisierung mit einer Sonde für den TRP-Vektorarm; c) Hybridisierung mit genomischer DNA; d) Hybridisierung mit dem Insert des Cosmids CF20b. 
Tab. 20: Fragmentlängen der YACs nach vollständiger Spaltung mit NotI

[ ]: keine exakte Größenangabe möglich, da Fragmente innerhalb der PFGE-Kompressionszone liegen.

\begin{tabular}{lllll}
\hline YAC & $\begin{array}{l}\text { Größe } \\
(\mathrm{kb})\end{array}$ & $\begin{array}{l}\text { TRP-Arm } \\
(\mathrm{kb})\end{array}$ & $\begin{array}{l}\text { URA-Arm } \\
(\mathrm{kb})\end{array}$ & $\begin{array}{l}\text { genomische DNA } \\
(\mathrm{kb})\end{array}$ \\
\hline 845C6 & {$[1300]$} & 140 & 77 & $480,200,140,130,120,100,77,31,20$ \\
931B10 & 1000 & 380,87 & 61 & $480,380,200,100,87,61,31,20$ \\
901G9 & 755 & 200 & 150 & $280,200,150,85,31,20$ \\
855A4 & 1080 & 100 & 200 & $780,200,100$ \\
983D12 & 100 & 30 & 70 & 70,30 \\
875C4 & 370 & 225 & 145 & 225,145 \\
\hline
\end{tabular}

Tab. 21: Fragmentlängen der YACs nach partieller Spaltung mit NotI

[ ]: keine exakte Größenangabe möglich, da Fragmente innerhalb der PFGE-Kompressionszone liegen.

\begin{tabular}{lll}
\hline YAC & TRP-Arm $(\mathrm{kb})$ & URA-Arm $(\mathrm{kb})$ \\
\hline 845C6 & {$[1300], 765,730,620,600,460,340$,} & {$[1300],[1200], 1020,880,750,720,610$,} \\
& 140 & 575,77 \\
901G9 & $755,610,335,305,220,200$ & $755,575,550,460,430,150$ \\
855A4 & $1080,880,100$ & $1080,980,200$ \\
983D12 & 100,30 & 100,70 \\
875C4 & 370,225 & 370,145 \\
\hline
\end{tabular}

Für den YAC 931B10 konnten die nach Hybridisierung mit dem TRP- und dem URA-Arm detektierten Fragmente der partiellen Spaltungen nicht ausgewertet werden, da die verwendete Präparation des YACs Deletionen enthielt. Dies ist in Abb. 7 daran zu erkennen, daß in der Spur mit der ungespaltenen DNA mehrere Fragmente auftreten. Andere Präparationen von YAC 931B10 zeigten jedoch nur einen YAC.

Anhand der Ergebnisse der Hybridisierungen auf Filter mit der vollständig oder partiell mit NotI gespaltenen YAC-DNA wurde die in Abbildung 8 dargestellte Restriktionskarte entwickelt. Dabei wurde bei der Auswertung der Hybridisierungsergebnisse auf partiell geschnittene DNA berücksichtigt, daß die Größenbestimmung von kleinen Fragmenten genauer ist als die von großen Fragmenten.

Die mittels der PCR in der Bruchpunktregion des Probanden AS kartierten ESTs WI-9461, WI9571 und stSG2549 und das Exon 1 von Karyopherin 2 alpha (KPNA2) (Locus KPNA2-E1) wurden in die Restriktionskarte eingeordnet, indem die PCR-Produkte dieser Loci ebenfalls auf die Filter mit der NotI-gespaltenen YAC-DNA hybridisiert wurden. Zudem wurden die Inserts der Cosmide 2G4 und 1B11, die aus der im Rahmen der vorliegenden Arbeit generierten Cosmid-Subbibliothek des YACs 875C4 stammen, und des aus einer Chromosom 17spezifischen Cosmidbibliothek (Nr. 105, Reference Library DataBase) isolierten Cosmids CF20b als Hybridisierungssonden eingesetzt (als Beispiel s. Abb. 7d). Die über diese Hybridisierungen detektierten Fragmente sind Tabelle 22 zu entnehmen. 

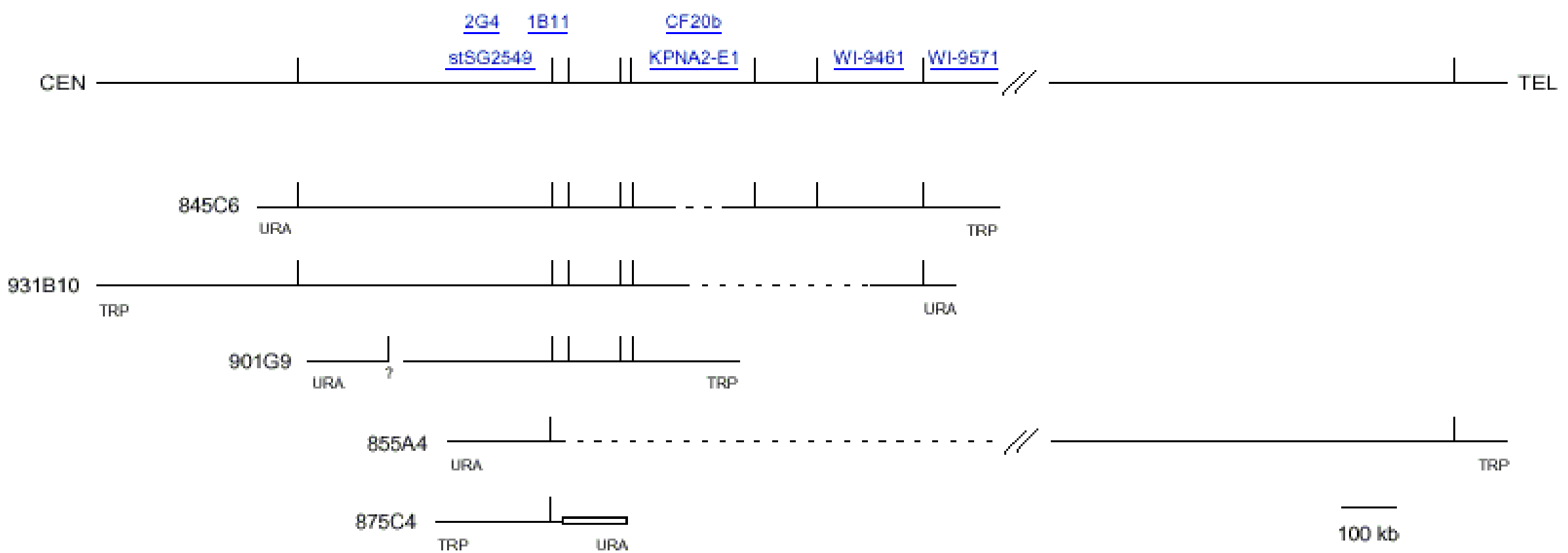

Abb. 8: NotI-Restriktionskarte von 5 YACs des RSS-kritischen Chromosomensegments in 17q23-q24. NotI-Schnittstellen sind durch senkrechte Striche gekennzeichnet. Die Zuordnung der Cosmide 2G4, 1B11 bzw. CF20b und der Loci stSG2549, KPNA2-E1, WI-9461 bzw. WI-9571 zu bestimmten NotI-Restriktionsfragmenten ist oberhalb der Basislinie gezeigt. Deletierte Bereiche der YAC-Klone sind durch gestrichelte Linien dargestellt. Der chimärische Anteil des YACs $875 \mathrm{C} 4$ ist durch einen offenen Balken dargestellt. (?: nicht eindeutige Positionierung der Schnittstelle). 
Tab. 22: Größe $(\mathrm{kb})$ der nach Hybridisierung mit verschiedenen Sonden detektierten Not IFragmente; -: negativ; n.g.: nicht getestet.

\begin{tabular}{llllllll}
\hline $\begin{array}{l}\text { ISonde } \\
\text { YACl }\end{array}$ & WI-9571 & WI-9461 & stSG2549 & $\begin{array}{l}\text { Cosmid } \\
\text { 2G4 }\end{array}$ & $\begin{array}{l}\text { Cosmid } \\
1 B 11\end{array}$ & $\begin{array}{l}\text { Cosmid } \\
\text { CF20b }\end{array}$ & $\begin{array}{l}\text { KPNA2- } \\
\text { Exon 1 }\end{array}$ \\
\hline 845C6 & 140 & 200 & 480 & n.g. & 480,31 & 130 & 130 \\
931B10 & 61 & 200 & 480 & n.g. & 480,31 & 200 & 200 \\
901G9 & 150 & - & 280 & n.g. & 280,31 & 200 & 200 \\
855A4 & - & - & n.g. & 200 & n.g. & n.g. & n.g. \\
983D12 & - & - & n.g. & - & n.g. & n.g. & n.g. \\
875C4 & - & - & n.g. & 225 & n.g. & n.g. & n.g. \\
\hline
\end{tabular}

Alle YACs, die in der erstellten Restriktionskarte (s. Abb. 8) enthalten sind, weisen Umordnungen auf.

Die Größe des YAC-Klons 983D4 war bei zuvor durchgeführten Analysen mit 1100 kb bestimmt worden. Dieser YAC wies jedoch nur noch eine Größe von $100 \mathrm{~kb}$ auf und konnte daher nicht in die Restriktionskarte integriert werden.

YAC 901G9 scheint komplex umgebaut zu sein, denn dieser YAC weist neben Deletionen, die bereits anhand der STS-Analyse deutlich wurden (s. Abb. 5), ein URA-Ende auf, welches mit der EST WI-9571 hybridisiert. Da dies nicht mit der Anordnung der Fragmente in YAC 845C6 übereinstimmen konnte, wurde eine STS für das URA-Ende von 901G9 generiert (siehe unten). Die Einordnung in das YAC-Contig (s. Abb. 5) zeigte, daß die STS URA901 nicht benachbart zu der EST WI-9571 ist.

Der YAC 845C6 zeigte nach PCR-Analyse mit der STS 81 T7 kein Produkt (s. Abb. 5), was auf eine Deletion innerhalb des YAC-Inserts hindeutet. Daher wurde unklonierte genomische DNA, die in Agaroseblöckchen präpariert worden war (s. 2.2.3.3), nach NotI-Spaltung über PFGE aufgetrennt und anschließend ein Southern-Blot der DNA angefertigt. Über die Hybridisierung dieses Blots mit dem Cosmid CF20b sowie mit einer Sonde für das erste Exon von KPNA2 wurde ein $230 \mathrm{~kb}$ großes genomisches Fragment detektiert, während mit diesen Sonden ein nur $130 \mathrm{~kb}$ großes Fragment des YACs 845C6 detektiert worden war. Der YAC 845C6 weist daher wahrscheinlich eine Deletion auf, die etwa $100 \mathrm{~kb}$ umfaßt.

Da der YAC 931B10 in der Spur mit der ungespaltenen DNA mehrere Banden zeigte, ist anzunehmen, daß dieser YAC Deletionen aufweist. Da der YAC ausgehend von einer Einzelkolonie angeimpft wurde, ist davon auszugehen, daß die Deletionen während der Kulturzeit des YACs de novo aufgetreten sind. Dies wird bestätigt dadurch, daß diese bei weiteren Präparationen des YACs nicht vorhanden waren. Zudem detektierten die Sonden CF20b, KPNA2-E1 und WI-9461 ein 200 kb großes Fragment des YACs, was jedoch nicht mit der Anordnung der Fragmente des YACs 845C6 übereinstimmen kann. Daher wird angenommen, daß YAC 931B10 eine Deletion aufweist, die ein 200 kb großes Fragment entstehen läßt (s. Abb. 8).

$\mathrm{Da}$ der YAC 855A4 eine große Deletion aufweist, war bereits aufgrund der STS-Kartierung deutlich geworden. Das $780 \mathrm{~kb}$ große Fragment dieses YACs kann zudem mit keinem Fragment der YACs 845C6, 931B10 oder 901G9 zur Deckung gebracht werden, was darauf hindeutet, daß dieses Fragment außerhalb dieser YACs lokalisiert ist. 
YAC 875C4 ist ein chimärischer Klon. Das URA-Ende dieses YACs wurde bei später durchgeführten Analysen auf Chromosom 4 kartiert.

\section{Generation einer STS-Stelle für das URA-Ende von YAC 901G9}

Da nach der Restriktionskartierung des YACs 901G9 unklar war, welche Position das URAEnde des YACs 901G9 innerhalb des YAC-Contigs einnimmt, wurde eine STS-Stelle für das URA-Ende des YACs 901G9 generiert. Ein 700 bp großes Endfragment dieses YACs wurde über eine Alu-Vektor-PCR mit den Primern CL2 und URA generiert. Die Sequenzierung dieses Endfragmentes mit dem URA-Primer ergab folgende Sequenz (428 bp):

1 GAATtCAgtg tTgtTAgCCC tTtTgCtTGA AAAACCCCCA CTCTtgGACA CAgAgGAAAT

61 AgGAgTCAGA TGTCTGCACC TTCTGCACCT GTGGTTTGAA CAGGACCCTC TGGGAGTCGC

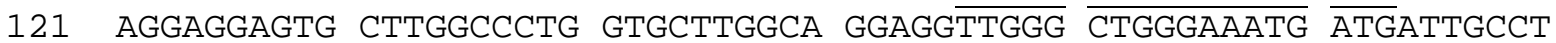

181 TGATCCTCTC TTTCAACTAC TTCATTCCAA CTGTTGGAAT ACCTCAgTAG TGAGTATTAA

241 TTTNCTNCCC CCCCAAATCC AGCAAGCAAT CTAGCTCCTT AAGAGAACAC TATGTTCCTG

301 CTATTAACAG GGCTTTGACT GTTTTTGCAA AATAATAACT GGGCATTCTT GTGTTAAGGA

361 CCATTTGTTT CCTTCACCTG CTTTTCTTCC CAATTTAGCT GAAAAGGGAC CTGANCCANT

421 TAGGAAAT

Die Primer, die den Locus URA901 amplifizieren, sind unterstrichen. Über die STS-contentKartierung der YACs mit diesem Locus (s. Tab. 19) konnte das URA-Ende von YAC 901G9 innerhalb der NotI-Restriktionskarte (s. Abb. 8) positioniert werden.

\subsection{Subklonierung von YAC 875C4 in Cosmide}

Um die Suche nach Kandidatengenen im Bereich der Bruchpunktregion des Probanden AS auf Chromosom 17 zu erleichtern, sollte die Region des Bruchpunktes zunächst weiter eingegrenzt werden. Dazu wurden kleinere genomische Klone, wie Cosmide, benötigt. Diese sollten über die Subklonierung eines den Bruchpunkt des Probanden AS überspannenden YAC-Klons erhalten werden. Um nur Cosmide der engeren Bruchpunktregion zu erhalten, sollte ein möglichst kleiner YAC subkloniert werden. Der kleinste YAC-Klon, von dem FISH-Analysen zufolge angenommen wurde, daß mit diesem der Bruchpunkt des Probanden AS überspannt wird, war YAC 875C4. Dieser Klon weist eine Größe von $370 \mathrm{~kb}$ auf. Da aber YAC 875C4 chimärisch ist (Chromosom 17 und 4), wurde die Größe des zu Chromosom 17 korrespondierenden Bereiches dieses YACs auf weniger als $300 \mathrm{~kb}$ geschätzt. Um Cosmide der Bruchpunktregion zu erhalten, wurde YAC 875C4 in Cosmide subkloniert.

\subsubsection{Konstruktion der Cosmid-Bibliothek}

Für die Etablierung einer Cosmid-Bibliothek aus dem YAC 875C4 wurde die DNA des YACs wie unter 2.2.16.2. beschrieben aus einem Pulsfeldgel isoliert und partiell mit MboI gespalten. DNA-Fragmente mit einer durchschnittlichen Länge zwischen $40 \mathrm{~kb}$ und $50 \mathrm{~kb}$ wurden durch Spaltung von 400 ng DNA mit 0,05 U Enzym bei Inkubationszeiten zwischen 5 und 20 min erhalten. Die DNA wurde in den Cosmid-Vektor sCos-1 kloniert (s. 2.2.16.3.) und die Konstrukte mit einem in vitro-Verpackungssystem in die Proteinhülle des $\lambda$-Phagen verpackt (s. 2.2.16.4.). Schließlich wurden Bakterien (XL1-blue-MR) mit diesen Phagen transfiziert 
(s.2.2.16.6.). Der zur Bestimmung der Verpackungseffizienz ermittelte Titer der CosmidBibliothek lag bei ungefähr $1,2 \times 10^{4}$ Transformanten pro $\mu$ g eingesetzte DNA.

\subsubsection{Charakterisierung der Bibliothek}

Da die Cosmid-Bibliothek neben humanen Klonen, aufgrund von Verunreinigungen der aus dem Gel isolierten DNA, auch Cosmide mit Hefe-DNA enthalten konnte, sollten zunächst humane Klone identifiziert werden. Dazu wurden 348 Cosmide auf Selektivplatten ausplattiert (s. 2.2.16.6.), Replika-Filter angefertigt (s. 2.2.16.7.) und diese anschließend mit radioaktiv markierter Cot-1-DNA hybridisiert. Dadurch wurden 218 Cosmide mit humanen Inserts identifiziert, was einem Anteil von $63 \%$ entspricht. Die humanen Klone wurden in Mikrotiterplatten überführt und bei $-70^{\circ} \mathrm{C}$ gelagert. Um zu überprüfen, ob die Cosmide unterschiedliche DNAInserts tragen und es nicht zu einem Klonierungsartefakt gekommen war, wurde die DNA von 20 zufällig ausgewählten Cosmiden präpariert (s. 2.2.1.1.) und eine Restriktionsanalyse durchgeführt (s. 2.2.5.). Nach dieser Analyse zeigten alle Klone ein für Cosmide typisches Restriktionsmuster, wobei die durchschnittliche Insertlänge der Klone ungefähr 40 kb betrug. Im Verlauf dieser Arbeit wurde die DNA von 108 Cosmiden präpariert, dabei zeigte sich, daß ungefähr $15 \%$ der Klone nur ein sehr kleines Insert von 3,5 kb oder kein Insert aufweisen. Insgesamt 192 Cosmide (2 Mikrotiterplatten) wurden mit Hilfe einer automatischen Pipettierstation auf Nylonmembranen transferiert (s. 2.2.16.8.) und auf den Filtern lysiert (s. 2.2.16.7.). Statistisch gesehen entsprechen 192 Cosmide mit einer durchschnittlichen Insertlänge von $40 \mathrm{~kb}$ einer 20,7-fachen Repräsentation des 370 kb großen YACs.

\subsection{Erstellung eines Contigs aus den 875C4-Cosmiden}

Die Cosmid-Bibliothek wurde generiert, um Cosmide für die Region des Translokationsbruchpunktes von Proband AS auf Chromosom $17 \mathrm{zu}$ isolieren. Die Kartierung der Cosmide in bezug zum Bruchpunkt sollte über FISH-Analysen erfolgen. Um die Anzahl der über FISHAnalyse zu kartierenden Cosmide zu begrenzen, wurden diese zunächst in einem Contig angeordnet. Dazu wurden überlappende Cosmide über T3-/T7-Endmarkierung der Cosmide (s. 2.2.16.9.) identifiziert. Zudem wurden Southern-Blots von ausgewählten Cosmiden angefertigt und diese zur Identifizierung identischer Fragmente mit Cosmid-Sonden hybridisiert.

\subsubsection{T3-/T7-Markierung der Cosmid-Enden}

Die T3-/T7-Markierung von Cosmiden ermöglichte die Erzeugung spezifischer Sonden für die Enden einzelner Cosmide. Die Hybridisierung dieser Sonden auf die gesamte Bibliothek führte zur schnellen Identifizierung von miteinander überlappenden Cosmiden. Dadurch war von vielen Startpunkten aus nach beiden Seiten hin der Aufbau mehrerer kleiner Contigs möglich, die dann im weiteren Verlauf miteinander verknüpft wurden.

Mittels PCR mit den vektorspezifischen Primern T3 und/oder T7 wurden von beiden Enden bzw. von einem Ende zufällig ausgewählter Cosmide radioaktive Sonden hergestellt (s. 2.2.16.9). Da diese Sonden repetitive Sequenzen enthalten konnten, erfolgte eine Präassoziation mit humaner Plazenta-DNA (2.2.9.3). Die Identifizierung von überlappenden Klonen 
erfolgte durch Hybridisierung der Sonden auf die Cosmid-Filter mit 96 bzw. 192 fixierten Cosmiden (s. 2.2.16.8.). Für weitere Hybridisierungen wurden solche Cosmide ausgewählt, die durch vorangegangene Hybridisierungen noch nicht erkannt worden waren. Auf diese Weise ließen sich alle Cosmide bestimmten Gruppen gegenseitig überlappender Cosmide zuordnen. Abb. 9 zeigt das Ergebnis einer Hybridisierung des am T3-Ende markierten Cosmids 2G4 auf einen Filter mit 192 Cosmiden.

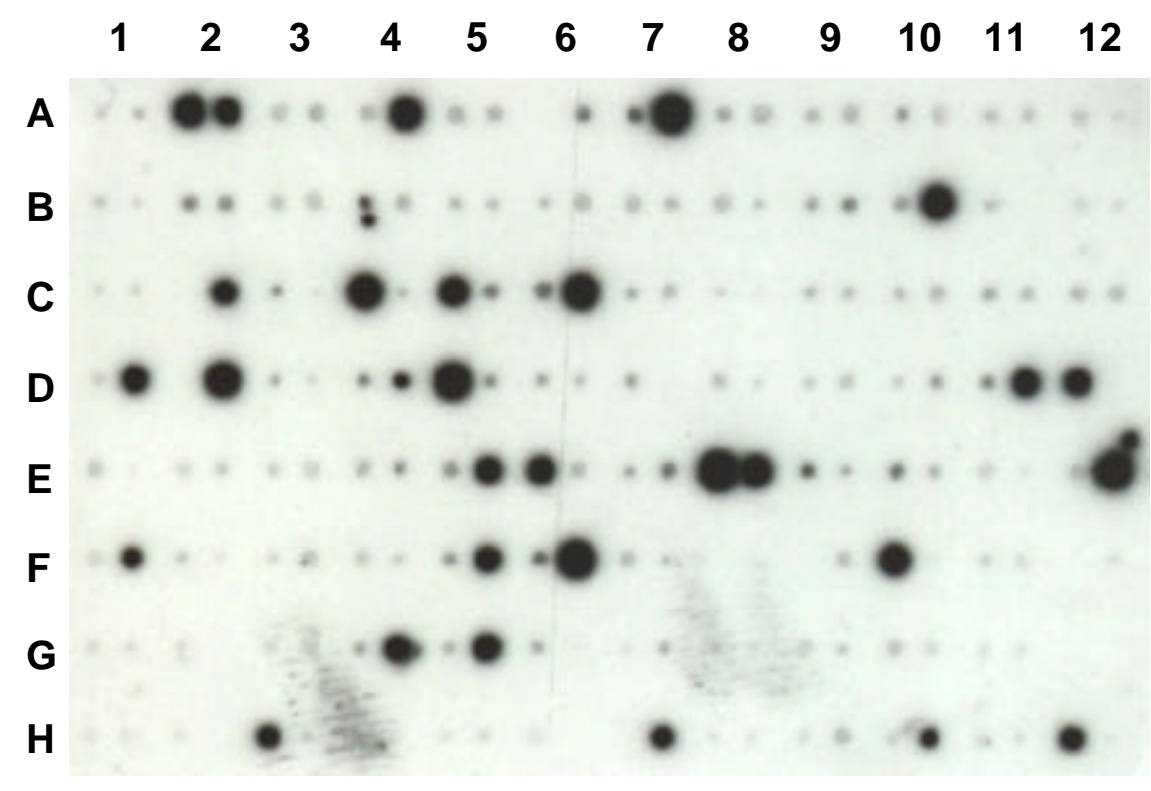

Abb. 9: Hybridisierung der Cosmid-Bibliothek aus dem YAC 875C4 mit dem T3-Ende des Cosmids 2G4.

\subsubsection{Erstellung einer EcoRI-Restriktionskarte von Cosmiden}

Um aufgrund der T3-/T7-Hybridisierungen erhaltene Ergebnisse zu bestätigen und gleichzeitig Aussagen über das Maß der Überlappung einzelner Klone treffen zu können, wurden SouthernBlots von Cosmiden mit der gesamten DNA ausgewählter Cosmide hybridisiert.

Cosmide, die aufgrund der Ergebnisse der T3-/T7-Hybridisierungen Contigs für YAC 875 bildeten, wurden mit EcoRI gespalten, auf einem 0,7 \% Agarosegel aufgetrennt (s. Abb. 10) und anschließend auf eine Nylonmembran transferiert (2.2.9.1.). Gemeinsame Fragmente von Cosmiden wurden durch Hybridisierungen mit einzelnen radioaktiv markierten Cosmiden erkannt, wobei möglicherweise vorhandene repetitive Bereiche der Cosmid-Sonden zuvor durch eine Präassoziation mit humaner Plazenta-DNA abgesättigt wurden (2.2.9.3.). Beispiele für diese Hybridisierungen sind in den Abbildungen 11 und $12 \mathrm{zu}$ sehen. Da die gesamte DNA von Cosmiden als Hybridisierungsonde zum Einsatz kam, wurden neben humanen Fragmenten über den Vektor-Anteil der Cosmid-Sonden auch die 6,7 kb Vektor-Fragmente der Cosmide detektiert. Die lineare Abfolge der erhaltenen Fragmente konnte durch Vergleich der Restriktionsmuster verschiedener Cosmide bestimmt werden. Die einzelnen Contigs konnten schließlich zu zwei Contigs vereinigt werden, die mit einer Lücke die Region von YAC 875C4 repräsentierten. Diese Lücke ließ sich aufgrund der T3-/T7- Hybridisierungsdaten der Cosmide 
2E11, 2G2 und 2D12 schließen. Durch Doppelspaltungen von Cosmiden mit EcoRI und EagI bzw. NotI ließen sich zwei EagI- und eine NotI-Schnittstelle in das Contig einordnen. Zudem wurden einige Endfragmente durch Hybridisierung mit dem T3- bzw. T7-Primer identifiziert. Das erhaltene Cosmid-Contig deckt einen genomischen Bereich von etwa $306 \mathrm{~kb}$ ab, dies entspricht nicht ganz der Größe des subklonierten YACs 875C4, welcher nach PFGE eine Größe von etwa $370 \mathrm{~kb}$ aufweist. Daher ist zu vermuten, daß ein Teil des YACs nicht in den Cosmiden repräsentiert ist. Abb. 13 zeigt eine zusammenfassende Darstellung des für den YAC 875C4 erstellten Cosmid-Contigs.

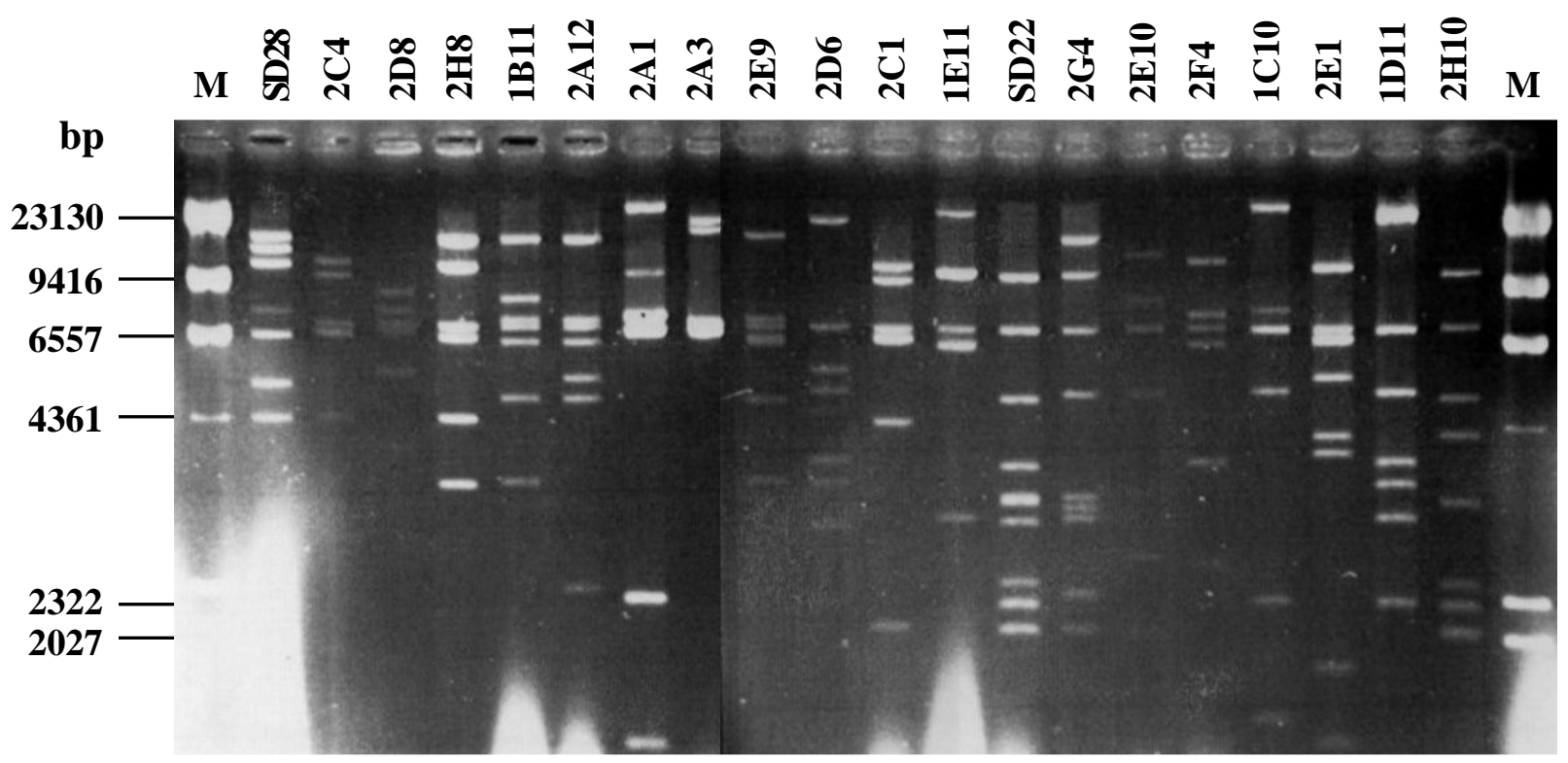

Abb. 10: EcoRI-Restriktionsmuster von 20 Cosmiden aus der Cosmid-Bibliothek des YACs 875C4. (M: Längenstandard lambda-DNA/HindIII gespalten). 


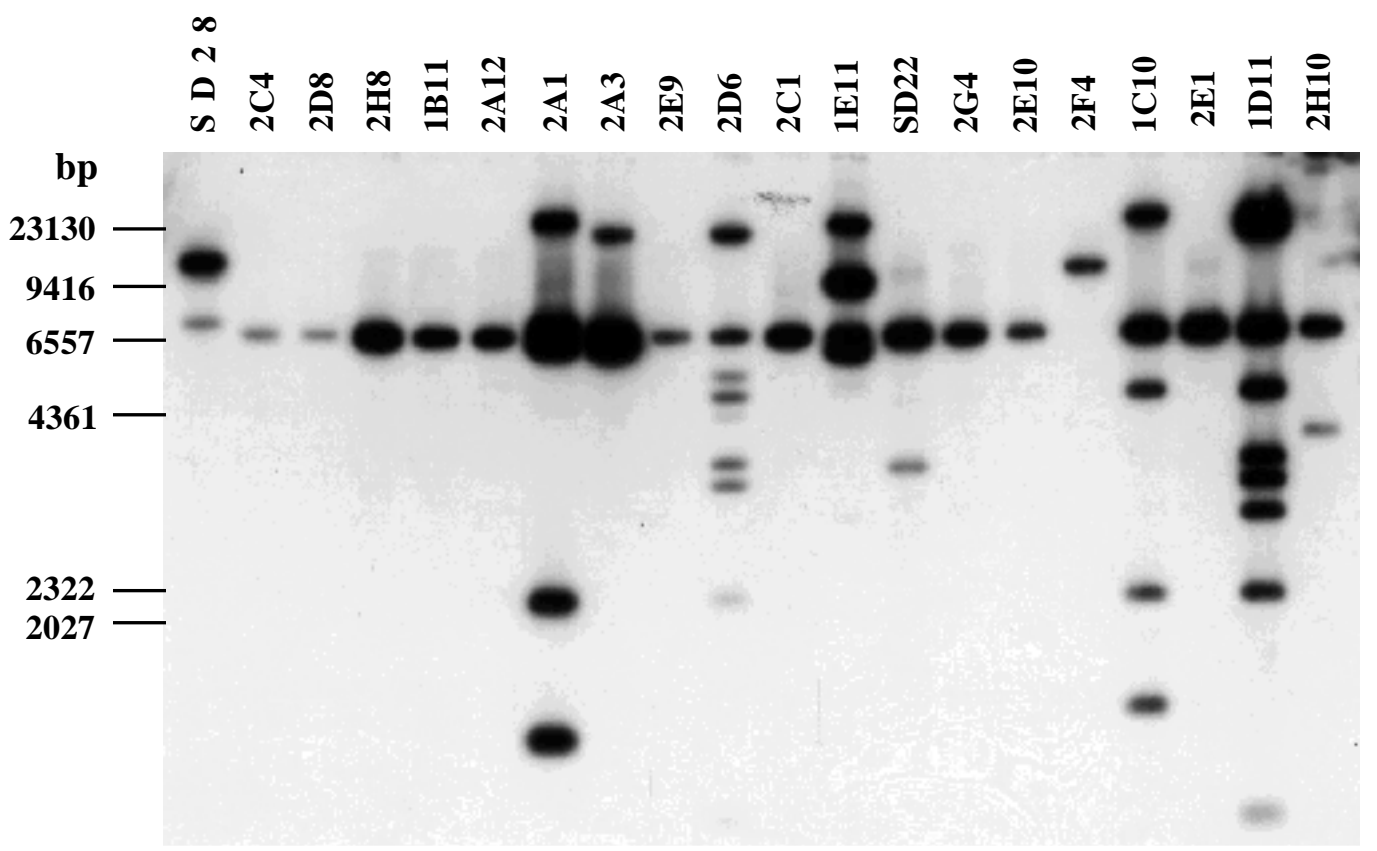

Abb. 11: Hybridisierung der mit EcoRI gespaltenen Cosmide des in Abb. 10 gezeigten Gels mit dem radioaktiv markierten Cosmid 1D11. Die Cosmide SD28, 1E11 und 2F4 weisen Banden auf, die vermutlich aufgrund repetitiver Sequenzen bzw. Vektor-Sequenzen bei Hybridisierung mit jedem Cosmid detektiert wurden (zum Vergleich siehe Abb. 12). Zudem hybridisierte jeweils das 4,3 kb-TRP-Fragment von 2H10, das 3,8 kb-TRPFragment von SD22 und der 6,7 kb lange Cosmid-Vektor.

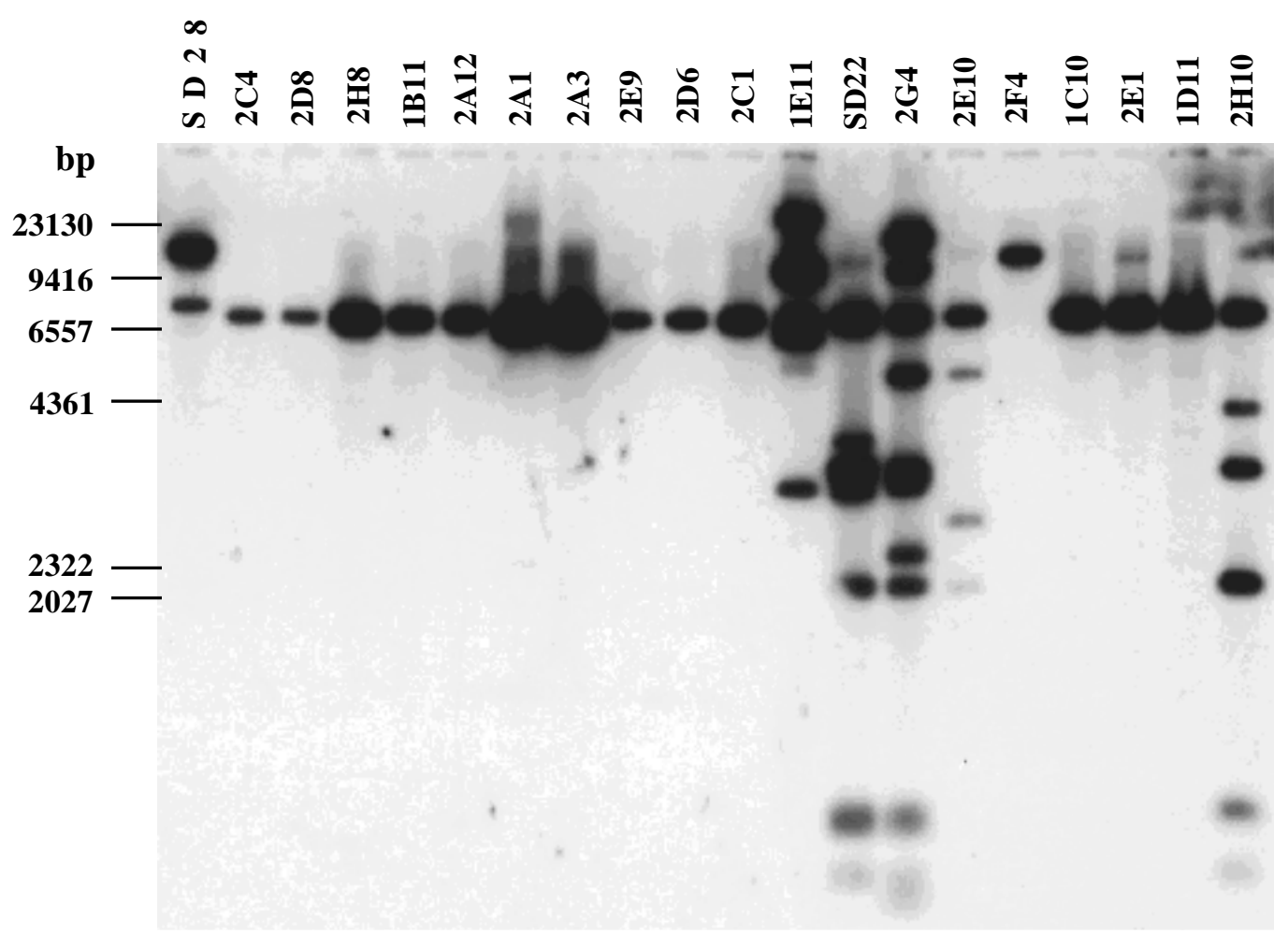

Abb. 12: Hybridisierung der mit EcoRI gespaltenen Cosmide des in Abb. 10 dargestellten Gels mit dem radioaktiv markierten Cosmid 2G4. Einzelne Banden der Cosmide SD28, $1 \mathrm{E} 11$ und 2F4 wurden bei Hybridisierung mit jedem Cosmid detektiert (zum Vergleich siehe Abb. 11). Auch das 4,3 kb-TRP-Fragment von 2H10, das 3,8 kb-TRP-Fragment von SD22 und der 6,7 kb lange Cosmid-Vektor wurden jeweils markiert. 


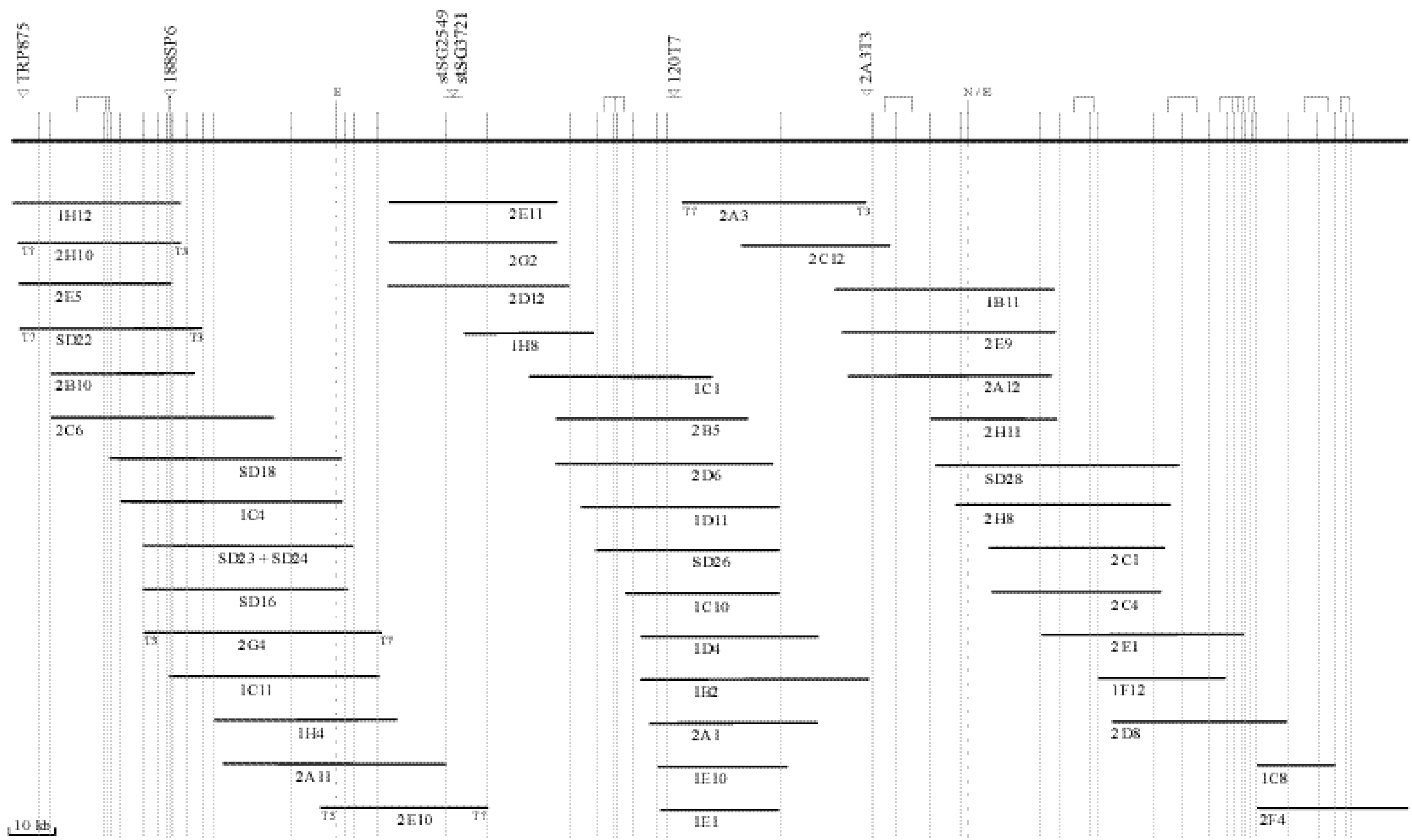

Abb. 13: EcoRI-Restriktionskarte der Cosmide des Contigs aus YACs 875C4. EcoRI-Schnittstellen sind durch kurze senkrechte Striche in der Basislinie gekennzeichnet. Zudem wurden dem Contig zwei EagI (E)- und eine NotI (N)-Schnittstelle zugeordnet, die durch lange senkrechte Striche gekennzeichnet sind. Die über PCR-Analysen innerhalb des Contigs positionierten 6 Loci wurden in das Contig integriert. $\Gamma \mid$ : Anordnung der Restriktionsfragmente nicht festgelegt. 


\subsubsection{Detektion von randständigen Cosmiden des Contigs}

Da die Größe des Cosmid-Contigs mit etwa 306 kb nicht der erwarteten Größe von 370 kb entsprach, sollte überprüft werden, ob die Enden des YACs 875C4 im Contig enthalten sind. Es wurde erwartet, daß die randständigen Cosmide des Contigs entweder das TRP- oder das URAEnde des YACs beinhalten.

Um Cosmide zu identifizieren, die das TRP- oder das URA-Ende enthalten, wurden die Primer TRP und URA durch Kinasierung radioaktiv markiert (s. 2.2.9.6) und anschließend auf die Cosmid-Filter mit 96 bzw. 192 fixierten Cosmiden (s. 2.2.16.8.) hybridisiert. Nach Hybridisierung mit dem TRP-Primer zeigten die Cosmide 1A2, 1C5, 1H12, 2A4, 2C2, 2F1, $2 \mathrm{H} 7$ und 2H10 schwache Signale, mit dem URA-Primer konnte dagegen kein Cosmid detektiert werden. Um die Ergebnisse für den TRP-Primer zu bestätigen, und um Cosmide für das URA-Ende detektieren zu können, wurden Sonden für die Enden des YACs 875C4 generiert. Dazu wurde DNA von YAC 875C4 für eine Alu-PCR (s. 2.2.10.2) eingesetzt, wobei die Primer TRP und URA mit verschiedenen Alu-Primern kombiniert wurden. Bei Kombination des TRP-Primers mit den Alu-Primern CL2, 154, 451, CL3 und 5' entstanden spezifische Endfragmente des YACs, die eine Größe von 400 bp, 390 bp, 600 bp, 300 bp bzw. 240 bp aufwiesen. Das URAEnde des YACs konnte durch die Kombination des URA-Primers mit dem Alu-Primer CL2 dargestellt werden, wobei ein spezifisches Endfragment von 400 bp erhalten wurde. Die mit den Primern TRP und CL2 bzw. 451 erhaltenen Endfragmente sowie das Endfragment für das URA-Ende wurden aus einem $2 \%$ igen Agarosegel isoliert (s. 2.2.7.1) und anschließend über eine lineare PCR radioaktiv markiert, wobei abweichend von der unter 2.2.16.9 beschriebenen Methode $200 \mathrm{ng}$ des TRP- bzw. URA-Primers für die Markierung eingesetzt wurden. Nach Hybridisierung dieser Sonden auf die Filter mit der Cosmid-Bibliothek konnte bestätigt werden, daß sämtliche Cosmide, die bereits mit dem TRP-Primer detektiert worden waren, dieses Ende beinhalten. Zusätzlich wurden die Cosmide 2D4 und 2E5 als positiv für das TRPEnde des YACs 875C4 identifiziert (s. Abb. 14). Für das URA-Ende konnte auch mit der über Alu-PCR generierten Sonde kein Cosmid identifiziert werden, so daß angenommen werden muß, daß dieses Ende nicht in der Cosmid-Bibliothek enthalten ist. 


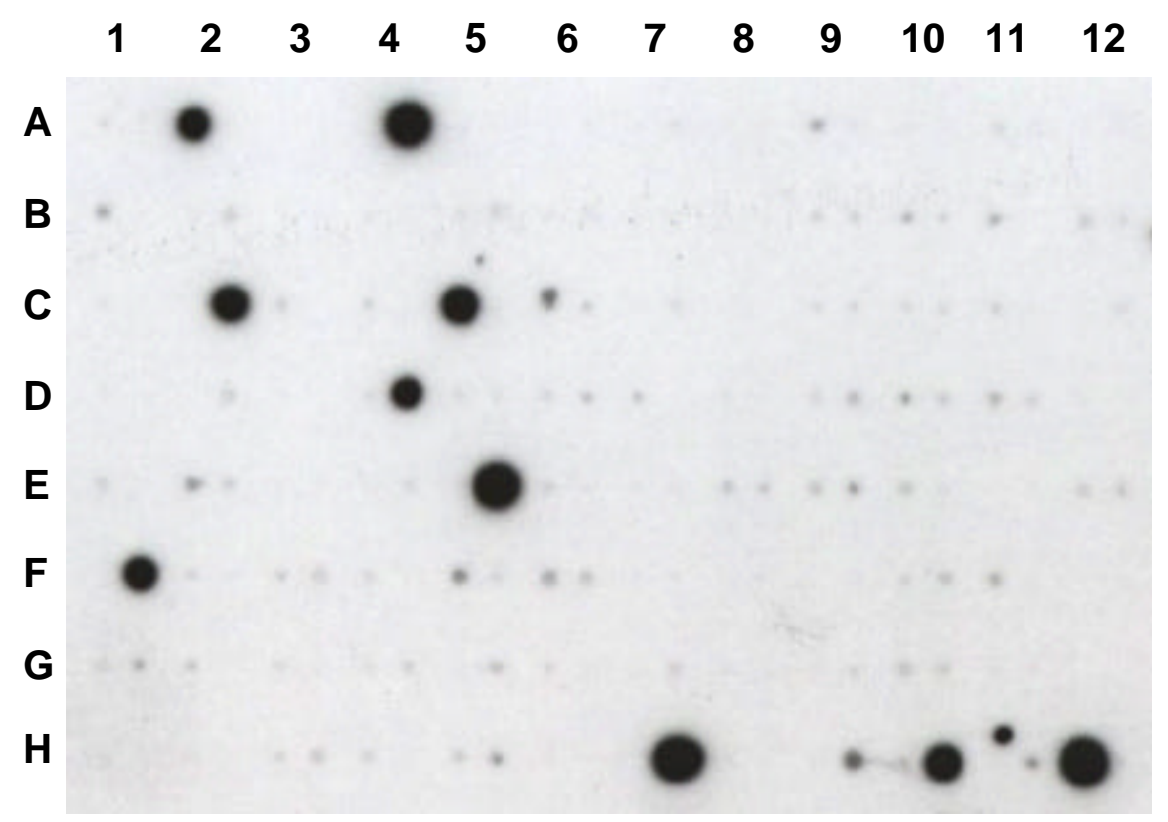

Abb. 14: Hybridisierung der Cosmid-Bibliothek aus YAC 875C4 mit dem TRP/CL2-Endfragment des YACs 875C4.

\subsubsection{PCR-Analyse von Cosmiden}

Marker, die im Verlauf der Arbeit auf YAC 875C4 lokalisiert werden konnten, sollten nachfolgend auch auf dem Cosmid-Contig positioniert werden. Bei diesen Markern handelt es sich um die ESTs stSG2549 und stSG3721, sowie um die im Rahmen der Erstellung des PAC-Contigs entstandenen STS-Stellen TRP875, URA875, 2A3T3 und 120T7. Um unter den Cosmiden aus 875C4 diejenigen zu identifizieren, die einen bzw. mehrere dieser Loci tragen, wurde eine PCR-Analyse (s. 2.2.10.1) durchgeführt. Dadurch wurden 4 Cosmide identifiziert, die die Loci stSG2549 und stSG3721 beinhalten (2E10, 2E11, 2D12, 2G2). Die für das TRP-Ende des YACs 875C4 spezifische STS TRP875 (3.6.1.1) wurde auf den Cosmiden 1C5, 1H12, 2C2, 2E5, 2F1, 2H10 und SD22 nachgewiesen. Die Cosmide 1A2, 2A4, 2H7 und 2D4, die über Hybridisierung mit dem TRP-Ende des YACs 875C4 detektiert werden konnten (s. 3.4.3), wurden nicht über PCR getestet. Mit der STS URA875 (s. 3.6.1.1) wurde nach PCR-Analyse kein Cosmid für das URA-Ende von YAC 875C4 identifiziert. Für 2A3T3 (s. 3.6.1.4) wurden sechs Cosmide (1B2, 1B11, 2A3, 2A12, 2C12 und 2E9) und für 120T7 elf Cosmide (1B2, 1C1, 1C10, 1D4, 1D11, 1E1, 1E10, 2A1, 2B5, 2D6 und SD26) positiv getestet. Die Marker, die auf Cosmiden des YACs 875C4 lokalisiert werden konnten, sind im Cosmid-Contig (s. Abb. 13) enthalten.

\subsection{FISH-Analyse mit den 875C4-Cosmiden}

Über FISH-Analysen an Metaphasen des Probanden AS mit einer 1; 17 Translokation sollten die durch Subklonierung des YACs $875 \mathrm{C} 4$ erhaltenen Cosmide in bezug zum Translokationsbruchpunkt positioniert werden. Da YAC 875C4 nach FISH-Analyse an Metaphasen dieses Probanden Signale an beiden derivativen Chromosomen gezeigt hatte, war angenommen worden, daß dieser YAC den Translokationsbruchpunkt auf Chromosom 17 überspannt (Dörr, 
1995). Neben Signalen an Chromosom 17 hatte dieser YAC Signale an Chromosom 4q gezeigt. Da der entsprechende Hefe-Klon nach PFGE-Analyse nur einen YAC aufwies, konnte daraus geschlossen werden, daß dieser YAC nur ein genomisches Insert enthält, welches aber chromosomale Bereiche von Chromosom 17 und 4 beinhaltet. Da die erhaltenen Cosmide aus YAC 875C4 stammen, wurde erwartet, daß nach FISH-Analyse an den Translokationschromosomen des Probanden AS sowohl distal als auch proximal zum Bruchpunkt auf Chromosom 17 lokalisierte Cosmide identifiziert werden würden. Darüber hinaus wurden Cosmide erwartet, die den Translokationsbruchpunkt überspannen sowie Cosmide für Chromosom 4q.

Zur Bestimmung der chromosomalen Lokalisierung wurden die Cosmide zunächst an Metaphasen von chromosomal unauffälligen Personen hybridisiert. Diese wurden ausgehend von 72 h-Kulturen von Lymphozyten peripheren Blutes hergestellt (s 2.2.17.1). Auf Chromosom 17 lokalisierte Cosmide wurden anschließend auf Metaphasen des Translokationsprobanden hybridisiert, die ausgehend von EBV-Kulturen erhalten worden waren (s. 2.2.17.2). Pro Cosmid-Sonde wurden mindestens 15 Metaphasen ausgewertet, wobei die Hybridisierungssignale in der Regel auf beiden Chromatiden des jeweiligen Chromosoms zu finden waren. Die Ergebnisse der FISH-Analyse sind in Tabelle 23 dargestellt. Abb. 15 zeigt Beispiele für FISHAnalysen mit Cosmiden.

Tab. 23: Physikalische Kartierung von Cosmiden mittels der Fluoreszenz-in situ-Hybridisierung (FISH).

\begin{tabular}{lll}
\hline Cosmid-Klon & Regionale Kartierung & $\begin{array}{l}\text { Lokalisierung auf den } \\
\text { Translokationschromosomen }\end{array}$ \\
\hline 2H10 & $17 \mathrm{q} 23-\mathrm{q} 24$ & $\operatorname{der}(17)$ \\
SD22 & $17 \mathrm{q} 23-\mathrm{q} 24$ & $\operatorname{der}(17)$ \\
$2 \mathrm{G} 4$ & $17 \mathrm{q} 23-\mathrm{q} 24$ & $\operatorname{der}(17)$ \\
$1 \mathrm{H} 4$ & $17 \mathrm{q} 23-\mathrm{q} 24$ & $\operatorname{der}(17)$ \\
$2 \mathrm{E} 10$ & $17 \mathrm{q} 23-\mathrm{q} 24$ & $\operatorname{der}(17)$ \\
$2 \mathrm{~B} 5$ & $17 \mathrm{q} 23-\mathrm{q} 24$ & $\operatorname{der}(17)$ \\
$2 \mathrm{D} 6$ & $17 \mathrm{q} 23-\mathrm{q} 24$ & $\operatorname{der}(17)$ \\
$1 \mathrm{D} 11$ & $17 \mathrm{q} 23-\mathrm{q} 24$ & $\operatorname{der}(17)$ \\
$2 \mathrm{~A} 3$ & $17 \mathrm{q} 23-\mathrm{q} 24$ & $\operatorname{der}(17)$ \\
$1 \mathrm{~B} 11$ & $17 \mathrm{q} 23-\mathrm{q} 24$ & $\operatorname{der}(17)$ \\
SD28 & $17 \mathrm{q} 23-\mathrm{q} 24$ und $4 \mathrm{q}$ & \\
$2 \mathrm{D} 8$ & $4 \mathrm{q}$ & \\
$2 \mathrm{~F} 4$ & $4 \mathrm{q}$ & \\
\hline
\end{tabular}



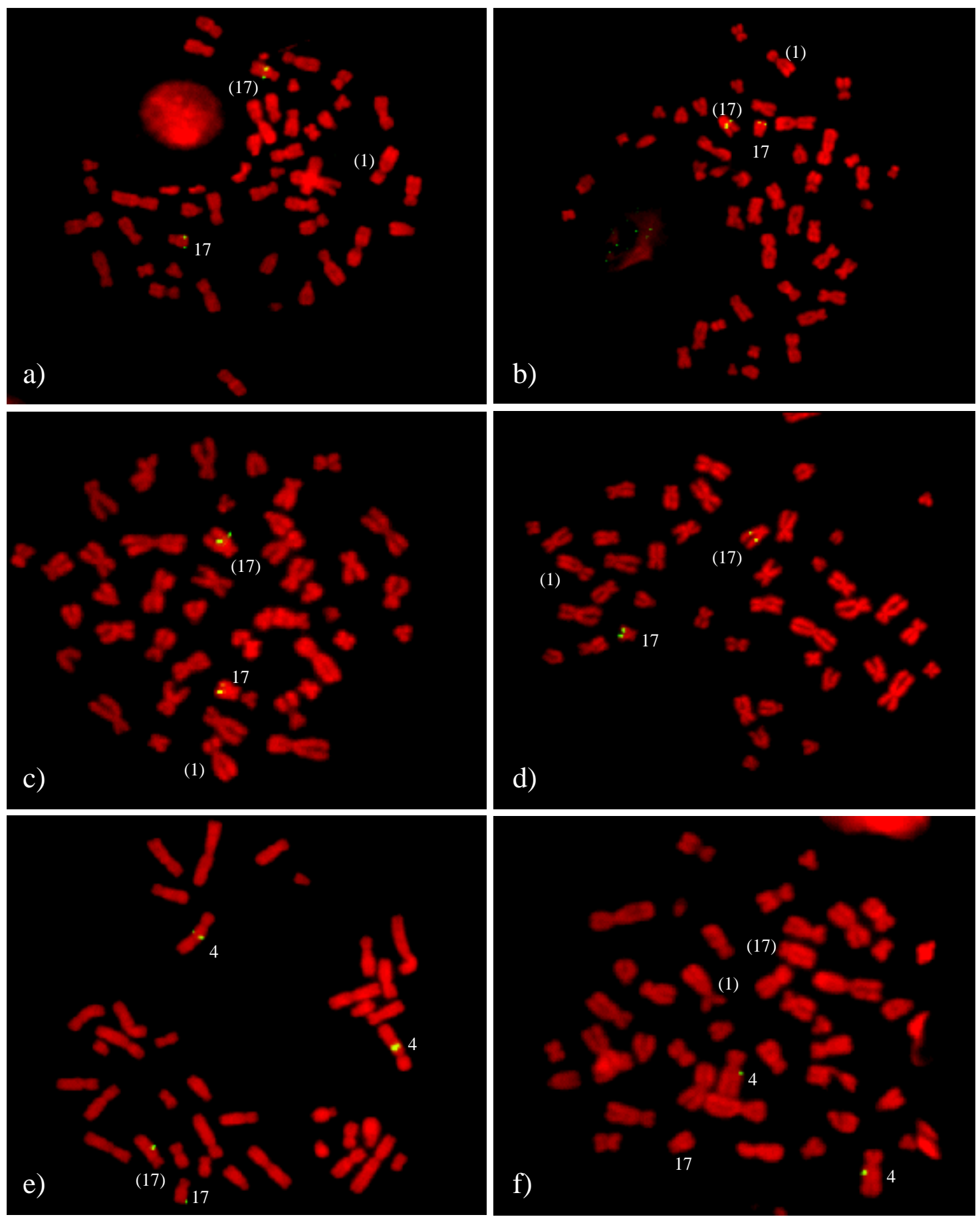

Abb. 15: Beispiele für FISH-Analysen mit Cosmid-Sonden an Metaphasen des Probanden AS. a) 2H10; b) SD22; c) 2B5; d) 1B11; e) SD28; f) 2D8. In a) bis d) tragen das normale Chromosom 17 und das der(17) [(17)] Signale. In e) tragen das normale Chromosom 17, das normale Chromosom 4 und das $\operatorname{der}(17)[(17)]$ Signale und in f) trägt nur das normale Chromosom 4 Signale. 
Wie Tabelle $23 \mathrm{zu}$ entnehmen ist, zeigten die Cosmide an Chromosomen von unauffälligen Kontrollpersonen erwartungsgemäß Signale in der Region 17q23-q24 oder auf Chromosom 4q. Cosmid SD28 zeigte sowohl Signale auf Chromosom 17 als auch auf Chromosom 4, dieses Cosmid beinhaltet somit den Übergang zwischen den verschiedenen chromosomalen Bereichen des chimärischen YACs 875C4.

Nach FISH-Analyse an den Translokationschromosomen zeigten sämtliche für Chromosom 17 spezifische Cosmide ein Signal an dem derivativen Chromosom 17. Es wurde jedoch kein Cosmid identifiziert, welches Signale an dem derivativen Chromosom 1 zeigte. Somit kartieren alle getesteten Cosmide proximal zum Translokationsbruchpunkt. Die getesteten Cosmide stammten aus verschiedenen Bereichen des Cosmid-Contigs (s. Abb. 13). Unter diesen Cosmiden befanden sich auch solche, die als randständig für den Chromosom 17-Anteil des YACs 875C4 anzusehen sind. Daher ist anzunehmen, daß sämtliche Cosmide, die durch Subklonierung des YACs $875 \mathrm{C} 4$ generiert wurden, proximal des Translokationsbruchpunktes von Proband AS kartieren.

Um zu überprüfen, ob YAC 875C4 aufgrund einer Deletion die Region des Translokationsbruchpunktes verloren hat, wurden wiederholte FISH-Analysen mit DNA aus verschiedenen Präparationen des YACs 875C4 durchgeführt. Darüber wurden die bisher für diesen YAC erhaltenen FISH-Ergebnisse bestätigt. Der YAC zeigte nach Hybridisierung auf die Translokationschromosomen des Probanden AS Signale an beiden derivativen Chromosomen, wobei die Signale des derivativen Chromosoms 1 allerdings deutlich schwächer waren als die des derivativen Chromosoms 17.

Als nächstes wurde die aus einem Pulsfeldgel isolierte DNA des YACs 875C4, die zur Erzeugung der Cosmid-Bibliothek eingesetzt worden war, über eine FISH-Analyse auf Chromosomen des Probanden AS überprüft. Es zeigte sich, daß mit dieser DNA nur Signale auf dem unveränderten Chromosom 17, dem derivativen Chromosom 17 und dem Chromosom 4 erhalten wurden. Es waren jedoch keine Signale auf dem derivativen Chromosom 1 vorhanden. Aufgrund der erhaltenen Hybridisierungsergebnisse wurde zunächst angenommen, daß ein Teil des YACs 875C4 bereits vor der Subklonierung verloren gegangen war, nämlich gerade jener Teil, der den Translokationsbruchpunkt von Proband AS beinhaltet. Im Verlauf dieser Arbeit ergaben sich jedoch Hinweise darauf, daß homologe Sequenzbereiche beiderseits des Bruchpunktes eine zweifache Hybridisierung mit YAC 875C4 ermöglicht hatten, und damit über FISH das Ergebnis eines den Bruchpunkt anscheinend überlappenden YACs erzeugt wurde. In diesem Fall ist das Hybridisierungssignal auf dem derivativen Chromosom 1 als unspezifisch für YAC 875C4 anzusehen und der YAC kartiert demnach proximal zum Translokationsbruchpunkt. 


\subsection{Isolierung von PAC-Klonen für die Bruchpunktregion von AS auf Chromosom 17}

Da durch die Subklonierung des YACs 875C4 keine den Translokationsbruchpunkt von Proband AS überspannenden Cosmide erhalten wurden, sollten über eine alternative Strategie PAC-Klone für diese Region identifiziert werden. Zur Identifizierung von PAC-Klonen standen zwei Methoden zur Auswahl. Eine Möglichkeit bestand darin, PAC-Klone durch Hybridisierung auf PAC-Filter zu identifizieren, die andere darin PAC-Klone durch PCRAnalyse zu isolieren.

Die Identifizierung der PAC-Klone sollte vorwiegend über PCR-Analyse erfolgen, da in Zusammenhang mit den vorliegenden Daten vermutet wurde, daß durch Hybridisierungsreaktionen relativ viele unspezifische Klone identifiziert würden. Für PCR-Analysen wurden spezifische Marker aus der engeren Bruchpunktregion benötigt. Zunächst standen nur die ESTs stSG2549, stSG3721, WI-9461, WI-9571 und die STS D17S1870 für die Durchmusterung zur Verfügung, wobei der Abstand der Loci WI-9461, WI-9571 und D17S1870 zum Bruchpunkt auf einige hundert kb geschätzt wurde (s. Abb. 8).

Da zunächst angenommen wurde, daß es sich bei dem subklonierten YAC 875C4 um einen den Translokationsbruchpunkt überspannenden YAC handelt, der aufgrund einer Deletion die Region des Translokationsbruchpunktes verloren hatte, wurde der in Cosmide subklonierte Teil dieses YACs in unmittelbarer Nähe zum Translokationsbruchpunkt vermutet. Daher sollten Marker für die Enden des Chromosom 17-Anteils dieses YACs generiert werden, um ausgehend von diesen mit der Suche nach PACs zu starten. Weiterhin waren bereits 2 Cosmide identifiziert worden, die proximal des Translokationsbruchpunktes auf einigen den Translokationsbruchpunkt überspannenden YACs lokalisiert werden konnten (Färber, 1996). Ausgehend von diesen Cosmiden sollten weitere STS-Stellen für die distale Region des Translokationsbruchpunktes von Proband AS generiert werden.

\subsubsection{Entwicklung von neuen sequence tagged sites (STS)}

Für die Isolierung von Endfragmenten wurden die Enden der jeweiligen YAC- und CosmidInserts durch eine Alu-PCR (s. 2.2.10.2.) unter Verwendung verschiedener Alu-Primer (s. 2.1.5.6) in Kombination mit spezifischen Vektorprimern von YACs und Cosmiden (s. 2.1.5.5) dargestellt. Die Endfragmente wurden aus dem Gel isoliert (s. 2.2.7.1.) und anschließend sequenziert (s. 2.2.14.), wobei die spezifischen Vektorprimer als Sequenzierungsprimer eingesetzt wurden. Neue STSs ließen sich anhand der erhaltenen Sequenzdaten durch Wahl geeigneter Primer generieren.

\subsubsection{Generierung von STS-Stellen für die Insert-Enden von YAC 875C4}

Spezifische Endfragmente für das TRP- und URA-Ende von YAC 875C4 waren bereits durch Alu-PCR generiert worden, um damit randständige Cosmide des Cosmid-Contigs für YAC 875C4 identifizieren zu können (s. 3.4.3). Das durch eine Alu-PCR mit dem TRP-Primer und dem CL2-Primer erhaltene, 400 bp große, Endfragment wurde mit dem TRP-Primer ansequenziert (407 bp): 


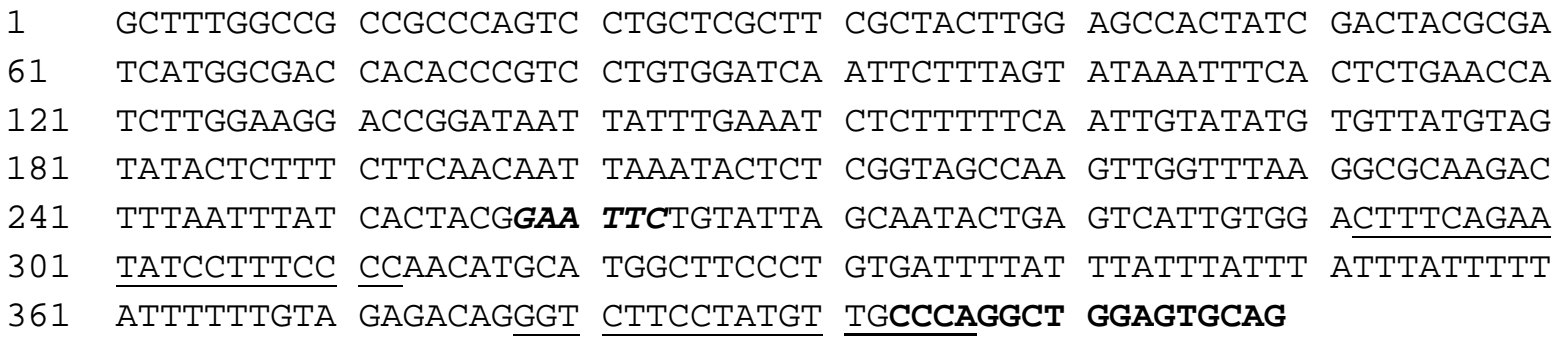

Die EcoRI-Schnittstelle (GAATTC), über die das humane Insert in den YAC-Vektor kloniert wurde, ist fett und kursiv dargestellt. Die Basenabfolge von Position 1 bis 257 entspricht dem Klonierungsvektor pYAC4. Durch einen Sequenzvergleich in der EMBL/GenBank-Datenbank wurden für die Basenpaare 258-407 keine Homologien zu bekannten Sequenzen festgestellt. Die für die Generierung des Locus TRP875 gewählten Primersequenzen sind unterstrichen und ergeben ein PCR-Produkt 105 bp. Die Sequenz des CL2-Primers ist fett dargestellt.

Die Sequenzierung des 400 bp langen Endfragmentes, welches durch eine Alu-PCR mit den Primern URA und CL2 dargestellt wurde, ergab mit dem URA-Primer folgende Sequenz (358 bp):

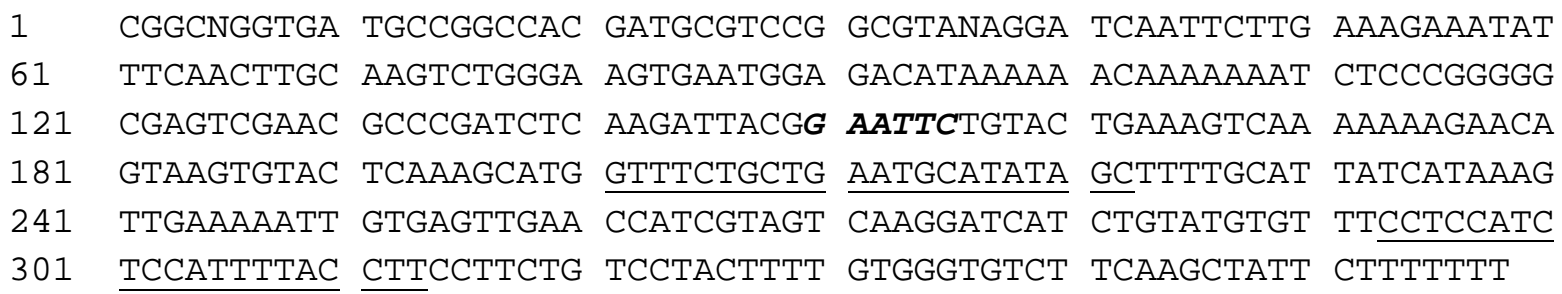

Die EcoRI-Schnittstelle (GAATTC) aus dem YAC-Vektor ist fett und kursiv dargestellt. Die Basenabfolge von Position 1 bis 149 entspricht dem Klonierungsvektor pYAC4. Durch einen Sequenzvergleich in der EMBL/GenBank-Datenbank konnten für die Basenpaare 150 bis 358 keine Homologien zu bekannten Sequenzen festgestellt werden. Die Primer, die den Locus URA875 amplifizieren, sind unterstrichen. Das korrespondierende PCR-Produkt hat eine Länge von 113 bp.

Durch PCR mit YAC 875C4 konnte das spezifische PCR-Produkt der STS URA875 erhalten werden, dieser Marker ist jedoch nicht im Cosmid-Contig von 875C4 (s. Abb. 13) enthalten. Da sich das Insert des chimärischen YACs 875C4 aus einem Chromosom 17- und einem Chromosom 4- spezifischen Anteil zusammensetzt, war unklar, ob der Locus 875URA auf dem Chromosom 17- oder dem Chromosom 4-Anteil des chimärischen YACs 875C4 lokalisiert ist. Um zu überprüfen, auf welchem Chromosom der Marker URA875 kartiert, wurde eine PCR mit Zellhybrid-DNA (Coriell Institute) durchgeführt, wobei in den Zellhybriden jeweils ein humanes Chromosom enthalten war. Das spezifische PCR-Produkt des Locus 875C4 wurde dabei mit Zellhybrid-DNA erhalten, die ausschließlich das humane Chromosom 4 enthielt. Mit Zellhybrid-DNA, die das humane Chromosom 17 enthielt, wurde dagegen kein PCR-Produkt erhalten. Dadurch konnte URA875 dem Chromosom 4 zugeordnet werden. Dieser Locus konnte somit nicht eingesetzt werden, um PACs für die Bruchpunktregion zu isolieren. 


\subsubsection{Sequenzierung des T7-Endes von Cosmid 1B11}

Aus der T7-Sequenzierung eines 450 bp langen T7/CL2-Endfragments des aus YAC 875C4 stammenden Cosmids 1B11 wurde folgende Sequenz (412 bp) erhalten:

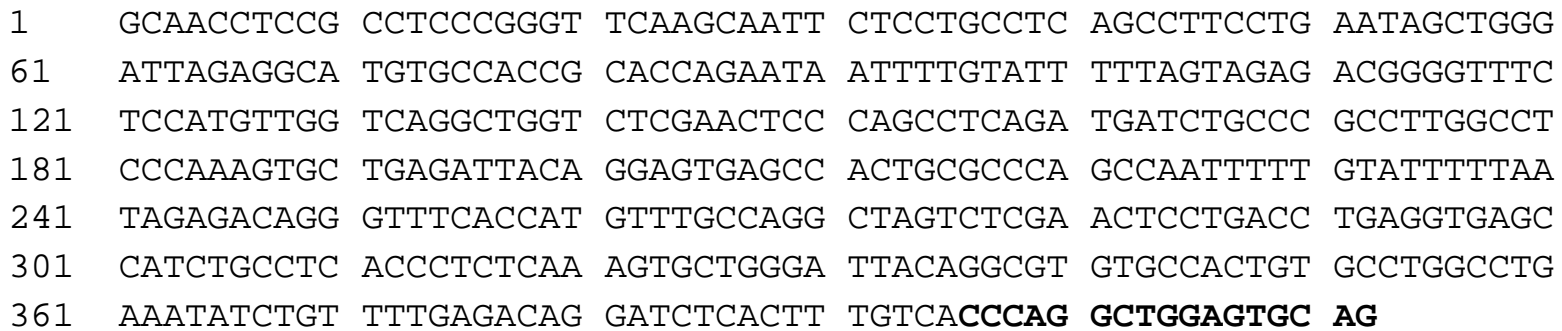

Durch einen Sequenzvergleich in der EMBL/GenBank-Datenbank wurde eine 90 \%ige Homologie der Basenpaare 1-219 zu humanen Alu-Sequenzen festgestellt. Anhand der verbleibenden nicht repetitiven Sequenz wurden keine Primer abgeleitet.

\subsubsection{Sequenzierung des T7-Endes von Cosmid $2 \mathrm{H8}$}

Für das T7-Ende des aus dem YAC 875C4 stammenden Cosmid 2H8 konnten T7/CL2-Endfragmente von 1,2 kb, 1,0 kb bzw. 300 bp dargestellt werden. Die Sequenzierung des 300 bp langen PCR-Produktes ergab mit dem T7-Primer folgende Sequenz (255 bp):

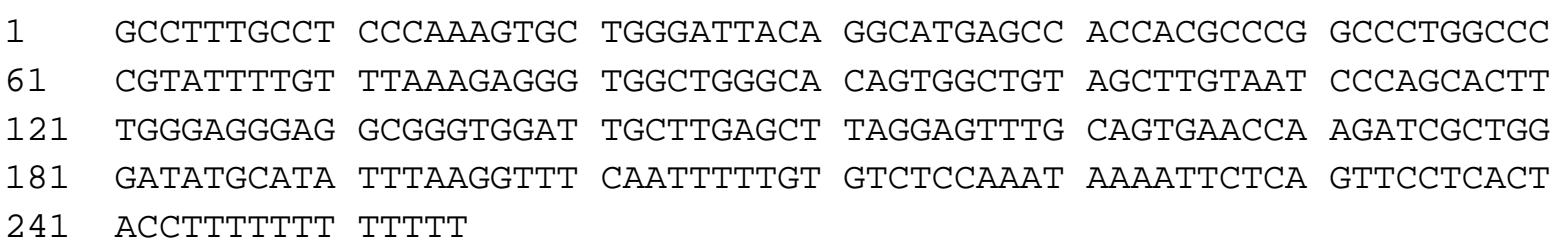

Durch einen Sequenzvergleich in der EMBL/GenBank-Datenbank wurde für die Basenpaare 153 eine $95 \%$ ige Homologie zu Alu-Sequenzen festgestellt. Für die verbleibenden 202 bp konnten keine Primer abgeleitet werden, die sich zur Generierung einer STS-Stelle eigneten.

\subsubsection{Sequenzierung des T3- und T7-Endes von Cosmid 2A3}

Spezifische Endfragmente für das T3-Ende des aus YAC 875C4 stammenden Cosmids 2A3 ließen sich durch eine Alu-PCR mit dem Primer T3 in Kombination mit den Primern CL2 oder 154 darstellen, wobei jeweils Endfragmente von 1,5 kb und 500 bp entstanden. Die Sequenzierung des 500 bp T3/CL2-Fragmentes mit dem T3-Primer ergab folgende Sequenz (268 bp):

\footnotetext{
1 ATtGTTTAAA ATCCTCATtT TGAgTAACAT AACCACAAAg TAAAGAATGT TATCATTGAT

61 TTAACCAGGA AAAGACAATA CTTAACAATA AAATTTTAAA AACATACGCC AgCCGgCTTA

121 CCTGGTGAAA AAAATAATTG CGgCTGCGAg CTGCATTTGC CAGACAATGg tTTtAgAtTT

181 GCTGTGCACG CTGAACGCCA TGAAAAATGg ACTGCCTGGC CTCTTCATAA GgAAATCACT

241 TACTTGCCTC ATTCTGAgTG AAAAGAAT
} 
Ein Sequenzvergleich in der EMBL/GenBank-Datenbank zeigte, daß die Basenpaare 8 bis 97 dieser Sequenz eine Identität von $92 \%$ mit dem tyrosinase-related protein 1 (TYRP1, Accession-Nr. L38952) aufweisen. Die unterstrichenen Oligonukleotidsequenzen wurden zur Generierung des Locus 2A3T3 gewählt. Das PCR-Produkt dieses Locus hat eine Länge von 112 bp.

Aus der T7-Sequenzierung eines 1,8 kb T7/CL2-Endfragmentes von $2 \mathrm{~A} 3$ wurde folgende Sequenz erhalten (215 bp):

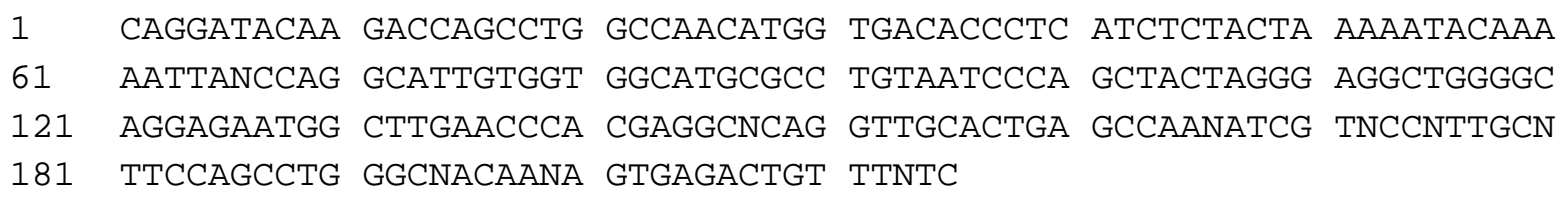

Nach einem Sequenzvergleich in der EMBL/GenBank-Datenbank zeigte sich, daß die Basenpaare 10 bis 198 dieser Sequenz eine $85 \%$ ige Identität mit humanen Alu-Sequenzen aufweisen. Diese Sequenz konnte daher nicht zur Generierung einer STS-Stelle genutzt werden.

\subsubsection{Sequenzierung des T7-Endes von Cosmid CF58}

Cosmid CF58 wurde von Färber (1996) distal des Translokationsbruchpunktes von Proband AS auf den YACs 845C6, 901G9 und 931B10 positioniert. Die T7-Sequenzierung von 450 bp langen T7/154- bzw. T7/CL2-Endfragmenten dieses Cosmids ergab folgende Sequenz (348 bp):

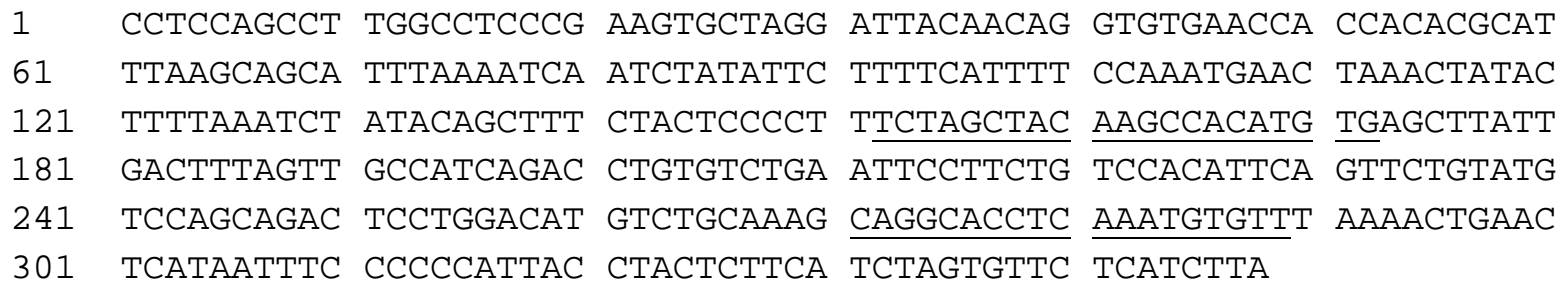

Der Sequenzvergleich in der EMBL/GenBank-Datenbank zeigte für die Basen 12-35 eine Identität von $95 \%$ mit Alu-Sequenzen. Die zur Konstruktion des Locus CF58T7 genutzten Primersequenzen sind unterstrichen und amplifizieren ein PCR-Produkt von 138 bp.

\subsubsection{Sequenzierung des T7-Endes von Cosmid CF20b}

Das Cosmid CF20b ist von Färber (1996) distal des Translokationsbruchpunktes von Proband AS auf den YAC-Klonen 845C6, $901 \mathrm{G} 9$ und 931B10 lokalisiert worden. Aus der Sequenzierung des 1,8 kb großen T7/CL3-Endfragmentes von CF20b mit dem T7-Primer wurde folgende Sequenz erhalten (342 bp): 


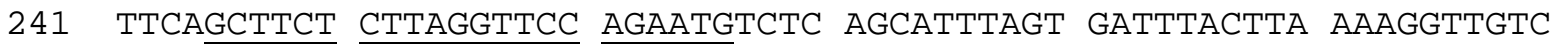

301 TGAAgtTCTA AACTCTTGAA tTgCATtTtA tAtTgGtTtT TA

Über einen Sequenzvergleich in der EMBL/GenBank-Datenbank wurden keine Homologien zu bekannten Sequenzen festgestellt. Die Primer, die den Locus CF20bT7 amplifizieren, sind unterstrichen. Das entsprechende PCR-Produkt hat eine Länge von 131 bp.

Die Sequenzierung desselben T7/CL3-Endfragmentes mit dem Alu-Primer CL3 ergab folgende Sequenz (344 bp):

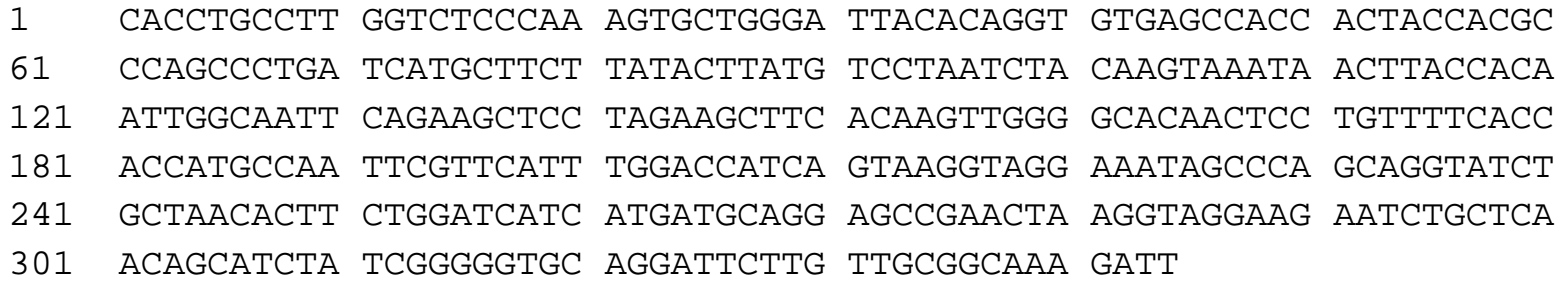

Durch einen Sequenzvergleich in der EMBL/GenBank-Datenbank konnte gezeigt werden, daß die Basen 6 bis 35 zu $100 \%$ mit humanen Alu-Sequenzen übereinstimmen. Zudem wurde für die Basenpaare 117 bis 344 eine $100 \%$ ige Identität mit verschiedenen humanen cDNA-Klonen von Karyopherin $\alpha 2$ (KPNA2)(Accession-Nr. U09559) festgestellt.

\subsubsection{Identifizierung von PAC-Klonen durch PCR-Analyse}

Um PAC-Klone über PCR-Analysen zu isolieren, wurde eine humane genomische PACBibliothek (s. 2.1.4.6) mit spezifischen Primern für Loci, die der Region des Translokationsbruchpunktes von Proband AS auf Chromosom 17 zugeordnet wurden, durchmustert. Dabei kamen sowohl Primer, die im Verlauf dieser Arbeit generiert wurden (s. 3.6.1, 3.8.2 und 3.13.1), als auch bereits beschriebene Primer (s. Tab. 6 und 8) zum Einsatz.

Die Durchmusterung der PAC-Bibliothek erfolgte in drei Stufen, wobei bei jeder PCR-Analyse eine Positivkontrolle mit humaner genomischer DNA sowie eine Negativkontrolle ohne DNA mitgeführt wurde. Zuerst wurden 21 Reaktionsgefäße (A-U), in denen jeweils 15 384-well Mikrotiterplatten vereinigt waren, getestet. Für positiv getestete 1. Pools wurden 2. Pools in 96well Mikrotiterplatten bezogen. Diese enthielten jeweils 15 Pools, bestehend aus je einer gepoolten 384-well Mikrotiterplatte. Für positiv getestete 2. Pools wurden 384-well Mikrotiterplatten mit individuellen Klonen bezogen und diese schließlich zur Identifizierung der positiven individuellen Klone durchmustert. Dafür wurden die 24 Einzelklone jeder Längsreihe einer Platte vereinigt, so daß 16 Reaktionsgefäße (A-P) mit jeweils 24 Klonen erhalten wurden. Nach Identifizierung von positiv getesteten 24er-Pools einer Längsreihe wurden schließlich die entsprechenden 24 Einzelklone getestet. Nach der DNA-Präparation (s. 2.2.1.2.) der PACs wurden positiv getestete Einzelklone bzw. potentiell positive PAC-Klone über eine weitere PCR-Analyse auf Anwesenheit der jeweiligen Loci überprüft.

Die Ergebnisse, die durch die Durchmusterung der PAC-Bibliothek erhalten wurden, sind in Tabelle 24 zusammengefaßt. Insgesamt wurden 21 Loci zum Durchmustern der Bibliothek eingesetzt, wobei 29 verschiedene PACs als potentiell positiv für die jeweiligen Loci identifiziert wurden. Von diesen wurden 24 präparierte Einzelklone über eine weitere PCR-Analyse 
überprüft. Auf diese Weise wurden 20 Klone identifiziert, die für mindestens einen Marker als positiv verifiziert werden konnten. Abbildung 16 zeigt den Ablauf der Durchmusterung der Bibliothek zur Identifizierung von PAC 81B9 mit den Primern für den Locus CF20bT7.

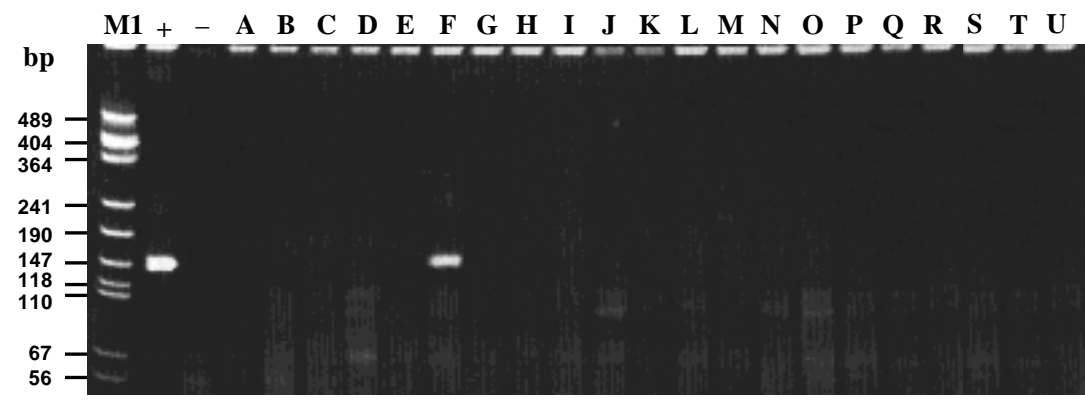

1. Pools

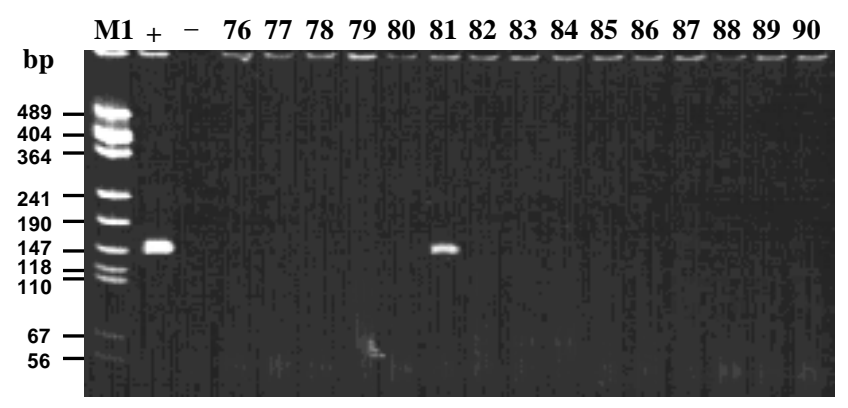

2. Pools

(Platte F)

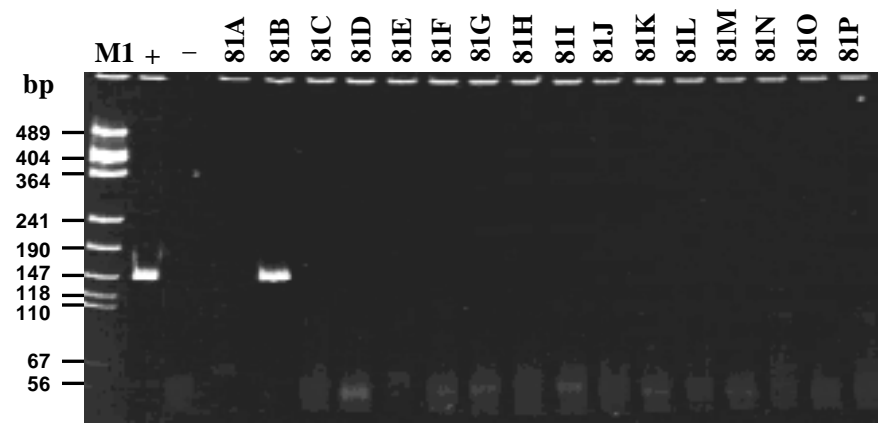

24er Pools

(Platte 81)

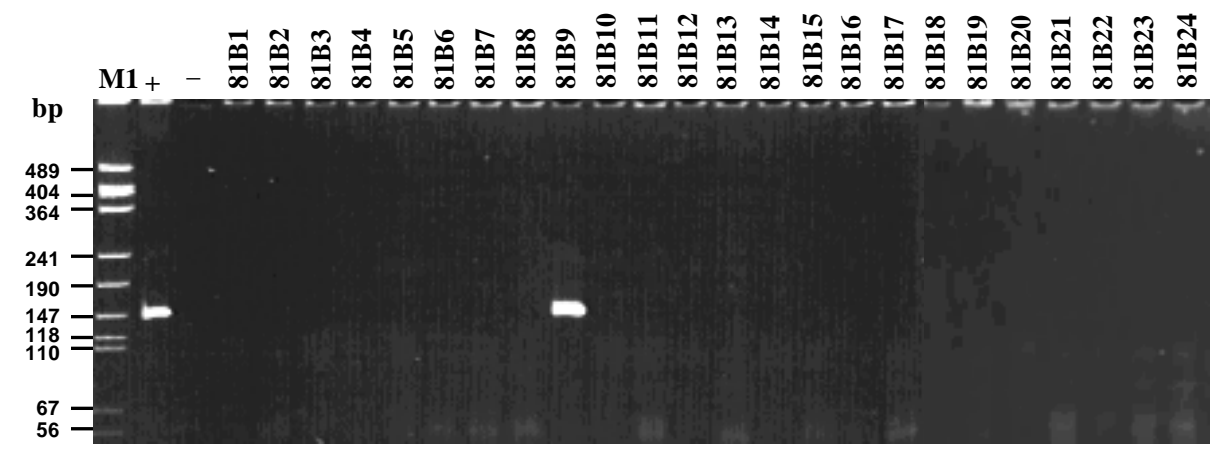

Einzelklone

Abb. 16: Durchmusterung der PAC-DNA-Pools mittels PCR für den Locus CF20bT7. (M1: Längenstandard pBluescript, HpaII-geschnitten; +: Positivkontrolle mit humaner genomischer DNA; -: Negativkontrolle ohne DNA). 
Tab. 24: PCR-Screening der PAC-Bibliothek. Die mit einem Stern gekennzeichneten STSStellen wurden im Verlauf dieser Arbeit generiert; n.b.: nicht bestimmt, ( ): schwache Intensität der PCR-Produkte.

\begin{tabular}{|c|c|c|c|c|c|}
\hline STS-Stelle & $\begin{array}{l}\text { positive } \\
\text { 1. Pools }\end{array}$ & $\begin{array}{l}\text { positive } \\
2 . \text { Pools }\end{array}$ & $\begin{array}{l}\text { positive } \\
24 \text { er-Pools }\end{array}$ & $\begin{array}{l}\text { potentiell } \\
\text { positive } \\
\text { PAC-Klone }\end{array}$ & $\begin{array}{l}\text { verifiziert } \\
\text { positive } \\
\text { PAC-Klone }\end{array}$ \\
\hline \multirow[t]{3}{*}{ TRP875* } & M & 188 & $188 \mathrm{D}$ & 188D1 & 188D1 \\
\hline & $\mathrm{N}$ & 209 & 209I & $209 \mathrm{I} 3$ & \\
\hline & $\mathrm{U}$ & 306 & 3060 & 30609 & 30609 \\
\hline \multirow[t]{2}{*}{ stSG3721 } & $\mathrm{N}$ & 209 & 209I & n.b. & $209 \mathrm{I} 3$ \\
\hline & $\mathrm{U}$ & 306 & 3060 & 30609 & 30609 \\
\hline stSG2549 & (U) & keine & & & \\
\hline 188SP6* & keine & & & & \\
\hline \multirow[t]{3}{*}{ 306SP6* } & M & 188 & $188 \mathrm{D}$ & 188D1 & 188D1 \\
\hline & $\mathrm{N}$ & 209 & 209I & n.b. & \\
\hline & $\mathrm{U}$ & 306 & 3060 & 30609 & 30609 \\
\hline \multirow[t]{4}{*}{$58 \mathrm{~T} 7 *$} & $\mathrm{D}$ & 58 & $(58 \mathrm{I})$ & $58 \mathrm{I} 13$ & n.b. \\
\hline & & & $58 \mathrm{~J}$ & $58 \mathrm{~J} 13$ & $58 \mathrm{~J} 13$ \\
\hline & & & $58 \mathrm{~N}$ & $58 \mathrm{~N} 13$ & n.b. \\
\hline & $\mathrm{H}$ & 112 & $112 \mathrm{~L}$ & 112L5 & 112L5 \\
\hline \multirow[t]{4}{*}{ 2A3T3* } & $\mathrm{D}$ & 58 & $(58 \mathrm{I})$ & $58 \mathrm{I} 13$ & n.b. \\
\hline & & & $58 \mathrm{~J}$ & $58 \mathrm{~J} 13$ & $58 \mathrm{~J} 13$ \\
\hline & & & $58 \mathrm{~N}$ & $58 \mathrm{~N} 13$ & n.b. \\
\hline & $\mathrm{H}$ & 120 & 1200 & $120 \mathrm{O} 4$ & 12004 \\
\hline D17S1870 & keine & & & & \\
\hline \multirow[t]{13}{*}{ WI-9461 } & A & 7 & $7 \mathrm{~B}$ & 7B12 & 7B12 \\
\hline & & 15 & $15 \mathrm{~N}$ & $15 \mathrm{~N} 15$ & $15 \mathrm{~N} 15$ \\
\hline & & & $15 \mathrm{~N}$ & $15 \mathrm{~N} 17$ & $15 \mathrm{~N} 17$ \\
\hline & B & 16 & $16 \mathrm{~A}$ & $16 \mathrm{~A} 23$ & $16 \mathrm{~A} 23$ \\
\hline & & 30 & $30 \mathrm{~F}$ & $30 \mathrm{~F} 12$ & $30 \mathrm{~F} 12$ \\
\hline & (D) & 49 & n.b. & & \\
\hline & $\mathrm{E}$ & 72 & n.b. & & \\
\hline & $\mathrm{F}$ & 79 & $79 \mathrm{~L}$ & 79L2 & 79L2 \\
\hline & & $(81)$ & $81 \mathrm{~B}$ & $81 B 4$ & n.b. \\
\hline & $(\mathrm{P})$ & $(238)$ & n.b. & & \\
\hline & $\mathrm{Q}$ & $(258)$ & n.b. & & \\
\hline & $(\mathrm{T})$ & (293) & $293 \mathrm{H}$ & $293 \mathrm{H} 5$ & n.b. \\
\hline & & & $293 \mathrm{H}$ & $293 \mathrm{H} 13$ & $293 \mathrm{H} 13$ \\
\hline \multirow[t]{3}{*}{ WI-9571 } & $\mathrm{F}$ & 83 & $83 \mathrm{D}$ & 83D4 & 83D4 \\
\hline & I & 131 & $131 \mathrm{P}$ & 131P15 & 131P15 \\
\hline & & & $131 \mathrm{P}$ & (131P16) & \\
\hline
\end{tabular}


Tab. 24: Fortsetzung

\begin{tabular}{|c|c|c|c|c|c|}
\hline STS-Stelle & $\begin{array}{l}\text { positive } \\
\text { 1. Pools }\end{array}$ & $\begin{array}{l}\text { positive } \\
2 \text {. Pools }\end{array}$ & $\begin{array}{l}\text { positive } \\
24 \mathrm{er}-\text { Pools }\end{array}$ & $\begin{array}{l}\text { potentiell } \\
\text { positive } \\
\text { PAC-Klone }\end{array}$ & $\begin{array}{l}\text { verifiziert } \\
\text { positive } \\
\text { PAC-Klone }\end{array}$ \\
\hline \multirow[t]{2}{*}{ WI-9571 } & $\mathrm{P}$ & 241 & $241 \mathrm{~A}$ & 241A12 & 241A12 \\
\hline & & 242 & $242 \mathrm{H}$ & $242 \mathrm{H} 16$ & $242 \mathrm{H} 16$ \\
\hline \multirow[t]{3}{*}{ CF58T7* } & A & 7 & $7 \mathrm{~B}$ & 7B12 & 7B12 \\
\hline & $\mathrm{P}$ & 241 & $241 \mathrm{~A}$ & 241A12 & 241A12 \\
\hline & $(\mathrm{T})$ & 293 & $293 \mathrm{H}$ & $293 \mathrm{H} 13$ & $293 \mathrm{H} 13$ \\
\hline \multirow[t]{10}{*}{$293 \mathrm{~T} 7 *$} & A & 7 & n.b. & & \\
\hline & & 12 & $12 \mathrm{H}$ & $12 \mathrm{H} 6$ & \\
\hline & & (15) & n.b. & & \\
\hline & $\mathrm{B}$ & 27 & $27 \mathrm{~F}$ & $27 \mathrm{~F} 10$ & \\
\hline & (G) & 97 & n.b. & & \\
\hline & $\mathrm{J}$ & $137 ; 150$ & n.b. & & \\
\hline & $\mathrm{Q}$ & 245 & $245 \mathrm{~A}$ & $245 \mathrm{~A} 13$ & \\
\hline & & $(255)$ & n.b. & & \\
\hline & $\mathrm{R}$ & 264 & n.b. & & \\
\hline & $(\mathrm{T})$ & 293 & $293 \mathrm{H}$ & n.b. & $293 \mathrm{H} 13$ \\
\hline 241SP6* & $\mathrm{P}$ & 241 & $241 \mathrm{~A}$ & n.b. & 241A12 \\
\hline CF20bT7* & $\mathrm{F}$ & 81 & $81 \mathrm{~B}$ & $81 B 9$ & $81 B 9$ \\
\hline \multirow[t]{5}{*}{$112 \mathrm{~T} 7 *$} & $\mathrm{~F}$ & 81 & $81 \mathrm{~B}$ & $81 \mathrm{~B} 9$ & $81 \mathrm{~B} 9$ \\
\hline & & 81 & $81 \mathrm{~B}$ & (81B10) & n.b. \\
\hline & & 90 & $90 \mathrm{~A}$ & $90 \mathrm{~A} 6$ & \\
\hline & $\mathrm{H}$ & 112 & $112 \mathrm{~L}$ & n.b. & 112L5 \\
\hline & $\mathrm{O}$ & 222 & $222 \mathrm{~L}$ & 222L3 & 222L3 \\
\hline \multirow[t]{4}{*}{ KPNA2-3'* } & A & 12 & $12 B$ & n.b. & \\
\hline & & & $12 \mathrm{H}$ & n.b. & \\
\hline & (F) & 81 & n.b. & & \\
\hline & $\mathrm{Q}$ & 245 & $245 \mathrm{~A}$ & $245 \mathrm{~A} 13$ & $245 \mathrm{~A} 13$ \\
\hline $81 \mathrm{~T} 7 *$ & $(\mathrm{~F})$ & n.b. & & & \\
\hline $\mathrm{K} 5-\mathrm{F} / \mathrm{R} *$ & keine & & & & \\
\hline KPNA2-E2* & keine & & & & \\
\hline KPNA2-E1* & keine & & & & \\
\hline
\end{tabular}

\subsubsection{Identifizierung von PAC-Klonen durch Hybridisierung auf PAC-Filter}

Die Arbeiten zur Identifizierung von PAC-Klonen durch Hybridisierung auf PAC-Filter wurden in Zusammenarbeit mit Beate Gawin aus der Arbeitsgruppe von M. Gessler durchgeführt, die PAC-Filter der Bibliothek von Pieter de Jong zur Verfügung stellte.

Durch die Hybridisierung von Sonden der YACs 875C4 und 845C6 auf die PAC-Filter sollten mit diesen YACs überlappende PACs der Bruchpunktregion identifiziert werden. Um Kreuz- 
hybridisierungen über den Vektor-Anteil der YACs zu verhindern, wurde die YAC-DNA jedoch nicht direkt auf die PAC-Filter hybridisiert, sondern es erfolgte zuvor eine Anreicherung der humanen Sequenzen durch eine IRS-PCR (2.2.10.3) mit Primern die spezifisch an repetitive Elemente humaner DNA binden.

Die Verwendung von IRS-PCR-Fragmenten des YACs 875C4 als Hybridisierungssonde führte zur Identifizierung von 8 positiven PACs (58J13, 165D17, 165D18, 188D1, 191A17, 209I3, 227A21 und 306O9). Nach Hybridisierung mit IRS-PCR-Fragmenten von YAC 845C6 konnten keine positiven PACs identifiziert werden.

\subsubsection{Identifizierung von PAC-Klonen anhand veröffentlichter Daten}

Bärlund et al. (1998) isolierten genomische Klone (YACs, BACs, PACs oder P1-Klone) für 23 Gene des Chromosoms 17. Für die bereits im YAC-Contig kartierte PRKCA wurde der PACKlon 120L21 identifiziert und für die bisher nicht im YAC-Contig enthaltene PRKAR1A (human cAMP-dependent protein kinase type I-alpha subunit) der PAC 250M4. Obwohl kein YAC des erstellten Contigs (s. Abb. 5) mit Primern für die PRKAR1A positiv getestet werden konnte (Dörr, 1995), erschien eine Lokalisierung in der Bruchpunktregion des Probanden AS wahrscheinlich, da die PRKAR1A über Sequenzvergleiche in der Region des Markers D17S789 kartiert werden konnte (s. 3.12.9).

Die PAC-Klone 120L21 und 250M4 wurden in weitere Analysen einbezogen und innerhalb der erstellten physikalischen Karte (s. Abb. 22) kartiert.

\subsection{Charakterisierung der PAC-Klone}

\subsubsection{Restriktionsanalyse der PAC-Klone}

Von den über das Durchmustern der PAC-Bibliothek identifizierten PAC-Klonen wurden entweder Agarkulturen vom UK HGMP Resource Centre bezogen und auf LB-Kanamycinplatten ausgestrichen oder die entsprechenden Glycerinstocks der 384-well Platten wurden ausplattiert. Anschließend wurden von mindestens 2 Einzelklonen DNA-Maxipräparationen angeimpft und die DNA isoliert.

Eine vergleichende Restriktionsanalyse wurde mit EcoRI durchgeführt. Auf diese Weise sollte über die Identifizierung identischer Fragmente überprüft werden, ob sich unter den identifizierten PACs miteinander identische Klone befinden. Zudem sollte über den Vergleich des Spaltmusters von jeweils mindestens 2 verschiedenen DNA-Präparationen des gleichen Klons festgestellt werden, ob es sich bei den Ursprungskolonien um Einzelkolonien oder Mischklone handelt und, ob möglicherweise Umlagerungen des Originalklons stattgefunden haben. Abb. 17 zeigt Beispiele der über Restriktionsanalyse getesteten PAC-Klone. 


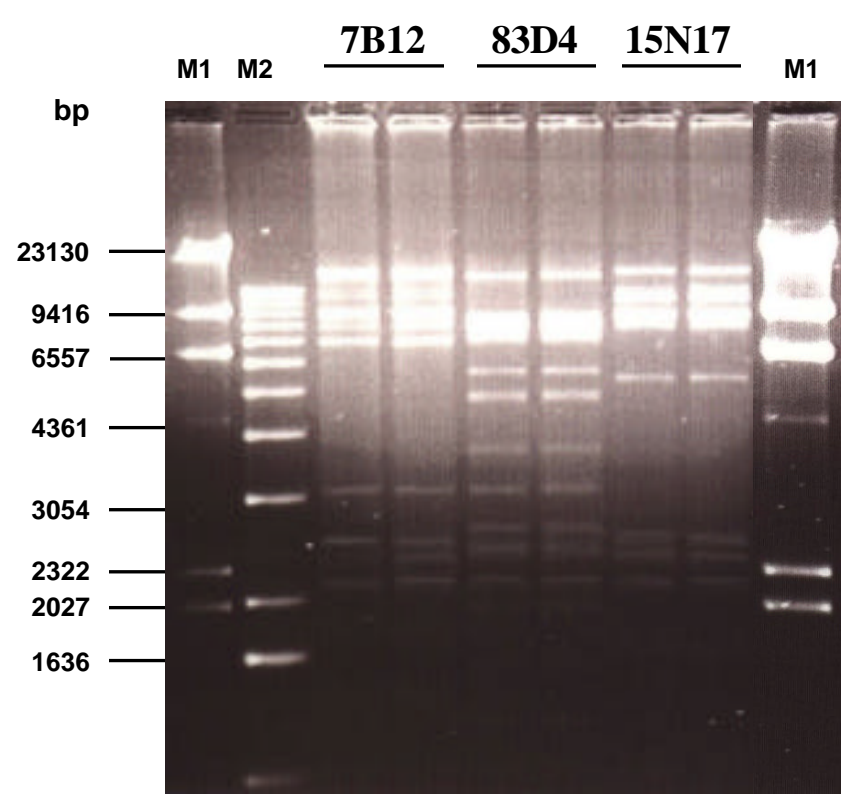

Abb. 17: EcoRI-Restriktionsanalyse der PACs 7B12, 83D4 und 15N17. (M1: Längenstandard lambda-DNA/HindIII-gespalten; M2: Längenstandard $1 \mathrm{~kb}$-Leiter).

Durch einen Vergleich der EcoRI-Spaltmuster der verschiedenen Klone konnte festgestellt werden, daß die Klone 15N15 und 15N17 nahezu identisch sind. Weiterhin konnten für die Klone 15N15, 15N17, 7B12 und 293H13 Banden gleicher Größe identifiziert werden, die auf Überlappungen dieser Klone hindeuten. Auch die Klone 30F12 und 79L2 zeigten teilweise Banden gleicher Größe. Für weitere PACs war aufgrund der relativ großen Bandenzahl keine eindeutige Aussage zu treffen.

Bei Vergleich der Spaltmuster von verschiedenen DNA-Präparationen des selben PACs zeigten 7 von 27 getesteten PAC-Klonen für die einzelnen DNA-Präparationen zwei differente EcoRIRestriktionsmuster (12H6, 58J13, 81B9, 209I3, 241A12, 245A13 und 293H13).

Nach Restriktionsanalyse von 2 verschiedenen Präparationen der PACs 241A12, 245A13 und 293H13 zeigte sich, daß die beiden zu einem PAC korrespondierenden Restriktionsmuster in einzelnen Banden voneinander abwichen. Die Klone 1 und 2 der entsprechenden PACs sind daher vermutlich durch Umlagerungen aus einem Originalklon entstanden. Bei weiteren Analysen wurden die Präparationen 1 und 2 dieser Klone parallel eingesetzt, wobei jeweils identische Ergebnisse für beide Präparationen erhalten wurden. Daher kann für diese Klone im folgenden auf die Unterscheidung der Präparationen 1 und 2 verzichtet werden.

Für die Klone 12H6, 58J13 und 81B9 wurden jeweils 4 Maxipräparationen durchgeführt, wobei jeweils 3 identische DNAs und eine in einzelnen Banden davon abweichende DNA erhalten wurden. Daher wurde davon ausgegangen, daß das dreifach vorhandene Restriktionsmuster jeweils dem des Originalklons entspricht. Die davon abweichende DNA wurde dennoch bei weiteren Analysen mitgeführt. Dadurch zeigte sich, daß dem abweichendem Klon von $81 \mathrm{~B} 9$ das 5'-Ende von Karyopherin $\alpha 2$ (KPNA2) fehlt. Alle weiteren Ergebnisse stimmten für 
die verschiedenen Präparationen überein, so daß der Übersicht wegen im folgenden auf die Unterscheidung der verschiedenen Präparationen verzichtet wird.

Auch für den Klon 209I3 wurden 4 DNA-Präparationen durchgeführt. Dabei zeigte jedoch nur die Präparation 1 ein für PAC-Klone zu erwartendes Spaltmuster, während die Präparationen 2 und 4 ein deutlich kürzeres Insert aufwiesen und die Präparation 3 kein Insert zeigte. Die Präparationen 2 und 4 zeigten bei PCR-Analysen mit dem Locus stSG2549 im Gegensatz zu Präparation 1 kein Produkt. Daher wurde für weitere Analysen dieses Klons nur die DNA der Präparation 1 eingesetzt. Im folgenden kann somit auf die Unterscheidung der einzelnen Präparationen von PAC 209I3 verzichtet werden, alle Angaben beziehen sich auf Präparation 1.

\subsubsection{Größenbestimmung der PAC-Inserts}

Für die Größenbestimmung wurde die DNA der PAC-Klone mit NotI geschnitten. Auf diese Weise läßt sich der PAC-Vektor pCYPAC2 (15942 bp) vom Insert abtrennen. Anschließend wurde die gespaltene DNA mit Hilfe der Pulsfeldelektrophorese (PFGE) aufgetrennt und nach Ethidiumbromidfärbung dargestellt. Die für die Elektrophorese verwendeten Laufbedingungen wurden so gewählt, daß eine gute Auftrennung von Fragmenten in einem Größenbereich von 5$145 \mathrm{~kb}$ möglich war (s. Tab. 17). Fragmente, die kleiner als 4 kb waren, sind bei den gewählten Bedingungen allerdings nicht darzustellen. Abb. 18 zeigt ein Beispiel einer PFGE-Auftrennung von NotI gespaltenen PACs. Die ermittelten Größen der PAC-Inserts sind Tabelle 25 zu entnehmen, es ergab sich eine durchschnittliche Insertgröße von 95 kb.

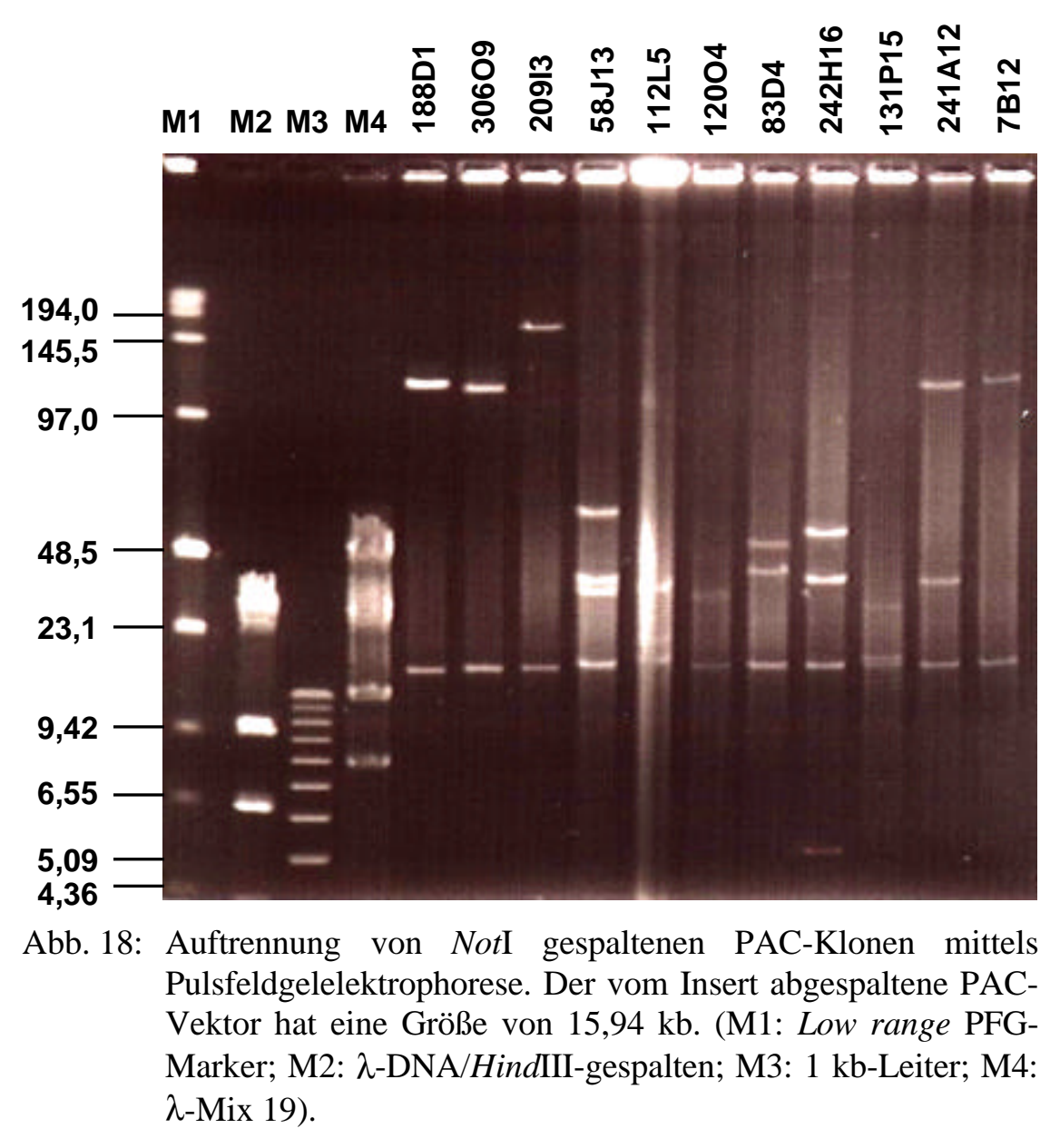


Tab. 25: PAC-Größenbestimmung

\begin{tabular}{lll}
\hline PAC-Klon & NotI-Insert-Banden $(\mathrm{kb})$ & Insertgröße $(\mathrm{kb})$ \\
\hline $188 \mathrm{D} 1$ & 109 & 109 \\
306O9 & 105 & 105 \\
209I3 & 155 & 155 \\
$58 \mathrm{~J} 13$ & $60 ; 37 ; 34$ & 131 \\
$112 \mathrm{~L} 5$ & $36 ; 21 ; 4,4$ & 61,4 \\
120O4 & $48 ; 32$ & 80 \\
$83 \mathrm{D} 4$ & $49 ; 40$ & 89 \\
$242 \mathrm{H} 16$ & $50 ; 36 ; 5$ & 91 \\
131P15 & $28 ; 17$ & 45 \\
$241 \mathrm{~A} 12$ & $111 ; 34$ & 145 \\
7B12 & 113 & 113 \\
293H13 & 119 & 119 \\
15N15 & 74 & 74 \\
15N17 & 74 & 74 \\
16A23 & 114 & 114 \\
30F12 & 17 & 17 \\
79L2 & $102 ; 28$ & 130 \\
81B9 & $38 ; 22$ & 60 \\
\hline
\end{tabular}

\subsubsection{Kartierung der PACs mit Hilfe der Fluoreszenz-in situ-Hybridisierung (FISH)}

Um die chromosomale Lokalisierung der PAC-Klone zu bestimmen, wurden die in dieser Arbeit isolierten Klone zunächst über eine FISH-Analyse an Metaphasen von chromosomal unauffälligen Kontrollpersonen hybridisiert. PAC-Klone, die Signale auf Chromosom 17 zeigten, wurden anschließend auf Chromosomenpräparate des Translokationsprobanden AS mit Russell-Silver-Syndrom hybridisiert. Die Metaphasen dieses Probanden wurden ausgehend von EBV-Kulturen präpariert (s. 2.2.17.2). Auf diese Weise sollten die PACs proximal oder distal des Translokationsbruchpunktes kartiert bzw. den Bruchpunkt überspannende PACs identifiziert werden.

Pro PAC-Sonde wurden mindestens 15 Metaphasen ausgewertet. Die Ergebnisse sind in Tabelle 26 zusammengefaßt. Die Abbildungen 19 und 20 zeigen Beispiele für FISH-Analysen mit PAC-Klonen. 
Tab. 26: Physikalische Kartierung von PACs mittels der Fluoreszenz-in situ-Hybridisierung.

\begin{tabular}{|c|c|c|c|}
\hline PAC-Klon & $\begin{array}{l}\text { zur Identifizierung } \\
\text { eingesetzte Loci }\end{array}$ & $\begin{array}{l}\text { chromosomale } \\
\text { Lokalisierung }\end{array}$ & $\begin{array}{l}\text { Lokalisierung auf } \\
\text { den Translokations- } \\
\text { chromosomen }\end{array}$ \\
\hline 120L21 & PRKCA & \multirow{2}{*}{$\begin{array}{l}17 q 23-q 24 \\
17 q 23-q 24\end{array}$} & $\operatorname{der}(17)$ \\
\hline 188D1 & YAC 875C4; TRP875; 306SP6 & & $\operatorname{der}(17)$ \\
\hline 30609 & $\begin{array}{l}\text { YAC 875C4; TRP875; } \\
\text { stSG3721; 306SP6 }\end{array}$ & $17 q 23-q 24$ & $\operatorname{der}(17)$ \\
\hline $209 I 3-1 / 2$ & YAC 875C4; stSG3721 & $17 q 23-q 24$ & $\operatorname{der}(17)$ \\
\hline $58 \mathrm{~J} 13$ & YAC 875C4; 58T7; 2A3T3 & $17 q 23-q 24$ & $\operatorname{der}(17)$ \\
\hline $120 \mathrm{O} 4$ & 2A3T3 & $17 q 23-q 24$ & $\operatorname{der}(17)$ \\
\hline 112L5 & $58 \mathrm{~T} 7 ; 112 \mathrm{~T} 7$ & $17 q 23-q 24$ & $\operatorname{der}(17)$ \\
\hline 222L3 & $112 \mathrm{~T} 7$ & $17 q 23-q 24,6 p$ & $\operatorname{der}(17), \operatorname{der}(1)$ \\
\hline $81 \mathrm{~B} 9$ & 112T7; CF20b & $17 q 23-q 24$ & $\operatorname{der}(17), \operatorname{der}(1)$ \\
\hline $293 \mathrm{H} 13$ & WI-9461; CF58T7; 293 T7 & $17 q 23-q 24$ & $\operatorname{der}(1)$ \\
\hline $7 \mathrm{~B} 12$ & WI-9461; CF58T7 & $17 q 23-q 24$ & $\operatorname{der}(1)$ \\
\hline 241A12 & WI-9571; CF58T7; 241SP6 & $17 q 23-q 24$ & $\operatorname{der}(1)$ \\
\hline $131 \mathrm{P} 15$ & WI-9571 & $17 q 23-q 24$ & $\operatorname{der}(1)$ \\
\hline 250M4 & PRKAR1A & $17 q 23-q 24$ & $\operatorname{der}(1)$ \\
\hline $30 \mathrm{~F} 12$ & WI-9461 & $17 q 23-q 24$ und 17q21 & $\operatorname{der}(17)$, der (17) \\
\hline 79L2 & WI-9461 & $17 q 23-q 24$ und 17q21 & n.b. \\
\hline $16 \mathrm{~A} 23$ & WI-9461 & $17 q 21,(17 q 23-q 24)$ & $\operatorname{der}(17),(17 q 23-q 24)$ \\
\hline $83 \mathrm{D} 4$ & WI-9571 & $17 q 23-q 24$ & $\operatorname{der}(17), \operatorname{der}(1)$ \\
\hline $242 \mathrm{H} 16$ & WI-9571 & 17q23-q24 und 17q11 & $\operatorname{der}(17)$, der (17) \\
\hline $245 \mathrm{~A} 13$ & KPNA3' & $17 q 23-q 24$ & $\operatorname{der}(17)$ \\
\hline 227A21 & YAC875 & $4 q$ & \\
\hline $165 \mathrm{D} 17$ & YAC875 & C-Gruppe, q-Arm & \\
\hline $165 \mathrm{D} 18$ & YAC875 & G-Gruppe, q-Arm & \\
\hline $12 \mathrm{H} 6$ & & $17 q 23-q 24$ und 17q21 & der (17), der (17) \\
\hline $27 \mathrm{~F} 10$ & & $17 \mathrm{q} 11$ & $\operatorname{der}(17)$ \\
\hline
\end{tabular}

Die PACs, die ausschließlich durch eine Hybridisierung mit der Sonde YAC 875C4 identifiziert wurden (227A21, 165D17 und 165D18), kartieren nicht auf Chromosom 17. PAC 227A21 wurde als spezifisch für den Chromosom 4-Anteil von YAC 875C4 identifiziert, während die PACs 165D17 und 165D18 als unspezifisch für YAC 875C4 anzusehen sind.

Die über PCR-Analyse identifizierten PACs zeigten mit Ausnahme des PACs 222L3 ausschließlich Signale an Chromosom 17q. Bei 18 dieser PACs traten diese Signale in der Region 17q23-q24 auf, welche der Region des Translokationsbruchpunktes von Proband AS entspricht. Vier der PACs (30F12, 79L2, 16A23 und 12H6) zeigten zwei Hybridisierungssignale an Chromosom 17q, und zwar im Bereich 17q23-q24 und dazu proximal in Bande 17q21 (s. Abb. 19). Daher ist zu vermuten, daß in diesen chromosomalen Bereichen ähnliche Sequenzen vor- 
handen sind. Das Hybridisierungssignal des PACs 16A23 war dabei im Bereich 17q21 deutlich stärker als in 17q23-q24, so daß anzunehmen ist, daß dieser PAC spezifisch für 17q21 ist. PAC 242H16 zeigte ebenfalls zwei Hybridisierungssignale an Chromosom 17q, wobei neben Signalen im Bereich 17q23-q24 Signale in der Bande 17q11 zu finden waren (s. Abb. 19). Daher wurde angenommen, daß auch in diesen chromosomalen Bereichen ähnliche Sequenzen vorkommen, die eine zweifache Hybridisierung mit einer Sonde ermöglichten. Bei der Hybridisierung des PACs 222L3 trat neben dem Hybridisierungsignal auf Chromosom 17 ein Signal auf Chromosom 6 auf (s. Abb. 20). Dieser PAC ist demnach chimärisch.

Nach Hybridisierung auf Chromosomenpräparate des Probanden AS zeigten 12 PACs Signale an dem unveränderten Chromosom 17 und dem derivativen Chromosom 17, diese PACs konnten somit proximal zum Translokationsbruchpunkt positioniert werden. 4 PACs zeigten Signale an dem unveränderten Chromosom 17 und dem derivativen Chromosom 1, diese PACs kartieren demnach distal zum Translokationsbruchpunkt.

Wie Tabelle $26 \mathrm{zu}$ entnehmen ist, zeigten PAC-Klone, die mit der EST WI-9461 identifiziert wurden, entweder Signale an dem derivativen Chromosom 17 (30F12, 16A23) oder an dem derivativen Chromosom 1 (293H13, 7B12) des Probanden AS. Daher wurde vermutet, daß WI9461 zweimal in der Region 17q23-q24 lokalisiert ist, und zwar einmal proximal und einmal distal zum Translokationsbruchpunkt. PAC-Klone, die für die EST WI-9571 identifiziert wurden, zeigten entweder Signale an dem derivativen Chromosom 17 (242H16), an dem derivativen Chromosom 1 (241A12, 131P15) oder an beiden derivativen Chromosomen (83D4). Das Signal von 83D4 auf dem unveränderten Chromosom 17 war jedoch als verdoppeltes Signal zu erkennen (s. Abb. 19 und 20). Daher wurde vermutet, daß auch WI-9571 zweimal in der Region 17q23-q24 kartiert, und zwar ebenfalls einmal proximal und einmal distal zum Translokationsbruchpunkt von AS.

Die PACs 81B9 und 222L3 zeigten Signale an beiden derivativen Chromosomen des Probanden AS (s. Abb. 20). Über die später durchgeführte STS-Analyse wurde zudem gezeigt, daß der PAC 81B9 mit dem distal zum Bruchpunkt kartierten PAC-Klon 112L5 und mit dem proximal zum Bruchpunkt kartierten Cosmid CF20b überlappt. Daher kann zumindest davon ausgegangen werden, daß der PAC-Klon 81B9 den Translokationsbruchpunkt von Proband AS überspannt.

Der für die PRKCA isolierte PAC-Klon 120L21 konnte distal zum Bruchpunkt positioniert werden und der für die PRKAR1A isolierte Klon 250M4 proximal zum Bruchpunkt (s. Abb. 20).

Die PACs der Region 17q23-q24 sind in der physikalischen Karte dieser Region (s. Abb. 22) enthalten.
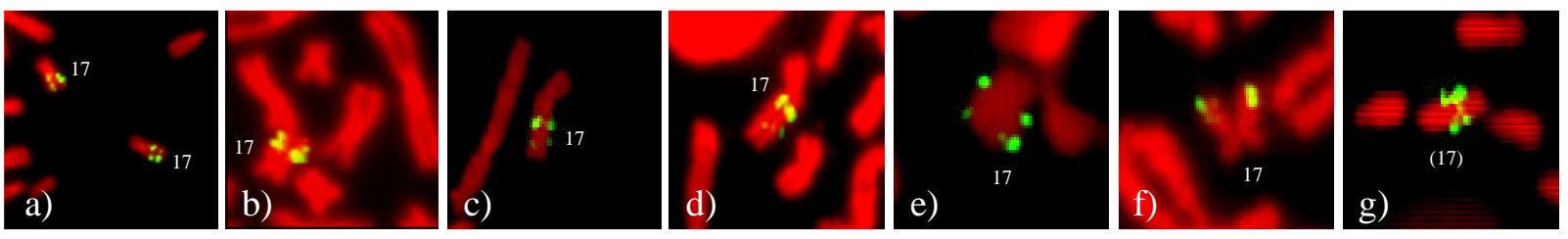

Abb. 19: Beispiele für FISH-Analysen mit PACs, die in 2 Regionen auf Chromosom 17 hybridisieren. a) bis f) Hybridisierungen an Metaphasen von unauffälligen Personen; g) Hybridisierung an Metaphasen des Probanden AS. PAC-Sonden: a), b) 79L2; c), d) 16A23; e) 242H16; f) 83D4; g) 30F12. 

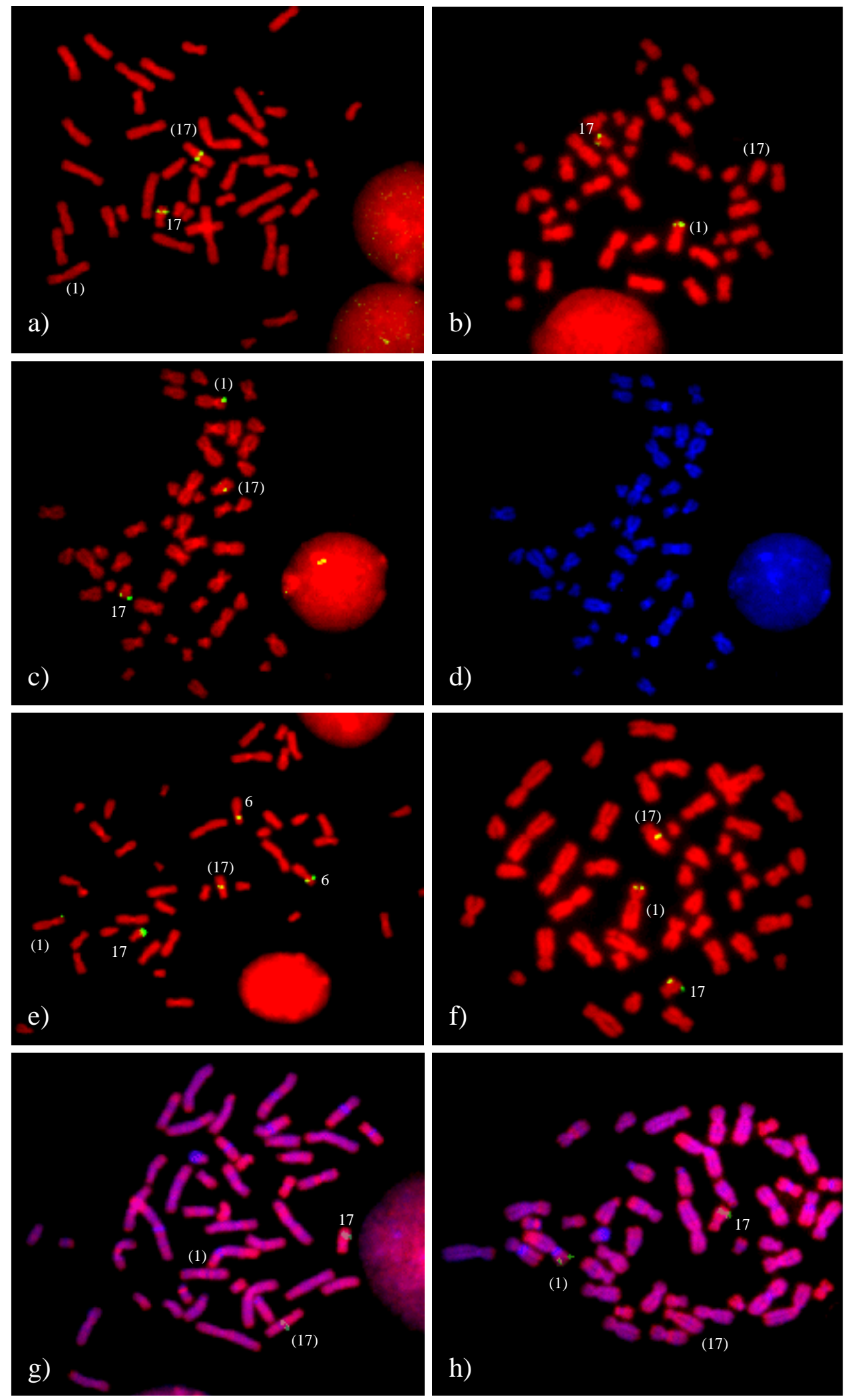

Abb. 20: Beispiele für FISH-Analysen mit PACs auf Metaphasen von Proband AS. a) 112L5; b) 293H13; c) 81B9; e) 222L3; f) 83D4; g) 120L21; h) 250M4. d) Gegenfärbung der in c gezeigten Metaphase mit DAPI. In a), b), c), e) und f) sind die Chromosomen mit Propidiumiodid gegengefärbt, in g) und h) mit Propidiumiodid und DAPI. 


\subsection{Isolierung von PAC-Endfragmenten und Erzeugung neuer STS-Stellen}

\subsubsection{Isolierung von PAC-Endfragmenten}

Um durch PCR-Analysen Überlappungen von benachbarten PACs feststellen, bzw. um ein Durchmustern der PAC-Bibliothek durchführen zu können, sollten möglichst endständige STSStellen für geeignete PAC-Klone generiert werden. Da nach direkter Sequenzierung der PACInserts mit Vektorprimern nur in wenigen Fällen Sequenzen erhalten wurden, die für die Erzeugung einer STS die nötige Qualität aufwiesen, wurden Endfragmente der PACs hergestellt und diese für die Sequenzierung eingesetzt. Für die Isolierung von PAC-Endfragmenten wurden die Enden der jeweiligen PAC-Inserts durch eine Alu-PCR (2.2.10.2) unter Verwendung verschiedener Alu-Primer (s. Tab. 11) in Kombination mit spezifischen Vektorprimern der PACs (s. Tab. 10) dargestellt. Tabelle 27 gibt eine Übersicht über die nach Alu-VektorPCR darstellbaren PAC-Endfragmente und Abbildung 21 zeigt ein Beispiel für eine Alu-PCR. Die Endfragmente wurden aus dem Gel isoliert (s. 2.2.7.1.) und anschließend z.T. sequenziert (s. 2.2.14), wobei die spezifischen Vektorprimer als Sequenzierungsprimer eingesetzt wurden. Neue STSs wurden anhand der erhaltenen Sequenzdaten durch Wahl geeigneter Primer generiert.

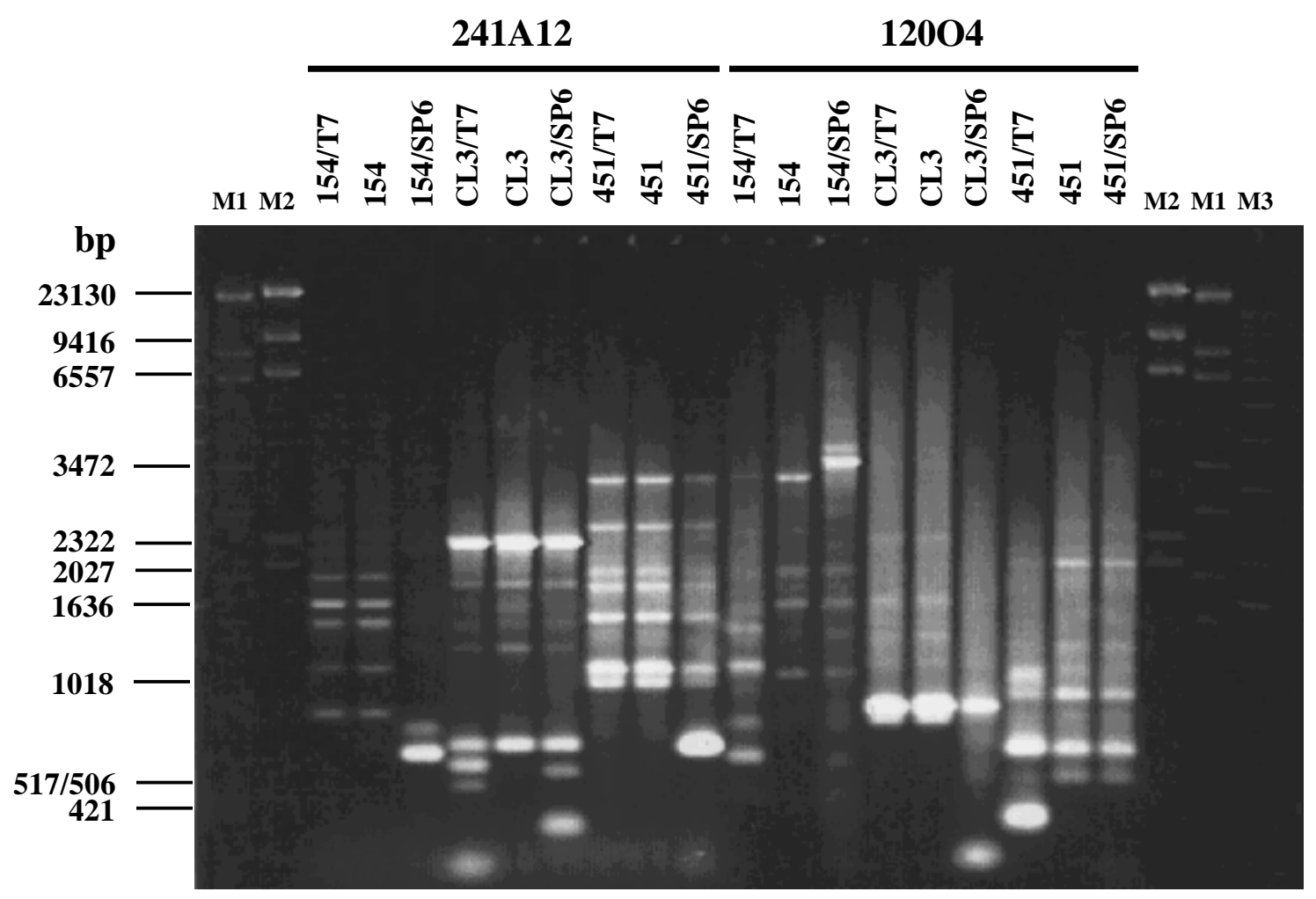

Abb. 21: Beispiel für eine Alu-Vektor-PCR zur Generierung von Endfragmenten der PACs 241A12 und 12004. Die vektorspezifischen Primer T7 und SP6 wurden jeweils mit den Alu-Primern 154, CL3 und 451 kombiniert. (M1: lambdaDNA/Eco130I-gespalten; M2: lambda-DNA/HindIII-gespalten; M3: 1 kbLeiter). 
Tab. 27: PAC-Endfragment-Darstellung mit Hilfe der Alu-Vektor-PCR

\begin{tabular}{|c|c|c|c|}
\hline PAC & Vektorprimer & Alu-Primer & Endfragment $(\mathrm{kb})$ \\
\hline \multirow[t]{2}{*}{ 188D1 } & $\mathrm{T} 7$ & CL3 & 1,3 \\
\hline & SP6 & 154 & 1,2 \\
\hline \multirow[t]{2}{*}{30609} & $\mathrm{~T} 7$ & 154 & 0,4 \\
\hline & SP6 & CL3 & 2,7 \\
\hline \multirow[t]{6}{*}{$209 \mathrm{I} 3$} & $\mathrm{~T} 7$ & 451 & 1,$0 ; 0,3$ \\
\hline & $\mathrm{T} 7$ & $3^{\prime}$ & 1,$0 ; 0,3$ \\
\hline & SP6 & 154 & 1,1 \\
\hline & SP6 & CL2 & 1,1 \\
\hline & SP6 & 451 & 1,1 \\
\hline & SP6 & $3^{\prime}$ & 1,1 \\
\hline \multirow[t]{7}{*}{$58 \mathrm{~J} 13$} & $\mathrm{~T} 7$ & $5^{\prime}$ & 0,6 \\
\hline & $\mathrm{T} 7$ & CL2 & 1,3 \\
\hline & $\mathrm{T} 7$ & CL3 & 0,66 \\
\hline & SP6 & 450 & 0,4 \\
\hline & SP6 & 154 & 1,3 \\
\hline & SP6 & CL2 & 1,3 \\
\hline & SP6 & 451 & 1,3 \\
\hline \multirow[t]{7}{*}{ 112L5 } & $\mathrm{T} 7$ & $3^{\prime}$ & 0,56 \\
\hline & $\mathrm{T} 7$ & CL2 & 1,$5 ; 0,56$ \\
\hline & $\mathrm{T} 7$ & 451 & 1,$5 ; 0,56$ \\
\hline & $\mathrm{T} 7$ & 154 & 0,56 \\
\hline & SP6 & 154 & 1,$6 ; 1,5$ \\
\hline & SP6 & CL2 & 1,6 \\
\hline & SP6 & 451 & 0,18 \\
\hline \multirow[t]{4}{*}{$120 \mathrm{O} 4$} & $\mathrm{~T} 7$ & 154 & 1,$5 ; 0,65$ \\
\hline & $\mathrm{T} 7$ & 451 & 1,$1 ; 0,35$ \\
\hline & SP6 & 154 & 3,5 \\
\hline & SP6 & CL3 & 0,3 \\
\hline \multirow[t]{2}{*}{ 7B12 } & $\mathrm{T} 7$ & CL3 & 1,$9 ; 0,5$ \\
\hline & SP6 & CL3 & 0,56 \\
\hline \multirow[t]{4}{*}{$293 \mathrm{H} 13$} & $\mathrm{~T} 7$ & 154 & 1,$3 ; 0,8$ \\
\hline & $\mathrm{T} 7$ & CL3 & 1,$3 ; 0,56$ \\
\hline & $\mathrm{T} 7$ & 451 & 0,5 \\
\hline & SP6 & CL3 & 1,$3 ; 0,56$ \\
\hline \multirow[t]{4}{*}{ 241A12 } & $\mathrm{T} 7$ & CL3 & 0,$6 ; 0,5 ; 0,29$ \\
\hline & SP6 & 154 & 0,65 \\
\hline & SP6 & 451 & 0,7 \\
\hline & SP6 & CL3 & 0,$56 ; 0,34$ \\
\hline 83D4 & $\mathrm{T} 7$ & CL3 & 0,5 \\
\hline
\end{tabular}


Tab. 27: Fortsetzung

\begin{tabular}{llll}
\hline PAC & Vektorprimer & Alu-Primer & Endfragment $(\mathrm{kb})$ \\
\hline 83D4 & T7 & $5^{\prime}$ & 0,8 \\
& SP6 & 451 & 0,45 \\
& SP6 & $3^{\prime}$ & 0,45 \\
& SP6 & CL2 & 0,6 \\
81B9 & SP6 & CL3 & 1,5 \\
& T7 & 154 & 0,3 \\
& T7 & CL2 & 0,3 \\
& SP6 & CL3 & 0,$75 ; 0,2$ \\
\hline
\end{tabular}

\subsubsection{Erzeugung neuer STS-Stellen}

Mit den über Sequenzierung von PAC-Endfragmenten erhaltenen Sequenzen wurde ein Sequenzvergleich in der EMBL/GenBank-Datenbank durchgeführt, um auf diese Weise Homologien zu bekannten Sequenzen zu identifizieren. Dabei wurden z.T. Homologien zu hochrepetitiven Alu-Sequenzen festgestellt. Sequenzabschnitte mit Homologie zu Alu-Sequenzen eignen sich jedoch nicht für die Generierung von STS-Stellen. Daher werden solche Homologien im folgenden aufgeführt, um aufzeigen zu können, warum für einige Sequenzen keine Primer abgeleitet werden konnten. Auf Homologien zu vom Whitehead Institute sequenzierten BAC-Klonen wird dagegen zunächst nicht eingegangen, da den auf diese Weise identifizierten BACs ein eigenes Kapitel (s. 3.12) gewidmet ist.

Der Übergang vom Vektor zum Insert kann bei direkter Sequenzierung von PAC-Endfragmenten mit den Primern T7 und Sp6 in der Regel nicht dargestellt werden, da zwischen dem T7-Primer und dem Insert-Beginn nur 9 bp vorhanden sind und zwischen dem Sp6-Primer und dem Insert-Beginn 12 bp.

\subsubsection{Generierung von STS-Stellen für die Insert-Enden von PAC 188D1}

Die Sequenzierung des T7/CL3-Endfragmentes mit dem T7-Primer ergab folgende Sequenz (115 bp):

1 CTCCCAAAGT GCTGgGATtA CAgGCATGA CCACCGCGCC CGGCCGAAgG TTtTCTAATA

61 ACTGAATCAA GCACCAGTCT TAAATTTAAA TGAATNAAAA TGAAAGAAAA tTTAA

Nach einem Sequenzvergleich in der EMBL/GenBank-Datenbank zeigte sich, daß die ersten 45 bp der Sequenz eine 97 \%ige Homologie zu humanen Alu-Sequenzen aufweisen. Da nur 70 bp der Sequenz nicht repetitiv waren, wurden keine Primer abgeleitet.

Aus der SP6-Sequenzierung des SP6/154-Endfragmentes wurde folgende Sequenz erhalten (357 bp):

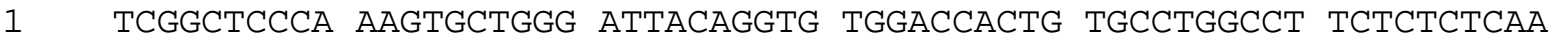

61 TTTCTAACAG CACTGGCATC ATCCAGACCC TGGAAGGGGA GAGGGCTCAG GGCCCGCGAT

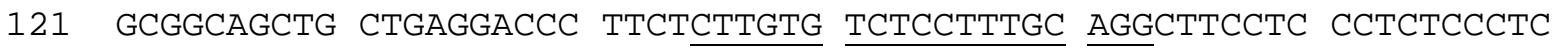


181 CAgtTtTAgA GGCTCCCACC AgGgACCCCT TTGGCAGCAg GgACTTCTCC CCATCCCAGT

241 GATGTCATCA AgTCCTCTTA TTTTCCAAGA AGCATGCAGg CCCCAGTAAg tTGGAACCCA

301 CTGCAAAACA GCTGCGTTAC TCTCAGAAAG AAACAGATGg ACTTGAGgGA AACGGGA

Der Sequenzvergleich in der EMBL/GenBank-Datenbank ergab für die ersten 44 bp eine 92 $\%$ ige Homologie mit humanen Alu-Sequenzen. Die aus der Sequenz abgeleiteten Oligonukleotide, die den Locus 188SP6 amplifizieren sind unterstrichen. Das mit den gewählten Primern erzielte PCR-Produkt weist eine Länge von 184 bp auf.

\subsubsection{Generierung von STS-Stellen für die Insert-Enden von PAC 30609}

Die Sequenzierung des T7/154-Endfragmentes resultierte in einer Sequenz, die für die Generierung einer STS-Stelle nicht die nötige Qualität aufwies.

Für das SP6/CL3-Endfragment ergab sich aus der Sequenzierung mit dem SP6-Primer folgende Sequenz (353 bp):

1 AATTGTTTCC CAAATgTtTg GCTCCTTTTC CCCCTCATAA TTACTgtggg AATACAgTGT

61 ACGTCACTTA AAAAAAATAA GGCACAGCTT TGCTGTTTAT TTACCTACAg CTTTGTGTTT

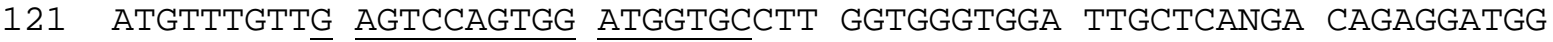

181 ACAGCAATCT TGGGTCGTGG AGCATTTTGG TGGAGAACAC TTGAGGAATC TGCCAAAAGC

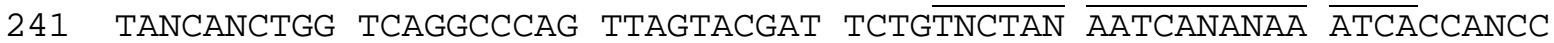

301 TTCGACCAAA TTNGgGtCCA AAgCANGgCT CTGCACCCAA NTGATAACGg GAC

Der Vergleich in der EMBL/GenBank-Datenbank zeigte keine nennenswerten Homologien zu bekannten Sequenzen. Die für die Generierung der STS-Stelle 306SP6 gewählten Primersequenzen sind unterstrichen und ergeben ein 105 bp langes PCR-Produkt.

\subsubsection{Generierung von STS-Stellen für die Insert-Enden von PAC 209I3}

Aus der Sequenzierung des T7/451-Endfragmentes mit dem T7-Primer wurde folgende Sequenz erhalten (331 bp):

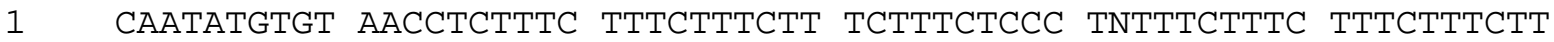

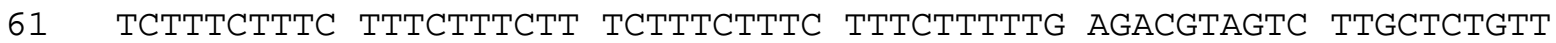

121 ACTCAGACTG GANTGCANTG GCGCAATCTT TGACTCACTG CAACCTCTAC CTCCTGGGTT

181 CAAGCAATTC TCTGCCTCAG CCTCCCGAGT ACCTGTGATT CCAGGNACCT GCTACCACGT

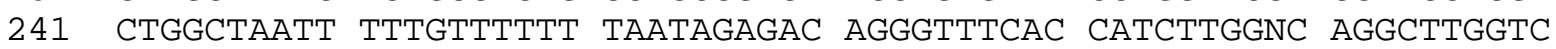

301 TTNAAACTCC TNTCCTCCGT GGANCCATCC G

Der Sequenzvergleich in der EMBL/GenBank-Datenbank ergab eine 84 \%ige Homologie zu Alu-Sequenzen für die Basenpaare 100-225 und eine 90 \%ige Homologie zu diesen Sequenzen für die Basenpaare 264-295, daher wurde diese Sequenz nicht zur Generierung einer STS verwendet.

Die aus der SP6-Sequenzierung des SP6/154-Endfragmentes erhaltene Sequenz ist im folgenden dargestellt (212 bp):

1 CAgGAgATCA AgACCATCCT GgCTAACATG GTGAAACCCC GTCTCTACTA AAAAAACAAA

61 AAATTAGCCG GGCGTGGTGG TGGGCACCTA TAGTCCCAGC TACTCAGGAG GCTGAGGCAG

121 GAgAATGGCA TGAACCCGgG AgGCGgAgCt TGCAgtgAgC CGAgAtTgCG CCACTGCACT

181 CCAGCCTGGG TGACACAGCG AGACTCAATC TC 
Durch einen Sequenzvergleich in der EMBL/GenBank-Datenbank konnte für die Basenpaare 10-48 eine 97 \%ige Homologie und für die Basenpaare 63-205 eine 94 \%ige Homologie zu Alu-Sequenzen festgestellt werden. Diese Sequenz eignete sich demnach nicht zur zur Herstellung einer STS.

\subsubsection{Generierung von STS-Stellen für die Insert-Enden von PAC58J13}

Die Sequenzierung der T7/5'- bzw T7/CL3- Endfragmente mit dem T7-Primer ergab folgende Sequenz (605 bp):

$\begin{array}{lllllll}1 & \text { GAGCACAGGA } & \text { TTCGAGACCA } & \text { GCCTGGCCAA } & \text { CACGACAAAA } & \text { CCCCATCTCT } & \text { ACTAAAAATA } \\ 61 & \text { CGAAAATAG } & \text { CCGGGCATTG } & \text { TGGTACTTGT } & \text { CTGTAATCCC } & \text { AGCTACTCAG } & \text { CAGGCTGAGG } \\ 121 & \text { CAGGAGAAT } & \text { GCTTGAAAC } & \text { AGGAGGTGGA } & \text { GGTTGCAGTG } & \text { AGCCGAGATG } & \text { GCGCCACTGC } \\ 181 & \text { CCTCTAGCCT } & \text { GGGCGACACA } & \text { GCAAGACTCT } & \text { GTCTCAAAAC } & \text { ACACAGACAC } & \text { ACACATGCGC } \\ 241 & \text { ACACACACAA } & \text { TTATTCCTAG } & \text { GTGCTGGAGG } & \text { TTTTTTTGT } & \text { TGTTGTTCCT } & \text { GGAATCTTCT } \\ 301 & \text { GCTTCATTAA } & \text { AATTTTCAAA } & \text { AATATGTAAA } & \text { ATGCAACCAG } & \text { GTTAAGAAAC } & \text { AGAACTTTAT } \\ 361 & \text { CTACAACCAA } & \text { TACATCAGAT } & \text { GCTTGTGTGT } & \text { CCAACTCCCT } & \text { GGCAATCAAT } & \text { ACTTTTGGC } \\ 421 & \text { TAAACATTCC } & \text { CTTGTTTTC } & \text { CTTATACTTT } & \text { TAGAACCTAT } & \text { GTGTGTGCAT } & \text { CCCAAACTGT } \\ 481 & \text { ATAAGTTTGC } & \text { CTTTTGAAAA } & \text { CTCAGCATAG } & \text { GCCGGGCGCG } & \text { GTGGCTCATG } & \text { CTTGTAATCC } \\ 541 & \text { CAGCACTTTG } & \text { GGAAGCCGAG } & \text { GTGGGCAGAT } & \text { CATGAGGTTG } & \text { GGAATCGGAG ACCAGCCTGG } \\ 601 & \text { CCAAC } & & & & \end{array}$

Nach einem Sequenzvergleich in der EMBL/GenBank-Datenbank zeigte sich, daß die Basenpaare 11-218 eine 87 \%ige Homologie und die Basenpaare 511-553 eine $95 \%$ ige Homologie zu Alu-Sequenzen besitzen. Die unterstrichenen Oligonukleotidsequenzen wurden für die Generierung der STS-Stelle 58T7 ausgewählt und amplifizieren ein PCR-Produkt 136 bp. Die Sequenzen der Alu-Primer 5' und CL3 sind fett dargestellt (vgl. Tab. 11).

Für die erhaltenen SP6-Endfragmente ergab sich aus der Sequenzierung mit dem SP6-Primer folgende Sequenz (253 bp):

1 AgCCTGACCA ACATGgTGAA ACCCCCTCTC TACTAAAAAT ACAAAATTAG CTGAgCATGg

61 TGgCGCGCAC CTGTAGTCCC AgtTACTCAg AAgGCTGAgA CAgGAgAACC GCTTGAACAC

121 GgGAAGCAGA GgTtGCAGTG AgCCAAGATC GCGCCATTGC ACTCCAGCCT GgGtgAtAgA

181 GCGAGACTCC ATCTCAAAAA AAAAAAAAAA AAATTAGCCA GGTGTGGTGG CATGTGTGTG

241 CCCTGTANTC CCA

Nach einem Sequenzvergleich dieser Sequenz in der EMBL/GenBank-Datenbank zeigte sich, daß die ersten 196 bp eine 89 \%ige Homologie zu Alu-Sequenzen aufweisen, daher wurden aus dieser Sequenz keine Primer abgeleitet.

\subsubsection{Generierung von STS-Stellen für die Insert-Enden von PAC 112L5}

Aus der Sequenzierung der T7-Endfragmente mit dem T7-Primer wurde folgende Sequenz erhalten (443 bp):

1 CCCACCTCAA CCCCTTCAAG TAGCTACAGg TGCTCACTAC CATGCCCAGC TAATTTTTTT

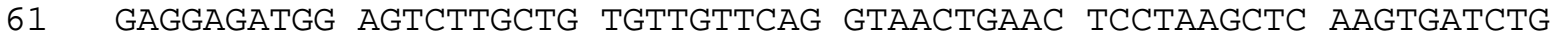

121 CCTGCCTGgG CCTCCCTAAg TGCTGgGATg ACAgGtATGA GCCACTTACA CCCGgCCATA

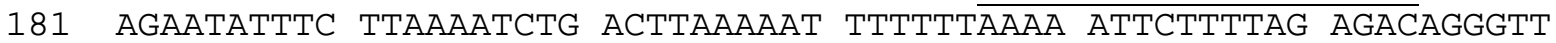


241 TCACCATGTA GGCTAGgCTG GTCTTCAATT CCTACCCTCA GgTGATCTGC CCACCTTGGC

301 CTCCCAAAGT GCTTGGATTA CAGGTGTGAg CCACTTTGGC CAAAATCCGA CACATTTATA

361 AATTTCTACA ATAATTTAAA GTACCAAAAA TATTCCCA AA ACATTTCATC ATGATTTATA

421 GTCTCTCAGG GAAAATAAAT TAG

Durch einen Sequenzvergleich in der EMBL/GenBank-Datenbank wurden keine Homologien zu repetitiven Sequenzen festgestellt. Die zur Konstruktion der STS-Stelle 112T7 genutzten Oligonukleotidsequenzen sind unterstrichen und ergeben ein PCR-Produkt von $201 \mathrm{bp}$.

Die Sequenzierung der SP6-Endfragmente mit dem SP6-Primer resultierte in folgender Sequenz (486 bp):

1 TACAGGCATG AGCCACCGCA CCTGGCAGTA CATAGCATTT TACACACTAT GTAGgATATA

61 CATTGCAAAC TAGTAGACTC TGgGCTATAT CCAAACTGCC TATTTTTTAT TTATTTTTTC

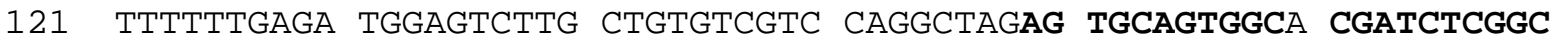

181 TGACTGCAAC CTCCACCTCC TGGGTTCAAG CAATTCTCCT GCCTCCCTAG TAGCTGGGAT

241 TGCAGGTGCA CAGCGCCACG CCCAGCTAAT TTTTGTACTT TTAGTGGAGA CGgGGTTTCA

301 CCATGTTGGC CAGAATGGTC TCAAACTCCT GACCTCAGGT GATCAACCCA CCCTAGACTC

361 CCATAGTGTT GGGATTACAG GTGTGAGCCA CCACACCGGG CCAAGACTGC TTATATTTTT

421 ATCAATCTGT ACTGTTTTGT TCTGAGACAG GGTCCTGCTC TGTCNCACAT GCTGGAGTGT

481 CAATAT

Nach einem Sequenzvergleich in der EMBL/GenBank-Datenbank zeigte sich, daß die Basenpaare 121-392 eine $85 \%$ ige Homologie zu Alu-Sequenzen aufweisen. Die aus der Sequenz abgeleiteten Primer, die den Locus 112SP6 amplifizieren sind unterstrichen. Das PCR-Produkt wies bei PCR mit den PAC-Klonen 112L5, 58J13 und $120 \mathrm{O} 4$ das erwartete Fragment von 462 bp auf, dieses PCR-Produkt war jedoch mit genomischer DNA nicht darstellbar, so daß dieser Locus nicht für weitere Analysen verwendet wurde. Die Bindungsstelle des Alu-Primers 451 ist fett gedruckt, wobei diese nicht exakt der Primer-Sequenz entspricht und Primer 451 somit in der PCR nicht exakt angelagert wurde (vgl. Tab. 11).

\subsubsection{Generierung von STS-Stellen für die Insert-Enden von PAC 120O4}

Folgende Sequenz wurde bei der Sequenzierung der T7-Endfragmente mit dem T7-Primer erhalten (493 bp):

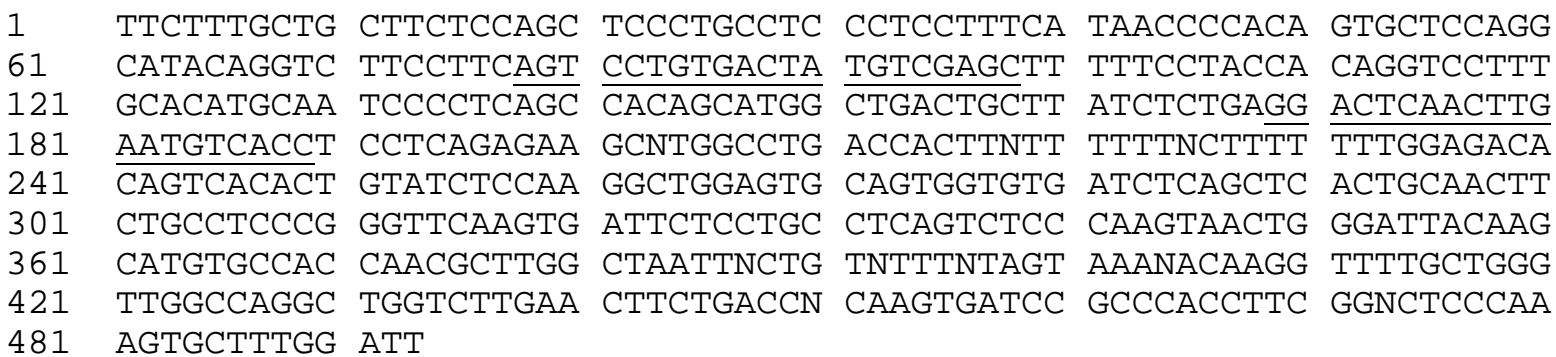

Bei einem Sequenzvergleich in der EMBL/GenBank-Datenbank wurde für die Basenpaare 260486 eine 84 \%ige Homologie zu Alu-Sequenzen festgestellt. Die Primer, die den Locus 120T7 amplifizieren sind unterstrichen. Das entsprechende PCR-Produkt weist für diesen Locus eine Länge von 112 bp auf. 
Die Sequenzierung des SP6/CL3-Endfragmentes mit dem SP6-Primer ergab folgende Sequenz (137 bp):

1 CtTCATCACA AtCCtgtAtg gCAAAtAAgA ACtAAtAtTC Atggtgggtg CggtggctCA

61 CACCTGTAAT CCCGgCACTT TGgGAgGCCG AgGAgGgCAg ATCACAAGgT CAGGAGTTCA

121 AGACCAGCCT GGCCAAC

Nach einem Sequenzvergleich in der EMBL/GenBank-Datenbank zeigte sich, daß diese Sequenz für die Basenpaare 50 - 137 eine 91 \%ige Homologie zu Alu-Sequenzen aufweist, daher wurde diese Sequenz nicht zur Erzeugung einer STS verwendet. Die Sequenz des CL3Primers ist fett gedruckt.

\subsubsection{Generierung von STS-Stellen für die Insert-Enden von PAC 7B12}

Aus der T7-Sequenzierung der T7-Endfragmente resultierte folgende Sequenz (354 bp):

1 TCAAAGCGAA AgtgGCCTAT GACTGTGCCA CTGCACTCCA GCCTGgGtgG CAGAgtgAgA

61 CCCTATCTCA ATAAATAATA GTAATAATAA TAATAGCAGT AATGTGGAAT GATTTAAGTT

121 CCCTGAAAAA GCAGTAACAT GGGATAAGTA CTCAGAGAAA GAACTGCTTC TAGCCCAGGA

181 TGCATAgCAA TTGgGATATC CTCCCTTGAA CTGGgTCTTG AAggAtgAgt AgGATtTGCC

241 AtgtgGCAAA CAGAACCAGA CAGAAGAgGT GAGAGgTGTG GGGCAAAGAA GCCATCTAGT

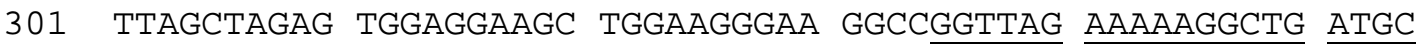

Durch einen Sequenzvergleich in der EMBL/GenBank-Datenbank wurde zunächst nur eine 96 \%ige Homologie der ersten $71 \mathrm{bp}$ zu Alu-Sequenzen gefunden. Die Primer, die den Locus 7T7 amplifizieren, sind unterstrichen. Das erhaltene PCR-Produkt hat eine Größe von 253 bp Die SP6-Sequenzierung des SP6/CL3-Endfragmentes ergab eine Sequenz, die für die Generierung einer STS nicht die nötige Qualität aufwies.

\subsubsection{Generierung von STS-Stellen für die Insert-Enden von PAC 293H13}

Aus der Sequenzierung der T7/154-Endfragmente wurde folgende Sequenz erhalten (291 bp):

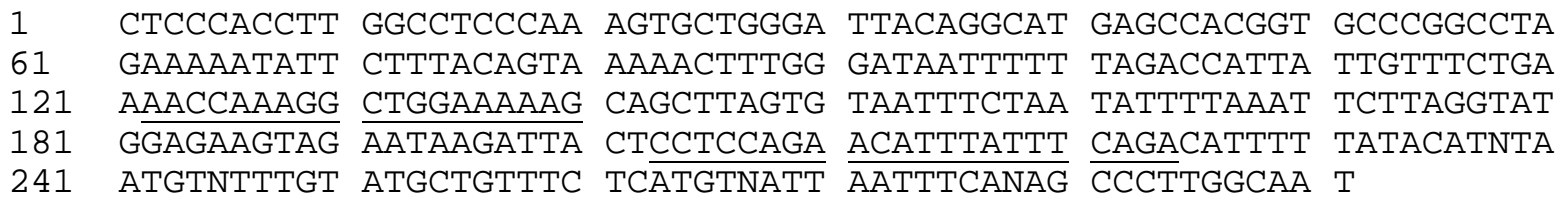

Bei einem Sequenzvergleich in der EMBL/GenBank-Datenbank wurde für die ersten 58 bp eine $91 \%$ ige Homologie zu humanen Alu-Sequenzen festgestellt. Die aus der Insert-Sequenz abgeleiteten Primer, die den Locus 29377 amplifizieren, sind unterstrichen. Das zu diesem Locus korrespondierende PCR-Produkt weist eine Länge von 103 bp auf.

Die Sequenzierung der SP6-Endfragmente mit dem SP6-Primer ergab folgende Sequenz (195 bp):

1 TTCTGCCTCT AAATGTTTAT TAAgTTTTTT CTTCATATAA AAGTAACCAA TGCTCTTTGT

61 AgAAAATTA GAgGACGgAg AAgTGTANAg AAgACAAAAT ATtTTGTGAT TCCCATCACT

121 CAGAAAAGT AACATTTTGC CATATTTACT TTTAATCTCT TTGCTAACTT TGTGGAGTGA

181 CNGAAGTCTC AGGAT 
Durch einen Sequenzvergleich in der EMBL/GenBank-Datenbank wurden keine Homologien zu repetitiven Sequenzen festgestellt. Die gewählten Primer, die den Locus 293SP6 amplifizieren, sind unterstrichen. Das entsprechende PCR-Amplifikat hat eine Größe von 114 bp.

\subsubsection{Generierung von STS-Stellen für die Insert-Enden von PAC 241A12}

Für die T7-Endfragmente ergab sich aus der Sequenzierung mit dem T7-Primer folgende Sequenz (407 bp):

1 CTAATCGAgA TGACACTGgC TtgtAtCACG GAgGgACAgT GgGAATGgAg AgAAACTGAT

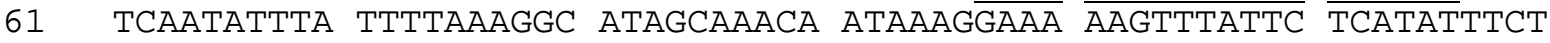

121 AgCTTGAgCA GCTGgTgGgA CAgtAATCCC ATtTACTAAg ATGAgAACAC TAGATGAAgA

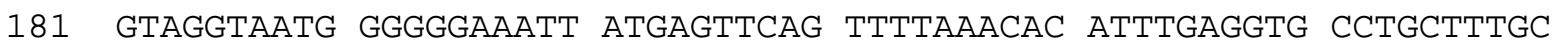

241 AgACATGTCC AGGAGTCTGC TGGACATACA GAACTGAATG TGGACAGAAG GAATTCAGAC

301 ACAGGTCTGA TGGCAACTAA AgTCAATAAg CTCACATGTG GCTTGTAGCT AgAAAgGgGA

$361 \overline{\text { GTAGAAAGCT }} \overline{\text { GTNTAGATTT AAAAGTNAG TTTAGTTCAT TTGGAAA }}$

Der Sequenzvergleich in der EMBL/GenBank zeigte keine Homologie zu repetitiven Sequenzen. Die aus dieser Sequenz abgeleiteten Primer, die den Locus 241T7 amplifizieren, sind unterstrichen. Das korrespondierende PCR-Produkt weist eine Länge von 283 bp auf.

Die Sequenzierung der SP6- Endfragmente mit dem SP6-Primer resultierte in folgender Sequenz (327 bp):

1 GAgACAgtgg GACtggaggA CGgtgtgtgg TGACCACACA AggCAgAgAA CAtAgCCCTG

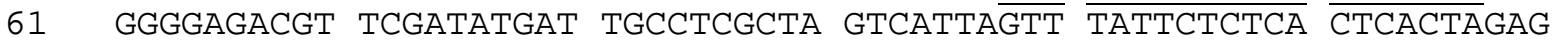

121 ATCCGTCTCT GCATTCAAAC AgGAGAAAgG AGAAAGAgGg GTTGgGgGtg AgtATGgTCT

181 TTGGATCTGA ACCTGGATCC CTGACATAGg TTGGTGTCGg GTGGgAgCCG GGTGAGAGGC

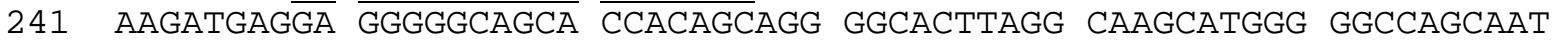

301 GAAGACGGAT AGTGAGTCAA GGAAAAC

Nach einem Sequenzvergleich in der EMBL/GenBank-Datenbank konnten keine Homologien zu bekannten Sequenzen festgestellt werden. Die anhand dieser Sequenz konstruierte STS 241SP6 läßt sich mit den unterstrichenen Primern amplifizieren. Das erhaltene PCR-Produkt weist eine Größe von 170 bp auf.

\subsubsection{Generierung von STS-Stellen für die Insert-Enden von PAC 83D4}

Aus der Sequenzierung der T7-Endfragmente mit dem T7-Primer wurde folgende Sequenz erhalten (443 bp):

1 AACCTCTGCC TCCCAGGTTC AAgCGATTCT CCTGCCTCAg CCTCCCGCGT AgtTGGGACT 61 ACAGGCACGT GCCATCACAC CCGACTAATT TTTGTAGTTT TAGTAGAGAC GAGGTTTCAC

121 TATGTTGGCC AGGATGGTCT CAAACTCCTG ACCTCAGGTG ATCCGCTCGC TTCGGCCTCC

181 CAAAATGCTG GGATAACAGG CATGAGCCAC CGCGCTCAGC CCCCCCAGTG ATCTTCCTTT

241 GAGGAAAAGC CACGgGgTGC TTTCTCTCTT CTGTAGCAAg GAAGATGgTT TCTAAGAGGG

301 TATTTTAAAG GCAGTTTACC TAAAATAAAA GTGAAAGGCC AGgCAAgGTG ACTTATGCCT

361 GTAATCCCAG TACTTTGGGA AGCCGANTGG GGAGAATANC TTGAAGCCAG GAGTTCAAGA

421 CCANCCT $\overline{\text { GGC }} \overline{\text { NAACATAGTG }} \overline{\mathrm{AAA}}$ 
Durch einen Sequenzvergleich in der EMBL/GenBank-Datenbank wurden keine Homologien $\mathrm{zu}$ repetitiven Sequenzen gefunden. Die Primer, die den Locus $83 \mathrm{~T} 7$ amplifizieren, sind unterstrichen. Das PCR-Produkt von diesem Locus weist eine Größe von 149 bp auf.

Für die SP6-Endfragmente ergab sich aus der Sequenzierung mit dem SP6-Primer folgende Sequenz (322 bp):

1 CCTTGACTTT CATCTTTCTT GgtgACCTGA AAgtTGCTTA AgGtTgtggC gCtATCATCC

61 TAgTGTTGA GCCAAGACAA GTGATCTGCA GTCATACCTC TCATGACACA TGAAACAGTC

121 TTCTTAGgCT CAAGTATTC $\overline{\text { ATGAAATGC }}$ CTAAgTACCA GTGAgCTAAT TACAAGAGGC

181 AACTGCTACC ATtTAGgAAA ATtATAATTA CAGTGgTTCT TGCAAGTAGA TGATGAGCAA

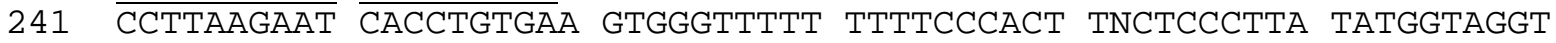

301 GGTATTTTTT TTTTTTTTTT TT

Durch einen Sequenzvergleich in der EMBL/GenBank-Datenbank wurden keine nennenswerten Homologien festgestellt. Die Primer, die den Locus 83SP6 amplifizieren, sind unterstrichen. Das mit diesen Primern erhaltene PCR-Produkt hat eine Größe von 128 bp.

\subsubsection{Generierung von STS-Stellen für die Insert-Enden von PAC 81B9}

Die Sequenzierung der T7-Endfragmente mit dem T7-Primer ergab folgende Sequenz (256 bp):

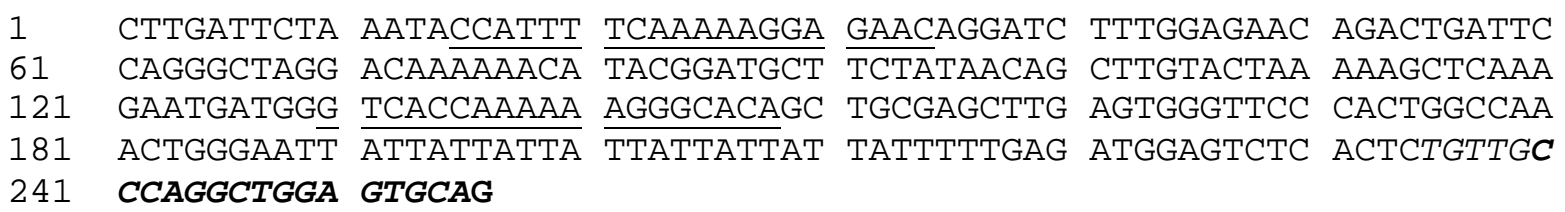

Durch einen Sequenzvergleich mit der EMBL/GenBank-Datenbank wurde eine 92 \%ige Homologie der Basenpaare 195-256 zu Alu-Sequenzen festgestellt. Die PCR-Primer, die den Locus $81 \mathrm{~T} 7$ amplifizieren, sind unterstrichen. Der reverse Primer dieser STS liegt zwar in einem Bereich, der Homologie zu Alu-Sequenzen aufweist, dieser Primer wurde jedoch so gelegt, daß sich die größtmöglichen Abweichungen zu Alu-Sequenzen im 3'-Bereich dieses Primers befinden. Das zu diesem Locus korrespondierende PCR-Produkt weist eine Länge von 134 bp auf. Die Sequenz des Alu-Primers 154 ist kursiv, die von CL2 fett dargestellt, diese Primer überlappen in einem Bereich von 16 bp miteinander.

Aus der Sequenzierung der SP6-Endfragmente mit dem SP6-Primer wurde folgende Sequenz erhalten (416 bp):

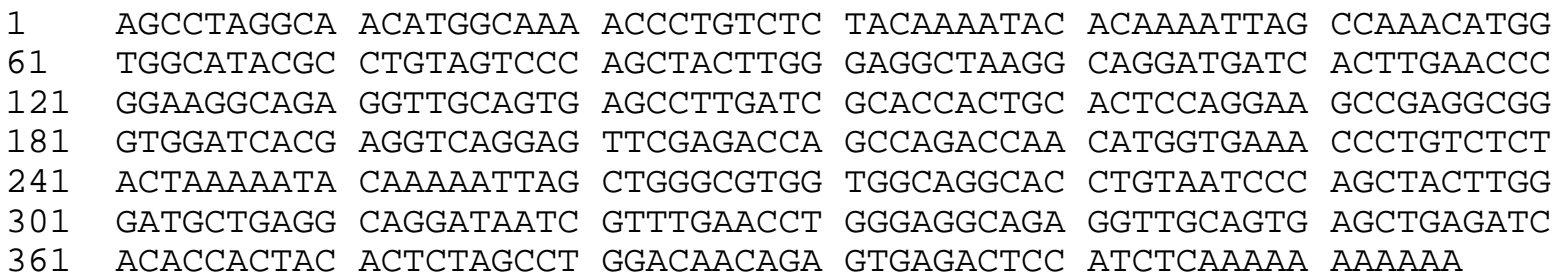

Über einen Sequenzvergleich in der EMBL/GenBank-Datenbank wurde festgestellt, daß die Basenpaare 171 bis 413 dieser Sequenz eine Identität von $89 \%$ mit humanen Alu-Sequenzen 
aufweisen. Anhand der nicht repetitiven Sequenz konnten keine Primer abgeleitet werden, die sich zur Generierung einer STS eignen.

\subsection{STS- und EST-content-Kartierung der PAC-Klone}

Mittels der STS-/EST-content-Kartierung sollten die erhaltenen PAC-Klone auf den Gehalt an STSs und ESTs untersucht werden, um auf diese Weise eine überlappende Anordnung der verschiedenen PACs zu ermitteln. Für die Kartierung wurden STSs und ESTs aus der Literatur, sowie anhand von Sequenzdaten in dieser Arbeit generierte Marker eingesetzt. Dabei erfolgte die PCR-Analyse der einzelnen PACs mit den verschiedenen Markern in der Regel einmal mit PCR-Programm Nr. 1 und einmal mit Nr. 6 (s. 2.2.10.1), wobei jeweils eine Positivkontrolle mit genomischer DNA sowie eine Negativkontrolle ohne DNA mitgeführt wurde. Insgesamt wurden für die PCR-Analyse 24 PAC-Klone eingesetzt und jeweils mit bis zu 33 Loci analysiert.

Die Marker WI-9461, WI-9571, 7T7, 293SP6, 293T7, 2A3T3, KPNA2-E2 und KPNA2-3' wurden über PCR-Analysen sowohl auf distal als auch auf proximal zum Translokationsbruchpunkt des Probanden AS kartierten PACs lokalisiert. Daher wurde angenommen, daß diese Marker in der Region 17q23-q24 verdoppelt vorliegen. Über eine Sequenzierung der PCR-Produkte einzelner Klone (s. 3.10) wurde diese Vermutung schließlich bestätigt. Eine Entscheidung darüber, ob ein Klon den einen oder den anderen dieser Marker enthält, kann nur aufgrund einer Sequenzierung getroffen werden, oder dadurch, daß der entsprechende Klon weitere zu diesen Markern benachbarte Loci enthält, die nicht verdoppelt vorliegen. Die Ergebnisse der PCR-Analyse sind in Tabelle 28 dargestellt. Verdoppelt vorliegende Loci wurden in diese Tabelle zweimal eingetragen, wobei Marker, die nicht die Originalsequenz beinhalten, in Klammern gesetzt sind. Die PCR-Ergebnisse der PACs sind zudem dem YAC/PAC/CosmidContig (s. Abb. 22) zu entnehmen. 
Tab. 28: STS-/EST-/Gen-content-Kartierung von 24 PAC-Klonen und Cosmid CF20b und CF58. (+: positiv, -: negativ, o: positiv aufgrund duplizierter Regionen in 17q23-q24, ?: STS-Analyse unklar, ( ): schwache Signale, x: Signale aufgrund duplizierter Regionen in 17q21). Genloci sind in blau, ESTs in grün, in der Literatur beschriebene STSs in schwarz und in dieser Arbeit generierte STSs (sofern sie nicht gleichzeitig Genloci darstellen) in rot dargestellt.

\begin{tabular}{|c|c|c|c|c|c|c|c|c|c|c|c|c|c|c|c|c|c|c|c|c|c|c|c|c|c|c|c|c|c|c|c|c|c|c|c|c|c|c|c|c|c|c|c|c|c|c|c|c|c|c|c|c|c|c|c|c|c|c|}
\hline & \begin{tabular}{|l}
$\infty$ \\
$\omega$ \\
$\omega$
\end{tabular} & & $\begin{array}{l}\infty \\
\stackrel{\infty}{\infty} \\
\infty\end{array}$ & & $\stackrel{\omega}{\omega}$ & & $\underline{w}$ & $\begin{array}{l}\infty \\
\omega\end{array}$ & & & & & & & 怘 & & $\begin{array}{lll}\bar{\sigma} & 0 \\
0 & \vdots \\
0\end{array}$ & & & $\frac{n}{n}$ & 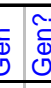 & $\begin{array}{l}0 \\
b \\
0\end{array}$ & $\frac{\infty}{5}$ & $\begin{array}{l}\bar{\Phi} \\
\mathbb{\Phi}\end{array}$ & $\begin{array}{l}\check{\Phi} \\
\mathbb{0} \\
\mathbb{0}\end{array}$ & 占 & & $\begin{array}{c}\infty \\
\infty \\
\infty\end{array}$ & क & $\begin{array}{c}\infty \\
\omega \\
\omega\end{array}$ & $\begin{array}{l}\omega \\
\omega\end{array}$ & & & 占 & & 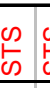 & & & $\begin{array}{c}\text { D. } \\
\text { D. } \\
\end{array}$ & שَّ & \begin{tabular}{c}
\multicolumn{1}{c}{} \\
$\overline{0}$ \\
0
\end{tabular} & & & $\begin{array}{c}\infty \\
\omega \\
\infty\end{array}$ & \begin{tabular}{|l} 
\\
$口$ \\
\end{tabular} & $\begin{array}{l}\omega \\
\omega \\
\omega \\
\end{array}$ & $\stackrel{\infty}{5}$ & $\stackrel{\omega}{\omega}$ & 告 & & $\begin{array}{ll}0 \\
0 \\
0\end{array}$ & & \begin{tabular}{c|c}
$p$ \\
$p$ \\
\end{tabular} & & & & & \\
\hline $\begin{array}{l}\text { PACs/ } \\
\text { Cos- } \\
\text { mide }\end{array}$ & $\begin{array}{l}\mathbb{E} \\
\mathbb{E} \\
\stackrel{\mathcal{Q}}{\mathcal{Q}} \\
\end{array}$ & $\begin{array}{l}\widehat{a} \\
\stackrel{1}{\alpha} \\
\tilde{z} \\
z \underline{z} \\
\underline{\alpha}\end{array}$ & 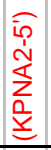 & & $\begin{array}{l}\widehat{\overline{0}} \\
\frac{1}{0} \\
\frac{1}{3} \\
3\end{array}$ & $\underset{\infty}{\stackrel{5}{\infty}}$ & 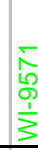 & $\begin{array}{l}0 \\
0 \\
0 \\
\text { న్ } \\
\end{array}$ & & & & & $\begin{array}{l}2 \\
0 \\
6 \\
\infty \\
\\
\frac{1}{0}\end{array}$ & & $\begin{array}{c}E \\
\\
\\
0 \\
\end{array}$ & $\begin{array}{l}N \\
\text { Dे } \\
0 \\
0 \\
\vdots \\
\end{array}$ & 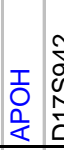 & & & & & 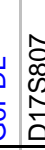 & $=\frac{N}{\Psi}$ & 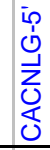 & 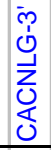 & 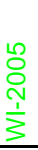 & $\begin{array}{l}\frac{m}{\infty} \\
\frac{\infty}{\infty} \\
\frac{N}{0} \\
\frac{D}{2}\end{array}$ & $\begin{array}{c}\overline{8} \\
\overline{8} \\
\frac{8}{2} \\
\frac{1}{5} \\
\end{array}$ & 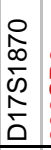 & $\begin{array}{l}0 \\
0 \\
0 \\
0 \\
0 \\
0\end{array}$ & $\begin{array}{l}n \\
\infty \\
\infty \\
0 \\
\underline{0} \\
\underline{1} \\
\end{array}$ & $\begin{array}{l}0 \\
0 \\
\infty \\
\infty \\
\infty \\
-1 \\
\end{array}$ & 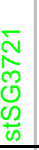 & 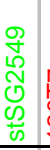 & & & F & & & & 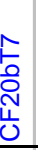 & 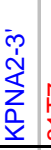 & & 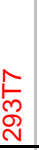 & $\begin{array}{l}\overline{5} \\
0 \\
0 \\
\frac{1}{3} \\
\end{array}$ & & $\underset{N}{E}$ & $\begin{array}{l}1 \\
\infty \\
\infty \\
\omega \\
0 \\
\end{array}$ & N & & & & $\begin{array}{l}0 \\
\frac{2}{2} \\
\text { L } \\
\end{array}$ & & & & & \\
\hline $245 \mathrm{~A} 13$ & & + & + & & & & & & & & & & & & & & & & & & & & & & & & & & & & & & & & & 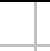 & - & - & & 0 & - & 0 & & & & & . & & & & & 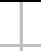 & & & & . & & \\
\hline $242 \mathrm{H} 16$ & - & - & - & - & - & + & + & - & - & 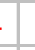 & - & - & - & - & - & & & & & & & & & & & & & & & & & & - & - & - & - & - & - & - & - & - & - & - & - & - & - & - & - & - & & $c$ & o. & - & & - & - & & \\
\hline 83D4 & + & - & - & - & - & + & + & $1+$ & )) &.+ & + & + & - & - & - & & & & & & & & & & & & & & & & & & - & - & - & - & - & - & - & - & - & - & - & 0 & - & - & - & - & 0 & ( & ) & o. & - & & - & - & & \\
\hline 188D1 & - & - & - & & - & - & - & - & - & . & & - & & & & & & & & & & & & & & - & - & - & + & + & + & + & - & - & - & - & - & - & - & - & - & - & - & - & - & - & - & - & - & & - & - & - & & & & & \\
\hline 30609 & - & - & - & & - & - & - & - & - & . & & - & & & & & & & & & & & & & & - & - & - & - & + & + & + & + & + & - & - & - & - & - & - & - & - & - & - & - & - & - & - & . & &. &.- & - & & & & & \\
\hline 20913 & - & - & - & & - & - & - & - & & . & & - & & & & & & & & & & & & & & - & - & - & - & - & - & - & + & + & - & - & - & - & - & - & - & - & - & - & - & - & - & - & . & & . &.- & - & & & & & \\
\hline 12004 & - & - & - & - & - & - & - & - & - & . & - & - & - & - & - & & & & & & & & & & & & & & & & . & & - & - & + & + & - & - & - & - & - & - & - & - & - & 0 & - & - & . & & . &.- & - & & - & - & & \\
\hline $58 \mathrm{~J} 13$ & - & - & - & - & - & - & - & - & - & . & - & - & - & - & - & & & & & & & & & & & - & - & - & - & - & - & - & - & - & + & + & + & - & - & - & - & - & - & - & - & 0 & - & - &. & &. &.- & - & & - & - & & \\
\hline 112L5 & - & - & - & - & - & - & - & - & - & . & - & - & - & - & - & & & & & & & & & & & & & & & & & & - & - & - & - & + & + & - & - & - & - & - & - & - & - & - & - & -1 & & - &.- & - & & - & - & & \\
\hline 222L3 & & - & - & & & & & & & & & & & & & & & & & & & & & & & & & & & & & & & & & & - & + & - & - & . & - & - & . & & & & & & & & & & & & & & \\
\hline $81 \mathrm{~B} 9$ & - & 0 & 0 & & & & & & & & & & & & & & & & & & & & & & & & & & & & & & & & & & - & + & + & + & + & + & + & - & & & & & & & & & & & & & & \\
\hline CF20b & - & 0 & - & & - & & - & - & - & . & & & & & . & & & & & & & & & & & & & & & & & & & 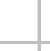 & & & - & - & - & - & + & + & + & - & - & & - & - & . & &. & - & - & & & & & \\
\hline 7B12 & 0 & - & - & - & 0 & - & - & - & - & ( & (o) & - & - & - & - & & & & & & & & & & & & & & & & & & - & - & - & 0 & - & - & - & - & - & - & - & + & + & + & + & + & + & &. & - & - & & - & - & & \\
\hline $293 \mathrm{H} 13$ & 0 & - & - & - & 0 & - & - & o & 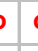 & & - & - & - & - & - & & & & & & & & & & & & & & & & & & - & - & - & 0 & - & - & - & - & - & - & - & + & + & + & + & + & + & & . & - & - & & - & - & & \\
\hline 15N15 & 0 & - & - & - & 0 & - & - & 0 & 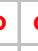 & & (o) & - & - & - & - & & & & & & & & & & & & & & & & & & - & - & - & - & - & - & - & - & - & - & - & + & + & - & ? & ? & ? & & ? & - & - & & - & - & & \\
\hline 15N17 & 0 & - & & - & 0 & - & - & - & - & & - & - & - & - & - & & & & & & & & & & & & & & & & & & - & - & - & - & - & - & & & - & - & & + & + & - & - & - & - & &. & - & - & & - & - & & \\
\hline 241A12 & - & - & - & - & - & - & o & 0 & 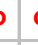 & & - & - & - & - & - & & & & & & & & & & & & & & & & & & - & - & - & 0 & - & - & - & - & - & - & - & - & - & + & + & + & + & . & + & + & + & & - & - & & \\
\hline CF58 & - & - & - & & - & & o & 0 & 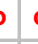 & & & & & & & & & & & & & & & & & & & & & & & & 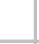 & & & & - & - & - & - & - & - & - & - & & & + & + & + & . & + & + & - & & & & & \\
\hline 131P15 & - & - & - & - & - & - & o & - & - & & - & - & - & - & - & & & & & & & & & & & & & & & & & & - & - & - & - & - & - & - & - & - & - & - & - & - & - & - & - & . & & + & + & - & & - & - & & \\
\hline 16A23 & $x$ & & & $x$ & $x$ & - & - & - & - & & (x) & - & - & - & - & & & & & & & & & & & & & & & & & & - & - & - & - & - & - & & & - & . & & $\mathbf{x}$ & $x$ & - & $\mathbf{x}$ & $\mathrm{x}$ & $x$ & &. & - & - & & - & - & & \\
\hline $30 \mathrm{~F} 12$ & + & - & & + & + & - & - & - & - & 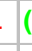 & (o) & - & - & - & - & & & & & & & & & & & & & & & & & & - & - & - & - & - & - & & & - & - & & 0 & 0 & - & - & - & - & 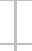 & . & - & - & & - & - & & \\
\hline 79L2 & + & - & & + & + & - & - & - & - & & - & - & - & - & - & & & & & & & & & & & & & & & & & & - & - & - & - & - & - & & & - & - & & 0 & 0 & - & - & - & $c$ & & 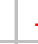 & - & - & & - & - & & \\
\hline 191A17 & & & & & & & & & & & & & & & & & & & & & & & & & & - & - & - & - & - & - & - & - & - & & - & - & - & & & & & & & & - & & & & & & & & & & & & \\
\hline $90 A 6$ & - & - & - & & - & - & & & & & & & & & & & & & & & & & & & & & & & & & & & & & & & - & - & & - & - & - & - & - & - & & & & & & & & & & & & & \\
\hline $12 \mathrm{H} 6$ & & - & & & & & & & & & & & & & & & & & & & & & & & & & & & & & & & & & & & - & - & & & - & & & & & & & & & & & & & & & & & \\
\hline $27 \mathrm{~F} 10$ & & - & & & & & & & & & & & & & & & & & & & & & & & & & & & & & & & & & & & - & - & & & - & & & & & & & & & & & & & & & & & \\
\hline
\end{tabular}




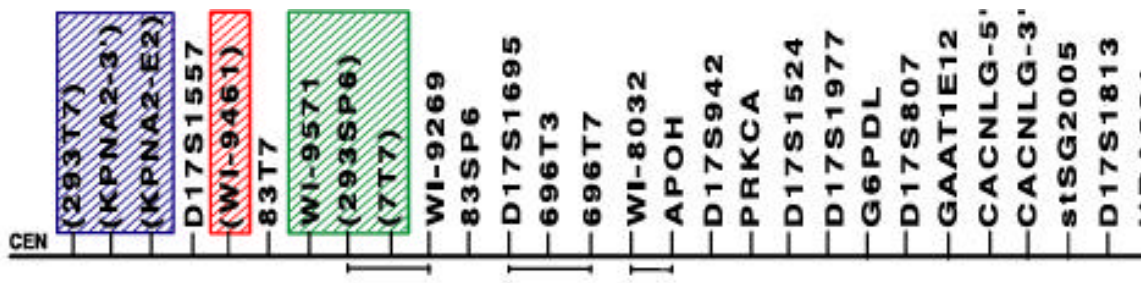

\section{ᄂ}

$1,1 \mathrm{~cm}$

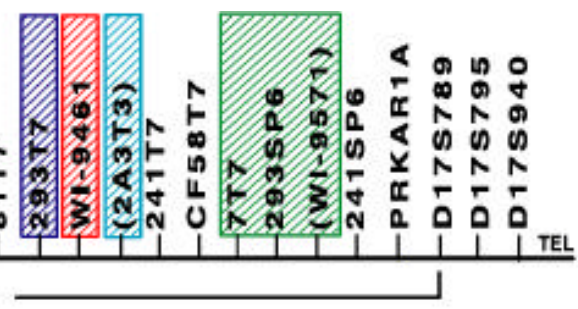

$804 \mathrm{H7} \perp \perp$

YACs

883в2 $\perp|\perp||| \mid$

$\perp|\perp| \perp+\cdots+\cdots++1$ 983D12

938F7

$963 C 7 \perp \perp|\perp| \perp|\perp| \perp|\perp| \perp \mid \perp$

$765 F 4 \perp|\perp| \perp|\perp| \perp \mid$

$853 \mathrm{FB} \perp|\perp||||| \mid$

$\perp|||||||||| \mid$ 929011

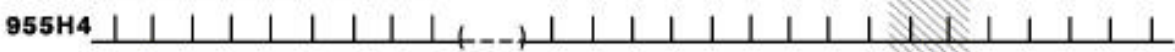

680F6 $\perp|\perp| \perp \mid$ 855A4 $\perp|\perp|$

$+11$

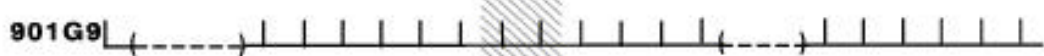

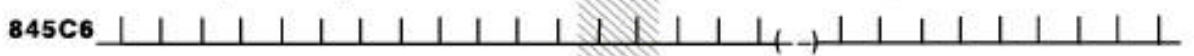

931810 $\perp|||||||||||||||||||||||||| \mid$

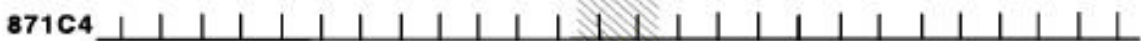

$742 A 4+$

PACs

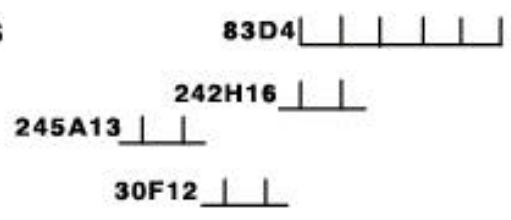

Cosmide

cCI17-696 $\perp \perp$
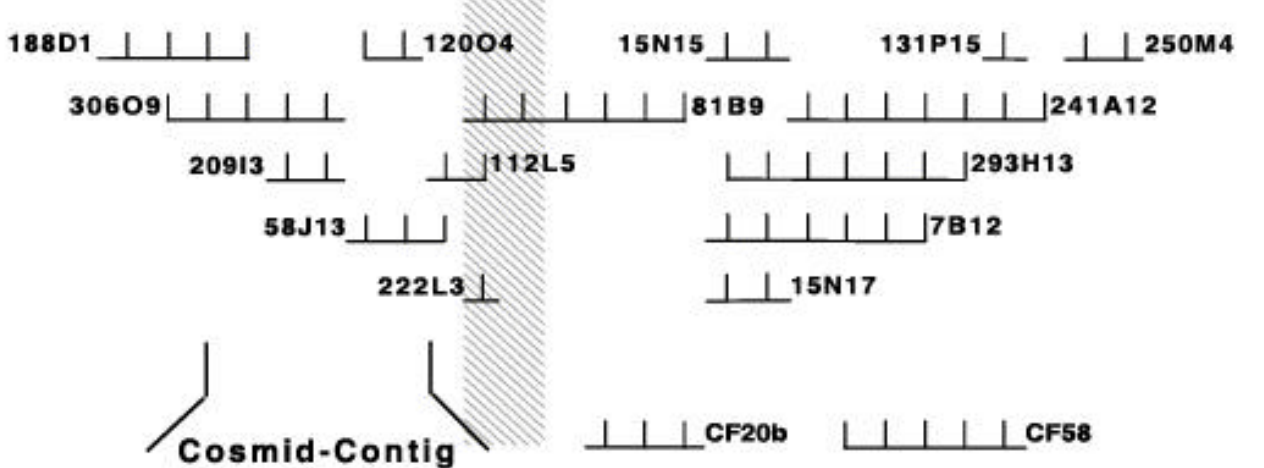

Abb. 22: Mit Hilfe von YACs, PACs und Cosmiden erstellte hochauflösende physikalische Karte der RSS-kritischen Chromosomenregion 17q23-q24. Die Region des Translokationsbruchpunktes von Proband AS ist durch einen schraffierten Balken dargestellt. Beiderseits des Bruchpunktes dupliziert vorliegende Loci sind durch farbige Kästen hervorgehoben. Das Cosmid-Contig ist in Abbildung 13 gezeigt. $\vdash$ : Anordnung der Loci nicht festgelegt; (---): deletierte Regionen von YACs. 


\subsection{Sequenzierung von PCR-Produkten von Klonen der Region 17q23-q24}

Da die über FISH- und PCR-Analyse erhaltenen Ergebnisse darauf hindeuteten, daß die Loci WI-9461, WI-9571, 7T7, 293SP6, 293 T7 und 2A3T3 in der Region 17q23-q24 verdoppelt vorkommen, wurden mit einzelnen Klonen erhaltene PCR-Produkte dieser Loci sequenziert. Dafür wurden die entsprechenden PCR-Produkte aus einem Polyacrylamidgel isoliert (2.2.7.3) und anschließend mit den forward- und/oder reverse-Primern der jeweiligen Loci sequenziert.

Im folgenden werden Vergleiche zwischen den jeweils generierten Sequenzen gezeigt, wobei forward- und/oder reverse-Primer kursiv dargestellt sind. Spezifische Unterschiede zwischen den Sequenzen sind fett hervorgehoben.

\subsubsection{Sequenzierung von PCR-Produkten der EST WI-9461}

Die mit den einzelnen Klonen für WI-9461 erhaltenen PCR-Produkte wurden mit dem forward-Primer sequenziert. Nach Sequenzierung der mit den PAC-Klonen 7B12, 15N15, 15N17 und 293H13 erhaltenen PCR-Produkte wurde Sequenz 1 erhalten. Die Sequenzierung der PCR-Produkte der PAC-Klone 30F12, 79L2 und des YAC-Klons 963C7 ergab Sequenz 2. Durch Sequenzierung des entsprechenden PCR-Produktes des PAC-Klons 16A23 wurde Sequenz 3 erhalten.

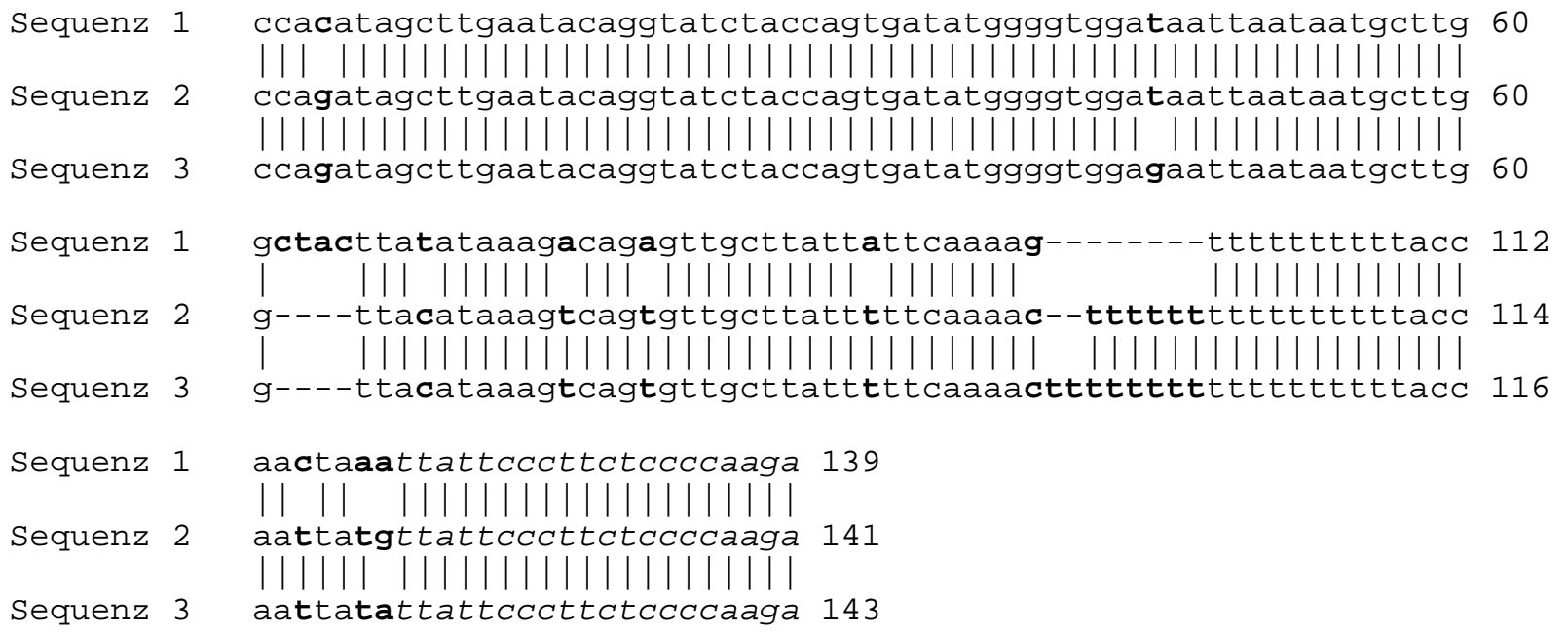

Sequenz 1 weist eine 86 \%ige Homologie zu Sequenz 2 und eine 85 \%ige Homologie zu Sequenz 3 auf. Sequenz 2 und 3 sind zu $97 \%$ zueinander homolog. Mit den Primern der EST WI-9461 lassen sich somit drei verschiedene Sequenzen amplifizieren. Sequenz 1 konnte spezifisch den über FISH-Analyse distal zum Translokationsbruchpunkt kartierten PACs der Region 17q23-q24 zugeordnet werden. Sequenz 2 ist dagegen für die proximal zum Bruchpunkt kartierten Klone der Region 17q23-q24 spezifisch. Sequenz 3 befindet sich entsprechend der FISH-Ergebnisse von PAC 16A23 in 17q21 und damit außerhalb der Region des Translokationsbruchpunktes und ist auch nicht im YAC/PAC/Cosmid-Contig (s. Abb. 22) enthalten. 


\subsubsection{Sequenzierung von PCR-Produkten der EST WI-9571}

Die forward- und reverse-Sequenzierung der PCR-Produkte, welche mit den Primern für WI9571 erhalten wurden, ergab für die PAC-Klone 241A12 und 131P15 Sequenz 1. Die entsprechende Sequenzierung ergab für das Cosmid CF58 Sequenz 2. Durch Sequenzierung der adäquaten PCR-Produkte der PAC-Klone 242H16 und 83D4 sowie des YACs 963 mit dem forward- und reverse-Primer wurde Sequenz 3 erhalten.

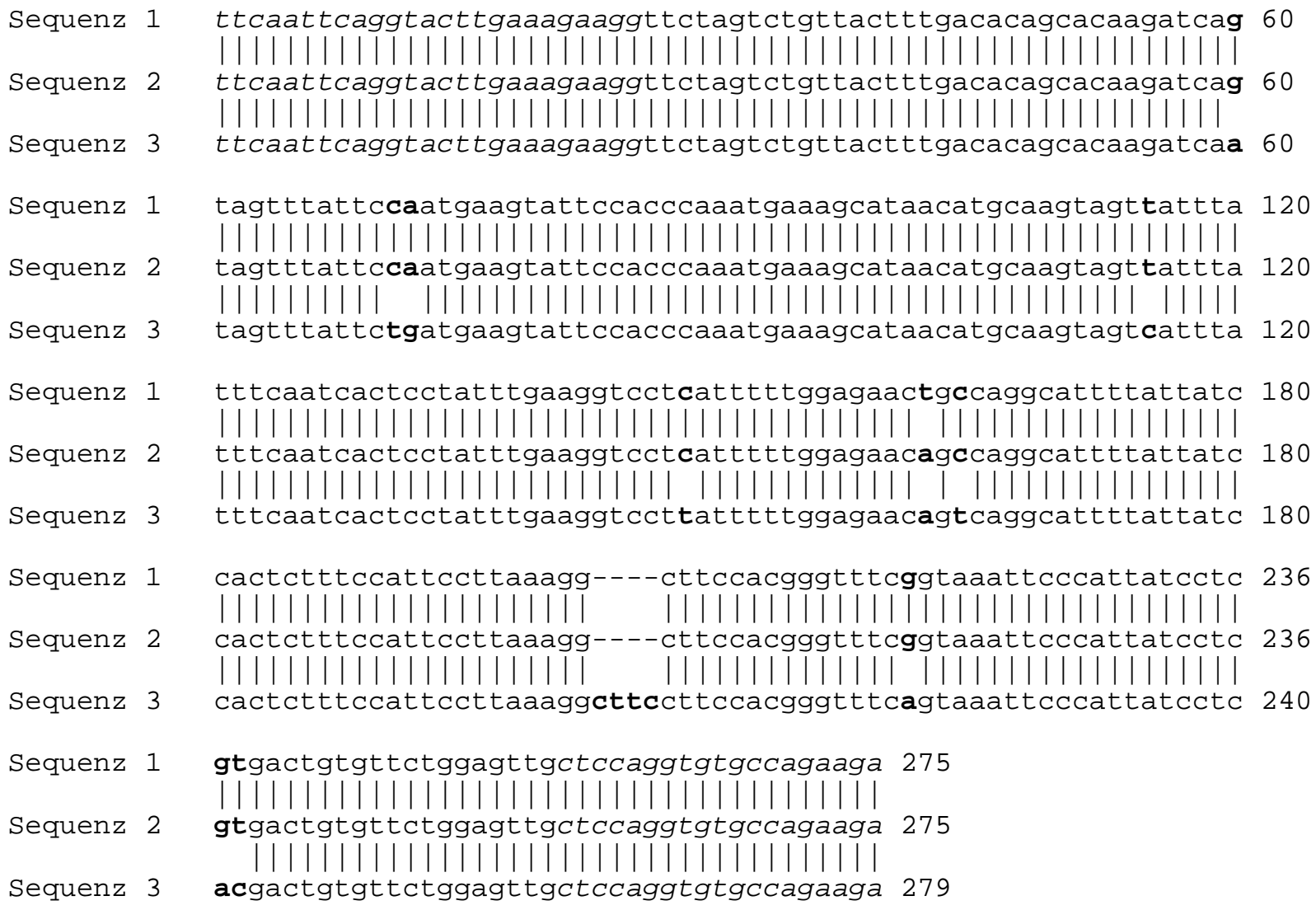

Sequenz 1 stimmt in $99 \%$ der Basen mit Sequenz 2 überein. Für die Sequenzen 1 und 3 wurde eine $94 \%$ ige Übereinstimmung festgestellt und für die Sequenzen 2 und 3 eine Übereinstimmung in $95 \%$. Somit wurden drei verschiedene Sequenzen identifiziert, die sich mit den Primern der EST WI-9571 amplifizieren lassen. Die Sequenzen 1 und 2 konnten den über FISH-Analyse distal zum Translokationsbruchpunkt kartierten Klonen der Region 17q23-q24 zugeordnet werden. Sequenz 3 befindet sich dagegen in den proximal zum Bruchpunkt kartierten Klonen der Region 17q23-q24.

\subsubsection{Sequenzierung von PCR-Produkten der STS 7T7}

Die Sequenzierung der PCR-Produkte, die mit den Primern für die STS 7T7 (s. 3.8.2.7) erhalten wurden, erfolgte mit dem forward-Primer. Für die PACs 7B12, 241A12, 15N15, 16A23 und das Cosmids CF58 wurde Sequenz 1 erhalten. Die Sequenzierung der entsprechenden PCR-Produkte des PACs 83D4 und des YACs 963 ergab Sequenz 2. 


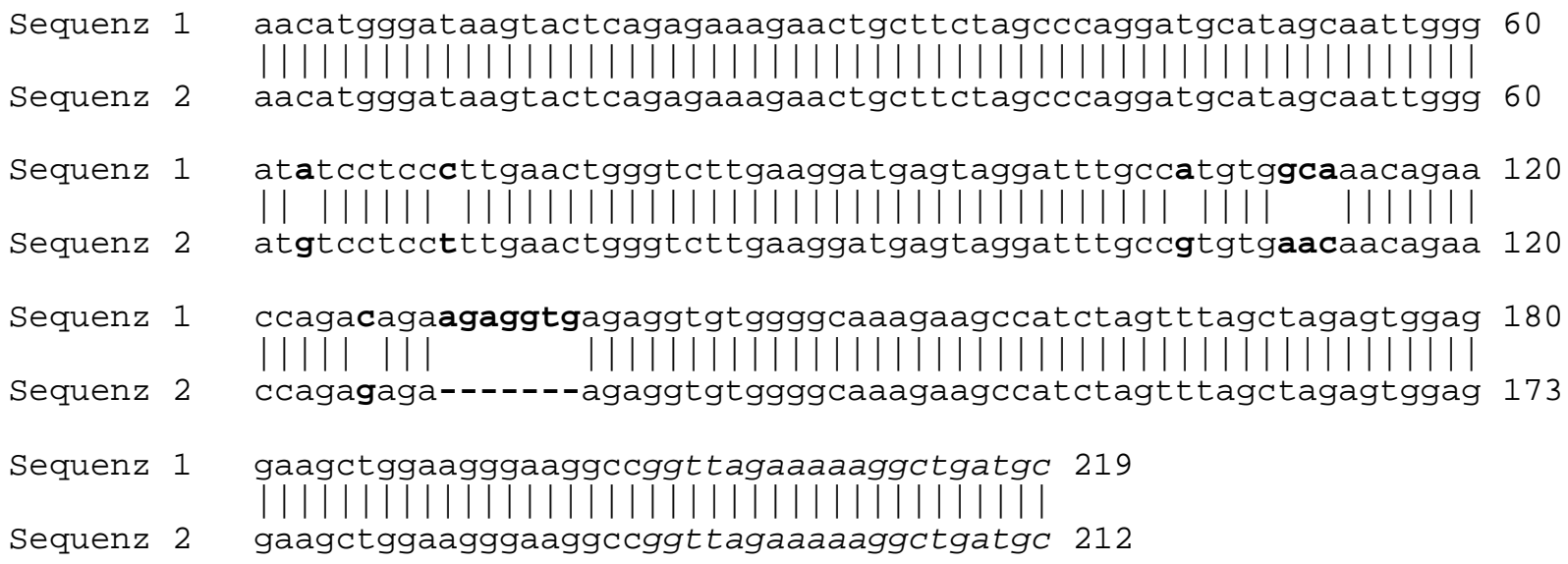

Durch einen Vergleich wurde eine 93 \%ige Homologie der Sequenzen festgestellt. Somit lassen sich mit den Primern der STS 7T7 zwei verschiedene Sequenzen amplifizieren. PAC 16A23 weist die gleiche Sequenz auf, wie über FISH-Analyse distal zum Translokationsbruchpunkt kartierte Klone der Region 17q23-q24. Dieser PAC zeigte jedoch nach Sequenzanalyse der EST WI-9461 spezifische Abweichungen zu der Sequenz dieser Klone. Somit ist Sequenz 1 nicht nur spezifisch für distal zum Bruchpunkt kartierte Klone der Region 17q23-q24, sondern auch für den in der Region 17q21 kartierten Klon 16A23. Sequenz 2 ist dagegen für proximal zum Bruchpunkt kartierte Klone der Region 17q23-q24 spezifisch.

\subsubsection{Sequenzierung von PCR-Produkten der STS 293T7}

PCR-Produkte der STS 29377 wurden mit dem forward- und dem reverse-Primer sequenziert. Nach Sequenzierung der mit den PAC-Klonen 7B12 und 293H13 erhaltenen PCR-Produkte ergab sich Sequenz 1. Durch Sequenzierung des entsprechenden PCR-Produktes von YACKlon 963C7 wurde Sequenz 2 erhalten. Der Sequenzvergleich zwischen 1 und 2 ist im folgenden dargestellt.

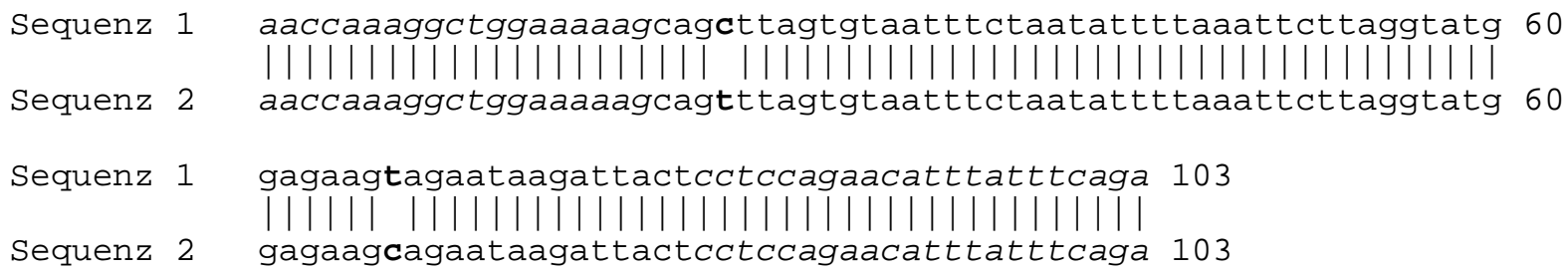

Zwischen den Sequenzen 1 und 2 wurde eine 98 \%ige Homologie festgestellt. Somit wurden zwei verschiedene Sequenzen identifiziert, die sich mit den Primern der STS 293T7 amplifizieren lassen. Sequenz 1 konnte spezifisch distal zum Translokationsbruchpunkt des Probanden AS lokalisierten PACs zugeordnet werden. Sequenz 2 ist dagegen spezifisch für einen proximal zum Bruchpunkt kartierten Klon. 


\subsubsection{Sequenzierung von PCR-Produkten der STS 2A3T3}

Die Sequenzierung von PCR-Produkten der STS 2A3T3 des PACs 293H13 ergab mit dem reverse-Primer Sequenz 1. Im folgenden wird ein Vergleich von Sequenz 1 mit der über T3Sequenzierung von $2 \mathrm{~A} 3$ erhaltenen Sequenz (s. 3.6.1.4) gezeigt.

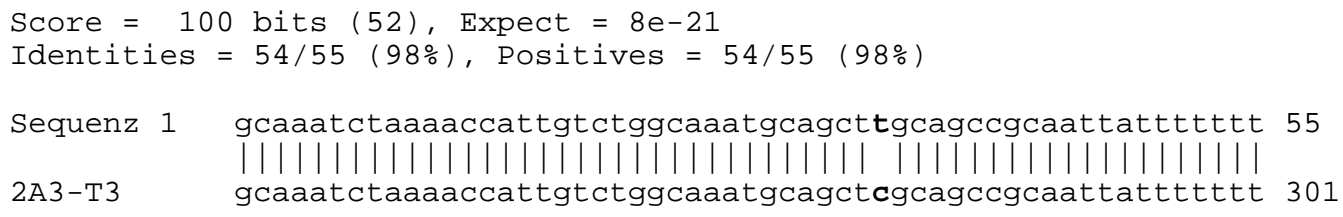

Durch einen Vergleich von Sequenz 1 mit der ursprünglich durch T3-Sequenzierung von 2A3 erhaltenen Sequenz wurde eine $98 \%$ ige Homologie festgestellt. Da über die Sequenzierung von PCR-Produkten der STS 2A3T3 des PAC-Klons 293H13 nur eine Base identifiziert wurde, die nicht mit der Sequenz des Cosmids 2A3 übereinstimmt, konnte somit zunächst keine Aussage darüber gemacht werden, ob der Marker 2A3T3 in der Region 17q23-q24 verdoppelt vorliegt. Um dies überprüfen zu können, wurde anhand der über T3-Sequenzierung des Cosmids 2A3 erhaltenen Sequenz folgender Primer abgeleitet:

Name: 2A3.rev, Sequenz: 5'-TCTTTTCCTGGTTAAATCAATG-3'

Dieser Primer wurde in Kombination mit verschiedenen Alu-Primern für eine Alu-PCR der PAC-Klone 58J13 und 7B12 eingesetzt. Die generierten Fragmente wurden anschließend mit dem Primer 2A3.rev sequenziert. Die Sequenzierung eines 950 bp 2A3.rev/154-Fragmentes des Klons 7B12 ergab Sequenz 1. Über die Sequenzierung eines 400 bp langen 2A3.rev/CL3Fragmentes von 58J13 wurde Sequenz 2 erhalten. Der Vergleich zwischen Sequenz 1 und 2 ist im folgenden gezeigt:

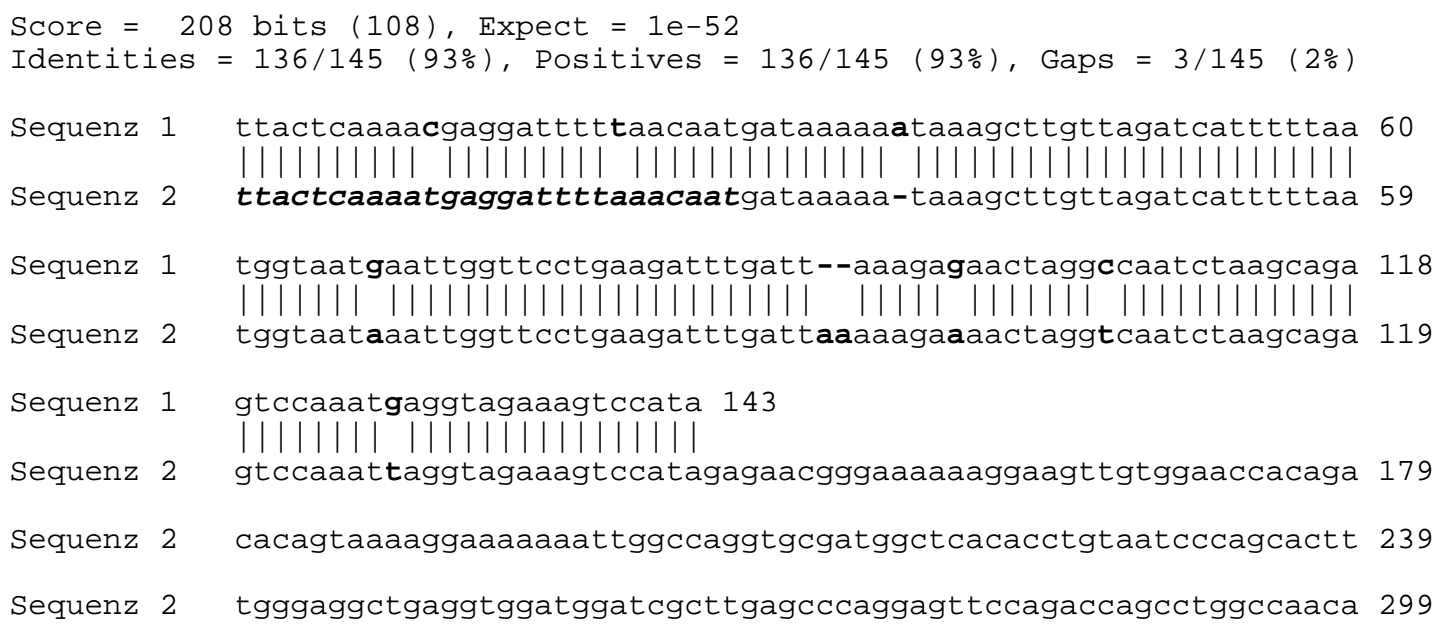

Sequenz 1 stimmt für die Basenpaare 1 bis 143 in $93 \%$ der Basen mit Sequenz 2 überein. Somit wurden zwei verschiedene Sequenzen identifiziert, die an die Sequenz der STS 2A3T3 angrenzen. Sequenz 1 wurde dem über FISH-Analyse distal zum Translokationsbruchpunkt des Probanden AS kartierten Klon 7B12 zugeordnet, Sequenz 2 ist für den proximal zum Bruch- 
punkt kartierten Klon 58J13 spezifisch. Die Basen 1 bis 27 der Sequenz 2 überlappen mit den Basen 1 bis 27 der über T3-Sequenzierung des Cosmids 2A3 erhaltenen Sequenz (reverse, fett und kursiv dargestellt). Daher wurden diese Sequenzen aneinandergefügt und gemeinsam für weitere Sequenzvergleiche eingesetzt.

Die Sequenzierung eines 220 bp langen 2A3.rev/451-Fragmentes von 7B12 ergab nach Sequenzierung mit dem Primer 2A3.rev folgende Sequenz (180 bp):

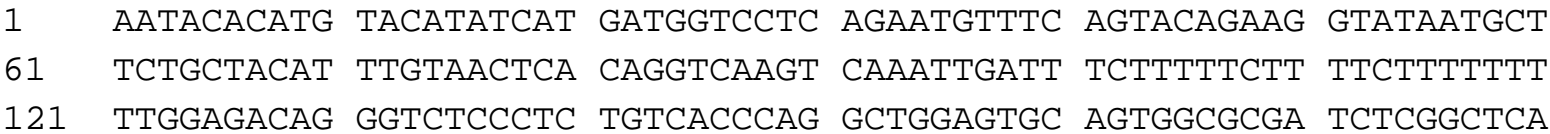

Nach Sequenzierung von Alu-PCR-Produkten des PAC-Klons 7B12 mit dem Primer 2A3.rev wurden somit zwei verschiedene Sequenzen erhalten. Die nach Sequenzierung des 2A3.rev/451-Fragments erhaltene Sequenz zeigte keine Homologie zu der über Sequenzierung des 2A3.rev/154-Fragments von 7B12 erhaltenen Sequenz.

\subsubsection{Sequenzierung von PCR-Produkten der STS 293SP6}

Da aufgrund des YAC-Contigs vermutet werden kann, daß auch die STS 293SP6 in der Region 17q23-q24 verdoppelt vorliegt, sollten auch PCR-Produkte dieser STS sequenziert werden. Die mit den YACs 765F4, 963C7 und 853F8 und dem PAC 83D4 erhaltenen PCR-Produkte waren in einem Polyacrylamidgel jedoch nur von schwacher Intensität. Diese PCR-Produkte eigneten sich nicht für eine Sequenzierung. Daher wurde nur ein PCR-Produkt des distal zum Bruchpunkt des Probanden kartierten PAC-Klons 241A12 für die Sequenzierung eingesetzt. Die erhaltene Sequenz zeigte keine Abweichung von der entsprechenden Sequenz des PAC-Klons 293H13 (s. 3.8.2.8).

\subsubsection{Sequenzierung von weiteren PCR-Produkten}

Um zu überprüfen, ob für weitere Loci der Region Repetition vorliegt, wurden weitere PCRProdukte einiger Loci sequenziert. Für die STS 112T7 wurden PCR-Produkte des PACs 81B9 sequenziert, wobei die erhaltenen Sequenzen keine Abweichungen zu der Sequenz des PACs 112L5 zeigten. Die Sequenzierung von PCR-Produkten des Locus CF20b ergab ebenfalls keine Abweichung der Sequenz des PACs 81B9 zu der des Cosmids CF20b. Für die STSs D17S1695 und cCI17-696T7 wurden die YAC-Klone 883B2, 765F4, 963C7 und 853F8 sequenziert. Die für diese YACs erhaltenen Sequenzen zeigten keine Abweichungen von der Sequenz dieser STSs.

\subsection{Charakterisierung von zwei expressed sequence tags aus der Bruchpunkt- region von Proband AS auf Chromosom 17}

Die ESTs WI-9461 und WI-9571 wurden über PCR-Analysen einigen den Translokationsbruchpunkt des Probanden AS überspannenden YACs zugeordnet (s. 3.1.1.2). Da es sich somit bei diesen Genen um mögliche Kandidatengene für das Russell-Silver-Syndrom handelt, 
wurden diese ESTs als cDNA-Klone von der American Type Culture Collection (ATCC) bezogen. Nach Datenbankanalyse mit der bisher bekannten Sequenz dieser ESTs (204 bp von WI9461 und 325 bp von WI-9571) wurden keine Homologien zu bisher bekannten Genen gefunden. Daher wurden die cDNA-Klone dieser ESTs sequenziert, um eventuell mit der neu generierten Sequenz Homologien feststellen zu können. Dazu wurde ein Sequenzvergleich in der EMBL/GenBank-Datenbank durchgeführt.

\subsubsection{Sequenzierung des cDNA-Klons 312967 (EST WI-9461)}

Der cDNA-Klon für die EST WI-9461 (ATCC Nummer 312967, GenBank Accession Nr. T56592 und T57277) stammt aus einer cDNA-Bibliothek aus humaner fetaler Milz. Der Klon enthält nach Angaben des ATCC ein 0,814 kb langes EcoRI/XhoI-Insert in dem Vektor pUC19. Es wurde eine Plasmidpräparation durchgeführt (s. 2.2.1.2) und das Insert nach Spaltung mit EcoRI und XhoI dargestellt. Das auf diese Weise dargestellte Insert hat eine Größe von etwa 700 bp. Über eine PCR mit den spezifischen EST-Primern wurde für diesen cDNA-Klon jedoch kein Amplifikat erhalten. Der cDNA-Klon wurde mit den Primern T3 (EcoRI-Seite) und T7 (XhoI-Seite) sequenziert, wobei folgende Sequenz (755 bp) erhalten wurde:

\begin{tabular}{|c|c|c|c|c|c|c|}
\hline \multicolumn{7}{|c|}{ EcoRI } \\
\hline 1 & GAACTAGTGG & ATCCCCCGGG & CTGCAGGAAT & TCGGCACGAG & CCACCCCATA & TCACTGGTAG \\
\hline 61 & ATACCTGTAT & TCAAGCTATC & TGGACATGAA & AGCAGTCACA & TTTTAGAAGT & CATGAAGTTG \\
\hline 121 & ATGCTAATAA & GCCTAATCTA & CAGAAACACT & CTTGAAAGCC & CTTGAGCGTT & TGTTCTGTGA \\
\hline 181 & ATAGAAAGGT & TTGAGATTCG & GAGCAAGTTC & AGAGTTGGAT & GGTCTAAGAA & TGGAAAAGCC \\
\hline 241 & СТССАТТССА & TTAGAAGAGC & CAGGTAGCAA & TTTCTGGTTA & TGGAACCAGA & AGCTCTCAGG \\
\hline 301 & СТТСАААТАА & AACAGCATCA & CTTGTACTCT & TATAAAACTG & TAAAAACAGA & AAGACCAAAA \\
\hline 361 & CCGTATCTAC & ATCTGTCCTA & TAAGGCAGAG & AGTACTTGAG & ATCTCATGGA & TTTAAAACCA \\
\hline 421 & GCTTACAAAC & TACATTGCAC & TATATGAAGA & AATTATCACT & GTGGGCAAAG & CATCAAGCAG \\
\hline 481 & AGAGCACAGT & ATACAGTGTG & TGGATGTTAA & TGTTATTCCC & TAGCCTTCCC & ATTCCTTTGT \\
\hline 541 & CTTGGTCCTT & TCTGCATATG & GAACAGTTCT & АТТАТТАААТ & TTTGTAATAG & TAACTGAGAA \\
\hline 601 & CCTGACTTTC & AGCAAGGGAG & TAGTTCGGAA & ATTGAGGGAG & TTTAACTCTG & AATGAGTAAA \\
\hline 661 & ТААААА ТААА & GCAATTATGT & CATTAGCTTA & АААТтTТАтС & АТСАТТАААА & ATAAAAAGTT \\
\hline 721 & TGGANACCAA & АААААААААА & АААААСTCGA & GGGGG & & \\
\hline
\end{tabular}

XhoI

Die EcoRI- (GAATTC) und XhoI- (CTCGAG) Klonierungsstellen sind fett und kursiv gedruckt. Die Sequenz des Inserts ist 719 bp lang und somit kürzer als von ATCC angegeben. Das XhoI-Ende des Klons enthält einen poly-d(A)-Schwanz mit dem zugehörigen Polyadenylierungssignal (AATAAA), das in der Sequenz unterstrichen ist.

Über einen Sequenzvergleich in der EMBL/GenBank-Datenbank wurden Homologien zu verschiedenen humanen cDNA-Klonen jedoch keine Homologien zu bekannten Genen festgestellt. Die deutlichsten Homologien sind im folgenden aufgelistet:

- 99 \% Identität in 630 bp mit dem humanen cDNA-Klon 1693209, 3'-Ende (Accession AI140364)

- $99 \%$ Identität in 559 bp mit dem humanen cDNA-Klon 2308138, 3'-Ende (Accession AI652871)

- $98 \%$ Identität in 559 bp mit dem humanen cDNA-Klon 2271889 (Accession AI681746)

- $96 \%$ Identität in 570 bp mit dem humanen cDNA-Klon 505121, 5'-Ende (Accession AA149869)

- $99 \%$ identität in 454 bp mit dem humanen cDNA-Klon 2075109 (Accession AI540072) 
Der direkte Sequenzvergleich der EST WI-9461 (204 bp, Accession-Nr. Z39035) mit cDNAKlon 312967 ergab eine 95 \%ige Übereinstimmung der beiden Sequenzen in 103 bp. Diese Homologie ist im folgenden dargestellt:

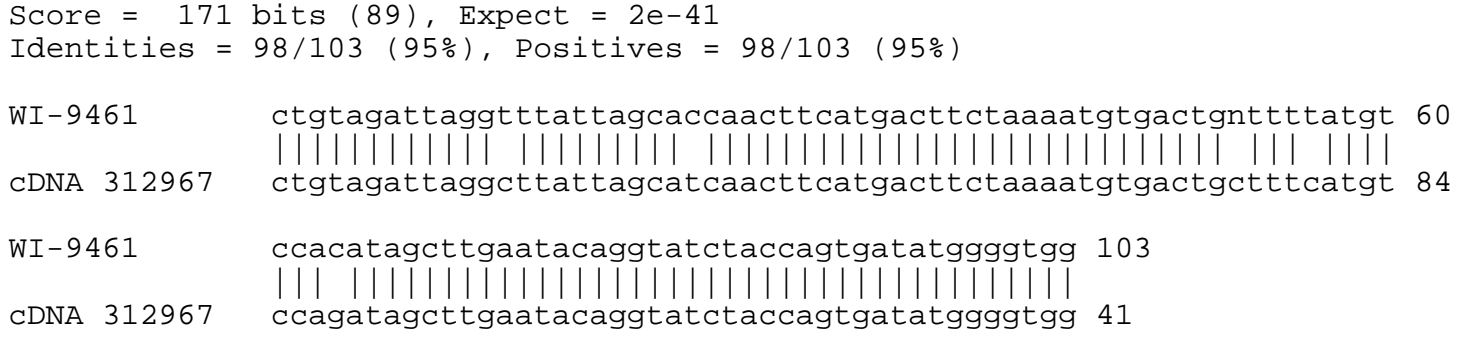

Der cDNA-Klon enthält somit nicht die exakte Sequenz der EST WI-9461. Die Sequenz des cDNA-Klons stimmt dagegen mit der Sequenz von PCR-Produkten dieser EST überein, die über Sequenzierung von PCR-Produkten der PAC-Klone 30F12, 79L2 und des YAC-Klons 963C7 erhalten wurden (s. unter 3.10.1).

Daneben zeigt der cDNA-Klon 312967 für die Basenpaare 41 bis 715 eine $92 \%$ Identität mit den Basenpaaren 198851 bis 198185 des BAC-Klons hRPK.147L13 (s. auch unter 3.12.1) und für die Basenpaare 90 bis 717 eine 92 \%ige Homologie zu den Basen 92017 bis 92639 des BAC-Klons 271K11. Es waren jedoch spezifische Abweichungen der cDNA-Sequenz von der der BAC-Klone festzustellen, so daß nicht anzunehmen ist, daß diese BACs den entsprechenden Abschnitt der cDNA enthalten. Die Sequenzen dieser beiden BAC-Klone wurden daraufhin miteinander verglichen, dadurch konnte festgestellt werden, daß diese Klone nicht überlappen.

\subsubsection{Sequenzierung des cDNA-Klons 339208 (EST WI-9571)}

Der cDNA-Klon für die EST WI-9571 (ATCC-Nummer 339208, GenBank Accession Nr. T89723 und T89821) stammt aus einer Bibliothek aus humaner Lunge. Von ATCC wurden keine Angaben zur Größe des EcoRI-/XhoI-Inserts in dem Vektor pUC19 gemacht. Nach einer Plasmidpräparation konnte das etwa 1300 bp lange Insert durch Spaltung mit EcoRI und XhoI dargestellt werden. Die Plasmid-DNA wurde mit den spezifischen EST-Primern durch PCR analysiert, wobei sowohl mit der als Kontrolle mitgeführten humanen genomischen DNA als auch mit der DNA des cDNA-Klons das 278 bp große Amplifikat erhalten wurde. Der cDNAKlon wurde mit den Primern T3 (EcoRI-Seite) und T7 (XhoI-Seite) sequenziert. Eine vollständige Sequenzierung dieses Klons wurde durch Wahl eines geeigneten reverse Primers innerhalb des Inserts erreicht. Dieser Primer ist in der folgenden Sequenz unterstrichen.

\begin{tabular}{|c|c|c|c|c|c|}
\hline \multicolumn{6}{|l|}{ Xhol } \\
\hline 1 & TCGAG TTTTтTтTт & ттттттттт & IGAGI I I & AGAGTTTTTA & TTATTC \\
\hline 61 & TGAGTTTCAT TTCAATTCAG & GTACTTGAAA & GAAGGTTCTA & GTCTGTTACT & $\overline{\mathrm{TT}} \mathrm{TACACAGC}$ \\
\hline 121 & ACAAGATCAA TAGTTTATTC & TGATGAAGTA & TTCCACCCAA & ATGAAAGCAT & AACATGCAAG \\
\hline 181 & TAGTCATTTA TTTCAATCAC & TCCTATTTGA & AGGTCCTTAT & TTTTGGAGAA & CAGTCAGGCA \\
\hline 241 & TTTTATTATC САСТСТTTCC & ATTCCTTAAA & GGCTTCCTTC & CACGGGTTTC & AGTAAATTCC \\
\hline 201 & ATTATCCTC ACGACTGTGT & & TGT & & \\
\hline 361 & TCCACCTCAC CAGTGCCATC & TGTCAAAGAG & GCCTGTCCAA & AGACAAAATT & CCACAAGTCT \\
\hline
\end{tabular}




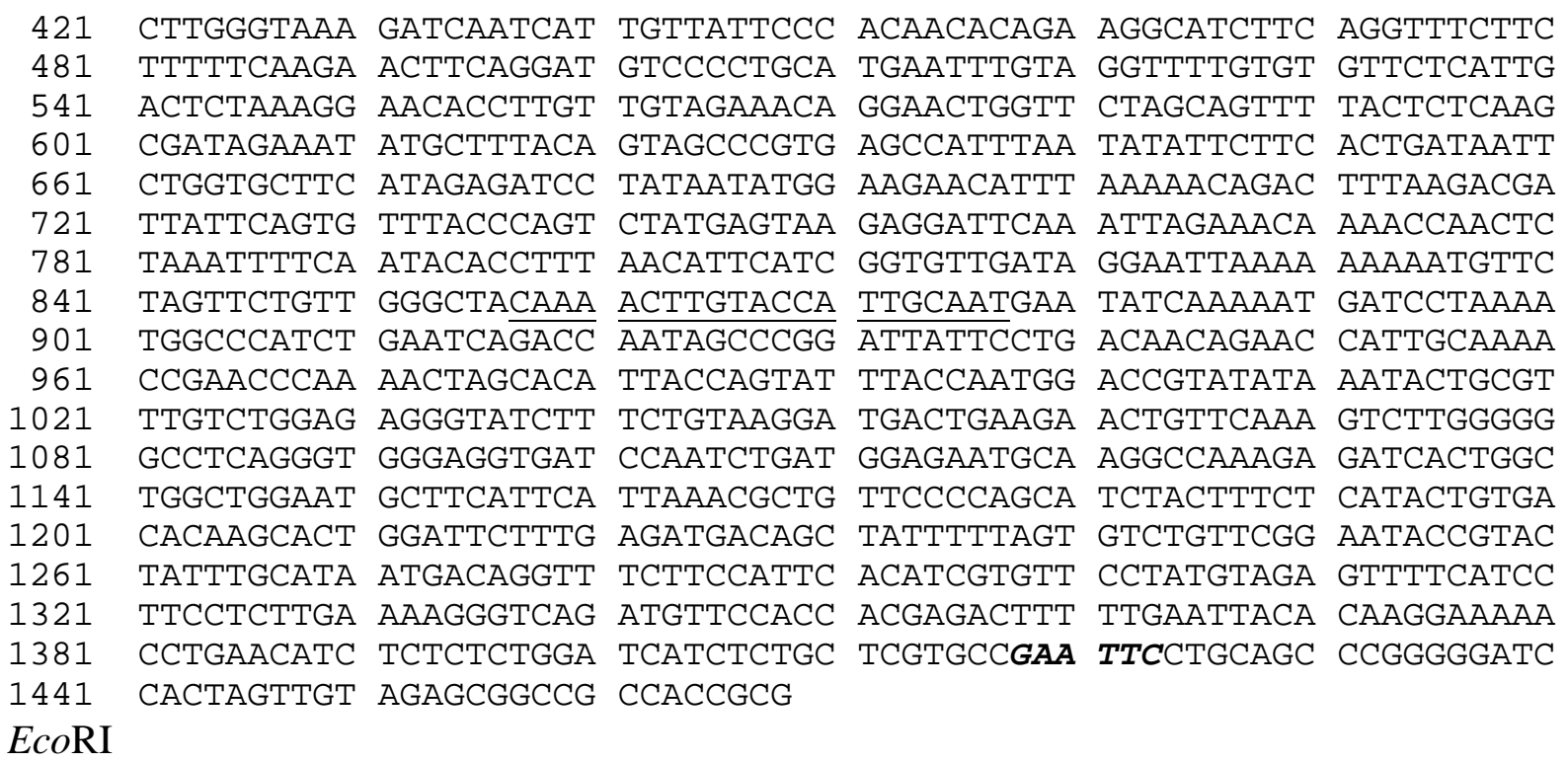

Die beiden Klonierungsstellen für EcoRI- (GAATTC) und XhoI- (CTCGAG) sind fett und kursiv dargestellt. Das XhoI-Ende des Klons enthält einen poly-d(A)-Schwanz (revers) mit dem zugehörigen Polyadenylierungssignal (AATAAA)(revers), das in der Sequenz unterstrichen ist. Der Sequenzvergleich in der EMBL/GenBank-Datenbank zeigte Homologien zu verschiedenen humanen cDNA-Klonen. Es wurde jedoch kein bekanntes Gen mit Homologie zu diesem cDNA-Klon identifiziert. Im folgenden sind die deutlichsten Homologien aufgelistet:

- $100 \%$ Identität in 525 bp mit dem humanen cDNA-Klon 1951686, 3'-Ende (Accession AI338757)

- $100 \%$ Identität in 435 bp mit dem humanen cDNA-Klon 1516893, 3'-Ende (Accession AA902995)

- 99 \% Identität in 422 bp mit dem humanen cDNA-Klon 324020, 3'-Ende (Accession W46552)

- $99 \%$ Identität in 414 bp mit dem humanen cDNA-Klon 1252875 (Accession AA888455)

- 99 \% identität in 410 bp mit dem humanen cDNA-Klon 785764, 5'-Ende (Accession AA448961)

Der direkte Sequenzvergleich der Sequenz der EST WI-9571 (325 bp, Accession-Nr. Z39152) mit der des cDNA-Klons 339208 ergab eine 99 \%ige Übereinstimmung der Basenpaare 4 bis 325 der EST-Sequenz mit den Basen 33 bis 354 der Sequenz der cDNA. Die Sequenz der EST WI-9571 ist somit in der Sequenz des cDNA-Klons enthalten. Zudem zeigten verschiedene Bereiche der cDNA hohe Homologien zu der Sequenz des BAC-Klons hRPK.147L13 (s. 3.12.1). Dieser BAC-Klon weist jedoch nicht die exakte Sequenz der cDNA auf.

\subsection{Zuordnung von BACs zu der Region 17q23-q24 anhand von Datenbankana- lysen}

Das Whitehead Institute startete 1996 ein Projekt zur Sequenzierung von PACs und BACs des Chromosoms 17. Daher waren in der EMBL/GenBank-Datenbank zunehmend auch vollständig sequenzierte PACs und BACs von Chromosom 17 enthalten. Um möglicherweise im Bereich der physikalischen Karte der Region 17q23-q24 lokalisierte, sequenzierte PACs oder BACs identifizieren zu können, wurden daher Vergleiche mit den in der EMBL/GenBank-Datenbank enthaltenen Sequenzen dieser Klone durchgeführt. Für diese Vergleiche wurden die Sequenzen 
aller im Contig kartierten Loci herangezogen. Auf diese Weise wurden der in dieser Arbeit kartierten Region 11 BAC-Klone zugeordnet (s. Abb. 23). Daneben war es aufgrund der bekannten Sequenz dieser BACs möglich, dem Contig 12 ESTs aufgrund von Sequenzvergleichen zuzuordnen (s. Abb. 23). Zudem konnte die Exon-Intron-Struktur einiger Gene durch Vergleich von cDNA-Sequenz und genomischer Sequenz der BACs vorhergesagt werden. Die Vorhersage der einzelnen Exons wurde anschließend durch Exon-Vorhersageprogramme wie XPound und grail überprüft. 


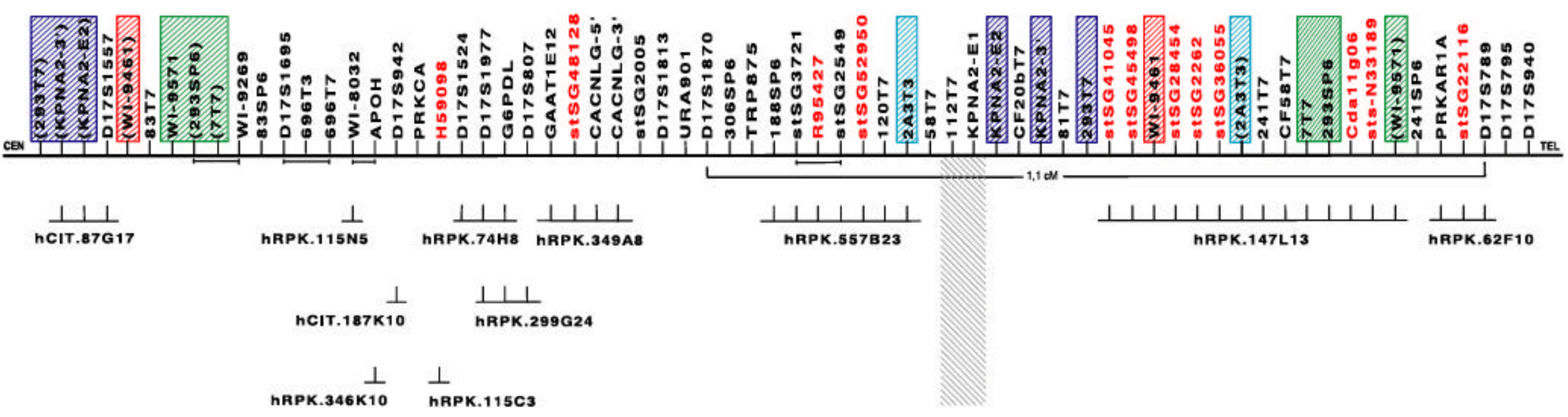

Abb. 23: Auf Sequenzvergleichen basierende Zuordnung von 11 BAC-Klonen zu der im Rahmen dieser Arbeit physikalisch kartierten Region 17q23-q24. Den BACs konnten aufgrund von Vergleichen mit in den Datenbanken zur Verfügung stehenden Sequenzdaten insgesamt 12 ESTs zugeordnet werden, die bisher nicht in der Region kartiert waren. Diese Loci wurden in die hier zu sehende Karte integriert. Zur besseren Übersicht sind diese ESTs in rot dargestellt. Die Region des Translokationsbruchpunktes von Proband AS ist durch einen schraffierten Balken dargestellt. Beiderseits des Bruchpunktes dupliziert vorliegende Loci sind durch farbige Kästen markiert. $\vdash$ : Anordnung der Loci nicht festgelegt. 


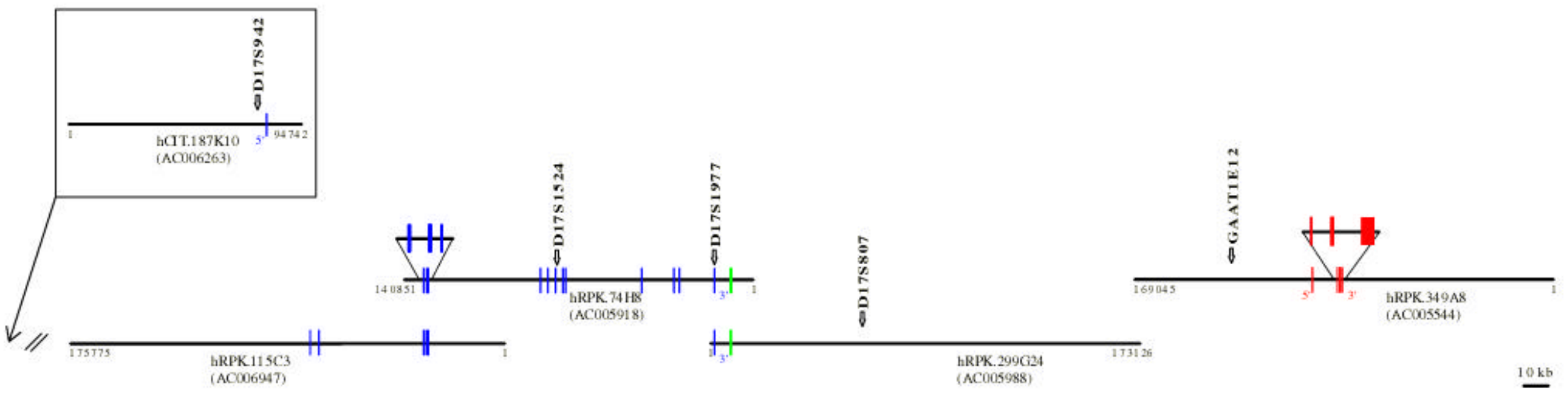

Abb. 24: Ausschnitt aus der physikalischen Karte der Region 17q23-q24. Gezeigt sind 5 der in dieser Region lokalisierten BAC-Klone. Der Abbildung ist der Überlappungsgrad zwischen den BACs, sowie die Position von in der Region kartierten Loci zu entnehmen. Die über Sequenzvergleiche identifizierten Exons der PRKCA (blau), G6PDL (grün) und CACNLG (rot) sind durch senkrechte Striche dargestellt. Zur besseren Übersicht sind zwei Bereiche, in denen die Exons dicht beieinanderliegen, vergrößert eingezeichnet. 


\subsubsection{Identifizierung von hRPK.147L13 (Accession-Nr. AC005332)}

Das sequenzierte Insert des seit 26. September 1998 in der EMBL/GenBank-Datenbank enthaltenen BAC-Klons hRPK.147L13 hat eine Länge von 216631 bp. Durch einen Vergleich zeigte sich, daß Teile der Sequenz dieses Klons sehr gut übereinstimmen mit den Sequenzen der Loci 241T7, CF58T7, 7T7, 293SP6 und 2A3T3 und somit auch mit den über Endfragment-Sequenzierung der jeweiligen Klone erhaltenen Daten. Tab. 29 gibt eine Übersicht über die Position dieser Sequenzen innerhalb von hRPK.147L13.

Tab. 29: Zuordnung von STSs zu dem BAC hRPK.147L13

\begin{tabular}{lll}
\hline Sequenz & Position in hRPK.147L13 & Identität \\
\hline Cosmid 2A3, T3-Ende (540 bp, s. 3.6.1.4. + 3.10.5) & $115460 \ldots 115024$ & $96 \%$ \\
PAC 241A12, T7-Ende (407 bp, s. 3.8.2.9) & $109397 \ldots 109803$ & $100 \%$ \\
Cosmid CF58, T7-Ende (348 bp, s. 3.6.1.5) & $109900 \ldots 109553$ & $100 \%$ \\
PAC 7B12, T7-Ende (354 bp, s. 3.8.2.7) & $108781 \ldots 109065$ & $100 \%$ \\
PAC 293H13, SP6-Ende (195 bp, s. 3.8.2.8) & $108042 \ldots 108233$ & $96 \%$ \\
\hline
\end{tabular}

Da die Sequenz des SP6-Endes von PAC 293H13 stimmt vermutlich aufgrund von Sequenzierungsfehlern nicht vollständig mit der Sequenz des BAC-Klons hRPK.147L13 überein.

Die für den Vergleich eingesetzte Sequenz des Cosmids 2A3 setzt sich aus der über T3Sequenzierung des Cosmids 2A3 erhaltenen Sequenz (s. 3.6.1.4) und der über Sequenzierung eines Alu-PCR-Produktes des PACs 58J13 erhaltenen, überlappenden Sequenz (s. 3.10.5) zusammen. Der BAC-Klon 147L13 beinhaltet einen zu diesen Klonen homologen Abschnitt. Für diesen Klon wurde für den entsprechenden Abschnitt exakt die Sequenz gefunden, die bereits über Sequenzierung eines 2A3.rev/154-Fragmentes von 7B12 erhalten wurde (s. 3.10.5). Somit sind die Unterschiede der Sequenz von 147L13 zu den Abschnitten des Cosmids 2A3 und des PACs 58J13 als spezifisch anzusehen.

Neben den bisher beschriebenen Übereinstimmungen zeigt der BAC-Klon hRPK.147L13 auch Homologien zu den Sequenzen der ESTs WI-9461 (204 bp, Accession-Nr. Z39035) und WI9571 (325 bp, Accession-Nr. Z39152). Die Basenpaare 1 bis 204 der EST WI-9461 weisen eine 99 \%ige Identität mit den Basenpaaren 198749 bis 198952 des BAC-Klons auf. Die Basenpaare 1 bis 325 der EST WI-9571 zeigen eine Identität von $95 \%$ mit den Basenpaaren 71174 bis 71494 von hRPK.147L13. Somit ist anzunehmen, daß die EST WI-9461 innerhalb des BACs lokalisiert ist. Die Sequenz der EST WI-9571 zeigt dagegen spezifische Abweichungen von der des BAC-Klons. Bereits in Kapitel 3.10.2 wurde beschrieben, daß sich mit den Primern der EST WI-9571 drei verschiedene Sequenzen amplifizieren lassen. Der BAC-Klon 147L13 zeigt für den entsprechenden Abschnitt die selbe Sequenz wie das Cosmid CF20b bzw. Sequenz 2. Da für die ESTs WI-9461 und WI-9571 cDNA-Klone sequenziert wurden (s. 3.11), konnten auch die Sequenzen dieser Klone für einen Sequenzvergleich eingesetzt werden. Bei der Beurteilung der mit den Sequenzen dieser cDNAs durchgeführten Vergleiche ist jedoch zu beachten, daß der für die EST WI-9461 sequenzierte cDNA-Klon 312967 nicht die Originalsequenz von WI-9461 beinhaltet. In Kapitel 3.10.1 wurde gezeigt, daß sich mit den Primern der 
EST WI-9461 drei verschiedene Sequenzen amplifizieren lassen. Die Sequenz der cDNA 312967 entspricht der Sequenz der Klone 30F12, 79L2 und 963C7. Der für die EST WI-9571 sequenzierte cDNA-Klon 339208 ist dagegen für die Sequenz der EST WI-9571 spezifisch. Tabelle 30 gibt eine Übersicht über die mit den cDNA-Sequenzen gefundenen Homologien.

Tab. 30: Übersicht über die Homologien der cDNAs 312967 und 339208 mit hRPK.147L13

\begin{tabular}{clll}
\hline cDNA & cDNA-Position & Position in hRPK.147L13 & Identität \\
\hline 312967 (WI-9461) & $41 \ldots 715$ & $198851 \ldots 198185$ & $92 \%$ \\
339208 (WI-9571) & $33 \ldots . .377$ & $71177 \ldots 71517$ & $95 \%$ \\
$"$ & $376 \ldots . .507$ & $77151 \ldots 77282$ & $99 \%$ \\
$"$ & $505 \ldots 835$ & $77362 \ldots 77691$ & $93 \%$ \\
$"$ & $848 \ldots 1269$ & $77714 \ldots 78142$ & $90 \%$ \\
$"$ & $1270 \ldots 1406$ & $79234 \ldots 79365$ & $90 \%$ \\
\hline
\end{tabular}

Durch einen Vergleich in der EST-Datenbank dbEST konnten auch für die in hRPK.147L13 enthaltene, zu WI-9571 homologe Sequenz, zahlreiche partielle cDNA-Sequenzen identifiziert wurden, die eine $100 \%$ ige Übereinstimmung mit dieser Sequenz zeigen.

Aufgrund von Vergleichen war es möglich dem Contig der Region 17q23-q24 ESTs zuzuordnen, die bis dahin nicht innerhalb des Contigs kartiert wurden. Die Bezeichnung und Position dieser ESTs ist Tabelle $31 \mathrm{zu}$ entnehmen.

Tab. 31: ESTs, die dem BAC 147L13 und somit dem Contig über einen Vergleich mit den in den Datenbanken verfügbaren Sequenzen zugeordnet wurden.

\begin{tabular}{llll}
\hline EST-Name & EST-Accession-Nr. & Position in hRPK.147L13 & Homologie \\
\hline sts-N33189 & AA182477 & $61302 \ldots 60967$ & $100 \%$ \\
Cda11g06 & AA449688 & $71177 \ldots 71489$ & $95 \%$ \\
stSG36055 & AA977218 & $120837 \ldots 121322$ & $99 \%$ \\
stSG2262 & R37753 & $166222 \ldots 166554$ & $88 \%$ \\
stSG28454 & AA078809 & $193547 \ldots 193095$ & $97 \%$ \\
stSG45498 & AA424332 & $198744 \ldots 199157$ & $100 \%$ \\
stSG41045 & AA491714 & $202429 \ldots .202773$ & $99 \%$ \\
\hline
\end{tabular}

\subsubsection{Identifizierung von hRPK.557B23 (Accession-Nr. AC006534)}

Der ist seit dem 13. Februar 1999 in der EMBL/GenBank-Datenbank enthaltene BAC-Klon 557B23 ist bisher nicht vollständig sequenziert. Vielmehr sind in den Datenbanken 8 ungeordnete Sequenzabschnitte enthalten, zwischen denen Lücken unbekannter Größe vorhanden sind. Der BAC-Klon 557B23 zeigt sehr hohe Homologien $\mathrm{zu}$ den Sequenzen folgender Loci: 188SP6, stSG3721, stSG2549, 120 T7 und 2A3T3. Diese Homologien sind in Tabelle 32 enthalten. Die 8 Sequenzabschnitte dieses Klons umfassen zur Zeit folgende Basenpaare: 1-7581, 
7582-17529, 17530-41685, 41686-69608, 69609-95261, 95262-123402, 123403-158938 und 158939-220438. Es ist jedoch davon auszugehen, daß sich die Nummerierung der Basenpaare des BAC-Klons ändert, sobald dieser vollständig sequenziert ist.

Tab. 32: Zuordnung von STSs zu dem BAC hRPK.557B23

\begin{tabular}{lcc}
\hline Sequenz & Position in hRPK.557B23 & Identität \\
\hline Cosmid 2A3, T3-Ende (540 bp, s. 3.6.1.4. + 3.10.5) & $83156 \ldots 82714$ & $99 \%$ \\
PAC 120O4, T7-Ende (493 bp, s. 3.8.2.6) & $132869 \ldots 132664$ & $98 \%$ \\
stSG3721 (297 bp, Accession-Nr. AA286807) & $159318 \ldots 159615$ & $99 \%$ \\
stSG2549 (475 bp, Accession-Nr. AA815089) & $161089 \ldots 161563$ & $98 \%$ \\
PAC 188D1, SP6-Ende (357 bp, s. 3.8.2.1) & $216504 \ldots 216854$ & $98 \%$ \\
\hline
\end{tabular}

Die Sequenz des T7-Endes von PAC 12004 stimmt zwar in 206 bp zu $98 \%$ mit dem BACKlon hRPK.557B23 überein, die Sequenz von 120O4, die für den Vergleich eingesetzt wurde, ist jedoch 493 bp lang. Die restlichen 289 bp der Sequenz des PACs weisen deshalb anscheinend keine Homologie zu der Sequenz des BACs hRPK.557B23 auf.

Dem Contig der Region 17q23-q24 konnten zudem aufgrund von Sequenzvergleichen mit dem BACs hRPK.557B23 zwei ESTs zugeordnet werden, die bis dahin nicht innerhalb des Contigs kartiert wurden. Die Bezeichnung und Position dieser ESTs ist Tabelle 33 zu entnehmen.

Tab. 33: ESTs, die dem BAC hRPK.557B23 und somit dem Contig über einen Vergleich mit den in den Datenbanken verfügbaren Sequenzen zugeordnet wurden.

\begin{tabular}{llll}
\hline EST-Name & EST-Accession-Nr. & Position in hRPK.557B23 & Homologie \\
\hline stSG52950 & AA705815 & $181569 \ldots 181175$ & $98 \%$ \\
R95427 & AA350226 & $160836 \ldots 160436$ & $97 \%$ \\
\hline
\end{tabular}

Bei der Sequenz des BAC-Klons hRPK.557B23 handelt es sich um eine working draft Sequenz, also um eine nicht vollständige Sequenz von bisher nicht allzu guter Qualität (die Sequenz weist viele nicht spezifizierte Nucleotide N auf). Dies erklärt vermutlich auch, warum die Sequenzen der ESTs nicht vollständig mit dieser Sequenz übereinstimmen.

\subsubsection{Identifizierung von hRPK.346K10 (Accession-Nr. AC006120)}

Das sequenzierte Insert des seit dem 22. Dezember 1998 in der EMBL/GenBank-Datenbank enthaltenen BAC-Klons hRPK.346K10 hat eine Größe von 168753 bp.

Durch einen Vergleich mit der bekannten cDNA-Sequenz von Apolipoprotein H (APOH) (Day et al., 1992; Accession-Nr. M62839) konnten 8 Exons von APOH innerhalb des Klons hRPK.346K10 identifiziert werden. Dieser Klon enthält die cDNA (1185 bp) von Position 2 bis 1177. Die erste Base der cDNA wurde in BAC-Klon hRPK.346K10 nicht gefunden. Daher ist anzunehmen, daß bei der Sequenzierung der cDNA oder des BAC-Klons ein Fehler 
aufgetreten ist. Die Basenpaare 1178 bis 1185 enthalten einen Teil vom Poly(A)-Schwanz, daher ist diese Sequenz nicht in hRPK.346K10 enthalten. Die Positionen der Exons innerhalb des BAC-Klons hRPK.346K10 sind Tab. 34 zu entnehmen. Mit Ausnahme der Sequenz von Exon 5 und 8 stimmt die Sequenz der cDNA und die Sequenz von hRPK.346K10 aller anderen Exons völlig überein. Die cDNA weist jedoch an der im Exon 5 lokalisierten Position 624 ein A auf, während hRPK.346K10 an der entsprechenden Position (55098) ein T aufweist. Ein $\mathrm{A} \rightarrow \mathrm{T}$-Austausch dieser Base würde die Aminosäuresequenz von APOH nicht verändern. In der 3'UTR (Exon 8) befindet sich an Position 1098 der cDNA ein T, der BAC-Klon weist an der entsprechenden Position (63559) ein C auf. Diese Variationen könnten Polymorphismen widerspiegeln bzw. Sequenzierungsfehler darstellen.

Tab. 34: Exon-Intron-Struktur von Apolipoprotein H (APOH)

\begin{tabular}{|c|c|c|c|c|c|c|}
\hline $\mathrm{APOH}$ & $\begin{array}{l}\text { cDNA- } \\
\text { Position }\end{array}$ & $\begin{array}{l}\text { Position in } \\
\text { hRPK.346K10 }\end{array}$ & $\begin{array}{l}\text { Exon- } \\
\text { länge } \\
\text { (bp) }\end{array}$ & 5'-Exon-Intron-Grenze & 3'-Exon-Intron-Grenze & $\begin{array}{l}\text { Intron- } \\
\text { länge } \\
\text { (bp) }\end{array}$ \\
\hline Exon 1 & $2 \ldots 103$ & $46254 \ldots 46355$ & 102 & & $\begin{array}{l}\text { GCAGGACGGAgtaag } \\
\text { tactttttgcttttgaaaaa }\end{array}$ & 1119 \\
\hline Exon 2 & $104 \ldots 280$ & $47475 \ldots .47651$ & 177 & $\begin{array}{l}\text { ccatctgctttgtgecctctttca } \\
\text { gCCTGTCCCAA }\end{array}$ & $\begin{array}{l}\text { AAATGTACACgtaag } \\
\text { tcagtaccttctctcacatt }\end{array}$ & 1895 \\
\hline Exon 3 & $281 \ldots 377$ & $49547 \ldots 49643$ & 97 & $\begin{array}{l}\text { aacattttttatctttgtatcacag } \\
\text { CCAGAGTATG }\end{array}$ & $\begin{array}{l}\text { GTAACACTGGgtaag } \\
\text { aactttcatggaactaagca }\end{array}$ & 2253 \\
\hline Exon 4 & $378 \ldots 454$ & $51897 \ldots . .51973$ & 77 & $\begin{array}{l}\text { tgatagaatgaattttccttttgc } \\
\text { agGTTTTATCTG }\end{array}$ & $\begin{array}{l}\text { GTCTGTGCTCgtaagt } \\
\text { ctgtgggcaaggtgatcag }\end{array}$ & 2955 \\
\hline Exon 5 & $455 \ldots 643$ & $54929 \ldots . .55117$ & 189 & $\begin{array}{l}\text { aaatgatagttctttattttccca } \\
\text { gCCATCATCTG }\end{array}$ & $\begin{array}{l}\text { GAATGCAGGGgtaag } \\
\text { tgcaatgatcagacaaaata }\end{array}$ & 3586 \\
\hline Exon 6 & $644 \ldots 823$ & $58704 \ldots . .58883$ & 180 & $\begin{array}{l}\text { atgtcttattgaataaatgtttta } \\
\text { gAAGTAAAATG }\end{array}$ & $\begin{array}{l}\text { AGTTGTAAAGgtatg } \\
\text { gaaatataggcgaggtcctg }\end{array}$ & 2137 \\
\hline Exon 7 & $824 \ldots 1021$ & $61021 \ldots 61218$ & 198 & $\begin{array}{l}\text { tgattacaagtattctctctttca } \\
\text { gCATCTTGTAA }\end{array}$ & $\begin{array}{l}\text { TGCTTCAAGGgtaagt } \\
\text { ctgcattggaacgtttagc }\end{array}$ & 2264 \\
\hline Exon 8 & $1022 \ldots 1177$ & $63483 \ldots 63638$ & 156 & $\begin{array}{l}\text { tgtttatctttttctcccccaaca } \\
\text { gAACACAGTTC }\end{array}$ & & \\
\hline
\end{tabular}

\subsubsection{Identifizierung von hCIT.187K10 (Accession-Nr. AC006263)}

Der BAC-Klon hCIT.187K10 ist seit dem 1. Januar 1999 in der EMBL/GenBank-Datenbank enthalten. Das sequenzierte Insert dieses Klons hat eine Länge von 94742 bp.

Der Klon hCIT.187K10 wurde über einen Vergleich mit der Sequenz von D17S942 (Accession-Nr. Z23919) identifiziert. Die Basen 1 bis 377 der STS D17S942 weisen $100 \%$ Identität mit den Basen 76834 bis 76458 des PAC-Klons hCIT.187K10 auf.

Über einen Vergleich mit der bekannten cDNA-Sequenz der Protein-Kinase C $\alpha$ (PRKCA) (Finkenzeller et al., 1990; Accession-Nr. X52479) konnte ein Exon dieses Gens innerhalb des Klons hCIT.187K10 lokalisiert werden (s. Abb. 24). Die Sequenz der cDNA stimmt im Bereich dieses Exons 100 \%ig mit der entsprechenden Sequenz von hCIT.187K10 überein. Die 
Spleißdonor- und Spleißakzeptorstelle entsprechen der GT-AG-Regel. Die detaillierte Information über dieses Exon ist in Tab. 35 enthalten. Die Exon-Intron-Struktur des Gens der PRKCA ist bisher nicht beschrieben worden. Da die ersten 132 bp der cDNA der PRKCA bisher in keinem sequenzierten Klon kartiert werden konnten, ist unklar wie viele Exons diese Sequenz enthält. Da jedoch von mindestens einem Exon auszugehen ist, das nicht erfaßt wird, werden die Exons der PRKCA mit einem $\geq$-Zeichen versehen. Da das nächste Exon der PRKCA in dem BAC-Klon hRPK.115C3 identifiziert wurde, dieser Klon jedoch nicht mit hCIT.187K10 überlappt, läßt sich die minimale Größe des Introns zwischen Exon $\geq 2$ und Exon $\geq 3$ anhand der Position der Exons innerhalb dieser Klone berechnen. Dieses Intron ist demnach mindestens 113700 bp groß.

Tab. 35: Exon-Intron-Struktur der PRKCA (Teil 1)

\begin{tabular}{lllllll}
\hline PRKCA & $\begin{array}{l}\text { cDNA- } \\
\text { Position }\end{array}$ & $\begin{array}{l}\text { Position in } \\
\text { hCIT.187K10 }\end{array}$ & $\begin{array}{l}\text { Exon- } \\
\text { länge (bp) }\end{array}$ & 5'-Exon-Intron-Grenze & 3'-Exon-Intron-Grenze & $\begin{array}{l}\text { Intron- } \\
\text { länge (bp) }\end{array}$ \\
\hline Exon $\geq 2$ & $233 \ldots 315$ & $79648 . . .79730$ & 83 & $\begin{array}{l}\text { ttttagtttcttttctctaccagT } \\
\text { TTGCTGTTT }\end{array}$ & $\begin{array}{l}\text { CGACACTGATgtaagt } \\
\text { agtcctgaaatcatgattt }\end{array}$ & 113700 \\
\hline
\end{tabular}

\subsubsection{Identifizierung von hRPK.115C3 (Accession-Nr. AC006947)}

Der BAC-Klon hRPK.115C3 ist seit dem 12. März 1999 in der EMBL/GenBank-Datenbank enthalten. Die Länge des sequenzierten Inserts dieses Klons beträgt 175775 bp.

Über einen Sequenzvergleich mit der cDNA-Sequenz der Protein-Kinase C $\alpha$ (PRKCA) (Finkenzeller et al., 1990; Accession-Nr. X52479) konnten 5 Exons dieses Enzyms innerhalb des BAC-Klons hRPK.155C3 kartiert werden (s. Abb. 24). Die Sequenz der cDNA stimmt für die einzelnen Exons völlig mit der Sequenz des BAC-Klons überein. Die detaillierte Information über die Exons ist in Tab. 36 enthalten.

Tab. 36: Exon-Intron-Struktur der PRKCA (Teil 2)

\begin{tabular}{|c|c|c|c|c|c|c|}
\hline PRKCA & $\begin{array}{l}\text { cDNA- } \\
\text { Position }\end{array}$ & $\begin{array}{l}\text { Position in } \\
\text { hRPK.115C3 }\end{array}$ & $\begin{array}{l}\text { Exon- } \\
\text { länge (bp) }\end{array}$ & 5'-Exon-Intron-Grenze & 3'-Exon-Intron-Grenze & $\begin{array}{l}\text { Intron- } \\
\text { länge (bp) }\end{array}$ \\
\hline Exon $\geq 3$ & $316 \ldots 427$ & $77049 \ldots 76938$ & 112 & $\begin{array}{l}\text { agcattgtgcttcttctcetccea } \\
\text { gGACCCCAGGA }\end{array}$ & $\begin{array}{l}\text { AAATGTGACAgtaagt } \\
\text { aagttttcttttccagttc }\end{array}$ & 3916 \\
\hline Exon $\geq 4$ & $428 \ldots . .556$ & $73021 \ldots 72893$ & 129 & $\begin{array}{l}\text { caccetctcctttcttgattcaca } \\
\text { gCCTGCGATAT }\end{array}$ & $\begin{array}{l}\text { CATGTCACAGgtaagg } \\
\text { cttgctcatcccggagcag }\end{array}$ & 41599 \\
\hline Exon $\geq 5$ & $557 \ldots 713$ & $31293 \ldots 31137$ & 157 & $\begin{array}{l}\text { tattttcttcettctctcttcacag } \\
\text { TACGAGATGC }\end{array}$ & $\begin{array}{l}\text { CCTTTACATTgtaagtg } \\
\text { gtctctccttgatcaaat }\end{array}$ & 1034 \\
\hline Exon $\geq 6$ & $714 \ldots 848$ & $30102 \ldots 29968$ & 135 & $\begin{array}{l}\text { gtttgcatgtgtgtgtgtcttgta } \\
\text { gCAAATTGAAA }\end{array}$ & $\begin{array}{l}\text { CCAGTGGATGgtatgg } \\
\text { aagccgcttaggttgagta }\end{array}$ & 514 \\
\hline Exon $\geq 7$ & $849 \ldots 945$ & $29453 \ldots 29357$ & 97 & $\begin{array}{l}\text { actcttcttctcccgtccttgaaa } \\
\text { gGTACAAGTTG }\end{array}$ & $\begin{array}{l}\text { GAAATTCGAGgtgag } \\
\text { gataacaaaatgcceggaaa }\end{array}$ & 44973 \\
\hline
\end{tabular}


Über Sequenzvergleiche konnte dem BAC hRPK.115C3 zudem die bisher nicht in der Region kartierte EST H59098 (Accession-Nr. H59098) zugeordnet werden. Die Basen 1 bis 430 dieser EST zeigen eine Identität von 96 \% mit den Basen 143703 bis 144059 des BACs. Die Lokalisierung von H59098 in der Region 17q23-q24 ist Abb. 23 zu entnehmen.

\subsubsection{Identifizierung von hRPK.74H8 (Accession-Nr. AC005918)}

Der BAC-Klon hRPK.74H8 ist seit dem 4. Mai 1999 in der EMBL/GenBank-Datenbank enthalten. Zur Zeit ist das Insert dieses Klons noch nicht vollständig sequenziert, sondern es existiert ein Sequenzcontig für die Basenpaare 1 bis 21003 und ein Contig für die Basenpaare 21004 bis 141077. Dazwischen befindet sich eine Lücke unbekannter Größe. Die Basenpaare 140851 bis 102686 dieses BAC-Klons überlappen mit den Basenpaaren 1 bis 38167 des BACKlons hRPK.115C3, diese Klone weisen somit einen Bereich von ungefähr $38 \mathrm{~kb}$ gemeinsam auf.

Die Basen 1 bis 199 des innerhalb der Protein-Kinase C $\alpha$ (PRKCA) lokalisierten Locus D17S1977 (Accession-Nr. G11166) weisen eine 99 \%ige Homologie zu den Basen 16162 bis 15962 des BAC-Klons hRPK.74H8 auf. Zudem wurden 12 Exons der PRKCA innerhalb dieses Klons identifiziert (s. Abb 24 und Tab. 37). Die Sequenz der cDNA stimmt im Bereich dieser Exons, mit Ausnahme der Exons $\geq 14$ und $\geq 16$, völlig mit der Sequenz von hRPK.74H8 überein. Die cDNA der PRKCA weist an Position 1729 (lokalisiert im Exon $\geq 14$ ) jedoch ein A auf, während hRPK.74H8 an der entsprechenden Position (32542) ein G aufweist. Durch einen $\mathrm{A} \rightarrow \mathrm{G}-$ Austausch würde es zu einem Einbau von Valin anstelle von Isoleucin kommen. Außerdem weist hRPK.74H8 in dem Sequenzabschnitt, der Exon $\geq 16$ entspricht, 2 Nukleotide auf (Nr. 16186 und 16105), die in der cDNA der PRKCA nicht enthalten sind. Diese Basen liegen in der 3'UTR der PRKCA.

Tab 37: Exon-Intron-Struktur der PRKCA (Teil 3)

\begin{tabular}{|c|c|c|c|c|c|c|}
\hline PRKCA & $\begin{array}{l}\text { cDNA- } \\
\text { Position }\end{array}$ & $\begin{array}{l}\text { Position in } \\
\text { hRPK.74H8 }\end{array}$ & $\begin{array}{l}\text { Exon- } \\
\text { länge } \\
\text { (bp) }\end{array}$ & 5'-Exon-Intron-Grenze & 3'-Exon-Intron-Grenze & $\begin{array}{l}\text { Intron- } \\
\text { länge } \\
\text { (bp) }\end{array}$ \\
\hline Exon $\geq 5$ & $557 \ldots 713$ & $133751 \ldots 133595$ & 157 & $\begin{array}{l}\text { tattttcttcettctctcttcacag } \\
\text { TACGAGATGC }\end{array}$ & $\begin{array}{l}\text { CCTTTACATTgtaagt } \\
\text { ggtctctcettgatcaaat }\end{array}$ & 1034 \\
\hline Exon $\geq 6$ & $714 \ldots 848$ & $132560 \ldots 132426$ & 135 & $\begin{array}{l}\text { gtttgcatgtgtgtgtgtcttgta } \\
\text { gCAAATTGAAA }\end{array}$ & $\begin{array}{l}\text { CCAGTGGATGgtatg } \\
\text { gaagccgcttaggttgagta }\end{array}$ & 514 \\
\hline Exon $\geq 7$ & $849 \ldots 945$ & $131911 \ldots 131815$ & 97 & $\begin{array}{l}\text { actcttcttctccegtcettgaa } \\
\text { agGTACAAGTTG }\end{array}$ & $\begin{array}{l}\text { GAAATTCGAGgtgag } \\
\text { gataacaaaatgcccggaaa }\end{array}$ & 44973 \\
\hline Exon $\geq 8$ & $946 \ldots 1083$ & $86839 \ldots 86702$ & 138 & $\begin{array}{l}\text { tttcccatttgtgettgttatttag } \\
\text { AAAGCCAAAC }\end{array}$ & $\begin{array}{l}\text { TTTTGGAAAGgtaag } \\
\text { aggacagtcgtctgcaaatt }\end{array}$ & 2663 \\
\hline Exon $\geq 9$ & $1084 \ldots 1257$ & $84038 \ldots 83865$ & 174 & $\begin{array}{l}\text { caggttgttcttgacgtgttctc } \\
\text { agGTGATGCTTG }\end{array}$ & $\begin{array}{l}\text { CCAGACAGTGgtaag } \\
\text { gaccetgggaatccetgcga }\end{array}$ & 3101 \\
\hline Exon $\geq 10$ & $1258 \ldots 1349$ & $80763 \ldots 80672$ & 92 & $\begin{array}{l}\text { tcatgtgttgaaccttggtctgc } \\
\text { agGATCGGCTGT }\end{array}$ & $\begin{array}{l}\text { CACAAGCAGTgtgag } \\
\text { tattattttttaagtccttt }\end{array}$ & 2803 \\
\hline
\end{tabular}


Tab. 37: Fortsetzung

\begin{tabular}{|c|c|c|c|c|c|c|}
\hline PRKCA & $\begin{array}{l}\text { cDNA- } \\
\text { Position }\end{array}$ & $\begin{array}{l}\text { Position in } \\
\text { hRPK.74H8 }\end{array}$ & $\begin{array}{l}\text { Exon- } \\
\text { länge } \\
\text { (bp) }\end{array}$ & 5'-Exon-Intron-Grenze & 3'-Exon-Intron-Grenze & $\begin{array}{l}\text { Intron- } \\
\text { länge } \\
\text { (bp) }\end{array}$ \\
\hline Exon $\geq 11$ & $1350 \ldots 1412$ & $77868 \ldots 77806$ & 63 & $\begin{array}{l}\text { acctgaagcccgttttcttttgc } \\
\text { agATTCTATGCG }\end{array}$ & $\begin{array}{l}\text { TCATTTATAGgtgtgt } \\
\text { attgaagccctcctaccag }\end{array}$ & 900 \\
\hline Exon $\geq 12$ & $1413 \ldots 1551$ & $76905 \ldots 76767$ & 139 & $\begin{array}{l}\text { ctgatgttaacccggttccttgc } \\
\text { agGGATCTGAAG }\end{array}$ & $\begin{array}{l}\text { CGCCCCAGAGgtagg } \\
\text { aaccccagtgatcgttttct }\end{array}$ & 31226 \\
\hline Exon $\geq 13$ & $1552 \ldots 1632$ & $45540 \ldots 45460$ & 81 & $\begin{array}{l}\text { aattgatgtgtttgtttcacaca } \\
\text { gATAATCGCTT }\end{array}$ & $\begin{array}{l}\text { TGCCGGGCAGgtaat } \\
\text { gtttgctacattttcatgt }\end{array}$ & 12799 \\
\hline Exon $\geq 14$ & $1633 \ldots 1740$ & $32660 \ldots 32553$ & 108 & $\begin{array}{l}\text { ccatctttctttttttccggaaca } \\
\text { gCCTCCATTTG }\end{array}$ & $\begin{array}{l}\text { CTGCAAAGGAgtaag } \\
\text { tcgatttggataccttttgt }\end{array}$ & 1864 \\
\hline Exon $\geq 15$ & $1741 \ldots 1881$ & $30688 \ldots 30548$ & 141 & $\begin{array}{l}\text { ctccttttctccttttcctttctag } \\
\text { CTGATGACCA }\end{array}$ & $\begin{array}{l}\text { GCCCAAAGTGgtgag } \\
\text { tccagaaaagcagcctgttt }\end{array}$ & $\begin{array}{l}\approx \\
14220\end{array}$ \\
\hline Exon $\geq 16$ & $1882 \ldots 2245$ & $16327 \ldots 15962$ & 364 & $\begin{array}{l}\text { cettcttttgtettttctccacag } \\
\text { TGTGGCAAAG }\end{array}$ & & \\
\hline
\end{tabular}

Neben den bisher beschriebenen Homologien zeigen die Basen 10252 bis 9477 des BAC-Klon hRPK.74H8 eine $100 \%$ ige Übereinstimmung mit den Basen 1664 bis 2439 der cDNA der auf dem X-Chromosom lokalisierten Glukose-6-Phosphat-Dehydrogenase (G6PD)(Accession-Nr. M12996). Innerhalb dieser Sequenz findet sich auch der Locus G6PDL (siehe auch unter 3.1.1.1). Falls es sich bei G6PDL um ein Gen handelt, ist die weitere Sequenz dieses Gens vermutlich nicht mit der G6PD homolog, da die Basenpaare 1 bis 1663 der cDNA der G6PD keine Homologien zu der Sequenz der BAC-Klone hRPK.74H8 oder hRPK.115C3 aufweisen. Die Sequenz der STS D17S1524 (Accession-Nr. G03566) konnte ebenfalls auf dem BAC-Klon hRPK.74H8 lokalisiert werden. Die Basenpaare 1 bis 208 der Sequenz von D17S1524 weisen eine 93 \%ige Übereinstimmung zu den Basen 79857 bis 80066 des BAC-Klons auf. Die relativ geringe Übereinstimmung ist vermutlich durch Sequenzierungsfehler in der Sequenz von D17S1524 zu erklären, zumal die Sequenz dieser STS einige nicht spezifizierte Nucleotide (N) aufweist.

\subsubsection{Identifizierung von hRPK.299G24 (Accession-Nr. AC005988)}

Der BAC-Klon hRPK.299G24 ist seit dem 15. Januar 1999 in der EMBL/GenBank-Datenbank enthalten. Das sequenzierte Insert dieses Klons hat eine Länge von 173126 bp. Die Basenpaare 1 bis 18724 dieses Klons überlappen mit den Basenpaaren 18724 bis 1 des BAC-Klons hRPK.74H8. Diese Klone weisen somit einen Bereich von ungefähr 19 kb gemeinsam auf (s. Abb. 24).

Durch einen Sequenzvergleich wurde festgestellt, daß die Basen 1 bis 341 der STS D17S807 (Accession-Nr. Z17055) eine 95 \%ige Homologie zu den Basen 61681 bis 61334 des BACKlons hRPK.299G24 aufweisen. Diese Sequenzen stimmen vermutlich aufgrund von fehlerhaften Sequenzierungen nicht völlig überein. 


\subsubsection{Identifizierung von hRPK.349A8 (Accession-Nr. AC005544)}

Der seit dem 25. September 1998 in der EMBL/GenBank-Datenbank enthaltene BAC-Klon hRPK.349A8 weist ein 169045 bp langes Insert auf. Die Sequenz dieses Klons stimmt von Basenpaar 169045 bis 167046 vollkommen mit den Basenpaaren 171127 bis 173126 des BACKlons hRPK.299G24 überein. Somit überlappen die BAC-Klone hRPK.349A8 und hRPK.299G24 in einem Bereich von 2000 bp (s. Abb. 24).

Die Basenpaare 1 bis 308 der Sequenz der STS GAAT1E12 (Accession-Nr. G09282) zeigen eine Übereinstimmung von $99 \%$ mit den Basen 130109 bis 129802 des BAC-Klons hRPK.349A8.

Daneben wurden über einen Sequenzvergleich mit der bekannten cDNA des CACNLG-Gens (Powers et al., 1993; Accession-Nr. L07738) die 4 Exons des CACNLG-Gens innerhalb der Sequenz des BAC-Klons hRPK.349A8 identifiziert (s. Abb. 24). Die Position der einzelnen Exons innerhalb des BAC-Klons hRPK.349A8 ist Tabelle $38 \mathrm{zu}$ entnehmen. Die Sequenz der cDNA stimmt für die ersten 3 Exons völlig mit der des BAC-KLons überein. Bis zum StopCodon in Exon 4 wurde ebenfalls keine Abweichung der cDNA-Sequenz von der des BACs hRPK.349A8 beobachtet. In der 3'UTR zeigen sich jedoch einige Abweichungen, so daß die Homologie der cDNA zu der des BACs in dem Abschnitt, der Exon 4 enthält, nur $97 \%$ beträgt.

Tab. 38: Exon-Intron-Struktur von CACNLG

\begin{tabular}{|c|c|c|c|c|c|c|}
\hline CACNLG & $\begin{array}{l}\text { cDNA- } \\
\text { Position }\end{array}$ & $\begin{array}{l}\text { Position in } \\
\text { hRPK.349A8 }\end{array}$ & $\begin{array}{l}\text { Exon- } \\
\text { länge } \\
\text { (bp) }\end{array}$ & $\begin{array}{l}\text { 5'-Exon-Intron- } \\
\text { Grenze }\end{array}$ & 3'-Exon-Intron-Grenze & $\begin{array}{l}\text { Intron- } \\
\text { länge } \\
\text { (bp) }\end{array}$ \\
\hline Exon 1 & $1 \ldots 300$ & $97059 \ldots 96760$ & 300 & & $\begin{array}{l}\text { CTGCCCGGGGgtaac } \\
\text { gtacccaccetccgtcccga }\end{array}$ & 9106 \\
\hline Exon 2 & $301 \ldots 375$ & $87653 \ldots 87579$ & 75 & $\begin{array}{l}\text { tcacagtctgtctcctcctttgc } \\
\text { agAGAAGAACTG }\end{array}$ & $\begin{array}{l}\text { ACTCAGAAGGgtgag } \\
\text { cctgggtggaaaggggtctg }\end{array}$ & 1032 \\
\hline Exon 3 & $376 \ldots . .513$ & $86546 \ldots 86409$ & 138 & $\begin{array}{l}\text { tgctgggtgtccettgtgtttgc } \\
\text { agAGTACAGCAT }\end{array}$ & $\begin{array}{l}\text { GCCTTTGCAGgtagac } \\
\text { tgggggatctgcctgagcg }\end{array}$ & 804 \\
\hline Exon 4 & $514 \ldots 1258$ & $85604 \ldots 84856$ & 745 & $\begin{array}{l}\text { tgagcatgcetggctctgccc } \\
\text { ccagGTCTCTGCAT }\end{array}$ & & \\
\hline
\end{tabular}

Daneben enthält der BAC hRPK.349A8 12 Exons eines bisher nicht beschriebenen Gens, welches in der NCBI-Datenbank unter der Bezeichnung KIAA0054 (Accession-Nr. D29677) geführt wird. Dieses Gen stammt aus einer humanen Myeloblast-Zellinie. Die zu den ersten 2914 bp der 6274 bp langen cDNA korrespondierenden Exons sind jedoch nicht in hRPK.349A8 enthalten. Die Exon-Intron-Grenzen der identifizierten 12 Exons dieses Gens sind Tabelle $39 \mathrm{zu}$ entnehmen. Die Sequenz der cDNA von KIAA0054 stimmt für die jeweiligen Bereiche der Exons, mit Ausnahme der Exons $>10$ und $>13$, völlig mit der Sequenz von hRPK.74H8 überein. Die cDNA weist an Position 4734 (lokalisiert im Exon > 10) jedoch ein $T$ auf, während hRPK.349A8 an der entsprechenden Position (33022) ein $C$ aufweist. Durch einen $\mathrm{T} \rightarrow \mathrm{C}$-Austausch würde es zu einem Einbau von Alanin anstelle von Valin kommen. Zudem weist hRPK.349A8 in dem Sequenzabschnitt, der Exon > 13 entspricht, 
ein $\mathrm{T}$ auf (Position 63402), welches in der cDNA von KIAA0054 nicht enthalten ist. Diese Base liegt in der 3'UTR.

Tab.39: In BAC hRPK.349A8 identifizierte Exons des Gens KIAA0054

\begin{tabular}{|c|c|c|c|c|c|c|}
\hline KIAA0054 & $\begin{array}{l}\text { cDNA- } \\
\text { Position }\end{array}$ & $\begin{array}{l}\text { Position in } \\
\text { hRPK.349A8 }\end{array}$ & $\begin{array}{l}\text { Exon- } \\
\text { länge } \\
\text { (bp) }\end{array}$ & $\begin{array}{l}\text { 5'-Exon-Intron- } \\
\text { Grenze }\end{array}$ & 3'-Exon-Intron-Grenze & $\begin{array}{l}\text { Intron- } \\
\text { länge } \\
\text { (bp) }\end{array}$ \\
\hline Exon $>2$ & $2915 \ldots 3098$ & $3535 \ldots .3718$ & 184 & $\begin{array}{l}\text { tgtatgtgtgtgtttgtttttaaa } \\
\text { gGTGTTTGAAG }\end{array}$ & $\begin{array}{l}\text { AATGTTCAAGgtaag } \\
\text { tgtcaattgaaatgaattca }\end{array}$ & 1732 \\
\hline Exon $>3$ & $3099 \ldots 3327$ & $5451 \ldots . .5679$ & 229 & $\begin{array}{l}\text { ttttcttaaaaattttctttgta } \\
\text { gGAAAGCAATT }\end{array}$ & $\begin{array}{l}\text { GAAGATGCAGgtaat } \\
\text { tatgtgttaatgttgagaca }\end{array}$ & 7114 \\
\hline Exon $>4$ & $3328 \ldots 3532$ & $12794 \ldots 12998$ & 205 & $\begin{array}{l}\text { ctgatcttgtaaatcttttctgta } \\
\text { gGAAATTTTGG }\end{array}$ & $\begin{array}{l}\text { ACCACCCAAGgtaaa } \\
\text { gcctctgttaatgaaattga }\end{array}$ & 4636 \\
\hline Exon $>5$ & $3533 \ldots 3584$ & $17635 \ldots 17686$ & 52 & $\begin{array}{l}\text { tatacatttgtgtttttctttaaa } \\
\text { gGGGAAAAGTC }\end{array}$ & $\begin{array}{l}\text { GATGGAATTGgtaag } \\
\text { tggaaaaattaccctatgaa }\end{array}$ & 802 \\
\hline Exon $>6$ & $3585 \ldots 3775$ & $18489 \ldots 18679$ & 191 & $\begin{array}{l}\text { catcctttttctgtttatttttcag } \\
\text { TTCAGCCCAA }\end{array}$ & $\begin{array}{l}\text { GCCTTTACCTgtaagt } \\
\text { ggacattcgaaatactttc }\end{array}$ & 2357 \\
\hline Exon $>7$ & $3776 \ldots 3987$ & $21037 \ldots 21248$ & 212 & $\begin{array}{l}\text { tgtattttattttttaataaccta } \\
\text { gGTACCATGGA }\end{array}$ & $\begin{array}{l}\text { GAAATGGTAAgttgt } \\
\text { acttcgctgttctcctgttc }\end{array}$ & 5997 \\
\hline Exon $>8$ & $3984 \ldots 4063$ & $27246 \ldots . .27325$ & 80 & $\begin{array}{l}\text { taaggatttttaaatattttctta } \\
\text { gGTAAAAGTGA }\end{array}$ & $\begin{array}{l}\text { ACCAAAACAGgtatg } \\
\text { ctgcttagttactgtgttgt }\end{array}$ & 4637 \\
\hline Exon $>9$ & $4064 \ldots 4634$ & $31963 \ldots 32533$ & 571 & $\begin{array}{l}\text { aaaaaggcttcttctttttttcta } \\
\text { gGTTGATTTGG }\end{array}$ & $\begin{array}{l}\text { GAGGCTTTAGgtaag } \\
\text { ttctattactgccagatgtg }\end{array}$ & 389 \\
\hline Exon $>10$ & $4635 \ldots 4869$ & $32923 \ldots 33157$ & 235 & $\begin{array}{l}\text { aaatttttcacaaatatttttgc } \\
\text { agATCGTATACA }\end{array}$ & $\begin{array}{l}\text { CATACTCAAGgtattc } \\
\text { cagcggactgaaaatagcc }\end{array}$ & 806 \\
\hline Exon $>11$ & $4870 \ldots 5386$ & $33964 \ldots 34480$ & 517 & $\begin{array}{l}\text { ctcatattttattgttttcatgta } \\
\text { gGTTTCAAGAC }\end{array}$ & $\begin{array}{l}\text { CTTAGAAGAGgtaaa } \\
\text { tgtcttcttattttcctttt }\end{array}$ & 20087 \\
\hline Exon $>12$ & 5387...5639 & $54568 \ldots . .54820$ & 253 & $\begin{array}{l}\text { tgaaatgttctttttctttgtgta } \\
\text { gTATGAGCCCA }\end{array}$ & $\begin{array}{l}\text { GAGTTGATAGgtaag } \\
\text { acagagttggtggctaaaac }\end{array}$ & 8242 \\
\hline Exon $>13$ & $5640 \ldots 6274$ & $63063 \ldots 63698$ & 635 & $\begin{array}{l}\text { ctgtgtcactgttctctgctttt } \\
\text { agCGCCACCCAA }\end{array}$ & & \\
\hline
\end{tabular}

Über Sequenzvergleiche konnte dem BAC hRPK.349A8 zudem die bisher nicht in der Region kartierte EST stSG48128 (Accession-Nr. AI093112) zugeordnet werden. Die Basen 1 bis 343 dieser EST zeigen eine 100 \%ige Identität mit den Basen 108252 bis 108594 des BACs. Die Lokalisierung von stSG48128 in der Region 17q23-q24 ist Abb. 23 zu entnehmen.

\subsubsection{Identifizierung von hRPK.62F10 (Accession-Nr. AC005799)}

Der BAC-Klon hRPK.62F10 ist seit dem 24. Oktober 1998 in der EMBL/GenBank-Datenbank enthalten. Das sequenzierte Insert dieses Klons hat eine Länge von 154902 bp.

Über einen Sequenzvergleich mit der Sequenz der STS D17S789 (Accession-Nr. Z16583) wurde eine 99 \%ige Übereinstimmung der Basen 1 bis 312 mit den Basen 110506 bis 110193 
des BAC-Klons hRPK.62F10 festgestellt. Zudem wurden über einen Sequenzvergleich mit der bekannten cDNA-Sequenz des Gens PRKAR1A (human cAMP-dependent protein kinase type I-alpha subunit) (Accession-Nr. M18468) 9 Exons innerhalb dieses BAC-Klons identifiziert. Die Position dieser Exons innerhalb des BAC-Klons hRPK.62F10 ist Tab. $40 \mathrm{zu}$ entnehmen. Für die ersten 280 bp der cDNA konnten keine Exons identifiziert werden. Die Exon-IntronStruktur dieses Gens wurde von Solberg et al. (1997) beschrieben. Demnach ist das erste Exon, welches innerhalb der Sequenz des BAC-Klons hRPK.62F10 identifiziert wurde, Exon 3.

Tab. 40: Exon-Intron-Struktur der PRKAR1A

\begin{tabular}{|c|c|c|c|c|c|c|}
\hline PRKAR1A & $\begin{array}{l}\text { cDNA- } \\
\text { Position }\end{array}$ & $\begin{array}{l}\text { Position in } \\
\text { hRPK.62F10 }\end{array}$ & $\begin{array}{l}\text { Exon- } \\
\text { länge } \\
\text { (bp) }\end{array}$ & 5'-Exon-Intron-Grenze & 3'-Exon-Intron-Grenze & $\begin{array}{l}\text { Intron- } \\
\text { länge } \\
\text { (bp) }\end{array}$ \\
\hline Exon 3 & $281 \ldots 451$ & $585 \ldots 755$ & 171 & $\begin{array}{l}\text { tttgcaaactcgtaatttctttca } \\
\text { gGAGGAGGCAA }\end{array}$ & $\begin{array}{l}\text { TGTTAGAAAGgtagtt } \\
\text { ttgatatttgaatatcggg }\end{array}$ & 798 \\
\hline Exon 4 & $452 \ldots . .543$ & $1554 \ldots 1645$ & 92 & $\begin{array}{l}\text { catttgaccttcagttcttttctag } \\
\text { GTTATACCAA }\end{array}$ & $\begin{array}{l}\text { ATGAGAGAAGgtagg } \\
\text { aacaggctctttcttaacac }\end{array}$ & 199 \\
\hline Exon 5 & $544 \ldots 605$ & $1845 \ldots 1906$ & 62 & $\begin{array}{l}\text { acacgaggccttctctcttttgc } \\
\text { agTGATATTTTT }\end{array}$ & $\begin{array}{l}\text { ATTCAGCAAGgtaag } \\
\text { ggcctctggagcatgcaata }\end{array}$ & 834 \\
\hline Exon 6 & $606 \ldots 652$ & $2741 \ldots 2787$ & 47 & $\begin{array}{l}\text { ttctaacttttttaccctcttttag } \\
\text { GTGATGAAGG }\end{array}$ & $\begin{array}{l}\text { AGAGACGGATgtaag } \\
\text { atttaccaatatcaaaaata }\end{array}$ & 795 \\
\hline Exon 7 & $653 \ldots 811$ & $3583 \ldots 3741$ & 159 & $\begin{array}{l}\text { ttttttgatgtcacttgcactttag } \\
\text { GTCTATGTTA }\end{array}$ & $\begin{array}{l}\text { AATCCTCATGgtaag } \\
\text { agaccatggtgtttgagagt }\end{array}$ & 1929 \\
\hline Exon 8 & $812 \ldots 872$ & $5671 \ldots .5731$ & 61 & $\begin{array}{l}\text { tcacttttgttatttttatttttagG } \\
\text { GAAGCACAC }\end{array}$ & $\begin{array}{l}\text { TCTATTTTAGgtgagt } \\
\text { tgtaaagtgtgttaacttt }\end{array}$ & 969 \\
\hline Exon 9 & $873 \ldots 994$ & $6701 \ldots 6822$ & 122 & $\begin{array}{l}\text { aattattttgattcttgtctttcag } \\
\text { AGTCTCTGGA }\end{array}$ & $\begin{array}{l}\text { TATTTTAGAGgtaaa } \\
\text { gaactcagaatttaatactt }\end{array}$ & 928 \\
\hline Exon 10 & $995 \ldots 1076$ & $7751 \ldots 7832$ & 82 & $\begin{array}{l}\text { tagctttttggtgattttattatag } \\
\text { GGGTCAGCTG }\end{array}$ & $\begin{array}{l}\text { GATTATTTTGgtatgt } \\
\text { atgaattccctcacaataa }\end{array}$ & 275 \\
\hline Exon 11 & $1077 \ldots 1464$ & $8108 \ldots 8496$ & 388 & $\begin{array}{l}\text { tgttacccatctttgetttctcca } \\
\text { gGTGAAATTGC }\end{array}$ & & \\
\hline
\end{tabular}

Zudem konnte dem Klon 62F10 die bisher nicht im Contig der Region 17q23-q24 enthaltene EST stSG22116 (Accession-Nr. AI128237) über Sequenzvergleiche zugeordnet werden. Dieser Locus weist eine 100 \%ige Homologie zu den Basen 14679 bis 15099 des BACs auf.

\subsubsection{Identifizierung von HCIT87G17 (AC003663)}

Das sequenzierte Insert des BAC-Klons HCIT87G17 ist seit dem 1. Mai 1998 in der EMBL/GenBank-Datenbank enthalten und hat eine Länge von 132070 bp.

Dieser Klon wurde im Verlauf der Generierung der genomischen Sequenz von Karyopherin $\alpha 2$ (KPNA2) über Homologien mit der Sequenz dieses Gens identifiziert. Der BAC-Klon beinhaltet die STS D17S1557 und weist zudem ähnliche Sequenzen wie 2 STS-Stellen von KPNA2 auf. Diese STS-Stellen liegen in der Region 17q23-q24 dupliziert vor und der BAC weist nicht 
die exakte Sequenz dieser STS-Stellen auf. Zudem konnte über einen Vergleich festgestellt werden, daß die Sequenz der STS $81 T 7$ in 187 bp eine 88 \%ige Identität mit der Sequenz des BAC-Klons HCIT87G17 aufweist. Die gefundenen Homologien zu den STS-Stellen werden in Tab. 41 dargestellt.

Tab. 41: Zuordnung von STS-Stellen zu dem BAC HCIT87G17

\begin{tabular}{lll}
\hline STS-Stelle & Position in HCIT87G17 & Identität \\
\hline D17S1557 (246 bp) (Accession-Nr. G03585) & $1234 \ldots 1480$ & $99 \%$ \\
KPNA2-E2 (259 bp) (s. 3.13.1) & $65846 \ldots 66103$ & $90 \%$ \\
KPNA2-3' (152 bp) (s. 3.13.1) & $74619 \ldots 74766$ & $96 \%$ \\
$81 T 7$ (256 bp) (s. 3.8.2.11) & $92686 \ldots 92566$ & $88 \%$ \\
\hline
\end{tabular}

Nachdem die vollständige Sequenz von KPNA2 im Rahmen dieser Arbeit ermittelt worden war, zeigte sich, daß der BAC HCIT87G17 zu großen Teilen zu KPNA2 homologe, jedoch nicht identische Sequenzen beinhaltet. Diese Homologien sind unter 3.13.4 aufgeführt. Über einen Vergleich der entsprechenden Abschnitte von HCIT87G17 in der EST-Datenbank konnten keine $\mathrm{zu}$ diesen Abschnitten korrespondierenden ESTs identifiziert werden, jedoch weist auch die zu KPNA2 homologe Sequenz des BACs HCIT87G17 einen offenen Leserahmen auf. Dieser BAC beinhaltet somit ein zu KPNA2 homologes Gen oder Pseudogen.

\subsubsection{Identifizierung von hRPK.115N5 (Accession-Nr. AC006440)}

Zur Zeit ist der ist seit dem 20. November 1999 in der EMBL/GenBank-Datenbank enthaltene BAC-Klon hRPK.115N5 nicht vollständig sequenziert. In den Datenbanken sind 3 geordnete Sequenzabschnitte enthalten, zwischen denen Lücken unbekannter Größe vorhanden sind. Die bisher ermittelte Sequenz des Inserts hat eine Länge von 170607 bp.

Durch einen Sequenzvergleich mit der in den Datenbanken verfügbaren Sequenz der EST WI8032 (Accession-Nr. T40812) wurde festgestellt, daß die Basen 1 bis 310 der EST eine 99 \%ige Homologie zu den Basen 123617 bis 123312 des BACs aufweisen. Daher konnte hRPK.115N5 der Region 17q23-q24 zugeordnet werden (s. Abb. 23). 


\subsection{Kartierung und Charakterisierung des Gens von Karyopherin alpha 2 (KPNA2) und Suche nach Mutationen in Probanden mit RSS}

Karyopherine, alternativ auch Importine genannt, sind Transportfaktoren, die am Proteinimport in den Zellkern beteiligt sind (Görlich und Mattaj, 1996). Da mit Ausnahme von Proteinen < 45 $\mathrm{kDa}$ sämtliche Proteine, die im Zellkern benötigt werden, aktiv über die Kernporen transportiert werden, wäre eine Zelle, in der dieser Transport nicht stattfindet, nicht überlebensfähig. Die am Kerntransport beteiligten Proteine gehören jedoch zu einer Multigenfamilie, so daß die reduzierte Expression bzw. das Ausfallen eines Mitgliedes dieser Genfamilie mit dem RSS assoziiert sein könnte.

\subsubsection{Kartierung von KPNA2 über PCR}

Bei einem Vergleich in der EMBL/GenBank-Datenbank mit der über CL3-Sequenzierung erhaltenen Sequenz eines Endfragmentes des Cosmids CF20b wurde für einen Teil der Sequenz eine Übereinstimmung mit der cDNA-Sequenz von KPNA2 (Accession-Nr. U09559) festgestellt (s. unter 3.6.1.6). Da das Cosmid CF20b in der Region des Translokationsbruchpunktes des Probanden AS auf Chromosom 17 kartiert wurde (s. Abb. 22), sollte überprüft werden, ob KPNA2 in der Region des Bruchpunktes von Proband AS lokalisiert ist.

Um KPNA2 innerhalb des YAC- bzw. PAC-Contigs lokalisieren zu können, wurden anhand der bekannten cDNA-Sequenz von KPNA2 die folgenden zwei Genloci konstruiert:

Tab. 42: Genloci für KPNA2 (Teil 1)

\begin{tabular}{lllll}
\hline Genlocus & $\begin{array}{l}\text { cDNA- } \\
\text { Position }\end{array}$ & $\begin{array}{l}\text { forward-Primer Sequenz }\left(5^{\prime} \rightarrow 3^{\prime}\right) \\
\text { reverse-Primer Sequenz }\left(5^{\prime} \rightarrow 3^{\prime}\right)\end{array}$ & $\begin{array}{l}\text { Größe des PCR- } \\
\text { Produkts der } \\
\text { cDNA (bp) }\end{array}$ & $\begin{array}{l}\text { Größe des } \\
\text { genomischen PCR- } \\
\text { Produkts (bp) }\end{array}$ \\
\hline KPNA2-E2 & $133 \ldots 151$ & $\begin{array}{l}\text { ATGTCCACCAACGAGAATG } \\
\text { CCACATTGACCTCTATTCTGC }\end{array}$ & 109 & 259 \\
KPNA2-3' & $241 \ldots 221$ & $\begin{array}{l}\text { 1806...1827 } \\
\text { ATGTGGTTTGTTACTGTAGCAC }\end{array}$ & 152 & 152 \\
& $1957 \ldots 1936$ & TGAATGTTTATTACAGGATGC & & \\
\hline
\end{tabular}

Über PCR konnten die Loci für dieses Gen auf den den Translokationsbruchpunkt des Probanden AS überspannenden YACs 955H4, 871C4, 845C6, 931B10 und 901G9 sowie auf dem den Bruchpunkt überspannenden PAC 81B9 lokalisiert werden. Daneben wurden auch die proximal zum Bruchpunkt lokalisierten YACs $765 \mathrm{~F} 4$ und 963C7 sowie der proximal zum Bruchpunkt lokalisierte PAC 245A13 für diese Loci positiv getestet. Auf dem distal zum Bruchpunkt lokalisierten Cosmid CF20b konnte nur der Locus KPNA2-3' nachgewiesen werden, dieses Cosmid beinhaltet demnach nur einen Teil der Sequenz von KPNA2.

Da aufgrund des erstellten YAC-Contigs (s. Abb. 5) anzunehmen ist, daß die YACs 765F4 und 963C7 nicht mit den den Translokationsbruchpunkt überspannenden Klonen überlappen, deuteten die erhaltenen PCR-Ergebnisse darauf hin, daß Sequenzen von KPNA2 innerhalb der Region des YAC-Contigs verdoppelt vorliegen. Aus diesem Grund wurden die mit den ver- 
schiedenen Klonen erhaltenen PCR-Produkte der Loci KPNA2-E2 und KPNA2-3' aus einem Polyacrylamidgel isoliert und anschließend mit dem jeweiligen forward Primer sequenziert. Die Sequenzierung von PCR-Produkten des Locus KPNA2-E2 ergab für die Klone 955H4, 871C4, 845C6, 931B10, $901 \mathrm{G} 9$ und 81B9 Sequenz 1. Über die Sequenzierung der entsprechenden PCR-Produkte der Klone 765F4 und 963C7 wurde Sequenz 2 erhalten. Der Vergleich zwischen Sequenz 1 und 2 ergab eine Identität dieser Sequenzen von $91 \%$. Dieser Sequenzvergleich ist im folgenden gezeigt. Die Sequenz des reverse-Primers ist fett dargestellt.

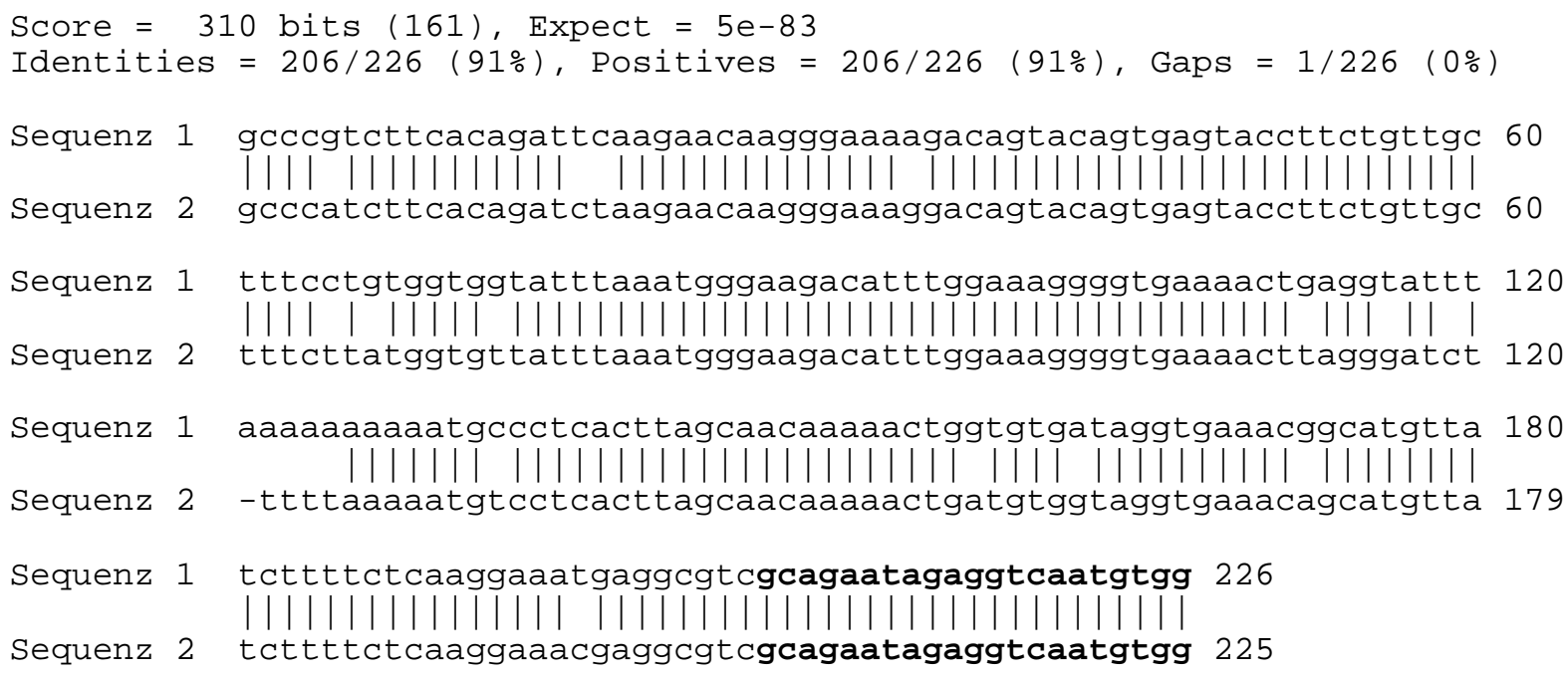

Die Sequenzierung von PCR-Produkten des Locus KPNA2-3' ergab für die Klone 955H4, 845C6, 931B10 und 81B9 Sequenz 1. Für die Klone 765F4, 963C7 und 245A13 wurde Sequenz 2 erhalten. Der Vergleich zwischen Sequenz 1 und 2 ergab eine $96 \%$ ige Übereinstimmung der Sequenzen. Dieser Sequenzvergleich ist im folgenden gezeigt, wobei die Sequenz des reverse-Primers fett dargestellt ist.

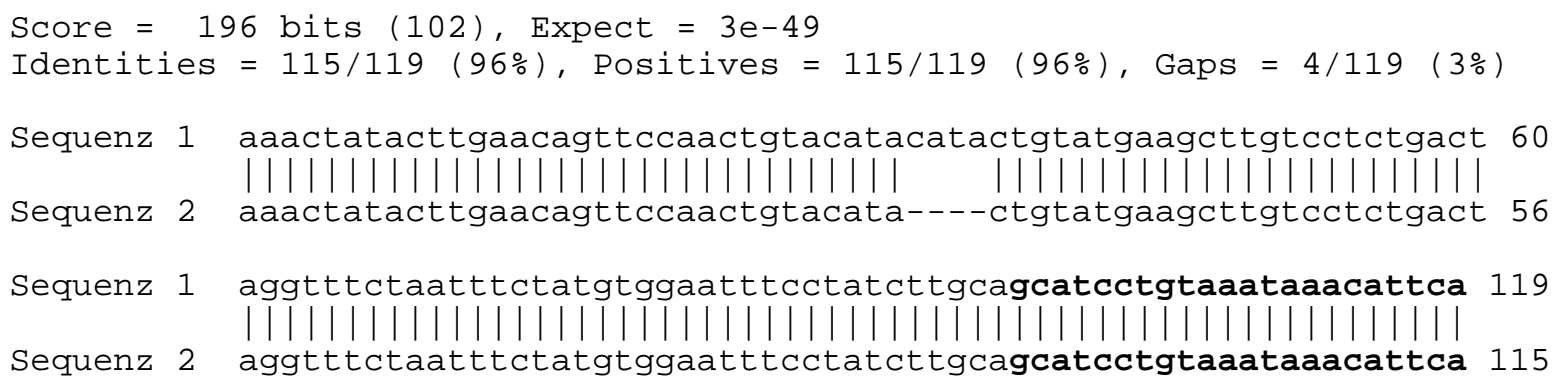

Die proximal zum Translokationsbruchpunkt des Probanden AS kartierten Klone zeigen somit in der Sequenz der beiden für KPNA2 konstruierten Loci spezifische Abweichungen von der entsprechenden Sequenz der den Bruchpunkt überspannenden Klone. Somit konnte gezeigt werden, daß die Loci KPNA2-E2 und KPNA2-3' in der Region 17q23-q24 verdoppelt vorliegen (s. Abb. 22). Eine Entscheidung darüber, ob ein Klon den einen oder den anderen dieser Loci enthält, kann nur aufgrund einer Sequenzierung getroffen werden, oder dadurch, daß der entsprechende Klon weitere zu diesen Markern benachbarte Loci enthält, die nicht verdoppelt vorliegen. 
Um festzustellen, welche der für die Loci KPNA2-E2 und KPNA2-3' erhaltenen Sequenzen für KPNA2 spezifisch ist, wurden diese mit der cDNA-Sequenz von KPNA2 verglichen. Dabei zeigte sich, daß die cDNA-Sequenz jeweils mit Sequenz 1 der Loci KPNA2-E2 und KPNA2-3' übereinstimmte. Für den Locus KPNA2-E2 stimmten die Basenpaare 1 bis 42 der Sequenz 1 mit den Basenpaaren 166 bis 207 der cDNA überein und die Basenpaare 193 bis 226 von Sequenz 1 mit den Basenpaaren 208 bis 241 der cDNA. Die Basen 43 bis 192 der Sequenz 1 enthalten ein 170 bp großes Intron, dessen Spleißdonor- und Spleißakzeptorstelle der GT-AGRegel entsprechen. Die für den Locus KPNA2-3' erhaltene Sequenz 1 stimmt mit den Basenpaaren 1839 bis 1957 der cDNA überein. Daraus konnte geschlossen werden, daß die den Bruchpunkt des Probanden AS überspannenden Klone, aus deren Sequenzierung Sequenz 1 resultierte, KPNA2 enthalten. Dagegen enthalten die proximal zum Bruchpunkt des Probanden AS kartierten Klone ein zu KPNA2 ähnliches Gen oder Pseudogen.

Um einen spezifischen Marker für KPNA2 zu erhalten, wurden anhand der cDNA-Sequenz von KPNA2 weitere Primer abgeleitet und auf ihre Spezifität analysiert. Dadurch konnte schließlich ein spezifischer Marker für KPNA2 gefunden werden. Dabei handelt es sich um den folgenden Locus:

Tab. 43: Genloci für KPNA2 (Teil2)

\begin{tabular}{lllll}
\hline Genlocus & $\begin{array}{l}\text { cDNA- } \\
\text { Position }\end{array}$ & $\begin{array}{l}\text { forward-Primer Sequenz }\left(5^{\prime} \rightarrow 3^{\prime}\right) \\
\text { reverse-Primer Sequenz }\left(5^{\prime} \rightarrow 3^{\prime}\right)\end{array}$ & $\begin{array}{l}\text { Größe des PCR- } \\
\text { Produkts der } \\
\text { cDNA (bp) }\end{array}$ & $\begin{array}{l}\text { Größe des } \\
\text { genomischen PCR- } \\
\text { Produkts (bp) }\end{array}$ \\
\hline KPNA2-E1 & $\begin{array}{rlll}1 \ldots 18 \\
100 \ldots 85\end{array}$ & $\begin{array}{l}\text { GCCACACGGTCTTTGAGC } \\
\text { GGGCCTGGGCTTCCAC }\end{array}$ & 100 & 100 \\
\hline
\end{tabular}

Dieser Locus wurde über PCR-Analysen auf den YACs 955H4, 871C4, 845C6, 931B10, 901G9 und auf dem PAC 81B9 nachgewiesen.

\subsubsection{Kartierung von KPNA2 über Hybridisierungen}

PAC 81B9 ist mit $60 \mathrm{~kb}$ Länge der kleinste Klon auf dem KPNA2 vollständig lokalisiert werden konnte. Dieser den Bruchpunkt von Proband AS überspannende Klon überlappt sowohl mit dem proximal zum Bruchpunkt kartierten PAC 112L5 als auch mit dem distal zum Bruchpunkt kartierten Cosmid CF20b, auf dem das 3'-Ende von KPNA2 lokalisiert wurde. Da angenommen wurde, daß der Bruchpunkt des Probanden in der Region lokalisiert ist, die der PAC 81B9 nicht mit dem Cosmid CF20b oder dem PAC 112L5 gemeinsam aufweist, sollte die Größe des Bereiches, den PAC 81B9 allein aufweist, bestimmt werden. Zudem sollte KPNA2 in dieser Region kartiert werden.

Um den Überlappungsgrad zwischen den PACs 81B9 und 112L5 feststellen zu können, wurde zunächst ein Southern-Blot mit EcoRI, XbaI, XbaI/EcoRI, PstI, PstI/EcoRI, BamHI, BamHI/EcoRI, HindIII, HindIII/EcoRI gespaltener DNA des PACs $81 \mathrm{~B} 9$ mit radioativ markierter DNA des PACs 112L5 hybridisiert. Unter Abzug der detektierten Vektor-Fragmente 
wurden dabei jeweils Fragmente mit einer Gesamtlänge von etwa $10 \mathrm{~kb}$ detektiert, so daß anzunehmen ist, daß PAC 112L5 und 81B9 etwa $10 \mathrm{~kb}$ gemeinsam aufweisen.

Um eine physikalische Karte für den PAC-Klon 81B9 zu generieren, aus der ersichtlich ist, welcher Teil des Klons nicht in dem PAC 112L5 oder dem Cosmid CF20b enthalten ist, wurde die DNA dieser Klone mit den seltener schneidenden Enzymen EagI, KpnI und SacI geschnitten. Anschließend wurde die DNA auf einem 0,8\% Agarosegel aufgetrennt und auf eine Nylonmembran transferiert. DNA des PAC-Klons 222L3, der nach FISH-Analyse wie PAC 81B9 ebenfalls Signale an beiden derivativen Chromosomen des Probanden AS gezeigt hatte, wurde ebenso gespalten und geblottet. Dieser Klon ist jedoch chimärisch (Chromosom 17 und Chromosom 6), und weist möglicherweise weitere Umordnungen auf. Zudem muß beachtet werden, daß bei Spaltung dieses Klons Fragmente entstehen, die sich aus einem Chromosom 17-Anteil als auch aus einem Chromosom 6-Anteil zusammensetzen. Einige Fragmente dieses Klons spiegeln also nicht die Verteilung von Schnittstellen in genomischer DNA wider.

Der auf diese Weise hergestellte Southern-Blot wurde nacheinander mit verschiedenen radioaktiv markierten Sonden hybridisiert. Eine Sonde für das Exon 1 des Gens KPNA2 wurde anhand einer PCR mit DNA des PACs 81B9 und den Primern für den Locus KPNA2-E1 (s. Tab. 43) hergestellt. Das erhaltene PCR-Produkt wurde aus einem 1,5\% Agarosegel isoliert und anschließend radioaktiv markiert. Eine Sonde für das Exon 11 von KPNA2 wurde durch Isolierung des mit den Primern K9.F2 und K9.R2 (s. Tab. 50) erhaltenen PCR-Produkts von 81B9 generiert und ebenso nach Isolierung aus einem Gel radioaktiv markiert. Eine Sonde für das T7-Ende von PAC 112L5 wurde generiert, indem das mit den Primern für den Locus 112T7 (s. 3.8.2.5) erhaltene PCR-Produkt des PACs $81 \mathrm{~B} 9$ aus einem Gel isoliert und radioaktiv markiert wurde. Zudem wurde auch die gesamte DNA des PACs $81 \mathrm{~B} 9$ als Sonde eingesetzt. Die entsprechenden Hybridisierungsergebnisse sind in Abbildung 25 dargestellt.

Die auf diese Weise festgestellten Überlappungen der einzelnen Klone ermöglichten die Erstellung von Restriktionskarten für die Enzyme EagI, KpnI und SacI (s. Abb. 26). Da jedoch, je nach verwendetem Enzym, unterschiedlich große Vektoranteile in den Endfragmenten der Klone enthalten waren, wurde keine gemeinsame Karte dieser Enzyme erstellt.

Nach Spaltung mit EagI werden für die PAC-Klone zwei Fragmente des Vektors pCYPAC2 (15611 bp und 331 bp) erhalten und an den Endfragmenten verbleibt kein Anteil des Vektors. Das Insert des Cosmids CF20b ist in den Vektor Lawrist 4 kloniert. Dieser Vektor enthält eine EagI-Schnittstelle und die Endfragmente des Cosmids beinhalten nach EagI-Spaltung einen Vektor-Anteil von 4272 bp bzw. 1366 bp. Nach Spaltung mit KpnI werden für die PAC-Klone zwei Vektor-Banden (6676 bp und 3485 bp) und zwei Endfragmente mit einem Vektor-Anteil von 3349 bp bzw. 2432 bp erhalten. Der Cosmid-Vektor Lawrist 4 weist keine KpnI-Schnittstelle auf. Bei Spaltung mit SacI wird weder der PAC-Vektor noch der Cosmid-Vektor geschnitten.

Den erstellten Restriktionskarten (s. Abb. 26) nach weist PAC $81 \mathrm{~B} 9$ etwa $17 \mathrm{~kb}$ mit dem Cosmid CF20b gemeinsam auf. Da die PAC-Klone 81B9 und 112L3 etwa $10 \mathrm{~kb}$ gemeinsam aufweisen, ist der Bereich des Klons 81B9, der nicht mit CF20b oder 112L5 überlappt etwa 33 kb groß. Dieser Bereich muß den FISH-Ergebnissen dieser Klone zufolge den Translokationsbruchpunkt des Probanden AS beinhalten. Da in diesem Bereich zudem das 5'-Ende von 
KPNA2 lokalisiert ist, kann davon ausgegangen werden, daß KPNA2 maximal $33 \mathrm{~kb}$ vom Translokationsbruchpunkt des Probanden AS entfernt lokalisiert ist.

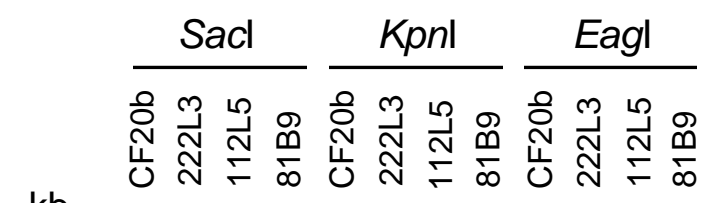

$\mathrm{kb}$

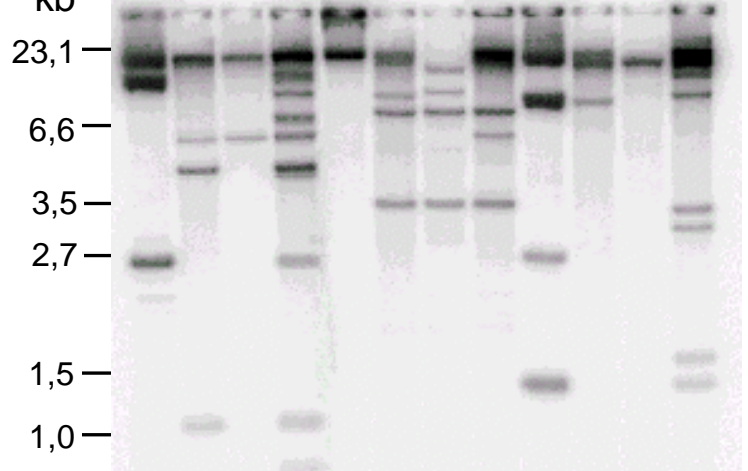

$0,5-$

a)

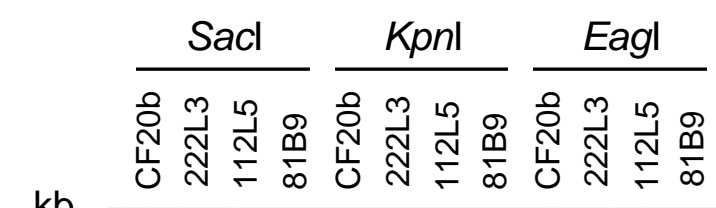

$\mathrm{kb}$

$23,1-$

$6,6-$

$3,5-$

2,7-

1,5-

$1,0-$

$0,5-$

c) $\mathrm{kb}$

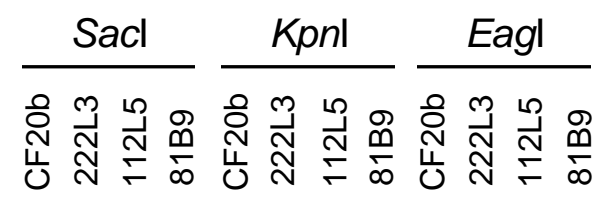

23,1-

6,6-

$3,5-$

2,7-

$1,5-$

$1,0-$

$0,5-$

b)

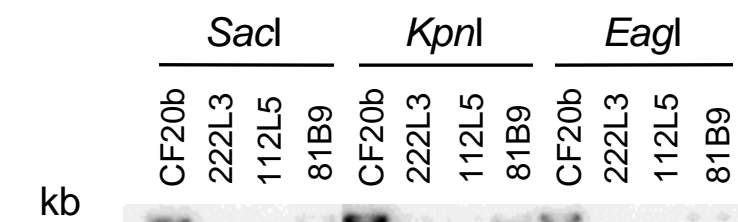

$\mathrm{kb}$

23,1-

6,6-

$3,5-$

$2,7-$

$1,5-$

$1,0-$

$0,5-$

d)

Abb. 25: Southern-Blot-Analyse der mit SacI, KpnI oder EagI gespaltenen PAC-Klone 222L3, 112L5 bzw. 81B9 und des Cosmids CF20b. a) Hybridisierung mit dem PAC 81B9; b) Hybridisierung mit dem PCR-Produkt des Locus 112T7; c) Hybridisierung mit dem PCR-Produkt des Locus KPNA2-E1; d) Hybridisierung mit dem PCR-Produkt des Locus K9-F2/R2. Die eingesetzten Sonden wurden nacheinander auf den gleichen Filter hybridisiert, um die Identifizierung identischer Fragmente zu erleichtern. 

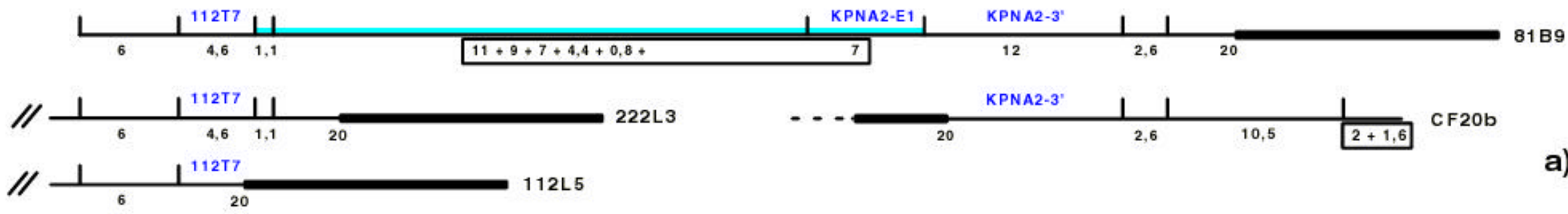

a)
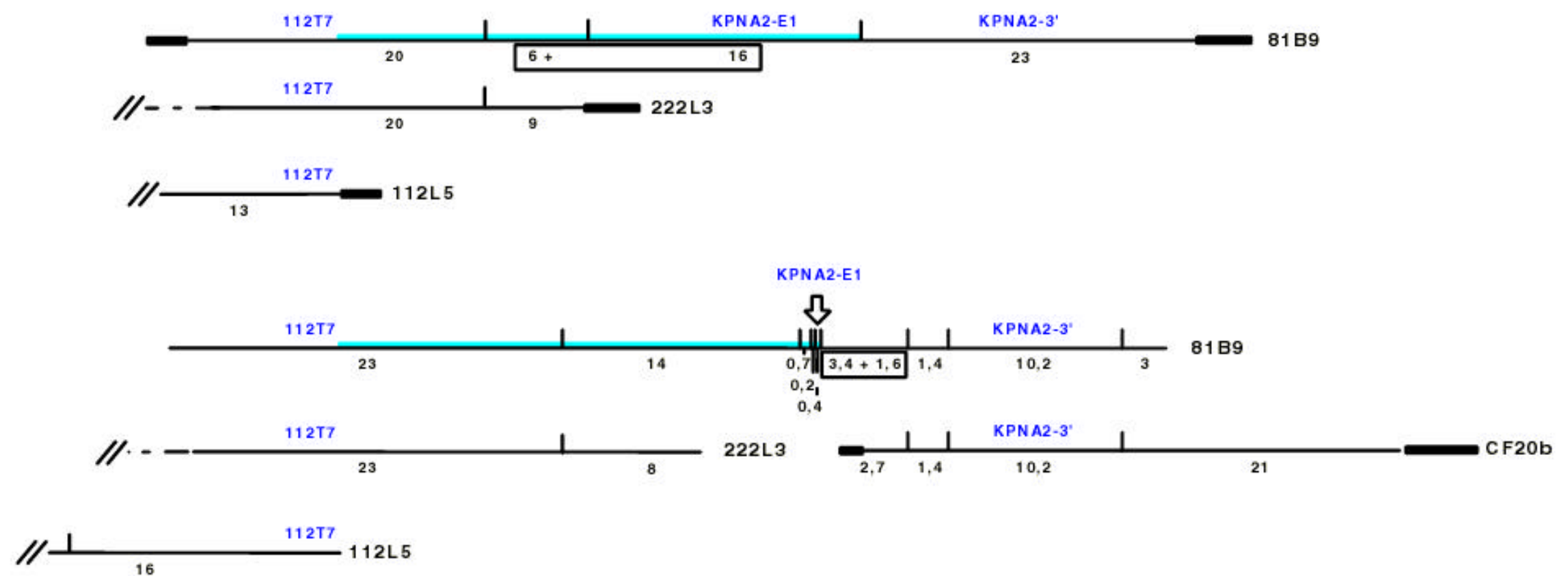

Abb. 26: Mit 3 Enzymen erstellte Restriktionskarten der PAC-Klone 81B9, 112L5 bzw. 222L3 und des Cosmids CF20b. Die senkrechten Striche symbolisieren in a) SacI-Schnittstellen, in b) KpnI-Schnittstellen und in c) EagI-Schnittstellen. Vektor-Anteile der detektierten Fragmente sind durch massive Balken dargestellt. Die Fragmentgrößen der einzelnen Fragmente sind in kb angegeben. Bei der linearen Anordnung der KPNA2 enthaltenden Fragmente wurde die unter 3.13.4 gezeigte Sequenzinformation berücksichtigt. Bei den in Kästen zusammengefaßten Fragmenten ist die Anordnung unklar. Die Loci 112T7, KPNA2-E1 und KPNA2-3' sind den jeweils detektierten Restriktionsfragmenten zugeordnet. Der maximale Abstand des KPNA2-Gens vom Translokationsbruchpunkt des Probanden AS ergibt sich jeweils durch Addition der Fragmentgrößen der distal von 112T7 und proximal von KPNA2-E1 kartierten Fragmente und der Größe des von KPNA2-E1 detektierten Fragments (hellblau dargestellt). 


\subsubsection{Detektion von abnormen KPNA2-Fragmenten bei Proband AS}

Um zu überprüfen, ob KPNA2 durch die Translokation des Probanden AS unterbrochen wurde, sollten Southern-Blots von genomischer DNA des Probanden und Kontrollpersonen mit der cDNA von KPNA2 hybridisiert werden. Es wurde erwartet, bei Unterbrechung des Gens abnorme Fragmente des Probanden zu identifizieren.

Für diese Untersuchung wurden die 4 cDNA-Klone 147454, 233334, 531850 und 151572 für KPNA2 (s. Tab. 5) vom RZPD bezogen. Zunächst wurden diese Klone über PCR-Analysen auf die Anwesenheit der Loci KPNA2-E2 und KPNA2-3' (s. Tab. 42) überprüft. Dadurch wurden die 4 cDNA-Klone für den Locus KPNA2-3' positiv getestet. Der Marker KPNA2-E2 wurde auf den Klonen 151572 und 531850 nachgewiesen, wobei der Klon 151572 jedoch neben dem cDNA-spezifischen Fragment von 289 bp, das ca. 430 bp große für genomische DNA spezifische Fragment zeigte. Daher ist anzunehmen, daß Klon 151572 Kontaminationen mit genomischer DNA enthält. Anschließend wurden die cDNA-Klone mit dem Vektorprimer T3 ansequenziert. Für die Klone 147454, 233334 und 151572 wurden auf diese Weise jeweils etwa 600 bp des 3'-Endes der veröffentlichten cDNA-Sequenz von KPNA2 (Accession-Nr. U09559) erhalten, während für den Klon 531850 etwa 650 bp des 5'-Endes generiert wurden. Die Sequenzierungen zeigten jeweils keine Abweichungen zur beschriebenen cDNA-Sequenz von KPNA2. Bei der Sequenzierung des Klons 151572 wurden jedoch für das 3'-Ende von KPNA2 17 bp erhalten, die in der veröffentlichten cDNA-Sequenz nicht mehr enthalten sind, wobei das letzte A der publizierten Sequenz nicht vorhanden war. Klon 531850 wurde schließlich vollständig sequenziert. Die Sequenz dieses Klons startet an Position 30 der beschriebenen Sequenz und endet 11 bp nach dem angegebenen Ende von KPNA2. Das letzte A der publizierten Sequenz war ebenfalls nicht vorhanden. Demnach ist davon auszugehen, daß die cDNA-Sequenz von KPNA2 länger ist, als die angegebene Länge von 1969 bp. Mit Ausnahme eines $\mathrm{G}$ nach A Austauschs in einer Wobble-Base an Position 933 der bekannten cDNA-Sequenz wurden keine Abweichungen beobachtet. Klon 531850 wurde für die Hybridisierungen auf Southern-Blots mit BamHI, PstI, MspI, XbaI oder SacI gespaltener DNA des Probanden und ebenso gespaltener DNA von unauffälligen Kontrollpersonen eingesetzt.

Bei der Hybridisierung der cDNA auf mit $M s p$ I gespaltene DNA zeigte der Proband AS ein etwa 1,45 kb großes Fragment, welches in den Kontrollpersonen nicht auftrat (s. Abb. 27). Um zu überprüfen, ob das Gen KPNA2 bei Proband AS durch die Translokation unterbrochen wurde oder, ob das abnorme Fragment aufgrund eines Polymorphismus auftrat, wurden MspISouthern-Blots mit weiteren Kontroll-DNAs angefertigt und diese ebenfalls mit der cDNA von KPNA2 hybridisiert. Dadurch wurde das $1,45 \mathrm{~kb}$ große Fragment auch bei einer von 16 Kontrollpersonen identifiziert (s. Abb. 27), was darauf hindeutet, daß das abnorme Fragment einen DNA-Polymorphismus widerspiegelt. Um den Bereich der cDNA identifizieren zu können, der mit diesem abnormen Fragment hybridisiert, wurden über PCR Fragmente der cDNA generiert, die nach Isolierung aus einem 1,5\% Agarosegel für nachfolgende Hybridisierungen eingesetzt wurden. Ein Fragment, welches nur die Basenpaare 648 bis 1190 der veröffentlichten cDNA-Sequenz beinhaltete, führte ebenfalls zur Detektion des 1,45 kb großen Fragments. 


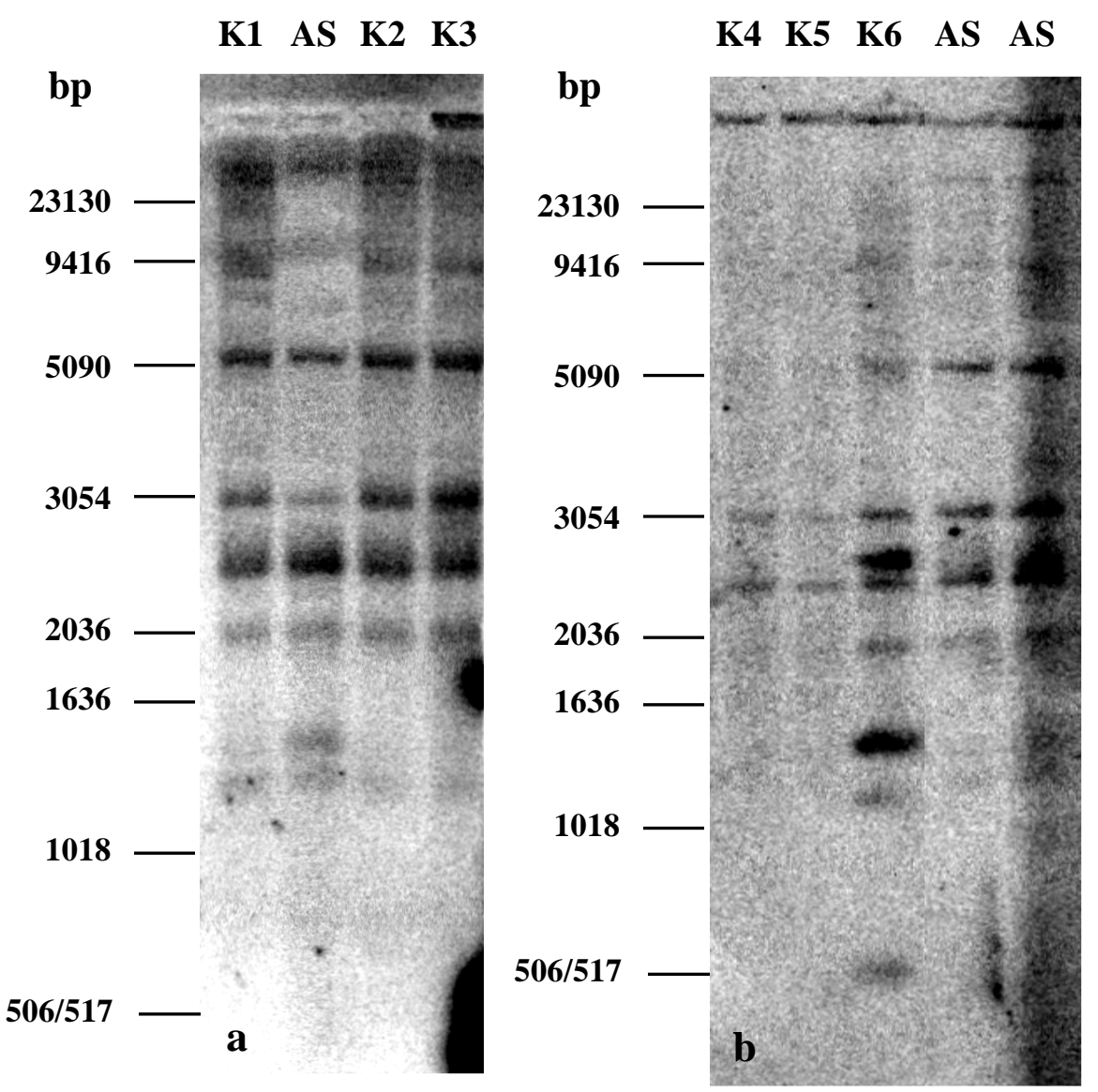

Abb. 27: Southern-Blot-Analyse $M s p I-$ gespaltener humaner genomischer DNA von RSS-Proband AS und klinisch unauffälligen Kontrollpersonen (K1 bis K6) nach Hybridisierung mit der cDNA von KPNA2. In a) zeigt DNA von Proband AS ein von den Kontrollen abweichendes Hybridisierungsmuster. Eine etwa $3 \mathrm{~kb}$ große Bande des Probanden weist eine geringere Intensität als in Kontrollpersonen auf. Zudem wurde eine etwa 1,45 kb große Bande detektiert, die in den Kontrollen nicht nachweisbar war. Dieses Hybridisierungsmuster des Probanden wurde bei mehrfachen Hybridisierungen erhalten. Hybridisierung b) ist von schlechterer Qualität, so daß das abnorme Bandenmuster von Proband AS hier nicht deutlich darstellbar ist. Die Kontrollperson K6 weist jedoch ein Fragment mit einer Größe von etwa 1,45 kb auf, so daß das entsprechende Fragment des Probanden vermutlich nicht in Zusammenhang mit der Tranlokation steht.

\subsubsection{Bestimmung der Exon-Intron-Struktur von Karyopherin alpha 2 (KPNA2)}

Da sich KPNA2 in einer Entfernung von maximal $33 \mathrm{~kb}$ zum Translokationsbruchpunkt des Probanden AS befindet (s. 3.13.2), ist dieses Gen als ein Kandidatengen für das RSS anzusehen. Um in Probanden mit RSS nach Mutationen in diesem Gen suchen zu können, war es jedoch erforderlich die Exon-Intron-Struktur des Gens aufzuklären. Da ein Teil der Sequenz des ansequenzierten 1,8 kb großen T7/CL3-Endfragments von CF20b (s. 3.6.1.6), mit der cDNA von KPNA2 übereinstimmt, sollte dieses Fragment zunächst vollständig sequenziert werden, um die gesamte Sequenz des ansequenzierten Exons bzw. die Sequenz eventuell vorhandener, weiterer Exons dieses Fragmentes auf Abweichungen von der cDNA-Sequenz von KPNA2 analysieren zu können. 
Die vollständige Sequenzierung dieses 1,8 kb langen Fragmentes wurde erreicht, indem ausgehend von den Sequenzen, die über T7- bzw. CL3-Sequenzierung dieses Fragmentes erhalten worden waren, geeignete Primer abgeleitet wurden, die für einen nächsten Sequenzierungsschritt eingesetzt wurden. Durch Wahl weiterer Primer innerhalb der Sequenz des T7/CL3Fragmentes wurden weitere Sequenzierungsschritte möglich, bis schließlich das gesamte Fragment sequenziert war. Die für die Sequenzierung gewählten Primer sind im folgenden aufgelistet:

Tab.44: Primer zur Sequenzierung des T7/CL3-Fragmentes

\begin{tabular}{lll}
\hline $\begin{array}{l}\text { Position innerhalb der } \\
\text { genomischen Sequenz von } \\
\text { KPNA2 }\end{array}$ & Primer-Name & Primer-Sequenz $\left(5^{\prime} \rightarrow 3^{\prime}\right)$ \\
\hline $5010 \ldots 5030$ & $20 \mathrm{bT7} .1$ & \\
$5113 \ldots 5134$ & $20 \mathrm{bT7}$. for & TCTGGAGTAGATTTCTGCAGG \\
$5488 \ldots 5506$ & $20 \mathrm{bT7}$. for 2 & ATCTCCCCATGCTCACATC \\
$5863 \ldots 5882$ & kpnseq.3 & GAGATTGAGACCATCCTGGC \\
$6140 \ldots 6119$ & CF20b.F3 & AACTGCACCGTACTTAATAACC \\
$6336 \ldots 6317$ & CF20b.F2 & GCGGCAAAGATTAGAAAGTG \\
$6427 . . .6406$ & CF20b.for & CTAACACTTCTGGATCATCATG \\
\hline
\end{tabular}

Durch Vergleich der erhaltenen genomischen Sequenz (Basenpaar 4875 bis 6668 der genomischen Sequenz von KPNA2 (s. unten)) mit der cDNA-Sequenz von KPNA2 konnten 3 Exons innerhalb des T7/CL3-Fragments identifiziert werden. Im Bereich dieser Exons wurde keine Abweichung von der cDNA-Sequenz von KPNA2 festgestellt. Die Spleißdonor- und Spleißakzeptorstellen entsprechen der GT-AG-Regel.

Um die genomische Sequenz von KPNA2 analysieren zu können, wurden 22 Primer (11 forward und 11 reverse Primer) anhand der cDNA-Sequenz von KPNA2 abgeleitet (s. Tab. 45). Diese Primer wurden so gewählt, daß durch Kombination eines forward- und eines reverse-Primers die Amplifikation von miteinander überlappenden Fragmenten möglich war, wobei der bereits sequenzierte Bereich des T7/CL3-Fragmentes (s.o.) ausgespart werden konnte. Es wurde erwartet, daß bei Vorhandensein von Introns innerhalb der amplifizierbaren Exonbereiche, PCR-Produkte erhalten würden, die größer sind als der entsprechende Bereich der cDNA. Die PCR-Amplifikation erfolgte mit genomischer Gesamt-DNA, DNA des PACs 81B9 und des Cosmids CF20b als template. DNA eines cDNA-Klons von KPNA2 (Nr. 531850) wurde ebenfalls amplifiziert, um die Größe der erhaltenen genomischen Fragmente direkt mit denen der cDNA vergleichen zu können. Die PCR-Produkte wurden auf einem 1,5\% Agarosegel aufgetrennt, anschließend aus dem Gel isoliert und mit den jeweiligen PCRPrimern sequenziert. Anschließend wurde die erhaltene genomische Sequenz mit der Sequenz der cDNA von KPNA2 verglichen, um die Exons dieses Gens identifizieren zu können. Die eingesetzten cDNA-Primer sind Tabelle $45 \mathrm{zu}$ entnehmen. 
Tab. 45: cDNA-Primer für KPNA2 (Nummerierung entsprechend der veröffentlichten cDNASequenz von KPNA2, Accession-Nr. U09559)

\begin{tabular}{|c|c|c|c|c|}
\hline $\begin{array}{l}\text { cDNA- } \\
\text { Position }\end{array}$ & $\begin{array}{l}\text { forward-Primer Sequenz } \\
\text { reverse-Primer Sequenz }\end{array}$ & $\begin{array}{l}\text { Primer- } \\
\text { Name }\end{array}$ & $\begin{array}{l}\text { Größe des PCR- } \\
\text { Produkts der } \\
\text { cDNA (bp) }\end{array}$ & $\begin{array}{l}\text { Größe des } \\
\text { genomischen PCR- } \\
\text { Produkts (bp) }\end{array}$ \\
\hline $\begin{array}{c}12 \ldots 30 \\
164 \ldots 144\end{array}$ & $\begin{array}{l}\text { TTTGAGCTGAGTCGAGGTG } \\
\text { GCTGGTGTATTAGCATTCTCG }\end{array}$ & $\begin{array}{l}\text { KPNA5.1 } \\
\text { KPNA5.2 }\end{array}$ & 153 & $\begin{array}{l}\text { keine } \\
\text { Amplifikation }\end{array}$ \\
\hline $\begin{array}{l}133 \ldots 151 \\
241 \ldots 221\end{array}$ & $\begin{array}{l}\text { ATGTCCACCAACGAGAATG } \\
\text { CCACATTGACCTCTATTCTGC }\end{array}$ & $\begin{array}{l}\text { KPNA5.3 } \\
\text { KPNA5.4 }\end{array}$ & 109 & 259 \\
\hline $\begin{array}{l}133 \ldots 151 \\
421 \ldots 402\end{array}$ & $\begin{array}{l}\text { ATGTCCACCAACGAGAATG } \\
\text { TAGCTTGGAGCTGATTTTCC }\end{array}$ & $\begin{array}{l}\text { KPNA5.3 } \\
\text { KPNA.R2 }\end{array}$ & 289 & $\begin{array}{l}\text { keine } \\
\text { Amplifikation }\end{array}$ \\
\hline $\begin{array}{l}363 \ldots 383 \\
\text { Intron-Primer }\end{array}$ & $\begin{array}{l}\text { TGTTGATGACATTGTCAAAGG } \\
\text { CATTCTGGAACCTAAGAGAAGC }\end{array}$ & $\begin{array}{l}\text { KPNA.F2 } \\
20 \mathrm{bT} 7.2\end{array}$ & $\begin{array}{l}\text { keine } \\
\text { Amplifikation }\end{array}$ & 1257 \\
\hline $\begin{array}{c}978 \ldots 996 \\
1190 \ldots 1170\end{array}$ & $\begin{array}{l}\text { AAATGAACGAATTGGCATG } \\
\text { TTCTGAATGTTAGTTTTGGGG }\end{array}$ & $\begin{array}{l}\text { KPNA.F1 } \\
\text { KPNA.R1 }\end{array}$ & 212 & 685 \\
\hline $\begin{array}{l}1102 \ldots 1123 \\
1251 \ldots 1231\end{array}$ & $\begin{array}{l}\text { ACAGATGAACAGACTCAGGTTG } \\
\text { AACTTGCTGTATCTGGTCCTG }\end{array}$ & $\begin{array}{l}\text { KPNA.F3 } \\
\text { KPNA.R3 }\end{array}$ & 150 & 150 \\
\hline $\begin{array}{l}1189 \ldots 1209 \\
1393 \ldots 1374\end{array}$ & $\begin{array}{l}\text { AGGAAGCTACGTGGACAATG } \\
\text { TGCCACAGTGAACAAGGTAC }\end{array}$ & $\begin{array}{l}\text { KPNA.F4 } \\
\text { KPNA.R4 }\end{array}$ & 204 & 453 \\
\hline $\begin{array}{l}1313 \ldots 1330 \\
1540 \ldots 1521\end{array}$ & $\begin{array}{l}\text { AAAAGGAAGCTGTGTGGG } \\
\text { AGCCTCCACATTCTTCAATC }\end{array}$ & $\begin{array}{l}\text { KPNA.F5 } \\
\text { KPNA.R5 }\end{array}$ & 228 & 1496 \\
\hline $\begin{array}{l}1464 \ldots 1484 \\
1649 \ldots 1629\end{array}$ & $\begin{array}{l}\text { TTCAAATATCTTTCAGGCTGC } \\
\text { ACGTTTTGATCTTCCTCTTCC }\end{array}$ & $\begin{array}{l}\text { KPNA.F6 } \\
\text { KPNA.R6 }\end{array}$ & 186 & 774 \\
\hline $\begin{array}{l}1575 \ldots 1596 \\
1723 \ldots 1702\end{array}$ & $\begin{array}{l}\text { TGAGTCTGTGTATAAGGCTTCG } \\
\text { TCTAAAAGTTAAAGGTCCCAGG }\end{array}$ & $\begin{array}{l}\text { KPNA.F7 } \\
\text { KPNA.R7 }\end{array}$ & 149 & 731 \\
\hline $\begin{array}{l}1634 \ldots 1655 \\
1905 \ldots 1884\end{array}$ & $\begin{array}{l}\text { AGGAAGATCAAAACGTTGTACC } \\
\text { GAAACCTAGTCAGAGGACAAGC }\end{array}$ & $\begin{array}{l}\text { KPNA.F8 } \\
\text { KPNA.R8 }\end{array}$ & 272 & 272 \\
\hline $\begin{array}{l}1806 \ldots 1827 \\
1957 \ldots 1936\end{array}$ & $\begin{array}{l}\text { ATGTGGTTTGTTACTGTAGCAC } \\
\text { TGAATGTTATTTACAGGATGC }\end{array}$ & $\begin{array}{l}\text { KPNA3.1 } \\
\text { KPNA3.2 }\end{array}$ & 152 & 152 \\
\hline
\end{tabular}

Nach Sequenzierung der einzelnen PCR-Produkte mit den jeweiligen PCR-Primern zeigte sich, daß Fragmente, die mit genomischer DNA als template erhalten worden waren, z.T. Sequenzüberlagerungen auftraten, die bei Sequenzierung von PCR-Produkten des PACs 81B9 und des Cosmids CF20b nicht vorhanden waren. Dies ist darauf zurückzuführen, daß in genomischer DNA sowohl KPNA2 als auch das zu diesem homologe Gen oder Pseudogen (s. 3.13.1) vorkommt. Daher wurde die Sequenz von KPNA2 ausschließlich über Sequenzierungen des dieses Gen enthaltenden PACs $81 \mathrm{~B} 9$ oder des Teile von KPNA2 beinhaltenden Cosmids CF20b bestimmt. Um schließlich spezifische Primer ableiten zu können, die zur Amplifikation der einzelnen Exons dienen sollten, war es jedoch erforderlich, auch die entsprechende Sequenz des zu KPNA2 homologen Abschnittes zu kennen. Dieser ist innerhalb der YACs 765 und 963 lokalisiert (s. 3.13.1). Daher wurden die Sequenzierungsschritte, die für den PAC 81B9 und das Cosmid CF20b durchgeführt wurden, auch mit den YACs 765 und 963 durchgeführt, sofern die jeweiligen PCR-Produkte auch mit den YACs erhalten werden konnten. Die Sequenz dieser 
YACs zeigte deutliche Unterschiede zu der Sequenz von 81B9, CF20b und der cDNA-Sequenz von KPNA2, wobei die Homologien zwischen $94 \%$ und $99 \%$ liegen.

Über die Amplifikation mit den jeweiligen Primer-Paaren wurden z.T. Introns von KPNA2 überbrückt. Die Sequenzierung mit den jeweils für die PCR eingesetzten Primern ergab einen Teil der genomischen Sequenz von KPNA2. Um eine vollständige Sequenzierung der genomischen Sequenz erreichen zu können, wurden anhand der erhaltenen Sequenz erneut Primer abgeleitet und diese für weitere Sequenzierungsschritte eingesetzt. Die folgende Tabelle gibt eine Übersicht darüber, welche Primer für die weitere Sequenzierung der PCR-Produkte eingesetzt wurden.

Tab.46: Primer für weitere Sequenzierungsschritte (Teil 1)

\begin{tabular}{llll}
\hline $\begin{array}{l}\text { Position in der } \\
\text { genomischen Sequenz } \\
\text { von KPNA2 }\end{array}$ & Primer-Sequenz $\left(5^{\prime} \rightarrow 3^{\prime}\right)$ & $\begin{array}{l}\text { Primer- } \\
\text { Name }\end{array}$ & $\begin{array}{l}\text { sequenziertes } \\
\text { PCR-Produkt }\end{array}$ \\
\hline $3979 \ldots 3999$ & GGGTAGCCTAAGAAATTTGTG & kpnseq.7 & KPNA.F2/20bT7.2 \\
$4908 \ldots 4888$ & TAGGATCTCACTCCACTCAGG & $20 b T 7.3$ & KPNA.F2/20bT7.2 \\
$4562 . .4544$ & CCAGGCTGGTCTCAAACTC & kpnseq.8 & KPNA.F2/20bT7.2 \\
$6808 . .6825$ & TTGCTTGAATCTGGGAGG & kpnseq.1 & KPNA.F1/KPNA.R1 \\
$7078 . . .7057$ & AGTCTGTTCATCTGTACCAGTG & kpnseq.4 & KPNA.F1/KPNA.R1 \\
$7744 . . .7765$ & TACTATTTAGACTTGGGGGAGG & kpnseq.2 & KPNA.F5/KPNA.R5 \\
$8126 . . .8145$ & GCAAGAATTAGCCATGTGTG & kpnseq.5 & KPNA.F5/KPNA.R5 \\
\hline
\end{tabular}

Über Sequenzierung mit den in Tabelle 46 enthaltenen Primern konnte das 1257 bp lange PCRProdukt KPNA.F2/20bT7.2 vollständig sequenziert werden.

Die Fragmente KPNA.F1/KPNA.R1 und KPNA.F5/KPNA.R5 enthalten eine Anhäufung der Base A und in einigem Abstand davon eine Ansammlung der Base T, was die Sequenzierung erschwerte. Daher wurden Primer abgeleitet, die zwischen diesen Anhäufungen plaziert sind, und diese für weitere Sequenzierungen eingesetzt. Auf diese Weise war es möglich die bereits erhaltenen Sequenzdaten zu überprüfen bzw. neue Sequenzdaten zu erhalten. Tabelle 47 gibt eine Übersicht über die Sequenzierungsprimer und die sequenzierten Fragmente.

Tab. 47: Primer für weitere Sequenzierungsschritte (Teil 2)

\begin{tabular}{llll}
\hline $\begin{array}{l}\text { Position in der } \\
\text { genomischen Sequenz } \\
\text { von KPNA2 }\end{array}$ & Primer-Sequenz $\left(5^{\prime} \rightarrow 3^{\prime}\right)$ & $\begin{array}{l}\text { Primer- } \\
\text { Name }\end{array}$ & $\begin{array}{l}\text { sequenziertes } \\
\text { PCR-Produkt }\end{array}$ \\
\hline $7003 \ldots 6983$ & GATGCTGGTTATTTTTTCCC & SEQ11 & kpnseq.1/SEQ11 \\
$8303 \ldots 8323$ & CCTTCAATAATGGATGCTAGC & SEQ12 & SEQ12/KPNA.R5 \\
$8948 . . .8927$ & AAAAAATCCAAGTTTACTGGC & SEQ13 & kpnseq.5/SEQ13 \\
\hline
\end{tabular}

Die Sequenzierung der PCR-Produkte erfolgte mit den jeweils für die PCR eingesetzten Primern (s. auch Tab. 45 und 46). 
Da mit verschiedenen Primerkombinationen keine PCR-Produkte erhalten werden konnten, die Intron 3 überspannen, wurden einige Primer in einer Alu-PCR mit verschiedenen Alu-Primern kombiniert. Ebenso wurde ein forward-Primer (E2.F) eingesetzt, um einen Teil der Sequenzen abwärts von KPNA2 zu generieren. Für jeden spezifischen Primer wurden anschließend mindestens zwei der erhaltenen Alu-PCR-Produkte für eine Sequenzierungsreaktion eingesetzt.

Tab. 48: Für die weitere Sequenzierung generierte Alu-PCR-Produkte

\begin{tabular}{|c|c|c|c|c|}
\hline $\begin{array}{l}\text { Primer- } \\
\text { name }\end{array}$ & Primersequenz & $\begin{array}{l}\text { Position in der } \\
\text { genomischen Sequenz } \\
\text { von KPNA2 }\end{array}$ & $\begin{array}{l}\text { Alu- } \\
\text { Primer }\end{array}$ & $\begin{array}{l}\text { Größe des } \\
\text { PCR-Produkts } \\
\text { (bp) }\end{array}$ \\
\hline $\mathrm{K} 2 . \mathrm{F}$ & AAATGCCCTCACTTAGCAAC & $2503 \ldots .2522$ & CL2 & 550 \\
\hline $\mathrm{K} 2 . \mathrm{F}$ & & & 154 & $550,900,1600$ \\
\hline KPNA.R2 & TAGCTTGGAGCTGATTTTCC & $3942 \ldots 3923$ & CL3 & 400 \\
\hline KPNA.R2 & & & CL2 & 600 \\
\hline KPNA.R2 & & & 154 & 900,1600 \\
\hline KPNA.R2 & & & CL1 & 350 \\
\hline KPNA.R2 & & & 450 & 400 \\
\hline KPNA.R2 & & & 451 & 300,900 \\
\hline KPNA.R2 & & & $5^{\prime}$ & 350 \\
\hline KPNA.R2 & & & $3^{\prime}$ & 300,600 \\
\hline kpnseq.9 & TAGCTACTAGCTGGGTACCTTG & $2941 \ldots .2962$ & 451 & 350 \\
\hline kpnseq.9 & & & 154 & 600 \\
\hline kpnseq.9 & & & CL3 & 500 \\
\hline kpnseq.9 & & & $3^{\prime}$ & 200 \\
\hline kpnseq.10 & GGTGGCTCACACCTGTAAG & $3573 \ldots 3555$ & CL2 & 350,550 \\
\hline kpnseq.10 & & & $3^{\prime}$ & 350,550 \\
\hline kpnseq.10 & & & 451 & 350,550 \\
\hline kpnseq.10 & & & $5^{\prime}$ & 2000 \\
\hline E2.F & TCTTTCTTAAATGTGGTTTGTTAC & $9857 \ldots 9880$ & 154 & 1500 \\
\hline
\end{tabular}

Die Sequenz vor Exon 1 sowie die des Introns 1 wurde anhand eines Subklons von PAC 81B9 bestimmt, der die Basenpaare 1 bis 2682 der genomischen Sequenz von KPNA2 enthält. Um diesen Subklon zu erhalten, wurde zunächst ein PCR-Produkt des Exons 1 auf Southern geblottete DNA von PAC 81B9 hybridisiert, die mit verschiedenen Enzymen gespalten worden war. Ein 2,7 kb PstI-Fragment von 81B9, welches mit dieser Sonde hybridisierte, wurde aus einem Agarosegel isoliert und in den Vektor pZErO-2 subkloniert. Die erhaltenen Subklone wurden über eine PCR auf die Anwesenheit des Exons 1 getestet. Ein positiver Subklon (Klon 31) wurde anschließend sequenziert. Dazu wurden die Vektorprimer T7 und SP6, sowie weitere Primer, die anhand der erhaltenen Sequenz abgeleitet wurden, für die Sequenzierung eingesetzt. Welche Primer neben den Vektorprimern für die Sequenzierung eingesetzt wurden, ist Tab. 49 zu entnehmen. 
Tab. 49: Primer für die Sequenzierung des Subklons 31

\begin{tabular}{lll}
\hline $\begin{array}{l}\text { Position innerhalb der } \\
\text { genomischen Sequenz von } \\
\text { KPNA2 }\end{array}$ & Primer-Name & Primer-Sequenz $\left(5^{\prime} \rightarrow 3^{\prime}\right)$ \\
\hline $303 \ldots 324$ & 31T7.F & AACCTTTTGTTTCCATATTTGC \\
$941 \ldots 958$ & KPNA2-E1.F & GCCACACGGTCTTTGAGC \\
$1041 \ldots 1025$ & KPNA2-E1.R & GGGCCTGGGCTTCCAC \\
$1634 \ldots 1613$ & 31SP6.F & GTCAACATTAAAAATGCAGTGC \\
$2189 \ldots 2170$ & L1.R & TTTCGGCACTATGAAATAGC \\
\hline
\end{tabular}

Die genomische Sequenz von KPNA2 ist auf den folgenden Seiten dargestellt. Die ExonIntron-Struktur dieses Gens wurde bestimmt, indem die genomische Sequenz von KPNA2 mit der cDNA-Sequenz verglichen wurde. Nucleotide, die zu Exons korrespondieren sind in dieser Sequenz fett hervorgehoben und durch Großbuchstaben dargestellt, zudem sind die Exons numeriert. Alle Exon-Intron-Übergänge entsprechen der GT-AG-Regel. Mit Ausnahme einzelner Abschnitte in großen Introns wurden alle Bereiche mindestens zweimal sequenziert. Die einzelnen Exons und an diese angrenzende Intron-Regionen wurden im Rahmen des Mutationsscreenings jeweils über 60x vorwärts als auch rückwärts sequenziert. Die Sequenz weist eine Lücke auf, die sich zwischen den Basenpaaren 3250 und 3252 befindet. Translations-Startund Stopcodon sind unterstrichen.

Die Basen 1 bis 30 stammen aus dem Klonierungsvektor von Klon 31 (pZErO-2, kursiv dargestellt). Die PstI-Klonierungsstelle dieses Klons ist fett und kursiv gedruckt.

\begin{tabular}{|c|c|c|c|c|c|c|}
\hline & & & & & & \\
\hline 61 & gagacac & cgtgaaacag & aggaaaagg & acatgattct & gaaacttct & cttaagtaa \\
\hline 121 & aa & tcacacatat & cacgcgt & zatatgtat & satatat & gtatagagaa \\
\hline 181 & ycatagca & aatgtggcaa & aatgttaaga & tttggcaaat & ctggataaag & atttgcaatt \\
\hline 241 & ctgctgcatt & tgaaattatt & taaaataaa & aacttgagt & ttttggagaa & acaggcataa \\
\hline 301 & gaaaccttt & gtttccatat & ttgcggcttc & tatacagtct & tttatgatgc & aattaaaaa \\
\hline 361 & aactaact & aaaatata & acacaatct & tccetcccat & agtagccaga & a acceccgcc \\
\hline 421 & gagtactttg & ggtgtcataa & aggaaaaa & atgcaaagca & atatgttttt & tataagat \\
\hline 481 & tacttatta & ctaattagaa & tettttatt & ttcatgaaga & tcaacaacaa & agttttaaa \\
\hline 541 & ataatgactt & agagatcat & tttgtggtat & ttgtttaagg & ctgtcgccca & ggaaacgcc \\
\hline 601 & caaggaccat & gcacgcttca & ccctatgga & aacacgaacg & cccagggaa & $\operatorname{cgcccct} \mathrm{c}$ \\
\hline 661 & gcgctgcttg & acgggatctg & agtcctccc & gttccgeccc & yccaggcgct & $\operatorname{ccgc}$ \\
\hline 721 & ccggengctc & cctcaccgcc & $\operatorname{ggccgctcc}$ & ctcatctcgn & atgccatcc & =tet \\
\hline 781 & tettetctt & $\operatorname{cccccctccc}$ & ctcgceccc & aagccetgtg & $\operatorname{actccctccc}$ & tcccaacgt \\
\hline 841 & gttttcaaa & caatg & gcacacagc & ttaggctcga & accagccaat & ggaatgcgg \\
\hline 901 & ggg & aaatttaaat & $\operatorname{gcgccggcc}$ & ggctgcacga & GCCACACGGT & ¿TTTGAGCTG \\
\hline 961 & GTCGAGGTG & АСССТTTGA & ACGCAGTCGC & CСTACAGCCG & СTGATTCCCC & CCGCATCGCC \\
\hline 021 & CCCGTGGAA & CCCAGGCCC & СTTCGCAGg & tacagactca & ggcggcggcc & cogagc \\
\hline 081 & aacggct & tgcccgtggg & ggcgttcgc & cttttgggtt & gggggaggga & gggt \\
\hline 1141 & cgccgag & cctggctctg & cetccegcgt & tgactaggcc & tcgggggcga & cgttcattga \\
\hline 1201 & gcgget & gagtttcgcg & gggtctgcgg & gtttagggcg & ccgacgctct & ycaacggca \\
\hline 1261 & yangcct & taacgenten & cggccgggag & aatcggagcg & agccaggctt & yagggcgaat \\
\hline 1321 & ggggag & gacttgtggc & gccetggtt & $\operatorname{cgcctcctc}$ & ctttctcgtt & catcttccc \\
\hline 1381 & Lgggg & ggggctg & gggtggcag & cac & tctgac & $\operatorname{gccc}$ \\
\hline 1441 & ggC & tom & gtcgtaggc & $\operatorname{tg}$ & caaga & attg \\
\hline 1501 & $\operatorname{ggc}$ & tet & ct & gca & ratgt & tt \\
\hline 1561 & & cctagtc & ctggaaatg & aat & agatg & 90 \\
\hline 1621 & & ataat & tga & tet & att & ctc \\
\hline 681 & & & & & & \\
\hline
\end{tabular}


1741

1801

1861

1921

1981

2041

2101

2161

2221

2281

2341

2401

2461

2521

2581

2641

2701

2761

2821

2881

2941

3001

3061

3121

3181

3241

3301

3361

3421

3481

3541

3601

3661

3721

3781

3841

3901

3961

4021

4081

4141

4201

4261

4321

4381

4441

4501

4561

4621

4681

4741

4801

4861

4921

4981

5041

5101

5161

5221

5281

5341

5401

5461

5521

5581 ttaactatta gggactctgg ctagtccaaa ttgaaatacg atggaaaag aatgtagaag atttggatat gttgggttaa ctcctttta aaatatggc tgatggagag ccctctccaa ttgggtaaag ctatt cata tggattcagt agatgcttga atgataagg aatatttt

CCATGTCCAC CAACGAGAAT AGGGAAAAGA CAGTACAgtg aagacatttg gaaaggggtg acaaaactg gtgtgatagg GCAGAATAGA GGTCAATGTG GGAGAAATGT AAGCTCATTT ACCAGgtaaa aatgtatt ctttcttag aaattcaagt gaacatctt ttctctgttt ctgaagctga tttaggatct tagctactag ctgggtacct tatttcttct ttttttttt gtgcagcagc acaatcagct ccacagcctc ctgagtagct tatttttttg tttttgtttc agtggcgcga Iltgagtgaaa ttgcctatga cttcatgtct aacgtanaa taatcttcag gcgacaggca aacaccacca tctcactgtg ttgctcaggc cccaaagtgc taggcttaca aattgttca aagctgcctt tccagtgagt ccatgacaac aacaggcaaa attaatgta ttacacttgc cttcacaagt

tgtgcaaact ttcacttttc AAGGCATAAA TAGCAGCAAT tcttgtctgC gatagcatgg gggtggggca ggaagggaca gccaatagt aggctggcct atttttatt ggatcacagg tgtgtgccat gtcactggca ggggaaggaa gatatatcca tttaggagat ttatgatata atagaaagga ttcaatggta aattatcatt cccagcactt tgggaggcca gggcaacatg gtgagagcca tgcctgtaat ctcacgtgtt ggaggttgca gtgagctgag ctgtctcaaa aataataa agctactaag gaggctgagg agctgtgatc gtggcactgc aaatgtgct taaccacaac gtgaaaagt tttttaaaa agggtaatct acattaattt atacaagtaa tctgttcagc cttaaaggt tgtctgaagt

aactccttt gttaatcact

ACTTTCCAGA GAAAAACAGC ATTTGTGTCC TTCTTGGGCA ACTCACTAAC ATTGCTTCTG CATCCCAGCA TTCATTTCTC CTGGGCTCTA GGAAACATTG aatcgtaatt agttggaaga tagctgtaa gttgacttgg agtatcgaac taggctgtca ctgtaagctt aaagtacaca atgtcagtta ttttatatat gtaaataca ttattaaat tactaggaag gaagtctcag gtgccgaaaa taattcagtt ctcttccccc GCTAATACAC agtaccttct aaactgagg tgaaacggca GAGCTGAGGA CCTGATGATG tagtttatga aacttaaca gcaattagta tccttagct tggcetgacc ttcccccgag cactgcaacc gggattatgg tttgagacag ttcaattta cccttcagat catgatgatc cttatttggt atctttagC

CAGCTGCCCG gttgctttcc tatttaaaa

gttatcttt

AAGCTAAGAA СТАСтTCTCC

gttacgtgaa tttctagtct attgtcttct ctgaccttcc agtgtgtcca atggagtctt tctgcctcat gtgcgcatca agtttgctc ccgtctcaa ttctccctca tctgctctga tgcetggata tggtctcacc ggtgtgagcc tttagcgac aagtttggaa gggctaata aagtgtggat aaaaaaaag aagtatatct ttcttgatt ttttttttt tgagctcaag accatgcctg aaacacttg actgttctac tttagtagct tttattgtt

tctagGGCA CTGTAAATTG GTGGAAAATC AGCTCCAAGC gtagcctaag gacagatagt tattaatttt ggttcaagca tgcacctgcc gaataata aagtataatt ttaataagtt aaaagttct aggggtcggt gttetacaa tgggaggctc atcttgccac ataaataac tgggaggatc actctagcet tatcagaaca gtgacaagat ctggaaaat

\section{aatttgtgt} acaaggaaag tttgagaggg gtcctctgac cataaagtt gtaagtggga tgacctttac ctatagcttg aggctgggcg tacttgagcc aagaattat aggcacaata tgcattccag ttgggtgtgg acttgagccc gagtggagtg aattcagtga ctggagtaga ggtagttaat ttctcttagg ttccagaatg tctaactct tgaattgcat gtcaacttt atttgtctt

CCCCCATAGA CAACATAATC GAACTGATTG TAGTCCCATT GGACATCAGA ACAAACCAAG TGTTGGCATC TCCCCATGCT CAGgtacttg gacttgaagt aaggccttgt tataagtaat

tcccctact ttgtcttgaa gaaacggtgg atacatgtgg aagatttca aagatggagt tgataacacg ttgaaatact tagtttcact tgtttcttt tatagcttgc attctatttc ggaaggggga cacttcccct ccccctctag tatacaggtg actattattg acaaaggaaa TTTCTCCCTT TGTCTCATAA E2 TCTTCACAGA TTCAAGAACA tgtggtggta tttaaatggg aaaatgccc tcacttagca ctcaagGAA ATGAGGCGTC E3 GGATGACCAG ATGCTGAAGA GCTGCAGGAA AACCGCAACA atccagaaa tcagtaggga taacggtttt aactatctgt ttcctgcctt ctgtaatcca ttcagacttc cctgcatttc gagccagcca gtttctggtt gctctgttgc tcaggctgga gggttcaagc aattctcctg ccacgcttgg ctagtttttg tgtcgcccag gctagagtgc aaagaaat cctcagaacg gaatgcaagt gattgagact ttgagacaag gtcttgtatg tttttttt tgttgggagg ccatcctcec tcctgagcet tccttctcgt tcattttta gatactccat aacttgagac atataaata atgaatatt ggctataagc ctaacgatgt gtatttaatc ttaatgataa GTCTGTTGAT GACATTGTCA E4 TACTCAAGCT GCCAGgtaag tttagattt ttttttgggg attaggccag ccagccataa gaggccttgc tattttgccc 
5641

5701

5761

5821

5881

5941

6001

6061

6121

6181

6241

6301

6361

6421

6481

6541

6601

6661

6721

6781

6841

6901

6961

7021

7081

7141

7201

7261

7321

7381

7441

7501

7561

7621

7681

7741

7801

7861

7921

7981

8041

8101

8161

8221

8281

8341

8401

8461

8521

8581

8641

8701

8761

8821

8881

8941

9001

9061

9121

9181

9241

9301

9361

9421

9481 agcttgcttt

ccatctaagt

tggacaaggt

ccagcacttt

gctaacacag

gggcgcctga

ccgagatcgc

aaaaaaaa

TTATTAAGTA

СтTTAGCAgt

atcttctcaa aagacagaac

CGTAATCTTA СCTGGACACT

GATGCTGTTG AGCAGATTCT

GTGTTAGCAG ATACCTGCTG

GGCATGGTGG

TGAAAACAGG

TTGCCAATTG

agggctgggc

TGgtaagtta

catctctact aaaatacaa

actactcggg aggctaaggc

cccgaatcg tgccattata

tagtaatatt gaaatattgc

ggtatagaat ttctaaagtg

tcagACTCCT GCCCTAAGAG

GGTTGTGATT GATGCAGGAG

TAACATTCAG AAGGAAGCTA GATACAGCAA GTTGTGAATC

aacgaagtct taggatttaa agcttcttca cgtgcaagaa gtaacccett ttacttaagg

aaaagtactc ttggaatctt

ttaatagGCA GATTTTAAGA TGGTGGAACA GTTGAACAGA GAACCTCTTA ACTGCAAAAG TATCTTTCAG

gtttactat

gtaagtccta

atacaaaga gacgacaagt ctcatcacac ctgtttactt

cattaaattt gaatgacttg

gaagtccgag

gtgatgacttg

gcgaaaccet gtctctgcta

aatcccagct actcagaagg

gcagtgagcc

aagttgtgt

aaaaaaaa aaaaagttg

taataattt gtcagtatgt

attttgaagc aatctgttt

aatttaaagg aaaactaacc

cacacattct gtttggggac

accttgacta caccttgtga

atagcagacc agttgaactg

tacatagaaa aggttgggag

tgctaaaagc aggtacagat

aactatgat aggcttgatg

attcaaatta ttgatgtttt

gattttttt tttttagGC

ATTGAAGAAT GTGGAGGCTT

GTGTATAAGG CTTCGTTAAG

tggtaatatt aataacaact

ttaaaataa gtgtcatatc

atgtacttat ttgcccctct

tttaaaagtc accagattag

ggtaagttaa cgggtgtcat

gctctgggcc taatacagtc

tcggcetgtt ttaggaatga aagtgtcgtc gtttttgctg gtgcattcag atcttgcctc ggccgggcat ggcgggtgga tcatgaggtc cctctactaa aatacaaa ggagaatggc tccagcctgg gcgacagaga cctttttt cagGTGATGG GACCCACTGT

catgagtaaa TGGCTCTCCT

gttactcact ttacaaagg cagcagaggg cactgaaaa ttgatggtgt ggtggctcac gcctgtaatc ggagattga gaccatcctg aattagccgg gcgtggtggc gaggcggagc ttgcagtgag gaaactccgt ctcaaaaaa CTCAGTGTTC CGAGACTTGG E6 tcttcattct aatttccccc TCTAATCTT TGCCGCAACA AGAATCCTGC ACCCCCGATA TCCTACCTTA GTTCGGCTCC TGCATCATGA TGATCCAGAA GGCTATTTCC TACCTTACTG ATGGTCCAAA TGAACGAATT AGTTGTGCCC CAACTTGTGA AGCTTCTAGG AGCTTCTGAA ttacttgta ct

gattaggaca ggctcacac ctgtgtaatc ccagcacttt gggagaccaa taagtataag aagcatgatc tcaggagttc aagaccagcc tggccaacat tgtgaaagcc agaattatc tggacatggt ggcacgtgtc tgtaatctca aggagaattg cttgaatctg ggaggcagag gctgcagtga ctccagtctc tcaaaaaaa aaaaagcat aatcagttga ctatttcagg ccatgatggg cctcttgtta aactttag ctggggaaa aataaccagc atcaacatat ttttttttt CCATAGgGAA TATTGTCACT GGTACAGATG AACAGACTCA CACTCGCCGT СTTTCCCAGC CTGCTCACCA ACCCCAAAAC CGTGGACAAT GTCAAACATC ACAGCCGGCC GCCAGGACCA ATGGATTAGT caagtcatt tcttgggttc ttggatagaa attgtgcaa

CACAAAAGGA TTGTGTACCT ATACCAAGAT tcaaggtggc ggagggcagc gccacccett ggatggtgtg ggttgattta gccaggcacg cacctgaggt aaatgcaag ctgaggcagg tattgcactc agccttcaat ggccagtatt tttcatcta tacataccat gtttagttta tgacatagga gaatgtagtg ctactactga ccaatcacat aaggaattgt cttcattaaa TGCTGAGAAA AGACAAAATT CTTAATTGAG tggaaacata ttgttaaat agtttggctt tttcaaatga tgtaggaggt tttcctatt CCCATTCCTT

tttagtatt tactaggagt ccttggtact ctgttctgaa

AGCTGTGTGG TGTTCACTGT TATTCTGGTT tttgtttgaa tgtaagtnta tgattaaaa acctgaatcg atttcccaat gtggctcatg caagagttcg aattagccat agaatcgctt cagcttgggc aatggatgct tcttcttccc tagatattta tccatatgtc gcactccata tgctttacga ttgttttaaa ttgtaagatc tgagtgtcaa taggtgctta ataaaccag CTAGGTGAAA GTCAGTGTTC GCCAGGACCA atagaaagct gtgcttgata cctttgctga acaataccca ttcagtcatt gtttttgtga ataaaccat ttccttatgt GCCGTGACCA ACTATACCAG E9 GGCATAATAG AACCGTTGAT ATCCTGGATG CCATTTCAAA tttggacttg ataataatca ctcactagta agccacagaa tgaggcaggc attataaag gagtcaggcg cttatgtgga ttcataccga tttttggtga cctgtaatca cagcactttg agaccagcct ggccaacatg gtgtggtggt gggcgcctat gaacccggga agcggaagtt agagtgaa ctgtcttaa agcgtatctg ttactgtgta ctcatctaat cccctaagtt tgtatctctt taaggttgaa cagtaatcc ttaataccaa ggccatcttt gcccttagac aacaatacac ccctgttccc agttgcccgc atgattttga tttggctcca gttgaagtag caaatataa aatggacata tttctgcctg acgtatcaat agtatatgcC agtaaacttg CTGAGAAACT TAGTATAATG GAAGCTCTAC AAAACCATGA AAATGAGTCT AAGTATTTCT CTGTAGAGgt gagtaatgga aagtcaaggc cataagcctt tttttccctt atagtaaat atcagtgtgc atgggacata gatggtaata aatctttt aaactgagat acaaccttga gaatcttaga atatcttgag gatagagaag taggccaaac tcatcaccat gaaaatgac ggttggggaa gaaaaaatc catttatgaa ttggcaaagt ttcagagacc 
9541 ctccctcctc tatgtcaat actataatat catacaggat taaaggtgta atatgcagat

9601 caagacctag agattaaata cagacttcag gtaggctgct gcttggaata cttatatcat

9661 ttt tatact attett tat atatttccag GAAGAGGAAG ATCAAAACGT TGTACCAGAA E11

9721 ACTACCTCTG AAGGCTACAC TTTCCAAGTT CAGGATGGGG CTCCTGGGAC CTTTAACTTT

9781 TAGATCATGT AGCTGAGACA TAAATTTGTT GTGTACTACG TTTGGTATTT TGTCTTATTG

9841 TTTCTCTACT AAGAACTCTT TCTTAAATGT GGTTTGTTAC TGTAGCACTT TTTACACTGA

9901 AACTATACTT GAACAGTTCC AACTGTACAT ACATACTGTA TGAAGCTTGT CCTCTGACTA

9961 GGTTTCTAAT TTCTATGTGG AATTTCCTAT CTTGCAGCAT CCTGTAAATA AACATTCAAG

10021 TCCACCСTTt tcttgacttc accatgccta tgtgttgctt tctaatntgg ggcctntaat

10081 gttgctagtg aaaggtaacc tgtccaaact gatgggatta accanaggta gtcctggctg

10141 cagtttt

In Abbildung 28 ist die Exon-Intron-Struktur von KPNA2 schematisch dargestellt.

Bei einem Sequenzvergleich der genomischen Sequenz von KPNA2 in der EMBL/GenBankDatenbank wurden schließlich für einzelne Sequenzabschnitte sehr hohe Homologien zu dem vom Whitehead Institute sequenzierten BAC-Klon hCIT.87G17 (Accession-Nr. AC003663) festgestellt. Die Sequenz dieses Klons entspricht den im Rahmen dieser Arbeit erhaltenen Teilsequenzen der YAC-Klone 765F4 und 963C7. Die gefundenen Homologien werden im folgenden dargestellt:

- $91 \%$ Identität, bp 2052 bis 3187 von KPNA2 mit bp 65555 bis 66684 von hCIT.87G17

- $88 \%$ Identität, bp 3286 bis 3760 von KPNA2 mit bp 68892 bis 69378 von hCIT.87G17

- $94 \%$ Identität, bp 6877 bis 7546 von KPNA2 mit bp 69646 bis 70321 von hCIT.87G17

- $92 \%$ Identität, bp 7563 bis 8286 von KPNA2 mit bp 70319 bis 71051 von hCIT.87G17

- $89 \%$ Identität, bp 8005 bis 8688 von KPNA2 mit bp 71217 bis 71899 von hCIT.87G17

- $91 \%$ Identität, bp 8678 bis 9291 von KPNA2 mit bp 72216 bis 72836 von hCIT.87G17

- 96 \% Identität, bp 9295 bis 10148 von KPNA2 mit bp 74048 bis 74896 von hCIT.87G17 

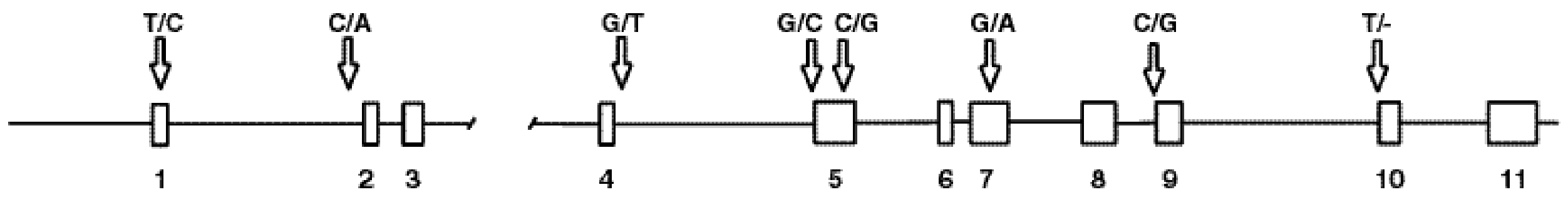

$1 \mathrm{~kb}$

Abb. 28: Schematische Darstellung der Exon-Intron-Organisation von KPNA2. Exons sind durch offene Rechtecke repräsentiert und numeriert. Die Pfeile zeigen auf die Lokalisierung der im KPNA2-Gen identifizierten Variationen (s. Tabelle 52). Zwischen den Exons 3 und 4 befindet sich eine Lücke bisher unbekannter Größe. 


\subsubsection{Suche nach Mutationen in KPNA2 bei Probanden mit RSS}

Da KPNA2 in der unmittelbaren Umgebung des Bruchpunktes von Proband AS kartiert werden konnte, stellte sich die Frage, ob dieses Gen für das RSS verantwortlich ist. Daher wurden 31 Probanden mit RSS auf Mutationen innerhalb des Gens KPNA2 analysiert, indem die 11 Exons des Gens sowie Teile der angrenzenden Introns der Probanden sequenziert wurden.

Zunächst wurden anhand der genomischen Sequenz von KPNA2 Primer abgeleitet, mit denen sich die Exons dieses Gens spezifisch darstellen ließen. Dies war erschwert dadurch, daß Teile des Gens nahezu identisch sind mit der Sequenz des BACs hCIT.87G17, der eine zu KPNA2 homologe jedoch nicht identische Sequenz beinhaltet. Die Primer wurden daher so gewählt, daß sie am 3'-Ende möglichst große Abweichungen zu der Sequenz des BACs enthalten. DNA der zwei YAC-Klone 765F4 und 963C7, die die gleiche zu KPNA2 homologe Sequenz wie hCIT.87G17 enthalten, diente als Negativkontrolle, um auszuschließen, daß die für KPNA2 gewählten Primer auch die in diesen Klonen enthaltene homologe Sequenz amplifizieren.

Tabelle 50 gibt eine Übersicht über die spezifischen Primer, die zur Amplifikation der Exons eingesetzt wurden.

Tab. 50: Primer zur Amplifikation der Exons von KPNA2

\begin{tabular}{|c|c|c|c|c|}
\hline Exon-Nr. & $\begin{array}{l}\text { Position der Primer in } \\
\text { der genomischen } \\
\text { Sequenz von KPNA2 }\end{array}$ & $\begin{array}{l}\text { forward Primer Sequenz }\left(5^{\prime} \rightarrow 3^{\prime}\right) \\
\text { reverse Primer Sequenz }\left(5^{\prime} \rightarrow 3^{\prime}\right)\end{array}$ & $\begin{array}{l}\text { Primer- } \\
\text { Name }\end{array}$ & $\begin{array}{l}\text { Größe des } \\
\text { PCR-Produkts } \\
\text { (bp) }\end{array}$ \\
\hline 1 & $\begin{array}{c}833 \ldots 852 \\
1127 \ldots 1110\end{array}$ & $\begin{array}{l}\text { CCCAACGTGTTTTTCAAATC } \\
\text { CTCCCCCAACCCAAAAG }\end{array}$ & $\begin{array}{l}\text { E1.F2 } \\
\text { E1.R2 }\end{array}$ & 295 \\
\hline 2 & $\begin{array}{l}2122 \ldots 2141 \\
2510 \ldots 2489\end{array}$ & $\begin{array}{l}\text { AAGTCTCAGCCCTTCAGATG } \\
\text { GGGCATTTTTTTTTAAATACC }\end{array}$ & $\begin{array}{l}\text { K1.F2(2) } \\
\text { K1.R2 }\end{array}$ & 389 \\
\hline 3 & $\begin{array}{l}2469 \ldots 2487 \\
2825 \ldots 2804\end{array}$ & $\begin{array}{l}\text { TGGAAAGGGGTGAAAACTG } \\
\text { TGTTCACAGATAGTTAAAACCG }\end{array}$ & $\begin{array}{l}\text { K2.F3 } \\
\text { K2.R3 }\end{array}$ & 357 \\
\hline 4 & $\begin{array}{l}3768 \ldots 3789 \\
4044 \ldots .4027\end{array}$ & $\begin{array}{l}\text { AGCCTAACGATGTTTACACTTG } \\
\text { TGTCTGTCCCTTCCTGCC }\end{array}$ & $\begin{array}{l}\text { K3.F2 } \\
\text { K3.R2 }\end{array}$ & 277 \\
\hline 5 & $\begin{array}{l}5189 \ldots . .5210 \\
5616 \ldots . .5595\end{array}$ & $\begin{array}{l}\text { CTTGAATTGCATTTTATATTGG } \\
\text { CTTATAACAAGGCCTTTCTTCC }\end{array}$ & $\begin{array}{l}\text { SSCP3.F } \\
\text { K3.R }\end{array}$ & 428 \\
\hline 6 & $\begin{array}{l}6029 \ldots 6047 \\
6258 \ldots 6238\end{array}$ & $\begin{array}{l}\text { GGGCGACAGAGAGAAACTC } \\
\text { TCTGTCTTTTGAGAAGATGGG }\end{array}$ & $\begin{array}{l}\text { K4.F } \\
\text { K4.R }\end{array}$ & 230 \\
\hline 7 & $\begin{array}{l}6220 \ldots 6240 \\
6627 \ldots 6610\end{array}$ & $\begin{array}{l}\text { TTCTTCATTCTAATTTCCCCC } \\
\text { TGAGCCACCACTACCACG }\end{array}$ & $\begin{array}{l}\text { K5.F } \\
\text { K5.R }\end{array}$ & 408 \\
\hline 8 & $\begin{array}{l}6940 \ldots 6961 \\
7350 \ldots 7331\end{array}$ & $\begin{array}{l}\text { GCCTCTTGTTAAAACTTTTAGG } \\
\text { GAACCCAAGATTCTTGCACG }\end{array}$ & $\begin{array}{l}\text { K6.F2 } \\
\text { K6.R }\end{array}$ & 411 \\
\hline 9 & $\begin{array}{l}7385 \ldots 7404 \\
7761 \ldots . .7739\end{array}$ & $\begin{array}{l}\text { CCCCTTTTACTTAAGGTTGG } \\
\text { CCCCAAGTCTAAATAGTAAACTG }\end{array}$ & $\begin{array}{l}\text { K7.F2 } \\
\text { K7.R2 }\end{array}$ & 377 \\
\hline 10 & $\begin{array}{l}8833 \ldots 8853 \\
9185 \ldots 9164\end{array}$ & $\begin{array}{l}\text { GCTTGATGAAGGAATTGTTAG } \\
\text { TTTAAAAGGGAAAAAAAGGCTT }\end{array}$ & $\begin{array}{l}\text { K8.F } \\
\text { K8.R }\end{array}$ & 353 \\
\hline 11 & $\begin{array}{l}9637 \ldots 9658 \\
9950 \ldots 9928\end{array}$ & $\begin{array}{l}\text { TGCTGCTTGGAATACTTATATC } \\
\text { ACAAGCTTCATACAGTATGTATG }\end{array}$ & $\begin{array}{l}\text { K9.F2 } \\
\text { K9.R2 }\end{array}$ & 314 \\
\hline
\end{tabular}


Die mit den jeweiligen Primerpaaren erhaltenen PCR-Produkte der Probanden wurden aus einem 1,5\% Agarosegel isoliert und anschließend vorwärts und rückwärts sequenziert. Dabei dienten die zur Amplifikation der Exons genutzten PCR-Primer in der Regel auch als Sequenzierungsprimer. Für die Exons 6, 8 und 10 wurden jedoch nicht die entsprechenden forwardPrimer, sondern neu gewählte Primer für die Sequenzierung eingesetzt, diese sind Tabelle 51 zu entnehmen.

Tab. 51: Für die Sequenzierung der Exons 6, 8 und 10 eingesetzte forward-Sequenzierungsprimer

\begin{tabular}{lllll}
\hline $\begin{array}{l}\text { Exon- } \\
\text { Nr. }\end{array}$ & $\begin{array}{l}\text { Position der Primer in } \\
\text { der genomischen } \\
\text { Sequenz von KPNA2 }\end{array}$ & forward Primer Sequenz $\left(5^{\prime} \rightarrow 3^{\prime}\right)$ & $\begin{array}{l}\text { Primer- } \\
\text { Name }\end{array}$ & $\begin{array}{l}\text { Sequenziertes } \\
\text { PCR-Produkt }\end{array}$ \\
\hline 6 & $6049 \ldots 6073$ & GTCTCAAAAAAAAAAAAAAAAATT & K4.F2 & K4.F/K4.R \\
8 & $7003 \ldots 7026$ & CAACATATTTTTTTTTTTTCAGAC & K6.F3 & K6.F2/K6.R \\
10 & $8935 \ldots 8958$ & AACTTGGATtTTTTTTTTTTTTAG & K8.F2 & K8.F/K8.R \\
\hline
\end{tabular}

31 Probanden mit RSS wurden mittels forward und reverse Sequenzierungen der 11 Exons von KPNA2 auf Mutationen in diesem Gen analysiert. Die Auswertung der Sequenzierungen erfolgte, indem die für die Probanden erhaltenen Sequenzdaten mit der über Sequenzierung der Klone 81B9 und CF20b erhaltenen genomischen Sequenz von KPNA2 (s. 3.13.4) verglichen wurde. Bei 25 der analysierten 31 Probanden wurden über diese Sequenzierungen keine Abweichungen $\mathrm{zu}$ der unter 3.13.4 gezeigten Sequenz festgestellt. Alle durch Sequenzierung gefundenen Variationen sind in der Tabelle 52 dargestellt.

Tab. 52: Bei RSS-Probanden gefundene Abweichungen von der unter 3.13.4 gezeigten genomischen Sequenz von KPNA2

\begin{tabular}{llrll}
\hline Position & Art der Mutation/Variation & $\begin{array}{l}\text { Position in der Sequenz } \\
\text { von KPNA2/betroffenes } \\
\text { Nukleotid }\end{array}$ & $\begin{array}{l}\text { gefunden bei den } \\
\text { Probanden }\end{array}$ \\
\hline Exon 1 & Basensubstitution & 993 & $\mathrm{~T} \rightarrow \mathrm{C}$ & LJ, DD, LM, KE, PZ, SS \\
Intron 1 & Basensubstitution & 2203 & $\mathrm{C} \rightarrow \mathrm{A}$ & LJ, DD, LM, KE, PZ, SS \\
Intron 4 & Basensubstitution & 4017 & $\mathrm{G} \rightarrow \mathrm{T}$ & LJ, DD, LM, KE, PZ, SS \\
Intron 4 & Basensubstitution & 5255 & $\mathrm{G} \rightarrow \mathrm{C}$ & LJ, DD, LM, KE, PZ, SS \\
Exon 5 & Aminosäureaustausch & 5466 & $\mathrm{C} \rightarrow \mathrm{G}$ & LJ \\
& (Pro $\rightarrow$ Arg) & & & LJ, DD, LM, KE, PZ, SS \\
Exon 7 & synonyme Substitution & 6423 & $\mathrm{G} \rightarrow \mathrm{A}$ & \\
& (wobble-Position) & & & FL I +II \\
Intron 8 & Basensubstitution & 7471 & $\mathrm{C} \rightarrow \mathrm{G}$ & LJ, DD, LM, KE, PZ, SS \\
Intron 9 & Deletion & 8943 & $\mathrm{del} \mathrm{T}$ &
\end{tabular}


Wie Tabelle $52 \mathrm{zu}$ entnehmen ist, zeigten 6 Probanden (LJ, DD, LM, KE, PZ und SS) an 6 Positionen Abweichungen zu der genomischen Sequenz von KPNA2. Zudem wurde bei einer Probandin (LJ) eine Basensubstitution identifiziert, die zum Austausch der Aminosäure Prolin gegen Arginin führt. Bei einem Probanden (FL) und bei dessen eineiigem Zwillingsbruder, der ebenfalls das RSS aufweist, wurde ein Basenaustausch im Intron 8 nachgewiesen.

\subsubsection{Identifizierung von Polymorphismen im KPNA2-Gen}

Werden für einen Locus zwei oder mehr Allele in einer Population gefunden, die nicht mit einem auffälligen Phänotyp assoziiert sind, wird von einem Polymorphismus gesprochen. Schon wenn das seltene Allel eine Häufigkeit von mehr als einem Prozent aufweist, wird der untersuchte Locus als polymorph bezeichnet (Passarge, 1995).

Um zu überprüfen, ob es sich bei den Variationen, die über Sequenzierung von Exons des Gens KPNA2 bei RSS-Probanden identifiziert wurden (s. Tab. 52), um funktionelle Mutationen oder um Polymorphismen handelt, wurde zunächst DNA der Eltern dieser Probanden auf diese Variationen hin analysiert. Dazu wurden die betreffenden Sequenzabschnitte, wenn möglich, auch von beiden Eltern der jeweiligen Probanden sequenziert. Es zeigte sich, daß alle gefundenen Variationen der Probanden auch bei den Eltern vorlagen und somit familiär vorkommen.

Tabelle 53 gibt eine Übersicht über die bei Probanden und deren Eltern identifizierten Allele von 6 Variationen. Wie dieser Tabelle zu entnehmen ist, sind die 6 identifizierten Variationen nicht zufällig verteilt, sondern es wurden bei den Probanden und deren Eltern 2 spezifische Haplotypen (1 und 2) identifiziert, welche aus 6 diallelischen Markern zusammengesetzt sind. Die Mehrzahl der Probanden weist, in Übereinstimmung mit der unter 3.13.4 gezeigten genomischen Sequenz von KPNA2, den Haplotyp 1 in homozygoter Form auf, während die Probanden LJ, DD, LM, KE und SS auf einem Chromosom den Haplotyp 1 und auf dem anderen den Haplotyp 2 aufweisen. Proband PZ ist für den Haplotyp 2 homozygot. In Abb. 29 werden die Sequenzausschnitte, welche die variablen Positionen dieser Haplotypen enthalten, dargestellt.

Um zu analysieren, ob die bei RSS-Probanden nachgewiesenen Haplotypen auch bei Kontrollpersonen ohne RSS vorkommen, wurde zunächst eine allelspezifische PCR durchgeführt, mit der die Allele an 2 der 6 variablen Positionen bestimmt werden konnten. Dazu wurden forward Primer abgeleitet, die am 3'-Ende die zu den Variationen an Position 2203 bzw. 5255 von KPNA2 entsprechende Sequenz aufweisen. Mit diesen Primern fand nur dann die Amplifikation eines PCR-Produktes statt, wenn die Abweichung von der unter 3.13.4 gezeigten genomischen Sequenz von KPNA2 vorhanden war. Bei diesen Primern handelt es sich um die folgenden Primer:

Name: Pol1B.F

Sequenz: CGAAAACATGATGATCCCA

Name: Pol2.F Sequenz: TTAATCACTGTCAACTTTTATTTC
Position: 2185-2203

Position: 5232-5255 
Der Primer Pol1B.F wurde in der PCR mit dem Primer K1.R2 (s. Tab. 50) kombiniert. Eine Amplifikation mit diesem Primerpaar findet nur statt, wenn an Position 2203 der genomischen Sequenz von KPNA2 ein A lokalisiert ist. Primer Pol2.F wurde mit dem Primer K3.R (s. Tab. 50) kombiniert. Ein PCR-Produkt wird bei dieser Kombination nur erhalten, wenn an Position 5255 der genomischen Sequenz von KPNA2 ein C vorhanden ist. Für die getesteten DNAs wurde jeweils eine Positivkontrolle mit Primern, die das Exon 2 von KPNA2 amplifizieren, mitgeführt. Nach allelspezifischer PCR mit DNA von 36 Kontrollpersonen fand in 17 Fällen mit beiden Primerpaaren keine Amplifikation statt, während die Kontrolle ein spezifisches PCR-Produkt zeigte. Diese Personen sind somit an dem polymorphen Locus des Introns 1 homozygot $\mathrm{CC}$ und an dem des Introns 4 homozygot GG (s. Tab. 54). In der Annahme, daß keine weiteren, bisher nicht identifizierten Haplotypen existieren, weisen diese 17 Kontrollpersonen somit den Haplotyp 1 auf.

Mit dem Primerpaar Pol1B.F/K1.R2 (Nachweis eines A an Position 2203) wurde mit Proben von 19 Kontrollpersonen ein spezifisches PCR-Produkt erhalten. Mit dem Primerpaar Pol2.F/K3.R (Nachweis eines $C$ an Position 5255) zeigten 15 dieser 19 Kontrollpersonen ein spezifisches PCR-Produkt. Da die zwei Variationen, die über allelspezifische PCR analysiert wurden, bei RSS-Probanden gemeinsam mit vier weiteren Veränderungen auftraten, sollte analysiert werden, ob die Kontrollpersonen, bei denen bereits eine (4 Kontrollpersonen) oder zwei (15 Kontrollpersonen) dieser Abweichungen von der in dieser Arbeit ermittelten genomischen Sequenz von KPNA2 (s. 3.13.4) festgestellt wurden, weitere Veränderungen aufweisen. Zudem sollte festgestellt werden, ob die über allelspezifische PCR identifizierten Variationen bei den Kontrollpersonen homo- oder heterozygot vorliegen. Daher wurden die Exons 1, 2, 4, 5, 7 und 10 von KPNA2 der 19 Kontrollpersonen mit Variationen mit den in Tabelle 50 angegebenen Primern amplifiziert, aus einem 1,5\% Agarosegel isoliert und anschließend entweder mit den zur Amplifikation eingesetzten forward oder reverse Primern sequenziert, je nachdem mit welchem Primer die Variation der jeweiligen Exons am besten darstellbar war. Tabelle 54 zeigt die Ergebnisse dieser Sequenzierungen.

Wie Tabelle $54 \mathrm{zu}$ entnehmen ist, kommen die bei RSS-Probanden identifizierten Haplotypen 1 und 2 auch bei Kontrollpersonen ohne RSS vor, so daß diese nicht unmittelbar für die Entstehung des RSS verantwortlich sein können. Somit handelt es sich bei den identifizierten Variationen um Polymorphismen. Bei Kontrollpersonen wurden zudem 2 zusätzliche Haplotypen (3 und 4) identifiziert, welche bei den RSS-Probanden nicht vorkommen. Eine Übersicht über die Häufigkeiten der einzelnen Allele dieser Haplotypen sowie Angaben über deren Heterozygotenfrequenz und Informationsgehalt (polymorphism information content, PIC) gibt Tabelle 55. Bei diesen Polymorphismen handelt es sich um Diallelpolymorphismen. Das Allel, welches mit der genomischen Sequenz von KPNA2 übereinstimmt, wurde als Allel A und jenes, welches eine davon abweichende Sequenz zeigt, als Allel B bezeichnet. Bei Diallelpolymorphismen kann die Heterozygotie nie höher als 50 \% und der PIC nicht größer als 37,5 $\%$ sein. 

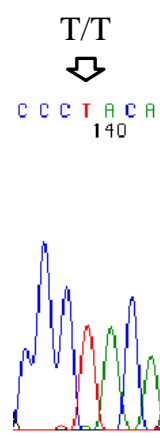

H1/H1
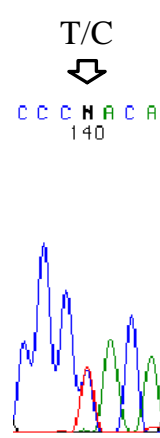

H1/H2
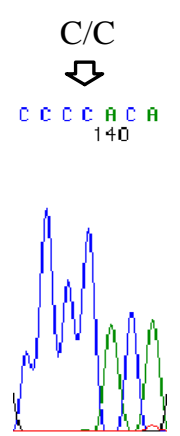

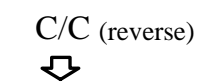

${ }_{31 C}^{A G 66060}$

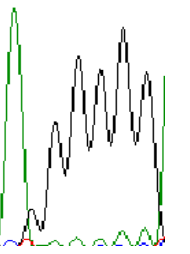

$$
\text { C/A (reverse) }
$$
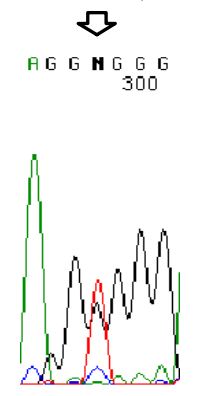

A/A (reverse)

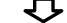

AG TGG G

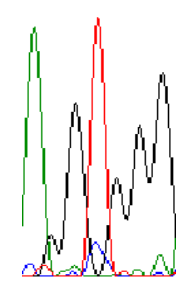

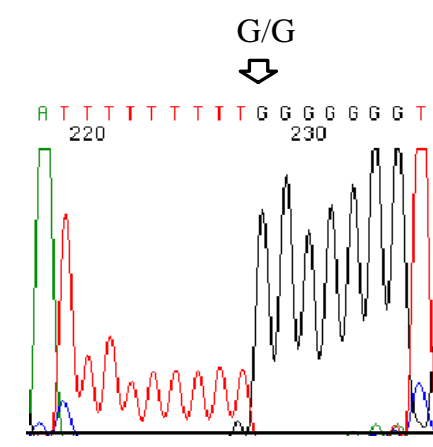

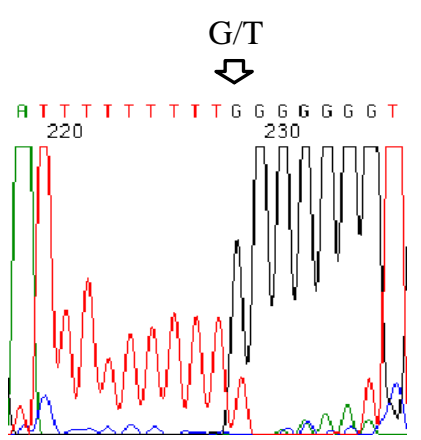

$\mathrm{T} / \mathrm{T}$

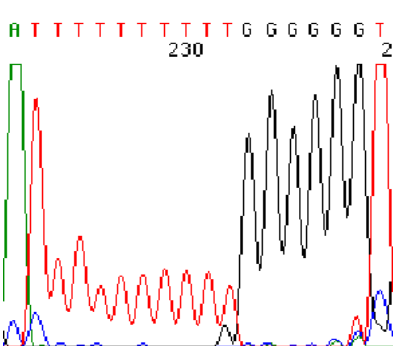

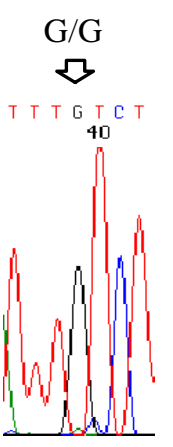

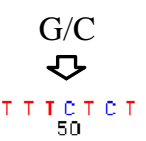$$
\text { G/A }
$$

${ }_{180}{ }_{18}$ A H A C T
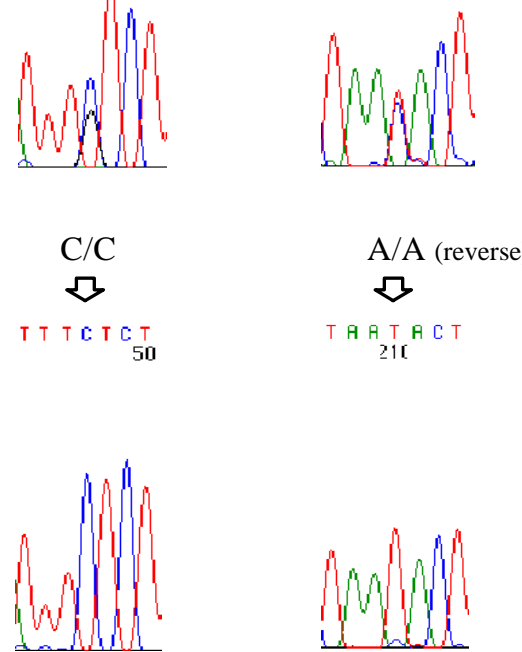

G/G (reverse)

${ }_{80}^{T \text { A }}$ C C A C T
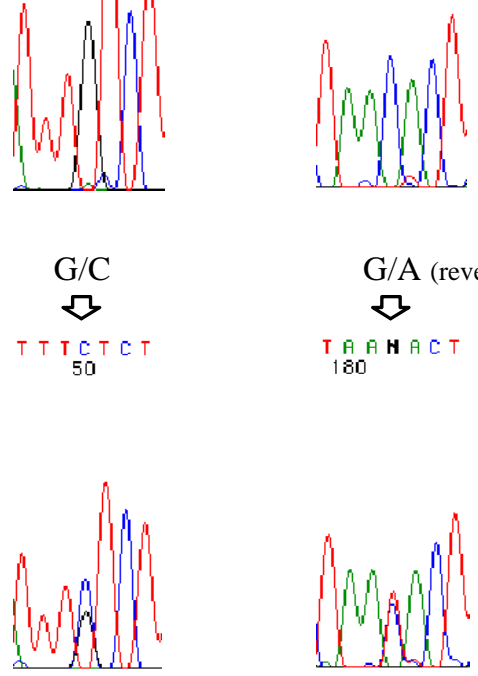

${ }_{211}$

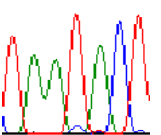

$\mathrm{T} / \mathrm{T}$ (reverse)

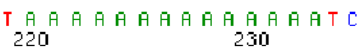

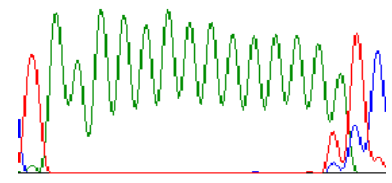

T/- (reverse)

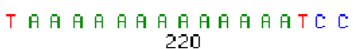

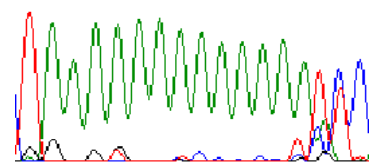

-/- (reverse)

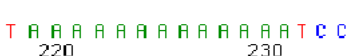

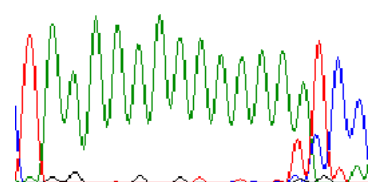

Abb 29: Im KPNA2-Gen identifizierte Haplotypen von RSS-Probanden. Dargestellt sind die Sequenzabschnitte der aus 6 Diallelpolymorphismen bestehenden Haplotypen H1 und H2. Oben: Sequenzen der für H1 homozygoten Probandin BW. Mitte: entsprechende Sequenzen der für H1 und H2 heterozygoten Probandin LJ. Unten: Sequenzausschnitte des für H2 homozygoten Probanden PZ. 
Tab. 53: Genotypisierung an 6 polymorphen intragenischen Loci des KPNA2-Gens bei 31 Probanden mit RSS.

a)

\begin{tabular}{|c|c|c|c|c|c|c|c|c|c|}
\hline Exon/Intron & Position & Vater & $\mathrm{LJ}$ & Mutter & Vater & $\mathrm{KE}$ & Mutter & $\mathrm{DD}$ & Mutter \\
\hline Exon 1 & 993 & $\mathrm{~T} / \mathrm{T}$ & $\mathrm{T} / \mathrm{C}$ & $\mathrm{C} / \mathrm{C}$ & $\mathrm{T} / \mathrm{T}$ & $\mathrm{T} / \mathrm{C}$ & $\mathrm{T} / \mathrm{C}$ & $\mathrm{T} / \mathrm{C}$ & $\mathrm{T} / \mathrm{C}$ \\
\hline Intron 1 & 2203 & $\mathrm{C} / \mathrm{C}$ & $\mathrm{C} / \mathbf{A}$ & $\mathbf{A} / \mathbf{A}$ & $\mathrm{C} / \mathrm{C}$ & $C / \mathbf{A}$ & $\mathrm{C} / \mathbf{A}$ & $\mathrm{C} / \mathbf{A}$ & $\mathrm{C} / \mathbf{A}$ \\
\hline Intron 4 & 4017 & $\mathrm{G} / \mathrm{G}$ & $\mathrm{G} / \mathbf{T}$ & $\mathbf{T} / \mathbf{T}$ & $\mathrm{G} / \mathrm{G}$ & $\mathrm{G} / \mathbf{T}$ & $\mathrm{G} / \mathbf{T}$ & $\mathrm{G} / \mathbf{T}$ & $\mathrm{G} / \mathbf{T}$ \\
\hline Intron 4 & 5255 & $\mathrm{G} / \mathrm{G}$ & $\mathrm{G} / \mathrm{C}$ & $\mathrm{C} / \mathrm{C}$ & $\mathrm{G} / \mathrm{G}$ & $\mathrm{G} / \mathrm{C}$ & $\mathrm{G} / \mathrm{C}$ & $\mathrm{G} / \mathrm{C}$ & $\mathrm{G} / \mathrm{C}$ \\
\hline Exon 7 & 6423 & G/G & $\mathrm{G} / \mathbf{A}$ & $\mathbf{A} / \mathbf{A}$ & G/G & $\mathrm{G} / \mathbf{A}$ & $\mathrm{G} / \mathbf{A}$ & $\mathrm{G} / \mathbf{A}$ & $\mathrm{G} / \mathbf{A}$ \\
\hline Intron 9 & 8943 & $\mathrm{~T} / \mathrm{T}$ & $\mathrm{T} /-$ & $-1-$ & $\mathrm{T} / \mathrm{T}$ & $\mathrm{T} /-$ & $\mathrm{T} /-$ & $\mathrm{T} /-$ & $\mathrm{T} /-$ \\
\hline Haplotyp & & $1 / 1$ & $1 / 2$ & $2 / 2$ & $1 / 1$ & $1 / 2$ & $1 / 2$ & $1 / 2$ & $1 / 2$ \\
\hline Exon/Intron & Position & Vater & $\mathrm{PZ}$ & Mutter & Vater & SS & Mutter & $\mathrm{LM}$ & Mutter \\
\hline Exon 1 & 993 & $\mathrm{~T} / \mathrm{C}$ & $\mathrm{C} / \mathrm{C}$ & $\mathrm{T} / \mathrm{C}$ & $\mathrm{T} / \mathrm{C}$ & $\mathrm{T} / \mathrm{C}$ & $\mathrm{C} / \mathrm{C}$ & $\mathrm{T} / \mathrm{C}$ & $\mathrm{T} / \mathrm{C}$ \\
\hline Intron 1 & 2203 & $\mathrm{C} / \mathbf{A}$ & $\mathbf{A} / \mathbf{A}$ & $\mathrm{C} / \mathbf{A}$ & $\mathrm{C} / \mathbf{A}$ & $\mathrm{C} / \mathbf{A}$ & $\mathbf{A} / \mathbf{A}$ & $\mathrm{C} / \mathbf{A}$ & $\mathrm{C} / \mathbf{A}$ \\
\hline Intron 4 & 4017 & $\mathrm{G} / \mathbf{T}$ & $\mathbf{T} / \mathbf{T}$ & $\mathrm{G} / \mathbf{T}$ & $\mathrm{G} / \mathbf{T}$ & $\mathrm{G} / \mathbf{T}$ & $\mathbf{T} / \mathbf{T}$ & $\mathrm{G} / \mathbf{T}$ & $\mathrm{G} / \mathbf{T}$ \\
\hline Intron 4 & 5255 & $\mathrm{G} / \mathrm{C}$ & $\mathrm{C} / \mathrm{C}$ & $\mathrm{G} / \mathrm{C}$ & G/C & $\mathrm{G} / \mathrm{C}$ & $\mathrm{C} / \mathrm{C}$ & $\mathrm{G} / \mathrm{C}$ & $\mathrm{G} / \mathrm{C}$ \\
\hline Exon 7 & 6423 & $\mathrm{G} / \mathbf{A}$ & $\mathbf{A} / \mathbf{A}$ & $\mathrm{G} / \mathbf{A}$ & $\mathrm{G} / \mathbf{A}$ & $\mathrm{G} / \mathbf{A}$ & $\mathbf{A} / \mathbf{A}$ & $\mathrm{G} / \mathbf{A}$ & $\mathrm{G} / \mathbf{A}$ \\
\hline Intron 9 & 8943 & $\mathrm{~T} /-$ & $-1-$ & $\mathrm{T} /-$ & $\mathrm{T} /-$ & $\mathrm{T} /-$ & $-1-$ & $\mathrm{T} /-$ & $\mathrm{T} /-$ \\
\hline Haplotyp & & $1 / 2$ & $2 / 2$ & $1 / 2$ & $1 / 2$ & $1 / 2$ & $2 / 2$ & $1 / 2$ & $1 / 2$ \\
\hline
\end{tabular}

\begin{tabular}{|c|c|c|}
\hline Exon/Intron & Position & $\begin{array}{l}25 \text { RSS- } \\
\text { Probanden }\end{array}$ \\
\hline Exon 1 & 993 & $\mathrm{~T} / \mathrm{T}$ \\
\hline Intron 1 & 2203 & $\mathrm{C} / \mathrm{C}$ \\
\hline Intron 4 & 4017 & $\mathrm{G} / \mathrm{G}$ \\
\hline Intron 4 & 5255 & $\mathrm{G} / \mathrm{G}$ \\
\hline Exon 7 & 6423 & $\mathrm{G} / \mathrm{G}$ \\
\hline Intron 9 & 8943 & $\mathrm{~T} / \mathrm{T}$ \\
\hline Haplotyp & & $1 / 1$ \\
\hline
\end{tabular}


Tab. 54: Genotypisierung an 6 polymorphen intragenischen Loci des KPNA2-Gens bei 36 Kontrollpersonen. Die unter a) und b) aufgeführten Personen wurden zunächst mittels allelspezifischer PCR für zwei Loci der identifizierten Haplotypen genotypisiert (Position 2203 und 5255 der genomischen Sequenz von KPNA2, s. 3.13.4). Da die unter a) aufgeführten Personen an diesen Positionen nicht die zu Haplotyp 1 korrespondierenden Allele aufweisen, wurden die Allele der identifizierten Haplotypen bei diesen Personen über eine Sequenzierung ermittelt.

a)

\begin{tabular}{|c|c|c|c|c|c|c|c|c|c|c|c|c|c|c|c|c|c|c|c|c|}
\hline $\begin{array}{l}\text { Exon/ } \\
\text { Intron }\end{array}$ & Position & $\begin{array}{l}\text { K1 } \\
\text { (L101) }\end{array}$ & $\begin{array}{l}\text { K2 } \\
\text { (L103) }\end{array}$ & $\begin{array}{l}\text { K3 } \\
\text { (L104) }\end{array}$ & $\begin{array}{l}\text { K4 } \\
\text { (L109) }\end{array}$ & $\begin{array}{l}\text { K5 } \\
\text { (L110) }\end{array}$ & $\begin{array}{l}\text { K6 } \\
\text { (L111) }\end{array}$ & $\begin{array}{l}\text { K7 } \\
\text { (L115) }\end{array}$ & $\begin{array}{l}\text { K8 } \\
\text { (L116) }\end{array}$ & $\begin{array}{l}\text { K9 } \\
(113 r)\end{array}$ & $\begin{array}{l}\text { K10 } \\
(101)\end{array}$ & $\begin{array}{l}\text { K11 } \\
(124)\end{array}$ & $\begin{array}{l}\text { K12 } \\
(140)\end{array}$ & $\begin{array}{l}\text { K13 } \\
\text { (146) }\end{array}$ & $\begin{array}{l}\text { K14 } \\
(148)\end{array}$ & $\begin{array}{l}\text { K15 } \\
(156)\end{array}$ & $\begin{array}{l}\text { K16 } \\
(158)\end{array}$ & $\begin{array}{l}\text { K17 } \\
\text { (TAH) }\end{array}$ & $\begin{array}{l}\text { K18 } \\
(315)\end{array}$ & $\begin{array}{l}\text { K19 } \\
\text { (LB) }\end{array}$ \\
\hline Exon 1 & 993 & $\mathrm{~T} / \mathrm{C}$ & $\mathrm{C} / \mathrm{C}$ & $\mathrm{T} / \mathrm{T}$ & $\mathrm{T} / \mathrm{C}$ & $\mathrm{T} / \mathrm{C}$ & $\mathrm{C} / \mathrm{C}$ & $\mathrm{T} / \mathrm{T}$ & $\mathrm{T} / \mathrm{T}$ & $\mathrm{T} / \mathrm{T}$ & $\mathrm{C} / \mathrm{C}$ & $\mathrm{C} / \mathrm{C}$ & $\mathrm{C} / \mathrm{C}$ & $\mathrm{C} / \mathrm{C}$ & $\mathrm{T} / \mathrm{C}$ & $\mathrm{T} / \mathrm{C}$ & $\mathrm{T} / \mathrm{C}$ & $\mathrm{T} / \mathrm{C}$ & $\mathrm{T} / \mathrm{C}$ & $\mathrm{T} / \mathrm{C}$ \\
\hline Intron 1 & 2203 & $\mathrm{C} / \mathrm{C}$ & $\mathbf{A} / \mathbf{A}$ & $\mathrm{C} / \mathbf{A}$ & $C / \mathbf{A}$ & $\mathrm{C} / \mathrm{C}$ & $C / \mathbf{A}$ & $C / \mathbf{A}$ & $C / \mathbf{A}$ & $C / \mathbf{A}$ & $C / \mathbf{A}$ & $\mathbf{A} / \mathbf{A}$ & $\mathbf{A} / \mathbf{A}$ & $\mathbf{A} / \mathbf{A}$ & $\mathrm{C} / \mathbf{A}$ & $C / A$ & $C / \mathbf{A}$ & $\mathrm{C} / \mathrm{C}$ & $C / \mathbf{A}$ & $\mathrm{C} / \mathrm{C}$ \\
\hline Intron 4 & 4017 & $G / T$ & $\mathbf{T} / \mathbf{T}$ & $\mathrm{G} / \mathbf{T}$ & $\mathrm{G} / \mathbf{T}$ & $\mathrm{G} / \mathbf{T}$ & $\mathbf{T} / \mathbf{T}$ & $\mathrm{G} / \mathbf{T}$ & $\mathrm{G} / \mathbf{T}$ & $\mathrm{G} / \mathbf{T}$ & $\mathbf{T} / \mathbf{T}$ & $\mathbf{T} / \mathbf{T}$ & $\mathbf{T} / \mathbf{T}$ & $\mathbf{T} / \mathbf{T}$ & $\mathrm{G} / \mathbf{T}$ & $\mathrm{G} / \mathbf{T}$ & $\mathrm{G} / \mathbf{T}$ & $\mathrm{G} / \mathbf{T}$ & $\mathrm{G} / \mathbf{T}$ & $\mathrm{G} / \mathbf{T}$ \\
\hline Intron 4 & 5255 & $G / C$ & $\mathrm{C} / \mathrm{C}$ & $G / C$ & $\mathrm{G} / \mathrm{C}$ & $\mathrm{G} / \mathrm{C}$ & $\mathrm{C} / \mathrm{C}$ & $\mathrm{G} / \mathrm{C}$ & $\mathrm{G} / \mathrm{C}$ & $\mathrm{G} / \mathrm{C}$ & $\mathrm{C} / \mathrm{C}$ & $\mathrm{C} / \mathrm{C}$ & $\mathrm{C} / \mathrm{C}$ & $\mathrm{C} / \mathrm{C}$ & $\mathrm{G} / \mathrm{C}$ & $\mathrm{G} / \mathrm{C}$ & $\mathrm{G} / \mathrm{C}$ & $\mathrm{G} / \mathrm{C}$ & $\mathrm{G} / \mathrm{C}$ & $\mathrm{G} / \mathrm{C}$ \\
\hline Exon 7 & 6423 & $\mathrm{G} / \mathbf{A}$ & $\mathbf{A} / \mathbf{A}$ & $\mathrm{G} / \mathbf{A}$ & $\mathrm{G} / \mathbf{A}$ & $\mathrm{G} / \mathbf{A}$ & $\mathbf{A} / \mathbf{A}$ & $\mathrm{G} / \mathbf{A}$ & $\mathrm{G} / \mathbf{A}$ & $\mathrm{G} / \mathbf{A}$ & $\mathbf{A} / \mathbf{A}$ & $\mathbf{A} / \mathbf{A}$ & $\mathbf{A} / \mathbf{A}$ & $\mathbf{A} / \mathbf{A}$ & $\mathrm{G} / \mathbf{A}$ & $\mathrm{G} / \mathbf{A}$ & $\mathrm{G} / \mathbf{A}$ & $\mathrm{G} / \mathbf{A}$ & $\mathrm{G} / \mathbf{A}$ & $\mathrm{G} / \mathbf{A}$ \\
\hline Intron 9 & 8943 & $\mathrm{~T} / \mathrm{T}$ & $-1-$ & $\mathrm{T} /-$ & $\mathrm{T} /-$ & $\mathrm{T} / \mathrm{T}$ & $\mathrm{T} /-$ & $\mathrm{T} /-$ & $\mathrm{T} /-$ & $\mathrm{T} /-$ & $\mathrm{T} /-$ & $-1-$ & $-1-$ & $-1-$ & $\mathrm{T} /-$ & $\mathrm{T} /-$ & $\mathrm{T} /-$ & $\mathrm{T} / \mathrm{T}$ & $\mathrm{T} /-$ & $\mathrm{T} / \mathrm{T}$ \\
\hline Haplotyp & & $1 / 3$ & $2 / 2$ & $1 / 4$ & $1 / 2$ & $1 / 3$ & $3 / 2$ & $1 / 4$ & $1 / 4$ & $1 / 4$ & $3 / 2$ & $2 / 2$ & $2 / 2$ & $2 / 2$ & $1 / 2$ & $1 / 2$ & $1 / 2$ & $1 / 3$ & $1 / 2$ & $1 / 3$ \\
\hline
\end{tabular}

b)

\begin{tabular}{l|c|c}
\hline $\begin{array}{l}\text { Exon/ } \\
\text { Intron }\end{array}$ & Position & $\begin{array}{c}17 \\
\text { Kontrollen }\end{array}$ \\
\hline Intron 1 & 2203 & $\mathrm{C} / \mathrm{C}$ \\
Intron 4 & 5255 & $\mathrm{G} / \mathrm{G}$ \\
\hline Haplotyp & & $1 / 1$ \\
\hline
\end{tabular}


Im Exon 5 des KPNA2-Gens wurde an Position 5466 der genomischen Sequenz bei Probandin LJ, ihrem Vater und ihrem Großvater väterlicherseits ein heterozygot vorliegender $\mathrm{C} \rightarrow \mathrm{G}$-Austausch festgestellt. Durch diesen Basenaustausch kommt es zu einer veränderten Aminosäuresequenz von KPNA2; anstelle von Arginin wird Prolin eingebaut. Um zu analysieren, ob diese Variation auch in Kontrollpersonen vorkommt, wurde eine SSCP-Analyse durchgeführt. Für diese Analysen wurden folgende Primer anhand der genomischen Sequenz von KPNA2 abgeleitet:

Name: SSCP4.F Sequenz: AGAAAAACAGCCCCCC

Name: SSCP4.R Sequenz: AAGCAAGCTCAAAACTTGAC
Position: 5290-5305

Position: 5649-5630

Diese Primer waren mit Cy5 fluoreszenzmarkiert. Die PCR-Reaktionen für die SSCP-Analysen erfolgten wie unter 2.2.11.1 beschrieben. Die Auftrennung der Fragmente erfolgte in einem Alf-express Sequenzierautomat unter nichtdenaturierenden Bedingungen (s. 2.2.11.2).

Mit den Primern SSCP4.F und SSCP4.R konnte die bei der Probandin LJ identifizierte Veränderung spezifisch dargestellt werden (s. Abb. 30). Über SSCP-Analyse von 58 Kontrollpersonen wurde das Bandenmuster, welches auf das Vorhandensein eines G an Position 5466 von KPNA2 hinweist, auch bei einer Kontrollperson ohne RSS beobachtet. PCR-Produkte dieser Kontrollperson die mit Primern, die das Exon 5 von KPNA2 und somit auch Position 5466 amplifizieren, erhalten wurden, wurden nach Isolierung aus einem 1,5\% Agarosegel sequenziert. Die Sequenzierung bestätigte, daß die Kontrollperson an Position 5466 von KPNA2 heterozygot ein $\mathrm{G}$ und ein $\mathrm{C}$ aufweist. Somit ist anzunehmen, daß die Variation an Position 5466 einen seltenen diallelischen Polymorphismus innerhalb von KPNA2 darstellt. Die Allelhäufigkeiten, die Heterozygotenfrequenz und der PIC dieses Polymorphismus sind Tabelle 55 zu entnehmen. Das mit der genomischen Sequenz von KPNA2 übereinstimmende Allel wurde mit A und das davon abweichende Allel als B bezeichnet.

Tab. 55: Polymorphismen bei RSS-Probanden und einer Vergleichsgruppe von nicht verwandten Personen ohne RSS. Neben der Anzahl der Untersuchten (n) wird die Häufigkeit der Allele, die nach dem Hardy-Weinberg-Gesetz errechnete Heterozygotenfrequenz (Het) und der Polymorphismus-Informationsgehalt (PIC) angegeben.

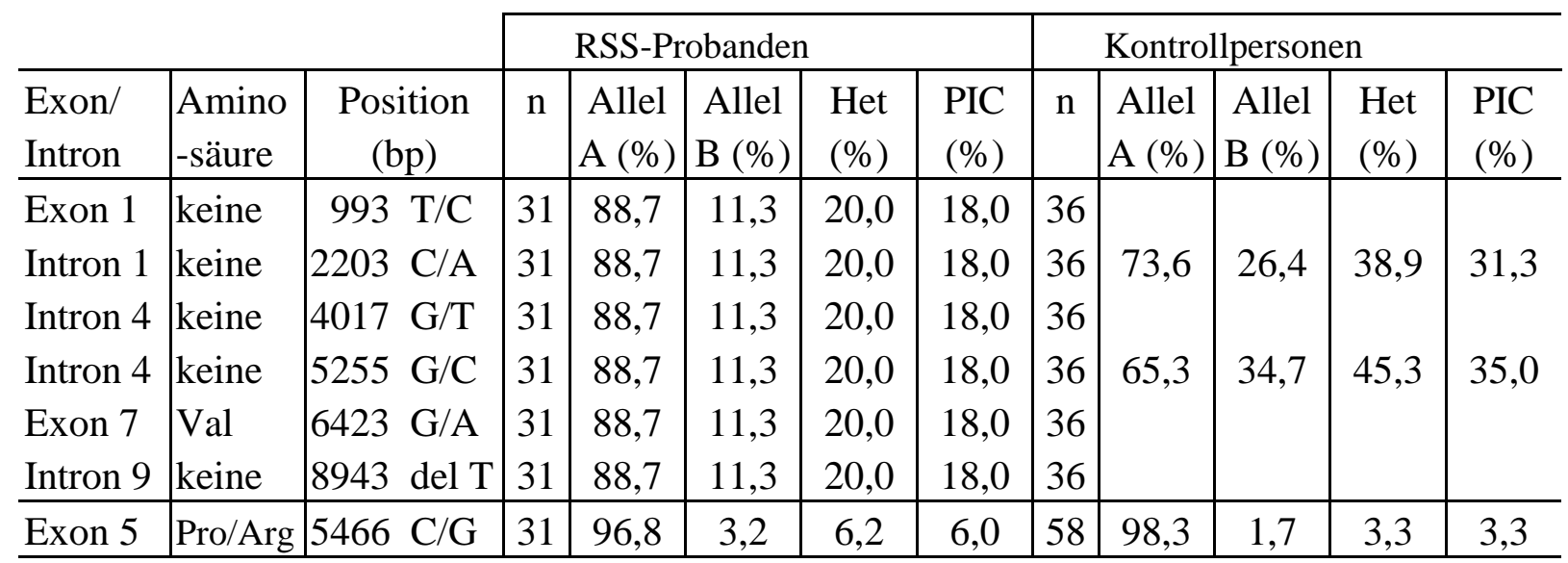



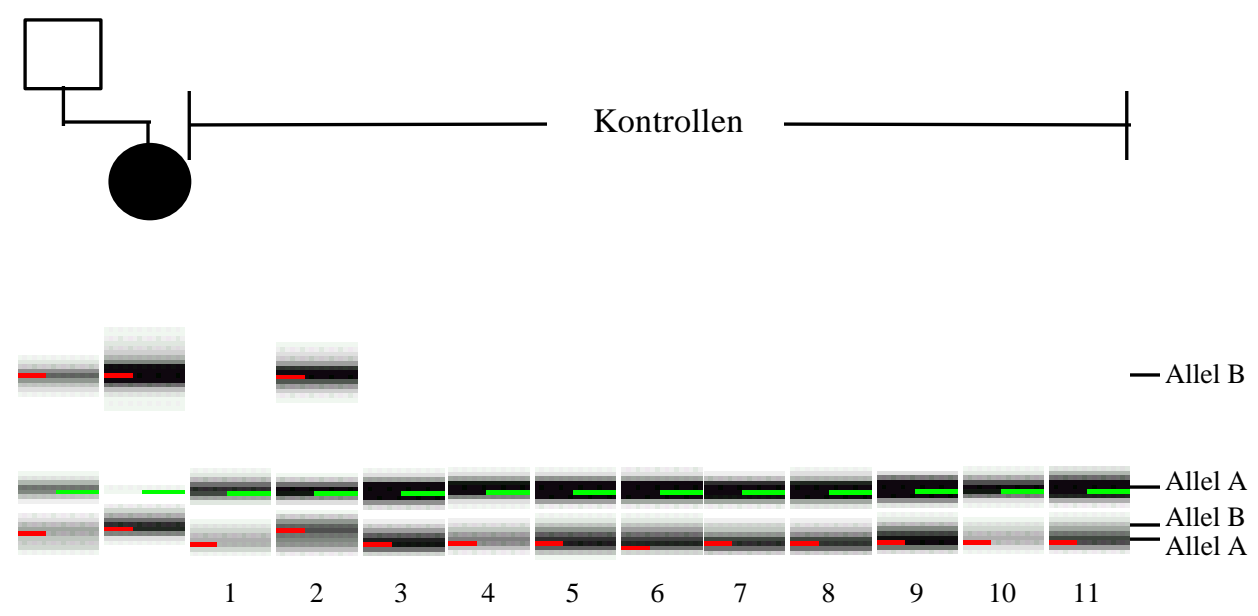

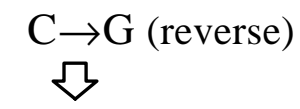

G A AT G C T HG G G A TG G C 130

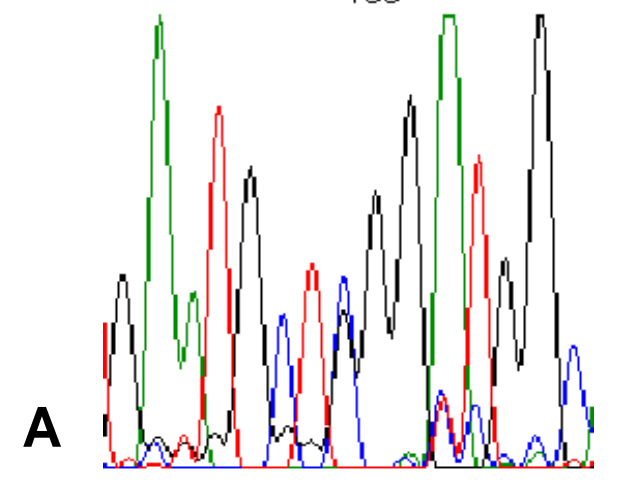

$\mathrm{C} / \mathrm{C}$ (reverse)

○

G A A T G C T G G G ATG G C 130

B

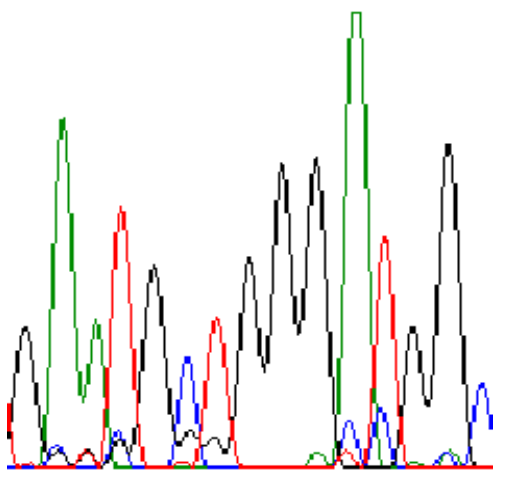

Abb. 30: Darstellung der $\mathrm{C} \rightarrow \mathrm{G}-$ Variation des Exons 5. Gezeigt sind SSCPAnalyse von RSS-Probandin LJ und von deren Vater sowie von 11 unauffälligen Personen (oben) und Sequenzausschnitte der betroffenen DNA-Region (unten). Das bei der Probandin LJ, deren Vater und Großvater väterlicherseits identifizierte Allel B (GNukleotid) wurde bei Analyse von 58 Kontrollpersonen einmal gefunden (Nr. 2). Die Sequenzierung zeigte, daß LJ heterozygot für die Allele A und B ist (siehe Sequenz A). Auch der Vater von LJ, deren Großvater sowie Kontrollperson 2 zeigten nach Sequenzierung eine Sequenz entsprechend A. 30 weitere RSS-Probanden sowie 19 Kontrollpersonen zeigten eine Sequenz entsprechend B. 
Ob die Variation, welche im Intron 8 an Position 7471 der genomischen Sequenz von KPNA2 gefunden wurde, auch in Kontrollpersonen ohne RSS vorkommt, wurde anhand einer SSCPAnalyse mit folgenden Cy5-markierten Primern analysiert:

\section{Name: K7F.SSCP Sequenz: ACCCCTTTTACTTAAGGTTGG Position: 7384-7404 Name: K7R.SSCP Sequenz: TTCCACCACTGGTATAGTTGG Position: 7568-7548}

Die diese Variation heterozygot aufweisenden eineiigen Zwillinge FL und deren für die Veränderung homozygoter Vater zeigten nach SSCP-Analyse ein Bandenmuster, welches sich deutlich von dem in Kontollen ohne diese Veränderung gefundenen Bandenmuster unterscheidet (s. Abb. 31). Nach Analyse von 39 Kontrollpersonen ohne RSS wurde jedoch in keinem Fall ein SSCP-Bandenmuster identifiziert, welches auf diese Veränderung hinweist. Somit kann aufgrund der durchgeführten Analysen nicht entschieden werden, ob es sich bei dieser Variation um einen Polymorphismus oder um eine funktionelle Mutation handelt. Da der nicht betroffene Vater der Zwillinge die Mutation homozygot aufweist, ist diese jedoch vermutlich nicht für das RSS verantwortlich.
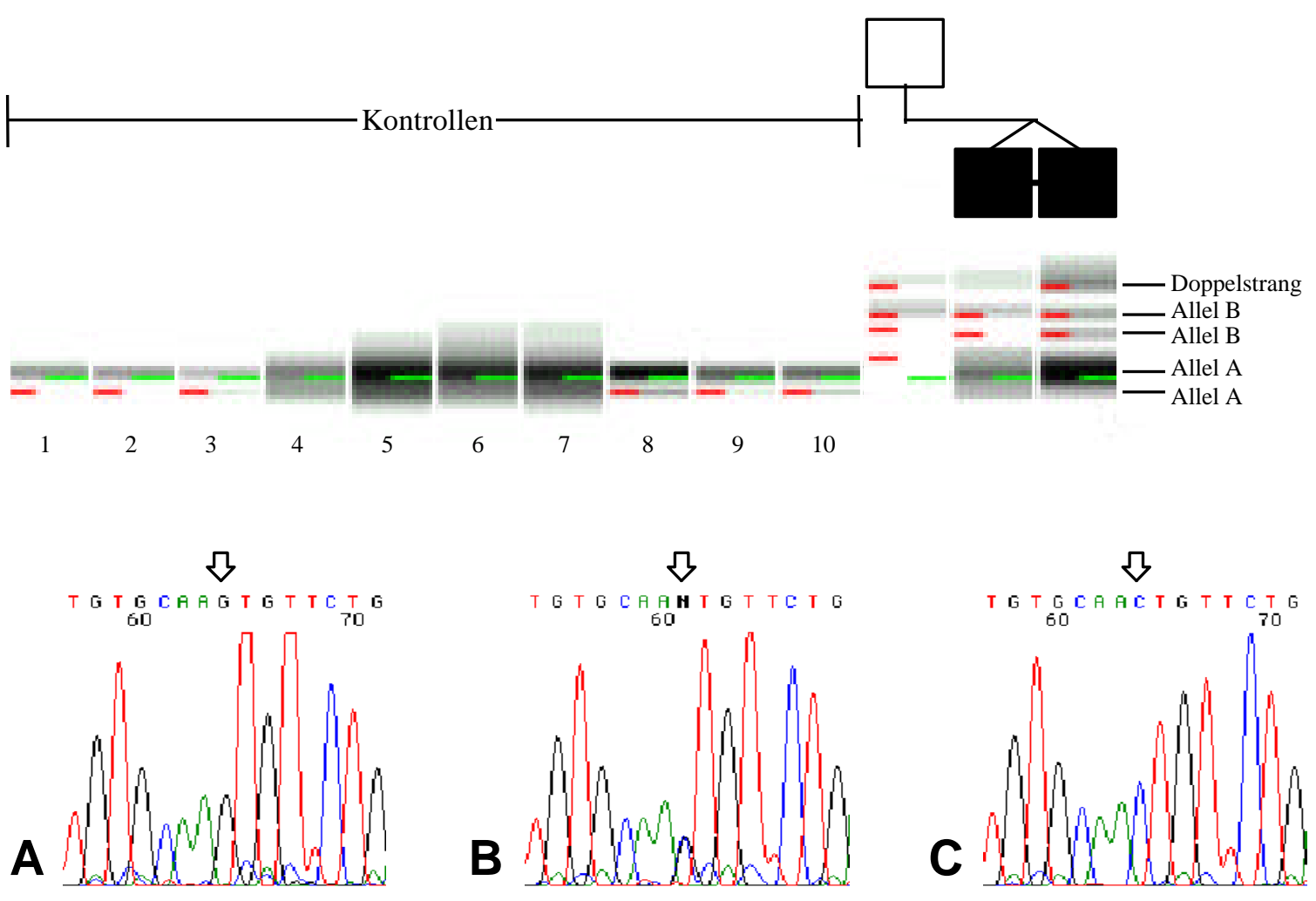

Abb. 31: Darstellung der $\mathrm{C} \rightarrow \mathrm{G}-$ Variation des Introns 8. Gezeigt sind SSCP-Analyse der eineiigen RSS-Zwillinge FL $I$ und II und von deren Vater sowie von 10 unauffälligen Personen (oben) und Sequenzausschnitte der betroffenen DNARegion (unten). Das Bandenmuster, welches in der SSCP die Anwesenheit des eines G-Nukleotids anzeigt (Allels B), konnte bei 39 Kontrollpersonen nicht nachgewiesen werden. Der Vater der Probanden weist Allel B homozygot auf (siehe Sequenz A), während FL $I$ und $I I$ heterozygot für die Allele A und B sind (siehe Sequenz B). Die Sequenzierung von 30 weiteren RSS-Probanden und 10 Kontrollpersonen ergab eine Sequenz entsprechend C. 


\subsubsection{Assoziationsstudie mit Markern des KPNA2-Gens}

Sehr eng mit einem Krankheitsgen gekoppelte Marker können eine nicht-zufällige Assoziation eines oder mehrerer Allele, in Abweichung zu ihrer nach dem Hardy-Weinberg-Äquilibrium erwarteten Frequenz zeigen. Das Gleichgewichtsprinzip nach Hardy-Weinberg setzt voraus, daß die Population ausreichend groß ist, keine Selektion für ein Allel vorkommt und die Paarung zufällig erfolgt. Unter bestimmten Bedingungen kommt es zur Verschiebung dieses Gleichgewichtes (Kopplungsungleichgewicht). Wenn eine Krankheits-Mutation zum ersten Mal in einer kleinen Population eingeführt wird (durch Neumutation oder Einwanderung von Mutationsträgern), stammt sie von einem Chromosom ab (Gründereffekt), das einen "Hintergrund"-Haplotyp von gekoppelten Markern besitzt. Bei Vergrößerung der Population wird sich dieses Chromosom ausbreiten. Durch Rekombinationen wird der ursprüngliche Chromosomenanteil schließlich immer kleiner und nur noch die am engsten gekoppelten Marker bleiben erhalten und zeigen eine Verschiebung des Gleichgewichtes eines oder mehrerer Marker-Allele. Ein Kopplungsungleichgewicht einzelner Marker oder ganzer Haplotypen ist ein guter Hinweis für eine unmittelbare Nähe zum Krankheitsgen (Jorde, 1995).

Die innerhalb des Gens KPNA2 identifizierten Haplotypen, welche sich aus 6 gekoppelten diallelischen Markern zusammensetzen, wurden auf ein Kopplungsungleichgewicht untersucht, indem die Häufigkeit der jeweiligen Haplotypen in der Gruppe der RSS-Probanden mit derjenigen in einer Kontrollgruppe verglichen wurde. Dabei wurde angenommen, daß die 17 Kontrollpersonen, bei denen die Allele nur an 2 Positionen (Intron 1 und 4) bestimmt wurden (s. Tab. 54), den Haplotyp 1 aufweisen. Es wurden jeweils die absoluten und relativen Häufigkeiten der Allele in den zwei Gruppen bestimmt und miteinander verglichen. Da zwischen den zwei Gruppen eine größere Diskrepanz festgestellt werden konnte, wurden Signifikanztests durchgeführt.

Um nachzuweisen, ob ein signifikantes Kopplungsungleichgewicht vorliegt, können der $\mathrm{X}^{2}$ Test (Chi-Quadrat-Test) oder der zweiseitige (two-tail) Fisher's Exakt Test angewendet werden (Weir, 1996).

Die Nullhypothese nimmt an, daß kein Kopplungsungleichgewicht vorliegt. Diese wird verworfen, wenn die Prüfgröße $\mathrm{X}^{2}$ höher als der kritische Wert bzw. gleich diesem ist. Der kritische Wert kann in Abhängigkeit von der Größe der Irrtumswahrscheinlichkeit $\alpha$ und der Anzahl der Freiheitsgrade aus der Tabelle der $\mathrm{X}^{2}$-Verteilung abgelesen werden (Köhler et al., 1996).

In Tabelle 56 sind die absolute und relative Häufigkeit, bezogen auf die Gesamtheit der untersuchten Chromosomen, die Gesamtheit der Chromosomen mit dem jeweiligen Haplotyp und die Gesamtzahl der Chromosomen von RSS-Probanden bzw. Kontrollen, aufgelistet.

Der anhand der Daten der Kontingenztafel (s. Tab. 56) ermittelte $\mathrm{X}^{2}$-Wert beträgt bei 3 Freiheitsgraden 12,862. Dieser Wert ist höher als der kritische Wert, welcher bei einer Irrtumswahrscheinlichkeit $\alpha$ von $5 \%$ und 3 Freiheitsgraden bei 7,81 liegt. Dies besagt, daß ein Kopplungsungleichgewicht (Abhängigkeit) zwischen Haplotyp 1 und dem RSS vorliegt.

Mit dem zweiseitigen Fisher's Exakt Test wurde eine Wahrscheinlichkeit p=0,00245 ermittelt. Signifikanz ist bei $\mathrm{p}<0,02 \mathrm{zu}$ erwarten, daher deutet dieses Ergebnis auf eine hochsignifikante Assoziation zwischen Haplotyp 1 und dem RSS. 
Tab. 56: Kontingenztafel zur Beziehung der jeweiligen Haplotypen (H1-4) mit dem RSS

\begin{tabular}{|c|c|c|c|c|c|}
\hline & & RSS-Probanden & Kontrollen & $\Sigma$ & \begin{tabular}{|l} 
relative \\
Zeilenhäufigkeit
\end{tabular} \\
\hline $\mathrm{H} 1$ & $\begin{array}{l}\text { Anzahl d. Chr. } \\
\% \text { aller Chr. } \\
\% \text { d. Chr. mit H1 } \\
\% \text { d. Chr. von Probanden } \\
\text { bzw. Kontrollen }\end{array}$ & $\begin{array}{l}55 \\
41,04 \\
53,92 \\
88,71\end{array}$ & \begin{tabular}{|l|}
47 \\
35,07 \\
46,08 \\
65,28
\end{tabular} & 102 & $102: 134=76,12 \%$ \\
\hline $\mathrm{H} 2$ & $\begin{array}{l}\text { Anzahl d. Chr. } \\
\% \text { aller Chr. } \\
\text { \% d. Chr. mit H2 } \\
\% \text { d. Chr. von Probanden } \\
\text { bzw. Kontrollen }\end{array}$ & $\begin{array}{r}7 \\
5,22 \\
31,82 \\
11,29\end{array}$ & $\begin{array}{l}15 \\
11,19 \\
68,18 \\
20,83\end{array}$ & 22 & $22: 134=16,42 \%$ \\
\hline $\mathrm{H} 3$ & $\begin{array}{l}\text { Anzahl d. Chr. } \\
\% \text { aller Chr. } \\
\% \text { d. Chr. mit H3 } \\
\% \text { d. Chr. von Probanden } \\
\text { bzw. Kontrollen }\end{array}$ & $\begin{array}{l}0 \\
0,00 \\
0,00 \\
0,00\end{array}$ & $\begin{array}{r}6 \\
4,48 \\
100,00 \\
8,33\end{array}$ & 6 & $6: 134=4,48 \%$ \\
\hline $\mathrm{H} 4$ & $\begin{array}{l}\text { Anzahl d. Chr. } \\
\% \text { aller Chr. } \\
\% \text { d. Chr. mit H4 } \\
\text { \% d. Chr. von Probanden } \\
\text { bzw. Kontrollen }\end{array}$ & $\begin{array}{l}0 \\
0,00 \\
0,00 \\
0,00\end{array}$ & \begin{tabular}{r}
\multicolumn{1}{l}{4} \\
2,99 \\
100,00 \\
5,56
\end{tabular} & 4 & $4: 134=2,99 \%$ \\
\hline \multicolumn{2}{|c|}{$\Sigma$ der Chromosomen } & 62 & 72 & 134 & \\
\hline \multicolumn{2}{|c|}{ relative Spaltenhäufigkeit } & $62: 134=46,27 \%$ & $72: 134=53,73 \%$ & & \\
\hline
\end{tabular}

\subsection{Analyse von Mikrosatelliten des Chromosoms 17 bei Probanden mit RSS}

Es wird vermutet, daß ein für das RSS verantwortliches Gen im Bereich des Translokationsbruchpunktes von Proband AS auf Chromosom 17 lokalisiert ist. Da sowohl proximal als auch distal von diesem Bruchpunkt Bereiche homologer Sequenzabschnitte identifiziert wurden (s. 3.1.3), stellte sich die Frage, ob diese homologen Bereiche möglicherweise bei den Eltern von RSS-Probanden zu einem falschen Crossing-over während der Meiose geführt haben. Dadurch wäre bei den Probanden das Auftreten von Deletionen, Duplikationen oder Inversionen möglich. Um zu überprüfen, ob einige RSS-Probanden eine Deletion des zwischen den verdoppelt vorliegenden Bereichen liegenden Segments aufweisen, wurde eine MikrosatellitenAnalyse (s. 2.2.12) mit zwischen diesen Bereichen liegenden polymorphen Markern durchgeführt. Auf diese Weise war es zudem möglich, die Probanden im Hinblick auf eine uniparentale Disomie (UPD) des entsprechenden Bereichs auf Chromosom $17 \mathrm{zu}$ analysieren. Für diese Analysen wurde ausgehend von Lymphozyten peripheren Bluts präparierte DNA von 31 Probanden eingesetzt. Von 25 Probanden konnte die DNA von beiden Eltern präpariert werden, während von 6 Probanden kein Blut der Väter zur Verfügung gestellt wurde. Die 
Vererbung der Allele von den Eltern an die Kinder wurde anhand von polymorphen Markern des Chromosoms 17 (s. Tab. 6) analysiert, wobei für die PCR-Reaktionen ein Cy5-markierter Primer mit einem unmarkierten Primer kombiniert wurde. Die Auftrennung der Fragmente erfolgte wie unter 2.2.12.2 beschrieben unter denaturierenden Bedingungen in einem Alfexpress Sequenzierautomat.

Für die Analysen wurden bis zu fünf der folgenden Marker eingesetzt: D17S807, GAAT.1E12, D17S1813, D17S1870 und D17S789. Die Ergebnisse der Mikrosatelliten-Analysen sind in Tabelle 57 enthalten.

Tab. 57: Ergebnisse der Mikrosatelliten-Analysen mit Markern von Chromosom 17. Die Genotypen werden von oben nach unten in der Reihenfolge Vater/Proband/Mutter aufgeführt; m: männlich; w: weiblich; -: kein Material verfügbar; keine UPD/Del: keine UPD und keine Deletion; keine mUPD/Del: keine maternale UPD und keine Deletion; keine pUPD/Del: keine paternale UPD und keine Deletion; n.i.: nicht informativ.

\begin{tabular}{|c|c|c|c|c|c|}
\hline $\begin{array}{l}\text { Loci } \\
\text { Probanden }\end{array}$ & D17S807 & 1E12 & D17S1813 & D17S1870 & D17S795 \\
\hline AA (m) & $\begin{array}{c}\mathrm{aa} \\
\mathrm{ab} \\
\mathrm{bc} \\
\text { - UPD/- Del } \\
\end{array}$ & & $\begin{array}{l}\mathrm{bb} \\
\mathrm{bb} \\
\mathrm{ab} \\
\text { n.i. }\end{array}$ & $\begin{array}{c}\mathrm{bc} \\
\mathrm{ac} \\
\mathrm{aa} \\
\text { - UPD/- Del } \\
\end{array}$ & $\begin{array}{c}\mathrm{ac} \\
\mathrm{ab} \\
\mathrm{bc} \\
\text { - UPD/- Del } \\
\end{array}$ \\
\hline AS (m) & & & $\begin{array}{c}\mathrm{ac} \\
\mathrm{ad} \\
\mathrm{bd} \\
\text { - UPD/- Del } \\
\end{array}$ & $\begin{array}{l}\mathrm{ab} \\
\mathrm{bb} \\
\mathrm{bb} \\
\text { n.i. }\end{array}$ & $\begin{array}{c}\mathrm{ac} \\
\mathrm{ab} \\
\mathrm{bc} \\
\text { - UPD/- Del } \\
\end{array}$ \\
\hline AS2 (m) & $\begin{array}{l}- \\
\text { aa } \\
\text { ab } \\
\text { n.i. }\end{array}$ & $\begin{array}{l}- \\
\text { aa } \\
\text { ab } \\
\text { n.i. }\end{array}$ & $\begin{array}{l}- \\
\text { aa } \\
\text { aa } \\
\text { n.i. }\end{array}$ & $\begin{array}{l}- \\
\text { aa } \\
\text { aa } \\
\text { n.i. }\end{array}$ & $\begin{array}{c}- \\
\text { ab } \\
\text { aa } \\
- \text { mUPD/- Del } \\
\end{array}$ \\
\hline AS3 (w) & & & $\begin{array}{l}\text { ab } \\
\text { aa } \\
\text { aa } \\
\text { n.i. }\end{array}$ & $\begin{array}{c}\mathrm{ab} \\
\mathrm{ab} \\
\mathrm{aa} \\
\text { - mUPD/- Del } \\
\end{array}$ & $\begin{array}{l}\mathrm{bb} \\
\mathrm{bb} \\
\mathrm{ab} \\
\text { n.i. }\end{array}$ \\
\hline BW (w) & $\begin{array}{l}\mathrm{ab} \\
\mathrm{bb} \\
\mathrm{bb} \\
\text { n.i. }\end{array}$ & & $\begin{array}{c}\mathrm{aa} \\
\mathrm{ab} \\
\mathrm{bc} \\
\text { - UPD/- Del } \\
\end{array}$ & $\begin{array}{l}\text { ab } \\
\text { aa } \\
\text { ac } \\
\text { n.i. }\end{array}$ & $\begin{array}{c}\mathrm{cd} \\
\mathrm{bc} \\
\mathrm{ab} \\
\text { - UPD/- Del } \\
\end{array}$ \\
\hline $\mathrm{DD}(\mathrm{m})$ & & & $\begin{array}{c}- \\
\mathrm{ab} \\
\mathrm{ac} \\
\text { - mUPD/- Del } \\
\end{array}$ & $\begin{array}{l}- \\
\text { aa } \\
\text { ab } \\
\text { n.i. }\end{array}$ & $\begin{array}{c}- \\
\mathrm{ab} \\
\mathrm{ac} \\
-\mathbf{m U P D} / \text { - Del } \\
\end{array}$ \\
\hline $\mathrm{EB}(\mathrm{m})$ & & & $\begin{array}{c}\mathrm{ac} \\
\mathrm{bc} \\
\mathrm{bb} \\
\text { - UPD/- Del } \\
\end{array}$ & $\begin{array}{c}\mathrm{bb} \\
\mathrm{ab} \\
\mathrm{a} a \\
\text { - UPD/- Del } \\
\end{array}$ & $\begin{array}{c}\mathrm{bd} \\
\mathrm{ab} \\
\mathrm{ac} \\
\text { - UPD/- Del } \\
\end{array}$ \\
\hline FL (m) & $\begin{array}{c}\mathrm{ac} \\
\mathrm{ab} \\
\mathrm{bd} \\
\text { - UPD/- Del } \\
\end{array}$ & $\begin{array}{l}\text { aa } \\
\text { aa } \\
\text { ab } \\
\text { n.i. }\end{array}$ & $\begin{array}{c}\mathrm{bd} \\
\mathrm{ad} \\
\mathrm{ac} \\
\text { - UPD/- Del } \\
\end{array}$ & $\begin{array}{l}\text { aa } \\
\text { aa } \\
\text { aa } \\
\text { n.i. }\end{array}$ & $\begin{array}{c}\mathrm{bc} \\
\mathrm{ac} \\
\mathrm{ad} \\
\text { - UPD/- Del } \\
\end{array}$ \\
\hline GR (w) & $\begin{array}{c}- \\
\mathrm{ab} \\
\mathrm{ab} \\
- \text { Del } \\
\end{array}$ & $\begin{array}{l}- \\
\text { aa } \\
\text { ab } \\
\text { n.i. }\end{array}$ & $\begin{array}{l}- \\
\text { aa } \\
\text { ab } \\
\text { n.i. }\end{array}$ & $\begin{array}{c}- \\
a b \\
a b \\
- \text { Del } \\
\end{array}$ & $\begin{array}{l}- \\
\text { aa } \\
\text { ab } \\
\text { n.i. }\end{array}$ \\
\hline GT (m) & $\begin{array}{l}- \\
\text { bb } \\
a b \\
\text { n.i. }\end{array}$ & $\begin{array}{l}- \\
\text { aa } \\
\text { aa } \\
\text { n.i. }\end{array}$ & $\begin{array}{l}- \\
\mathrm{bb} \\
\mathrm{ab} \\
\text { n.i. }\end{array}$ & $\begin{array}{l}- \\
\text { aa } \\
\text { aa } \\
\text { n.i. }\end{array}$ & $\begin{array}{l}- \\
\mathrm{bb} \\
\mathrm{ab} \\
\text { n.i. }\end{array}$ \\
\hline
\end{tabular}


Tab. 57: Fortsetzung

\begin{tabular}{|c|c|c|c|c|c|}
\hline $\begin{array}{l}\text { Loci } \\
\text { Probanden }\end{array}$ & D17S807 & $1 \mathrm{E} 12$ & D17S1813 & D17S1870 & D17S795 \\
\hline HA (m) & $\begin{array}{c}\mathrm{ab} \\
\mathrm{bc} \\
\mathrm{cc} \\
\text { - UPD/- Del }\end{array}$ & $\begin{array}{l}\text { aa } \\
\text { aa } \\
\text { aa } \\
\text { n.i. }\end{array}$ & $\begin{array}{l}\mathrm{ac} \\
\mathrm{cc} \\
\mathrm{bc} \\
\text { n.i. }\end{array}$ & $\begin{array}{l}\text { aa } \\
\text { aa } \\
\text { ab } \\
\text { n.i. }\end{array}$ & $\begin{array}{c}\mathrm{bc} \\
\mathrm{ac} \\
\mathrm{ab} \\
\text { - UPD/- Del }\end{array}$ \\
\hline $\mathrm{HE}(\mathrm{m})$ & $\begin{array}{l}\mathrm{bc} \\
\mathrm{bb} \\
\mathrm{ab} \\
\text { n.i. }\end{array}$ & $\begin{array}{l}\text { aa } \\
\text { aa } \\
\text { aa } \\
\text { n.i. }\end{array}$ & $\begin{array}{l}\mathrm{bc} \\
\mathrm{cc} \\
\mathrm{ac} \\
\text { n.i. }\end{array}$ & $\begin{array}{c}\mathrm{aa} \\
\mathrm{ab} \\
\mathrm{ab} \\
\text { - pUPD/- Del } \\
\end{array}$ & $\begin{array}{c}\mathrm{bd} \\
\mathrm{bc} \\
\mathrm{ac} \\
\text { - UPD/- Del } \\
\end{array}$ \\
\hline IM (w) & & & $\begin{array}{c}\mathrm{ab} \\
\mathrm{bc} \\
\mathrm{cd} \\
\text { - UPD/- Del }\end{array}$ & $\begin{array}{c}\mathrm{ab} \\
\mathrm{ac} \\
\mathrm{cc} \\
\text { - UPD/- Del } \\
\end{array}$ & $\begin{array}{c}\mathrm{ac} \\
\mathrm{ab} \\
\mathrm{ab} \\
\text { - pUPD/- Del }\end{array}$ \\
\hline $\mathrm{KE}(\mathrm{m})$ & & & $\begin{array}{c}\mathrm{ad} \\
\mathrm{cd} \\
\mathrm{bc} \\
\text { - UPD/-Del } \\
\end{array}$ & $\begin{array}{l}\mathrm{bc} \\
\mathrm{bb} \\
\mathrm{ab} \\
\text { n.i. }\end{array}$ & $\begin{array}{l}a b \\
a b \\
a b \\
\text { n.i. }\end{array}$ \\
\hline $\mathrm{KD}(\mathrm{m})$ & & & $\begin{array}{c}\mathrm{bc} \\
\mathrm{cc} \\
\mathrm{ac} \\
\text { n.i. }\end{array}$ & $\begin{array}{c}\mathrm{bb} \\
\mathrm{ab} \\
\mathrm{a} a \\
\text { - UPD/- Del } \\
\end{array}$ & $\begin{array}{c}\mathrm{ac} \\
\mathrm{ac} \\
\mathrm{bc} \\
\text { - mUPD/- Del }\end{array}$ \\
\hline $\mathrm{KD} 2(\mathrm{~m})$ & & & $\begin{array}{c}\mathrm{cc} \\
\mathrm{bc} \\
\mathrm{ab} \\
\text { - UPD/-Del } \\
\end{array}$ & $\begin{array}{c}\mathrm{bb} \\
\mathrm{bc} \\
\mathrm{ac} \\
\text { - UPD/- Del } \\
\end{array}$ & $\begin{array}{c}\mathrm{ac} \\
\mathrm{ac} \\
\mathrm{bc} \\
\text { - mUPD/-Del } \\
\end{array}$ \\
\hline $\mathrm{KW}(\mathrm{m})$ & & & $\begin{array}{c}\mathrm{ac} \\
\mathrm{bc} \\
\mathrm{bc} \\
\text { - } \mathbf{p U P D / - D e l} \\
\end{array}$ & $\begin{array}{l}\mathrm{ab} \\
\mathrm{bb} \\
\mathrm{bc} \\
\text { n.i. }\end{array}$ & \\
\hline $\mathrm{LG}(\mathrm{w})$ & $\begin{array}{c}\mathrm{ac} \\
\mathrm{bc} \\
\mathrm{bc} \\
\text { - pUPD/-Del }\end{array}$ & $\begin{array}{c}\mathrm{ab} \\
\mathrm{ab} \\
\mathrm{aa} \\
-\mathbf{m U P D} /- \text { Del } \\
\end{array}$ & $\begin{array}{c}\mathrm{bb} \\
\mathrm{ab} \\
\mathrm{ab} \\
\text { - pUPD/-Del } \\
\end{array}$ & $\begin{array}{l}a b \\
b b \\
b c \\
\text { n.i. }\end{array}$ & $\begin{array}{l}\text { ac } \\
\text { aa } \\
\text { ab } \\
\text { n.i. }\end{array}$ \\
\hline $\mathrm{LJ}(\mathrm{w})$ & $\begin{array}{c}\mathrm{bb} \\
\mathrm{ab} \\
\mathrm{ac} \\
\text { - UPD/-Del } \\
\end{array}$ & & $\begin{array}{c}\mathrm{ac} \\
\mathrm{cd} \\
\mathrm{bd} \\
\text { - UPD/-Del } \\
\end{array}$ & $\begin{array}{c}\mathrm{ab} \\
\mathrm{ab} \\
\mathrm{aa} \\
\text { - mUPD/- Del } \\
\end{array}$ & $\begin{array}{c}\mathrm{ab} \\
\mathrm{ab} \\
\mathrm{ac} \\
\text { - mUPD/- Del }\end{array}$ \\
\hline LM (m) & & & $\begin{array}{c}- \\
\mathrm{bc} \\
\mathrm{ab} \\
\text { - mUPD/-Del } \\
\end{array}$ & $\begin{array}{c}- \\
\mathrm{ac} \\
\mathrm{ab} \\
\text { - mUPD/- Del } \\
\end{array}$ & $\begin{array}{c}- \\
\mathrm{bc} \\
\mathrm{ac} \\
\text { - mUPD/-Del } \\
\end{array}$ \\
\hline MA (m) & & & $\begin{array}{c}\mathrm{ab} \\
\mathrm{ad} \\
\mathrm{cd} \\
\text { - UPD/-Del } \\
\end{array}$ & $\begin{array}{c}\mathrm{ab} \\
\mathrm{ab} \\
\mathrm{bc} \\
\text { - mUPD/-Del }\end{array}$ & $\begin{array}{c}\mathrm{cd} \\
\mathrm{bc} \\
\mathrm{ab} \\
\text { - UPD/- Del } \\
\end{array}$ \\
\hline $\mathrm{MD}(\mathrm{m})$ & $\begin{array}{c}\text { aa } \\
\text { ac } \\
\text { bc } \\
\text { - UPD/- Del }\end{array}$ & $\begin{array}{l}\text { aa } \\
\text { aa } \\
\text { aa } \\
\text { n.i. }\end{array}$ & $\begin{array}{c}\mathrm{ab} \\
\mathrm{ac} \\
\mathrm{ac} \\
\text { - } \mathbf{p U P D} /- \text { Del } \\
\end{array}$ & $\begin{array}{c}\mathrm{a} a \\
\mathrm{a} \\
\mathrm{bb} \\
\text { (keine } \mathbf{m} \text { Allele) } \\
\end{array}$ & $\begin{array}{c}\mathrm{ad} \\
\mathrm{ab} \\
\mathrm{bc} \\
\text { - UPD/- Del }\end{array}$ \\
\hline MD2 (m) & & & $\begin{array}{c}\mathrm{bb} \\
\mathrm{bc} \\
\mathrm{ac} \\
\text { - UPD/-Del }\end{array}$ & $\begin{array}{c}\mathrm{bb} \\
\mathrm{ab} \\
\mathrm{aa} \\
\text { - UPD/- Del } \\
\end{array}$ & $\begin{array}{c}\mathrm{ac} \\
\mathrm{ac} \\
\mathrm{bc} \\
\text { - mUPD/- Del }\end{array}$ \\
\hline $\mathrm{MF}(\mathrm{m})$ & $\begin{array}{c}\mathrm{ab} \\
\mathrm{ac} \\
\mathrm{cc} \\
\text { - UPD/- Del } \\
\end{array}$ & & $\begin{array}{c}\text { bd } \\
\mathrm{cd} \\
\mathrm{ac} \\
\text { - UPD/-Del } \\
\end{array}$ & $\begin{array}{c}\mathrm{ad} \\
\mathrm{bd} \\
\mathrm{bc} \\
\text { - UPD/- Del } \\
\end{array}$ & $\begin{array}{c}\mathrm{ab} \\
\mathrm{bc} \\
\mathrm{cc} \\
\text { - UPD/- Del } \\
\end{array}$ \\
\hline
\end{tabular}


Tab. 57: Fortsetzung

\begin{tabular}{|c|c|c|c|c|c|}
\hline $\begin{array}{l}\text { Loci } \\
\text { Probanden }\end{array}$ & D17S807 & 1E12 & D17S1813 & D17S1870 & D17S795 \\
\hline $\mathrm{MP}(\mathrm{m})$ & $\begin{array}{c}\mathrm{a} a \\
\mathrm{ab} \\
\mathrm{ab} \\
\text { - pUPD/- Del } \\
\end{array}$ & $\begin{array}{l}\text { ab } \\
\text { aa } \\
\text { aa } \\
\text { n.i. }\end{array}$ & $\begin{array}{l}\mathrm{ac} \\
\mathrm{cc} \\
\mathrm{bc} \\
\text { n.i. }\end{array}$ & $\begin{array}{c}\mathrm{ab} \\
\mathrm{a} \\
\mathrm{bb} \\
\text { (keine } \mathbf{m} \text { Allele) }\end{array}$ & $\begin{array}{l}\mathrm{bb} \\
\mathrm{bb} \\
\mathrm{ab} \\
\text { n.i. }\end{array}$ \\
\hline MS (m) & & & $\begin{array}{c}\mathrm{aa} \\
\mathrm{ac} \\
\mathrm{bc} \\
\text { - UPD/- Del } \\
\end{array}$ & $\begin{array}{c}\mathrm{bb} \\
\mathrm{ab} \\
\mathrm{a} a \\
\text { - UPD/- Del } \\
\end{array}$ & $\begin{array}{c}\mathrm{bd} \\
\mathrm{bc} \\
\mathrm{ac} \\
\text { - UPD/- Del } \\
\end{array}$ \\
\hline $\mathrm{PD}(\mathrm{m})$ & & & $\begin{array}{c}\mathrm{bc} \\
\mathrm{ab} \\
\mathrm{a} a \\
\text { - UPD/- Del } \\
\end{array}$ & $\begin{array}{l}\text { ab } \\
\text { aa } \\
\text { aa } \\
\text { n.i. }\end{array}$ & $\begin{array}{c}\mathrm{cd} \\
\mathrm{ac} \\
\mathrm{ab} \\
\text { - UPD/- Del } \\
\end{array}$ \\
\hline $\mathrm{PZ}(\mathrm{m})$ & & & $\begin{array}{c}\mathrm{ab} \\
\mathrm{ac} \\
\mathrm{cc} \\
\text { - UPD/- Del } \\
\end{array}$ & $\begin{array}{c}\mathrm{ab} \\
\mathrm{ab} \\
\mathrm{bb} \\
\text { - mUPD/- Del }\end{array}$ & $\begin{array}{c}\mathrm{bc} \\
\mathrm{ab} \\
\mathrm{ac} \\
\text { - UPD/- Del } \\
\end{array}$ \\
\hline SB (w) & & & $\begin{array}{c}\mathrm{ad} \\
\mathrm{cd} \\
\mathrm{bc} \\
-\mathbf{U P D} /- \text { Del } \\
\end{array}$ & $\begin{array}{c}\mathrm{bb} \\
\mathrm{bc} \\
\mathrm{ac} \\
\text { - UPD/- Del } \\
\end{array}$ & \\
\hline TA (m) & & & $\begin{array}{c}\mathrm{cc} \\
\mathrm{ac} \\
\mathrm{ab} \\
\text { - UPD/- Del } \\
\end{array}$ & $\begin{array}{c}\mathrm{bc} \\
\mathrm{bc} \\
\mathrm{ab} \\
\text { - mUPD/- Del }\end{array}$ & $\begin{array}{c}\mathrm{ab} \\
\mathrm{bc} \\
\mathrm{ac} \\
\text { - UPD/- Del } \\
\end{array}$ \\
\hline TK (m) & & & $\begin{array}{c}- \\
\mathrm{ab} \\
\mathrm{bc} \\
\text { - mUPD/- Del }\end{array}$ & $\begin{array}{c}-\bar{c} \\
\mathrm{ab} \\
\mathrm{ab} \\
-\mathrm{Del} \\
\end{array}$ & \\
\hline
\end{tabular}

Bei Analyse des Markers D17S1870 wurden für die Probanden MD und MP keine maternalen Allele nachgewiesen. Daher wurde zunächst vermutet, daß diese Probanden für den Bereich des Locus D17S1870 eine maternale Deletion oder eine paternale uniparentale Disomie aufweisen. Weitere Analysen zeigten jedoch, daß diese Probanden für den entsprechenden Bereich nicht deletiert sind (s. 3.15). Schließlich konnte gezeigt werden, daß bei den Probanden MD und MP und bei deren Müttern ein Allel nicht amplifiziert worden war (s. 3.16).

Eine Deletion innerhalb von 17q23-q24 oder eine uniparentale Disomie konnte somit bei keinem der getesteten RSS-Probanden nachgewiesen werden. In einigen Fällen war es jedoch nicht möglich eine Deletion oder eine uniparentale Disomie der entsprechenden Region auszuschließen.

Eine Deletion des zwischen den homologen Sequenzabschnitten lokalisierten Bereiches kann bei den Probanden AS2 und GT nicht ausgeschlossen werden, da die Loci D17S807, GAAT.1E12, D17S1813 und D17S1870 in den Familien dieser Probanden eine nicht informative Allelsituation zeigen. Für alle weiteren getesteten Probanden konnte dagegen aufgrund der Ergebnisse der Mikrosatelliten-Analyse gezeigt werden, daß keine Deletion dieses Bereiches vorliegt.

Für die Probanden AS2, GR, GT, HE und KW kann keine Aussage darüber gemacht werden, ob eine maternale uniparentale Disomie (mUPD) für den entsprechenden Bereich vorliegt. Eine paternale uniparentale Disomie (pUPD) der Region konnte nicht ausgeschlossen werden, wenn 
kein Material der Väter zur Verfügung stand. Zudem konnte eine pUPD17 bei der Probandin AS3 nicht ausgeschlossen werden, obwohl Material ihres Vaters verfügbar war.

Bei den Probanden GT und GR war es aufgrund der getesteten Marker auch nicht möglich eine uniparentale Disomie des gesamten Chromosoms 17 auszuschließen. Für die Probandin GR war jedoch bereits eine Mikrosatelliten-Analyse mit den Markern D17S250, D17S513, D17S515, D17S520, D17S787 und D17S799 erfolgt, wodurch gezeigt werden konnte, daß diese Probandin keine UPD17 aufweist (Ayala-Madrigal et al., 1996).

\subsection{FISH-Analyse von Probanden mit RSS zur Suche nach Deletionen auf Chromosom 17}

Da über Mikrosatelliten-Analyse des in der Region 17q23-q24 kartierten Markers D17S1870 bei den Probanden MD und MP keine maternalen Allele nachgewiesen werden konnten (s. 3.14), sollte überprüft werden, ob diese Probanden eine Deletion in der Region 17q23-q24 aufweisen. Dies erfolgte, indem PAC- und Cosmid-Klone, die in der Umgebung des Locus D17S1870 lokalisiert worden waren, über eine FISH auf Chromosomenpräparate der Probanden MD und MP hybridisiert wurden (s. Abb. 32). Diese Chromosomenpräparate wurden ausgehend von Vollblut präpariert. Pro PAC- bzw. Cosmid-Sonde wurden 15 bis 20 Metaphasen ausgewertet. Die PAC-Klone 188D1, 306O9, 58J13, 112L5 und 81B9 wurden für die FISHAnalysen des Probanden MD und des Probanden MP eingesetzt. Für Proband MD wurde zudem der PAC-Klon 209I3 als Sonde eingesetzt und für Proband MP das Cosmid 2H10. Die entsprechenden Klone zeigten jeweils Doppelsignale auf den beiden Chromosomen 17. Somit konnte über diese FISH-Analysen gezeigt werden, daß die Probanden MD und MP für keinen der analysierten Klone eine Deletion aufweisen.
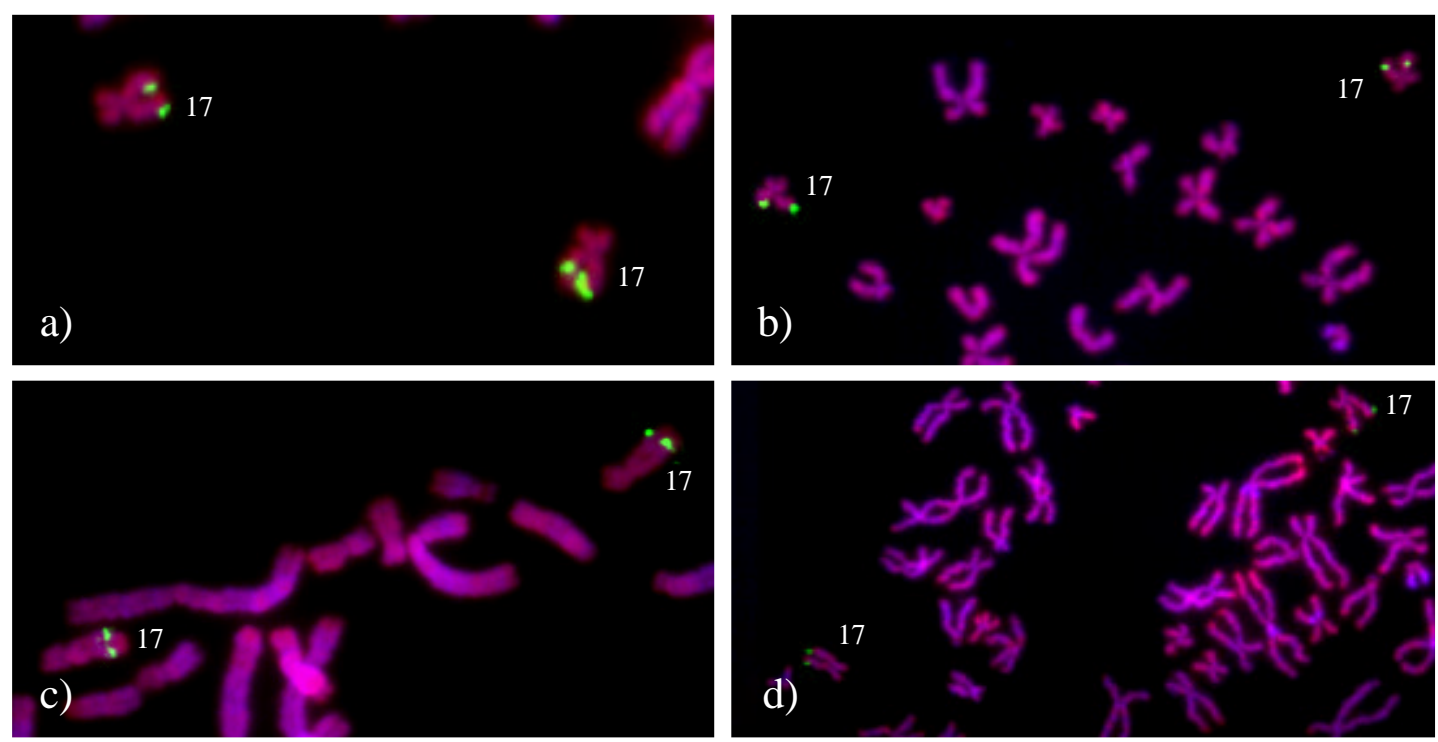

Abb. 32: Beispiele für FISH-Analysen an Metaphasen der RSS-Probanden MP (a, c) und MD (b, d) mit PAC-Sonden. a) und b) 306O9; c) 58J13; d) 188D1. Es tragen jeweils beide Chromosomen 17 ein Signal. 


\subsection{Detektion von allelischer nicht-Amplifikation des Markers D17S1870}

Koorey et al. (1993) beschrieben, daß Basensubstitutionen am 3'-Ende der Primer-bindenden Sequenz von Mikrosatellitenmarkern dazu führen können, daß Allele nicht amplifiziert werden. Da bei den Probanden MD und MP nach Mikrosatelliten-Analyse mit dem Marker D17S1870 keine Weitergabe von mütterlichen Allelen beobachtet wurde (s. 3.14), diese Probanden nach FISH-Analyse jedoch keine Deletion des entsprechenden Bereichs zeigen (s. 3.15), sollte überprüft werden, ob möglicherweise ein mütterliches Allel dieser Probanden nicht amplifiziert worden war. Dazu wurden anhand der veröffentlichten Sequenz, die die Primersequenzen des Locus D17S1870 beinhaltet (Accession-Nr. Z51374), neue forward und reverse Primer abgeleitet, die den CA-Repeat und die angrenzende Sequenz amplifizieren. Bei diesen Primern handelt es sich um die folgenden Primer:

1870.F3: GGAGTGAAGACATTTGTTTTCC

1870.R2: CCGTCACCACGCCTG

Abbildung 33 zeigt die mit den Originalprimern der STS D17S1870 dargestellten Allele sowie die mit den Primern 1870.F3 und 1870.R2 amplifizierten Allele der Probanden MD und MP. Wie dieser Abbildung zu entnehmen ist, ist die mit den Primern 1870.F3 und 1870.R2 dargestellte Allelsituation, im Gegensatz zu der mit den Originalprimern dargestellten Situation, mit einer normalen Weitergabe von je einem Allel beider Eltern an die Probanden vereinbar. Somit konnte gezeigt werden, daß die Probanden MD und MP keine Deletion oder UPD für den Marker D17S1870 aufweisen. Zudem wurde gezeigt, daß bei Mikrosatelliten-Analyse mit dem Locus D17S1870 allelische nicht-Amplifikation möglich ist. 
MD

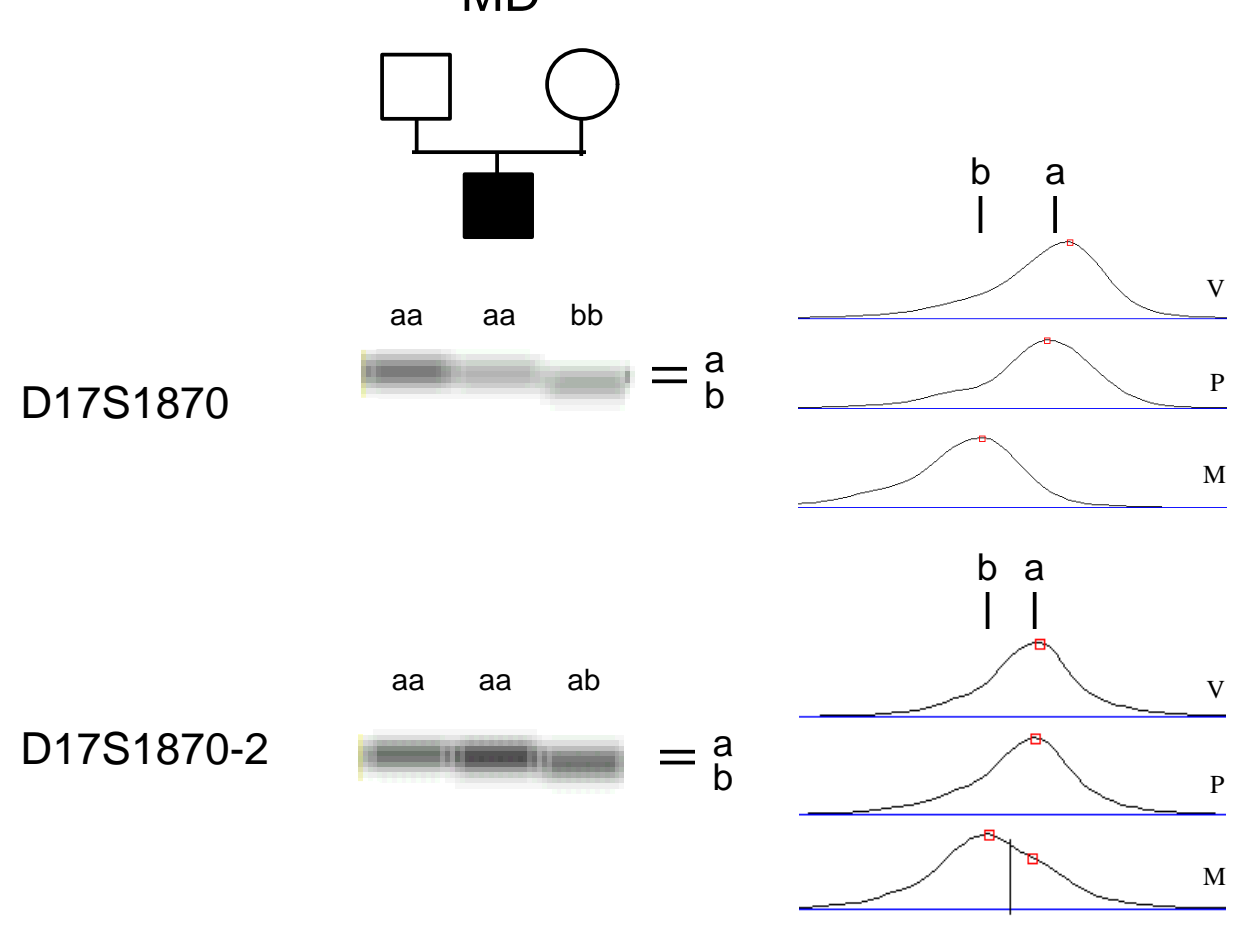

MP

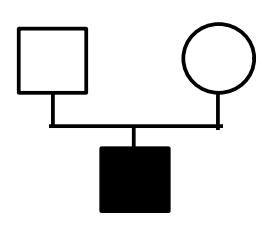

$\mathrm{ab}$

aa $\mathrm{bb}$

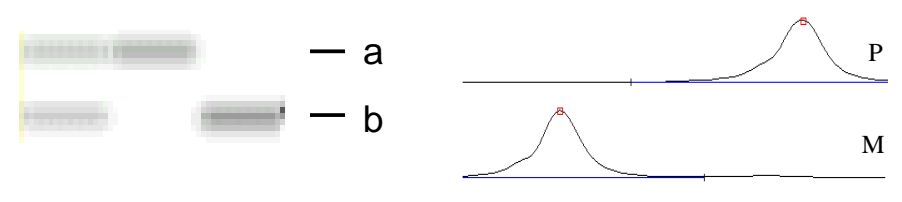

$a c \quad a b \quad b c$
$=a$


$-\quad b$
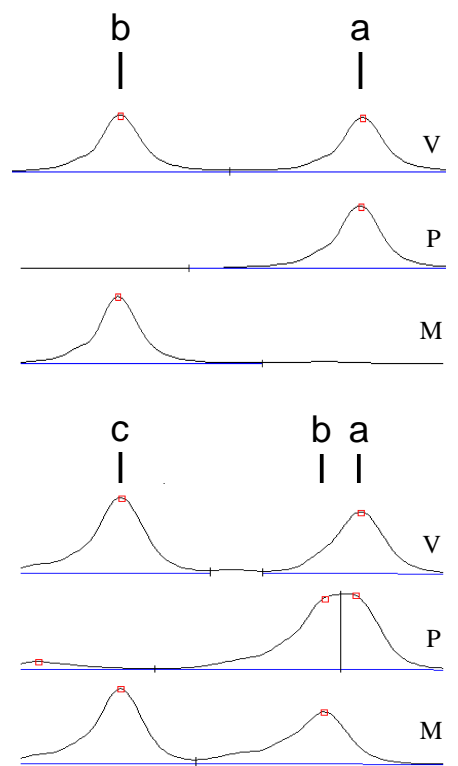

Abb. 33: Mikrosatelliten-Analyse der Familien von MD und MP mit den Loci D17S1870 und D17S1870-2, die den gleichen CA-Repeat amplifizieren. Dargestellt sind jeweils die entsprechenden Banden der Allele sowie die vom Programm Allelink errechneten Peaks. Mit den Primern für den Locus D17S1870 wird jeweils ein mütterliches Allel nicht amplifiziert, dieses ist jedoch mit den neu generierten Primern für den Locus D17S1870-2 darstellbar. (V: Vater; P: Proband; M: Mutter). 


\subsection{Charakterisierung eines mit Russell-Silver-Syndrom einhergehenden Trans- lokationsbruchpunktes in der Region 17q25}

Bei der Probandin GR mit Russell-Silver-Syndrom wurde nach mikroskopischen Kriterien eine balancierte Translokation t(17;20)(q25;q13) nachgewiesen (Ramirez-Dueñas et al., 1992). Abbildung 34 zeigt ein Ideogramm der Translokation.

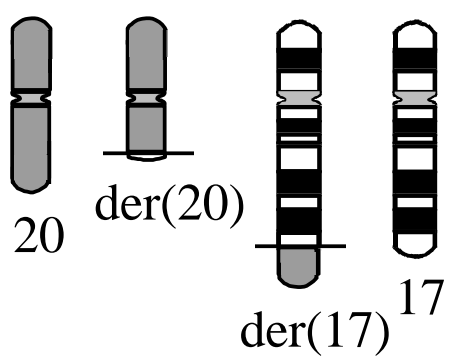

Abb. 34: Darstellung der reziproken 17;20 Translokation der von Ramirez-Dueñas et al. (1992) beschriebenen Probandin GR anhand eines Ideogramms. Chromosom 20 ist aus Gründen der Übersicht nicht gebändert dargestellt.

Diese Translokation hat die Probandin von ihrem gesunden Vater geerbt. Da der Translokationsbruchpunkt der Probandin GR auf Chromosom 17 cytogenetisch in derselben Chromosomenregion wie der Bruchpunkt des von Midro et al. (1993) beschriebenen Probanden AS lokalisiert worden war, sollte überprüft werden, ob diese Bruchpunkte auch auf molekularer Ebene in derselben Region kartieren.

$\mathrm{Zu}$ einer ersten Eingrenzung des Translokationsbruchpunktes wurden 4 cytogenetisch bereits kartierte Cosmide aus der von Inazawa et al. (1993) konstruierten Cosmid-Bibliothek des Chromosoms 17 sowie 4 YAC-Klone der YAC-Bibliothek von CEPH, Paris durch FISH auf Metaphasechromosomen der Probandin GR lokalisiert. Pro Sonde wurden jeweils mindestens 15 Metaphasen ausgewertet. Die Ergebnisse der FISH-Analysen sind in Tabelle 58 zusammengefaßt. Abb. 35 zeigt Beispiele für die FISH-Analysen.

Tab. 58: FISH-Analyse mit Cosmiden und YACs an Methaphasen von Probandin GR

\begin{tabular}{lll}
\hline Klon & $\begin{array}{l}\text { Cytogenetische Lokalisierung } \\
\text { auf normalen Chromosomen }\end{array}$ & $\begin{array}{l}\text { Signale an den Transloka- } \\
\text { tionschromosomen }\end{array}$ \\
\hline YAC 845C6 & $17 \mathrm{q} 23-\mathrm{q} 24$ & $\operatorname{der}(17)$ \\
YAC 931B10 & $17 \mathrm{q} 23-\mathrm{q} 24$ & $\operatorname{der}(17)$ \\
YAC 723H7 & $17 \mathrm{q} 24$ & $\operatorname{der}(17)$ \\
YAC 738E4 & $17 \mathrm{q} 25, \mathrm{Cq}$ & $\operatorname{der}(17)$ \\
Cosmid cCI17-591 & $17 \mathrm{q} 24$ & $\operatorname{der}(17)$ \\
Cosmid cCI17-464 & $17 \mathrm{q} 24.3-\mathrm{q} 25.1$ & $\operatorname{der}(17)$ \\
Cosmid cCI17-546 & $17 \mathrm{q} 24.3-\mathrm{q} 25.1$ & $\operatorname{der}(20)$ \\
Cosmid cCI17-469 & $17 \mathrm{q} 25.2-\mathrm{q} 25.3$ & \\
\hline
\end{tabular}


Wie Tab. 58 zu entnehmen ist, zeigten mit Ausnahme des Cosmids cCI17-469, alle getesteten Klone nach einer FISH an die Translokationschromosomen der Probandin GR Signale am derivativen Chromosom 17, aber nicht am derivativen Chromosom 20. Diese Klone kartieren somit proximal zum Translokationsbruchpunkt. Das Cosmid cCI17-469 wies dagegen ein Signal am derivativen Chromosom 20 auf. Dieses Cosmid wurde daher distal zum Bruchpunkt lokalisiert. Der Translokationsbruchpunkt wird somit auf der proximalen Seite durch die Klone cCI17-464, cCI17-546 und 738E4 und auf der distalen Seite durch das Cosmid cCI17-469 begrenzt. Ausgehend von dieser Kartierung muß der Bruchpunkt der Probandin GR in Übereinstimmung mit der cytogenetischen Kartierung von Ramirez-Dueñas et al. (1992) der Bande 17q25 zugeordnet werden. Dieser Bruchpunkt befindet sich demnach nicht in derselben Region wie der Translokationsbruchpunkt des von Midro et al. (1993) beschriebenen Probanden AS, der der Region 17q23-q24 zugeordnet wurde. Dem proximal zum Translokationsbruchpunkt der Probandin GR kartierten YAC 738E4 wurde zudem der Marker D17S785 zugeordnet (CEPH). Nach der genetischen Karte von Dib et al. (1996) ist dieser Marker 13,2 cM von dem innerhalb der Bruchpunktregion des Probanden AS kartierten Marker D17S1870 entfernt. Der minimale Abstand zwischen den Translokationsbruchpunkten der Probandin GR und des Probanden AS beträgt somit 13,2 cM.
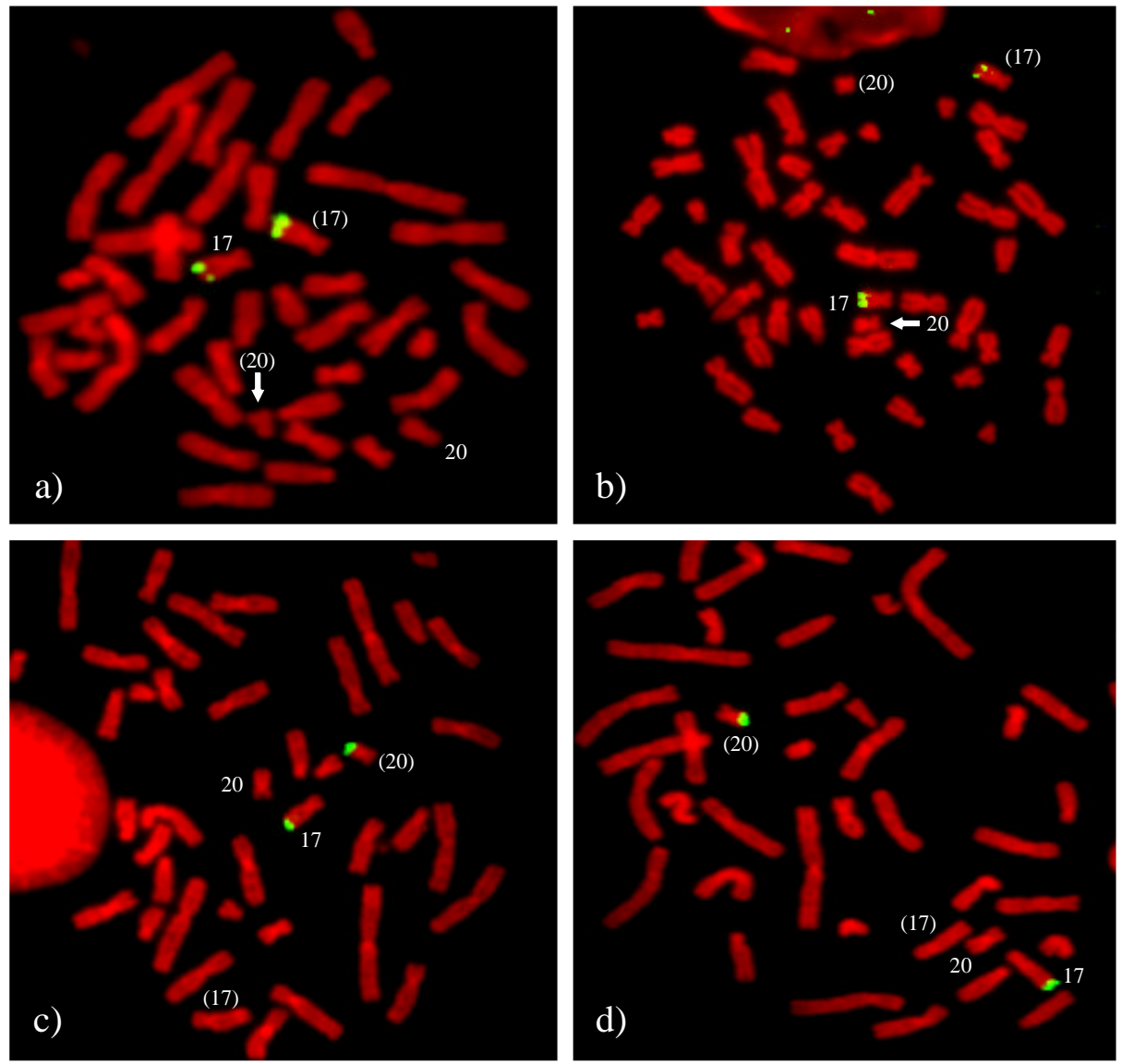

Abb. 35: Beispiele für FISH-Analysen mit Cosmid-Sonden an Metaphasen der Probandin GR. a) cCI17-546; b) cCI17-464; c) und d) cCI17-469. In a) und b) tragen das normale Chromosom 17 und das der(17) [(17)] Signale. In c) und d) tragen das normale Chromosom 17 und das $\operatorname{der}(20)[(20)]$ Signale. 


\subsection{Charakterisierung eines mit Russell-Silver-Syndrom einhergehenden Trans- lokationsbruchpunktes auf Chromosom 1q}

Da die Translokationsbruchpunkte des Probanden AS und der Probandin GR auf Chromosom 17 nicht in derselben chromosomalen Region lokalisiert werden konnten (s. unter 3.17), stellte sich die Frage, ob bei dem Probanden AS mit einer de novo 1;17 Translokation der Translokationsbruchpunkt auf Chromosom 17 oder auf Chromosom 1 für die Entstehung des RussellSilver-Syndroms verantwortlich war. Daher sollte auch der Bereich des Bruchpunktes auf Chromosom 1 des Probanden AS eingegrenzt werden, um überprüfen zu können, ob in der entsprechenden Chromosomenregion Kandidatengene für das RSS kartieren. Diese Eingrenzung erfolgte mit Hilfe von Klonen der YAC-Bibliothek von CEPH, Paris.

Bei der Auswahl der YAC-Klone aus der CEPH-Datenbank lieferten die chimärischen YACs 864B4 und 765F4, deren Insert sich aus Chromosomensegmenten von Chromosom 1 und 17 zusammensetzt, erste Hinweise. Diese YACs waren bei der Kartierung des Bruchpunktes auf Chromosom 17 zum Einsatz gekommen und daher über FISH auf Metaphasen des Probanden AS hybridisiert worden (s. Tab. 1 und Kapitel 3.1.4.1). Da das Chromosom 1-spezifische Signal dieser YACs auf dem derivativen Chromosom 17 lokalisiert wurde, konnte der Chromosom 1-Anteil dieser YACs distal zum Translokationsbruchpunkt auf Chromosom 1 kartiert werden. Da diese YACs in das Contig WC1.17 des Chromosoms 1 eingeordnet sind (Whitehead Institute), wurden für die nachfolgende Kartierung YAC-Klone ausgewählt, die proximal von den YACs 864B4 und 765F4 in dieses Contig eingeordnet wurden. Diese YACs wurden über FISH auf Metaphasen des Probanden AS hybridisiert, die ausgehend von EBVKulturen gewonnen wurden. Pro YAC-Sonde wurden mindestens 15 Metaphasen ausgewertet. Die Ergebnisse dieser FISH-Analysen sind Tabelle $59 \mathrm{zu}$ entnehmen. Beispiele für FISHAnalysen mit Chromosom 1-spezifischen YACs sind in Abbildung 36 gezeigt.

Tab. 59: FISH-Kartierung des Chromosom 1-spezifischen Bruchpunktes von Proband AS

\begin{tabular}{|c|c|c|c|}
\hline $\begin{array}{l}\text { YAC- } \\
\text { Klon }\end{array}$ & $\begin{array}{l}\text { Positiv für Loci auf Chromosom } 1 \\
\text { (Whitehead Institute) }\end{array}$ & $\begin{array}{l}\text { Cytogenetische } \\
\text { Lokalisierung auf } \\
\text { normalen Chromosomen }\end{array}$ & $\begin{array}{l}\text { Signale an den } \\
\text { Translokations- } \\
\text { chromosomen }\end{array}$ \\
\hline $918 \mathrm{H} 5$ & $\begin{array}{l}\text { D1S431, D1S445, WI-6347, } \\
\text { D1S2799, WI-6381, D1S2658 }\end{array}$ & $1 q 23-q 24$ & $\operatorname{der}(1)$ \\
\hline $895 \mathrm{~F} 3$ & $\begin{array}{l}\text { D1S1569, WI-7045, WI-9125, } \\
\text { WI-6302 }\end{array}$ & $1 q 24-q 25$ & $\operatorname{der}(1)$ \\
\hline 792D9 & D1S452, D1S210, WI-10286 & $1 q 24-q 25+3 p+5 q$ & $\operatorname{der}(1)$ \\
\hline 874B 11 & $\begin{array}{l}\text { D1S2815, CHLC.ATA14D03, } \\
\text { NIB1475, WI-6210, NIB1951 }\end{array}$ & $1 q 24-q 25$ & $\operatorname{der}(1)$ \\
\hline 941F11 & $\begin{array}{l}\text { NIB1475, WI-6210, NIB1951, } \\
\text { WI-5780 }\end{array}$ & $1 q 24-q 25+14 q$ & $\operatorname{der}(1)+\operatorname{der}(17)$ \\
\hline 854B9 & $\begin{array}{l}\text { WI-3774, D1S2790, WI-5545, } \\
\text { WI-7792, WI-7237 }\end{array}$ & $1 q 25-q 31$ & $\operatorname{der}(17)$ \\
\hline
\end{tabular}


Tab. 59: Fortsetzung

\begin{tabular}{|c|c|c|c|}
\hline $\begin{array}{l}\text { YAC- } \\
\text { Klon }\end{array}$ & $\begin{array}{l}\text { Positiv für Loci auf Chromosom } 1 \\
\text { (Whitehead Institute) }\end{array}$ & $\begin{array}{l}\text { Cytogenetische } \\
\text { Lokalisierung auf } \\
\text { normalen Chromosomen }\end{array}$ & $\begin{array}{l}\text { Signale an den } \\
\text { Translokations- } \\
\text { chromosomen }\end{array}$ \\
\hline 744A9 & $\begin{array}{l}\text { WI-9787, D1S2786, AFM296WF1, } \\
\text { D1S212, D1S2791, WI-3070, } \\
\text { WI-5460 }\end{array}$ & $1 q 25-q 31$ & $\operatorname{der}(17)$ \\
\hline 920B6 & $\begin{array}{l}\text { D1S215, D1S2883, WI-9721, } \\
\text { WI-6293, WI-9655, D1S2640 }\end{array}$ & $1 q 25-q 31$ & $\operatorname{der}(17)$ \\
\hline $789 \mathrm{H} 12$ & $\begin{array}{l}\text { WI-2775; WI-9007, STSG-10176, } \\
\text { D1S2818, D1S466, D1S2619 }\end{array}$ & $1 q 25-q 31$ & $\operatorname{der}(17)$ \\
\hline 940F12 & $\begin{array}{l}\text { WI-8876, WI-6860, WI-7043, } \\
\text { CHLC.GATA12F10 }\end{array}$ & $1 \mathrm{q} 31$ & $\operatorname{der}(17)$ \\
\hline $765 \mathrm{~F} 4$ & WI-5858, D1S240, WI-6876 & $1 q 31,17 q 23-q 24$ & $\operatorname{der}(17)$ \\
\hline 864B4 & D1S444, D1S254 & $1 \mathrm{q} 31,17 \mathrm{q} 23-\mathrm{q} 24$ & $\operatorname{der}(17)$ \\
\hline
\end{tabular}

Wie Tabelle $59 \mathrm{zu}$ entnehmen ist, zeigten die YAC-Klone 918H5, 895F3 und 792D9 nur Signale am derivativen Chromosom 1, aber nicht am derivativen Chromosom 17. Diese Klone konnten somit proximal zum Translokationsbruchpunkt auf Chromosom 1 kartiert werden. Die YACs 854B9, 920B6 und 940F12 zeigten dagegen, wie die YACs 765F4 und 864B4, die bereits im Rahmen der Kartierung des Bruchpunktes auf Chromosom 17 eingesetzt wurden, Signale auf dem derivativen Chromosom 17, aber nicht auf dem derivativen Chromosm 1. Somit wurden diese YACs distal zum Translokationsbruchpunkt auf Chromosom 1 lokalisiert. Der YAC-Klon 941F11 zeigte Signale an beiden derivativen Chromosomen. Dieser YAC überspannt demnach den chromosomalen Bruchpunkt auf Chromosom 1. Die Größe von YAC 941F11 beträgt nach Angaben des Whitehead Institue/CEPH $1270 \mathrm{~kb}$. Dieser YAC weist gemeinsam mit dem proximal zum Bruchpunkt lokalisierten YAC 874B11 die Loci NIB1475, WI-6210 und NIB1951 auf. Der Locus WI-5780 ist jedoch nur auf YAC 941F11 und nicht auf YAC 874B11 vorhanden. Daher ist anzunehmen, daß der Translokationsbruchpunkt des Probenden AS auf Chromosom 1 in der Region der STS-Stelle WI-5780 lokalisiert ist. 

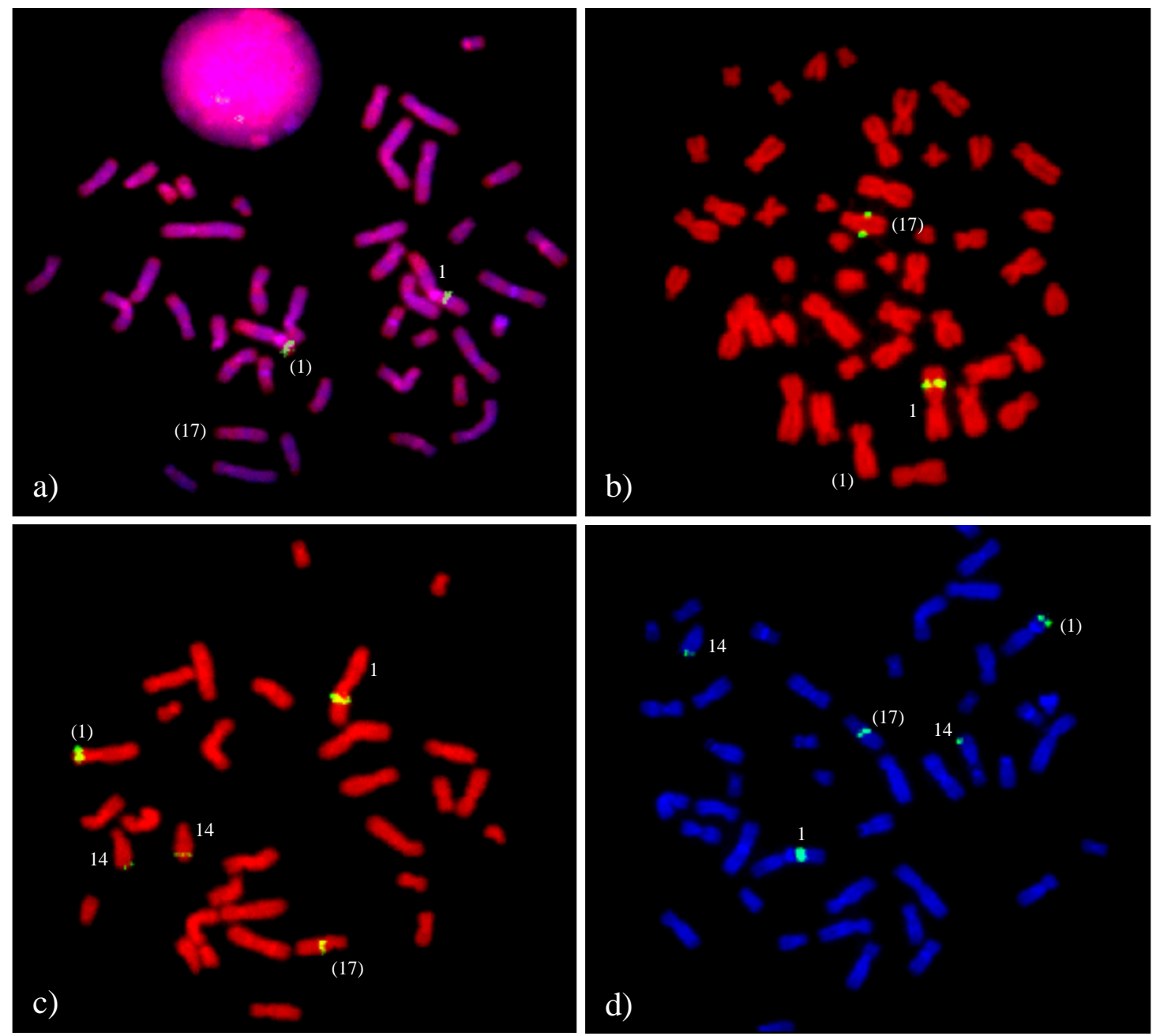

Abb. 36: Beispiele für FISH-Analysen mit Y ACs des Chromosoms 1 auf Metaphasen von Proband AS. a) 874B11; b) $789 \mathrm{H} 12$; c) und d) 941F11. In a) sind die Chromosomen mit Propidiumiodid und DAPI gegengefärbt, in b) und c) mit Propidiumiodid und in d) mit DAPI.

\subsection{Analyse von Mikrosatelliten des Chromosoms 7 bei Probanden mit RSS}

Bei etwa $7 \%$ von Probanden mit RSS wurde eine uniparentale Disomie für das Chromosom 7 festgestellt (Kotzot et al., 1995; Preece et al., 1997; Eggermann et al., 1997, Preece et al., 1999). Daher wird vermutet, daß ein Gen auf Chromosom 7 bei einem Teil der Probanden mit RSS für die Entstehung des Krankheitsbildes verantwortlich ist. Da Probanden mit UPD 7 vermutlich keinen weiteren Defekt auf Chromosom 17 aufweisen, sollten diese aus der Mutationsanalyse des auf Chromosom 17 lokalisierten RSS-Kandidatengens KPNA 2 ausgeschlossen werden. Für diese Untersuchungen konnte in 23 Fällen DNA von RSS-Probanden und von deren Eltern präpariert werden. Bei 6 weiteren RSS-Probanden konnte nur DNA von Probanden und deren Müttern präpariert werden. Hier stand Material der Väter nicht zur Verfügung. Die Probanden FL, HA, KE und TA wurden nicht in die Analysen einbezogen, da die Suche nach mUPD7 bei diesen Probanden bereits erfolgt war, wobei keine uniparentale Disomie für das Chromosom 7 festgestellt werden konnte (Michaelis, pers. Mitteilung). 
Die Weitergabe der Allele von den Eltern an die Kinder wurde anhand von polymorphen Mikrosatellitenmarkern des Chromosoms 7 analysiert (s. Tab. 7). Die dazu durchgeführten PCR-Reaktionen erfolgten wie unter 2.2.12.1 beschrieben mit einem Cy5-fluoreszenzmarkierten forward-Primer und einem unmarkierten reverse-Primer. Die Auftrennung der erhaltenen Fragmente erfolgte in einem Alf-express-Sequenzierautomat.

Verwendet wurden die folgenden Marker: D7S493, D7S502, D7S527, D7S483 (Weissenbach et al., 1992) und D7S684 (Gyapay et al., 1994). Die Ergebnisse der Mikrosatelliten-Analysen sind in Tabelle 60 zusammengefaßt.

Tab. 60: Ergebnisse der Mikrosatelliten-Analyse mit Markern von Chromosom 7. Die Genotypen werden von oben nach unten in der Reihenfolge Vater/Proband/Mutter aufgeführt.; m: männlich; w: weiblich; -: kein Material verfügbar; - UPD: keine UPD; - mUPD: keine maternale UPD; n.i.: nicht informativ.

\begin{tabular}{|c|c|c|c|c|c|}
\hline $\begin{array}{l}\text { Loci } \\
\text { Probanden }\end{array}$ & D7S493 & D7S502 & D7S527 & D7S684 & D7S483 \\
\hline $\mathrm{AA}(\mathrm{m})$ & $\begin{array}{c}\mathrm{ac} \\
\mathrm{bc} \\
\mathrm{bb} \\
-\mathbf{U P D} \\
\end{array}$ & $\begin{array}{l}a b \\
b b \\
a b \\
\text { n.i. }\end{array}$ & $\begin{array}{l}\text { ab } \\
\text { aa } \\
\text { ac } \\
\text { n.i. }\end{array}$ & $\begin{array}{c}\text { bc } \\
a b \\
\text { aa } \\
- \text { UPD }\end{array}$ & $\begin{array}{c}\mathrm{ab} \\
\mathrm{ac} \\
\mathrm{cc} \\
-\mathbf{U P D} \\
\end{array}$ \\
\hline AS (m) & $\begin{array}{c}\mathrm{ab} \\
\mathrm{ac} \\
\mathrm{bc} \\
-\mathbf{U P D} \\
\end{array}$ & $\begin{array}{c}\mathrm{ab} \\
\mathrm{ac} \\
\mathrm{bc} \\
-\mathbf{U P D} \\
\end{array}$ & $\begin{array}{l}\text { ab } \\
\text { aa } \\
\text { ab } \\
\text { n.i. }\end{array}$ & $\begin{array}{c}\mathrm{bd} \\
\mathrm{ab} \\
\mathrm{ac} \\
- \text { UPD } \\
\end{array}$ & $\begin{array}{l}\text { aa } \\
\text { aa } \\
\text { ab } \\
\text { n.i. }\end{array}$ \\
\hline $\mathrm{AS} 2(\mathrm{~m})$ & $\begin{array}{c}- \\
\mathrm{ab} \\
\mathrm{bc} \\
-\mathbf{m U P D} \\
\end{array}$ & $\begin{array}{c}- \\
\mathrm{ab} \\
\mathrm{ac} \\
-\mathbf{m U P D}\end{array}$ & $\begin{array}{c}- \\
\mathrm{ab} \\
\mathrm{bc} \\
-\mathbf{m U P D}\end{array}$ & $\begin{array}{c}- \\
\mathrm{ab} \\
\mathrm{bc} \\
-\mathbf{m U P D}\end{array}$ & $\begin{array}{c}- \\
\mathrm{ab} \\
\mathrm{bb} \\
-\mathbf{m U P D} \\
\end{array}$ \\
\hline AS3 (w) & $\begin{array}{r}\mathrm{cd} \\
\mathrm{ad} \\
\mathrm{ab} \\
-\mathbf{U P D} \\
\end{array}$ & $\begin{array}{r}\mathrm{ac} \\
\mathrm{cd} \\
\mathrm{bd} \\
-\mathbf{U P D} \\
\end{array}$ & $\begin{array}{l}\mathrm{bb} \\
\mathrm{ab} \\
\mathrm{ab} \\
\text { n.i. }\end{array}$ & $\begin{array}{c}\mathrm{ab} \\
\mathrm{bc} \\
\mathrm{cd} \\
-\mathbf{U P D} \\
\end{array}$ & $\begin{array}{r}\mathrm{ac} \\
\mathrm{bc} \\
\mathrm{ab} \\
-\mathbf{U P D} \\
\end{array}$ \\
\hline BW (w) & $\begin{array}{c}\mathrm{ab} \\
\mathrm{bc} \\
\mathrm{cd} \\
-\mathbf{U P D} \\
\end{array}$ & $\begin{array}{c}\text { bd } \\
a b \\
a c \\
- \text { UPD } \\
\end{array}$ & $\begin{array}{l}a b \\
a b \\
a b \\
\text { n.i. }\end{array}$ & $\begin{array}{l}\text { aa } \\
\text { aa } \\
\text { ab } \\
\text { n.i. }\end{array}$ & $\begin{array}{l}a b \\
a b \\
a b \\
\text { n.i. }\end{array}$ \\
\hline $\mathrm{DD}(\mathrm{m})$ & $\begin{array}{c}- \\
\mathrm{ac} \\
\mathrm{bc} \\
-\mathbf{m U P D} \\
\end{array}$ & $\begin{array}{c}- \\
\mathrm{bc} \\
\mathrm{ab} \\
-\mathbf{m U P D} \\
\end{array}$ & $\begin{array}{c}- \\
\mathrm{ab} \\
\mathrm{aa} \\
-\mathbf{m U P D} \\
\end{array}$ & $\begin{array}{c}- \\
\mathrm{ab} \\
\mathrm{bc} \\
-\mathbf{m U P D} \\
\end{array}$ & $\begin{array}{c}- \\
\mathrm{ac} \\
\mathrm{bc} \\
-\mathbf{m U P D}\end{array}$ \\
\hline $\mathrm{EB}(\mathrm{m})$ & $\begin{array}{l}\mathrm{bb} \\
\mathrm{ab} \\
\mathrm{ab} \\
\text { n.i. }\end{array}$ & $\begin{array}{c}\mathrm{aa} \\
\mathrm{ac} \\
\mathrm{bc} \\
-\mathbf{U P D} \\
\end{array}$ & $\begin{array}{c}\mathrm{ad} \\
\mathrm{ac} \\
\mathrm{bc} \\
-\mathbf{U P D} \\
\end{array}$ & $\begin{array}{l}\mathrm{bc} \\
\mathrm{bb} \\
\mathrm{ab} \\
\text { n.i. }\end{array}$ & $\begin{array}{l}\mathrm{ab} \\
\mathrm{ab} \\
\mathrm{ab} \\
\text { n.i. }\end{array}$ \\
\hline GR (w) & $\begin{array}{c}- \\
\mathrm{ac} \\
\mathrm{ab} \\
-\mathbf{m U P D} \\
\end{array}$ & $\begin{array}{c}- \\
\mathrm{ab} \\
\mathrm{ac} \\
-\mathbf{m U P D} \\
\end{array}$ & $\begin{array}{c}- \\
\mathrm{bc} \\
\mathrm{ac} \\
-\mathbf{m U P D} \\
\end{array}$ & $\begin{array}{c}- \\
\mathrm{ab} \\
\mathrm{ab} \\
\text { n.i. }\end{array}$ & $\begin{array}{c}- \\
\text { aa } \\
\text { aa } \\
\text { n.i. }\end{array}$ \\
\hline GT (m) & $\begin{array}{l}- \\
\text { aa } \\
\text { ab } \\
\text { n.i. }\end{array}$ & $\begin{array}{l}- \\
\mathrm{bb} \\
\mathrm{ab} \\
\text { n.i. }\end{array}$ & $\begin{array}{c}- \\
\mathrm{ac} \\
\mathrm{bc} \\
-\mathbf{m U P D}\end{array}$ & $\begin{array}{c}- \\
a b \\
b b \\
- \text { mUPD }\end{array}$ & $\begin{array}{c}- \\
\mathrm{ab} \\
\mathrm{ac} \\
-\mathbf{m U P D}\end{array}$ \\
\hline $\mathrm{HE}(\mathrm{m})$ & $\begin{array}{c}\mathrm{ad} \\
\mathrm{cd} \\
\mathrm{bc} \\
-\mathbf{U P D}\end{array}$ & $\begin{array}{c}\mathrm{bc} \\
\mathrm{ab} \\
\mathrm{ac} \\
-\mathbf{U P D}\end{array}$ & $\begin{array}{c}\mathrm{ac} \\
\mathrm{cd} \\
\mathrm{bd} \\
-\mathbf{U P D}\end{array}$ & $\begin{array}{c}\mathrm{cd} \\
\mathrm{ac} \\
\mathrm{ab} \\
-\mathbf{U P D}\end{array}$ & $\begin{array}{c}\mathrm{ac} \\
\mathrm{ad} \\
\mathrm{bd} \\
-\mathbf{U P D}\end{array}$ \\
\hline
\end{tabular}


Tab. 60: Fortsetzung

\begin{tabular}{|c|c|c|c|c|c|}
\hline $\begin{array}{l}\text { Loci } \\
\text { Probanden }\end{array}$ & D7S493 & D7S502 & D7S527 & D7S684 & D7S483 \\
\hline IM (w) & $\begin{array}{r}\mathrm{ab} \\
\mathrm{ac} \\
\mathrm{bc} \\
-\mathbf{U P D} \\
\end{array}$ & $\begin{array}{r}\mathrm{cc} \\
\mathrm{bc} \\
\mathrm{ab} \\
-\mathbf{U P D} \\
\end{array}$ & $\begin{array}{r}\text { bd } \\
\text { cd } \\
\text { ac } \\
- \text { UPD } \\
\end{array}$ & $\begin{array}{l}\text { ab } \\
\text { aa } \\
\text { ac } \\
\text { n.i. }\end{array}$ & $\begin{array}{r}\text { bc } \\
\text { ac } \\
\text { aa } \\
- \text { UPD } \\
\end{array}$ \\
\hline $\mathrm{KD}(\mathrm{m})$ & $\begin{array}{r}\mathrm{cd} \\
\mathrm{ad} \\
\mathrm{ab} \\
-\mathbf{U P D} \\
\end{array}$ & $\begin{array}{c}\mathrm{bc} \\
\mathrm{bc} \\
\mathrm{ac} \\
-\mathbf{m U P D} \\
\end{array}$ & $\begin{array}{r}\mathrm{bd} \\
\mathrm{ab} \\
\mathrm{ac} \\
-\mathbf{U P D} \\
\end{array}$ & $\begin{array}{l}\text { ac } \\
\mathrm{cc} \\
\mathrm{bc} \\
\text { n.i. }\end{array}$ & $\begin{array}{c}a b \\
a b \\
\text { aa } \\
-\mathbf{m U P D} \\
\end{array}$ \\
\hline KD2 (m) & $\begin{array}{r}\mathrm{ab} \\
\mathrm{bc} \\
\mathrm{cd} \\
-\mathbf{U P D} \\
\end{array}$ & $\begin{array}{c}\mathrm{bc} \\
\mathrm{bc} \\
\mathrm{ab} \\
-\mathbf{m U P D} \\
\end{array}$ & $\begin{array}{r}a d \\
a b \\
b c \\
-\mathbf{U P D} \\
\end{array}$ & $\begin{array}{r}\mathrm{bd} \\
\mathrm{bc} \\
\mathrm{ac} \\
-\mathbf{U P D} \\
\end{array}$ & $\begin{array}{r}a c \\
a b \\
b d \\
-\mathbf{U P D} \\
\end{array}$ \\
\hline KW (m) & $\begin{array}{c}\mathrm{bc} \\
\mathrm{ad} \\
\mathrm{ad} \\
\text { (m Heterodisomie) } \\
\end{array}$ & $\begin{array}{l}\mathrm{bc} \\
\mathrm{bb} \\
\mathrm{ab} \\
\text { n.i. }\end{array}$ & $\begin{array}{c}\mathrm{bb} \\
\mathrm{ac} \\
\mathrm{ac} \\
\text { (m Heterodisomie) }\end{array}$ & $\begin{array}{l}\mathrm{bc} \\
\mathrm{bb} \\
\mathrm{ab} \\
\text { n.i. }\end{array}$ & $\begin{array}{c}\mathrm{ac} \\
\mathrm{bb} \\
\mathrm{bb} \\
\text { (m Isodisomie) }\end{array}$ \\
\hline LG (w) & $\begin{array}{c}\mathrm{bc} \\
\mathrm{bc} \\
\mathrm{ac} \\
-\mathbf{m U P D}\end{array}$ & $\begin{array}{c}\mathrm{ab} \\
\mathrm{ac} \\
\mathrm{cc} \\
-\mathbf{U P D} \\
\end{array}$ & $\begin{array}{l}\mathrm{ab} \\
\mathrm{bb} \\
\mathrm{ab} \\
\text { n.i. }\end{array}$ & $\begin{array}{c}\text { bd } \\
\text { ad } \\
\text { ac } \\
- \text { UPD } \\
\end{array}$ & $\begin{aligned} \mathrm{ac} \\
\mathrm{cd} \\
\mathrm{bd} \\
-\mathbf{U P D} \\
\end{aligned}$ \\
\hline $\mathrm{LJ}(\mathrm{w})$ & $\begin{array}{r}\mathrm{ac} \\
\mathrm{ad} \\
\mathrm{bd} \\
-\mathbf{U P D} \\
\end{array}$ & $\begin{array}{l}\mathrm{bb} \\
\mathrm{bb} \\
\mathrm{ab} \\
\text { n.i. }\end{array}$ & $\begin{array}{l}\text { bc } \\
\mathrm{cc} \\
\mathrm{ac} \\
\text { n.i. }\end{array}$ & $\begin{array}{l}\text { bc } \\
\mathrm{cc} \\
\mathrm{ac} \\
\text { n.i. }\end{array}$ & $\begin{array}{r}\mathrm{aa} \\
\mathrm{ab} \\
\mathrm{bb} \\
-\mathbf{U P D} \\
\end{array}$ \\
\hline $\mathrm{LM}(\mathrm{m})$ & $\begin{array}{c}- \\
\mathrm{ac} \\
\mathrm{ab} \\
-\mathbf{m U P D} \\
\end{array}$ & $\begin{array}{c}- \\
\mathrm{ab} \\
\mathrm{ac} \\
-\mathbf{m U P D} \\
\end{array}$ & $\begin{array}{l}-\bar{c} \\
\mathrm{bb} \\
\mathrm{ab} \\
\text { n.i. }\end{array}$ & $\begin{array}{l}- \\
\mathrm{ab} \\
\mathrm{ab} \\
\text { n.i. }\end{array}$ & $\begin{array}{c}- \\
\text { aa } \\
\text { aa } \\
\text { n.i. }\end{array}$ \\
\hline MA (m) & $\begin{array}{c}\mathrm{ac} \\
\mathrm{bb} \\
\mathrm{ab} \\
\text { (m Isodisomie) } \\
\end{array}$ & $\begin{array}{c}\mathrm{ab} \\
\mathrm{cc} \\
\mathrm{ac} \\
\text { (m Isodisomie) } \\
\end{array}$ & $\begin{array}{c}\mathrm{bd} \\
\mathrm{aa} \\
\mathrm{ac} \\
\text { (m Isodisomie) } \\
\end{array}$ & $\begin{array}{c}\mathrm{bb} \\
\mathrm{cc} \\
\mathrm{ac} \\
\text { (m Isodisomie) } \\
\end{array}$ & $\begin{array}{c}\mathrm{ab} \\
\mathrm{cc} \\
\mathrm{bc} \\
\text { (m Isodisomie) } \\
\end{array}$ \\
\hline $\mathrm{MD}(\mathrm{m})$ & $\begin{array}{r}b c \\
b d \\
a d \\
- \text { UPD } \\
\end{array}$ & $\begin{array}{l}\text { ac } \\
\text { aa } \\
\text { ab } \\
\text { n.i. }\end{array}$ & $\begin{array}{c}\mathrm{ac} \\
\mathrm{ab} \\
\mathrm{bb} \\
-\mathbf{U P D} \\
\end{array}$ & $\begin{array}{c}\mathrm{cc} \\
\mathrm{bc} \\
\mathrm{ab} \\
- \text { UPD } \\
\end{array}$ & $\begin{array}{c}\mathrm{bc} \\
\mathrm{ac} \\
\mathrm{ab} \\
-\mathbf{U P D} \\
\end{array}$ \\
\hline MD2 (m) & $\begin{array}{r}\mathrm{ac} \\
\mathrm{bc} \\
\mathrm{ab} \\
-\mathbf{U P D} \\
\end{array}$ & $\begin{array}{c}\mathrm{bb} \\
\mathrm{ab} \\
\mathrm{ac} \\
-\mathbf{U P D} \\
\end{array}$ & $\begin{array}{r}\mathrm{ac} \\
\mathrm{cd} \\
\mathrm{bd} \\
-\mathbf{U P D} \\
\end{array}$ & $\begin{array}{c}a b \\
a c \\
b c \\
- \text { UPD } \\
\end{array}$ & $\begin{array}{l}\text { aa } \\
\text { aa } \\
\text { aa } \\
\text { n.i. } \\
\end{array}$ \\
\hline $\mathrm{MF}(\mathrm{m})$ & $\begin{array}{r}c d \\
b c \\
a b \\
- \text { UPD } \\
\end{array}$ & $\begin{array}{c}\mathrm{ab} \\
\mathrm{ab} \\
\mathrm{bc} \\
-\mathbf{m U P D} \\
\end{array}$ & $\begin{array}{r}\mathrm{ad} \\
\mathrm{cd} \\
\mathrm{bc} \\
-\mathbf{U P D} \\
\end{array}$ & $\begin{array}{l}\mathrm{ac} \\
\mathrm{bc} \\
\mathrm{bc} \\
\text { n.i. }\end{array}$ & $\begin{array}{c}\mathrm{ac} \\
\mathrm{bc} \\
\mathrm{ab} \\
-\mathbf{U P D} \\
\end{array}$ \\
\hline MP (m) & $\begin{array}{c}\mathrm{bd} \\
\mathrm{bc} \\
\mathrm{ac} \\
- \text { UPD } \\
\end{array}$ & $\begin{array}{l}\mathrm{ab} \\
\mathrm{aa} \\
\mathrm{ac} \\
\mathbf{n . i} .\end{array}$ & $\begin{array}{c}\mathrm{ab} \\
\mathrm{ab} \\
\mathrm{bc} \\
-\mathbf{m U P D} \\
\end{array}$ & $\begin{array}{c}\mathrm{bc} \\
\mathrm{ab} \\
\mathrm{ac} \\
-\mathbf{U P D} \\
\end{array}$ & $\begin{array}{r}\mathrm{ac} \\
\mathrm{cd} \\
\mathrm{bd} \\
-\mathbf{U P D} \\
\end{array}$ \\
\hline MS (m) & $\begin{array}{c}\mathrm{ac} \\
\mathrm{bc} \\
\mathrm{ab} \\
- \text { UPD } \\
\end{array}$ & $\begin{array}{c}\mathrm{ac} \\
\mathrm{bc} \\
\mathrm{ab} \\
- \text { UPD } \\
\end{array}$ & $\begin{array}{l}\mathrm{bc} \\
\mathrm{ab} \\
\mathrm{ab} \\
\text { n.i. }\end{array}$ & $\begin{array}{l}\mathrm{bc} \\
\mathrm{cc} \\
\mathrm{ac} \\
\text { n.i. }\end{array}$ & $\begin{array}{c}\mathrm{ab} \\
\mathrm{ab} \\
\mathrm{bc} \\
-\mathbf{m U P D} \\
\end{array}$ \\
\hline MS2 (w) & $\begin{array}{c}\mathrm{ac} \\
\mathrm{bc} \\
\mathrm{ab} \\
-\mathbf{U P D}\end{array}$ & $\begin{array}{c}\mathrm{ac} \\
\mathrm{bc} \\
\mathrm{ab} \\
- \text { UPD }\end{array}$ & $\begin{array}{l}\mathrm{bc} \\
\mathrm{ab} \\
\mathrm{ab} \\
\text { n.i. }\end{array}$ & $\begin{array}{l}\mathrm{bc} \\
\mathrm{cc} \\
\mathrm{ac} \\
\text { n.i. }\end{array}$ & $\begin{array}{c}\mathrm{ab} \\
\mathrm{ab} \\
\mathrm{bc} \\
-\mathbf{m U P D}\end{array}$ \\
\hline
\end{tabular}


Tab. 60: Fortsetzung

\begin{tabular}{|c|c|c|c|c|c|}
\hline $\begin{array}{l}\text { Loci } \\
\text { Probanden }\end{array}$ & D7S493 & D7S502 & D7S527 & D7S684 & D7S483 \\
\hline PD (m) & $\begin{array}{r}\mathrm{bc} \\
\mathrm{ac} \\
\mathrm{ad} \\
-\mathbf{U P D} \\
\end{array}$ & $\begin{array}{c}\mathrm{bc} \\
\mathrm{bc} \\
\mathrm{ab} \\
-\mathbf{m U P D} \\
\end{array}$ & $\begin{array}{c}\mathrm{cc} \\
\mathrm{bc} \\
\mathrm{ab} \\
-\mathbf{U P D} \\
\end{array}$ & $\begin{array}{c}\mathrm{ac} \\
\mathrm{bc} \\
\mathrm{ab} \\
-\mathbf{U P D} \\
\end{array}$ & $\begin{array}{l}a b \\
b c \\
b c \\
\text { n.i. }\end{array}$ \\
\hline PZ (m) & $\begin{array}{l}\mathrm{ab} \\
\mathrm{bc} \\
\mathrm{bc} \\
\text { n.i. }\end{array}$ & $\begin{array}{l}\mathrm{ab} \\
\mathrm{aa} \\
\mathrm{aa} \\
\text { n.i. }\end{array}$ & $\begin{array}{c}\mathrm{bb} \\
\mathrm{ab} \\
\mathrm{ac} \\
-\mathbf{U P D} \\
\end{array}$ & $\begin{array}{l}\mathrm{bb} \\
\mathrm{bb} \\
\mathrm{ab} \\
\text { n.i. }\end{array}$ & $\begin{array}{c}\mathrm{aa} \\
\mathrm{ab} \\
\mathrm{bb} \\
-\mathbf{U P D} \\
\end{array}$ \\
\hline SB (w) & $\begin{array}{c}\text { bd } \\
\text { aa } \\
\text { ac } \\
\text { (m Isodisomie) }\end{array}$ & $\begin{array}{l}\mathrm{ab} \\
\mathrm{bb} \\
\mathrm{ab} \\
\text { n.i. }\end{array}$ & $\begin{array}{c}\text { bc } \\
\text { aa } \\
\text { ab } \\
\text { (m Isodisomie) }\end{array}$ & $\begin{array}{c}\mathrm{cd} \\
\mathrm{ab} \\
\mathrm{ab} \\
\text { (m Heterodisomie) }\end{array}$ & $\begin{array}{c}\mathrm{ac} \\
\mathrm{bd} \\
\mathrm{bd} \\
\text { (m Heterodisomie) }\end{array}$ \\
\hline TK (m) & $\begin{array}{c}- \\
\mathrm{bc} \\
\mathrm{ab} \\
-\mathbf{m U P D}\end{array}$ & $\begin{array}{c}- \\
b c \\
a b \\
- \text { mUPD }\end{array}$ & $\begin{array}{c}- \\
\mathrm{ab} \\
\mathrm{bc} \\
-\mathbf{m U P D}\end{array}$ & $\begin{array}{c}- \\
\mathrm{ab} \\
\mathrm{aa} \\
-\mathbf{m U P D}\end{array}$ & $\begin{array}{c}- \\
\mathrm{ac} \\
\mathrm{ab} \\
-\mathbf{m U P D}\end{array}$ \\
\hline YD (w) & $\begin{array}{l}a b \\
b b \\
a b \\
\text { n.i. }\end{array}$ & $\begin{array}{c}\mathrm{cd} \\
\mathrm{bd} \\
\mathrm{ab} \\
-\mathbf{U P D}\end{array}$ & $\begin{array}{c}\mathrm{aa} \\
\mathrm{ab} \\
\mathrm{bc} \\
-\mathbf{U P D}\end{array}$ & $\begin{array}{l}\text { ac } \\
\text { aa } \\
\text { ab } \\
\text { n.i. }\end{array}$ & $\begin{array}{c}\mathrm{bd} \\
\mathrm{ab} \\
\mathrm{ac} \\
-\mathbf{U P D}\end{array}$ \\
\hline
\end{tabular}

Es wurden 2 Loci von Chromosom 7p (D7S493 und D7S502) und 3 Marker von Chromosom 7q getestet. Für jede Familie waren mindestens zwei der überprüften Loci informativ. Die analysierten Probanden MS und MS2 sind betroffene Geschwister.

Die vorliegenden Ergebnisse der informativen Marker zeigten, daß drei der 29 analysierten RSS-Probanden (KW, MA und SB) keine väterlichen Allele besitzen. Abbildung 37 zeigt die amplifizierten, Chromosom 7-spezifischen Allele von diesen Probanden und von deren Eltern.

Bei der Probandin SB liegen die Marker D7S493 und D7S527 homozygot vor, während die Mutter zwei verschiedene Allele aufweist. Die Allele der Probandin entsprechen jeweils einem der Allele der Mutter. Für diese Loci wurde damit eine maternale, uniparentale Isodisomie nachgewiesen. Für die Loci D7S684 und D7S483 ist die Probandin SB heterozygot, wobei die Allele dem maternalen Genotyp entsprechen. Für diese Marker wurde somit eine maternale, uniparentale Heterodisomie festgestellt. Der Marker D7S502 ist für die Probandin SB nicht informativ, da sie theoretisch auch ein Allel vom Vater geerbt haben könnte. Es ist jedoch wahrscheinlich, daß die Probandin eine maternale UPD für das gesamte Chromosom 7 aufweist. Da die Probandin für D7S502 homozygot ist, während die Mutter heterozygot ist, kann davon ausgegangen werden, daß für diesen Marker eine maternale, uniparentale Isodisomie vorliegt.

Der Proband KW ist für die Marker D7S493 und D7S527 heterozygot und weist die gleichen Allele wie die Mutter auf. Daher ist davon auszugehen, daß für diese Loci eine maternale, uniparentale Heterodisomie vorliegt. Für den Locus D7S483 sind sowohl der Proband als auch die Mutter homozygot. Daher kann für diesen Locus nicht zwischen maternaler Iso- oder Heterodisomie entschieden werden. Für die Loci D7S502 und D7S684 ist der Proband homozygot, während die Mutter heterozygot ist. Unter der Annahme, daß Proband KW eine UPD für das gesamte Chromosom 7 aufweist, liegt für diese Marker eine maternale Isodisomie vor. 
Der Proband MA weist neben dem RSS auch die Merkmale der Cystischen Fibrose (CF) auf. Er ist für alle getesten Loci homozygot, während die Mutter jeweils heterozygot ist. Die Allele des Probanden entsprechen jeweils einem der Allele der Mutter. Somit weist Proband MA für alle getesteten Loci eine maternale, uniparentale Isodisomie auf.

Somit wurden in einer Gruppe von 29 RSS-Probanden 3 Fälle nachgewiesen, die eine maternale uniparentale Disomie des Chromosoms 7 aufweisen. Bei 2 Probanden liegt diese sowohl als Iso- als auch als Heterodisomie vor. Das gleichzeitige Auftreten von Iso- und Heterodisomie bei den Probanden SB und KW deutet darauf hin, daß bei diesen Probanden Rekombinationsereignisse während der maternalen Meiose I stattgefunden haben. Proband MA zeigt dagegen mit den getesteten Markern ausschließlich Isodisomie.

Um die angegebene Vaterschaft bei Probanden mit UPD7 zu überprüfen, wurden weitere Mikrosatellitenmarker der Chromosomen 17, 18 und 20 analysiert. Die Ergebnisse dieser Analysen sind in Tabelle 61 enthalten. Alle getesteten Marker waren mit der angegebenen Vaterschaft vereinbar.

Tab. 61: Mikrosatelliten-Analyse mit Loci von Chromosom 17, 18 und 20.

(V: Vater; P: Proband; M:Mutter; m: männlich; w: weiblich; n.g.: nicht getestet)

\begin{tabular}{|c|c|c|c|c|}
\hline $\begin{array}{l}\text { Proband/ } \\
\text {-in }\end{array}$ & $\begin{array}{c}\mathrm{D} 17 \mathrm{~S} 1566 \\
(\mathrm{~V} / \mathrm{P} / \mathrm{M})\end{array}$ & $\begin{array}{c}\text { D18S554 } \\
\text { (V/P/M) }\end{array}$ & $\begin{array}{c}\text { D18S1009 } \\
(\mathrm{V} / \mathrm{P} / \mathrm{M})\end{array}$ & $\begin{array}{c}\text { D20S1154 } \\
\text { (V/P/M) }\end{array}$ \\
\hline $\mathrm{KW}(\mathrm{m})$ & $\mathrm{ab} / \mathrm{ab} / \mathrm{ab}$ & $\mathrm{bb} / \mathrm{bb} / \mathrm{ab}$ & $\mathrm{ab} / \mathrm{bc} / \mathrm{bc}$ & $\mathrm{bc} / \mathrm{ac} / \mathrm{ab}$ \\
\hline MA (m) & $\mathrm{ac} / \mathrm{bc} / \mathrm{bd}$ & n.g. & $\mathrm{ab} / \mathrm{ab} / \mathrm{ab}$ & ab/aa/aa \\
\hline SB (w) & n.g. & bc/ac/aa & $\mathrm{aa} / \mathrm{aa} / \mathrm{aa}$ & $\mathrm{bd} / \mathrm{cd} / \mathrm{ac}$ \\
\hline
\end{tabular}



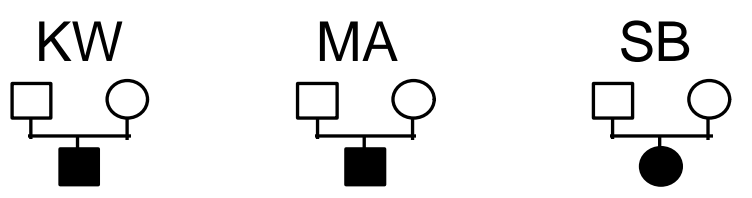

D7S493

(7p21-p13)

D7S502

(7p11.2-p11.1)

bc bb ab

$==\frac{a}{b}$

ab cc ac

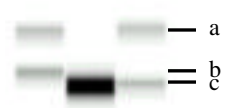

ab bb ab

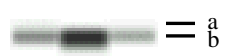

\section{D7S527}

(7q21.3)

bb ac ac

bd aa ac
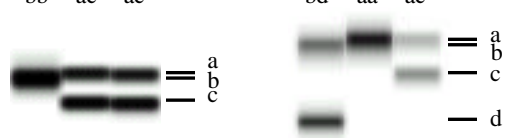

bc aa ab

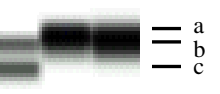

\section{D7S684}

(7q32-q34)

D7S483

(7q35-qter)

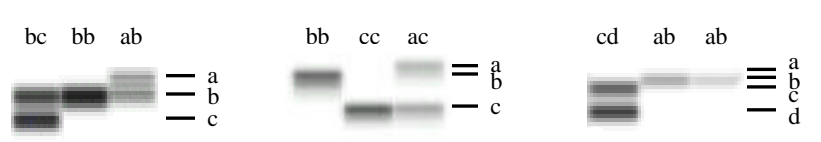

ac bb bb
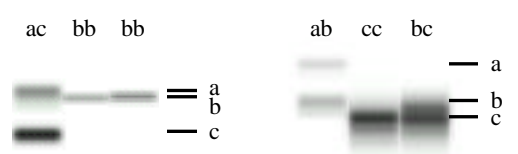

ac bd bd

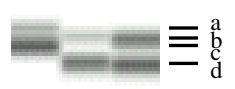

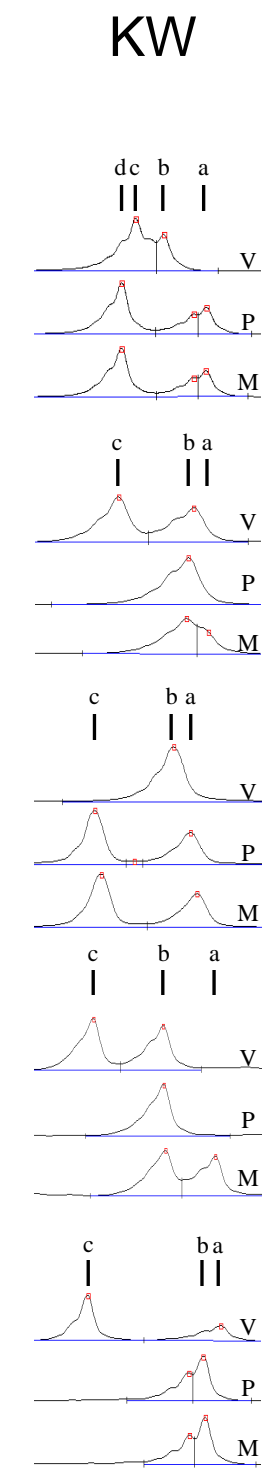

MA

SB
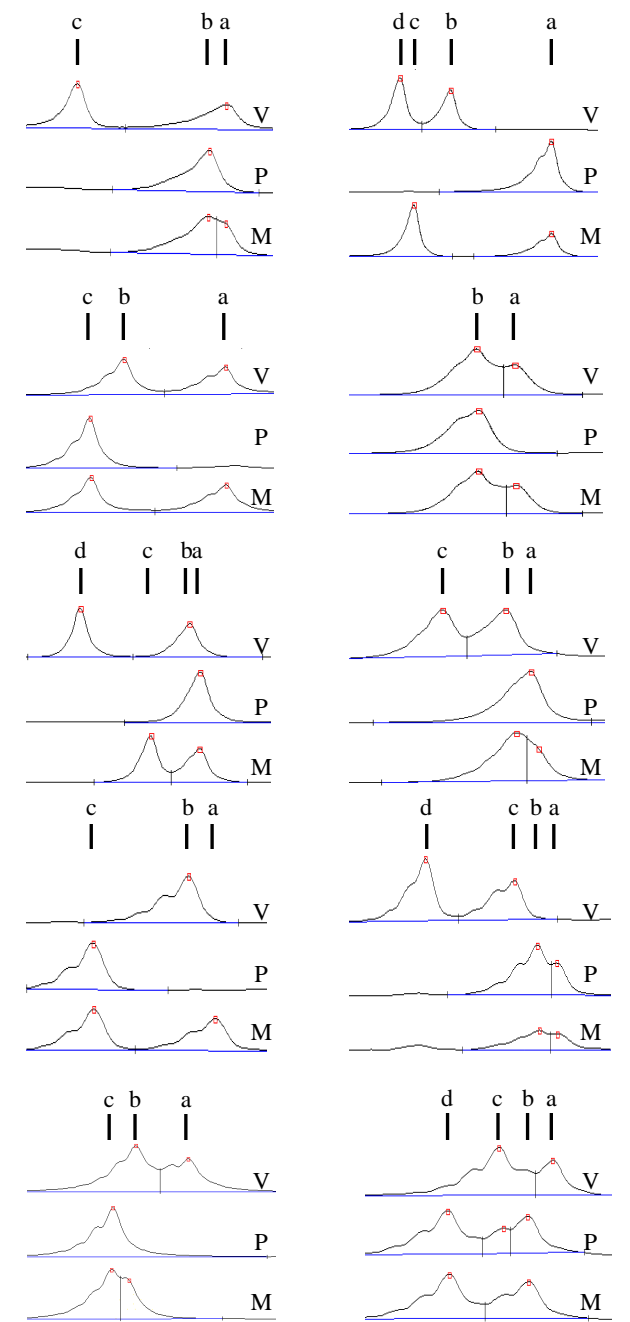

Abb. 37: Mikrosatelliten-Analyse von Probanden mit mUPD7 (KW, MA und SB) und deren Eltern mit den Loci D7S493, D7S502, D7S527, D7S684 und D7S483. Die chromosomale Lokalisierung dieser Loci ist jeweils angegeben. Dargestellt sind jeweils die entsprechenden Banden der Allele sowie die vom Programm Allelink errechneten Peaks. (V: Vater; P: Proband; M: Mutter). 


\section{Diskussion}

Die cytogenetische und molekulare Analyse von krankheitsassoziierten balancierten Chromosomenaberrationen ist eine effiziente Strategie, um Krankheitsgene zu kartieren und zu klonieren.

Das Gen für das Rubinstein-Taybi-Syndrom (RSTS, MIM 180849) konnte beispielsweise der Chromosomenregion 16p13.3 zugeordnet werden, da bei zwei Probanden mit RSTS balancierte de novo Translokationen mit einem Bruchpunkt in dieser Region festgestellt wurden (Imaizumi und Kuroki, 1991; Tommerup et al., 1991 und 1992). Die Lokalisierung in 16p13.3 wurde anschließend durch eine Probandin mit einer Inversion und einem Bruchpunkt in derselben Region bestätigt (Lacombe et al., 1992). Schließlich konnte gezeigt werden, daß das in der Bruchpunktregion lokalisierte Gen für das CREB-Bindeprotein für die Erkrankung verantwortlich ist (Petrij et al., 1995).

Auch die Einschränkung der Kandidatenregion des Gens für die Aniridie Typ II (AN2, MIM 106210) erfolgte durch die Charakterisierung von Translokationen. Das verursachende Gen konnte der Chromosomenregion 11p13 zugeordnet werden, da die Aniridie in zwei Familien mit Translokationen einher ging, die jeweils einen Bruchpunkt in der Region 11p13 aufwiesen (Simola et al., 1983 und 1984; Moore et al., 1986). Durch die Analyse der zur Aniridie Typ II homologen Maus- und Ratten-Mutanten 'Small eye' (Sey) wurden Hinweise dafür gefunden, daß Sey aufgrund einer Mutation im Pax6-Gen entsteht (Hill et al., 1991; Matsuo et al., 1993). Ton et al. (1991) klonierten eine bei zwei Patienten mit Aniridie komplett oder partiell deletierte cDNA aus der Region 11p13, bei der es sich um das zum murinen Pax6-Gen homologe humane Gen handelt (Walther und Gruss, 1991). Schließlich beschrieben Hanson et al. (1993) bei Patienten mit Aniridie Punktmutationen im PAX6-Gen und zeigten somit, daß PAX6Mutationen für die meisten Fälle der Aniridie verantwortlich sind. Fantes et al. (1995) und Crolla et al. (1996) zeigten, daß auch chromosomale Brüche, die mehr als 85 kb vom 3'-Ende des PAX6-Gens entfernt sind, zu Aniridie führen können.

Beim Russell-Silver-Syndrom (RSS) wurden bisher zwei Probanden mit Translokationen beschrieben (Ramirez-Dueñas et al., 1992; Midro et al., 1993). Bei dem Probanden AS mit Russell-Silver-Syndrom wurde nach mikroskopischen Kriterien eine balancierte Translokation $\mathrm{t}(1 ; 17)(\mathrm{q} 31 ; \mathrm{q} 25)$ nachgewiesen (Midro et al., 1993). Die Translokation trat bei diesem Probanden gemeinsam mit dem Russell-Silver-Syndrom de novo auf, d.h. die Eltern dieses Probanden weisen weder die Translokation noch das Krankheitsbild auf. Daher ist zu vermuten, daß das Russell-Silver-Syndrom bei diesem Probanden durch die Translokation verursacht wurde. Zudem wurde 1992 ein weiterer Fall mit Russell-Silver-Syndrom und einer Translokation $\mathrm{t}(17 ; 20)(\mathrm{q} 25 ; \mathrm{q} 13)$ mit Beteiligung des langen Arms von Chromosom 17 beschrieben (Ramirez-Dueñas et al., 1992). Da die Translokationsbruchpunkte auf Chromosom 17 bei beiden Translokationen cytogenetisch übereinstimmen, wurde vermutet, daß diese Bruchpunkte in derselben Region liegen. Dies deutete darauf hin, daß ein molekularer Defekt auf Chromosom 17 im Zusammenhang mit dem RSS steht. Ob diese Translokationsbruchpunkte auch auf molekularer Ebene in derselben Region auf Chromosom 17 lokalisiert sind, konnte jedoch vorerst nicht überprüft werden, da Material der Probandin mit der 17;20 Translokation nicht zur Verfügung stand. Daher wurde eine positionelle Kartierung des 
krankheitsverursachenden Gens zunächst nur anhand von Untersuchungsmaterial des von Midro et al. (1993) beschriebenen Probanden angestrebt. Dazu wurde die Region des Translokationsbruchpunktes dieses Probanden auf Chromosom 17 molekular kartiert und auf einen bestimmten Bereich, in dem ein RSS-Gen vermutet wird, eingeengt.

\subsection{Erstellung eines detaillierten YAC-Contigs für die Region 17q23-q24}

Die erste Eingrenzung des Translokationsbruchpunktes von Proband AS war bereits im Rahmen einer vorangegangenen Arbeit (Dörr, 1995) erfolgt, indem neun cytogenetisch kartierte Cosmide (Inazawa et al., 1993) und 30 YACs (CEPH, Paris) der Region 17q21-q25 über FISHAnalysen an Metaphasen des Probanden hybridisiert wurden. Über die FISH-Analyse mit Cosmiden konnte der Translokationsbruchpunkt des Probanden AS abweichend von der cytogenetischen Analyse von Midro et al. (1993) der Region 17q23-q24 zugeordnet werden. Die FISH-Analyse der YACs führte zur Identifizierung von sieben YACs, die den Bruchpunkt des Probanden auf Chromosom 17 überspannen. Anhand einer STS-content-Kartierung war ein erstes Contig (s. Abb. 1) erstellt worden, wobei den YACs jedoch nur wenige Loci zugeordnet waren.

Um ein detaillierteres Contig der Region zu erhalten, sollten den YACs im Rahmen dieser Arbeit weitere Loci zugeordnet werden. Dazu wurden die YACs des Contigs auf die Anwesenheit von 13 Genen, zehn ESTs und 23 anonymen Markern getestet. Analysiert wurden Gene, die nach Angaben der Genome Database (GDB) oder der Literatur in der Region 17q23-q24 kartieren. Die getesteten ESTs entstammen z.T. dem vom Whitehead Institute erstellten YACContig WC17.9. Zudem wurden aus der NCBI-Datenbank ESTs ausgewählt, die zwischen den Markern D17S794 und D17S795 kartieren. Die anonymen Marker wurden z.T. der genetischen Karte von Dib et al. (1996) oder dem vom Whitehead erstellten Contig WC17.9 entnommen. Ein großer Teil der analysierten anonymen Marker wurde jedoch erst im Rahmen dieser Arbeit generiert.

Über die STS-content-Kartierung mit diesen Markern konnte ein YAC-Contig, welches 56 STS-Stellen beinhaltet, erstellt werden. In dieses Contig wurden fünf bekannte Gene (APOH, PRKCA, CACNLG, KPNA2 und PRKAR1A) und ein Gen oder Pseudogen (G6PDL) eingeordnet. Für einige dieser Gene wurden jedoch mehrere Loci analysiert, so daß diesen fünf Genen elf STS-Stellen zugeordnet werden können. Weiterhin wurden dem Contig acht ESTs (WI-9571, WI-9269, WI-8032, stSG2005, stSG3721, stSG2549, WI-9461 und stSG9224) und 29 anonyme Loci zugeordnet. Von den anonymen Markern waren 13 bereits beschrieben, während 16 Loci im Rahmen dieser Arbeit ausgehend von Klon-Endfragmenten generiert wurden.

Zudem wurden drei weitere YACs (765F4, 963C7 und 853F8) in das Contig eingeordnet. Diese wurden über FISH-Analysen auf Metaphasechromosomen des Probanden AS proximal zum Translokationsbruchpunkt dieses Probanden kartiert.

Bei einer erneut durchgeführten FISH-Analyse des YACs 955H4 auf Metaphasen des Probanden AS wurde festgestellt, daß dieser YAC den Translokationsbruchpunkt des Probanden AS überspannt. Dies war bei einer vorangegangenen FISH (Dörr, 1995) vermutlich aufgrund schwacher Signale auf dem derivativen Chromosom 1nicht erkannt worden. 
Aufgrund von Sequenzamplifikationen (low-copy Repeats), die den Translokationsbruchpunkt auf beiden Seiten begrenzen, wurden acht Loci (KPNA2-E2, KPNA2-3', 293T7, WI-9461, 2A3T3, 7T7, 293SP6 und WI-9571) sowohl in proximal als auch in distal zum Translokationsbruchpunkt lokalisierten Klonen nachgewiesen. Aufgrund dieser Ergebnisse wurden die entsprechenden Loci zweifach in das YAC-Contig eingeordnet, und zwar auf beiden Seiten des Translokationsbruchpunktes von AS. Somit sind dem Contig 56 Loci zugeordnet, PCR-Analysen wurden dabei für 48 dieser Marker durchgeführt. Die Sequenzierung von PCR-Produkten dieser Marker, die entweder mit proximal oder distal zum Bruchpunkt kartierten Klonen erhalten wurden, zeigte, daß sich für die einzelnen Loci unterschiedliche Sequenzen ergeben, je nachdem, ob die PCR-Produkte ausgehend von proximal oder distal vom Bruchpunkt kartierten Klonen erhalten wurden. Über diese Sequenzierungen konnte somit auch bewiesen werden, daß einzelne Marker innerhalb des YAC-Contigs zweifach vorkommen. Zudem konnte gezeigt werden, daß sich die doppelt vorliegenden Marker auf molekularer Ebene unterscheiden. Ist ein bestimmter Klon für einen dieser mindestens zweifach vorkommenden Marker positiv, so kann über eine Sequenzierung des zu diesem Locus korrespondierenden PCR-Produktes und einen Sequenzvergleich mit den in dieser Arbeit ermittelten Sequenzdaten für die jeweiligen Loci entschieden werden, welchen Marker dieser Klon trägt. Falls ein Klon keine weiteren, für die eine oder andere Region spezifischen Marker trägt, ist eine Sequenzierung erforderlich, um diesen Klon exakt zu lokalisieren. Um die dupliziert vorliegenden Loci der proximalen Region von denen der distalen Region unterscheiden zu können, wurden Marker, die nicht die Originalsequenz beinhalten, in Klammern gesetzt. Beispielsweise ist die Sequenz des Locus (WI9571) nicht mit der in der Datenbank für die EST WI-9571 angegebenen Sequenz identisch und der Marker (7T7) amplifiziert nicht exakt die über T7-Sequenzierung des PACs 7B12 erhaltene Sequenz.

Die duplizierten Loci scheinen in zwei Clustern beiderseits des Bruchpunktes vorzuliegen, wobei ein Cluster die Loci 293T7, KPNA2-3' und KPNA2-E2 und ein anderes die Loci 7T7, 293SP6 und WI-9571 beinhaltet. Die duplizierten Loci WI-9461 und 2A3T3 lassen sich jedoch keinem dieser Cluster zuordnen. Aufgrund der Anordnung im YAC-Contig kann angenommen werden, daß die Cluster im proximalen Bereich des YAC-Contigs in entgegengesetzter Richtung zu denen im distalen Bereich des YAC-Contigs orientiert sind. Auf die Beteiligung von low-copy Repeats an der Entstehung von Erkrankungen wird im folgenden noch eingegangen.

Das erstellte YAC-Contig (s. Abb. 5) deckt mit einer Lücke zwischen den Loci 241SP6 und D17S789 die gesamte Region zwischen den Markern (293T7) und D17S940 ab. Der maximale Abstand zwischen den Loci (293T7) und 241SP6 wurde ermittelt, indem die Größen der YACs, die für eine einfache Abdeckung des Bereiches benötigt werden, addiert wurden. Nach Addition der Größen der YACs 963C7 (1480 kb), 883B2 (> $1600 \mathrm{~kb})$, 929D11 (500 kb), 983D12 (1100 kb) und 931B10 (1050 kb) ergibt sich ein maximaler Abstand zwischen (293T7) und 241SP6 von etwa 5,7 Mb. Es ist jedoch unklar, inwieweit die einzelnen YACs sich gegenseitig überlappen. Zudem handelt es sich bei dem YAC 929D11 um einen chimärischen Klon. Daher ist davon auszugehen, daß der Abstand zwischen den Loci (293T7) und 241SP6 etwa 4 bis $5 \mathrm{Mb}$ beträgt. 
In der von Dib et al. (1996) konstruierten genetischen Karte sind einige Loci enthalten, die in das YAC-Contig der Bruchpunktregion eingeordnet wurden. Die angegebene Anordnung dieser Loci ist Abb. 38 zu entnehmen.

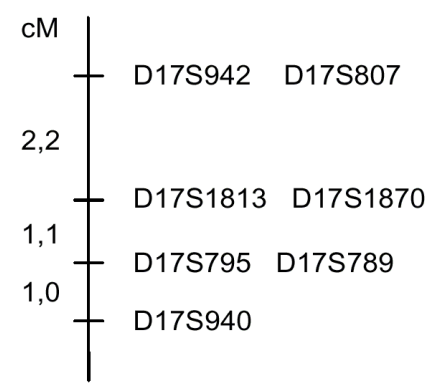

Abb. 38: Genetische Karte für den Bereich des YAC-Contigs der Region 17q23-q24 (nach Dib et al., 1996).

Die im Rahmen dieser Arbeit ermittelte Anordnung (s. Abb. 5 und 22) stimmt mit den von Dib et al. (1996) publizierten Ergebnissen der genetischen Karte überein. Über die Erstellung des YAC-Contigs konnten jedoch auch die Loci, die von Dib et al. (1996) aufgrund von fehlenden Rekombinationen zwischen einzelnen Markern nicht angeordnet werden konnten, linear zueinander positioniert werden. Durch die YAC-Kartierung wurde folgende Anordnung erhalten:

cen - D17S942 - D17S807 - D17S1813 - D17S1870 -BP- D17S789 - D17S795 - D17S940 - tel

Der Translokationsbruchpunkt (BP) des Probanden AS wurde zwischen den Loci D17S1870 und D17S789 kartiert. Nach der genetischen Karte von Dib et al. (1996) beträgt der genetische Abstand zwischen diesen Markern 1,1 cM, was theoretisch einem physikalischen Abstand von 1,1 Mb entspricht (Stephens et al., 1990).

Bray-Ward et al. (1996) erstellten eine Karte des humanen Genoms, in der cytogenetische, genetische und physikalische Karten vereinigt wurden. YAC 883B2 ist in dieser Karte enthalten. Nach dieser Karte ist davon auszugehen, daß die Rekombinationsfrequenz in der Region telomerwärts von YAC 883B2 im Vergleich zur durchschnittlichen Rekombinationsfrequenz leicht erhöht ist. Es erfolgt jedoch keine weitere Unterteilung dieser Region, so daß diese Karte keine Rückschlüsse auf die Rekombinationsfrequenz in der Bruchpunktregion zuläßt. Wird von der Annahme ausgegangen, daß in dieser Region ein genetischer Abstand von $1 \mathrm{cM}$ einem Abstand von $1 \mathrm{Mb}$ entspricht, so wäre der Abstand zwischen den Markern D17S942 und D17S940 nach der genetischen Karte von Dib et al. (1996) 4,3 Mb groß.

Von Chumakov et al. (1995) wurde eine YAC-Contig-Karte von 222 Contigs für das gesamte humane Genom vorgestellt, welche $75 \%$ des Genoms abdeckt. Diese Contigs wurden generiert, indem 33000 YACs mit verschiedenen Methoden analysiert wurden. Überlappungen von YACs wurden z.T. über STS-content-Kartierung festgestellt. Zudem wurden Inter-Alu-PCR- 
Produkte von YACs als Hybridisierungssonden auf Filter mit Alu-PCR-Produkten von YACs hybridisiert und Fingerprint-Analysen durchgeführt. Die chromosomale Zuordnung von YACKlonen wurde erreicht, indem Alu-PCR-Produkte von YACs auf Alu-PCR-Produkte von somatischen Zellhybriden mit nur einem oder zwei humanen Chromosomen hybridisiert wurden. Zudem wurden 650 YACs über FISH auf Metaphasechromosomen hybridisiert.

Die von Chumakov et al. (1995) vorgestellte Karte beinhaltet mit Ausnahme der Klone 901G9, 931B10 und 742A4 alle YACs, die in das in dieser Arbeit erstellte YAC-Contig der Region 17q23-q24 (s. Abb. 5) integriert wurden. Insgesamt wurden diesen YACs von Chumakov et al. (1995) acht Marker (D17S1874, D17S113, D17S1309, D17S807, D17S942, D17S789, D17S795, D17S940) zugeordnet. Fünf dieser Marker (D17S807, D17S942, D17S789, D17S795, D17S940) sind ebenfalls in das in dieser Arbeit erstellte Contig integriert. Alle YACs, die von Chumakov et al. (1995) für diese Loci positiv getestet wurden, sind auch im Rahmen der Erstellung des YAC-Contigs positiv getestet worden. Einige dieser Loci konnten jedoch auf weiteren YACs, die von Chumakov et al. (1995) nicht als positiv angegeben wurden, nachgewiesen werden. So wurde der Locus D17S942 auf dem YAC 929D11 nachgewiesen, der Marker D17S807 auf dem YAC 680F6 und der Locus D17S940 auf dem YAC 938F7. Insgesamt stimmt die lineare Anordnung der Loci des in dieser Arbeit erweiterten Contigs mit den von Chumakov et al. (1995) erhaltenen Ergebnissen überein. Die in dieser Arbeit erstellte Karte ist jedoch detaillierter, da sie mehr Loci enthält und diese linear zueinander angeordnet werden. Chumakov et al. (1995) teilen die YACs der Bruchpunktregion des Probanden AS dagegen lediglich in fünf Gruppen ein und ordnen diesen maximal 1 bis 2 Loci zu, die nicht in Bezug zueinander kartiert werden. Der von Chumakov et al. (1995) erstellten Karte ist für diese Loci folgende Anordnung zu entnehmen:

cen - (D17S807, D17S942) - (D17S789, D17S795) - (D17S940) - tel

So ist nach der von Chumakov et al. (1995) erstellten Karte keine Aussage darüber zu machen, ob D17S807 distal oder proximal zu D17S942 kartiert. Auch die Loci D17S789 und D17S795 werden nicht in Bezug zueinander angeordnet.

Ein anderes YAC-Contig, nämlich WC17.9, welches die Bruchpunktregion des Probanden AS einschließt, wurde zwischenzeitlich in der Datenbank des Whitehead Institute veröffentlicht (http://carbon.wi.mit.edu:8000/cgi-bin/contig/lookup_contig). Dem Contig WC17.9 und dem in dieser Arbeit erstellten Contig sind folgende YACs gemeinsam: 963C7, 765F4, 853F8, 883B2, 929D11, 955H4, 845C6, 931B10, 871C4, 855A4, 938F7 und 804H7. Alle Marker, die vom Whitehead Institute positiv für diese YACs angegeben werden, wurden im Rahmen dieser Arbeit ebenfalls positiv getestet. Zudem konnten einigen YACs zusätzliche Loci zugeordnet werden, die vom Whitehead Institute nicht auf den jeweiligen YACs nachgewiesen wurden. Dies betrifft den YAC 871C4, welcher im Rahmen dieser Arbeit für die Loci WI-9571 und WI9461 positiv getestet wurde, den YAC 938F7, welcher für den Marker D17S940 positiv getestet wurde, und den YAC 804H7, der für den Locus D17S795 positiv getestet wurde.

Für die Loci, die sowohl im Contig WC17.9 als auch in dem in dieser Arbeit generierten YACContig enthalten sind, wird vom Whitehead Institute folgende Anordnung angegeben: 
cen - D17S1524 - WI-7259 (CACNLG) - D17S807 - GAAT1E12 - D17S942 - WI-8032 D17S1695 - WI-9269 - D17S1557 - WI-9571 - D17S1813 - D17S1870 - WI-9461 - D17S789 D17S795 - D17S940 - tel

Obwohl ein großer Teil der YAC-Klone sowie 16 Loci sowohl im Contig WC17.9 als auch in dem in dieser Arbeit erstellten Contig enthalten sind, unterscheidet sich die Anordnung der Marker in beiden Contigs erheblich. Dies ist jedoch kaum auf unterschiedliche Ergebnisse der STS-content-Kartierung zurückzuführen, da diese bis auf einige Ausnahmen miteinander übereinstimmen. Vom Whitehead Institute wurde jedoch nicht erkannt, daß einzelne Loci des YAC-Contigs dupliziert vorliegen. Vor allem dadurch, daß in Contig WC17.9 aufgrund der positiven STS-Ergebnisse mit dem Locus WI-9571 auf Überlappungen zwischen den YACs 963C7, 765F4 und 853F8 mit den YACs 845C6, 931B10 und 871C4 geschlossen wird, weichen die Ergebnisse des Whitehead Institut, was die lineare Anordnung der Loci betrifft, deutlich von den Ergebnissen dieser Arbeit ab. Die vom Whitehead Institute angegebene lineare Anordnung der Loci ist daher für den verglichenen Bereich als fehlerhaft anzusehen.

Die größte Übereinstimmung der eigenen Ergebnisse ergibt sich mit der von Foster et al. (1996) vorgestellten RH-Karte der Region 17q22-q25.3, welche 39 STS-Marker enthält. Von diesen Loci sind sieben ebenfalls in das im Rahmen dieser Arbeit erstellte Contig integriert. Die wahrscheinlichste lineare Anordnung dieser Marker sieht in Übereinstimmung mit den eigenen Ergebnissen nach Foster et al. (1996) folgendermaßen aus:

cen - D17S942 - PRKCA - D17S807 - PRKAR1A - D17S789 - D17S795 - D17S940 - tel

Plummer et al. (1997) ordneten somatischen Zellhybriden des gesamten Chromosoms 17 104 anonyme Loci, 288 ESTs und 26 bereits beschriebene Gene zu. Bei den anonymen Loci, die sowohl in der von Plummer et al. (1997) erstellten Karte als auch in dem im Rahmen dieser Arbeit erstellten YAC-Contig der Region 17q23-q24 enthalten sind, handelt es sich um die Loci D17S1695, D17S942, D17S807, D17S795, D17S789, D17S940 und D17S1557. Diese werden in folgender Orientierung angeordnet:

cen - (D17S1695, D17S942) - D17S807 -(D17S795, D17S789, D17S940) - D17S1557 -tel

Plummer et al. (1997) positionierten die Loci D17S1695 und D17S942 proximal von D17S807. Dies stimmt mit den im Rahmen dieser Arbeit erhaltenen Ergebnissen überein, spricht jedoch gegen die vom Whitehead Institute angegebene Anordnung. Der Locus D17S807 ist sowohl in der von Plummer et al. (1997) erstellten Karte als auch in den für den Translokationsbruchpunkt des Probanden AS erstellten Contigs proximal von den Loci D17S795, D17S789 und D17S940 lokalisiert. Der Locus D17S1557 wurde von Plummer et al. (1997) auf dem am weitesten distal lokalisierten somatischen Zellhybrid nachgewiesen. Demnach würde sich D17S1557 weit außerhalb des YAC-Contigs der Region 17q23-q24 befinden. D17S1557 wurde jedoch auch vom Whitehead Institute auf den YACs 963C7 und 765F4 kartiert. Zudem wurde über Sequenzvergleiche in der EMBL/GenBank-Datenbank ein BAC-Klon 
(hCIT.87G17) identifiziert, welcher diesen Locus und weitere im YAC-Contig lokalisierte Marker beinhaltet. Der Locus D17S1557 ist also mit Sicherheit im erstellten YAC-Contig der Region 17q23-q24 enthalten. Möglicherweise liegen jedoch auch in der Region 17q25 Sequenzen, die sich mit den Primern für diesen Locus amplifizieren lassen.

Dem Zellhybrid, welches für den Locus D17S807 positiv getestet wurde, ordneten Plummer et al. (1997) das Gen CACNLG zu. Dieses Gen ist benachbart zu dem Marker D17S807 in das im Rahmen dieser Arbeit erstellte Contig eingeordnet. Dem von Plummer et al. (1997) positiv für die Loci D17S789, D17S795 und D17S940 getesteten Zellhybrid wurden die Gene bzw. ESTs PRKAR1A, FAC1, 211S1, 225S2, D17S1474 und D17S1496 zugeordnet. Das Gen PRKAR1A konnte im Rahmen dieser Arbeit über Sequenzvergleiche in der EMBL/GenBank-Datenbank und über Analyse eines PAC-Klons innerhalb der Lücke des YAC-Contigs zwischen den Markern 241SP6 und D17S789 kartiert werden. Alle weiteren Gene bzw. ESTs, die von Plummer et al. (1997) auf demselben Zellhybrid wie das Gen PRKAR1A kartieren, wurden nicht analysiert.

In der RH-Karte des NCBI (http://www.ncbi.nlm.nih.gov/genemap) von 1999, welche die erweiterte Karte von Deloukas et al. (1989) darstellt, sind zwischen den Markern D17S807 und D17S795 derzeit 34 Gene bzw. ESTs lokalisiert. Vier dieser ESTs wurden dem YAC-Contig der Region 17q23-q24 im Verlauf dieser Arbeit über PCR-Analysen zugeordnet. Zehn weitere ESTs konnten sequenzierten BAC-Klonen der Region über Sequenzvergleiche in der EMBL/GenBank-Datenbank zugeordnet werden. Die verbleibenden 20 Gene bzw. ESTs wurden bisher nicht analysiert, so daß keine Angaben darüber gemacht werden können, ob sich unter diesen Genen/ESTs ein RSS-Kandidatengen befindet.

Die Gene, die im Rahmen dieser Arbeit nicht auf den YACs der Bruchpunktregion des Probanden AS positioniert werden konnten, sind inzwischen in die von Deloukas et al. (1998) vorgestellte RH-Karte integriert worden. Demnach sind die Gene ITGA2B, ITGB3, TBX2, DCP1, PECAM1 und ICAM2 proximal vom YAC-Contig der Region 17q23-q24 lokalisiert. Die Gene GALK1, ACOX1 und GAA werden dagegen von Deloukas et al. (1998) distal von diesem Contig positioniert.

Im Rahmen dieser Arbeit konnte gezeigt werden, daß der Translokationsbruchpunkt des Probanden AS von low-copy Repeats flankiert wird. Solche duplizierten Regionen des humanen Genoms begünstigen ungleiche Crossing-over und fördern somit das Auftreten von Deletionen, Duplikationen oder Inversionen, die in Zusammenhang mit einer Erkrankung stehen können (Mazzarella und Schlessinger, 1998; Lupski, 1998). Rekombinationen zwischen regionsspezifischen low-copy wiederholten Sequenzen können dazu führen, daß ein Krankheitsgen in vielen Fällen nahezu identisch verändert wird. Erkrankungen, die vorwiegend dadurch entstehen, daß die Anzahl der Genkopien von dosisabhängigen Genen verändert wird, oder dadurch, daß ein Gen unterbrochen wird, werden von Lupski (1998a) als genomische Erkrankungen bezeichnet, da die Genomarchitektur in diesen Fällen zur Entstehung der Krankheit beiträgt. Dieser Mechanismus steht nach Lupski (1998a) in scharfem Kontrast zum klassischen Entstehungsmechanismus von genetischen Erkrankungen, bei denen ein abnormer Phänotyp vorwiegend 
aufgrund von Punktmutationen entsteht. Welche Veränderung durch eine Rekombination zwischen duplizierten Regionen entsteht, ist abhängig von der Orientierung der Repeats zueinander (Weinstock et al., 1998). Befinden sich diese in derselben Orientierung, so kann es aufgrund einer Rekombination zu einer Deletion oder Duplikation des zwischen den Repeats lokalisierten genetischen Materials kommen, während eine Rekombination zwischen entgegengesetzt orientierten homologen Bereichen in einer Inversion des zwischen den Repeats lokalisierten Bereiches resultiert (s. Abb. 39). Bei den duplizierten Bereichen kann es sich um Gene, aber auch um andere relativ seltene Sequenzen handeln. Im folgenden soll die Bedeutung von duplizierten Regionen des Genoms für genetisch bedingte Erkrankungen anhand einiger Beispiele verdeutlicht werden.

a)

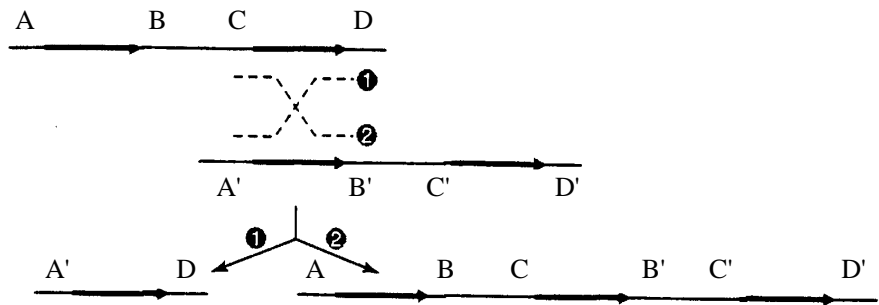

b)

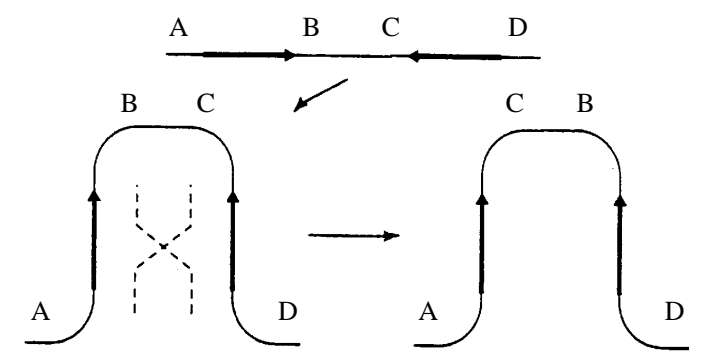

Abb. 39: Aufgrund von Sequenzduplikationen resultierende genomische Umordnungen (nach Lupski, 1998a). Repeats sind als Pfeile dargestellt, deren Orientierung durch die Pfeilspitzen angezeigt wird. Buchstaben vor und nach diesen Repeats entsprechen flankierenden, nicht verdoppelten Sequenzen. Gestrichelte Linien stellen ein Rekombinationsereignis dar. a) Es werden beide homologen Chromosomen gezeigt. Ein Rekombinationsereignis zwischen Repeats, welche in derselben Orientierung hintereinanderliegen, hat eine Deletion und/oder Duplikation zur Folge. b) Eine Rekombination zwischen invertierten Repeats führt zu einer Inversion.

Klassische Beispiele für autosomale Erkrankungen, die aufgrund von Rekombinationen zwischen tandemartig hintereinanderliegenden duplizierten Genen entstehen, sind die Hämoglobinopathien (Maniatis et al., 1980; Collins und Weissman, 1984; Orkin und Kazazian, 1984; Antonarakis et al., 1985; Higgs et al., 1989). Die Mehrzahl der $\alpha$-Thalassämien entsteht durch Deletionen im $\alpha$-Globin-Gencluster in 16p13.3 (Higgs et al., 1980; Lauer et al., 1980). Dieses ist zusammengesetzt aus zwei aktiven $\alpha$-Genen $\left(\alpha_{1}\right.$ und $\left.\alpha_{2}\right)$, zwei Pseudogenen $\left(\psi \alpha_{1}\right.$ und $\left.\psi \alpha_{2}\right)$, dem im Embryo exprimierten $\alpha$-ähnlichem $\zeta_{2}$-Gen und seinem Pseudogen $\left(\psi \zeta_{1}\right)$. Die $\alpha_{1}$ - und $\alpha_{2}$-Gene codieren identische Proteine und sind auch auf der Nukleotidebene fast identisch. Zudem verlängert sich die Homologie zwischen den zwei Genen in Richtung 5'-flankierende Region um $1 \mathrm{~kb}$, so daß die zwei Gene in einem Bereich von mehr als 4 kb sehr homolog 
zueinander sind. Dadurch scheint ungleiches Crossing-over begünstigt zu werden, was zu Chromosomen mit zusätzlichen Globin-Genen oder zu Chromosomen mit weniger oder keinem Globin-Gen führen kann (Weatherall et al., 1995). Individuen, die insgesamt zwei Globin-Gene besitzen, zeigen eine milde Form der $\alpha$-Thalassämie (OMIM-Nr. 141850), während solche mit insgesamt nur einem Gen schwer betroffen sind.

Auch bei anderen Erkrankungen dienen tandemartig hintereinanderliegende Gene oder zu diesen benachbarte Sequenzen als Substrate für homologe Rekombinationen. Die Rekombination zwischen diesen Repeats führt entweder zum Verlust einer Genkopie, was in Haploinsuffizienz resultiert, oder es entstehen rekombinante Hybridgene mit veränderten Eigenschaften. $\mathrm{Zu}$ den Erkrankungen, die aufgrund dieses Mutations-Mechanismus entstehen, gehören neben der $\alpha$-Thalassämie auch die $\beta$-Thalassämie (OMIM-Nr. 141900; Weatherall, 1995), das isolierte Fehlen von Wachstumshormon (GH1; OMIM-Nr. 139250; Vnencak-Jones et al., 1988 und 1990), Rot-Grün-Blindheit (OMIM-Nr. 303800 und 303900; Nathans et al., 1992; Neitz und Neitz, 1995), Glucocorticoid-heilbarer Aldosteronismus (GRA; OMIM-Nr. 103900; Lifton et al., 1992), Kongenitale adrenale Hyperplasie (CAH; OMIM-Nr. 201910; Donohoue et al., 1989), Bartter-Syndrom Typ III (BS; OMIM-Nr. 241200; Simon et al., 1997) und Gaucher-Krankheit (OMIM-Nr. 230800; Zimran et al., 1990).

Duplizierte Repeats können jedoch auch dann zu genetisch bedingten Erkrankungen führen, wenn die Repeats in einiger Entfernung von dem für die Erkrankung verantwortlichen Gen lokalisiert sind. In diesem Fall flankieren die duplizierten Sequenzen eine genomische Region, die ein oder mehrere Gene beinhalten kann. Das für den Phänotyp verantwortliche Gen ist dosisabhängig, aber es wirkt nicht als Substrat für die Rekombination, welche zu einer DNAUmordnung führt. Ein Beispiel für eine solche Erkrankung ist die X-gekoppelte Ichthyosis (OMIM-Nr. 308100), welche durch ein Fehlen der Steroid-Sulfatase (STS) verursacht wird. Bei ungefähr $90 \%$ der Patienten mit dieser Erkrankung ist das gesamte in der Region Xp22.3 lokalisierte STS-Gen deletiert (Ballabio et al., 1989; Shapiro et al., 1989). Bei der Mehrzahl der Patienten liegen die Bruchpunkte der Deletion innerhalb eines low-copy Repeats, welches mit S232 bezeichnet wird (Yen et al., 1990). Die S232-Repeats sind 1,9 Mb voneinander entfernt und $5 \mathrm{~kb}$ lang. Zudem sind zwei Elemente, die aus VNTRs (variable number of tandem Repeats) bestehen, wiederholt (Li et al., 1992).

Eine weitere Erkrankung, die aufgrund von Rekombinationen zwischen tandemartig angeordneten Repeats entsteht, ist die Charcot-Marie-Tooth-Krankheit Typ 1A (CMT1A; OMIMNr. 118220). Diese Erkrankung ist assoziiert mit 1,5 Mb Duplikationen in 17p12 (Lupski, 1997, 1998a und 1998b), die aufgrund von Rekombinationen zwischen 24 kb großen zu 98,7 \% identischen Repeats (CMT1A-REP) entstehen (Pentao et al., 1992). Schiavon et al. (1994) zeigten, daß von 56 nicht verwandten Patienten $76 \%$ die CMT1A-Duplikation aufwiesen. Das für die Erkrankung verantwortliche dosisabhängige Myelingen PMP22 ist 0,5 Mb von der proximalen Kopie des Repeats und 1,0 Mb von der distalen Kopie entfernt lokalisiert (Reiter et al., 1997).

Auch das Smith-Magenis-Syndrom (SMS; OMIM-Nr. 182290) entsteht aufgrund von Rekombinationen zwischen Repeats. Bei der Mehrzahl der Patienten ist eine ungefähr $5 \mathrm{Mb}$ große Region in 17p11.2 deletiert (Greenberg et al., 1991; Guzzetta et al., 1992; Juyal et al., 1996). Diese deletierte Region wird von einem ungefähr 200 kb langen Repeat-Gen-Cluster flankiert. 
Mehr als $90 \%$ der Patienten zeigen nach PFGE ein verändertes Fragment anscheinend gleicher Größe, was auf ein präzises Rekombinationsereignis schließen läßt (Chen et al., 1997).

Obwohl die Entstehung von Williams-Beuren-Syndrom (WBS; OMIM-Nr. 194050), PraderWilli-Syndrom (PWS; OMIM-Nr. 176270), Angelmann-Syndrom (AS; OMIM-Nr. 105830) und DiGeorge-Syndrom (DGS; OMIM-Nr. 188400)/Velocardiofacial-Syndrom (VCFS; OMIM-Nr. 192430) auf der molekularen Ebene noch nicht vollständig geklärt ist, liegen Hinweise vor, daß auch diese Syndrome genomische Erkrankungen sind (Dutly und Schinzel, 1996; Urban et al., 1996; Perez Jurado et al., 1996 und 1998; Robinson et al., 1996; Osborne et al., 1997; Wu et al., 1998; Christian et al., 1995 und 1999; Carrozzo et al., 1997; Wandstrat et al., 1998; Halford et al., 1993; Morrow et al., 1995; Lindsay et al., 1995, Edelmann et al., 1999). Low-copy-Sequenzwiederholungen wurden in der Umgebung der Loci für die jeweiligen Erkrankungen bereits identifiziert, zudem werden bei der Mehrzahl der Patienten übereinstimmende Deletionen gefunden, was darauf hindeutet, daß ungleiches Crossing-over an der Entstehung dieser Erkrankungen beteiligt ist.

Wenn eine Kopie eines Repeats innerhalb eines Gens lokalisiert ist, kann die Rekombination zwischen entgegengesetzt orientierten Repeats zu einer Inversion des zwischen den Repeats liegenden Segments führen und so das Gen unterbrechen. Beispielsweise wird die Hämophilie A bei ungefähr $45 \%$ der schwer betroffenen Patienten durch eine Inversion von einem Teil des Faktor VIII-Gens verursacht (Lakich et al., 1993; Naylor et al., 1993; Tuddenham et al., 1994, Antonarakis et al., 1995). Diese Veränderung wird durch Rekombinationen zwischen Repeats, die innerhalb und 5' zum Gen liegen, hervorgerufen. Die Repeatsequenz ist in diesem Fall ein intronloses Gen (Gen A), welches im Intron 22 des Faktor VIII-Gens lokalisiert ist. Zwei weitere Kopien dieses Gens sind in entgegengesetzter Orientierung ungefähr $500 \mathrm{~kb}$ upstream lokalisiert (Freije und Schlessinger, 1992). Eine Rekombination zwischen der Kopie im Intron und einer der upstream gelegenen Kopien führt zu einer Inversion der Exons 1 bis 22 des Faktor VIII-Gens. Interessanterweise entsteht eine Rekombination häufiger mit der weiter proximal lokalisierten Kopie, was auf ein spezifisches Rekombinationsereignis hindeutet (Naylor et al., 1995). Auch beim Hunter-Syndrom (MPS II; OMIM-Nr. 309900) wird das verantwortliche Gen Iduronat-2-Sulfatase (IDS) bei ungefähr $13 \%$ der Patienten aufgrund von Rekombinationen mit entgegengesetzt orientierten IDS-ähnlichen Sequenzen durch eine Inversion unterbrochen (Bondeson et al., 1995).

Anhand der gezeigten Beispiele sollte verdeutlicht werden, daß auch Sequenzen in der Umgebung eines Krankheitslocus eine große Rolle bei der Entstehung von Mutationen spielen können. Da auch der in dieser Arbeit charakterisierte, in Zusammenhang mit dem RSS stehende Translokationsbruchpunkt der Region 17q23-q24 von low-copy duplizierten Sequenzen umgeben wird, könnte es sich auch beim RSS um eine genomische Erkrankung handeln. Demnach wären für die Entstehung der Krankheit vorwiegend Deletionen, Duplikationen oder Inversionen verantwortlich, die aufgrund eines ungleichen Crossing-overs zwischen den duplizierten low-copy Repeats entstehen könnten. Da sich im Verlauf der Kartierung der Region 17q23-q24 herausstellte, daß der Translokationsbruchpunkt des Probanden AS vermutlich von zwei entgegengesetzt zueinander orientierten low-copy Repeats flankiert wird, könnte in dieser Region vor allem das Auftreten von Inversionen begünstigt sein. 


\subsection{Restriktionskartierung der Region 17q23-q24}

Für die Restriktionskartierung von großen, in YACs klonierten DNA-Bereichen bieten sich selten schneidende Endonukleasen an. Die Auftrennung der großen Restriktionsfragmente kann anschließend mit Hilfe der PFGE erfolgen. Auf diese Weise wurde beispielsweise eine low range Restriktionskarte der Xp22-Region des menschlichen X-Chromosoms erstellt (Vetrie et al., 1993).

Die physikalische Restriktionskartierung der Bruchpunktregion des Probanden AS auf Chromosom 17 erfolgte anhand der YACs 845C6, 931B10, 901G9, 855A4, 983D12 und 875C4. Der ebenfalls den Bruchpunkt überspannende YAC $871 \mathrm{C} 4$ wurde nicht für die Restriktionskartierung eingesetzt, da verschiedene Präparationen dieses YACs nach PFGEAnalyse multiple Banden zeigten und dieser YAC somit als instabil anzusehen ist.

Die für die Restriktionskartierung eingesetzten YACs wurden zunächst auf ihren Gehalt an Schnittstellen für die selten schneidenden Enzyme BssHII, XhoI, MluI und NotI analysiert. Dabei zeigte sich, daß die DNA dieser YACs mit den Enzymen BssHII, XhoI und MluI relativ häufig geschnitten wurde. Die mit diesen Enzymen erhaltenen Fragmente hatten eine durchschnittliche Größe von etwa 50 kb. Das Auftreten von vielen relativ kleinen Restriktionsfragmenten erschwert jedoch die Grobkartierung einer Region. Mit dem Enzym NotI wurden dagegen größere Fragmente erhalten, daher wurde dieses Enzym für die Restriktionskartierung eingesetzt. Die erstellte Restriktionskarte ist in Abb. 8 dargestellt. Wie aus dieser Abbildung ersichtlich ist, weisen alle YACs, die in diese Karte integriert wurden, Umordnungen auf.

Es wurde vermutet, daß das Insert des YACs 845C6 eine Deletion aufweist, da verschiedene Präparationen dieses YACs nach PCR-Analyse mit der STS 81 T7 kein Produkt zeigten. Daher wurden Sonden, die auf dem gleichen NotI-Fragment wie die STS 81 T7 lokalisiert sind (Cosmid CF20b und KPNA2-E1) auf NotI-gespaltene unklonierte genomische DNA hybridisiert, wobei ein $230 \mathrm{~kb}$ großes Fragment detektiert wurde. Da nach Hybridisierung mit diesen Sonden ein nur $130 \mathrm{~kb}$ großes Fragment des YACs 845C6 detektiert wurde, ist davon auszugehen, daß YAC 845C6 eine etwa $100 \mathrm{~kb}$ große Deletion aufweist. Dabei scheint es sich um eine stabile Deletion zu handeln, da diese wie oben erwähnt über eine STS-Analyse von verschiedenen Präparationen des YACs feststellbar war.

Eine stabile Deletion scheint auch der YAC 855A4 aufzuweisen, wie durch die STS-contentKartierung feststellbar war.

YAC 931B10 zeigte dagegen vermutlich eine de novo Deletion, die während der Kulturzeit dieses YACs aufgetreten ist. Dies ist daran zu erkennen, daß dieser YAC in der Spur mit der ungespaltenen YAC-DNA mehrere Banden aufwies, während andere Präparationen dieses YACs nur eine Bande zeigten. Eine Mischung von verschiedenen Kulturen dieses YACs kann nicht vorgelegen haben, da dieser YAC ausgehend von einer Einzelkolonie angeimpft wurde.

YAC 901G9 wies zum einen Deletionen auf, die bereits aufgrund der STS-Analyse zu erkennen waren. Zum andern beinhaltet dieser YAC vermutlich zwei Fragmente, die in der genomischen DNA nicht benachbart sind. Dies deutet darauf hin, daß zwei Fragmente aus der Bruchpunktregion nach Coligation in einen YAC-Vektor eingebaut wurden.

Bei YAC 875C4 handelt es sich um einen chimärischen Klon, der ein genomisches Insert enthält, welches sich aus einem Chromosom 17- und einem Chromosom 4-Anteil zusammensetzt. Daher wurden bei der Generierung dieses YACs vermutlich 2 genomische Fragmente, die in 
der genomischen DNA nicht benachbart sind, in einen YAC-Vektor coligiert.

YAC 983D12 wies eine Deletion von etwa $1 \mathrm{Mb}$ auf, so daß eine Einordnung dieses YACs in die Restriktionskarte nicht erfolgen konnte. Daß dieser YAC instabil ist, wird bestätigt durch die Angaben von Chumakov et al. (1995). Die Autoren stellten fest, daß dieser YAC nach PFGE-Analyse multiple Banden aufwies.

Die Tatsache, daß alle analysierten YACs der Bruchpunktregion des Probanden AS Umordnungen aufweisen, zeigt, daß diese Region in YACs instabil ist. Zudem wurden bei einigen Präparationen der YACs 871C4, 931B10 und 845C6 multiple Banden festgestellt, was in diesen Fällen auf de novo Deletionen während der Kulturzeit der YACs hindeutet. Chumakov et al. (1995) stellten über die Größenbestimmung der YAC-Klone 883B2 und 680F6 auch für diese Klone multiple Banden fest. Zudem konnte über FISH-Analysen, die im Rahmen einer vorangegangenen Arbeit bzw. für diese Arbeit durchgeführt wurden, festgestellt werden, daß die YACs 765F4, 929D11, 955H4, 680F8 und 742A4 ein chimärisches Insert aufweisen (s. 3.1.2 und Tab. 1). Der YAC 804H7 könnte ebenfalls chimärisch sein. Dieser Klon enthält jedoch zwei YACs, so daß nicht entschieden werden kann, ob der YAC, welcher einen Abschnitt des Chromosoms 17 beinhaltet chimärisch ist. Insgesamt liegen somit nur für 3 YACs (963C7, 853F8 und 938F7) aus dem Contig der Bruchpunktregion des Probanden AS keine Hinweise vor, die auf eine Umordnung im Insert schließen lassen. Somit beträgt der Anteil umgebauter YACs in der analysierten Region etwa $82 \%$.

Die häufigste Entstehungsweise von instabilen Klonen dürfte die Folge von instabilen Sequenzabschnitten des menschlichen Genoms sein, die während des Hefewachstums verloren gehen können und in stabile Deletionen übergehen (Vilageliu und Tyler-Smith, 1992). Die einfachste Art, instabile YAC-Klone zu erkennen, ist das Auftreten von mehreren Banden nach einer PFGE-Analyse, wenn für den jeweiligen Klon nur ein YAC erwartet wird.

Instabile YAC-Klone wurden bereits mehrfach beschrieben. Wada et al. (1990) fanden bei einem von 127 YACs multiple Banden, Abidi et al. (1990) stellten multiple Banden bei 2 von 467 YACs fest und Bellis et al. (1991) fanden bei 2 von 140 analysierten YACs multiple Banden. Chumakov et al. (1995) fanden multiple Banden bei $12 \%$ der YACs aus der Mark IIYAC-Bibliothek und bei 6,8\% der YACs aus der Mega-YAC-Bibliothek. Chevillard et al. (1993) stellten bei der Kartierung von Bruchpunkten, die im Zusammenhang mit dem SmithMagenis-Syndrom auftraten, fest, daß sich alle YACs, die ein bestimmtes genomisches Segment beinhalten, als instabil erwiesen. Diese YACs wiesen mehrere deletierte Formen auf.

Bei der im Rahmen dieser Arbeit kartierten Region handelt es sich um die Bruchpunktregion eines Translokationsprobanden. Daher könnte das Auftreten der Translokation mit der Instabilität der Region in Zusammenhang stehen.

Zudem deuten die Eigenschaften der kartierten Region darauf hin, daß sich der Bruchpunkt des Probanden AS in einer G-negativen (hellen) Bande befindet. Diese Banden zeichnen sich durch einen hohen GC- und damit Gengehalt, wenig LINE- und viele Alu-Sequenzen aus (Korenberg und Rykowski, 1988; Gardiner, 1995). Daß diese Region einen hohen GC-Gehalt aufweist, kann vermutet werden, da diese Region häufig von den seltenschneidenden Enzymen BssHII, XhoI und MluI mit GC-reicher Erkennungssequenz gespalten wurde. Ein hoher Gengehalt kann angenommen werden, da 34 ESTs in der Region zwischen den Markern D17S807 und D17S795 kartiert wurden (Deloukas et al., 1998). Zudem zeigten die im Verlauf der Gene- 
rierung von neuen STS-Stellen erhaltenen Sequenzen häufig Homologien zu Alu-Sequenzen, aber es wurden keine Homologien zu LINE-Sequenzen festgestellt. Der Bruchpunkt des Probanden AS wurde der Region 17q23.3-q24 zugeordnet. Da der Bruchpunkt aus den oben genannten Gründen wahrscheinlich in einer G-negativen Bande lokalisiert ist, kann angenommen werden, daß sich dieser in der Bande 17q23.3 befindet.

Die erstellte NotI-Restriktionskarte diente als Grundlage für die Kartierung von Sonden dieser Region. Zu ESTs korrespondierende PCR-Produkte wurden über eine Hybridisierung definierten Restriktionsfragmenten der YACs zugeordnet. Zudem wurden 3 Cosmide (2G4, 1B11 und $\mathrm{CF} 20 \mathrm{~b}$ ) in die Karte eingeordnet, indem die Inserts dieser Cosmide über Hybridisierungen bestimmten Restriktionsfragmenten zugeordnet wurden. Auf diese Weise wurde folgende Anordnung dieser Loci erhalten:

cen - (2G4, stSG3721) - 1B11 - KPNA2-E1 - CF20b -WI-9461 - (WI-9571) - tel

Diese Anordnung stimmt mit der Anordnung dieser Loci in den verschiedenen Contigs der Region 17q23-q24, die im Rahmen dieser Arbeit generiert wurden, überein.

Die NotI-Schnittstelle des Cosmids 1B11 wurde auch in das Cosmid-Contig des YACs 875C4 (s. Abb. 13) integriert. Diesem Contig zufolge ist stSG3721 etwa $100 \mathrm{~kb}$ proximal von der NotI-Schnittstelle des Cosmids 1B11 entfernt lokalisiert. Nach der NotI-Restriktionskarte befindet sich die EST (WI-9571) etwa $780 \mathrm{~kb}$ distal von der NotI-Schnittstelle des Cosmids 1B11. Demnach beträgt der Abstand zwischen den ESTs stSG3721 und (WI-9571) etwa 880 $\mathrm{kb}$.

\subsection{Generierung und Charakterisierung von Cosmid-Klonen}

YACs eignen sich aufgrund ihrer hohen Klonierungskapazität besonders gut zur Abdeckung und Überbrückung größerer genomischer Regionen. Die Konstruktion eines YAC-Contigs für die Region des Translokationsbruchpunktes in 17q23-q24 war daher ein wichtiger Schritt, um ein in dieser Region vermutetes RSS-Kandidatengen auf einen bestimmten Bereich einzugrenzen. Um die Suche nach RSS-Kandidatengenen zu erleichtern, sollte die Region des Translokationsbruchpunktes zunächst weiter eingegrenzt werden. Dazu sollten kleinere genomische Klone, wie z.B. Cosmide, für die Region des Translokationsbruchpunktes isoliert werden. Von Färber (1996) war eine Chromosom 17-spezifische Cosmidbibliothek (REFERENCE LiBRARY DATABASE) mit Sonden der Bruchpunktregion (YAC 875C4, WI-9461 und WI-9571) durchgemustert worden. Auf diese Weise konnten zwei Cosmide (CF20b und CF58) für die Bruchpunktregion isoliert werden, die jedoch den Translokationsbruchpunkt nicht überspannen (Färber, 1996).

Eine andere Möglichkeit Cosmide für die Bruchpunktregion zu isolieren, bestand darin, einen YAC der Bruchpunktregion in Cosmide umzuklonieren (Bellanné-Chantelot et al., 1991). Ein Nachteil der Subklonierung ist darin zu sehen, daß mögliche chimäre Anteile, Deletionen oder Umlagerungen der YACs auf die Cosmid-Ebene übertragen werden. Andererseits stehen nach der Subklonierung eines YACs schnell viele Cosmide zur Verfügung, die den Bereich des 
YACs abdecken, während beim Durchmustern von Cosmid-Bibliotheken oft sehr arbeitsintensive Cosmid-walking-Schritte notwendig sind.

Die Subklonierung von YACs kann erfolgen, indem die gesamte DNA des Hefe-Klons verwendet wird. Hierbei entstehen Cosmide mit Hefe- als auch mit humanen Inserts. Die humanen Klone können anschließend mit radioaktiv markierten spezifischen humanen Sonden, wie z.B. Cot-1-DNA identifiziert und isoliert werden. Der zu subklonierende YAC kann jedoch auch, wie im Rahmen der vorliegenden Arbeit erfolgt, vor der Subklonierung durch eine präparative PFGE von den natürlichen Hefe-Chromosomen abgetrennt werden. Ein Vorteil dieser Methode ist darin zu sehen, daß größere Umordnungen, die während der Kulturzeit des YAC-Klons entstehen können, im Pulsfeldgel direkt sichtbar werden, sofern sie die Größe des YACs verändern. Zudem wird die Identifizierung der humanen Klone erleichtert, da deren Anteil an den Gesamtklonen deutlich vergrößert wird. Auf eine Hybridisierung mit spezifischen humanen Sonden sollte dennoch nicht verzichtet werden, da es aufgrund eines gewissen DNA-Hintergrunds unwahrscheinlich ist, daß nur der spezifische YAC aus dem Pulsfeldgel isoliert wird.

Um im Rahmen dieser Arbeit Cosmide für die engere Bruchpunktregion des Probanden AS isolieren zu können, sollte ein möglichst kleiner, den Bruchpunkt des Probanden überspannender YAC in Cosmide subkloniert werden. Daher wurde für die Subklonierung YAC 875C4 gewählt, denn bei diesem $370 \mathrm{~kb}$ großen YAC handelt es sich um den kleinsten YAC, der nach einer FISH an Metaphasen des Probanden AS Signale an beiden derivativen Chromosomen gezeigt hatte. Dies ließ darauf schließen, daß dieser YAC den Bruchpunkt des Probanden überspannt. Zur Konstruktion der Cosmid-Bibliothek wurde die aus einem präparativen Pulsfeldgel isolierte DNA des YACs verwendet. Aus 348 Klonen wurden durch Hybridisierung mit einer radioaktiv markierten Cot-1-Sonde 218 humane Cosmide identifiziert. Dies entspricht einem Anteil der humanen Klone von $63 \%$.

Um ein Cosmid-Contig für den YAC 875C4 erstellen zu können, wurden verschiedene Strategien parallel verfolgt.

Mit den vektorspezifischen Primern T3 und T7 ließen sich über lineare PCR spezifische radioaktiv markierte Endproben einzelner Cosmide gewinnen, die zur Identifizierung überlappender Cosmide eingesetzt wurden. Dazu wurden die radioaktiv markierten Proben auf Cosmidfilter hybridisiert, wobei unspezifische Hybridisierungen der Proben durch eine Präassoziation mit humaner Plazenta-DNA unterdrückt wurden. Für weitere Hybridisierungen wurden jeweils Cosmid-Endproben von solchen Cosmiden eingesetzt, die durch vorangegangene Hybridisierungen nicht detektiert worden waren. Auf diese Weise ließen sich ausgehend von vielen Cosmid-Enden viele kleine Contigs aufbauen, die im weiteren Verlauf der Kartierung miteinander verknüpft werden konnten.

Um die genaue Anordnung von Cosmiden in einem Contig festlegen zu können, wurde eine EcoRI-Restriktionskarte der Cosmide erstellt. Dazu wurden Southern-Blots von EcoRI-gespaltenen Cosmiden mit radioaktiv markierter DNA einzelner Cosmide hybridisiert. Das erstellte Cosmid-Contig (s. Abb. 13) deckt einen genomischen Bereich von etwa $306 \mathrm{~kb}$ ab und repräsentiert somit nicht den gesamten YAC (370 kb). Der für die Präparation der Cosmide aus einem Pulsfeldgel isolierte YAC wies jedoch die ursprüngliche Größe von $370 \mathrm{~kb}$ auf. Eine Deletion, die zu einem 306 kb großen YAC führte, hätte jedoch im Pulsfeldgel erkennbar sein müssen. Eine mögliche Erklärung für die nicht repräsentierte YAC-Sequenz ist die, daß ein 
Teil des YAC-Klons nicht in Cosmide subkloniert wurde.

Um zu überprüfen, ob die Enden des YACs 875C4 im Cosmid-Contig enthalten sind, sollten Cosmide, die das TRP- oder das URA-Ende des YACs beinhalten, identifiziert werden. Dazu wurden die Cosmidfilter sowohl mit radioaktiv markierten TRP- und URA-Primern als auch mit YAC-Endproben, die über Alu-PCR hergestellt wurden, hybridisiert. Auf diese Weise konnten 10 Cosmide für das TRP-Ende des YACs 875C4 detektiert werden, während kein Cosmid für das URA-Ende identifiziert werden konnte. Das URA-Ende ist somit vermutlich nicht in der Cosmid-Bibliothek enthalten. Da jedoch nur ein Teil der hergestellten Cosmide ausplattiert wurde, wäre es theoretisch denkbar, daß sich unter den nicht angezogenen Cosmiden auch solche für das URA-Ende befinden. Demnach wäre das URA-Ende des YACs in der Bibliothek jedoch deutlich unterrepräsentiert. Soeda et al. (1995) machten bei der Erstellung von Cosmid-Contigs für das Chromosom 21 die Beobachtung, daß nicht nur instabile genomische Bereiche und besondere Sequenzabschnitte Einfluß auf die Repräsentanz einzelner genomischer Regionen in einer Cosmid-Bank haben, sondern daß auch die experimentellen Bedingungen während der Konstruktion der Bibliothek eine Rolle spielen.

Da es sich bei dem für die Subklonierung eingesetzten YAC 875C4 um einen chimärischen YAC handelt (Chromosom 17 und 4), wurden aus diesem YAC stammende Cosmide zur Bestimmung der chromosomalen Lokalisierung zunächst über eine FISH auf Kontrollmetaphasen hybridisiert. Für diese Analysen wurden 13 Cosmide aus verschiedenen Bereichen des Cosmid-Contigs eingesetzt. Von diesen hybridisierten 10 Cosmide in der Region 17q23-q24 und zwei Cosmide auf dem langen Arm von Chromosom 4. Ein Cosmid (SD 28) hybridisierte sowohl in der Region 17q23-q24 als auch auf Chromosom 4q. Dieses Cosmid beinhaltet somit den Übergang zwischen den verschiedenen chromosomalen Bereichen des chimärischen YACs 875C4. Da die über FISH getesteten Klone im Cosmid-Contig enthalten sind, läßt sich somit berechnen, wie groß der Chromosom 17- und wie groß der Chromosom 4-Anteil des CosmidContigs ist. Da sich der Übergang vom Chromosom 17-Anteil zum Chromosom 4-Anteil in Cosmid SD28 befindet und zudem das Cosmid 1B11 proximal und das Cosmid 2D8 distal zu diesem Bruchpunkt kartieren, ist der in Cosmid klonierte YAC-Anteil des Chromosoms 17 zwischen $227 \mathrm{~kb}$ und $240 \mathrm{~kb}$ groß, während der klonierte Anteil des Chromosoms 4 eine Größe zwischen $64 \mathrm{~kb}$ und $77 \mathrm{~kb}$ aufweist.

Um die Cosmide des erstellten Contigs in bezug zum Translokationsbruchpunkt des Probanden AS mit einer 1;17 Translokation positionieren zu können, wurden die auf Chromosom 17 lokalisierten Cosmide über FISH-Analysen auf Metaphasen des Probanden hybridisiert. Dabei zeigten sämtliche für Chromosom 17 spezifische Cosmide ausschließlich ein Signal am derivativen Chromosom 17 und kein Signal am derivativen Chromosom 1. Diese Cosmide wurden somit proximal vom Translokationsbruchpunkt des Probanden kartiert. Da über FISH-Analyse Cosmide aus verschiedenen Bereichen des Contigs getestet wurden, ist anzunehmen, daß sämtliche Cosmide, die durch Subklonierung des YACs 875C4 erhalten wurden, proximal vom Translokationsbruchpunkt lokalisiert sind. Der für die Subklonierung verwendete YAC 875C4 hatte nach FISH-Analyse an Metaphasen des Probanden jedoch Signale auf beiden derivativen Chromosomen gezeigt und war daher als ein den Bruchpunkt überspannender YAC identifiziert worden. Bei Subklonierung dieses YACs hätten demnach auch Cosmide erhalten werden müssen, die den Bruchpunkt des Probanden überspannen. Da dies nicht der Fall war, sollte 
überprüft werden, ob der subklonierte YAC möglicherweise die Region des Translokationsbruchpunktes aufgrund einer Deletion verloren hatte. Dazu wurde eine FISH mit DNA aus verschiedenen Präparationen des YACs 875C4 durchgeführt. Über diese FISH-Analysen konnte bestätigt werden, daß YAC 875C4 Signale auf dem derivativen Chromosom 17 und dem derivativen Chromosom 1 zeigt. Die Signale auf dem der(1) waren jedoch deutlich schwächer als die auf dem der(17). Zudem wurde eine FISH mit der aus einem Pulsfeldgel isolierten DNA des YACs 875C4 durchgeführt, wobei mit dieser DNA nur FISH-Signale auf dem der(17) erhalten wurden. Dies könnte dadurch erklärt werden, daß in der für die Subklonierung eingesetzten DNA eine Deletion der Bruchpunktregion des Translokationsprobanden AS vorliegt. Andererseits zeigte der aus einem Pulsfeldgel isolierte YAC die für diesen YAC erwartete Größe von $370 \mathrm{~kb}$, was gegen eine größere Deletion innerhalb dieses YACs spricht. Über die spätere Einordnung von PAC-Klonen in ein Contig der Bruchpunktregion des Probanden AS wurden weitere Hinweise dafür gefunden, daß der YAC 875C4 die Bruchpunktregion vermutlich nicht über eine Deletion verloren haben kann. Beispielsweise wurde der 61,4 kb große PAC-Klon 112L5 distal von YAC 875C4 in das Contig eingeordnet (s. Abb. 22). Dieser PAC liegt jedoch proximal zum Translokationsbruchpunkt des Probanden AS. Hätte YAC 875C4 die Region des Bruchpunktes aufgrund einer Deletion verloren, so müßte die Deletion mindestens den von PAC 112L5 abgedeckten genomischen Bereich umfassen und somit mindestens $61,4 \mathrm{~kb}$ groß sein. Dies ist wie oben erwähnt unwahrscheinlich, denn eine Deletion dieser Größe hätte im Pulsfeldgel erkennbar sein müssen.

Eine andere Erklärungsmöglichkeit dafür, daß kein über die Subklonierung erhaltenes Cosmid die Bruchpunktregion des Probanden AS beinhaltet, ist darin zu sehen, daß das Signal des YACs $875 \mathrm{C} 4$ auf dem der(1) aufgrund von unspezifischer Hybridisierung zustande kam. Demnach würde es sich bei dem YAC 875C4 nicht um einen den Bruchpunkt überspannenden YAC handeln, sondern um einen YAC der proximal vom Bruchpunkt des Probanden AS lokalisiert ist. Für diese Annahme spricht, daß das FISH-Signal des YACs 875C4 auf dem der(1) deutlich schwächer war als auf dem der(17). Zudem zeigte sich, daß der Locus 2A3T3, der ausgehend von dem aus YAC 875C4 stammenden Cosmid 2A3 generiert wurde, im Contig der Bruchpunktregion (s. Abb. 22) dupliziert vorliegt. Der Marker 2A3 konnte sowohl auf den distal als auch auf den proximal zu dem Bruchpunkt lokalisierten Klonen nachgewiesen werden. Außerdem konnten über Sequenzvergleiche mit diesem Locus Homologien zu zwei bereits sequenzierten BACs (557B23 und 147L13) festgestellt werden. Zu dem BAC 557B23 wurde für die Sequenz dieser STS eine Sequenzhomologie von $99 \%$ festgestellt. Da dieser BAC auch hohe Homologien (98-99 \%) zu den Loci 120T7, stSG3721, stSG2549 und 188SP6 aufweist, ist anzunehmen, daß es sich bei dem BAC-Klon 557B23 um einen proximal vom Bruchpunkt des Probanden AS lokalisierten Klon handelt. Der BAC-Klon 147L13 zeigte dagegen neben Homologien zu dem Locus 2A3T3 auch Homologie zu den distal vom Bruchpunkt lokalisierten Loci 241T7, CF58T7, 7T7 und 293SP6. Somit handelt es sich bei 147L13 um einen distal vom Bruchpunkt des Probanden AS lokalisierten Klon.

Der BAC-Klon 557B23 weist für die Basenpaare 82654 bis 83235 eine $95 \%$ ige Übereinstimmung mit den Basenpaaren 114964 bis 115541 des BACs hRPK.147L13 auf. Zudem weisen die Basenpaare 83249 bis 84177 des BACs hRPK.557B23 eine Identität von $87 \%$ mit den Basenpaaren 115544 bis 116448 des BACs hRPK.147L13 auf. Insgesamt weisen diese 
BAC-Klone somit homologe Sequenzbereiche mit einer Größe von etwa 1,5 kb auf. Falls der YAC 875C4 proximal vom Bruchpunkt des Probanden AS lokalisiert ist, hat diese Sequenzhomologie möglicherweise ausgereicht, um mit dem YAC 875C4 auch ein distal vom Bruchpunkt lokalisiertes Signal zu erhalten.

\subsection{Isolierung und Charakterisierung von PAC-Klonen der Region 17q23-q24}

Da über die Subklonierung des YACs 875C4 keine Cosmide erhalten wurden, die den Translokationsbruchpunkt des Probanden AS überspannen, sollten über eine alternative Strategie PACKlone für die Bruchpunktregion isoliert werden. PAC-Klone sind mit einer durchschnittlichen Länge von 130-150 kb gut für eine detaillierte Kartierung von genomischen Regionen geeignet. Zudem sind diese Klone genetisch stabil und weisen nur selten Umordnungen auf (Ioannou et al., 1994).

Die verwendete PAC-Bibliothek (RPCI-1) wurde von Pieter de Jong und Kollegen konstruiert. Sie enthält 115200 Klone mit einer durchschnittlichen Insert-Größe von 110 kb und deckt das humane Genom 3 x ab (UK HGMP Resource Centre, http://bacpac.med.buffalo.edu). Für die Identifizierung von spezifischen Klonen aus dieser Bibliothek können entweder gepoolte Klone für PCR-Analysen eingesetzt werden oder es können Sonden auf Filter mit dieser Bibliothek hybridisiert werden. Um Klone für die Bruchpunktregion des Probanden AS zu isolieren, wurden beide Strategien parallel angewendet.

Für die Isolierung von PAC-Klonen mittels der PCR wurden STS- bzw. EST-Marker der engeren Bruchpunktregion benötigt. Bei den Markern, die zu Beginn des PAC-Screenings am nächsten zum Bruchpunkt des Probanden AS kartiert worden waren, handelte es sich um die ESTs stSG3721, stSG2549, WI-9461 und WI-9571 sowie um den STS-Marker D17S1870. Aufgrund der erstellten NotI-Restriktionskarte (s. Abb. 8) und des Cosmid-Contigs (s. Abb. 13) wird der genomische Bereich, der alle vier ESTs umfaßt, auf etwa $940 \mathrm{~kb}$ geschätzt. D17S1870 wurde nicht in diese Karte integriert, wegen des erstellten YAC-Contigs (s. Abb. 5) ist jedoch von einer Lokalisierung proximal zu allen vier ESTs auszugehen.

Um die PAC-Bibiothek mit möglichst vielen Markern durchmustern zu können, sollten zunächst weitere Marker für die engere Bruchpunktregion generiert werden. Da zunächst nicht bekannt war, daß YAC 875C4 vermutlich proximal vom Translokationsbruchpunkt kartiert, wurde dieser Klon, wie auch aus diesem hergestellte Cosmide, zur Erzeugung von STS-Stellen herangezogen. Zudem standen 2 Cosmide aus einer Chromosom 17- spezifischen Cosmidbibliothek zur Verfügung, die auf einigen den Translokationsbruchpunkt des Probanden AS überspannenden YACs kartiert worden waren (Färber, 1996). Diese Cosmide konnten daher ebenfalls genutzt werden, um weitere Marker für die Bruchpunktregion zu generieren.

In der Literatur wurden verschiedene Techniken zur Isolierung von Klon-Enden vorgestellt. Ochman et al. (1988) beschrieben in diesem Zusammenhang die inverse PCR, Riley et al. (1990) die Blasen-Linker-PCR (Vektoretten-PCR) und Shero et al. (1991) die Plasmid-rescueMethode. In dieser Arbeit wurde zur Darstellung von Klon-Enden die von Nelson et al. (1989) beschriebene Alu-Vektor-PCR angewendet, bei der spezifische Vektor-Primer in Kombination mit verschiedenen $A l u$-Primern eingesetzt werden.

Über die Alu-Vektor-PCR ließen sich beide Enden des YACs 875C4 sowie ein bzw. zwei 
Enden der aus diesem YAC stammenden Cosmide 1B11, 2H8 und 2A3 darstellen. Anhand der Sequenzdaten, die über Sequenzierung dieser Endfragmente generiert wurden, konnten STSStellen für beide Enden des YACs 875C4 und für das T3-Ende des Cosmids 2A3 generiert werden. Die für die übrigen Klone erhaltenen randständigen Sequenzen zeigten Homologien zu Alu-Sequenzen und konnten somit nicht zur Generierung von STSs eingesetzt werden. Die T3Sequenzierung eines Endfragmentes des Cosmids 2A3 zeigte zudem in 90 Basenpaaren eine 92 \%ige Identität mit dem in der Region 9p23 lokalisierten tyrosinase-related protein 1 (TYRP1), so daß möglicherweise ein zu TYRP1 ähnliches Gen innerhalb der Bruchpunktregion lokalisiert ist. TYRP1 ist am Melanozyten-Stoffwechsel beteiligt. Mutationen dieses Gens wurden in Patienten mit bestimmten Formen von Albinismus identifiziert (Boissy et al., 1996; Manga et al., 1997).

Über die Sequenzierung von Klon-Endfragmenten konnten ebenso STS-Stellen für die T7Enden der von Färber (1996) isolierten Cosmide CF58 und CF20b isoliert werden. Ein Sequenzvergleich mit der über CL3-Sequenzierung eines T7/CL3-Endfragmentes von CF20b erhaltenen Sequenz zeigte zudem in 228 bp eine 100 \%ige Identität zu Karyopherin $\alpha 2$ (KPNA2). Auf diese Weise wurde ein erster Hinweis dafür gefunden, daß KPNA2 in der Bruchpunktregion des Probanden AS auf Chromosom 17 lokalisiert ist. Auf die Rolle von KPNA2 als Kandidatengen für das RSS wird im folgenden noch eingegangen.

Die Durchmusterung der PAC-Bibliothek wurde mit den Loci TRP875, stSG3721, stSG2549, 2A3T3, D17S1870, WI-9461, WI-9571 und CF58T7 begonnen. Anhand der mit diesen Loci isolierten PAC-Klone wurden schließlich weitere endständige Marker generiert. Diese wurden im Rahmen eines sogenannten PAC-walkings z.T. ebenfalls für das Durchmustern der PACBibiothek eingesetzt. Insgesamt wurde die PAC-Bibiothek über PCR-Analysen mit 20 Markern durchsucht. Dabei wurden 29 PACs als potentiell positiv für einzelne Loci identifiziert. Für die Loci WI-9461 und 29377 wurden jedoch sehr viele erste und zweite Pools positiv getestet, was darauf zurückzuführen ist, daß diese Loci im humanen Genom mindestens zweifach vorkommen. Daher wurde für einige dieser Pools auf das arbeitsintensive Herstellen der 24erPools und somit auf die Identifizierung von einigen potentiell positiven Klonen verzichtet.

Dagegen wurden mit anderen Markern keine positiven PAC-Klone identifiziert, obwohl dies erwartet wurde. Beispielsweise wurde mit der STS 188SP6 kein positiver PAC identifiziert. Diese STS wurde jedoch anhand eines Endfragmentes des PACs 188D1 generiert, so daß wenigstens die Identifizierung dieses PACs mit der STS 188SP6 erwartet wurde. Daß PAC 188D1 dennoch nicht positiv getestet wurde, dürfte an der Qualität der PAC-Bibliothek liegen. In den 1. Pools ist die Konzentration an einzelnen Klonen relativ gering, so daß möglicherweise in einigen Fällen keine PCR-Amplifikation stattfindet. Dafür spricht auch, daß z.B. mit der STS CF20bT7 zunächst kein 1. Pool positiv getestet wurde. Daher wurden neue 1. Pools vom UK HGMP Resource Centre bezogen und schließlich konnte ein positiver Pool identifiziert werden. Vom UK HGMP Resource Centre wird angegeben, daß die Qualität der Pools nach 7-8 maligem Auftauen rapide abnimmt. Daher wurden die Pools stets aliquotiert und die Aliquots nur 3 mal für nachfolgende PCR-Analysen aufgetaut. Möglicherweise war die Qualität einzelner Pools jedoch schon nach zwei- oder dreimaligem Auftauen zu schlecht, um mit einzelnen Markern noch positive Signale erhalten zu können. Insgesamt wurden für sechs der zum Durchmustern eingesetzten Loci (stSG2549, 188SP6, D17S1870, K5-F/R, KPNA2-E2 
und E1-F/R) keine positiven PAC-Klone identifiziert. Für diese Marker hätte jedoch jeweils mindestens ein positiver Klon identifiziert werden müssen, da diese Loci über STS-contentKartierung jeweils auf mindestens einem Klon dieser Bibliothek nachgewiesen wurden.

Von den als potentiell positiv identifizierten 29 PAC-Klonen wurden 24 präparierte Einzelklone über weitere PCR-Analysen auf die Anwesenheit der jeweiligen Suchloci überprüft. Auf diese Weise konnten 20 Klone für mindestens einen der eingesetzten Suchloci positiv verifiziert werden.

Über eine vergleichende Restriktionsanalyse mit EcoRI sollte überprüft werden, ob sich unter den identifizierten PACs auch solche mit identischem Insert befinden. Dies war jedoch nicht der Fall, alle identifizierten PACs wiesen ein individuelles Bandenmuster auf. Es ergaben sich jedoch in einigen Fällen Hinweise auf Überlappungen zwischen einzelnen PAC-Klonen.

Zudem wurde über den Vergleich des Spaltmusters von jeweils mindestens 2 verschiedenen DNA-Präparationen des gleichen Klons überprüft, ob es sich bei den Ursprungsklonen um Einzelkolonien oder Mischklone handelt oder ob Umlagerungen des Originalklons stattgefunden haben. Von den analysierten 27 Klonen zeigten 7 bei Vergleich der Spaltmuster von verschiedenen DNA-Präparationen desselben PACs eine Umlagerung in Form einer zusätzlichen bzw. veränderten Insertbande. Dies entspricht einem Anteil von $26 \%$. Dies deutet darauf hin, daß nicht nur die YACs sondern z.T. auch die PACs der Bruchpunktregion des Probanden AS instabil sind.

Um mit Hilfe der PAC-Klone dennoch zuverlässige Kartierungsdaten zu erhalten, wurden 2 Strategien verfolgt. In der Regel wurden die 2 unterschiedlichen DNA-Präparationen vermutlich instabiler Klone für weitere Analysen parallel eingesetzt. Zudem wurden für einige dieser Klone 2 weitere DNA-Präparationen durchgeführt. Wurden dadurch 3 identische und eine davon abweichende DNA erhalten, wurde angenommen, daß das dreifach vorhandene Restriktionsmuster dem des Originalklons entspricht. Eine Ausnahme bildete der Klon 209I3. Nur eine Präparation dieses Klons zeigte ein für PAC-Klone erwartetes Spaltmuster, während 2 Präparationen ein identisches, jedoch deutlich kürzeres Insert aufwiesen und eine weitere Präparation kein Insert zeigte. In diesem Fall wurde angenommen, daß das Spaltmuster des größten Klons dem Originalklon entspricht. Alle Angaben beziehen sich auf die Klon-Präparationen, von denen angenommen wird, daß sie dem Originalklon entsprechen. In 3 Fällen wurden nur 2 DNA-Präparationen durchgeführt, diese jedoch bei weiteren Analysen parallel eingesetzt. In diesen Fällen ergaben sich jedoch keine Unterschiede zwischen den verschiedenen DNA-Präparationen.

Die Größenbestimmung der PAC-Klone erfolgt mittels der Pulsfeldgelelektrophorese (PFGE). Die ermittelten Größen der PAC-Inserts lagen in einem Größenbereich von 17-155 kb und es ergab sich eine durchschnittliche Insertgröße von $95 \mathrm{~kb}$. Somit waren die PAC-Inserts der analysierten Region im Durchschnitt kleiner als die Inserts der Gesamtbibliothek, deren durchschnittliche Größe mit $110 \mathrm{~kb}$ angegeben wird (UK HGMP Resource Centre).

Um die chromosomale Lokalisierung der PAC-Klone zu ermitteln, erfolgte zunächst eine FISH an Kontrollmetaphasen. Über diese Analysen wurden 20 der 23 untersuchten Klone auf dem qArm von Chromosom 17 lokalisiert. 18 dieser Klone zeigten Signale in der Region 17q23-q24, d.h. in der Bruchpunktregion des Probanden AS. 4 dieser Klone zeigten neben den Signalen in 
der Bruchpunktregion auch Signale in der Bande 17q21. Daher ist anzunehmen, daß in den Regionen 17q23-q24 und 17q21 ähnliche Sequenzen vorkommen, die den entsprechenden Klonen eine Hybridisierung in 2 chromosomalen Regionen ermöglichten. Ein Klon zeigte neben Signalen in der Region 17q23-q24 solche in 17q11. Somit kann angenommen werden, daß auch in der Region 17q11 Sequenzen vorhanden sind, die zu der Region 17q23-q24 homo$\log$ sind.

Ein PAC-Klon (222L3) wurde über die Hybridisierungen auf Kontrollobjektträger als chimärischer Klon erkannt.

Bei den 3 Klonen, die nicht auf Chromosom 17 lokalisiert wurden, handelt es sich ausschließlich um PAC-Klone, die über Hybridisierung auf PAC-Filter identifiziert worden waren. Einer dieser Klone ist für den chimärischen Anteil des für die Hybridisierungen als Sonde eingesetzten YACs $875 \mathrm{C} 4$ spezifisch, während die anderen 2 Klone vermutlich aufgrund unspezifischer Hybridisierungen detektiert worden waren.

Um die auf Chromosom 17 lokalisierten PAC-Klone in bezug zum Translokationsbruchpunkt des Probanden AS zu kartieren, erfolgte eine FISH an Metaphasen des Probanden. Über diese Analysen wurden 12 PACs proximal und 4 PACs distal zum Bruchpunkt des Probanden positioniert.

Da die ESTs WI-9461 und WI-9571 in der Region 17q23-q24 dupliziert vorliegen, wurden Klone, die für diese ESTs positiv sind, entweder proximal oder distal vom Bruchpunkt kartiert. Ein für die EST WI-9571 positiver Klon (83D4) zeigte Signale an beiden derivativen Chromosomen des Probanden AS. Zudem war das Signal dieses Klons auf dem normalen Chromosom 17 als verdoppeltes Signal zu erkennen. ESTs für die Enden dieses Klons wurden jedoch nur auf proximal vom Translokationsbruchpunkt kartierten Klonen nachgewiesen, so daß davon auszugehen ist, daß dieser Klon proximal vom Bruchpunkt des Probanden lokalisiert ist.

Zwei PAC-Klone zeigten Signale an beiden derivativen Chromosomen des Probanden AS. Dies deutete an, daß diese Klone den Bruchpunkt des Probanden AS überspannen. Um ausschließen zu können, daß dieses Ergebnis aufgrund der Sequenzduplikationen erhalten wurde, waren jedoch weitere Analysen erforderlich. Die durchgeführte STS-content-Kartierung zeigte, daß diese Klone mit dem proximal vom Bruchpunkt kartierten PAC 112L5 überlappen. Der PAC 81B9 zeigte zudem Überlappungen mit dem distal vom Bruchpunkt lokalisierten Cosmid CF20b. Daher ist zumindest davon auszugehen, daß der PAC-Klon 81B9 den Bruchpunkt des Probanden AS überspannt. Die Größe des im Gegensatz zu 222L3 nicht chimärischen PACKlons $81 \mathrm{~B} 9$ beträgt $60 \mathrm{~kb}$. Die Region des Bruchpunktes wurde somit durch diesen PAC auf eine Größe von $60 \mathrm{~kb}$ eingeengt.

Im Verlauf dieser Arbeit wurden über die von Nelson et al. (1989) beschriebene Alu-VektorPCR eine Reihe von PAC-Endfragmenten generiert, die anschließend für eine Sequenzierungsreaktion eingesetzt wurden, um anhand der Sequenzdaten STSs herzustellen. Auf diese Weise konnten insgesamt 12 STS-Stellen für spezifische PAC-Endfragmente generiert werden, während sich die Sequenzen von weiteren Endfragmenten aufgrund von Homologien zu repetitiven Sequenzen nicht zur Generierung von STSs eigneten. Von diesen neu generierten STS-Stellen wurden 7 eingesetzt, um aus der PAC-Bibliothek neue PACs für die Bruchpunktregion des Probanden AS zu identifizieren. Zudem wurden alle 12 STS-Stellen für die STS-content-Kartierung von PACs, YACs und Cosmiden eingesetzt, um Überlappungen von 
benachbarten Klonen feststellen zu können. Über die Einordnung dieser STSs in die Contigs der Region 17q23-q24 konnte die Markerdichte der Region im Bereich des Bruchpunktes von Proband AS extrem erhöht werden. Dies verbesserte zudem die Genauigkeit der Kartierung dieser Region.

Für die STS/EST-content-Kartierung wurde neben den in dieser Arbeit generierten Loci auch ein Teil der bereits für die Kartierung von YAC-Klonen eingesetzten STSs und ESTs verwendet. Insgesamt wurden 24 PAC-Klone auf die Anwesenheit von bis zu 33 Markern analysiert. Über diese Analysen bestätigte sich, daß die Loci WI-9461, WI-9571, 7T7, 293SP6, 293T7, 2A3T3, KPNA2-E2 und KPNA2-3' aufgrund von low-copy Repeats beiderseits des Translokationsbruchpunktes sowohl auf distal als auch auf proximal zum Bruchpunkt des Probanden AS kartierten PACs lokalisiert sind.

In das YAC-/PAC-/Cosmid-Contig der Bruchpunktregion konnten 20 PAC-Klone eingeordnet werden (s. Abb. 22). Zwischen den Klonen 30609 und 209I3 und dem Klon 58J13 existiert eine Lücke, die jedoch mit den Cosmiden des YACs $875 \mathrm{C} 4 \mathrm{zu}$ schließen ist. Eine weitere Lücke befindet sich zwischen dem PAC-Klon 81B9 und den PACs 7B12, 15N15 und 15N17. Diese Lücke wird von den STS-Stellen $81 T 7$ und 293T7 begrenzt. Versuche diese Lücke zu schließen, waren bisher nicht erfolgreich. Da über die Durchmusterung der PAC-Bibliothek mit der STS $81 T 7$ nur der 1. Pool F positiv war, ist für diese STS vermutlich nur der PAC 81B9 in der PAC-Bibliothek enthalten. Mit der STS 29377 wurden neben dem Klon 293H13, aus dem diese STS stammt, auch die Klone 12H6, 27F10 und 245A13 identifiziert. Die Klone 12H6 und 27F10 konnten jedoch nicht als positiv verifiziert werden und der Klon 245A13 trägt nicht die Originalsequenz der dupliziert vorliegenden STS 293 T7.

\subsection{Analyse von BAC-Klonen über Sequenzvergleiche}

Das Whitehead Institute verfolgt seit 1996 in Rahmen des Human Genome Project das Ziel das gesamte humane Chromosom $17 \mathrm{zu}$ sequenzieren. Dazu werden BACs und PACs, die für Loci des Chromosoms 17 positiv getestet wurden, sequenziert. Ein Contig, welches große Teile des Chromosoms 17 mit überlappenden BACs und PACs abdeckt, existiert jedoch bisher nicht.

Bis zum Oktober 1999 wurden vom Whitehead Institute bereits 34,27 Mb des humanen Chromosoms 17 sequenziert. In der EMBL/GenBank-Datenbank waren zunehmend auch sequenzierte BACs der Chromosomenregion 17q23-q24 enthalten. Über Sequenzvergleiche mit den im YAC-Contig der Region kartierten STSs und ESTs konnten schließlich 11 sequenzierte BACs in das Gesamtcontig der Region 17q23-q24 integriert werden (s. Abb. 23). Diesen BACKlonen konnten über Sequenzvergleiche 11 bisher nicht im Contig enthaltene ESTs zugeordnet werden (s. Abb. 23). Zudem konnte die Exon-Intron-Struktur einiger Gene der Region ermittelt werden, indem die bekannte cDNA- oder mRNA-Sequenz dieser Gene mit der genomischen Sequenz der entsprechenden BAC-Klone verglichen wurde.

Auf diese Weise konnten 15 Exons der Protein-Kinase C $\alpha$ (PRKCA) lokalisiert werden (s. Abb. 24). Die Exon-Intron-Struktur dieses Gens ist bisher nicht beschrieben. Für die ersten 232 bp der cDNA der PRKCA konnten jedoch bisher keine Exons identifiziert werden. Das erste entdeckte Exon, welches mit $\geq 2$ bezeichnet wurde, befindet sich innerhalb des Klons hCIT.187K10. Die nächsten 5 Exons sind in dem Klon hRPK.115C3 lokalisiert. Die Klone 
hCIT.187K10 und hRPK.115C3 überlappen jedoch nicht, so daß sich zwischen dem ersten und dem zweiten identifizierten Exon eine Lücke unbekannter Größe befindet. Diese ist jedoch aufgrund der Position der Exons innerhalb dieser Klone mindestens 113737 bp groß. Der Klon hRPK.74H8, welcher bisher noch nicht vollständig sequenziert ist und noch eine Lücke aufweist, überlappt etwa $38 \mathrm{~kb}$ mit dem distalen Bereich des Klons hRPK.115C3. In dem Bereich, der beiden Klonen gemeinsam ist, sind 3 Exons der PRKCA lokalisiert. Der BAC hRPK.74H8 beinhaltet daneben 9 weitere Exons der PRKCA. Das am weitesten distal gelegene Exon, welches das 3'-Ende des Gens darstellt, ist zudem in dem Klon hRPK.299G24 enthalten. Somit besteht das Gen der PRKCA aus mindesten 16 Exons, diese decken einen genomischen Bereich von mindestens $357241 \mathrm{bp}$ ab.

In dem BAC-Klon hRPK.346K10 konnten über Vergleiche mit der cDNA des Apolipoproteins $\mathrm{H}(\mathrm{APOH})$ die 8 Exons dieses Gens nachgewiesen werden. Diese befinden sich in einem genomischen Bereich von 17384 bp. Die gefundenen Exon-Intron-Übergänge dieses Gens stimmen mit den von Okkels et al. (1999) veröffentlichten Exon-Intron-Grenzen von APOH überein, jedoch ergaben sich in 2 Fällen Sequenzabweichungen in der Akzeptor-Spleißstelle. So weist der BAC-Klon hRPK.346K10 10 bp vor Beginn des Exons 3 ein T auf, während Okkels et al. (1999) an dieser Position ein A nachwiesen. Die von Okkels et al. (1999) angegebene Sequenz der Akzeptor-Spleißstelle von Exon 8 (ccxxaactagAACACAGT) weicht zudem von der im Rahmen dieser Arbeit identifizierten Sequenz dieser Spleißstelle (ccccaacagAACACAGT) ab. Welche Angaben den korrekten Spleißstellen entsprechen, ist unklar. Die Abweichungen könnten aufgrund von Sequenzierungsfehlern aufgetreten sein, könnten jedoch auch Polymorphismen widerspiegeln. Okkels et al. (1999) veröffentlichten jeweils 9-10 bp der Sequenz der an die Exons von APOH angrenzenden Introns. Die Sequenz der gesamten Introns stand jedoch bisher nicht zur Verfügung. In hCIT.187K10 ist jedoch auch die Sequenz der Introns von APOH enthalten. Diese wird benötigt, wenn z.B. Intron-Primer zur Amplifikation einzelner Exons abgeleitet werden sollen. Solche Primer werden beispielsweise im Rahmen einer Mutationssuche, welche über SSCP oder über die direkte Sequenzierung der Exons erfolgen soll, benötigt.

In der Sequenz des BAC-Klons hRPK.349A8 konnten über Vergleiche mit der cDNA-Sequenz des calcium channel, L type polypeptid (CACNLG) die 4 Exons dieses Gens identifiziert werden. Diese sind in einem genomischen Bereich von 12204 bp lokalisiert. Die Exon-IntronGrenzen stimmen mit den von Powers et al. (1993) angegebenen Sequenzen überein. Die Spleißakzeptorstelle des Exons 4 weist jedoch in hRPK.349A8 für die Basenpaare 3-7 vor Beginn des Exons ein C auf, während Powers et al. (1993) nur für die Basenpaare 3-6 ein C angeben. Dies könnte, wie oben beschrieben, auf einen Sequenzierungsfehler oder auf einen Polymorphismus zurückzuführen sein. Da in hRPK.349A8 die gesamte genomische Sequenz von CACNLG enthalten ist, steht somit auch die vollständige Sequenz der Introns für weitere Analysen zur Verfügung.

Innerhalb der Sequenz des Inserts von BAC-Klon hRPK.62F10 wurden 9 Exons des Gens PRKAR1A (human cAMP-dependent protein kinase type I-alpha subunit) lokalisiert. Die Exon-Intron-Struktur dieses Gens wurde von Solberg et al. (1997) beschrieben. Die Autoren identifizierten 2 verschiedene 5' gelegene Exons, die mit Exon 1a und $1 \mathrm{~b}$ bezeichnet wurden, sowie 9 weitere Exons. Das erste Exon, welches in hRPK.62F10 identifiziert wurde, ist dem- 
nach das Exon 3 des Gens. Der Vergleich der in hRPK.62F10 identifizierten Exon-IntronGrenzen mit den von Solberg et al. (1997) angegebenen, brachte einige deutliche Unterschiede zutage. Beispielsweise wurde über die im Rahmen dieser Arbeit durchgeführten Sequenzvergleiche ein Exon identifiziert, welches von Solberg et al. (1997) nicht beschrieben wurde. So werden die im Rahmen dieser Arbeit nachgewiesenen Exons 4 und 5 von Solberg et al. (1997) zu Exon 4 zusammengefaßt. Das in hRPK.62F10 zwischen den Exons 4 und 5 identifizierte Intron hat eine Größe von 199 bp und die Spleißdonor- und Spleißakzeptorstelle entsprechen der GT-AG-Regel. Zudem entsprechen die von Solberg et al. (1997) angegebenen Spleißstellen in 2 Fällen nicht der GT-AG-Regel, während die in hRPK.62F10 nachgewiesenen Spleißstellen dieser Regel entsprechen. Dies betrifft zum einen die Spleißakzeptorstelle des Introns 2 und zum anderen die Spleißdonorstelle von Intron 5 (bei Solberg et al. (1997) Intron 4). Da die im Rahmen dieser Arbeit in hRPK.62F10 identifizierten Spleißstellen im Gegensatz zu den von Solberg et al. (1997) beschriebenen Spleißstellen der Spleiß-consensus-Sequenz entsprechen, ist anzunehmen, daß die aus hRPK.62F10 stammenden Spleißstellen die korrekte Sequenz aufweisen. Ansonsten stimmen die Sequenzen der in hRPK.62F10 identifizierten Spleißstellen mit den von Solberg et al. (1997) veröffentlichten überein. Die Autoren gaben jedoch vermutlich aufgrund von Berechnungsfehlern leicht abweichende Exongrößen an. So bestimmten Solberg et al. (1997) die Größe von Exon 3 mit 170 bp anstelle von 171 bp, die in hRPK.62F10 identifizierten Exons 4 (92 bp) und 5 (62 bp) werden zu einem 155 bp langen Exon 4 zusammengefaßt und auch die Größe der weiteren Exons weicht trotz gleicher Exon-IntronGrenzen fast grundsätzlich um 1 bp von der im Rahmen dieser Arbeit ermittelten Größe ab. Auch die ermittelten Introngrößen weichen z.T. deutlich von den von Solberg et al. (1997) angegebenen Größen ab. Diese Abweichungen werden im folgenden aufgelistet.

Tab. 62: Introngrößen des Gens PRKAR1A

\begin{tabular}{llll}
$\begin{array}{l}\text { Intron } \\
\text { von Solberg et al. (1997) } \\
\text { angegebene Größe }\end{array}$ & $\begin{array}{l}\text { Intron } \\
\text { in dieser Arbeit anhand der Sequenz des } \\
\text { BAC-Klons hRPK.62F10 ermittelte Größe }\end{array}$ \\
\hline 3 & $\sim 1300$ & 3 & 798 \\
4 & 746 & 5 & 834 \\
5 & 789 & 6 & 795 \\
6 & $\sim 1900$ & 7 & 1929 \\
7 & 253 & 8 & 969 \\
8 & $\sim 1700$ & 9 & 928 \\
9 & $\sim 1600$ & 10 & 275 \\
\hline
\end{tabular}

In der Annahme, daß nur ein PRKAR1A-Gen existiert, geben wahrscheinlich die in hRPK.62F10 ermittelten Größen die tatsächlichen Introngrößen an. Dies kann angenommen werden, da Solberg et al. (1997) die Introngrößen nur z.T. über Sequenzierungen und in den anderen Fällen über PCR oder Restriktionskartierung ermittelten. In den Fällen, in denen die Introngrößen voneinander abweichen, obwohl die Größen von Solberg et al. (1997) ebenfalls über Sequenzierungen bestimmt wurde, kann nicht entschieden werden, welche Größen die jeweiligen Introns aufweisen. Da die im Rahmen des Human Genome Project ermittelten 
Sequenzen jedoch in der Regel nicht mehr als einen Fehler in 5000 bp aufweisen (Felsenfeld et al. (1999), ist vermutlich die vom Whitehead Institute für den Klon hRPK.62F10 angegebene Sequenz von besserer Qualität als die von Solberg et al. (1997) angegebene.

Die Loci WI-9461, 7T7, 293SP6 und (WI-9571) wurden über Sequenzvergleiche in der EMBL/GenBank-Datenbank auf dem vollständig sequenzierten BAC-Klon hRPK.147L13 nachgewiesen. Der Abstand zwischen den Loci WI-9461 und (WI-9571) kann daher mit etwa $120 \mathrm{~kb}$ angegeben werden. Die STS 293SP6 befindet sich etwa $90 \mathrm{~kb}$ distal von WI-9461 entfernt. Der PAC 293H13 und der BAC hRPK.147L13 weisen daher $90 \mathrm{~kb}$ gemeinsam auf. Da die Größe von 293H13 mit 119 kb bestimmt wurde und der Locus 293T7, der das T7-Ende von 293H13 darstellt, proximal von WI-9461 kartiert wurde, ist anzunehmen, daß der Abstand zwischen den Markern 293 T7 und WI-9461 etwa 29 kb groß ist.

\subsection{Karyopherin $\alpha 2$ (KPNA2) als Kandidatengen für das RSS}

Der Nukleus einer eukaryotischen Zelle ist von einer Doppelmembran umgeben, so daß das Nukleoplasma vom Cytoplasma getrennt wird. Dies ermöglicht eine Reihe von Mechanismen, um die Genexpression zu regulieren. Gentranskription und -translation finden in unterschiedlichen subzellulären Kompartimenten statt, so daß spezifische Transportvorgänge zwischen diesen Kompartimenten erforderlich sind, damit die Zelle funktionieren kann. Die mRNA muß aus dem Nukleus ins Cytoplasma transportiert werden, um in ein Protein translatiert zu werden. Andererseits müssen Proteine, die im Zellkern benötigt werden, inklusive der Enzyme für die DNA-Replikation, Genregulation und Transkription, vom Ort ihrer Synthese im Cytoplasma in den Zellkern transportiert werden (Görlich und Mattaj, 1996). Dieser Transport erfolgt durch die Kernporen. Nur Moleküle, die kleiner als 40-45 kDa sind, können frei zwischen Cytoplasma und Nukleus diffundieren (Jans und Huebner, 1996). Größere Moleküle benötigen dagegen spezifische Signale (nuclear localization sequences, NLSs), um in den Zellkern transportiert zu werden. Dies bietet der Zelle die Möglichkeit den Transportprozeß von Proteinen in den Nukleus zu regulieren (Jans und Huebner, 1996).

Eukaryotische Zellen haben eine Reihe von Mechanismen entwickelt, um Informationen der extrazellulären Umgebung zum Nukleus zu übermitteln (Jans und Hassan, 1998). Cytosolische Signale, die auf dem Niveau der Membran über die Aktivierung von Rezeptoren durch Hormone, Wachstumsfaktoren oder Cytokine erzeugt werden, müssen in nukleäre Signale umgewandelt werden. Dies erfordert nahezu ohne Ausnahmen den Transport von Proteinen aus dem Cytoplasma in den Nukleus (Jans, 1994; Jans und Huebner, 1996).

Karyopherine, alternativ auch Importine genannt, sind Transportfaktoren, die am Proteinimport in den Zellkern beteiligt sind. Karyopherin $\alpha$-Untereinheiten erkennen klassische nukleäre Lokalisationssequenzen und binden an diese. Über eine Karyopherin $\beta$-bindende Domäne bindet Karyopherin $\alpha$ zusammen mit dem NLS-Protein an Karyopherin $\beta$. Karyopherin $\beta$ seinerseits dockt an die Kernpore an (Görlich und Mattaj, 1996). Für den Transport durch die Kernpore werden weitere Faktoren wie die kleine Ras-ähnliche GTPase Ran und der nukleäre Transportfaktor NTF2 benötigt (Moore und Blobel, 1993 und 1994; Melchior et al., 1993; Paschal und Gerace, 1995). Durch die von Ran katalysierte GTP-Hydrolyse wird vermutlich 
die Energie für den Import bereitgestellt. Der trimere Komplex aus NLS-Protein, Karyopherin $\alpha$ und Karyopherin $\beta$ gelangt schließlich ins Kerninnere. Im Nukleoplasma wird RanGDP in die RanGTP-Form umgewandelt, das dann an Karyopherin $\beta$ bindet, was den Importkomplex dissoziieren läßt. Das nukleäre NLS-Protein wird ins Kerninnere abgegeben und Karyopherin $\alpha$ und Karyopherin $\beta$ werden durch verschiedene Exportrouten wieder zurück ins Cytoplasma befördert (Görlich und Mattaj, 1996).

Bis jetzt wurden 5 unterschiedliche humane Karyopherin $\alpha$-Homologe identifiziert, KPNA1/NPI/hSRP1 (Cortes et al., 1994; O'Neill und Palese, 1995), KPNA2/RCH1/hSRP1 $\alpha$ (Cuomo et al., 1994; Weis et al., 1995), KPNA3 (Takeda et al., 1997), KPNA4/QIP1 (Seki et al., 1997) und hSRP1 $\gamma$ (Nachury et al., 1998). Nachury et al. (1998) konnten zudem über Sequenzvergleiche in der EST-Datenbank weitere humane Karyopherin $\alpha$-Homologe identifizieren, was auf eine große Multigenfamilie hindeutet. Northern-Blot-Analysen zeigten, daß die einzelnen Mitglieder dieser Genfamilie in verschiedenen Geweben unterschiedlich stark exprimiert werden. Dies deutet darauf hin, daß die Funktion dieser Proteine gewebespezifisch kontrolliert wird (Nachury et al., 1998). KPNA2 konnte über einen Northern-Blot in allen getesteten Geweben nachgewiesen werden, wobei die stärksten Signale in Niere, Leber und Plazenta festgestellt wurden, gefolgt von Signalen in Lunge und Gehirn. Die schwächsten Signale wurden in Pankreas, Skelettmuskel und Herzmuskel gefunden (Nachury et al., 1998). KPNA1 zeigte dagegen in Pankreas und Plazenta die stärkste Expression (Nachury et al., 1998). hSRP1 zeigte fast nur im Skelettmuskel Signale. Auf einem anderen Northern-Blot mit weiteren Geweben zeigte hSRP1 auch im Testis starke Signale, wobei hier 3 Transkripte identifiziert wurden (Nachury et al., 1998). KPNA3 konnte vor allem in Gewebe von Herzmuskel, Skelettmuskel und Testis nachgewiesen werden. Eine Expression von KPNA3 konnte aber auch in allen anderen getesteten Geweben gezeigt werden. Im Testis wurden zudem zwei kleinere Transkripte detektiert (Takeda et al., 1997). Um die Relevanz der RNA-Expressionsmuster zu analysieren, untersuchten Nachury et al. (1998) auch die Proteinexpression von KPNA1, KPNA2 und hSRP1 $\gamma$ in Skelettmuskel, Testis, Gehirn und Plazenta. Überraschenderweise zeigten die über Western-Blotting erhaltenen Expressionsmuster einige deutliche Unterschiede zum erhaltenen Muster der mRNA-Expression. Demnach war KPNA2 vor allem im Testis vorhanden, während KPNA1 und hSRP1 $\gamma$ vor allem in Skelettmuskel und Gehirn nachgewiesen wurden.

Nachury et al. (1998) wiesen darauf hin, daß eine Familie von Adaptern (Karyopherin $\alpha$ Homologe), die zwischen den NLS-Proteinen und Karyopherin $\beta$-Homologen (auch eine Multigenfamilie) vermitteln, eine größere Flexibilität bei der Erkennung von verschiedenen NLS-Motiven ermöglichen. Dieses Modell wird gestützt durch Daten, die zeigen, daß KPNA1 und KPNA2 mit unterschiedlicher Spezifität an verschiedene nukleäre Proteine binden (Wang et al., 1997; Nadler et al., 1997). Zudem konnte gezeigt werden, daß ein Mitglied der Karyopherin $\alpha$-Genfamilie (Pendulin/oho31) in Drosophila nicht essentiell für das Überleben ist. Die Inaktivierung von Pendulin/oho31 führt dagegen $\mathrm{zu}$ einer malignen Transformation von hämatopoetischen Vorläuferzellen (Küssel und Frasch, 1995; Török et al., 1995).

Da KPNA2 möglicherweise an der Übermittlung von Signalen von Wachstumsfaktoren an den Zellkern beteiligt ist, könnte der Defekt von KPNA2 zu den Symptomen des RSS führen. Da 
KPNA2 zudem in der Region des Translokationsbruchpunktes von Proband AS kartiert wurde, stellt dieses Protein ein positionelles Kandidatengen für das RSS dar.

Ein erster Hinweis darauf, daß KPNA2 in der Region des Translokationsbruchpunktes von Proband AS lokalisiert ist, wurde über die Sequenzierung eines Endfragmentes des in der Bruchpunktregion des Probanden AS kartierten Cosmids CF20b erhalten. Die Sequenz dieses Endfragmentes zeigte für 228 bp eine vollständige Übereinstimmung mit der veröffentlichten cDNA-Sequenz von KPNA2 (Accession-Nr. U09559). Deshalb wurden anhand der cDNASequenz von KPNA2 für das Exon 2 und das 3'-Ende dieses Gens STS-Stellen generiert. Über PCR-Analysen mit diesen Markern wurden die den Bruchpunkt überspannenden YACs 955H4, 871C4, 845C6, 931B10 und 901G9 sowie der den Bruchpunkt überspannende PAC 81B9 positiv getestet. Daneben wurden diese Loci jedoch auch auf den proximal vom Bruchpunkt lokalisierten Klonen 765F4, 963C7 und 245A13 nachgewiesen. Dies deutete darauf hin, daß Sequenzen von KPNA2 in der Region 17q23-q24 dupliziert vorliegen. Durch eine Sequenzierung der entsprechenden PCR-Produkte dieser Loci konnten schließlich spezifische Unterschiede zwischen den Sequenzen von proximal vom Bruchpunkt kartierten Klonen und den Klonen der Bruchpunktregion selbst festgestellt werden. Der sequenzierte Bereich des Exons 2 war für diese 2 Regionen zu $91 \%$ identisch, während die sequenzierten Bereiche aus der 3'Region von KPNA2 eine Identität von $96 \%$ aufwiesen. Bei einem Vergleich der erhaltenen Sequenzdaten mit der veröffentlichten cDNA-Sequenz von KPNA2 zeigte sich, daß die über Sequenzierung von Klonen der Bruchpunktregion erhaltenen Sequenzen mit Teilen der cDNASequenz von KPNA2 übereinstimmten, während die Sequenzen der proximal vom Bruchpunkt lokalisierten Klone spezifische Abweichungen von der cDNA-Sequenz zeigten. Daher kann angenommen werden, daß die Klone der Bruchpunktregion des Probanden AS KPNA2 enthalten, während die proximal zu diesem Bruchpunkt lokalisierten Klone ein zu KPNA2 ähnliches Gen oder Pseudogen aufweisen.

Schließlich konnte auch ein spezifischer Marker (KPNA2-E1) für das Exon 1 von KPNA2 generiert werden, der nur auf Klonen nachgewiesen wurde, welche den Translokationsbruchpunkt des Probanden überspannen. Mit diesem Marker läßt sich somit spezifisch überprüfen, ob ein Klon die Sequenz von KPNA2 oder die eines zu KPNA2 ähnlichen Gens oder Pseudogens enthält.

Sowohl das 5'- als auch das 3'-Ende von KPNA2 wurde auf dem $60 \mathrm{~kb}$ langen, den Bruchpunkt von Proband AS überspannenden PAC-Klon 81B9, nachgewiesen. Der Abstand von KPNA2 zum Translokationsbruchpunkt beträgt daher weniger als $60 \mathrm{~kb}$. Den Ergebnissen der STS-Analyse zufolge überlappt der PAC-Klon 81B9 auf der proximalen Seite mit dem proximal vom Translokationsbruchpunkt des Probanden AS lokalisierten PAC 112L5 und auf der distalen Seite mit dem distal von diesem Bruchpunkt kartierten Cosmid CF20b. Zudem überlappt der PAC-Klon 81B9 mit dem PAC 222L3, welcher den FISH-Analysen auf Metaphasen des Probanden AS zufolge ebenfalls den Bruchpunkt dieses Probanden auf Chromosom 17 überspannt. Um genauere Angaben über die Lokalisierung von KPNA2 in Bezug zum Translokationsbruchpunkt des Probanden AS machen zu können, wurden für die Klone 112L5, 222L3, 81B9 und CF20b Restriktionskarten für die Enzyme EagI, KpnI und SacI erstellt (s. Abb. 26). Der Bereich des PACs 81B9, der nicht mit den Klonen 112L5 und CF20b überlappt, ist diesen Karten zufolge etwa $35 \mathrm{~kb}$ groß und enthält das 5'-Ende von KPNA2. Der PAC-Klon 
222L3, der den Bruchpunkt des Probanden AS anscheinend ebenfalls überspannt, enthält jedoch keinen Anteil von KPNA2. Da dieser Klon chimärisch ist und auch einen auf Chromosom 7 lokalisierten Anteil beinhaltet, ist jedoch unklar, ob dieser Klon weitere Umordnungen aufweist. Zudem kann nicht ausgeschlossen werden, daß die FISH-Ergebnisse dieses Klons aufgrund von weiteren duplizierten Regionen zustande kommen. Überspannt dieser Klon den Translokationsbruchpunkt des Probanden AS, so müßte dieser jedoch in dem Bereich lokalisiert sein, den die Klone 81B9 und 222L3 gemeinsam aufweisen. Der Bereich den ausschließlich diese Klone beinhalten, hat eine Größe von etwa 20 kb. Ist der Translokationsbruchpunkt des Probanden AS in diesem Bereich lokalisiert, so würde der Abstand zwischen diesem Bruchpunkt und dem 5'-Ende von KPNA2 etwa 7 kb groß sein.

Um zu überprüfen, ob KPNA2 durch die Translokation des Probanden AS unterbrochen wurde, wurden Southern-Blots mit gespaltener genomischer DNA des Probanden und gespaltenen Kontroll-DNAs angefertigt und diese mit der cDNA von KPNA2 hybridisiert. Die mit BamHI, PstI, XbaI oder SacI gespaltene DNA des Probanden zeigte bei diesen Hybridisierungen kein von den Kontrollen abweichendes Bandenmuster, was darauf hindeutet, daß KPNA2 eher nicht durch die Translokation des Probanden AS unterbrochen wurde. Die Hybridisierung mit der cDNA von KPNA2 auf MspI gespaltene DNA des Probanden ergab jedoch ein von den Kontrollen abweichendes Bandenmuster. Dies ließ 2 Erklärungsmöglichkeiten zu. Entweder war mit den Enzymen BamHI, PstI, XbaI oder SacI nicht erkannt worden, daß KPNA2 den Translokationsbruchpunkt des Probanden AS überspannt oder das veränderte Fragment des Probanden AS war aufgrund eines Polymorphismus aufgetreten. Da von den Eltern des Probanden AS nicht genügend Material für Southern-Blot-Analysen zur Verfügung stand, konnte nicht überprüft werden, ob das abnorme Fragment des Probanden aufgrund eines von den Eltern geerbten Polymorphismus zustande kam. Da der Translokationsbruchpunkt des Probanden AS in unmittelbarer Umgebung von KPNA2 kartiert wurde, erschien es zunächst eher wahrscheinlich, daß KPNA2 den Bruchpunkt des Probanden AS überspannt. Über Hybridisierungen auf 10 weitere MspI-gespaltene Kontroll-DNAs wurde das abnorme Fragmentmuster jedoch schließlich auch bei einer Kontrollperson festgestellt. Dies deutet darauf hin, daß das abnorme Fragmentmuster einen DNA-Polymorphismus widerspiegelt.

Durch diese Hybridisierungen konnte somit nicht gezeigt werden, daß KPNA2 den Translokationsbruchpunkt des Probanden AS überspannt. Dennoch ist dies kein Beweis dafür, daß KPNA2 den Bruchpunkt des Probanden AS nicht überspannt. Beispielsweise kann ein Bruchereignis in einem Intron über Hybridisierungen mit einer cDNA unter bestimmten Voraussetzungen nicht nachgewiesen werden. Dies wäre dann der Fall, wenn der Bruchpunkt auf beiden Seiten von Schnittstellen des für den Southern-Blot eingesetzten Enzyms begrenzt wird.

Um in den Exons des KPNA2-Gens und in den daran angrenzenden Spleißstellen nach $\mathrm{Mu}$ tationen in Probanden mit RSS suchen zu können, wurde die Exon-Intron-Struktur dieses Gens aufgeklärt. Dies wurde erreicht, indem die genomische Sequenz von KPNA2 über Sequenzierungen von PCR-Produkten genomischer Klone oder eines genomischen Subklons ermittelt und diese mit der cDNA-Sequenz von KPNA2 verglichen wurde. Unklonierte genomische Gesamt-DNA eignete sich dagegen nicht zur Generierung der zu sequenzierenden PCRProdukte, da mit genomischer DNA als template nicht nur die Sequenz von KPNA2 sondern 
auch die Sequenz von einem zu diesem Gen ähnlichen Gen oder Pseudogen amplifiziert wurde. In den Klonen 81B9 und CF20b ist das homologe Gen oder Pseudogen jedoch nicht enthalten, so daß über eine PCR mit DNA von diesen Klonen spezifisch nur die Sequenz von KPNA2 amplifiziert werden konnte. Die genomische Sequenz von KPNA2 wurde daher ausschließlich über Sequenzierungen der Klone 81B9 und CF20b generiert.

Über PCR-Analysen mit 2 Markern von KPNA2 (KPNA2-E2 und KPNA2-3') war zuvor bereits gezeigt worden, daß die YAC-Klone 765F4 und 963C7 ein zu KPNA2 ähnliches Gen oder Pseudogen der Region 17q23-q24 enthalten. Die über Sequenzierung von genomischen Fragmenten erhaltene Sequenz setzte sich in der Tat zusammen aus den Sequenzen, die über Sequenzierung der Klone 81B9 und CF20b erhalten wurden und den Sequenzen, die über Sequenzierung der Klone 765F4 und 963C7 generiert wurden.

Über den Vergleich der genomischen Sequenz mit der cDNA-Sequenz konnte gezeigt werden, daß KPNA2 aus 11 Exons (89 bp bis 339 bp) und 10 Introns besteht, die einen genomischen Bereich von über $10 \mathrm{~kb}$ abdecken. Die exakte Größe des KPNA2-Gens kann zur Zeit jedoch noch nicht angegeben werden, da das Intron 3 noch eine Lücke bisher unbekannter Größe beinhaltet. Die identifizierten Spleißdonor- und Spleißakzeptorstellen entsprechen jeweils der GTAG-Regel.

Um zu überprüfen, ob ein Defekt im KPNA2-Gen bei einem Teil der RSS-Probanden für die Entstehung des Krankheitsbildes verantwortlich ist, wurde eine Mutationsanalyse in diesem Gen durchgeführt. Dazu wurden die 11 Exons des KPNA2-Gens von 31 RSS-Probanden sequenziert. Über diese Analysen konnten 8 Abweichungen von der in dieser Arbeit ermittelten Sequenz dieses Gens festgestellt werden. Eine Gruppe von 6 Variationen trat gleichermaßen bei 6 Probanden auf, wogegen 2 Variationen nur jeweils einmal festgestellt werden konnten. Über die Analyse der Eltern von Probanden mit Variationen zeigte sich, daß alle Variationen vererbt worden waren. Die als Gruppe, also gekoppelt auftretenden Variationen spiegeln zwei Haplotypen (H1 und H2) wider. Diese Haplotypen setzen sich zusammen aus 6 gekoppelt vererbten, im KPNA2-Gen lokalisierten, diallelischen Loci. Um zu überprüfen, ob es sich bei den beobachteten Variationen des KPNA2-Gens nur um Polymorphismen oder um funktionelle Mutationen handelt, wurden zudem nicht verwandte Kontrollpersonen ohne RSS auf diese Variationen hin überprüft. 7 der identifizierten Abweichungen konnten über diese Analysen auch bei den Kontrollpersonen nachgewiesen werden, was für Polymorphismen spricht. Eine Variation, welche bei eineiigen Zwillingen mit RSS identifiziert wurde, konnte über die Analyse von 39 Kontrollpersonen nicht nachgewiesen werden. Diese wurde jedoch bei dem nicht betroffenen Vater der Zwillinge homozygot nachgewiesen. Daher ist es als sehr unwahrscheinlich anzusehen, daß diese Variation für das RSS verantwortlich ist. Somit ist wohl eher davon auszugehen, daß auch diese Sequenzvariation einen Polymorphismus, wenn auch einen seltenen, widerspiegelt. Allerdings wäre es dann eher unwahrscheinlich, daß der Vater homozygot für das Allel ist. Ein anderer Grund, weshalb diese Veränderung in Kontrollpersonen bisher nicht identifiziert wurde, könnte darin zu sehen sein, daß diese Familie aus den USA stammt. Möglicherweise ist diese Variation dort stärker verbreitet als in Europa und somit in einem Kollektiv von vorwiegend aus Deutschland stammenden Kontrollpersonen nicht oder nur sehr selten nachweisbar. 
Über die Mutationsanalyse im KPNA2-Gen wurden somit bei 31 RSS-Probanden keine funktionellen Mutationen nachgewiesen. Dies bedeutet, daß Punktmutationen bzw. andere Mutationen, die innerhalb der amplifizierten Exonbereiche auftreten, bei der Mehrzahl der RSS-Probanden nicht für das RSS verantwortlich sind. Die Mutationsanalyse kann jedoch nicht als komplett betrachtet werden, so daß KPNA2 nach wie vor als Kandidatengen für das RSS in Betracht gezogen werden muß. Denn bei direkter Sequenzierung der Exons eines Gens werden bestimmte Mutationstypen, nämlich solche, die ganze Exons betreffen, nicht erfaßt. Beispielsweise kann über Sequenzierung der Verlust oder die Duplikation der amplifizierten Genbereiche nicht nachgewiesen werden. Auch Inversionen innerhalb des Gens können über diese Methode nicht festgestellt werden. Um aufzeigen zu können, ob KPNA2 ein für die Erkrankung verantwortliches Gen ist, wäre es daher erforderlich dieses nach Deletionen, Duplikationen und Inversionen zu durchmustern.

Über eine durchgeführte Assoziationsstudie konnte eine hochsignifikante Assoziation des identifizierten Haplotyps 1 (H1) mit dem RSS festgestellt werden. Es zeigte sich, daß die Häufigkeit des Haplotyps 1 in der Gruppe der RSS-Probanden signifikant erhöht ist, zudem sind die Probanden deutlich zu häufig homozygot für den Haplotyp 1 (H1/H1). Ein zu beobachtendes Kopplungsungleichgewicht zwischen dem gesuchten Genort und den flankierenden Markern ist ein wichtiger Hinweis auf die unmittelbare Nähe dieser beiden Loci. Falls das KPNA2-Gen nicht für das RSS verantwortlich ist, kann den erhaltenen Ergebnissen der Assoziationsstudie zufolge davon ausgegangen werden, daß sich KPNA2 in der Nähe des gesuchten Genorts befindet. Die Ergebnisse der Assoziationsstudie lassen sich folgendermaßen erklären:

Zum einen können die oben genannten Ergebnisse darauf hindeuten, daß der Haplotyp 1 bei einem signifikanten Teil der Probanden gemeinsam mit einer Mutation in dem für das RSS verantwortlichen Gen vererbt wird. In diesem Fall ist es unwahrscheinlich, daß das RSS in der Mehrzahl der Fälle durch eine Neumutation entsteht. Da jedoch auch Kontrollpersonen ohne das RSS identifiziert wurden, welche den Haplotyp 1 homozygot aufweisen, kann vermutet werden, daß sich der Haplotyp 1 bereits vor Auftreten der krankheitsverursachenden Mutation in der Bevölkerung verteilt hat. Die Mutation könnte schließlich auf einem Chromosom mit Haplotyp 1 aufgetreten sein. Demnach würden sowohl Chromosomen mit Haplotyp 1 und Mutation als auch solche mit Haplotyp 1 ohne Mutation existieren.

Ein anderer Erklärungsmechanismus könnte in Zusammenhang mit den identifizierten lowcopy Repeats dieser Region stehen. Bei Vergleich der Sequenzen der Haplotypen 1 und 2 des KPNA2-Gens mit den entsprechenden duplizierten Sequenzen des zu KPNA2 ähnlichen Gens oder Pseudogens der Region 17q23-q24 zeigte sich nämlich, daß jeweils die Sequenz des Haplotyps 1 mit der zu diesem Gen oder Pseudogen homologen Sequenz übereinstimmte. Da intra- oder interhomologe Rekombinationen vorwiegend in Bereichen stattfinden, in denen die Homologie sehr hoch ist, kann ein Rekombinationsereignis zwischen dem zu KPNA2 homologen Gen oder Pseudogen mit dem KPNA2-Gen als wahrscheinlicher angesehen werden, wenn im Bereich des KPNA2-Gens der Haplotyp 1 und nicht der Haplotyp 2 vorkommt. Daher könnte Haplotyp 1 auch deshalb mit dem RSS assoziiert sein, weil dieser das Auftreten von inhomologem Crossing-over begünstigt. In diesem Fall könnten vorwiegend Neumutationen für das Auftreten des RSS verantwortlich sein. 
Bei der Beurteilung der Relevanz der Assoziationsstudie ist zu berücksichtigen, daß das Familienkollektiv der 31 analysierten RSS-Probanden vorwiegend solche aus Deutschland und Polen beinhaltete, während die unverwandten Kontrollpersonen vorwiegend aus Deutschland stammen. Die Verteilung der Haplotypen war bei den analysierten Probanden aus Deutschland und Polen annähernd gleich, so daß auf eine Unterteilung in Untergruppen verzichtet wurde. Es verbleibt jedoch eine gewisse Wahrscheinlichkeit, daß die Frequenzen der einzelnen Haplotypen innerhalb der analysierten Subpopulationen unterschiedlich sind. Das Kontrollkollektiv wurde jedoch auch von Röpke (1998) eingesetzt, um die Allelfrequenzen von Polymorphismen im JAG1-Gen zwischen Kontrollpersonen und Personen mit Alagille-Syndrom zu vergleichen. Das Kollektiv der Probanden stammte bei diesen Analysen ebenfalls aus Deutschland und Polen. Im Rahmen der von Röpke durchgeführten Analysen konnten jedoch nur sehr geringfügige Abweichungen der Allelfrequenzen zwischen den analysierten Gruppen festgestellt werden. Daher ist nicht davon auszugehen, daß die festgestellte Assoziation des Haplotyps 1 mit dem RSS aufgrund unterschiedlicher Allelfrequenzen in den analysierten Subpopulationen zustande kommt.

\subsection{Analyse von Mikrosatelliten des Chromosoms 17 bei Probanden mit RSS}

Der Bruchpunkt des Probanden AS wird, wie bereits beschrieben, von low-copy Repeats flankiert, die ein irreguläres Crossing-over begünstigen können. Daher stellte sich die Frage, ob es aufgrund dieser duplizierten Bereiche bei einem Teil der RSS-Probanden zu Deletionen, Duplikationen oder Inversionen der Region zwischen den Sequenzduplikationen kommt.

Da die duplizierten Loci im proximalen Bereich des Contigs zunächst nicht linear zueinander positioniert werden konnten, war jedoch nicht bekannt, ob die Struktur der Region eher das Auftreten von Deletionen, Duplikationen oder Inversionen begünstigt. Da bei der Mehrzahl der bis jetzt beschriebenen genomischen Erkrankungen Deletionen an der Entstehung der jeweiligen Erkrankungen beteiligt sind (Mazzarella und Schlessinger, 1998; Lupski, 1998a), wurde das Auftreten von Deletionen in der Bruchpunktregion von Proband AS zunächst für das wahrscheinlichste Ereignis gehalten. Ob bei RSS-Probanden Deletionen der Region zwischen den Sequenzduplikationen auftreten, wurde anhand von Mikrosatelliten-Analysen mit zwischen den Repeats lokalisierten polymorphen Markern untersucht. Über diese Analysen konnte zudem überprüft werden, ob die RSS-Probanden eine uniparentale Disomie für den entsprechenden Abschnitt des Chromosoms 17 aufweisen. Daher kann eine Aussage über die Assoziation von UPD17 mit RSS bei diesen Patienten gemacht werden.

In die Analysen wurde Material von 31 RSS-Probanden einbezogen. Diese Probanden wurden mit bis zu 4 Markern (D17S807, GAAT.1E12, D17S1813, D17S1870) aus der Region zwischen den Repeats und mit dem distal von dieser Region liegenden Marker D17S789 analysiert (s. Tab. 6).

Bei 2 Probanden (MD und MP) konnten über die Analyse mit dem Marker D17S1870 keine maternalen Allele nachgewiesen werden. Bei den anderen Probanden waren alle analysierten Marker mit einer biparentalen Weitergabe von je einem Allel der Eltern an die Kinder vereinbar. 
Da die Probanden MD und MP mit dem Locus D17S1870 keine maternalen Allele zeigten, wurde vermutet, daß diese Probanden im Bereich des Markers eine Deletion aufweisen. Theoretisch bestand zudem die Möglichkeit, daß diese Probanden eine paternale uniparentale Disomie (pUPD) für den entsprechenden Bereich zeigen. Dies wurde jedoch als unwahrscheinlich angesehen, da die zu D17S1870 benachbarten Marker mit einer normalen biparentalen Vererbung vereinbar sind. Um zu überprüfen, ob die Probanden MD und MP im Bereich des Locus D17S1870 eine Deletion aufweisen, wurden PAC- bzw. Cosmid-Klone aus der entsprechenden Region über eine FISH auf Metaphasen der Probanden hybridisiert. Über diese Analysen war jedoch keine Deletion feststellbar, mit den eingesetzten Sonden wurden jeweils Signale auf beiden Chromosomen 17 der Probanden nachgewiesen.

Koorey et al. (1993) beschrieben einen Fall, in dem ein Basenaustausch am 3'-Ende eines Primers dazu führte, daß ein Allel nicht amplifiziert wurde. Um zu überprüfen, ob eventuell ein maternales Allel der Probanden MD und MP nicht amplifiziert worden war, wurden daher neue Primer für den CA-Repeat des Locus D17S1870 abgeleitet. Die mit den neu abgeleiteten Primern dargestellte Allelsituation war schließlich mit einer normalen Weitergabe von je einem Allel der Eltern an die Probanden vereinbar, da mit den neuen Primern jeweils ein weiteres Allel von den Probanden und von deren Müttern darstellbar war. Auf diese Weise konnte schließlich gezeigt werden, daß die Probanden MD und MP weder eine Deletion noch eine UPD im Bereich des Markers D17S1870 aufweisen. Über die Mikrosatelliten-Analysen der 31 RSS-Probanden konnte somit keine Deletion oder UPD des zwischen den Sequenzduplikationen lokalisierten Bereiches nachgewiesen werden. Somit ist es unwahrscheinlich, daß das RSS bei einem signifikanten Teil der Probanden durch Deletionen oder uniparentale Disomien des analysierten Bereiches entsteht.

Schließlich zeigte sich, daß die 2 Cluster der dupliziert vorliegenden Loci, denen mit Ausnahme der Loci WI-9461 und 2A3T3 alle doppelt vorliegenden Loci zugeordnet werden können, im proximalen Bereich des YAC-Contigs in entgegengesetzter Richtung zu denen im distalen Bereich des Contigs orientiert sind. Dies würde das Auftreten von Inversionen begünstigen. Daher sollte in weiterführenden Analysen überprüft werden, ob Inversionen an der Entstehung des RSS-Phänotyps beteiligt sind.

Bisher wurden zwei Fälle mit einer maternalen uniparentalen Disomie des Chromosoms 17 (mUPD17) beschrieben (Jin et al., 1996; Genuardi et al., 1999).

Jin et al. (1996) beschrieben einen Probanden mit der rezessiv vererbten Glanzmann Thrombasthenie, bei dem eine homozygote Mutation im GPIIIa-Gen festgestellt wurde, während die Mutter diese Veränderung heterozygot aufweist. Der Vater stand für die Untersuchungen nicht zur Verfügung, aber die Wahrscheinlichkeit, daß dieser ebenfalls ein mutiertes Gen trägt, ist als äußerst gering einzuschätzen, da Jin et al. (1996) diese Veränderung in 206 Chromosomen von Kontrollpersonen nicht nachweisen konnten. Zudem ist der Proband homozygot für drei Polymorphismen im GPIIIa-Gen, während die Mutter heterozygot ist. Bei Analyse von 5 Mikrosatellitenmarkern des Chromosoms 17 zeigte sich, daß der Proband stets homozygot für eines der mütterlichen Allele war. Die Wahrscheinlichkeit, daß ein Individuum homozygot für diese 5 Marker ist, wird von Jin et al. (1996) mit 1:2000 angegeben. Bei Berücksichtigung von einem der GPIIIa-Polymorphismen beträgt diese Wahrscheinlichkeit nur noch 1:5000. Da der Proband zudem die festgestellte Mutation, welche in 206 normalen Chromosomen nicht nachgewiesen 
werden konnte, homozygot aufweist, ist nahezu sicher, daß der von Jin beschriebene Proband eine maternale uniparentale Disomie des Chromosoms 17 aufweist. Der Proband zeigte ausschließlich die Symptome der Glanzmann Thrombasthenie (Jin et al., 1996), so daß nicht anzunehmen ist, daß dieser Proband Symptome aufweist, die aufgrund der mUPD17 verursacht werden.

Ein weiterer Fall mit einer maternalen uniparentalen Disomie des Chromosoms 17 wurde von Genuardi et al. (1999) beschrieben. Die Autoren stellten über eine Amniozentese eine MosaikTrisomie 17 fest. Bei Analyse von fötalem Blut wurde dagegen ein normaler männlicher Karyotyp festgestellt. Über eine Mikrosatelliten-Analyse des Kindes wurde schließlich eine mUPD17 nachgewiesen, wobei diese sowohl als Iso- als auch als Heterodisomie vorliegt. Das inzwischen 2 Jahre alte Kind weist keine Symptome einer Erkrankung auf (Genuardi et al., 1999).

Da die mUPD17 bei 2 Probanden keine phänotypischen Auswirkungen hatte, ist zu vermuten, daß Chromosom 17 keine paternal exprimierten Gene trägt, deren Verlust zu einer Erkrankung führt. Zudem ist anzunehmen, daß Chromosom 17 auch keine ausschließlich maternal exprimierten Gene trägt, deren verdoppelte Dosis zu einer Erkrankung führt.

\subsection{Charakterisierung eines mit Russell-Silver-Syndrom einhergehenden Translo- kationsbruchpunktes in der Region 17q25}

Im Rahmen dieser Arbeit wurde vorrangig der Translokationsbruchpunkt des von Midro et al. (1993) beschriebenen Probanden AS mit einer 1;17 Translokation kartiert. In der Literatur war jedoch ein weiterer Fall mit RSS und einer Translokation mit Beteiligung des langen Arms von Chromosom 17 beschrieben worden (Ramirez-Dueñas et al., 1992), bei der die Probandin GR mit RSS eine balancierte Translokation $\mathrm{t}(17 ; 20)(\mathrm{q} 25 ; \mathrm{q} 13)$ aufwies, welche vom gesunden Vater vererbt worden war (Ramirez-Dueñas et al., 1992). Da der Translokationsbruchpunkt des Probanden AS zunächst ebenfalls in der Region 17q25 kartiert worden war (Midro et al., 1993), wurde vermutet, daß beide Translokationsbruchpunkte in derselben Region auf Chromosom 17 lokalisiert sind. Um dies auf molekularer Ebene überprüfen zu können, sollte auch die Bruchpunktregion der Probandin GR auf eine bestimmte Chromosomenregion eingegrenzt werden.

Um zu überprüfen, ob die Translokationsbruchpunkte der Probanden AS und GR in derselben Region lokalisiert sind, wurden zunächst zwei YACs (845C6 und 931B10), die den Bruchpunkt des Probanden AS überspannen, über eine FISH auf Chromosomenpräparate der Probandin GR hybridisiert. Diese Analysen zeigten jedoch, daß diese YACs den Bruchpunkt der Probandin GR nicht überspannen, sondern proximal zum Translokationsbruchpunkt der Probandin GR kartieren. Auch 2 weiter distal auf dem Chromosom 17 lokalisierte YACs (723H7 und 738E4) wurden über eine FISH proximal zum Translokationsbruchpunkt der Probandin GR positioniert. YAC 738E4 ist der am weitesten distal auf dem Chromosom 17 kartierte YAC, der für FISH-Analysen auf Metaphasen der Probandin GR eingesetzt wurde. Dieser YAC trägt nach Chumakov et al. (1995) den Locus D17S785. Dieser Marker ist nach der genetischen Karte von Dib et al. (1996) 13,2 cM bzw. 12,2 cM distal von den den Bruchpunkt des Probanden AS begrenzenden polymorphen Markern D17S1870 bzw. D17S789 entfernt 
lokalisiert. Der Abstand zwischen den Translokationsbruchpunkten der Probanden AS und GR muß daher größer sein als 12,2 cM.

Die cytogenetische Eingrenzung der Region des Translokationsbruchpunktes der Probandin GR erfolgte, indem 4 Cosmide, welche von Inazawa et al. (1993) in eine hochaufgelöste cytogenetische Karte des Chromosoms 17 integriert worden waren, für FISH-Analysen auf Metaphasen der Probandin GR eingesetzt wurden. Auf diese Weise konnte der Translokationsbruchpunkt der Probandin GR auf eine Region eingegrenzt werden, die proximal durch die Cosmide cCI17-464 und cCI17-546 und distal durch das Cosmid cCI17-469 begrenzt ist. Die Cosmide cCI17-464 und cCI17-546 wurden über FISH-Analysen von Inazawa et al. (1993) der Chromosomenregion 17q24.3-q25.1 zugeordnet und das Cosmid cCI17-469 der Region 17q25.2-q25.3. Demnach ist der Translokationsbruchpunkt der Probandin GR in dem Bereich 17q24.3-q25.3 lokalisiert. Der Translokationsbruchpunkt des Probanden AS wurde dagegen über FISH-Analysen mit Cosmiden aus der cytogenetischen Karte von Inazawa et al. (1993) der Chromosomenregion 17q23.3-q24 zugeordnet.

Die weitere Eingrenzung der Bruchpunktregion der Probandin GR auf Chromosom 17 erfolgte von L. Ayala-Madrigal im Rahmen ihrer Doktorarbeit (1999). Dadurch konnte der Translokationsbruchpunkt der Probandin GR zwischen den polymorphen Markern D17S801 und D17S937 positioniert werden (Ayala-Madrigal, pers. Mitteilung). Der Abstand zwischen den Translokationsbruchpunkten der Probanden AS und GR beträgt daher nach der genetischen Karte von Dib et al. (1996) etwa 15 cM.

Da die Translokationsbruchpunkte der Probanden AS und GR auf Chromosom 17 ungefähr 15 cM entfernt voneinander lokalisiert sind, ist es sehr unwahrscheinlich, daß durch beide Translokationen die Expression ein und desselben Gens verändert worden sein könnte. In den letzten Jahren wurden zwar bei einer Reihe von Patienten mit bestimmten Erkrankungen chromosomale Umordnungen festgestellt, deren Bruchpunkte in einiger Entfernung von dem für die Erkrankung verantwortlichen Gen lokalisiert wurden, jedoch sind diese Bruchpunkte nie mehr als $1 \mathrm{Mb}$ von dem verantwortlichen Gen entfernt (Kleinjan und van Heyningen, 1998). Es wird vermutet, daß die Erkrankungen in diesen Fällen entweder entstehen, indem ein regulatorisches Element vom Gen getrennt oder zerstört wird, oder, indem das Gen unter den Einfluß eines Kontrollelementes eines anderen Gens gestellt wird. Zudem könnte eine veränderte chromosomale Umgebung zu einer veränderten Genexpression führen (Kleinjan und van Heyningen, 1998).

Die bisher am entferntesten von dem für eine Erkrankung verantwortlichen Gen lokalisierten chromosomalen Umordnungen wurden bei Patienten mit X-gekoppelter Taubheit (DFN3) festgestellt. Bei einigen Probanden mit dieser Erkrankung wurden Mikrodeletionen gefunden, die 900 kb vom 5'-Ende des für DFN3 verantwortlichen Gens POU3F4 lokalisiert sind (De Kok et al., 1995 und 1996). Bei Probanden mit Kampomeler Dysplasie (CMPD1) wurden Translokationsbruchpunkte 5' des für die Erkrankung verantwortlichen SOX9-Gens festgestellt, die 50$850 \mathrm{~kb}$ von der Transkriptions-Startstelle des SOX9-Gens entfernt waren (Wirth et al., 1996). Alle anderen chromosomalen Bruchpunkte, die außerhalb des für die jeweilige Erkrankung verantwortlichen Gens lokalisiert wurden, waren jedoch weniger als $450 \mathrm{~kb}$ von dem verantwortlichen Gen entfernt lokalisiert (Kleinjan und van Heyningen, 1998). 
Falls die Translokationsbruchpunkte der Probanden AS und GR die Expression von demselben Gen auf Chromosom 17q beeinflussen würden, so wäre dies eine Neuheit, da in der Literatur bisher kein Fall beschrieben wurde, in dem Positionseffekte über eine derart große Entfernung wirken. Dies würde die Frage aufwerfen, in welch großer Entfernung eine Chromosomenveränderung das krankheitsverursachende Gen noch beeinflussen könnte. Wenn Positionseffekte über dermaßen große Entfernungen wirken könnten, so hätte dies auch bei anderen Erkrankungen Auswirkungen auf die Mutationsanalyse in den jeweils verantwortlichen Genen. In diesem Fall müßte die DNA der Probanden, falls diese keine Mutation in dem entsprechenden Gen aufweist, auch in sehr weit vom entsprechenden Gen entfernten Regionen nach Mutationen durchmustert werden. Dies würde die Mutationssuche in Genen extrem erschweren.

Da die Probandin GR die 17;20 Translokation von ihrem gesunden Vater geerbt hat, wäre es möglich, daß diese Translokation nicht für das RSS verantwortlich ist. Auch sekundär zur Translokation entstandene Mutationen könnten den Phänotyp der Probandin GR erklären. Größere Deletionen konnten jedoch weder in der Bruchpunktregion auf Chromosom 17 noch auf Chromosom 20 festgestellt werden (Ayala-Madrigal, pers. Mitteilung). Eine andere Möglichkeit ist, daß durch die Translokation ein rezessives Gen unterbrochen wurde und die Probandin ein ebenfalls defektes Gen von der Mutter erhalten hat. In diesem Fall könnte das für das RSS verantwortliche Gen auf Chromosom 17 oder 20 lokalisiert sein. Die Probandin GR weist keine uniparentale Disomie für die Chromosomen 7, 8, 17 und 20 auf (Ayala-Madrigal, 1996), so daß parallel zu der Translokation entstandene uniparentale Disomien dieser Chromosomen als Ursache für das RSS ausgeschlossen werden können. Möglicherweise wird ein durch die Translokation unterbrochenes Gen nur vom paternalen Chromosom exprimiert. Wenn bei dem Vater der Probandin GR das maternale Chromosom 17 oder 20 von der Translokation betroffen ist, wäre erklärbar, warum dieser nicht vom RSS betroffen ist.

\subsection{Charakterisierung eines mit RSS einhergehenden Translokationsbruchpunktes auf Chromosom 1}

Die Translokationsbruchpunkte der Probanden AS und GR wurden auf molekularer Ebene nicht in der gleichen Region lokalisiert. Nachdem diese Daten bekannt wurden, konnte nicht mehr davon ausgegangen werden, daß bei beiden Translokationsprobanden die gleiche molekulare Ursache des RSS zugrunde liegt. Da die Translokation des Probanden AS gemeinsam mit dem RSS de novo auftrat, wird jedoch weiterhin angenommen, daß das RSS bei diesem Probanden durch die Translokation verursacht wurde. Es stellt sich jedoch die Frage, welcher der durch die Translokation entstandenen chromosomalen Bruchpunkte für die Entstehung des RSS verantwortlich ist. Um möglicherweise auf Chromosom 1 vorhandene Kandidatengene für das RSS identifizieren zu können, war es daher erforderlich, auch die Region des auf Chromosom 1 lokalisierten Translokationsbruchpunktes des Probanden AS einzugrenzen. Eine Orientierung in dieser Region wurde dadurch ermöglicht, daß bereits chimärische YACs mit einem Chromosom 17- und einem Chromosom 1-Anteil (765F4 und 864B4) über FISH auf Metaphasen des Probanden AS hybridisiert worden waren. Die Chromosom 1-Anteile dieser YACs waren distal vom Bruchpunkt auf Chromosom 1 lokalisiert worden und bildeten somit die distale Begrenzung der Bruchpunktregion auf Chromosom 1. Zudem waren den YACs 765F4 
und 864B4 vom Whitehead Institute Marker des Chromosoms 1 zugeordnet worden, die als distal vom Bruchpunkt lokalisierte Orientierungspunkte in genetischen und physikalischen Karten des Chromosoms 1 dienten.

Um eine Eingrenzung der Bruchpunktregion durchführen zu können, wurden zunächst 6 YACs, die vom Whitehead Institute für proximal von den Orientierungspunkten lokalisierte Loci positiv angegeben wurden, in Bezug zum Translokationsbruchpunkt des Probanden AS lokalisiert. Dazu wurden die YACs über FISH-Analysen auf Metaphasen des Probanden AS hybridisiert, wodurch zunächst der Bruchpunkt auf Chromosom 1 zwischen den YACs 918H5 und 854B9 lokalisiert wurde. Anschließend wurden FISH-Analysen mit 4 weiteren YACs, die zwischen den YACs 918H5 und 854B9 lokalisiert wurden, durchgeführt. Dadurch wurde der Translokationsbruchpunkt innerhalb des YACs 941F11 positioniert.

Von Belmouden et al. wurde 1997 ein YAC-Contig der Region 1q23-q25 vorgestellt, welches den YAC 941F11 und die in dieser Arbeit proximal bzw. distal zu diesem YAC positionierten YACs 874B11 und 854B11 enthält. Für die Region dieses Contigs wurde zudem auf der Basis von 3 seltenschneidenden Enzymen ( $S a c \mathrm{I}, M l u \mathrm{I}$ und NotI) eine Restriktionskarte erstellt (Belmouden et al., 1997). Dieser Karte ist zu entnehmen, daß der den Bruchpunkt überspannende YAC 941F11 den proximal vom Bruchpunkt lokalisierten YAC 874B11 vollständig einschließt. Der distale Bereich des YACs 941F11, der nicht mit dem YAC 874B11 überlappt und zudem den Translokationsbruchpunkt enthalten muß, hat eine Größe von $500 \mathrm{~kb}$. Dieser Bereich des YACs 941F11 überlappt wiederum $60 \mathrm{~kb}$ mit dem distal vom Bruchpunkt lokalisierten YAC 854B9. Demnach kann der Bereich des YACs 941F11, der den Translokationsbruchpunkt umfaßt, auf eine genomische Region von $440 \mathrm{~kb}$ eingegrenzt werden. Dieser Region wurden von Belmouden et al. (1997) zwar 3 STS-Stellen (R902C1, D1S2496 = WI5780 und AFM107yg1) zugeordnet, jedoch repräsentieren diese weder Gene noch ESTs.

Von Vollrath und Jaramillo-Babb (1999) wurde vor kurzem ein 2,2 Mb umfassendes BACContig des Chromosomensegments 1q24 vorgestellt, welches die Bruchpunktregion des Probanden AS enthält. Um die Bruchpunktregion exakt lokalisieren zu können, wurden die Daten der STS-Analysen der YACs 874B11 und 854B9 zu Hilfe genommen. Da die Bruchpunktregion des Probanden AS auf der proximalen Seite durch den YAC 874B11 begrenzt wird, stellen Marker, die auf diesem YAC lokalisiert wurden, die proximale Begrenzung der Bruchpunktregion dar. Marker, die auf dem distal zur Bruchpunktregion kartierten YAC 854B9 lokalisiert sind, begrenzen die Bruchpunktregion dagegen distal. Bei dem am weitesten distal gelegenen Marker, der dem YAC 874B11 zugeordnet wurde, handelt es sich nach Belmouden et al. (1997) um den Locus L928G11. Der am weitesten proximal gelegene Locus des YACs 854B9, der in das Contig von Vollrath und Jaramillo-Babb (1999) eingeordnet wurde, ist der Marker WI-3774 (Whitehead Institute). Somit kann der Translokationsbruchpunkt des Probanden AS innerhalb des von Vollrath und Jaramillo-Babb (1999) erstellten Contigs zwischen den Markern L928G11 und WI-3774 positioniert werden. Die Größe dieses Bereiches beträgt nach Vollrath und Jaramillo-Babb (1999) $600 \mathrm{~kb}$. Für die vollständige Abdeckung dieses Bereiches werden nach dem Contig von Vollrath und Jaramillo-Babb (1999) 7 BACs benötigt. Die weitere Eingrenzung der Bruchpunktregion ist somit schnell und einfach möglich.

In der $600 \mathrm{~kb}$ großen Bruchpunktregion wurden nach Vollrath und Jaramillo-Babb (1999) 4 ESTs (SGC33401, SHGC-11872, SGC33416 und stSG8166) kartiert. Da es prinzipiell möglich 
ist, daß das RSS aufgrund eines molekularen Defekts in der Region 1q24 entstanden ist, handelt es sich bei diesen ESTs um positionelle Kandidatengene für das RSS.

\subsection{Suche nach uniparentaler Disomie 7 in Probanden mit RSS}

Erbt eine Person beide Exemplare eines bestimmten Chromosoms von einem Elternteil, so liegt für dieses Chromosom eine uniparentale Disomie (UPD) vor (Engel, 1980). Je nachdem, ob beide homologen Chromosomen oder zwei identische Exemplare eines Chromosoms von einem Elternteil weitergegeben wurden, wird zwischen Hetero- und Isodisomie unterschieden. Durch Rekombinationen in der Meiose I des Elternteils kann es dazu kommen, daß für einige Abschnitte eines Chromosoms Heterodisomie und für andere Abschnitte Isodisomie vorliegt (Engel und DeLoizier-Blanchet, 1991).

Da eine maternale uniparentale Disomie des Chromosoms 7 (mUPD7) bei etwa $7 \%$ der RSSProbanden gefunden wird (Preece et al., 1999), ist davon auszugehen, daß bei einem Teil der Probanden ein oder mehrere Gene auf Chromosom 7 für die Entstehung des RSS verantwortlich sind. Die Suche nach UPD7 in RSS-Probanden wurde durchgeführt, um Probanden mit mUPD7 aus der Mutationsanalyse in Kandidatengenen auf Chromosom 17 ausschließen zu können, denn diese weisen vermutlich keinen Defekt in einem auf Chromosom 17 lokalisierten Gen auf. Die erzielten Ergebnisse konnten zudem im Rahmen einer genetischen Beratung genutzt werden, da nach Feststellung einer mUPD7 bei Probanden mit RSS das Wiederholungsrisiko der Eltern, ein erneut betroffenes Kind zu bekommen, als gering eingeschätzt werden kann (Kotzot, 1999).

Um eine UPD7 feststellen zu können, kamen 5 Mikrosatellitenmarker des Chromosoms 7 zum Einsatz. Es wurden 29 RSS-Probanden und deren Eltern, bzw. in 6 Fällen nur deren Mütter, genotypisiert. Für die Probanden war jeweils für mindestens 2 Loci eine eindeutige Aussage darüber zu treffen, von welchem Elternteil welches Allel geerbt wurde. Bei 3 Probanden (KW, MA und SB) wurde eine mUPD7 gefunden, da bei diesen ausschließlich maternale Allele nachgewiesen werden konnten. Es wurden sowohl reine Isodisomie (1x, Proband MA) als auch die Kombination von Iso- und Heterodisomie (2x, Proband KW und SB) beobachtet. Die Häufigkeit von mUPD7 bei RSS-Probanden läßt sich nach den vorliegenden Ergebnissen mit ca. $10 \%$ beziffern. Somit stimmt die in der vorliegenden Arbeit bei RSS-Probanden ermittelte Frequenz von mUPD7 ungefähr mit der von Preece et al. (1999) ermittelten Frequenz (7 \%) überein. Der Ansatz, Probanden mit RSS nach mUPD7 zu durchmustern, kann somit für die Diagnostik und die genetische Beratung als lohnenswert angesehen werden. Weiterhin kommen diese 3 Probanden mit mUPD7 für eine Mutationsanalyse in einem RSS-Kandidatengen auf Chromosom 17 nicht in Betracht.

\subsubsection{Entstehungsmechanismen von uniparentalen Disomien}

An der Entstehung von uniparentalen Disomien sind in der Regel zwei Ereignisse beteiligt: zwei meiotische, ein meiotisches und ein mitotisches oder zwei mitotische Ereignisse. Diese müssen innerhalb einer kurzen Zeitspanne auftreten, da ansonsten Mosaike mit einem großen Abortionsrisiko entstehen (Kotzot, 1999).

Mögliche Entstehungsmechanismen einer UPD sind: 
1. Eine disome Gamete wird von einer monosomen Gamete befruchtet. Die dadurch entstehende trisome Zygote verliert anschließend in frühen mitotischen Teilungen ein Chromosom. In einem Drittel dieser Fälle entsteht eine UPD (Kotzot, 1999).

Der Verlust eines Chromosoms aus einer trisomen Zellinie ist wahrscheinlich der häufigste Entstehungsmechanismus für uniparentale Disomien. Nahezu alle Fälle mit maternaler UPD15 zeigen Heterodisomie, was darauf schließen läßt, daß mindestens ein meiotisches Ereignis an der Entstehung dieser uniparentalen Disomien beteiligt ist (Kotzot, 1999). Zudem war es in einigen Fällen möglich, eine trisome Zellinie in Chorionzotten nachzuweisen (Cassidy et al., 1992). Ähnliche Beobachtungen wurden in Zusammenhang mit mUPD7 (Langlois et al., 1995) und mUPD16 (Robinson et al., 1997) gemacht.

2. Eine disome Gamete wird von einer nullisomen Gamete befruchtet.

Dieser Mechanismus kann nicht von der unter 1. aufgeführten Möglichkeit unterschieden werden (Kotzot, 1999).

3. Eine monosome Gamete wird von einer nullisomen Gamete befruchtet. Anschließend wird das monosom vorliegende Chromosom in frühen mitotischen Teilungen dupliziert.

Die Befruchtung einer nullisomen maternalen Gamete mit einer monosomen paternalen Gamete wird in den meisten Fällen mit paternaler UPD15 angenommen. Nahezu alle analysierten Fälle mit pUPD15 zeigen Isodisomie für das gesamte Chromosom 15, was am besten durch eine monosome Zygote und ein folgendes nondisjunction in frühen mitotischen Teilungen erklärbar ist.

4. Eine normale Gamete wird von einer normalen Gamete befruchtet. Anschließend geht in frühen mitotischen Teilungen ein homologes Chromosom verloren und das andere wird dupliziert.

Ein Mechanismus dieser Art wurde dreimal in der Literatur beschrieben. Petersen et al. (1992) berichteten von einem Fall mit mUPD21 und von einem Fall mit pUPD21. In diesen Fällen zeigten wiederholte cytogenetische Analysen den Verlust einer Zellinie mit deletiertem Chromosom 21 (Proband mit mUPD7) bzw. Ringchromosom 21 (Proband mit pUPD7). Diese Zellinien wurden durch solche mit zwei Chromosomen 21, die von einem Elternteil stammten, ersetzt. Eine UPD als Konsequenz von zwei mitotischen Ereignissen wird zudem in einem Fall mit Mosaik paternaler Isodosomie 11 angenommen (Dutly et al., 1998).

Bei den Probanden KW und SB, bei denen im Rahmen dieser Arbeit eine mUPD7 festgestellt wurde, lag für einen Teil des Chromosoms Heterodisomie und für einen anderen Teil Isodisomie vor. Daher ist davon auszugehen, daß bei diesen Probanden mindestens ein meiotisches Ereignis an der Entstehung der UPD beteiligt war. Da die Befruchtung einer disomen mit einer nullisomen Gamete sehr unwahrscheinlich ist (Antonarakis et al., 1993), hat die UPD bei diesen Probanden wahrscheinlich mit einer trisomen Zygote begonnen, die in nachfolgenden Teilungsschritten ein Chromosom verloren hat. Dieser Entstehungsmechanismus kann zu Mosaiken führen.

Bei dem Probanden MA wurde dagegen für alle getesteten Marker Isodisomie festgestellt. Diese UPD ist daher vermutlich das Ergebnis eines postzygotischen mitotischen Nondisjunction des maternalen Chromosoms 7 und dem Verlust des paternalen homologen Chromosoms. Dieser kann prämeiotisch, meiotisch oder postmeiotisch erfolgt sein. Ist der Verlust 
des paternalen Chromosoms 7 postmeiotisch erfolgt, so kann dies zu einem Mosaik mit trisomen Zellen in verschiedenen Geweben geführt haben. Da inklusive des CFTR-Locus nur 6 Loci des Chromosoms 7 analysiert wurden, ist jedoch nicht auszuschließen, daß für einen Teil des Chromosoms auch Heterodisomie vorliegt. Um eine nahezu sichere Angabe über den Entstehungsmechanismus dieser UPD treffen zu können, müßten etwa 35 weitere Loci des Chromosoms 7 untersucht werden (s. Preece et al., 1999).

\subsubsection{Phänotypische Konsequenzen von uniparentalen Disomien}

Beim Menschen sind 47 verschiedene uniparentale Disomien möglich: 44 für die 22 Autosomen eines jeden Elternteils, zwei für das maternale oder das paternale $\mathrm{X}$ und eine für das XY-Paar (Ledbetter und Engel, 1995). Bisher wurden 30 dieser Möglichkeiten beobachtet, wobei einige uniparentale Disomien mit einem Phänotyp verbunden waren.

Phänotypische Effekte, die in Zusammenhang mit uniparentalen Disomien auftreten, können auf verschiedene Ursachen zurückgeführt werden.

1. Ein Trisomie-Effekt kann während der Embryonalentwicklung zu spontanen Aborten oder zu einer Wachstumsretardierung führen (Kalousek et al., 1991 und 1993).

2. Durch eine UPD kann es dazu kommen, daß ein mutiertes rezessives Gen eines Elternteils bei dem Kind homozygot vorliegt. Beispielsweise wurde in Zusammenhang mit einer mUPD7 das homozygote Vorliegen von CFTR- und COL1A2-Mutationen beschrieben (Spence et al., 1988; Voss et al., 1989; Spotila et al., 1992). Befindet sich das rezessive Gen auf dem XChromosom, so ist auch das Auftreten seltener rezessiver X-chromosomaler Erkrankungen bei weiblichen Personen möglich, die zwei, wenigstens teilweise gleiche Kopien des X-Chromosoms von einem Elternteil erhalten haben (Engel und DeLoizier-Blanchet, 1991). Bisher ist jedoch nur ein solcher Fall bekannt (Quan et al., 1997). Zudem ist durch eine UPD die Übertragung einer X-gekoppelten Erkrankung vom Vater auf den Sohn möglich, wenn dieser sowohl das X- als auch das Y-Chromosom vom Vater erhalten hat. In diesem Zusammenhang beschrieben Vidaud et al. (1989) einen Jungen, der aufgrund einer paternalen Heterodisomie für die Chromosomen X und Y die Hämophilie A vom Vater erbte.

3. Ein durch eine UPD verursachter Phänotyp kann zudem auf einen Imprinting-Effekt zurückzuführen sein (Ledbetter und Engel, 1995). Genomisches Imprinting ist ein epigenetischer Prozeß, durch den in der männlichen und weiblichen Keimbahn eine geschlechtsspezifische Markierung einer chromosomalen Subregion stattfindet, so daß nur das maternale oder das paternale Allel der Nachkommen aktiv ist. Das nicht exprimierte Gen eines Elternteils wird als imprinted bezeichnet. Genomisches Imprinting wird nur bei Säugern gefunden. Es wird vermutet, daß dieses Phänomen an der Wachstumskontrolle und der Entwicklung des Embryos beteiligt ist (Bartolomei und Tilghman, 1997). Unterschiedliche Methylierungsmuster sind sehr wahrscheinlich das biochemische Äquivalent.

Die Existenz von imprinting Genen wurde zuerst in Mäusen gezeigt (Cattanach und Jones, 1994). Jedoch sind solche Gene, die bei Mäusen dem Imprinting unterliegen, nicht unbedingt auch beim Menschen geschlechtsspezifisch geprägt. Beim Menschen sind inzwischen jedoch mindestens 18 geschlechtsspezifisch exprimierte Gene beschrieben worden (Morison und Reeve, 1998). Ein in der Chromosomenregion 11p15.5 lokalisiertes maternal exprimiertes Gen 
ist für das Beckwith-Wiedemann-Syndrom verantwortlich und in der Region 15q11-q13 liegt sowohl ein für das Prader-Willi-Syndrom verantwortliches paternal exprimiertes Gen als auch ein für das Angelmann-Syndrom verantwortliches maternal exprimiertes Gen.

Genomisches Imprinting kann auf bestimmte Entwicklungsstadien oder bestimmte Gewebe begrenzt sein. Beispielsweise zeigten Kishino et al. (1997), daß das mit dem AS in Zusammenhang gebrachte Gen UBE3A der Chromosomenregion 15q11-q13 nur im Gehirn dem Imprinting unterliegt. Zudem ist es möglich, daß das imprinting Gen nicht vollständig ausgeschaltet ist, so daß partielles Imprinting vorliegt.

Bei Probanden mit RSS und einer mUPD7 könnte die Erkrankung ebenfalls auf einen Imprinting-Effekt zurückzuführen sein. Dies wird von verschiedenen Autoren vorgeschlagen, da bei der Genotypenanalyse verschiedener RSS-Probanden mit zahlreichen Loci kein Hinweis auf eine übereinstimmende Region mit Isodisomie gefunden wurde (Kotzot et al., 1995; Preece et al., 1999). Daß das RSS aufgrund des homozygoten Vorliegens eines mutierten rezessiven Gens entsteht, ist somit unwahrscheinlich. Das Vorhandensein eines spezifischen Phänotyps in Zusammenhang mit einer UPD deutet jedoch nicht zwangsläufig auf die Beteiligung von imprinting Genen hin, da UPD häufig mit plazentalen Mosaiken einhergeht, welche ihrerseits mit intrauteriner Wachstumsretardierung gekoppelt sind. Liegt ein plazentales Mosaik vor, so entsteht der mit UPD einhergehende Phänotyp eher aufgrund einer Population von trisomen Zellen in der Plazenta als aufgrund einer veränderten Dosis eines oder mehrerer geschlechtsspezifischer Gene (Morison und Reeve, 1998). Jedoch sind Probanden mit auf die Plazenta beschränkten Mosaiken mit trisomen Zellinien des Chromosoms 7 in der Regel phänotypisch unauffällig. Dies könnte jedoch in dem geringen Anteil normalerweise vorhandener trisomer Zellinien begründet sein (Robinson et al., 1997). Auch eine bisher nicht detektierte trisome Zellinie des Chromosoms 7 könnte für den RSS-Phänotyp verantwortlich sein (Joyce et al., 1999). Ein allgemeines Merkmal des RSS ist das Auftreten von Asymmetrien, die das Gesicht, den Rumpf oder die Extremitäten betreffen können. Diese Asymmetrien werden wahrscheinlich durch regionale Wachstumsunterschiede verursacht, welche durch das Vorhandensein von somatischen Mosaiken erklärbar wären (Joyce et al., 1999).

Bei den im Rahmen dieser Arbeit identifizierten Probanden KW, MA und SB mit einer mUPD7 ist das Auftreten des RSS somit vermutlich auf einen Imprinting-Effekt oder auf plazentale bzw. somatische Mosaike zurückzuführen.

Der Proband MA weist neben dem RSS auch die Symptome der Cystischen Fibrose (CF) auf. Molekulare Analysen zeigten, daß MA für die in Zusammenhang mit CF häufig auftretende Mutation $\Delta$ F508 homozygot ist, während die Mutter des Probanden heterozygot für $\Delta$ F508 ist und der Vater an dieser Position 2 normale Allele aufweist (Hehr et al., 1999). Somit ist die Entstehung der CF bei Proband MA darauf zurückzuführen, daß dieser aufgrund einer mUPD7 zwei Exemplare des mutierten Chromosoms der Mutter erhalten hat.

Der im Rahmen dieser Arbeit analysierte Proband MA ist der dritte Fall, bei dem im Zusammenhang mit einer maternalen UPD7 das homozygote Vorliegen einer Mutation im CFTRGen festgestellt wurde. Zwei weitere Fälle wurden bereits in der Literatur beschrieben (Spence et al. ,1988; Voss et al. 1989). Das Wiederholungsrisiko der Eltern des Probanden MA, ein 
erneut betroffenes Kind mit CF und RSS zu bekommen, ist gering, da ein weiteres Kind dieser Eltern nur dann die CF bzw. RSS aufweisen würde, wenn es erneut zu einer mUPD7 kommen würde.

\subsection{Suche nach RSS-Kandidatengenen auf Chromosom 7 und 15}

Da für das RSS von verschiedenen Autoren eine heterogene Ursache vorgeschlagen wurde, ist es möglich, daß durch die verschiedenen, in Zusammenhang mit dem RSS aufgetretenen, Chromosomenanomalien Hinweise auf die Lokalisierung verschiedener RSS-Gene erhalten werden können. Andererseits ist es auch möglich, daß sich hinter der Diagnose RSS verschiedene bisher nicht unterscheidbare Krankheiten verbergen (Graham et al., 1981; Wilson et al., 1985, Rogan, 1996).

Bisher wurden einige Kandidatengene für das RSS analysiert, die sich auf dem Chromosom 7 befinden, sowie ein Kandidatengen auf Chromosom 15. Diese Analysen werden im folgenden dargestellt.

Eine Möglichkeit, Hinweise auf die Entstehung des RSS zu erhalten, besteht darin, geschlechtsspezifisch exprimierte Gene des Chromosoms $7 \mathrm{zu}$ identifizieren und diese anschließend in RSS-Probanden ohne mUPD7 nach Mutationen zu durchsuchen. Dies setzt jedoch voraus, daß das RSS-Gen auf Chromosom 7 dem Imprinting unterliegt, was wie oben beschrieben nicht der Fall sein muß.

Führt der Verlust eines paternal exprimierten, das Wachstum fördernden Gens zum RSSPhänotyp, so kann dieser durch eine mUPD7 oder durch Deletionen bzw. andere Mutationen der paternalen Kopie des Gens verursacht werden. Ist der Phänotyp dagegen darauf zurückzuführen, daß ein maternal exprimiertes, das Wachstum unterdrückendes Gen in doppelter Dosis vorliegt, so könnte dieser entweder durch eine mUPD7 oder durch Duplikationen der maternalen Genkopie bzw. durch die Expression des Gens steigernde Mutationen verursacht werden. Zudem könnten Imprinting-Mutationen auftreten, die die geschlechtsspezifische Prägung des Gens verhindern, so daß von der Mutter erhaltene Genkopien ein paternales Imprinting oder vom Vater erhaltene Kopien ein maternales Imprinting aufweisen könnten (Kotzot et al., 1995; Preece et al., 1999).

Eggerding et al. (1994) beschrieben eine Probandin mit einem Isochromosom 7p und einem Isochromosom 7q. Molekulare Analysen zeigten eine paternale Isodisomie 7p und eine maternale Isodisomie 7q. Die Probandin wies zum Zeitpunkt der Geburt eine normale Größe auf, entwickelte jedoch nachträglich eine Wachstumsretardierung. Mit zwei Jahren wies sie eine leichte Extremitätenasymmetrie, ein dreiecksförmiges Gesicht und bilaterale Klinodactylie der fünften Finger auf. Diese Probandin ist die einzige mit mUPD7 ohne intrauterine Wachstumsretardierung und die einzige, welche nur eine mUPD für den langen Arm von Chromosom 7 aufweist. Da die zur Disomie führende Umordnung postmeiotisch erfolgt sein muß, kann sie somit auf den Fetus beschränkt sein (Kotzot et al., 1995). Kotzot et al. (1995) vermuteten, daß aufgrund von Aneuploidie auftretende Funktionsstörungen der Plazenta die pränatale Wachstumsretardierung von RSS-Probanden verursachen. Ein dem Imprinting unterliegendes RSSGen muß demnach auf dem q-Arm von Chromosom 7 liegen, da die von Eggerding beschrie- 
bene Probandin nur disomisch für den maternalen q-Arm dieses Chromosoms ist (Kotzot et al., 1995).

Miyoshi et al. (1999) beschrieben eine RSS-Probandin mit mUPD7 und einem paternalen Ringchromosom, welches die Region 7p13-q11 beinhaltet. Wenn ein vermeintliches RSS-Gen auf Chromosom 7 paternal exprimiert wird, so ist demnach ein Ausschluß aus der Region 7p13-q11 möglich, da ein paternal exprimiertes Gen dieses Bereiches exprimiert würde (Miyoshi et al., 1999).

Aufgrund der Beteiligung an der Wachstumskontrolle wurde das epidermal growth factor receptor gene (EGFR) als Kandidatengen für das RSS vorgeschlagen, obwohl dieses Gen auf dem kurzen Arm von Chromosom 7 lokalisiert ist und ein RSS-Gen, welches dem Imprinting unterliegt, eher auf dem langen Arm vermutet wird (Kotzot et al., 1995). EGFR kartiert in der Region 7p12. Der Vergleich mit dem Genom der Maus zeigte, daß die syntäne Region auf dem Chromosom 11 der Maus geschlechtsspezifisch exprimiert wird. In Mäusen führt UPD dieser Region zu Größenunterschieden der Mäuse. Daher analysierten Wakeling et al. (1998), ob EGFR beim Menschen geschlechtsspezifisch exprimiert wird. Die Autoren konnten jedoch keinen Hinweis auf Imprinting finden, statt dessen wurde die biallelische Expression in einer Reihe von humanen Geweben gezeigt. Auch Fibroblasten und Lymphoblasten von RSS-Probanden zeigten normale Expression, so daß es als unwahrscheinlich anzusehen ist, daß Defekte im EGFR-Gen für das RSS verantwortlich sind.

Auch die insulin-like growth factor binding proteins 1 und 3 (IGFBP1, IGFBP3) sind auf dem p-Arm lokalisiert und zwar in der Region 7p12-p13, die, wie oben beschrieben, eine syntäne Region auf dem Chromosom 11 der Maus besitzt. Da vermutet wird, daß diese Gene das Zellwachstum regulieren (Ehrenborg et al., 1992) suchten Eggermann et al. (1999a) über SSCPAnalysen in Proben von 49 RSS-Probanden nach Mutationen in diesen Genen. Die Autoren konnten jedoch keine funktionellen Mutationen feststellen. Kurz darauf wurde gezeigt, daß IGFBP1 und IGFBP3 in einer Reihe von Geweben biallelisch exprimiert werden (Eggermann et al., 1999b), so daß eine Beteiligung dieser Gene an der Entstehung des RSS-Phänotyps unwahrscheinlich ist.

Das paternal exprimierte Gen PEG1/MEST (PEG = paternally expressed gene; MEST = mesoderm-specific transcript) unbekannter Funktion wurde von Nishita et al. (1996) und Kobayashi et al. (1997) der humanen Chromosomenregion 7q32 zugeordnet. Da dieses Gen paternal exprimiert wird und auf Chromosom 7q lokalisiert ist, suchten Riesewijk et al. (1998) über SSCP-Analysen in 49 RSS-Probanden nach Mutationen innerhalb dieses Gens. Die Autoren konnten jedoch keine funktionellen Mutationen feststellen. Auch die Methylierungsmuster in der 5'-Region von PEG1/MEST waren in 35 RSS-Probanden normal, so daß anzunehmen ist, daß dieses Gen in der Mehrheit der RSS-Fälle nicht an der Entstehung des RSS beteiligt ist (Riesewijk et al., 1998). Lefebvre et al. (1998) unterbrachen das Mest-Gen von Mäusen durch Gen-Targeting in embryonalen Stammzellen. Die Autoren zeigten so, daß die paternale Weitergabe des unterbrochenen Gens zu Wachstumsretardierung, erhöhter prä- und postnataler Sterblichkeit und einem auffälligen mütterlichen Verhalten führte.

Miyoshi et al. (1998) identifizierten ein maternal exprimiertes Gen der Maus, welches identisch mit dem growth factor receptor-bound protein 10 (Grb10) ist. Das humane GRB10-Gen wurde 
von Jerome et al. (1997) über FISH in der Region 7p11.2-p12 kartiert. Dieses Gen codiert einen negativen Regulator des Insulin- und IGFI/II-Signalweges. Daher schlugen Miyoshi et al. (1998) GRB10 als Kandidatengen für das RSS vor. Mergenthaler et al. (1999) fanden geschlechtsspezifische Methylierungsmuster in der 5'-Region von GRB10, was darauf hindeutet, daß GRB10 auch beim Menschen dem Imprinting unterliegt. Die Autoren analysierten die codierende Region von GRB10 in 52 RSS-Probanden, fanden jedoch keine funktionellen Mutationen. Die Suche nach Imprinting-Mutationen steht jedoch noch aus (Mergenthaler et al., 1999).

Hinweise darauf, daß ein auf Chromosom 7 lokalisiertes RSS-Gen möglicherweise nicht dem Imprinting unterliegt, wurden vor kurzem von Joyce et al. (1999) publiziert. Die Autoren fanden bei Mutter und Tochter mit RSS-Symptomen, jedoch ohne intrauterine Wachstumsretardierung, eine invertierte Duplikation in der Region 7p12.1-p13 und wiesen nach, daß die Duplikation bei der Mutter de novo auf dem Chromosom 7 paternalen Ursprungs entstanden ist. Daher vermuteten Joyce et al. (1999), daß das verantwortliche RSS-Gen nicht dem Imprinting unterliegt, sondern daß eine Extrakopie der Region 7p12.1-p13 in einem RSSähnlichen Phänotyp resultiert. Die Autoren untersuchten 8 RSS-Probanden auf submikroskopische Duplikationen dieser Region, konnten solche jedoch nicht feststellen, was möglicherweise auf die geringe Anzahl an untersuchten Probanden zurückzuführen ist. Joyce et al. (1999) vermuten, daß der RSS-Phänotyp bei Probanden mit mUPD7 aufgrund einer nicht detektierten trisomen Zellinie des Chromosoms 7 entsteht. Dafür spricht möglicherweise auch der Umstand, daß bei Probanden mit paternaler UPD7 kein zu dem des RSS entgegengesetzter Phänotyp mit Hochwuchs festgestellt wird. Höglund et al. (1994) beschrieben eine Probandin mit rezessiv vererbter kongenitaler Chlorid-Diarrhoe (CLD; OMIM 214700) und einer pUPD7, welche eine normale Größe aufwies. Zudem wurde von Pan et al. (1998) ein Proband mit pUPD7 beschrieben, welcher zudem homozygot für die CFTR-Mutation $\triangle$ F508 ist. Dieser Proband wies neben den Symptomen der CF einen kompletten Situs inversus, unbewegliche Cilien und mit 6 Monaten eine Wachstumsretardierung auf. Kotzot et al. (1995) sehen die Möglichkeit, daß undetektierte Mosaike mit trisomen Zellinien für den RSS-Phänotyp verantwortlich sind dagegen als sehr unwahrscheinlich an, da die Autoren in diesem Fall ein schwereres Krankheitsbild mit mentaler Retardierung erwarten würden.

Verschiedene Autoren berichteten über Merkmale des RSS in Probanden mit einem Ringchromosom 15 [r(15)] (Wilson et al., 1985; Francke et al, 1988; Dolon et al., 1993; Tamura et al., 1993; Rogan, 1996) oder einer Deletion del(15)(q26.1-qter) (Roback et al., 1991). Ob diese Probanden mit r(15) bzw. del(15) jedoch ein 'echtes' RSS aufweisen, ist unklar. Von einigen Autoren wurden Probanden mit einem r(15) unter einem Ringchromosom 15-Syndrom zusammengefaßt (Wilson et al., 1985; Rogan et al., 1996), während andere Autoren diese als RSS-Probanden bezeichneten (Tamura et al., 1993; Abu-Amero et al., 1997).

Francke et al. (1988) vermuteten, daß in der Region, die bei allen Probanden mit r(15) deletiert ist, ein oder mehrere Gene lokalisiert sind, die den RSS-ähnlichen Phänotyp verursachen. Durch Vergleich der cytogenetischen Beschreibungen verschiedener Ringchromosomen 15 ordneten Tamura et al. (1993) die SRO (smallest region of deletion overlap, kleinster Überlappungsbereich aller Deletionen) der Region 15q26.3 zu. 
Bei mehreren Probanden mit r(15) bzw. del(15) wurde eine Deletion einer Kopie des Gens für den Rezeptor des insulinähnlichen Wachstumsfaktors (IGF1R) festgestellt (Francke et al., 1988; Roback et al., 1991; Tamura et al., 1993; Rogan et al., 1996). Die Liganden, Rezeptoren und Bindeproteine der Insulin-ähnlichen Wachstumsfaktoren spielen sowohl prä- als auch postnatal eine wichtige Rolle bei der Regulierung von Wachstum und Entwicklung (Milner et al., 1984). Daher vermuteten Tamura et al. (1993), daß die reduzierte Expression von IGF1R bei Probanden mit Deletionen im IGF1R-Gen für die Wachstumsretardierung verantwortlich ist. IGF1R wurde in der Region 15q26.1 kartiert (Roback et al., 1991). Tamura et al. (1993) berichteten jedoch, daß das IGF1R-Gen bei einer Probandin mit Ringchromosom 15 deletiert ist, die nur eine Deletion der Region 15q26.3 aufweist. Da Tamura et al. (1993) die Deletionsregion aufgrund von cytogenetischen Analysen bestimmten, ist es jedoch möglich, daß die Deletion der Probandin größer ist, als von den Autoren angegeben.

Francke et al. (1988) stellten bei 3 von 5 Probanden mit r(15) eine Deletion des IGF1R-Gens fest. Rogan et al. (1996) fanden diese Deletion bei 4 von 5 Probanden mit $r(15)$ und in einem Proband mit del(15)(q26.1-qter), jedoch in keinem von 5 Probanden mit RSS und normalem Karyotyp. Klinisch waren Probanden mit r(15) bei denen das IGF1R-Gen deletiert ist, nicht von solchen ohne die Deletion dieses Rezeptors zu unterscheiden (Rogan et al., 1996). Die Wachstumsretardierung der Probanden mit r(15) ist somit nicht immer mit einem IGF1RDefekt assoziiert (Rogan et al., 1996).

Um zu analysieren, ob die Wachstumsdefizienz in RSS-Probanden ohne Chromosom 15Abnormalitäten mit IGF1R-Mutationen assoziiert ist, suchten Abu-Amero et al. (1997) in Proben von 33 RSS-Probanden nach Deletionen im IGF1R-Gen. Die Autoren konnten jedoch keine Deletion feststellen. Zudem wurden zwei wichtige funktionelle Regionen des IGF1RGens in diesen Probanden über SSCP-Analysen auf Mutationen durchsucht, wobei keine funktionelle Mutation identifiziert werden konnte.

In diesem Zusammenhang ist es interessant zu erwähnen, daß knock out-Mäuse, die hemizygot für den Igf1r-Locus sind, keine Wachstumsretardierung aufweisen, während homozygote nullMäuse wachstumsretardiert sind, eine verzögerte Ossification, ZNS-Abnormalitäten und Hypoplasie aufweisen (Liu et al., 1993; Baker et al., 1993).

Die Wachstumsretardierung in Probanden mit r(15) könnte wenigstens zum Teil auf Fehlverteilungen des Ringchromosoms während der frühen Embryonalentwicklung zurückgeführt werden. Durch den Verlust des Ringchromosoms während der Mitose können somatische Mosaike entstehen, die häufig mit reduziertem Wachstum einhergehen (Kosztolányi, 1987). Die skeletale Asymmetrie der Probanden könnte demnach durch asymmetrische Mosaike hervorgerufen worden sein.

Ist die monosome Zellinie der somatischen Mosaike nicht überlebensfähig, kann durch ein zweites somatisches Nondisjunction eine Zellinie mit uniparentaler Disomie von Chromosom 15 entstehen. Sowohl Monosomie als auch Disomie des intakten Chromosoms kann durch uneinheitliche Repräsentation von maternalen und paternalen Allelen in Mosaikzellinien entdeckt werden. In der Tat fanden Rogan et al. (1996) bei einem Probanden für verschiedene Loci der Region 15q eine bevorzugte Amplifikation eines Allels.

Rogan et al. (1996) wiesen zudem darauf hin, daß bei Probanden mit r(15) zum Teil Symptome festgestellt werden, die typischerweise beim Prader-Willi-Syndrom (PWS) oder Angelman- 
Syndrom (AS) vorkommen. Beispielsweise weisen $39 \%$ der Probanden mit r(15) keine oder eine verzögerte Sprachentwicklung auf (Symptom des AS), 30 \% zeigen Kryptorchismus und 23 \% haben kleine Hände (Symptome des PWS). Basierend auf dem Phänotyp von Probanden mit r(15) und der elterlichen Herkunft der Ringchromosomen stellten Rogan et al (1996) die Vermutung auf, daß mitotische Instabilität der Ringchromosomen in einigen Fällen zu Mosaiken mit UPD15 führt.

Da das IGF1R-Gen nicht bei allen Probanden mit $\mathrm{r}(15)$ deletiert ist, könnte ein anderes auf Chromosom 15 lokalisiertes Gen für den Phänotyp der Probanden verantwortlich sein. Um dieses identifizieren zu können, wäre es unabdingbar, die Deletionsregion der Probanden mit r(15) molekular zu charakterisieren. Rogan et al. (1996) führten bereits MikrosatellitenAnalysen bei 5 Probanden mit r(15) oder del(15) durch. Bei einem Probanden waren alle Loci proximal von D15S3 nicht deletiert. D15S3 war ebenfalls nicht deletiert, so daß ein Kandidatengen distal von diesem Locus lokalisiert sein müßte.

\subsection{Ausblick}

Im Rahmen dieser Arbeit wurde das Gen von Karyopherin alpha 2 (KPNA2) in unmittelbarer Umgebung des auf Chromosom 17 lokalisierten Translokationsbruchpunktes des RSS-Probanden AS kartiert. Zudem wurde eine hochsignifikante Assoziation zwischen dem im KPNA2Gen identifizierten Haplotyp 1 und dem RSS festgestellt. Das gefundene Kopplungsungleichgewicht ist ein guter Hinweis darauf, daß sich ein für das RSS verantwortliches Gen in unmittelbarer Nähe zum Haplotyp 1 befindet.

Da in der vorliegenden Arbeit die Häufigkeit der Haplotypen bei RSS-Probanden mit der in einer Reihe von gesunden Kontrollpersonen verglichen wurde, ist jedoch nicht mit Sicherheit auszuschließen, daß die untersuchte Gruppe der Probanden und die Kontrollgruppe aus genetisch unterschiedlichen Subpopulationen stammen. In diesem Fall könnten sich die Häufigkeiten der Haplotypen in den verschiedenen Untergruppen der Bevölkerung unterscheiden. Daher sollten die Haplotypen der Eltern von allen analysierten 31 Probanden bestimmt werden, um die nicht an die Probanden weitergegebenen Haplotypen als interne Kontrollen nutzen zu können. Die auf diese Weise erhaltenen Daten könnten mit dem HRR-Test (haplotype relative risk test) (Knapp et al., 1993) oder dem TDT (transmission disequilibrium test) (Spielman et al., 1993) ausgewertet werden. Kann über diese Tests bestätigt werden, daß eine Assoziation zwischen dem RSS und Haplotyp 1 vorliegt, so wäre davon auszugehen, daß sich in der Umgebung von Haplotyp 1 ein RSS-Gen befindet.

Da der Haplotyp 1 im KPNA2-Gen identifiziert wurde und sich dieses Gen zudem in der Region des Translokationsbruchpunktes von Proband AS befindet, ist KPNA2 ein gutes Kandidatengen für das RSS. Bei einer Mutationssuche in 31 RSS-Probanden wurden über die direkte Sequenzierung der Exons dieses Gens zwar keine Mutationen identifiziert, jedoch werden über diese Methode bestimmte Mutationstypen, nämlich solche, die ganze Exons betreffen, nicht erfaßt. Um aufzuklären, ob KPNA2 ein für die Erkrankung verantwortliches Gen ist, wäre es daher erforderlich aufzuklären, ob die RSS-Probanden beispielsweise Deletionen oder Duplikationen der amplifizierten Genbereiche oder Inversionen in diesem Gen aufweisen. 
Sollte KPNA2 bei diesen Analysen als RSS-Kandidatengen ausgeschlossen werden, so wäre es für die Fortsetzung der positionellen Klonierung des RSS vor allem wichtig in der Bruchpunktregion 17q23-q24 des Probanden AS weitere RSS-Kandidatengene zu identifizieren. Dies kann erfolgen, indem der vorgestellten physikalischen Karte dieser Region weitere ESTs zugeordnet werden. Für diese Analysen bieten sich zunächst ESTs an, die in der RH-Karte des NCBI zwischen den Markern D17S807 und D17S795 lokalisiert sind. ESTs, die in der Region des den Bruchpunkt überspannenden PAC-Klons 81B9 kartiert würden, müßten anschließend als Kandidatengene für das RSS analysiert werden.

Langfristig wird die Möglichkeit angestrebt, durch die Identifizierung des RSS-Gens die Voraussetzung für eine genaue Diagnose und genetische Beratung betroffener Personen zu schaffen. 


\section{Zusammenfassung}

Im Rahmen der positionellen Klonierung eines für das Russell-Silver-Syndrom (RSS) verantwortlichen Gens wurde eine hochauflösende physikalische Karte der Region 17q23-q24 erstellt, da in dieser Region der Translokationsbruchpunkt des RSS-Probanden AS mit einer 1;17 de novo Translokation lokalisiert ist. Diese Karte enthält 17 YACs, 20 PACs und 3 Cosmide. Die etwa $5 \mathrm{Mb}$ genomischer DNA umfassende Karte wurde ausgehend von einem in Vorversuchen erstellten YAC-Contig generiert, indem im Rahmen dieser Arbeit 51 Loci für eine sequence tagged site (STS)-content-Kartierung der YACs eingesetzt wurden. Da nicht alle getesteten Loci in der Region kartiert werden konnten, wurden dem Contig unter Einbeziehung der bereits zur Verfügung stehenden Daten 48 Loci (30 STSs/18 Loci für Gene/ESTs) zugeordnet und diese in eine physikalische Karte integriert. 21 dieser Loci wurden im Verlauf dieser Arbeit über die Sequenzierung von Klon-Endfragmenten generiert. Aufgrund der Ergebnisse der STS-content-Kartierung, FISH-Analyse und Sequenzierung von PCR-Produkten verschiedener Klone wurde festgestellt, daß 8 Loci in der kartierten Region dupliziert vorliegen. Daher wurden diese Loci zweifach in das YAC-Contig integriert, so daß 56 Loci in der Region kartiert wurden.

Eine restriktionsenzymatische Kartierung erfolgte mit 6 den Bruchpunkt überspannenden YACs. Für 5 dieser YACs wurde eine etwa 1,7 Mb umfassende NotI-Restriktionskarte aufgestellt. Die Anordnung der jeweiligen Fragmente in den YACs wurde durch partielle Spaltungen der YAC-DNA ermittelt. Darüber hinaus konnte eine Zuordnung von 3 Cosmiden, 3 ESTs und einer Sonde für das Exon 1 des Gens KPNA2 zu bestimmten Restriktionsfragmenten der YACs erreicht werden.

Um die Bruchpunktregion weiter einzugrenzen, sollte diese zunächst mit Cosmid-Klonen überbrückt werden. Daher wurde aus dem YAC 875C4 eine Cosmid-Bibliothek konstruiert, da dieser YAC FISH-Ergebnissen zufolge als den Bruchpunkt überspannend angesehen wurde. Für die $370 \mathrm{~kb}$ lange genomische Region des YACs 875C4 wurde eine physikalische EcoRIRestriktionskarte aus 45 Klonen erstellt. Überlappende Cosmide wurden über Hybridisierungen mit T3-/T7-Endsonden, Southern-Blot-Analysen sowie über PCR-Analyse mit in dieser Arbeit generierten oder bereits bekannten Loci aus der Region identifiziert. Cosmide aus verschiedenen Bereichen des erstellten Contigs wurden durch Fluoreszenz-in situ-Hybridisierungen (FISH) an Metaphasechromosomen des Probanden AS hybridisiert. Dadurch zeigte sich, daß sämtliche Cosmide des Contigs proximal zum Translokationsbruchpunkt des Probanden kartieren. Somit wurden über die Subklonierung des YACs 875C4 in Cosmide keine den Bruchpunkt überspannenden Klone erhalten.

Um die in YACs klonierte Bruchpunktregion dennoch weiter eingrenzen zu können, wurde eine humane genomische PAC-Bibliothek (UK HGMP Resource Center) durch PCR-Analyse oder Hybridisierungen auf PAC-Filter durchmustert. Die PCR-Analyse erfolgte mit insgesamt 20 Loci der Bruchpunktregion, darunter 15 im Rahmen dieser Arbeit generierte Loci, 1 bekannte STSs und 4 ESTs. Auf diese Weise wurden insgesamt 20 PAC-Klone der Region identifiziert, die für mindestens einen der eingesetzten Suchloci als positiv verifiziert werden konnten. Diese Klone wurden mittels Restriktionsanalyse, Pulsfeldgelelektrophorese, STScontent-Kartierung und FISH an Metaphasen des RSS-Probanden AS mit 1;17 Translokation 
hinsichtlich ihrer Größe und Lokalisierung charakterisiert und in die hochauflösende physikalische Karte der Bruchpunktregion integriert. Über die durchgeführten Analysen konnten 2 PAC-Klone identifiziert werden, die den Translokationsbruchpunkt des Probanden AS auf Chromosom 17 überspannen.

Über Datenbankanalysen konnten der Bruchpunktregion 17q23-q24 von Proband AS 11 sequenzierte BACs zugeordnet werden, wobei jedoch kein Klon in der unmittelbaren Umgebung des Bruchpunktes identifiziert wurde. Indem die Sequenzen dieser Klone mit bekannten cDNA-Sequenzen verglichen wurden, konnte die Exon-Intron-Struktur der Gene APOH und CACNLG ermittelt werden. Zudem konnte von den Genen PRKCA, PRKAR1A und KIAA0054 ein Teil der Exons identifiziert werden. Aufgrund von Sequenzvergleichen mit veröffentlichten Daten ließen sich diesen BACs weiterhin 12 ESTs zuordnen, die vorher nicht in der Region kartiert waren.

Da Probanden mit mUPD7 nicht für Mutationsanalysen in Kandidatengenen auf Chromosom 17 in Betracht kommen, wurden 29 RSS-Probanden mit 5 polymorphen Markern des Chromosoms 7 analysiert. Über diese Analysen wurde bei 3 Probanden eine mUPD7 festgestellt.

Über Sequenzvergleiche mit einer im Rahmen dieser Arbeit generierten STS wurde festgestellt, daß das Gen Karyopherin $\alpha 2$ (KPNA2) in der Bruchpunktregion des Probanden AS auf Chromosom 17 kartiert. Dieses Gen wurde im Verlauf dieser Arbeit über PCR-Analysen mit in dieser Arbeit generierten Loci und über Southern-Blot-Analysen mit einem maximalen Abstand von $35 \mathrm{~kb}$ zum Translokationsbruchpunkt kartiert. Über Sequenzierung der genomischen Sequenz dieses Gens und einen anschließenden Vergleich mit der bekannten cDNA-Sequenz wurde die Exon-Intron-Struktur dieses Gens ermittelt. Anschließend wurde über die Sequenzierung der identifizierten 11 Exons dieses Gens in 31 RSS-Probanden nach Mutationen gesucht. Über diese Analysen waren keine funktionellen Mutationen feststellbar. Bei den Probanden wurden jedoch zwei Haplotypen bestehend aus 6 im KPNA2-Gen lokalisierten Diallelpolymorphismen, welche im Rahmen der vorliegenden Arbeit identifiziert wurden, gefunden. In einer Kontrollgruppe aus 36 gesunden Personen wurden bei Analyse dieser Polymorphismen 4 Haplotypen identifiziert. In einer Assoziationsstudie wurde schließlich festgestellt, daß Haplotyp 1 eine signifikante Assoziation mit dem RSS zeigt. Neben der Lokalisierung dieses Haplotyps in unmittelbarer Umgebung des Translokationsbruchpunktes von Proband AS auf Chromosom 17 liefert die gefundene Assoziation einen weiteren Hinweis darauf, daß in dieser Region ein RSS-Gen lokalisiert ist.

Um zu überprüfen, ob ein Teil der RSS-Probanden eine Deletion oder eine uniparentale Disomie (UPD) in der Region 17q23-q24 aufweist, wurde bei 31 RSS-Probanden eine Mikrosatelliten-Analyse mit bis zu 5 Markern der Region durchgeführt. Über diese Analysen konnte jedoch bei keinem Probanden eine Deletion oder UPD nachgewiesen werden.

Über FISH-Analysen mit YAC-Klonen des Chromosoms 1 an Metaphasen des Probanden AS wurde der Translokationsbruchpunkt auf Chromosom 1 der Region 1q24 zugeordnet.

FISH-Analysen mit YACs und Cosmiden an Metaphasen einer Probandin mit RSS und einer 17;20 Translokation führten zur Kartierung des Bruchpunktes auf Chromosom 17 in der Region $17 \mathrm{q} 25$. 


\section{Literaturverzeichnis}

Abidi F. E., Wada M., Little R. D., Schlessinger D. (1990). Yeast artificial chromosomes containing human Xq24-Xq28 DNA: library construction and representation of probe sequences. Genomics 7: 363-376.

Abramowicz H. K., Nitowsky H. M. (1977). Reproductive ability of an adult female with Silver-Russell syndrome. J. Med. Genet. 14: 134-137.

Abu-Amero S., Price S., Wakeling E., Stanier P., Trembath R., Preece M. A., Moore G. E. (1997). Lack of hemizygosity for the Insulin-like growth factor I receptor gene in a quantitative study of 33 Silver Russell syndrome probands and their families. Eur. J. Hum. Genet. 5: 235-241.

Adams M. D., Kelley J. M., Gocayne J. D., Dubnick M. H., Polymeropoulos H., Xiao H., Merril A., Wu B., Olde R. F., Moreno R. F., Kerlavage A. R., McCombie W. R., Venter J. C. (1991). Complementary DNA sequencing: Expressed sequence tags and human genome project. Science 252: 1651-1656.

Al-Fifi S., Teebi A. S., Shevell M. (1996). Autosomal dominant Russell-Silver syndrome. Am. J. Med. Genet. 61: 96-97.

Antequera F., Bird A. (1994). Predicting the total number of human genes. Nat. Genet. 8: 114.

Antonarakis S. E., Blouin J.-L., Maher J., Avramopoulos D., Thomas G., Talbot C. C. Jr. (1993). Maternal uniparental disomy for human chromosome 14, due to loss of a chromosome 14 from somatic cells with $\mathrm{t}(13 ; 14)$ trisomy 14 . Am. J. Hum. Genet. 52: 11451152 .

Antonarakis S. E., Kazazian H. H., Orkin S. H. (1985). DNA polymorphism and molecular pathology of the human globin gene clusters. Hum. Genet. 69: 1-14.

Antonarakis S. E., Kazazian H. H., Tuddenham G. D. (1995). Molekular etiology of factor VIII deficiency in hemophilia A. Hum. Mutat. 5: 1-22.

Ayala-Madrigal M. L., Shaffer L. G., Ramirez-Dueñas M. L. (1996). Silver-Russell syndrome and exclusion of uniparental disomy. Clin. Genet. 50: 494-497.

Baas F., Bikker H., van Ommen G. J., de Vijlder J. J. (1984). Unusual scarcity of restriction site polymorphism in the human thyroglobulin gene. A linkage study suggesting autosomal dominance of a defective thyroglobulin allele. Hum. Genet. 67: 301-305.

Bärlund M., Nupponen N. N., Karhu R., Tanner M. M., Paavola P., Kallioniemi O.-P., Kallioniemi A. (1998). Molecular cytogenetic mapping of $24 \mathrm{CEPH}$ YACs and 24 genespecific large insert probes to chromosome 17. Cytogenet. Cell Genet. 82: 189-191.

Baker J., Liu J. P., Robertson E. J., Efstratiadis A. (1993). Role of insulin-like growth factors in embryonic and postnatal growth. Cell 75: 73-82. 
Balaban-Mahlenbaum G., Gilbert F., Nichols W. W., Hill R., Shields J., Meadows A. T. (1981). A deleted chromosome no. 13 in human retinoblastoma cells: relevance to tumorigenesis. Cancer Genet. Cytogenet. 3: 243-250.

Baldini A., Ross M., Nizetic D., Vatcheva R., Lindsay E. A., Lehrach H., Siniscalco M. (1992). Chromosomal assignment of human YAC clones by fluorescence in situ hybridization: use of single-yeast-colony PCR and multiple labeling. Genomics 14:181-184.

Ballabio A., Carozzo R., Parerti G., Gil A., Zollo M., Persico M. G., Gillard E., Affara N., Yates J., Ferguson-Smith M. A., Frants R. R., Eriksso A. W., Andria G. (1989). Molecular heterogeneity of steroid sulfatase deficiency: A multicenter study on 57 unrelated patients, at DNA and protein levels. Genomics 4: 36-40.

Ballabio A. (1993). The rise and fall of positional cloning? Nat. Genet. 3: 277-279.

Ballhausen W. G. (1998). Molekulare Screeningmethoden in der Humangenetik. Medgen 10: 313-315.

Bartolomei M. S., Tilghman S. M. (1997). Genomic imprinting in mammals. Annu. Rev. Genet. 31: 493-525.

Bass E., Smith jr. S. W., Stevenson R. E., Rosse W. F. (1983). Further evidence for location of the sperocytosis gene on chromosome 8. Ann. Intern. Med. 99: 192-193.

Bates G. ,Valdes J., Hummerich H., Baxendale S., Le Paslier D., Monaco A., Tagle D., McDonald M., Altherr M., Ross M., Brownstein B., Bentley D., Wasmutrh J., Gusella J., Cohen D., Collins F., Lehrach H. (1992). Characterization of a yeast artificial chromosome contig spanning the Huntington's disease gene candidate region. Nat. Genet. 1: 180-187.

Behar E., Chao N. J., Hiraki D. D., Krishnaswamy S., Brown B. W., Zehnder J. L., Grumet F. C. (1996). Polymorphism of adhesion molecule CD31 and ist role in acute graft-versus-hostdisease. New Eng. J. Med. 334: 286-291.

Bellanné-Chantelot C., Barrillot E., Lacroix B., LePaslier D., Cohen D. (1991). A test case for physical mapping of human genome by repetitive sequence fingerprints: construction of a physical map of a $420 \mathrm{~kb}$ YAC subcloned into cosmids. Nucleic Acids Res. 19: 505-510.

Bellis M., Gerard A., Charlieu J. P., Marcais B., Brun M. E., Viegas-Pequignot E., Carter D. A., Roizes G. (1991). Construction and characterization of a partial library of yeast artificial chromosomes from human chromosome 21. DNA Cell Biol. 10: 301-310.

Belmouden A., Adam M. F., Dupont de Dinechin S., Brezin A. P., Rigault P., Chumakov I., Bach J. F., Garchon H. J. (1997). Recombinational and physical mapping of the locus for primary open-angle glaucoma (GLC1A) on chromosome 1q23-q25. Genomics 39:348-58.

Bickmore W., Bird A. P. (1992). The use of restriction endonuclease to detect and isolate genes from mammalian cells. Methods Enzymol. 216: 224-244. 
Bird A. P. (1987). CpG islands as gene markers in the vertebrate nucleus. Trends Genet. 3: 342-347.

Birnboim H. C., Doly J. (1979). A rapid alkaline extraction procedure for screening recombinant plasmid DNA. Nucleic Acids Res. 7: 1513-1523.

Black J. (1961). Low birth weight dwarfism. Arch. Dis. Child. 36: 633-644.

Boissy R.E., Zhao H., Oetting W.S., Austin L.M., Wildenberg S.C., Boissy Y.L., Zhao Y., Sturm R.A., Hearing V.J., King R.A., Nordlund J.J. (1996). Mutation in and lack of expression of tyrosinase-related protein-1 (TRP-1) in melanocytes from an individual with brown oculocutaneous albinism: a new subtype of albinism classified as "OCA3". Am. J. Hum. Genet. 58: 1145-1156.

Bolivar F. (1978). Construction and characterization of new cloning vehicles. III. Derivatives of plasmid pBR322 carrying unique EcoRI sites for selection of Eco RI generated recombinant DNA molecules. Gene 4:121-136.

Bondeson M. L., Dahl N., Malmgren H., Kleijer W. J., Tonnesen T., Carlberg B. M., Pettersson U. (1995). Inversion of the IDS gene resulting from recombination with IDS-related sequences is a common cause of the Hunter syndrome. Hum. Mol. Genet. 4: 615-621.

Botstein D., White R., Skolnick M., Davis R. W. (1980). Construction of a genetic linkage map using restriction fragment length polymorphism. Am. J. Hum. Genet. 32: 314-331.

Bray P. F., Barsh G., Rosa J. P., Luo X. Y., Magenis E., Shuman M. A. (1988). Physical linkage of the genes for platelet membrane glycoproteins IIb and IIIa. Proc. Natl. Acad. Sci. U $S$ A 22: 8683-8687.

Bray-Ward P., Menninger J., Lieman J., Desai T., Mokady N., Banks A., Ward D. C. (1996). Integration of the cytogenetic, genetic, and physical maps of the human genome by FISH mapping of CEPH YAC clones. Genomics 32: 1-14.

Breen M., Arveiler B., Murray I., Gosden J.R., Poteous D.J. (1992). YAC Mapping by FISH Using Alu-PCR- Generated Probes. Genomics 13: 726-730.

Buckler A. J., Chang D. D., Graw S. L., Brook J. D., Haber D. A., Sharp P. A., Housman D. E. (1991). Exon amplification: A strategy to isolate mammalian genes based on RNA splicing. Proc. Natl. Acad. Sci. U S A 88: 4005-4009.

Bullock W. O., Fernandez J. M., Short J. M. (1987). XL1-Blue: A high efficiency plasmid transforming recA Escherichia coli strain with beta-galactosidase selection. BioTechniques 5: 376.

Burke D. T., Carle G. F., Olson M. V. (1987). Cloning of large segments of exogenous DNA into yeast by means of artificial chromosome vectors. Science 236: 806-812.

Camerino G., Grzeschik K. H., Jaye M., De La Salle H., Tolotoshev P., Lecoq J. R., Heilig R., Mandel J. L. (1984). Regional localization on the human X chromosome and polymorphism 
of the coagulationg factor IX gene (hemophilia B locus). Proc. Natl. Acad. Sci. U S A 81: 498-502.

Campbell C., Goodrich K., Casey G., Beatty B. (1995). Cloning and mapping of a human gene (TBX2) sharing a highly conserved protein motif with the Drosophila omb gene. Genomics 28: $255-260$.

Cariello N. F., Skopek T. R. (1993). Mutational analysis using denaturing gradient gel electrophoresis and PCR. Mutat. Res. 288: 103-112.

Carle G. F., Frank M. \& Olson M. V. (1986). Electrophoretic separation of large DNA molecules by periodic inversion of the electric field. Science 232: 65-68.

Carrozzo R., Rossi E., Christian S. L., Kittikamron K., Livieri C., Corrias A., Pucci L., Fois A., Simi P., Bosio L., Beccaria L., Zuffardi O., Ledbetter D. H. (1997). Inter- and intrachromosomal rearrangements are both involved in the origin of 15q11-q13 deletions in Prader-Willi syndrome. Am. J. Hum. Genet. 61: 228-231.

Cassidy S. B., Lai L.-W., Erickson R. P., Magnuson L., Thomas E., Gendron R., Herrmann J. (1992). Trisomy 15 with loss of the paternal 15 as a cause of Prader-Willi syndrome due to maternal disomy. Am. J. Hum. Genet. 51: 701-708.

Cattanach B. M., Jones J. (1994). Genetic imprinting in the mouse: implications for gene regulation. J. Inher. Metab. Dis. 17: 403-420.

Chen K.-S., Manian P., Koeuth T., Potocki L., Zhao Q., Chinault A. C., Lee C. C., Lupski J. R. (1997). Homologous recombination of a flanking repeat gene cluster is a mechanism for a common contiguous gene deletion syndrome. Nat. Genet. 17: 154-163.

Chevillard C., Le Paslier D., Passage E., Ougen P., Billault A., Boyer S., Mazan S., Bachellerie J. P., Vignal A., Cohen D., Fontes M. (1993). Relationship between Charcot-Marie-Tooth 1A and Smith-Magenis regions. snU3 may be a candidate gene for the Smith-Magenis syndrome. Hum. Mol. Genet. 8: 1235-1243.

Christensen M. F., Nielsen J. (1978). Deletion short arm 18 and Silver-Russell syndrome. Acta Paediatr. Scand. 67: 101-103.

Christian S. L., Fantes J. A., Mewborn S. K., Huang B., Ledbetter D. H. (1999). Large genomic duplicons map to sites of instability in the Prader-Willi/Angelman syndrome chromosome region (15q11-q13). Hum. Mol. Genet. 8:1025-1037.

Christian S. L., Robinson W. P., Huang B., Mutirangura A., Line M. R., Nakao M., Surti U., Chakravarti A., Ledbetter D. H. (1995). Molecular charakterization of two proximal deletion breakpoint regions in both Prader-Willi and Angelman syndrome patients. Am. J. Hum. Genet. 57: 40-48.

Chumakov I., Rigault P., LeGall I., Bellanné-Chantelot C., Billaut A., Guillou S., Soularue P., Guasconi G., et al. (1995). A YAC contig map of the human genome. Nature 377: 175-298. 
Church D. M., Stotler C. J., Rutter J. L., Murrell J. R., Trofatter J. A., Buckler A. J. (1994). Isolation of genes from complex sources of mammalian genomic DNA using exon amplification. Nat. Genet. 6: 98-105.

Cohen D., Chumakov I., Weissenbach J. (1993). A first-generation physical map of the human genome. Nature 366: 698-701.

Cole C. G., Goodfellow P. N., Bobrow M., Bentley D. R. (1991). Generation of novel sequence tagged sites (STSs) from discrete chromosomal regions using Alu-PCR. Genomics 10: 816826

Collins F. S. (1992). Positional cloning: Let's not call it reverse anymore. Nat. Genet. 1: 3-6.

Collins F. S. (1995). Positional cloning moves from perditional to traditional. Nat. Genet. 9: 347-350.

Collins F. S., Patrinos A., Jordan E., Chakravarti A., Gesteland R., Walters L. and the members of the DOE and NIH planning groups (1998). New goals for the U.S. human genome project: 1998-2003. Science 282: 682-689.

Collins F. S., Weissmann S. M. (1984). The molecular genetics of human hemoglobin. Prog. Nucleic Acid Res. Mol. Biol. 31: 315-462.

Cortes P., Ye Z. S., Baltimore D. (1994). RAG-1 interacts with the repeated amino acid motif of the human homologue of the yeast protein SRP1. Proc. Natl. Acad Sci. U S A 91: 76337637.

Coussens L., Parker P. J., Rhee L., Yang-Feng T. L., Chen E., Waterfield M. D., Francke U., Ullrich A. (1986). Multiple, distinct forms of bovine and human protein kinase C suggest diversity in cellular signaling pathways. Science 233: 859-866.

Crolla J. A., Cross I., Atkey N., Wright M., Oley C. A. (1996). FISH studies in a patient with sporadic aniridia and t(7;11)(q31.2;p13). J. Med. Genet. 33: 66-68.

Cross I., Delhanty J., Chapman P., Bowles L. V., Griffin D., Wolstenholme J., Bradburn M., Brown J., Wood C., Gunn A., Burn J. (1992). An intrachromosomal insertion causing 5q22 deletion and familial adenomatous polyposis coli in two generations. J. Med. Genet. 29: 175179.

Cuisset L., LeStunff C., Dupont J. M. et al. (1997). PEG1 expression in maternal uniparental disomy 7. Ann. Genet. 40: 211-215.

Cuomo C. A., Kirch S. A., Gyuris J., Brent R., Oettinger M. A. (1994). Rch1, a protein that specifically interacts with the RAG-1 recombination-activating protein. Proc. Natl. Acad. Sci. U S A 91: 6156-6160.

D'Ancona G. G., Wurm J., Croce C. M. (1979). Genetics of type II glycogenosis: assignment of the human gene for acid alpha-glucosidase to chromosome 17. Proc. Natl. Acad. Sci. US A 76: $4526-4529$. 
Davies P. S. W., Valley R., Preece M. A. (1988). Adolescent growth and pubertal progression in the Silver-Russell syndrome. Arch. Dis. Child. 63: 130-135.

Day J. R., O'Hara P. J., Grant F. J., Lofton-Day C., Berkaw M. N., Werner P., Arnaud P. (1992). Molecular cloning and sequence analysis of the cDNA encoding human apolipoprotein H (beta 2-glycoprotein I). Int. J. Clin. Lab. Res. 21: 256-263.

Dean M. (1995). Resolving DNA mutations. Nat. Genet. 9: 103-104.

de Kok Y. J., Merkx G. F., van der Maarel S. M., Huber I., Malcom S., Ropers H. H., Cremers F. P. (1995). A duplication/paracentric inversion associated with familial X-linked deafness (DFN3) suggests the presence of a regulatory element more than $400 \mathrm{~kb}$ upstream of the POU3F4 gene. Hum. Mol. Genet. 4: 2145-2150.

de Kok Y. J., Vossenaar E. R., Cremers C. W., Dahl N., Laporte J., Hu L. J., Lacombe D., Fischel-Ghodsian N., Friedman R. A., Parnes L. S., Thorpe P., Bitner-Glindzicz M., Pander H. J., Heilbronner H., Graveline J., den Dunnen J. T., Brunner H. G., Ropers H. H., Cremers F. P. (1996). Identification of a hot spot for microdeletions in patients with X-linked deafness type 3 (DFN3) $900 \mathrm{~kb}$ proximal to the DFN3 gene POU3F4. Hum. Mol. Genet. 9: 1229-1235.

Deloukas P., Schuler G. D., Gyapay G., Beasley E. M., Soderlund C., Rodriguez-Tome’' P., Hui L., Matise C., McKusick K. B., Beckmann J. S. et al. (1998). A physical map of 30,000 human genes. Science 282: 744-746.

Biochem Biophys Res Commun 1966 Jun 13;23(5):641-6

Denhardt D. T. (1966). A membrane-filter technique for the detection of complementary DNA. Nature 287: 560-561.

Dib C., Faure'S., Fizames C., Samson D., Drouot N., Vignal A., Millaseau P., Marc S., Hazan J., Seboun E., Lathrop M., Gyapay G., Morissette J., Weissenbach J. (1996). A comprehensive genetic map of the human genome based on 5,264 microsatellites. Nature 380: $152-154$.

Dörr S. (1995). Molekulare Kartierung eines krankheitsassoziierten Bruchpunktes auf Chromosom 17q. Diplomarbeit.

Dolon T. A. (1993). Report of the first international workshop on human chromosome 15 mapping. Cytogenet. Cell Genet. 61: 161-166.

Donis-Keller H., Green P., Helms C., Cartinhour S., Weiffenbach B., Stephens K., Keith T. P., Bowden D. W., Smith D. R., Lander E. S., Botstein D., Akots G., Rediker K. S., Gravius T., Brown V. A., Rising M. B., Parker C., Powers J. A., Watt D. E., Kauffman E. R., Bricker A., Phipps P., Muller-Kahle H., Fulton T. R., Ng S., Schumm J. W., Braman J. C., Knowlton R. G., Barker D. F., Crooks S. M., Lincoln S. E., Daly M. J., Abrahamson J. (1987). A genetic linkage map of the human genome. Cell 51: 319-337. 
Donohoue P., Jospe N., Migeon C. J., Van Dop C. (1989). Two distinct areas of unequal crossing over within the steroid 21-hydroxilase genes produce absence of CYP21B. Genomics 5: 397-406.

Dryja T. P., McGee T. L., Reichel E., Hahn L. B., Cowley G. S., Yandell D. W., Sandberg M. A., Berson E. L. (1990). A point mutation of the rhodopsin gene in one form of retinitis pigmentosa. Nature 343: 1990.

Duncan P. A., Hall J. G., Shapiro L. R. and Vibert B. K. (1990). Three-generation dominant tranmission of the Silver-Russell syndrome. Am. J. Med. Genet. 35: 245-250.

Dutly F., Baumer A., Kayserili H., Yüksel-Apak M., Zerova T., Schinzel A. (1998). Seven cases of Wiedemann-Beckwith syndrome, including the first reported case of mosaic paternal isodisomy along the whole chromosome 11. Am. J. Med. Genet. 79: 347-353.

Dutly F., Schinzel A. (1996). Unequal interchromosomal rearrangements may result in elastin gene deletions causing the Williams-Beuren syndrome. Hum. Mol. Genet. 5: 1893-1898.

Duyk G. M., Kim S., Myers R. M., Cox D. R. (1990). Exon trapping: A genetic screen to identify candidate transcribed sequences in cloned mammalian DNA. Proc. Natl. Acad. Sci. U S A 87: 8995-8999.

Edelmann L., Pandita R. K., Morrow B. E. (1999). Low-Copy Repeats Mediate the Common 3Mb Deletion in Patients with Velo-cardio-facial Syndrome. Am. J. Hum. Genet. 64: 10761086.

Eggerding F. A., Schonberg S. A., Chehab F. F., Norton M. E., Cox V. A., Epstein C. J. (1994). Uniparental isodisomy for paternal $7 \mathrm{p}$ and maternal $7 \mathrm{q}$ in a child with growth retardation. Am. J. Hum. Genet. 55:253-265.

Eggermann K., Wollmann H. A., Tomiuk J., Ranke M. B., Kaiser P., Eggermann T. (1999a). Screening for mutations in the promoter and the coding region of the IGFBP1 and IGFBP3 genes in Silver-Russell syndrome patients. Hum. Hered. 49:123-128.

Eggermann K., Wollmann H. A., Binder G., Kaiser P., Ranke M. B., Eggermann T. (1999b). Biparental expression of IGFBP1 and IGFBP3 renders their involvement in the etiology of Silver-Russell syndrome unlikely. Ann. Genet. 42:117-121.

Eggermann T., Wollmann H. A., Kuner R., Eggermann K., Enders H., Kaiser P., Ranke M. B. (1997). Molecular studies in 37 Silver-Russell syndrome patients: frequency and etiology of uniparental disomy. Hum. Genet. 100: 415-419.

Ehrenborg E., Larson C., Stern I., Janson M., Powell D. R., Luthman H. (1992). Contiguous localization of the genes encoding human insulin-like growth factor-binding proteins 1 (IGBP1) and 3 (IGBP3) on chromosome 7. Genomics 12: 479-502.

Elsevier S. M., Kucherlapati R. S., Nichols E. A., Willecke K., Creagan R. P., Giles R. E., McDougall J. K., Ruddle F. H. (1975). Assignment and regional localization of a gene coding for galactokinase to human chromosome 17q21-22. Birth Defects 11: 117-119. 
Engel E. (1980). A new genetic concept: Uniparental disomy and its potential effect, isodisomy. Am. J. Med. Genet. 6: 137-143.

Engel E., DeLoizier-Blanchet C. D. (1991). Uniparental disomy, isodisomy, and imprinting: Probable effects in man and strategies for their detection. Am. J. Med. Genet. 40: 432-439.

Escobar V., Gleiser S. and Weaver D. D. (1978). Penotypic and genetic analysis of the SilverRussell syndrome. Clinical Genetics 13: 278-288.

Evans G. A., Lewis K., Rothenberg B. E. (1989). High efficiency vectors for cosmid microcloning and genomic analysis. Gene 79: 9-20.

Färber C. (1996). Molekulare Charakterisierung und Klonierung einer mit dem Russell-SilverSyndrom einhergehenden Bruchpunktregion. Diplomarbeit.

Fantes J., Redeker B., Breen M., Boyle S., Brown J., Fletcher J., Jones S., Bickmore W., Fukushima Y., Mannens M., Danes S., van Heyningen V., Hanson I. (1995). Aniridiaassociated cytogenetic rearrangements suggest that a position effect may cause the mutant phenotype. Hum. Molec. Genet. 4: 415-422, 1995.

Feinberg A., Vogelstein B., (1984). A technique for radiolabeling endonuclease fragments to high specific activity. Anal. Biochem. 137: 266-267.

Felsenfeld A., Peterson J., Schloss J., Guyer M. (1999). Assessing the quality of the DNA sequence from the Human Genome Project. Genome Res. 9:1-4.

Fields C., Adams M. D., White O., Venter J. C. (1994). How many genes in the human genome? Nat. Genet. 7: 345-346.

Finkenzeller G., Marmé D. \& Hug H. (1990). Sequence of human protein kinase C $\alpha$. Nucl. Acids Res. 18: 2183.

Foster J. W., Schafer A. J., Critcher R., Spillett D. J., Feakes R. W., Walter M. A., DominguezSteglich M., Guioli S., Brook J. D., Goodfellow P. N. (1996). A high-resolution whole genome radiation hybrid map of human chromosome 17q22-q25.3 across the genes for GH and TK. Genomics 33: 185-192.

Francke U., Darras B. T., Foellmer B. E. (1988). Loss of IGF-1 receptor gene in patients with ring chromosome 15 is related to Russell-Silver like phenotype. Proceedings of the 9th Annual David W. Smith Workshop on Malformations: Oakland.

Francke U., Oliver N. (1978). Quantitative analysis of high resolution trypsin-Giemsa bands on human prometaphase chromosomes. Hum. Genet. 45: 137-165.

Freije D., Schlessinger D. (1992). A 1.6-Mb contig of yeast artificial chromosomes around the human factor VIII gene reveals three regions homologous to probes for the DXS115 locus and two for the DXYS64 locus. Am. J. Hum. Genet. 51: 66-80. 
Fukushima Y., Kuroki Y., Ito T., Kondo I., Nishigaki I. (1987). Familial retinoblastoma (mother and son) with 13q14 deletion. Hum. Genet. 77: 104-107.

Fuleihan D. S., Kaloustian V. M., Najjar S. S. (1971). The Russell-Silver syndrome: report of three siblings. J. Pediat. 78: 654-657.

Galli M., Comfurius P., Maassen C., Hemker H. C., de Baets M. H., van Breda-Vriesman P. J., Barbui T., Zwaal R. F., Bevers E. M. (1990). Anticardiolipin antibodies (ACA) directed not to cardiolipin but to a plasma protein cofactor. Lancet 335:1544-1547.

Gardiner K. (1995). Human genome organization. Curr. Opin. Genet. Develop. 5: 315-322.

Genuardi M., Tozzi C., Pomponi M. G., Stagni M. L., Della Monica M., Scarano G., Calvieri F., Torrisi L., Neri G. (1999). Mosaic trisomy 17 in amniocytes: phenotypic outcome, tissue distribution, and uniparental disomy studies. Eur. J. Hum. Genet. 7: 421-426.

Giannelli F., Choo K. H., Rees D. J., Boyd Y., Rizza C. R., Brownlee G. G. (1983). Gene deletions in patients with haemophilia B and anti-factor IX antibodies. Nature 303: 181-182.

Görlich D., Mattaj I. W. (1996). Nucleocytoplasmic transport. Science 271: 1513-1519.

Goodman L. (1998). The human genome project aims for 2003. Genome Research 8: 997-999.

Goodman R. M., Gorlin R. J. (1983). The malformed infant and child. New York, Oxford University press.

Grace E., Drennan J., Colver D., Gordon R. R. (1971). The 13q deletion syndrome. J. Med. Genet. 8: 351-357.

Graham jr. J. M., Hoehn H., Lin M. S. (1981). Diploid-triploid mixoploidy: clinical and cytogenetic aspects. Pediatrics 68: 23-28.

Grenn E. D., Riethmann H. C., Dutchik J. E., Olsen M. V. (1991). Chromosomal region of the cystic fibrosis gene in yeast artificial chromosomes. Genomics 11: 658-669.

Greenberg F., Guzzetta V., Montes de Oca-Luna R., Magenis R. E., Smith A. C. M., Richter S. F., Kondo I., Dobyns W. B., Patel P. I., Lupski J. R. (1991). Molecular analysis of the SmithMagenis syndrome: a possible contiguous-gene syndrome associated with del(17)(p11.2). Am. J. Hum. Genet. 49: 1207-1218.

Gumina R. J., Kirschbaum N. E., Rao P. N., van Tuinen P., Newman P. J. (1996). The human PECAM1 gene maps to 17q23. Genomics 34: 229-232.

Guzzetta V., Franco B., Trask B.J., Zhang H., Saucedo-Cardenas O., Montes de Oca-Luna R., Greenberg F., Chinault A.C., Lupski J.R., Patel P.I. (1992). Somatic cell hybrids, sequencetagged sites, simple repeat polymorphisms, and yeast artificial chromosomes for physical and genetic mapping of proximal 17p. Genomics 13: 551-559. 
Gyapay G., Morissette J., Vignal A., Dib C., Fizames C., Millasseau P., Marc S., Bernardi G., Lathrop M. \& Weissenbach J. (1994). The 1993-94 généthon human genetic linkage map. Nat Genetics 7: 246-339.

Haagerup A., Kristensen T., Kruse T. A. (1991). Polymorphism and genetic mapping of the gene encoding human beta-2-glycoprotein I to chromosome 17. Cytogenet. Cell Genet. 58: 2005 .

Halford S., Lindsay E., Nayudu M., Carey A. H., Baldini A., Scambler P. J. (1993). Low-copynumber repeat sequences flank the DiGeorge/velo-cardio-facial syndrome loci at 22q11. Hum. Mol. Genet. 2:191-196.

Halley D. J. J., Konings A., Hupkes P., Galjaard H. (1984). Regional mapping of the human gene for lysosomal alpha-glucosidase by in situ hybridization. Hum. Genet. 67: 326-328.

Hanahan D. (1983). Studies on transformation of Escherichia coli with plasmids. J. Mol. Biol. 166: $557-580$.

Hanson I. M., Seawright A., Hardman K., Hodgson S., Zaletayev D., Fekete G., van Heyningen V. (1993). PAX6 mutations in aniridia. Hum. Molec. Genet. 2: 915-920.

Hehr U., Dörr S., Hagemann M., Hansmann I., Preiss U., Brömme S. (1999) Silver-Russell syndrome and cystic fibrosis associated with maternal uniparental disomy 7. Am. J. Med. Genet.: eingereicht.

Herman F., Fink G. R., Hicks J. B. (1987). Methods in Yeast Genetics. Cold Spring Harbour Laboratory Press, Cold Spring Harbour, NY.

Herrmann B. G., Labeit S., Poustka A., King T. R., Lehrach H. (1990). Cloning of the T gene required in mesoderm formation in the mouse. Nature 343: 617-622.

Higgs D.R., Old J.M., Pressley L., Clegg J.B., Weatherall D.J. (1980). A novel alpha-globin gene arrangement in man. Nature 284: 632-635.

Higgs D. R., Vickers M. A., Wilkie A. O. M., Pretorius I.-M., Jarman A. P., Weatherall D. J. (1989). A review of the molecular genetics of the human $\alpha$-globin gene cluster. Blood 73: 1081-1104.

Hill R. E., Favor J., Hogan B. L. M., Ton C. C. T., Saunders G. F., Hanson I. M., Prosser J., Jordan T., Hastie N. D., van Heyningen V. (1991) Mouse small eye results from mutations in a paired-like homeobox-containing gene. Nature 354: 522-525.

Hockey K. A., Mulcahy M. T., Montgomery P., Levitt S. (1989). Deletion of chromosome 5q and familial adenomatous polyposis. J. Med. Genet. 26: 61-62.

Höglund P., Holmberg C., de la Chapelle A., Kere J. (1994). Paternal isodisomy for chromosome 7 is compatible with normal growth and development in a patient with congenital chloride diarrhea. Am. J. Hum. Genet. 55:747-52. 
Hoeg J. M., Segal P., Gregg R. E., Chang Y. S., Lindgren F. T., Adamson G. L., Frank M., Brickman C., Brewer H. B. Jr. (1985). Characterization of plasma lipids and lipoproteins in patients with beta 2-glycoprotein I (apolipoprotein H) deficiency. Atherosclerosis 55:25-34.

Huie M. L., Hirschhorn R., Chen A. S., Martiniuk F., Zhong N. (1994). Mutation at the catalytic site (M519V) in glycogen storage disease type II (Pompe disease). Human Mutation 4: 291-293.

Imaizumi K., Kuroki Y. (1991). Rubinstein-Taybi syndrome with de novo reciprocal translocation t(2;16)(p13.3;p13.3). Am. J. Med. Genet. 38: 636-639.

Inazawa J., Inoue K., Nishigaki H., Tsuda S., Taniwaki M., Misawa S., Abe T. (1989). Assignment of the human myeloperoxidase gene (MPO) to bands q21.3-q23 of chromosome 17. Cytogenet. Cell. Genet. 50: 135-136.

Inazawa J., Saito H., Ariyama T., Abe T. \& Nakamura Y. (1993). High-resolution cytogenetic mapping of 342 new cosmid markers including 43 RFLP markers on human chromosome 17 by fluorescence in situ hybridization. Genomics 17: 153-162.

Ioannou P. A., Amemiya C. T., Garnes J., Kroisel P. M., Shizuya H., Chen C., Batzer M. A., de Jong P. J. (1994). A new bacteriophage P1-derived vector for the propagation of large human DNA fragments. Nat. Genet. 6: 84-89.

Ish-Horowicz D., Burke J. F. (1981). Rapid and efficient cosmid cloning. Nucleic Acids Res. 9: 2989-2998.

Jans D. A. (1994). Nuclear signalling pathways for polypeptide ligands and their membranereceptors. FASEB J. 8: 841-847.

Jans D. A., Hassan G. (1998). Nuclear targeting by growth factors, cytokines, and their receptors: a role in signaling? BioEssays 20: 400-411.

Jans D. A., Huebner S. (1996). Regulation of protein transport to the nucleus: Central role of phosphorylation. Physiol. Rev. 76: 651-685.

Jerome C. A., Scherer S. W., Tsui L. C. , Gietz R. D., Triggs-Raine B. (1997). Assignment of growth factor receptor-bound protein 10 (GRB10) to human chromosome 7p11.2-p12. Genomics 15:215-216.

Jin Y., Dietz H. C., Montgomery R. A., Bell W. R., McIntosh I., Coller B., Bray P. F. (1996). Glanzmann thrombasthenia: cooperation between sequence variants in Cis during splice site selection. J. Clin. Invest. 98: 1745-1754.

Jorde L. B. (1995). Linkage disequilibrium as a gene-mapping tool. Am. J. Hum. Genet. 56: 1114.

Joslyn G., Carlson M., Thliveris A., Albertsen H., Gelbert L., Samowitz W., Groden J., Stevens J., Spirio L., Robertson M., Sargeant L., Krapcho K., Wolff E., Burt R., Hughes J. P., Warrington J., McPherson J., Wasmuth J., LePaslier D., Abderrahim H., Cohen D., Leppert 
M., White R. (1991). Identification of deletion mutations and three new genes at the familial polyposis locus. Cell 66: 601-613.

Joyce C. A., Sharp A., Walker J. M., Bullman H., Temple I. K. (1999). Duplication of 7p12.1p13, including GRB10 and IGFBP1, in a mother and daughter with features of Silver-Russell syndrome. Hum. Genet. 105: 273-280.

Juyal R.C., Figuera L.E., Hauge X., Elsea S.H., Lupski J.R., Greenberg F., Baldini A., Patel P.I. (1996). Molecular analyses of 17p11.2 deletions in 62 Smith-Magenis syndrome patients. Am. J. Hum. Genet. 58: 998-1007.

Kalousek D.K., Howard-Peebles P.N., Olson S.B., Barret I.J., Dorfmann A., Black S.H., Schulman J.D., Wilson R.D. (1991). Confirmation of CVS mosaicism in term placentae and high frequency of intrauterine growth retardation association with confined placental mosaicism. Prenat. Diag. 11: 743-750.

Kalousek D.K., Thérien S. (1976). Deletion of the short arms of chromosome 20. Hum. Genet. 34: 89-92.

Kariya Y., Kato K., Hayashizaki Y., Himeno S., Tarui S., Matsubara K. (1987). Revision of consensus sequence of human Alu repeats-a review. Gene 53: 1-10.

Keen J., Lester D., Inglehearn C., Curtis A., Bhattacharya S. (1991). Rapid detection of single base mismatches as heteroduplexes on Hydrolink gels. Trends Genet. 7: 5.

Kennerknecht I., Rodens K. (1991). Russell-Silver syndrome (RSS) associated with $\operatorname{dup}(1)(\mathrm{q} 42 \rightarrow$ qter). Clin. Genet. 40: 117-118.

Kerem B., Rommens J. M., Buchanan J. A., Markiewicz D., Cox T. K., Chakravarti A., Buchwald M., Tsui L.-C. (1989). Identification of the cystic fibrosis gene: genetic analysis. Science 245: 1073-1080.

Kimberling W. J., Fulbeck T., Dixon L., Lubs H. A. (1975). Localization of spherocytosis to chromosome 8 or 12 and report of a family with sperocytosis and a reciprocal translocation. Am. J. Hum. Genet. 27: 586-594.

Kimberling W. J., Taylor R. A., Chapman R. G. and Lubs H. A. (1978). Linkage and gene localization of hereditary spherocytosis (HS). Blood 46: 859-867.

Kishino T., Lalande M., Wagstaff J. (1997). UBE3A/E6-AP mutations cause Angelman syndrome. Nat. Genet. 15: 70-73.

Kleczkowska A., Fryns J. P., Berghe H. van den (1986). A patient with t(5p7p;5q7q) type rearrangement and review of the literature. Clin. Genet. 30: 72-75.

Kleinjan D. J., van Heyningen V. (1998). Position effect in human genetic disease. Hum. Mol. Genet. 7: 1611-1618. 
Knapp M., Seuchter S. A., Baur M. P. (1993). The haplotype-relative-risk (HRR) method for analysis of association in nuclear families. Am. J. Hum. Genet. 52: 1085-1093.

Kobayashi S., Kohda T., Miyoshi N., Kuroiwa Y., Aisaka K., Tsutsumi O., Kaneko-Ishino T., Ishino F. (1997). Human PEG1/MEST, an imprinted gene on chromosome 7. Hum. Mol. Genet. 6:781-786.

Köhler W., Schachtel G., Voleske P. (1996). Biostatistik. 2. Springer-Verlag Berlin Heidelberg New York: 270.

Koenig M., Monaco A. P., Kunkel L. M. (1987). The complete sequence of dystrophin predicts a rod-shaped cytoskeletal protein. Cell 53: 219-228.

Koorey D. J., Bishop G. A., McCaughan G. W. (1993). Allele non-amplification: a source of confusion in linkage studies employing microsatellite polymorphisms. Hum. Mol. Genet. 3:289-291

Korenberg J. R., Rykowski M. C. (1988). Human genome organization: Alu, Lines, and the molecular structure of metaphase chromosome bands. Cell 53: 391-400.

Kosztolányi G. (1987). Does ring syndrome exist? An analysis of 207 case reports on patients with a ring autosome. Hum. Genet. 75: 174-179.

Kotzot D. (1999). Abnormal phenotypes in uniparental disomy (UPD): Fundamental aspects and a critical review with bibliography of UPD other than 15. Am. J. Med. Genet. 82: 265274.

Kotzot D., Schmitt S., Bernasconi F., Robinson W. P., Lurie I. W., Ilyina H., Méhes K., Hamel B. C. J., Otten B. J., Hergersberg M., Werder E., Schoenle E., Schinzel A. (1995). Uniparental disomy 7 in Silver-Russell syndrome and primordial growth retardation. Hum. Mol. Genet. 4: 583-587.

Küssel P., Frasch M. (1995). Pendulin, a Drosophila protein with cell cycle-dependent nuclear localization, is required for normal cell proliferation. J. Cell. Biol. 129: 1491-1507.

Kunkel L. M. and co-authors (1986). Analysis of deletions in DNA from patients with Becker and Ducchenne muscular dystrophy. Nature 322: 73-77.

Kuo W.-L., Hirschhorn R., Huie M. L., Hirschhorn K. (1996). Localization and ordering of acid alpha-glucosidase (GAA) and thymidine kinase (TK1) by fluorescence in situ hybridization. Hum. Genet. 97: 404-406.

Lacombe D., Saura R., Taine L., Battin J. (1992). Confirmation of assignment of a locus for Rubinstein-Taybi syndrome gene to 16p13.3. Am. J. Med. Genet. 44: 126-128, 1992.

Lakich D., Kazazian H. H. Jr., Antonarakis S. E., Gitschier J. (1993). Inversions disrupting the factor VIII gene are a common cause of severe haemophilia A. Nat. Genet. 5: 236-241. 
Langlois S., Yong S. L., Wilson R. D., Kwong L. C., Kalousek D. K. (1995). Prenatal and postnatal growth failure associted with maternal heterodisomy for Chromosome 7. J. Med. Genet. 32: 871-875.

Larionov V., Kouprina N., Nikolaishvili N., Resnick M. A. (1994). Recombination during transformation as a source of chimeric mammalian artificial chromosomes in yeast (YACs). Nucleic Acids Res. 22: 4154-4162.

Latos-Bielenska A., Klett C., Just W., Hameister H. (1991). Refinement of localization of the human genes for myeloperoxidase (MPO), protein kinase $\mathrm{C}$, alpha polypeptide, PRKCA, and the DNA fragment D17S21 on chromosome 17q. Hereditas 115: 69-72.

Lauer J., Shen C.K., Maniatis T. (1980). The chromosomal arrangement of human alpha-like globin genes: sequence homology and alpha-globin gene deletions. Cell 20: 119-130.

Law D. J., Gebhur T., Garvey N., Agulnik S. I., Silver L. M. (1995). Identification, charakterization, and localization to chromosome 17q21-22 of the human TBX2 homolog, member of a conserved developmental gene family. Mammalian Genome 6: 793-797.

Lawrence J. B., Singer R. H., McNeil J. A. (1990). Interphase and metaphase resolution of different distances within the human dystrophin gene. Science 249: 923-932.

Ledbetter D. H., Engel E. (1995). Uniparental disomy in humans: development of an imprinting map and its implications for prenatal diagnosis. Hum. Mol. Genet. 4: 1757-1764.

Lefebvre L., Viville S., Barton S. C., Ishino F., Keverne E. B., Surani M. A. (1998). Abnormal maternal behaviour and growth retardation associated with loss of the imprinted gene Mest. Nat. Genet. 20:163-169.

Lengauer C., Green E.D., Cremer T. (1992). Fluorescence in situ hybridization of YAC clones after Alu-PCR amplification. Genomics 13: 826-828.

Li X. M., Yen P. H., Shapiro L. J. (1992). Characterization of a low copy repetitive element S232 involved in the generation of frequent deletions of the distal short arm of the human $X$ chromosome. Nucleic Acids Res. 20: 1117-22.

Lichter P., Cremer T., Borden J., Manuelidis L., Ward D. C. (1988). Delineation of individual human chromosomes in metaphase and interphase cells by in situ suppression hybridization using recombinant DNA libraries. Hum. Genet. 80: 224-234.

Lichter P., Ledbetter S. A., Ledbetter D. H., Ward D. C. (1990). Fluorescence in situ hybridization with Alu and L1 polymerase chain reaction probes for rapid characterization of human chromosomes in hybrid cell lines. Proc. Natl. Acad. Sci. U S A 87: 6634-6638.

Lifton R. P., Dluhy R. G., Powers M., Rich G. M., Cook S., Ulick S., Lalouel J.-M. (1992). A chimaeric 11ß-hydroxilase/aldosterone synthase gene causes glucocorticoid-remediable aldosteronism and human hypertension. Nature 355: 262-265. 
Lindsay E. A., Morris M. A., Gos A., Nestadt G., Wolyniec P. S., Lasseter V. K., Shprintzen R., Antonarakis S. E., Baldini A., Pulver A. E. (1995). Schizophrenia and chromosomal deletions within 22q11.2. Am. J. Hum. Genet. 56: 1502-1503.

Lindsay S., Bird A. P. (1987). Use of restriction enzymes to detect potential gene sequences in mammalian DNA. Nature 327: 336-338.

Linnenbach A. J., Huebner K., Reddy E. P., Herlyn M., Parmiter A. H., Nowell P. C., Koprowski H. (1988). Structural alteration in the MYB protooncogene and deletion within the gene encoding alpha-type protein kinase $\mathrm{C}$ in human melanoma cell lines. Proc. Natl. Acad. Sci. U S A 85: 74-78.

Liu J. P., Baker J., Perkins A. S., Robertson E. J., Efstratiadis A. (1993). Mice carrying null mutations of the genes encoding insulin-like growth factor I (Igf-1) and type 1 IGF receptor (Igf1r). Cell 75: 59-72.

Luo X. Y., Bray P. F., Magenis R. E. (1989). Precise localization of the gene for platelet membrane glycoprotein IIb to 17q21.32 using structural rearrangements of chromosome 17 . Cytogenet. Cell Genet. 51: 1036.

Lupski J.R. (1997). Charcot-Marie-Tooth disease: a gene-dosage effect. Hosp. Pract. 32: 8384, 89-91, 94-95.

Lupski J. R. (1998a). Genomic disorders: structural features of the genome can lead to DNA rearrangements and human disease traits. Trends Genet. 14: 417-422.

Lupski J.R. (1998b). Charcot-Marie-Tooth disease: lessons in genetic mechanisms. Mol. Med. 4: 3-11.

Lux S. E., Tse W. T., Menninger J. C., John K. M., Harris P., Shalev O., Chilcote R. R., Marchesi S. L., Watkins P. C., Bennett V., McIntosh S., Collins F. S., Francke U., Ward D. C., Forget B. G. (1990). Hereditary spherocytosis associated with deletion of human erythrocyte ankyrin gene on chromosome 8 . Nature 345: 736-739.

Manga P., Kromberg J.G., Box N.F., Sturm R.A., Jenkins T., Ramsay M. (1997). Rufous oculocutaneous albinism in southern African Blacks is caused by mutations in the TYRP1 gene. Am. J. Hum. Genet. 61: 1095-1101.

Maniatis T., Fritsch E. F., Lauer J., Lawn R. M. (1980). The molecular genetics of human hemoglobins. Annu. Rev. Genet. 14: 145-178.

Marchuk D., Drumm M., Saulino A., Collins F. S. (1991). Construction of T-vectors, a rapid and general system for direct cloning of unmodified PCR products. Nucleic Acids Res. 19: 1154.

Martiniuk F., Ellenbogen A., Hirschhorn K., Hirschhorn R. (1985). Further regional localization of the genes for human acid alpha glucosidase (GAA), peptidase D (PEPD), and alpha mannosidase B (MANB) by somatic cell hybridization. Hum. Genet. 69: 109-111. 
Matsuo T., Osumi-Yamashita N., Noji S., Ohuchi H., Koyama E., Myokai F., Matsuo N., Taniguchi S., Doi H., Iseki S., Ninomiya Y., Fujiwara M., Watanabe T., Eto K. (1993). A mutation in the Pax-6 gene in rat small eye is associated with impaired migration of midbrain crest cells. Nat. Genet. 3: 299-304.

Mattei M.-G., Hubert C., Alhenc-Gelas F., Roeckel N., Corvol P., Soubrier F. (1989). Angiotensin-I converting enzyme gene is on chromosome 17. Cytogenet. Cell Genet. 51: 1041.

Mazzarella R., Schlessinger D. (1998). Pathological consequences of sequence duplications in the human genome. Genome Research 8: 1007-1021.

McKusik V. A. (1994). Mendelian Inheritance in Man, 11th ed.; John Hopkins Univ. Press, Baltimore, London.

McKusick V. A. (1989). The Human Genome Organisation: history, purposes, and membership. Genomics 5: 385-387.

McNeil H. P., Simpson R. J., Chesterman C. N., Krilis S. A. (1990). Anti-phospholipid antibodies are directed against a complex antigen that includes a lipid-binding inhibitor of coagulation: beta 2-glycoprotein I (apolipoprotein H). Proc. Natl. Acad. Sci. U S A 87: 41204124.

McWilliam P., Farrar G. J., Kenna P., Bradley D. G., Humphries M. M., Sharp E. M., McConnell D. J., Lawner M., Sheils D., Ryan C., Stevens K., Daiger S. P., Humphries P. (1989). Autosomal dominant retinitis pigmentosa (ADRP): Localization of an ADRP gene to the long arm of chromosome 3. Genomics 5: 619-622.

Melchior F., Paschal B., Evans J., Gerace L. (1993). Inhibition of nuclear protein import by nonhydrolyzable analogues of GTP and identification of the small GTPase Ran/TC4 as an essential transport factor. J. Cell. Biol. 123: 1649-1659 und 124: 217.

Mergenthaler S., Blagitko N. B., Schulz U. S., Ropers H. H., Kaiser P., Ranke M. B., Wollmann H. A., Eggermann T., Kalscheuer V. K. (1999). Molecular genetic investigations on growth factor receptor bound protein (GRB10), a candidate gene for Silver-Russell syndrome. Eur. J. Hum. Genet.: P-372.

Midro A. T., Debek K., Sawicka A., Marchinkiewicz D., Rogowska M. (1993). Second observation of Silver-Russell syndrome in a carrier of a reciprocal translocation with one breakpoint at site 17q25. Clin. Genet. 44: 53-55.

Miller S. A., Dykes D. D., Polesky H. F. (1988). A simple salting out procedure for extracting DNA from human nucleated cells. Nucl. Acid Res. 16: 1215-1216.

Milner R. D., Hill D. J. (1984). Fetal growth control: the role of insulin and related peptides. Clin. Endocrinol. 21: 415-433. 
Moghrabi N. N., Dawson D. B., Bennett M. J. (1995). Assignment of the human peroxisomal palmitoyl-CoA oxidase gene to chromosome 17q23-qter by PCR technique. J. Inherit. Metab. Dis. 18: 705-709.

Monaco A. P., Neve R. L., Colletti-Feener C., Bertelson C. J., Kurnit D. M., Kunkel L. M. (1986). Isolation of candidate cDNAs for portions of the muscular dystrophy gene. Nature 322: 646-650.

Moore M.S., Blobel G. (1994). Purification of a Ran-interacting protein that is required for protein import into the nucleus. Proc. Natl. Acad. Sci. U S A 91: 10212-10216.

Moore M.S., Blobel G. (1993). The GTP-binding protein Ran/TC4 is required for protein import into the nucleus. Nature 365: 661-663.

Moore J. W., Hyman S., Antonarakis S. E., Mules E. H., Thomas G. H. (1986). Familial isolated aniridia associated with a translocation involving chromosomes 11 and 22 [t(11;22)(p13;q12.2)]. Hum. Genet. 72: 297-302.

Morison I. A., Reeve A. E. (1998). A catalogue of imprinted genes and parent-of-origin effect in humans and animals. Hum. Mol. Genet. 7: 1599-1609.

Morrow B., Goldberg R., Carlson C., Das Gupta R., Sirotkin H., Collins J., Dunham I., O'Donnell H., Scambler P., Shprintzen R., et al. (1995). Molecular definition of the 22q11 deletions in velo-cardio-facial syndrome. Am. J. Hum. Genet. 56: 1391-1403.

Murray J. C., Buetow K. H., Weber J. L., Ludwigsen S., Scherpbier-Heddema T., Manion F., Quillen J., Sheffield V. C., Sunden S., Duyk G. M. L., Weissenbach J., Gyapay G., Dib C., Morissette J., Lathrop G. M., Vignal A., White R., Matsunami N., Gerken S., Melis R., Albertsen H., Plaetke R., Odelberg S., Ward D., Dausset J., Cohen D., Cann H. (1994). A comprehensive human linkage map with centimorgan density. Science 265: 2049-2054.

Miyoshi N., Kuroiwa Y., Kohda T., Shitara H., Yonekawa H., Kawabe T., Hasegawa H., Barton S. C., Surani M. A., Kaneko-Ishino T., Ishino F. (1998). Identification of the Meg1/Grb10 imprinted gene on mouse proximal chromosome 11, a candidate for the SilverRussell syndrome gene. Proc. Natl. Acad. Sci. U S A 95:1102-7

Miyoshi O., Kondoh T., Taneda H., Otsuka K., Matsumoto T., Niikawa N. (1999). 47, XX, UPD(7)mat,+r(7)pat/46,XX,UPD(7)mat mosaicism in a girl with Silver-Russell syndrome (SRS): possible exclusion of the putative SRS gene from a 7p13-q11 region. J. Med. Genet. 36: 326-329.

Nachury M. V., Ryder U. W., Lamond A. I., Weis K. (1998). Cloning and characterization of hSRP1 gamma, a tissue-specific nuclear transport factor. Proc. Natl. Acad. Sci. U S A 95: 582-587.

Nadler S. G., Tritschler D., Haffar O. K., Blake J., Bruce A. G., Cleaveland J. S. (1997). Differential expression and sequence-specific interaction of karyopherin alpha with nuclear localization sequences. J. Biol. Chem. 272: 4310-4315. 
Nagaraja R., Kere J., MacMillan S., Masisi M. J., Johnson D., Molini B. J., Halley G. R., Wein K., Trusgnich M., Eble B. et al. (1994). Characterization of four human YAC libraries for clone size, chimerism and $\mathrm{X}$ chromosome sequence representation. Nucleic Acids Res. 22: 3406-3411.

Nakaya Y., Schaefer E. J., Brewer H. B. Jr. (1980). Activation of human post heparin lipoprotein lipase by apolipoprotein H (beta 2-glycoprotein I). Biochem. Biophys. Res. Commun. 95:1168-1172.

Nair P. M., Sabarinathan K. (1984). Russell-Silver syndrome. Indian J. Pediatr. 51: 367-369.

Nakamura Y., Leppert M., O'Connell P., Wolff R., Holm T., Culver M., Martin C., Fujimoto E., Hoff M., Kumlin E., White R. (1987). Variable number of tandem repeat (VNTR) markers for human gene mapping. Science 235: 1616-1622.

Nathans J., Merbs S. L., Sung C. H., Weitz C. J., Wang Y. (1992). Molecular genetics of human visual pigments. Annu. Rev. Genet. 26: 403-424.

Nathans J., Piantanida T. P., Eddy R. L., Shows T. B., Hogness D. S. (1986). Molecular genetics of inherited variation in human color vision. Science 232: 203-210.

Naylor J. A., Buck D., Green P., Williamson H., Bentley D., Giannelli F. (1995). Investigation of the factor VIII intron 22 repeated region (int22h) and the associated inversion junctions. Hum. Mol. Genet. 4: 1217-1224.

Naylor J., Brinke A., Hassock S., Green P. M., Giannelli F. (1993). Characteristic mRNA abnormality found in half the patients with severe haemophilia $\mathrm{A}$ is due to large DNA inversions. Hum. Mol. Genet. 2:1773-1778.

Neitz M., Neitz J. (1995). Numbers and ratios of visual pigment genes for normal red-green color vision. Science 267:1013-1016.

Nelson D. L., Ledbetter S. A., Corbo L., Victoria M. F., Ramirez-Solis R., Webster T. D., Ledbetter D. H., Caskey C. T. (1989). Alu polymerase chain reaction: A method for rapid isolation of human-specific sequences from complex DNA sources. Proc. Natl. Acad. Sci. U $S$ A 86: 6686-6690.

Niklaus A. F., Marchese S. G., Mulvihill J. J., Brostoff L. M., Wenger S. L., Steele M. W. (1992). Interstitial deletion of 18 (p11.22p11.23) in a patient with phenotype of RussellSilver-Syndrome. Am. J. Hum. Genet. 51: A307

Nimpf J., Bevers E. M., Bomans P. H., Till U., Wurm H., Kostner G. M., Zwaal R. F. (1986). Prothrombinase activity of human platelets is inhibited by beta 2-glycoprotein-I. Biochim. Biophys. Acta 884:142-149.

Nishita Y., Yoshida I., Sado T., Takagi N. (1996). Genomic imprinting and chromosomal localization of the human MEST gene. Genomics 15:539-542 
Ochman H., Hood L., Cantor C., Botstein D. (1988). Genetic applications of an inverse polymerase chain reaction. Genetics 120: 621-623.

Okkels H., Rasmussen T. E., Sanghera D. K., Kamboh M. I., Kristensen T. (1999). Structure of the human beta2-glycoprotein I (apolipoprotein H) gene. Eur. J. Biochem. 259:435-440.

Olkers A., Jedlicka A. E., Powers P. A., Hogan K., Gregg R. G. \& Levitt R. C. (1993). G to A polymorphism in the CACNLG gene. Hum. Mol. Genet. 2: 2198.

Olson M., Hood L., Cantor C., Botstein D. (1989). A common language for physical mapping of the human genome. Science 245: 1434-1435.

O'Neil R. E., Palese P. (1995). NPI-1, the human homolog of SRP-1, interacts with influenza virus nucleoprotein. Virology 206: 116-125.

Orita M., Iwahana H., Kanazawa H., Hayashi K., Sekiya T. (1989). Detection of polymorphisms of human DNA by gel electrophoresis as single-Strand conformation polymorphisms. Proc. Natl. Acad. Sci. U S A. 86: 2766-2770.

Orkin S. H., Kazazian H. H. (1984). The mutation and polymorphism of the human $\beta$-globin gene and ist surrounding DNA. Annu. Rev. Genet. 18: 131-171.

Oryne E., Delbeke M. J., Vandenabeele B. (1971). Retinoblastoma and D-chromosome deletions. Lancet II: 1376.

Osborne L. R., Herbrick J. A., Greavette T., Heng H. H., Tsui L. C., Scherer S. W. (1997). PMS2-related genes flank the rearrangement breakpoints associated with Williams syndrome and other diseases on human chromosome 7. Genomics 45: 402-406.

Pan Y., McCaskill C. D., Thompson K. H., Hicks J., Casey B., Shaffer L. G., Craigen W. J. (1998). Paternal isodisomy of chromosome 7 associated with complete situs inversus and immotile cilia. Am. J. Hum. Genet. 62:1551-1555.

Partington M. W. (1986). X-linked short stature with skin pigmentation: evidence for heterogeneity of the Russell-Silver syndrome. Clin. Genet. 29: 151-156.

Paschal B. M., Gerace L. (1995). Identification of NTF2, a cytosolic factor for nuclear import that interacts with nuclear pore complex protein p62. J. Cell. Biol. 129: 925-937.

Passarge E. (1995). Color Atlas of Genetics. Georg Thieme-Verlag Stuttgart New York: 156.

Patton M. A. (1988). Russell-Silver syndrome. J. Med. Genet. 25: 557-560.

Perez Jurado L. A., Peoples R., Kaplan P., Hamel B. C., Francke U. (1996). Molecular definition of the chromosome 7 deletion in Williams syndrome and parent-of-origin effects on growth. Am. J. Hum. Genet. 59: 781-792.

Perez Jurado L. A., Wang Y. K., Peoples R., Coloma A., Cruces J., Francke U. (1998). A duplicated gene in the breakpoint regions of the 7q11.23 Williams-Beuren syndrome deletion 
encodes the initiator binding protein TFII-I and BAP-135, a phosphorylation target of BTK. Hum. Mol. Genet. 7: 325-334.

Pentao L., Wise C. A., Chinault A. C., Patel P. I., Lupski J. R. (1992). Charcot-Marie-Tooth type $1 \mathrm{~A}$ duplication appears to arise from recombination at repeat sequences flanking the 1.5 Mb monomer unit. Nat. Genet. 2: 292-300.

Petersen M. B., Bartsch O., Adelsberger P. A., Mikkelsen M., Schwinger E., Antonarakis S. E. (1992). Uniparental isodisomy due to duplication of chromosome 21 occurring in somatic cells monosomic for chromosome 21. Genomics 13: 269-274.

Petrij F., Giles R. H., Dauwerse H. G., Saris J. J., Hennekam R. C. M., Masuno M., Tommerup N., van Ommen G.-J. B., Goodman R. H., Peters D. J. M., Breuning M. H. (1995). Rubinstein-Taybi syndrome caused by mutations in the transcriptional co-activator CBP. Nature 376: 348-351.

Pinkel D., Landegent J., Collins C., Fuscoe J., Segraves R., Lucas J., Gray J. (1988). Fluorescence in situ hybridization with human chromosome-specific libraries: detection of trisomy 21 and translocations of chromosome 4. Proc. Natl. Acad. Sci. U S A 85: 9138-9142.

Pinkel D., Straume, T., Gray J. W. (1986). Cytogenetic analysis using quantitative highsensitivity, fluorescence hybridization. Proc. Natl. Acad. Sci. U S A 83: 2934-2938.

Plummer S. J., Simmons J. A., Adams L., Casey G. (1997). Mapping of 228 ESTs and 26 genes into an integrated physical and genetic map of human chromosome 17. Genomics 45: 140-146.

Polz E., Kostner G. M. (1979). The binding of beta 2-glycoprotein-I to human serum lipoproteins: distribution among density fractions. FEBS Lett. 102:183-186.

Powers P. A., Liu S., Hogan K., Gregg R. G. (1993). Molecular characterization of the gene encoding the gamma subunit of the human skeletal muscle 1,4-dihydropyridine-sensitive $\mathrm{Ca} 2+$ channel (CACNLG), cDNA sequence, gene structure, and chromosomal location. $J$. Biol. Chem. 268: 9275-9279.

Preece M. A., Abu-Amero S. N., Ali Z., Abu-Amero K. K., Wakeling E. L., Stanier P., Moore G. E. (1999). An analysis of the distribution of hetero- and isodisomic regions of chromosome 7 in five mUDP7 Silver-Russell syndrome probands. Med. Genet. 36: 457-460.

Preece M. A., Price S. M., Davies V., Clough L., Stanier P., Trembath R. C., Moore G. E. (1997). Maternal uniparental disomy 7 in Silver-Russell syndrome. Med. Genet. 34: 6-9.

Quan F. Janas J., Toth-Fejel S. E., Johnson D. B., Wolford J. K., Popovich B. W. (1997). Uniparental disomy of the entire $\mathrm{X}$ chromosome in a female with Duchenne muscular dystrophy. Am. J. Hum. Genet. 60: 160-165.

Ramirez-Dueñas M. L., Medina C., Ocampo-Campos R., Rivera H. (1992). Severe SilverRussell syndrome and translocation (17;20)(q25;q13). Clin.Genet. 41: 51-53 
Reiter L.T., Murakami T., Koeuth T., Gibbs R.A., Lupski J.R. (1997). The human COX10 gene is disrupted during homologous recombination between the $24 \mathrm{~kb}$ proximal and distal CMT1A-REPs. Hum. Mol. Genet. 6: 1595-1603.

Riccardi V. M., Hittner H. M., Francke U., Pippin S., Holmquist G. P., Kretzer F. L., Ferrell R. (1979). Partial triplication and deletion of 13q: study of a family presenting bilateral retinoblastomas. Clin. Genet. 15: 332-345.

Rigat B. (1992). PCR detection of the insertion/deletion polymorphism of the human angiotensin converting enzyme gene (DCP1) (dipeptidyl carboxypeptidase 1). Nucleic Acids Res. 20:1433.

Rigby P. W. J., Dieckmann M., Rhodes C., Berg P. (1976). Labeling deoxyribonucleic acid to high specific activity in vitro by nick translation with DNA polymerase I. J. Mol. Biol. 113: 237-256.

Riley J., Butler R., Ogilvie D., Finniear R., Jenner D., Powell S., Anand R., Smith J. C., Markham A. F. (1990). A novel, rapid method for the isolation of terminal sequences from yeast artificial chromosome (YAC) clones. Nucleic Acids Res. 18: 2887-2890.

Rimoin D. L. (1969). The Silver syndrome in twins. Malformation Syndromes, ed. D. Bergsma, Birth Defects: Original Article Series, Vol. V, No 2, 183-187.

Riordan J. R., Rommens J. M., Kerem B., Alon N., Rozmahel R., Grzelczak Z., Zielenski J., Lok S., Plavsic N., Chou J. L., Drumm M. L., Iannuzzi M. C., Collins F. S., Tsui L.-C. (1989). Identification of the cystic fibrosis gene: cloning and characterization of complementary DNA. Science 245: 1066-1073.

Riesewijk A. M., Blagitko N., Schinzel A. A., Hu L., Schulz U., Hamel B. C., Ropers H. H., Kalscheuer V. M. (1998). Evidence against a major role of PEG1/MEST in Silver-Russell syndrome. Eur. J. Hum. Genet. 6:114-120.

Roback E. W., Barakat A. J., Dev V. G., Mbikay M., Chrétien M., Butler M. G. (1991). An infant with deletion of the distal long arm of chromosome 15(q26.1-qter) and loss of insulinlike growth factor 1 receptor gene. Am. J. Med. Genet. 38: 74-79.

Robichaux V., Fraikor A., Favara B., Richer M. (1981). Silver-Russell syndrome. A family with symmetric and asymmetric siblings. Arch. Pathol. Lab. Med. 105: 157-159.

Robinson W. P., Barrett I. J., Bernard L., Telenius A., Bernasconi F., Wilson R. D., Best R. G., Howard-Peebles P. N., Langlois S., Kalousek D. K. (1997). Meiotic origin of trisomy in confined placental mosaicism is correlated with presence of fetal uniparental disomy, high levels of trisomy in trophoblast, and increased risk of fetal intrauterine growth restriction. Am. J. Hum. Genet. 60: 917-927.

Robinson W. P., Waslynka J., Bernasconi F., Wang M., Clark S., Kotzot D., Schinzel A. (1996). Delineation of 7q11.2 deletions associated with Williams-Beuren syndrome and mapping of a repetitive sequence to within and to either side of the common deletion. Genomics 34: 17-23. 
Röpke A. (1998). Molekulare Charakterisierung von Mutationen beim Alagille Syndrom. Diplomarbeit.

Roest PA, Roberts RG, Sugino S, van Ommen GJ, den Dunnen JT (1993). Protein truncation test (PTT) for rapid detection of translation-terminating mutations. Hum. Mol. Genet. 2 (10): 1719-1721.

Rogan P. K., Seip J. R., Driscoll D. J., Papenhausen P. R., Johnson V. P., Raskin S., Woodward A. L., Butler M. G. (1996). Distinct 15q genotypes in Russell-Silver and ring 15 syndromes. Am. J. Hum. Genet. 62: 10-15.

Rommens J. M., Iannuzzi M. C., Kerem B., Drumm M. L., Melmer G., Dean M., Rozmahel R., Cole J., Kennedy D., Hidaka N., Zsiga M., Buchwald M., Riordan J. R., Tsui L., Collins F. S. (1989). Identification of the cystic fibrosis gene: Chromosome walking and jumping. Science 245: 1059-1065.

Royle N. J., Clarkson R., Wong Z., Jeffreys A. J. (1988). Preferential localization of hypervariable minisatellites near human telomeres. Human gene mapping 9. Cytogenet. Cell Genet. 46: 685.

Russell A. (1954). A syndrome of "intrauterine" dwarfism recognizable at birth with craniofacial dysostosis, disproportionately short arms, and other anomalies (5 examples). Proc. roy. Soc. Med. 47: 1040-1044.

Saal H. M., Pagon R. A., Pepin M. G. (1985). Reevaluation of Russell-Silver syndrome. J. Pediatr. 107: 733-737.

Saiki R. K., Gelfand D. H., Stoffel S., Scharf S. J., Higuchi R., Horn G. T., Mullis K. B., Erlich H. A. (1988). Primer-directed enzymatic amplification of DNA with a thermostable DNA polymerase. Science 239: 487-491.

Sambrook J., Fritsch E. F., Maniatis T. (1989). Molecular cloning. A laboratory manual. Second edition. Cold Spring Harbor Press, New York.

Sandison A., Broadhead D. M., Bain A. D. (1982). Elucidation of an unbalanced chromosome translocation by gene dosage studies. Clin. Genet. 22: 30-36.

Sanger F., Nicklen S., Coulsen A. R. (1977). DNA sequencing with chain termination inhibitors. Proc. Natl. Acad. Sci. U S A 74: 5463-5467.

Sansom D., Borrow J., Solomon E., Trowsdale J. (1991). The human ICAM2 gene maps to 17q23-25. Genomics 11: 462-464.

Schiavon F., Mostacciuolo M. L., Saad F., Merlini L., Siciliano G., Angelini C., Danieli G. A. (1994). Non-radioactive detection of 17p11.2 duplication in CMT1A: a study of 78 patients. J. Med. Genet. 31: 880-883. 
Schinzel A. A., Robinson W. P., Binkert F., Fanconi A. (1994). An interstitial deletion of proximal $8 \mathrm{q}$ (q11-q13) in a girl with Silver-Russell syndrome-like features. Clin. Dysmorphol. 3: 63-69.

Schuler G. D., Boguski M. S., Stewart E. A., Stein L. D., Gyapay G., Rice K., White R. E., Rodriguez-Tome'P., Aggarwal A., Bajorek E. et al. (1996). A gene map of the human genome. Science 274: 540-546.

Schwartz D. C., Cantor C. R. (1984). Separation of yeast chromosome-sized DNAs by pulsedfield-gradient gel-elektrophoresis. Cell 37: 67-75.

Scott A. F., Schmeckpeper B. J., Abdelrazik M., Comey C. T., O'Hara B., Rossiter J. P., Cooley T., Heath P., Smith K. D., Margolet L. (1987). Origin of the human L1 elements: proposed progenitor genes deduced from a consensus DNA sequence. Genomics 1: 113-125.

Seki T., Tada S., Katada T., Enomoto T. (1997). Cloning of a cDNA encoding a novel importin-alpha homologue, Qip1: discrimination of Qip1 and Rch1 from hSrp1 by their ability to interact with DNA helicase Q1/RecQL. Biochem. Biophys. Res. Commun. 234: 4853.

Shapiro L. J., Yen P., Pomerantz D., Martin E., Rolewic L., Mohandas T. (1989). Molecular studies of deletions at the human steroid sulfatase locus. Proc. Natl. Acad. Sci. U S A 86: 8477-8481.

Shero J. H., McCormick M. K., Antonarakis S. E., Hieter P. (1991). Yeast artificial chromosome vectors for efficient clone manipulation and mapping. Genomics 10: 505-508.

Short J. M., Fernandez J. M., Sorge J. A., Huse W. D. (1988). Lambda ZAP: a bacteriophage lambda expression vector with in vivo excision properties. Nucleic Acids Res. 16: 7583-7600.

Shuman C., Weksberg R., Nedelcu R., Scherer S. (1996). Chromosome 7 uniparental disomy in Silver-Russell syndrome. Am. J. Hum. Genet. 59: A648.

Silver H., Kiyasu W., George J., Deamer W. (1953). Syndrome of congenital hemihypertrophy, shortness of stature and elevated urinary gonadotropins. Pediatrics 12: 368-376.

Simola K. O. J., Knuutila S., Kaitila I., de la Chapelle A. (1984). A separate gene for aniridia at 11p13. Cytogenet. Cell Genet. 37: 584.

Simola K. O. J., Knuutila S., Kaitila I., Pirkola A., Pohja P. (1983). Familial aniridia and translocation t(4;11)(q22;p13) without Wilms' tumor. Hum. Genet. 63: 158-161.

Simon D.B., Bindra R.S., Mansfield T.A., Nelson-Williams C., Mendonca E., Stone R., Schurman S., Nayir A., Alpay H., Bakkaloglu A., Rodriguez-Soriano J., Morales J.M., Sanjad S.A., Taylor C.M., Pilz D., Brem A., Trachtman H., Griswold W., Richard G.A., John E., Lifton R.P. (1997). Mutations in the chloride channel gene, CLCNKB, cause Bartter's syndrome type III. Nat. Genet. 17: 171-178. 
Soeda E., Hou D.-X., Osoegawa K., Atsuchi Y., Yamagata T., Shimokava T., Kishida H., Soeda E., Okano S., Chumakov I., Cohen D., Raff M., Gardiner K., Graw S. L., Patterson D., de Jong P., Ashworth L. K., Slezak T., Carrano A. V. (1995). Cosmid assembly and anchoring to human chromosome 21. Genomics 25: 73-84.

Solberg R., Sandberg M., Natarajan V., Torjesen P. A., Hansson V., Jahnsen T., Tasken K. (1997). The human gene for the regulatory subunit RI alpha of cyclic adenosine 3', 5'monophosphate-dependent protein kinase: two distinct promoters provide differential regulation of alternately spliced messenger ribonucleic acids. Endocrinology 138:169-181.

Solomon E., Swallow D. M., Burgess S., Evans L. (1979). Assignment of the human acid alpha-glucosidase gene (alpha-GLU) to chromosome 17 using somatic cell hybrids. Ann. Hum. Genet. 42: 273-281.

Sosnoski D. M., Emanuel B. S., Hawkins A. L., van Tuinen P., Ledbetter D. H., Nussbaum R. L., Kaos F. T., Schwarz E., Phillips D., Bennett J. S., et al. (1988). Chromosomal localization of the genes for the vitronectin and fibronectin receptors alpha subunits and for platelet glycoproteins IIb and IIIa. J. Clin. Invest. 81: 1993-1998.

Southern E. M. (1975).Detection of specific sequences among DNA fragments separated by gel elektophoresis. J. Mol. Biol. 98: 503-517.

Spence J. E., Persiaccante R. G., Greig G. M., Huntington F. W., Ledbetter D. H., Hejtmanik J. F., Pollack M. S., O'Brien W. E., Beaudet A. L. (1988). Uniparental disomy as a mechanism for human genetic disease. Am. J. Hum. Genet. 42: 217-226.

Spielman R. S., McGinnis R. E., Ewens W. J. (1993). Transmission test for linkage disequilibrium: The insulin gene region and insulin-dependent diabetes mellitus (IDDM). Am. J. Hum. Genet. 52: 506-516.

Spotila L. D., Sereda L., Prockop D. J. (1992). Partial isodisomy for maternal chromosome 7 and short stature in an individual with a mutation at the COL1A2 locus. Am. J. Hum. Genet. 51: 1396-1405.

Stambolian D., Ai Y., Sidjanin D., Nesburn K., Sathe G., Rosenberg M., Bergsma D. J. (1995). Cloning of the galaktokinase cDNA and identification of mutations in two families with cataracts. Nat Genet. 10: 307-312.

Steinkasserer A., Cockburn D. J., Black D. M., Boyd Y., Solomon E., Sim R. B. (1992). Assignment of apolipoprotein $\mathrm{H}$ (APOH: beta-2-glycoprotein I) to human chromosome $17 \mathrm{q} 23 \rightarrow$ qter; determination of the major expression site (1992). Cytogenet. Cell Genet. 60: 31-33.

Steinkasserer A., Dörner C., Würzner R., Sim R. B. (1993). Human $\beta_{2}$-glycoprotein I: molecular analysis of DNA and amino acid polymorphism. Hum. Genet. 91: 401-402.

Stephens J. C., Cavanaugh M. L., Gradie M. I., Mador M. L., Kidd K. K. (1990). Mapping the human genome: Current status. Science 250: 237-244. 
Stoffel M., Bell G. I. (1992). Microsatellite polymorphism in the human platelet glycoprotein IIIa gene (GP3A) on chromosome 17. Nucleic Acids Res. 20:1172.

Stubbs L. (1992). Long-range walking techniques in positional cloning strategies. Mammalian Genome 3: 127-142.

Tagle D.A., Collins F.S. (1992). An optimized Alu-PCR primer pair of human-spezific amplification of YACs and somatic cell hybrids. Hum. Mol. Genet. 1: 121-122

Takeda S., Fujiwara T., Shimizu F., Kawai A., Shinomiya K., Okuno S., Ozaki K., Katagiri T., Shimada Y., Nagata M., Watanabe T., Takaichi A., Kuga Y., Suzuki M., Hishigaki H., Takahashi E., Shin S., Nakamura Y., Hirai Y. (1997). Isolation and mapping of karyopherin alpha 3 (KPNA3), a human gene that is highly homologous to genes encoding Xenopus importin, yeast SRP1 and human RCH1. Cytogenet. Cell Genet. 76: 87-93.

Tamura T., Tohma T., Ohta T., Soejima H., Harada N., Abe K., Niikawa N. (1993). Ring chromosome 15 involving deletion of the insulin-like growth factor 1 receptor gene in a patient with features of Silver-Russell syndrome. Clin. Dysmorphol. 2: 106-113.

Tanner J. M., Lejarraga H. and Cameron N. (1975). The natural history of the Silver-Russell syndrome: a longitudinal study of thirty-nine cases. Pediat. Res. 9: 611-623.

Tapia J. E., Hauser G. A., Gander M. (1983). Schwangerschaft und Geburt bei einer Mutter mit Silver-Russell-Syndrom. Schweiz. Med. Wochenschr. 113: 716-719.

Teebi A. S. (1992). Autosomal recessive Silver-Russell syndrome. Clin. Dysmorphol. 1: 151156.

The Fifth Wellcome Summer School (1990). DNA related methods in human genetics: YAC cloning in genome analysis. Ed.: M. J. Morgan, The Trustees of the Wellcome Trust.

The Sanger Centre and The Washington University Genome Sequencing Center (1998). Toward a complete human genome sequence. Genome Research 8: 1097-1108.

Tocharoentanaphol C., Cremer M., Schröck E., Blonden L., Kilian K., Cremer T., Ried T. (1994). Multicolor fluorescense in situ hybridization on metaphase chromosomes and interphase Halo-preparations using cosmid and YAC clones for the simultaneous high resolution mapping of deletions in the dystrophin gene. Hum. Genet. 93: 229-235.

Török I., Strand D., Schmitt R., Tick G., Torok T., Kiss I., Mechler B. M. (1995). The overgrown hematopoietic organs-31 tumor suppressor gene of Drosophila encodes an Importin-like protein accumulating in the nucleus at the onset of mitosis. J. Cell. Biol. 129: 1473-1489.

Tommerup N., van der Hagen C. B., Heiberg A. (1991). Tentative assignment of a locus for Rubinstein-Taybi syndrome to $16 \mathrm{p} 13.3$ by a de novo reciprocal translocation, t(7;16)(q34;p13.3). Cytogenet. Cell Genet. 58: 2002-2003. 
Tommerup N., van der Hagen C. B., Heiberg A. (1992). Tentative assignment of a locus for Rubinstein-Taybi syndrome to $16 \mathrm{p} 13.3$ by a de novo reciprocal translocation, t(7;16)(q34;p13.3). Am. J. Med. Genet. 44: 237-241.

Ton C. C. T., Hirvonen H., Miwa H., Weil M. M., Monaghan P., Jordan T., van Heyningen V., Hastie N. D., Meijers-Heijboer H., Drechsler M., Royer-Pokora B., Collins F., Swaroop A., Strong L. C., Saunders G. F. (1991). Positional cloning and characterization of a paired boxand homeobox-containing gene from the aniridia region. Cell 67: 1059-1074.

Tuddenham E. G., Schwaab R., Seehafer J., Millar D. S., Gitschier J., Higuchi M., Bidichandani S., Connor J. M., Hoyer L. W., Yoshioka A., et al. (1994). Haemophilia A: database of nucleotide substitutions, deletions, insertions and rearrangements of the factor VIII gene, second edition. Nucleic Acids Res. 22: 3511-3533 und 4851-4868.

Uberbacher E. C., Mural R. J. (1991). Locating protein-coding regions in human DNA sequences using a multiple sensor-neural network approach. Proc. Natl. Acad. Sci. U S A 88: 11262-11265.

Urban Z., Helms C., Fekete G., Csiszar K., Bonnet D., Munnich A., Donis-Keller H., Boyd C. D. (1996). 7q11.23 deletions in Williams syndrome arise as a consequence of unequal meiotic crossover. Am. J. Hum. Genet. 59: 958-962.

Van Cong N., Uzan G., Gross M. S., de Tand M. F., Frachet P., Boucheix C., Marguerie G., Frezal J. (1989). Assignment of GP3A gene to chromosome 17 (somatic cell hybrid analysis), region q21.1-q21.3 (in situ hybridization). Cytogenet. Cell Genet. 51: 1096-1097.

Van Ommen G. J. B., Verkerk J. M. H., Hofker M. H., Monaco A. P., Kunkel L. M., Ray P., Worton R., Wieringa B., Bakker E., Pearson P. L. (1986). A physical map of 4 million bp around the Duchenne muscular dystrophy gene on the human X-chromosome. Cell 47: 499504.

Varanasi U., Chu R., Chu S., Espinosa R., LeBeau M. M. (1994). Isolation of the human peroxisomal acyl-CoA oxidase gene: Organization, promotor analysis, and chromosomal localization. Proc. Natl. Acad. Sci. U S A. 91: 3107-3111.

Venter J. C., Adams M. D., Sutton G. G., Kerlavage A. R., Smith H. O., Hunkapiller M. (1998). Shotgun sequencing of the human genome. Science 280: 1540-1542.

Verkerk A. J. M. H., Pieretti M., Sutcliffe J. S., Fu Y.-H., Kuhl D. P. A., Pizzuti A., Reiner O., Richards S., Victoria M. F., Zhang F., Eussen B. E., van Ommen G.-J. B., Blonden L. A. J., Riggins G. J., Chastain J. L., Kunst C. B., Galjaard H., Caskey C. T., Nelson D. L., Oostra B. A., Warren S. T. (1991). Identification of a gene (FMR-1) containing CGG repeat coincident with a breakpoint cluster region exhibiting length variation in fragile $\mathrm{X}$ syndrome. Cell $\mathbf{6 5}$ : 905-914.

Vetrie D., Bobrow M., Harris A. (1993). Construction of a 5.2 Mb-physical map of the human $\mathrm{X}$ chromosome at $\mathrm{Xq} 22$ using pulse-field gel electrophoresis and yeast artificial chromosomes. Genomics 15: 631-642. 
Vidaud D., Vidaud M., Plassa F., Gazengel C., Noel B., Goossens B. (1989). Father-to-son transmission of hemophilia A due to uniparental disomy. Am. J. Hum. Genet. 45: 889.

Vilageliu L., Tyler Smith C. (1992). Structural instability of YAC clones and the use of recombination deficient yeast host strains, pp. 93-112 in: Techniques for the analysis of complex genomes, edited by R. Anand. Academic Press, San Diego.

Vnencak-Jones C. L., Phillips J. A. (1990). Science 250: 1745-1748.

Vnencak-Jones C. L., Phillips J. A., Chen E. Y., Seeburg P. H. (1988). Molecular basis of human growth hormone gene deletions. Proc. Natl. Acad. Sci. U S A 85: 5615-5619.

Vogel F., Motulsky A. G. (1986). Human Genetics, Problems and Approaches, 2nd ed.; Springer, Berlin-Heidelberg-New York-Tokio.

Vollrath D., Jaramillo-Babb V. L. (1999). A sequence-ready BAC clone contig of a 2.2-Mb segment of human chromosome 1q24. Genome. Res. 9: 150-157.

Voss R., Ben-Simon E., Avital A., Godrey S., Zlotogora J., Dagan J., Tikochinski Y., Hillel J. (1989). Isodisomy for chromosome 7 in a patient with cystic fibrosis: Could uniparental disomy be common in humans? Am. J. Hum. Genet. 45: 373-380.

Wada M., Little R. D., Abid F., Porta G., Labella T., Cooper T., Della Valle G., D’Urso M., Schlessinger D. (1990). Human Xq24-28: approaches to mapping with yeast artificial chromosomes. Am. J. Hum. Genet. 46: 95-106.

Wagner T., Wirth J., Meyer J., Zabel B., Held M., Zimmer J., Pasantes J., Bricarelli F. D., Keutel J., Hustert E., Wolf U., Tommerup N., Schempp W., Scherer G. (1994). Autosomal sex reversal and campomelic dysplasia are caused by mutations around the SRY-related gene SOX9. Cell 79: 1111-1120.

Wahlström J., Holmgren G., Albertson-Wikland K. (1989). Russell-Silver-Syndromes with mental retardation and del(13) (q22-32). Human Gene Mapping 10. Cytogenet. Cell. Genet. 51: 1101 .

Wakeling E. L., Abu-Amero S. N., Stanier P., Preece M. A., Moore G. E. (1998). Human EGFR, a candidate gene for the Silver-Russell syndrome, is biallelically expressed in a wide range of fetal tissues. Eur. J. Hum. Genet. 6: 158-164.

Walther C., Gruss P. (1991). Pax-6, a murine paired box gene, is expressed in the developing CNS. Development 113: 1435-1449.

Wandstrat A. E., Leana-Cox J., Jenkins L., Schwartz S. (1998). Molecular cytogenetic evidence for a common breakpoint in the largest inverted duplications of chromosome 15. Am. J. Hum. Genet. 62: 925-936.

Wang P., Palese P., O'Neill R. E. (1997). The NPI-1/NPI-3 (karyopherin alpha) binding site on the influenza a virus nucleoprotein NP is a nonconventional nuclear localization signal. $J$. Virol. 71: 1850-1856. 
Watson N. (1988). A new revision of the sequence of plasmid pBR322. Gene 70: 399-403.

Watson J. D., Jordan E. (1989). The human genome programm at the national institutes of health. Genomics 5: 654-656.

Weatherall D. J., Clegg J. B., Higgs D. R., Wood W. G. (1995). The metabolic and molecular bases of inherited disease. 7. Auflage. McGraw-Hill: 3417-3484.

Weber J. L. (1990). Human DNA polymorphisms based on length variations in simplesequence tandem repeats. Genome analysis 1: 159-181.

Weber J. L., May P. E. (1989). Abundant class of human DNA polymorphisms wich can be typed using the polymerase chain reaction. Am. J. Hum. Genet. 44: 388-396.

Weinstock G. M., Lupski J. R. (1998).: Bacterial Genomes: Physical structure and analysis. Chapman \& Hall. (de Bruin F. J., Lupski J. R., Weinstock G. M., eds): 112-118.

Weir B. S. (1990). Genetic data analysis. Sinauer, Sunderland, MA

Weis K., Mattaj I. W., Lamond A. I. (1995). Identification of hSRP1 alpha as a functional receptor for nuclear localization sequences. Science 268:1049-1053.

Weiss M. C., Green H. (1967). Human-mouse hybrid cell lines containing partial complements of human chromosomes and functioning human genes. Proc. Natl. Acad. Sci. U S A 58: 11041111.

Weissenbach J., Gyapay G., Dib C., Vignal A., Morissette J., Millasseau P., Vaysseix G. \& Lathrop M. (1992). A second-generation linkage map of the human genome. Nature 359: 794-801.

White R. A., Birkenmeier C. S., Lux S. E., Barker J. E. (1990). Ankyrin and the hemolytic anemia mutation, $\mathrm{nb}$, map to mouse chromosome 8: presence of the nb allele is associated with a truncated erythrocyte ankyrin. Proc. Natl. Acad. Sci. U S A 87: 3117-3121.

White R., Leppert M., Bishop D. T., Barker D., Berkowitz J., Brown C., Callahan P., Holm T., Jerominski (1985). Construction of linkage maps with DNA markers for human chromosomes. Nature 313: 101-105.

Wicking C., Williamson B. (1991). From linked marker to gene. Trends Genet. 7: 288-293.

Wilson G. N., Sauder S. E., Bush M. and Beitins I. Z. (1985). Phenotyping delineation of ring chromosome 15 and Russell-Silver syndromes. J. Med. Genet. 22: 233-236.

Wilson M. G., Towner J. W., Fujimoto A. (1973). Retinoblastoma and D-chromosome deletions. Am. J. Hum. Genet. 25: 57-61. 
Wirth J., Wagner T., Meyer J., Pfeiffer R. A., Tietze H. U., Schempp W., Scherer G. (1996). Translocation breakpoints in three patients with campomelic dysplasia and autosomal sex reversal map more than $130 \mathrm{~kb}$ from SOX9. Hum. Genet. 97:186-193.

Wollmann H. A., Kirchner T., Enders H., Preece M. A., Ranke M. B. (1995). Growth and symptoms in Silver-Russell syndrome: review on the basis of 386 patients. Eur. J. Pediatr. 154: 958-968.

Wu Y. Q., Sutton V. R., Nickerson E., Lupski J. R., Potocki L., Korenberg J. R., Greenberg F., Tassabehji M., Shaffer L. G. (1998). Delineation of the common critical region in Williams syndrome and clinical correlation of growth, heart defects, ethnicity, and parental origin. Am. J. Med. Genet. 78: 82-89.

Yen P. H., Li X.-M., Tsai S.-P., Johnson C., Mohandas T., Shapiro L. J. (1990). Frequent deletions of the human $\mathrm{X}$ chromosome distal short arm result from recombination between low copy repetitive elements. Cell 61: 603-610.

Yoshida A., Lebo R. V. (1986). Existence of glucose-6-phosphate dehydrogenase-like locus on chromosome 17. Am. J. Hum. Genet. 39: 203-206.

Zanchetta S., Praderio R., Marcer G., Bagnani A. (1990). La sindrome di Silver-Russell. Presentazione di un casi ad ereditarietà autosomica dominante. Pediatr. Med. Chir. 12: 277279.

Zimran A., Sorge J., Gross E., Kubitz M., West C., Beutler E. (1990). A glucocerebrosidase fusion gene in Gaucher disease. Implications for the molecular anatomy, pathogenesis, and diagnosis of this disorder. J. Clin. Invest. 85:219-222.

Zuliani G., Hobbs H. H. (1990). A high frequency of length polymorphisms in repeated sequences adjacent to Alu sequences. Am. J. Hum. Genet. 46: 963-969. 


\section{Danksagung}

Bei Herrn Prof. Dr. W. Engel möchte ich mich sehr für die Überlassung des Themas und für seine ständige Diskussionsbereitschaft bedanken.

Herrn Prof. Hansmann danke ich für seine vielfältige Unterstützung und sein Interesse am Werdegang dieser Arbeit.

Bei Prof. M. Schäfer bedanke ich mich für die Übernahme des Korreferats.

Meinen Kollegen danke ich für die immer gute, freundschaftliche Zusammenarbeit und die erfahrene Hilfsbereitschaft.

Bei Jannis Giannakudis bedanke ich mich für zahlreiche fachliche Ratschläge und bei Dietmar Schlote für seine Einsatzbereitschaft Computerprobleme zu lösen.

Mein besonderer Dank gilt Carsten Gunkel, der immer für mich da war und mich sehr unterstützt hat. 
Persönliche Daten:

Sylvia Dörr

geboren am 27. April 1970 in Oldenburg

als Tochter von Horst und

Ingeborg Dörr, geb. Possekel

Bildungsweg:

$1976-1980$

Besuch der Grundschule in Oldenburg

$1980-1982$

Besuch der Orientierungsstufe in Oldenburg

$1982-1986$

Besuch der Realschule in Oldenburg

$1986-1989$

Besuch des Gymnasiums Liebfrauenschule in

Oldenburg; Erwerb der allgemeinen Hochschulreife

Oktober 1989

Beginn des Studiums der Biologie an der GeorgAugust-Universität in Göttingen

Oktober 1991

Diplom-Vorprüfung

Oktober 1995

Diplom-Hauptprüfung

$1994-1995$

Experimentelle Arbeiten zur Diplomarbeit am Institut für Humangenetik der Georg-AugustUniversität in Göttingen; Abschluß des Studiums Biologie mit Diplom

seit Oktober 1995

Experimentelle Arbeiten zur Dissertation am Institut für Humangenetik in Göttingen

seit 1997

Experimentelle Arbeiten zur Dissertation am Institut für Humangenetik in Göttingen und am Institut für Humangenetik und Medizinische Biologie in Halle 